\title{
Global Aromaticity in a Partially Fused 8-Porphyrin Nanoring
}

Sebastian M. Kopp, Henrik Gotfredsen, Jie-Ren Deng, Tim D. W. Claridge, and Harry L. Anderson*

Department of Chemistry, University of Oxford, Chemistry Research Laboratory, Oxford OX1 3TA, UK

Correspondence to: harry.anderson@chem.ox.ac.uk.

\section{Table of Contents}

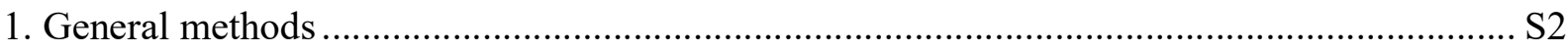

2. Overview of Porphyrin Nanoring Complexes .................................................................. S4

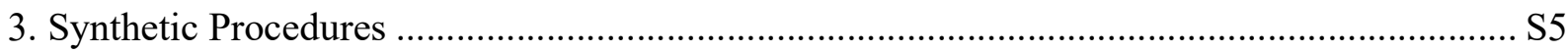

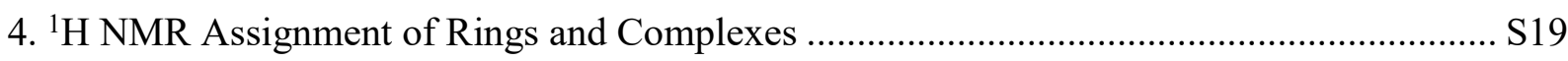

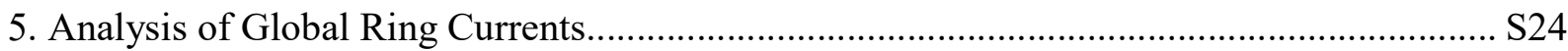

6. Overview of NMR Spectra of Nanoring Complexes....................................................... S27

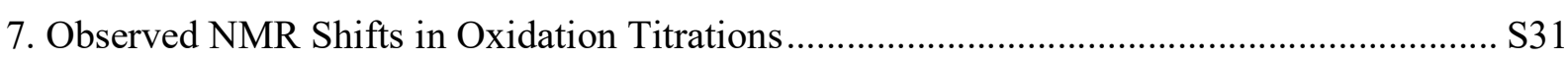

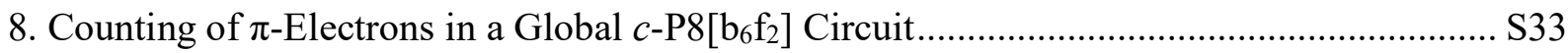

9. Summary of Experimental Results and NICS Calculations .............................................. S34

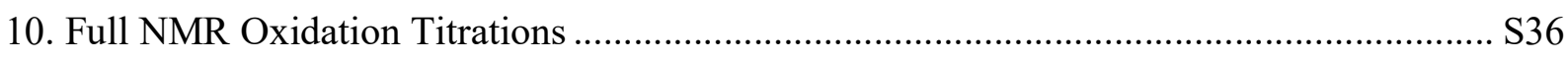

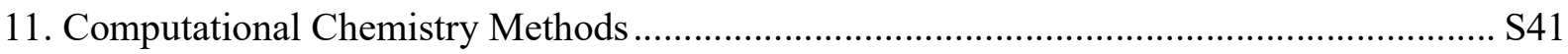

12. Time-Dependent Density Functional Theory ............................................................. S42

13. Natural Transition Orbital Pair Calculations ................................................................. S46

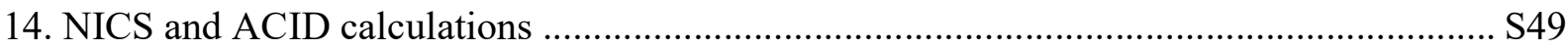

15. NMR and Mass Spectra of Novel Compounds ................................................................. S55

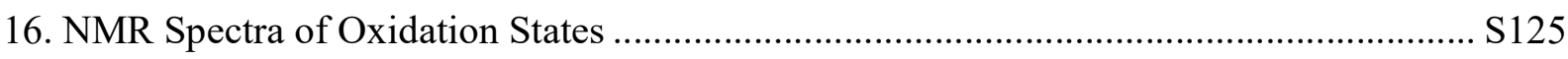

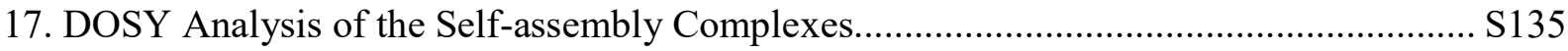

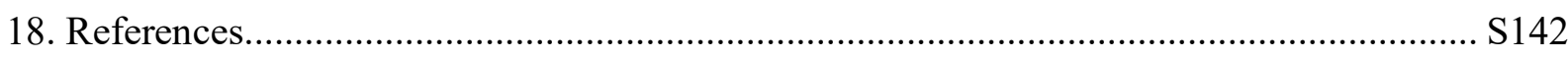




\section{General methods}

Diisopropylamine $\left(i-\mathrm{Pr}_{2} \mathrm{NH}\right)$ and dichloromethane for reactions were obtained from an MBraun MBSPS-5BenchTop solvent purification system kept under nitrogen. Copper(I) chloride was prepared before use according to a known procedure. ${ }^{1}$ Chloroform- $d$ for NMR was stored over $\mathrm{K}_{2} \mathrm{CO}_{3}$ prior to use. All other reagents and solvents were obtained from commercial suppliers and used as received unless otherwise stated. Thin-layer chromatography (TLC) was carried out using commercially available aluminum sheets precoated with silica gel with fluorescence indicator and visualized under UV light at 254 or $360 \mathrm{~nm}$. Purification by column chromatography was carried out on silica gel $\left(\mathrm{SiO}_{2}, 60 \AA, 40-63 \mu \mathrm{m}\right)$. Petroleum ether (PE) of boiling range: $40-60{ }^{\circ} \mathrm{C}$ was used for chromatography. Size exclusion chromatography (SEC) was carried out using Bio-Rad Bio-Beads S-X1 (40-80 $\mu \mathrm{m}$ bead size). Analytical GPC was carried out using JAIGEL-3H-A $(8 \times 500 \mathrm{~mm})$ and JAIGEL-4H-A $(8 \times 500 \mathrm{~mm})$ columns in THF $+1 \%$ pyridine as eluent with a flow rate of $1.0 \mathrm{~mL} / \mathrm{min}$. Semipreparative GPC was carried out on a Shimadzu recycling GPC system equipped with a LC-20 AD pump, SPD$20 \mathrm{~A}$ UV detector and a set of JAIGEL $3 \mathrm{H}(20 \times 600 \mathrm{~mm})$ and JAIGEL $4 \mathrm{H}(20 \times 600 \mathrm{~mm})$ columns in toluene + $1 \%$ pyridine as the eluent at a flow rate of $3.5 \mathrm{~mL} / \mathrm{min}$.

${ }^{1} \mathrm{H}$ and ${ }^{13} \mathrm{C}$ NMR spectra were recorded on either a Bruker AVIII HD 400, a Bruker AVIII HD 500, a Bruker AVII 500 with a ${ }^{13} \mathrm{C}\left({ }^{1} \mathrm{H}\right)$ dual cryo-probe, or a Bruker AVIII 600 with a broadband cryo-probe. ${ }^{19} \mathrm{~F}$ NMR spectra were recorded on a Bruker AVIIIHD 500 instrument. Chemical shift values are quoted in ppm and coupling constants $(J)$ in Hertz to the nearest $0.1 \mathrm{~Hz} .{ }^{1} \mathrm{H}$ and ${ }^{13} \mathrm{C}$ NMR spectra are referenced against the residual solvent peak $\left(\mathrm{CHCl}_{3} \delta_{\mathrm{H}}=7.26 \mathrm{ppm}, \mathrm{CDCl}_{3} \delta \mathrm{C}=77.16 \mathrm{ppm} ; \mathrm{CHDCl}_{2} \delta_{\mathrm{H}}=5.32 \mathrm{ppm}, \mathrm{CD}_{2} \mathrm{Cl}_{2} \delta \mathrm{C}=53.84 \mathrm{ppm}\right) .{ }^{19} \mathrm{~F}$ NMR spectra are referenced against hexafluorobenzene $(\delta F=-164.8 \mathrm{ppm})$ which was added to the samples. Unless stated otherwise, NMR spectra were recorded at $298 \mathrm{~K} .{ }^{1} \mathrm{H}-{ }^{1} \mathrm{H}$ NOESY spectra were recorded with a mixing time of

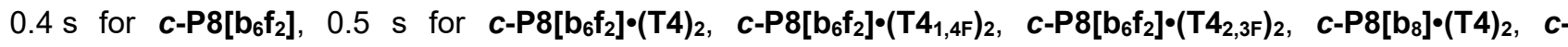

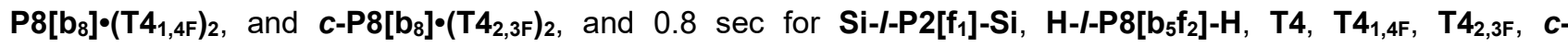

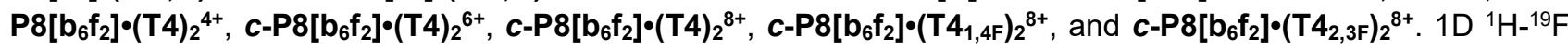
HOESY spectra were recorded with $0.4 \mathrm{~s}$ mixing time.

UV-Vis-NIR measurements were carried out in a $1 \mathrm{~cm}$ path length quartz cuvette at $298 \mathrm{~K}$ using either a PerkinLambda 20 or a Jasco V770 spectrophotometer. Chloroform (stored over $\mathrm{K}_{2} \mathrm{CO}_{3}$ ) was used as solvent.

MALDI-ToF mass spectra were measured at the EPSRC UK National Mass Spectrometry Facility (NMSF, Swansea) on a Bruker ultrafleXtreme MALDI-TOF/TOF instrument or at the University of Oxford using a Bruker MALDI Autoflex Speed instrument. Either dithranol or trans-2-[3-(4-tert-butylphenyl)-2-methyl-2propenylidene]malononitrile (DCTB) was used as matrix. ESI spectra were measured at the University of Oxford on a Thermo Orbitrap Exactive mass spectrometer.

Nanoring complexes containing fluorinated templates: $c-P 8\left[b_{6} f_{2}\right]_{\bullet}\left(T_{4_{1,4 F}}\right)_{2}, c-P 8\left[b_{6} f_{2}\right] \cdot\left(T 4_{2,3 F}\right)_{2}, c-P 8\left[b_{8}\right] \cdot\left(T 4_{1,4 F}\right)_{2}$, and $c-P 8\left[b_{8}\right] \cdot\left(T 4_{1,4 F}\right)_{2}$ were formed from the corresponding T4-complexes: $c-P 8\left[b_{6} f_{2}\right] \cdot(T 4)_{2}$ and $c-P 8\left[b_{8}\right]_{\bullet} \cdot(T 4)_{2}$ isolated from synthesis. Template removal was done in accordance with a previously published procedure ${ }^{2}$ by passing the nanoring complexes through either a $2.5 \mathrm{M} \mathrm{DABCO}$ or a $30 \%$ pyridine/toluene solution on a SEC column (toluene). Formation of the fluorinated complexes was achieved by titrating an excess amount of template into a $\mathrm{CDCl}_{3}$ solution of free nanoring. The ${ }^{1} \mathrm{H}-\mathrm{NMR}$ signals of free template marked the endpoint of the titration, and the solution was passed through a SEC column $\left(\mathrm{CHCl}_{3}\right)$ followed (in some instances) by filtration through a short pad of silica $\left(\mathrm{CHCl}_{3} / n\right.$-hexane 1:5) for removing minor aliphatic impurities.

Oxidative NMR titrations on porphyrin nanoring complexes were carried out similarly to previous descriptions..$^{3,4}$ The nanoring complexes were transferred to J. Young NMR tubes, dissolved in $\mathrm{CD}_{2} \mathrm{Cl}_{2}$, and handled under argon using standard Schlenk techniques. A well-stirred suspension of the oxidant, thianthrenium hexafluoroantimonate $\left(\mathrm{Thn}^{+}, \mathrm{E}_{\text {red }}=0.86 \mathrm{~V}\right.$ versus $\mathrm{Fc} / \mathrm{Fc}^{+}$) in $\mathrm{CD}_{2} \mathrm{Cl}_{2}$ (ca. 20-30 mM), kept under argon was used for the titrations. The titrations were carried out using a Schlenk adaptor for the J. Young NMR tubes, enabling 
the addition of oxidant under a counterflow of argon. While having the NMR tube positioned in the Schlenk adaptor, the lower part of the tube was simultaneously immersed in a dry ice/acetone mixture $\left(-78{ }^{\circ} \mathrm{C}\right)$ in a Dewar to preserve the integrity of oxidized nanoring complexes. After the first addition of oxidant, the samples were kept at low-temperatures throughout the titration experiments using either a dry ice/acetone Dewar or the $\mathrm{N}_{2}$ cooling $\left(-50^{\circ} \mathrm{C}\right)$ as used for the NMR probe. Only during transfers ( $\leq 30$ seconds) from the NMR instrument to the Dewar or from the NMR tube adaptor to the Dewar were the samples momentarily subjected to room temperature conditions. Prior to each titration, a ${ }^{1} \mathrm{H}$ spectrum was recorded at $298 \mathrm{~K}$ to confirm integrity and purity of the porphyrin nanoring complex. At the end of a titration, the oxidized porphyrin nanoring complex was reduced (using decamethylferrocene) back to recover the neutral state, as confirmed by ${ }^{1} \mathrm{H}$ NMR at $298 \mathrm{~K}$. The titration endpoint (at which each porphyrin unit is oxidized to the 1+ state) is evident from the disappearance of the neutral oxidant (thianthrene) ${ }^{1} \mathrm{H}$ signals, resulting from signal broadening caused by exchange between neutral thianthrene and excess thianthrenium. 


\section{Overview of Porphyrin Nanoring Complexes}

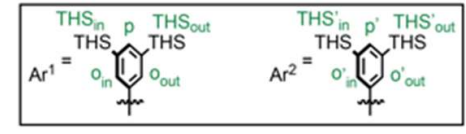
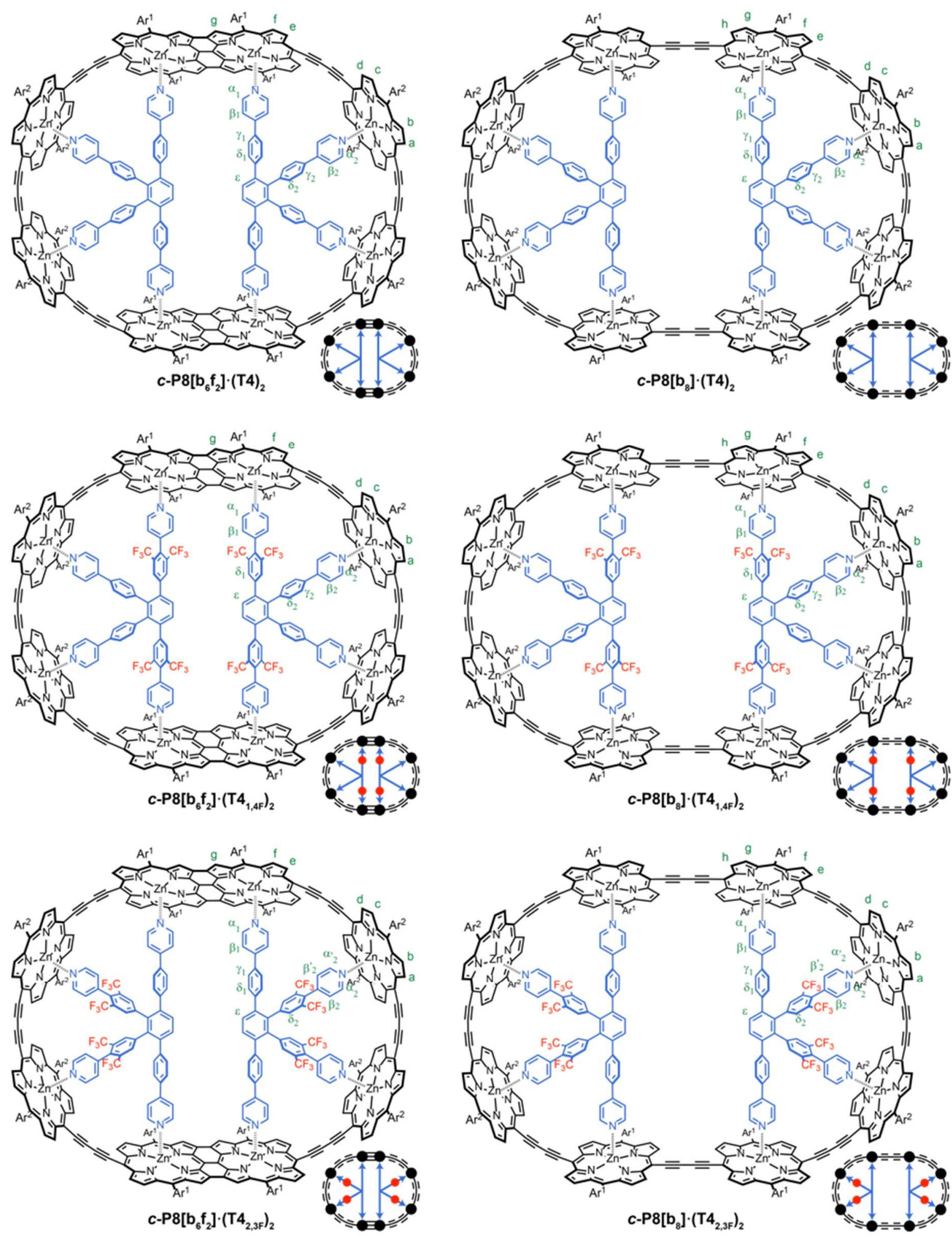

Figure S1. Overview of all nanoring-template complexes included in this study. $\mathrm{Ar}^{1}=\mathrm{Ar}^{2}=3,5$-bis(trihexylsilyl)phenyl. 


\section{Synthetic Procedures}

Porphyrin derivatives: $\mathbf{P 1},{ }^{5}$ Si-I-P1-H, ${ }^{6}$ sl-P2, ${ }^{7} \mathbf{B r}-\mathbf{s} /-\mathbf{P 2}-\mathbf{B r},{ }^{7} \mathbf{B r}-\mathbf{I}-\mathbf{P 2}\left[\mathbf{f}_{1}\right]-\mathbf{B r},{ }^{7}$ and $\mathbf{S i}-I-\mathbf{P} 4\left[\mathbf{b}_{3}\right]-\mathbf{S i}{ }^{6}$ as well as template precursors: $1,2,3,4$-tetrabromobenzene, ${ }^{8}$ 1,4-bis(trimethylsilyl)-2,3-dibromobenzene, ${ }^{9}$ and arylboronic acid pinacol esters $\mathbf{1}^{10}$ and $\mathbf{2}^{4}$ were synthesized as reported previously (Scheme S1).

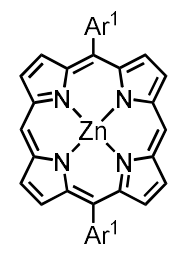

P1

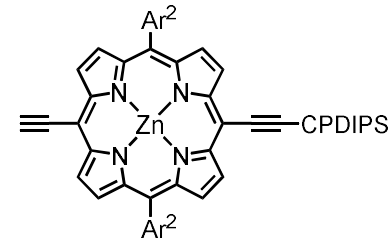

Si-I-P1-H<smiles></smiles><smiles>[Mg]c1ccc(Br)c(Br)c1Br</smiles><smiles>Brc1ccc(-c2ccccc2)cc1</smiles>

1<smiles>FC(F)(F)c1c[12cH]c(-c2ccncc2)c(C(F)(F)F)c1</smiles>

2

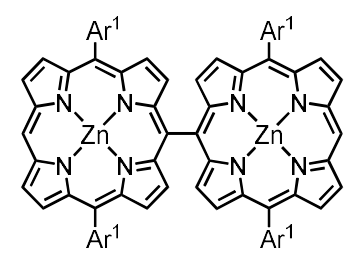

sl-P2

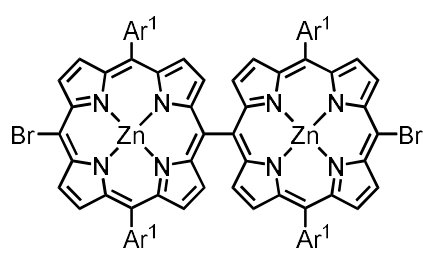

$\mathrm{Br}-\mathrm{s} / \mathrm{P} 2-\mathrm{Br}$

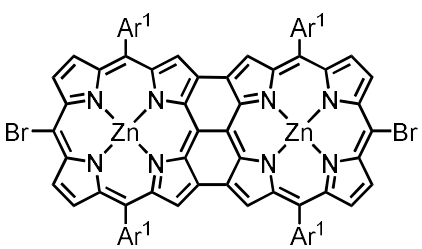

$\mathrm{Br}-\mathrm{l}-\mathrm{P} 2\left[\mathrm{f}_{1}\right]-\mathrm{Br}$

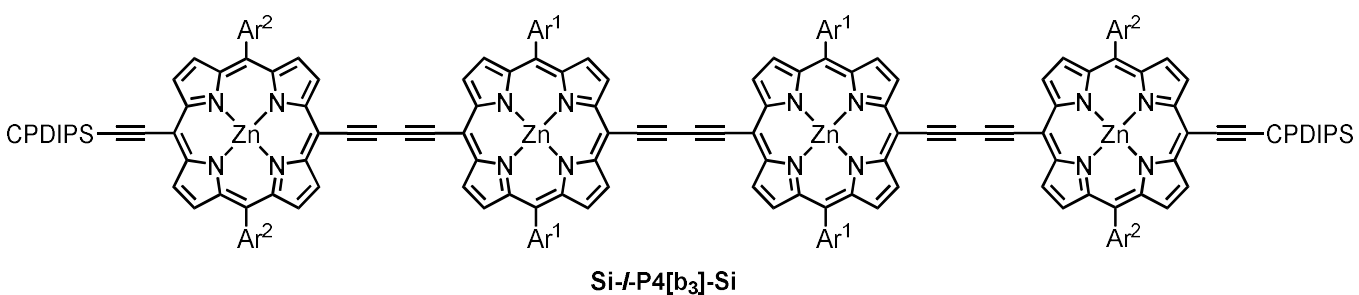

Scheme S1. Compounds prepared according to reported procedures. 


\section{Synthesis of $c-\mathrm{P} 8\left[\mathrm{~b}_{6} \mathrm{f}_{2}\right] \cdot(\mathrm{T} 4)_{2}, c-\mathrm{P} 8\left[\mathrm{~b}_{6} \mathrm{f}_{2}\right] \cdot\left(\mathrm{T} 4_{1,4 F}\right)_{2}$, and $c-\mathrm{P} 8\left[\mathrm{~b}_{6} \mathrm{f}_{2}\right]_{\bullet}\left(\mathrm{T} 4_{2,3 F}\right)_{2}$}

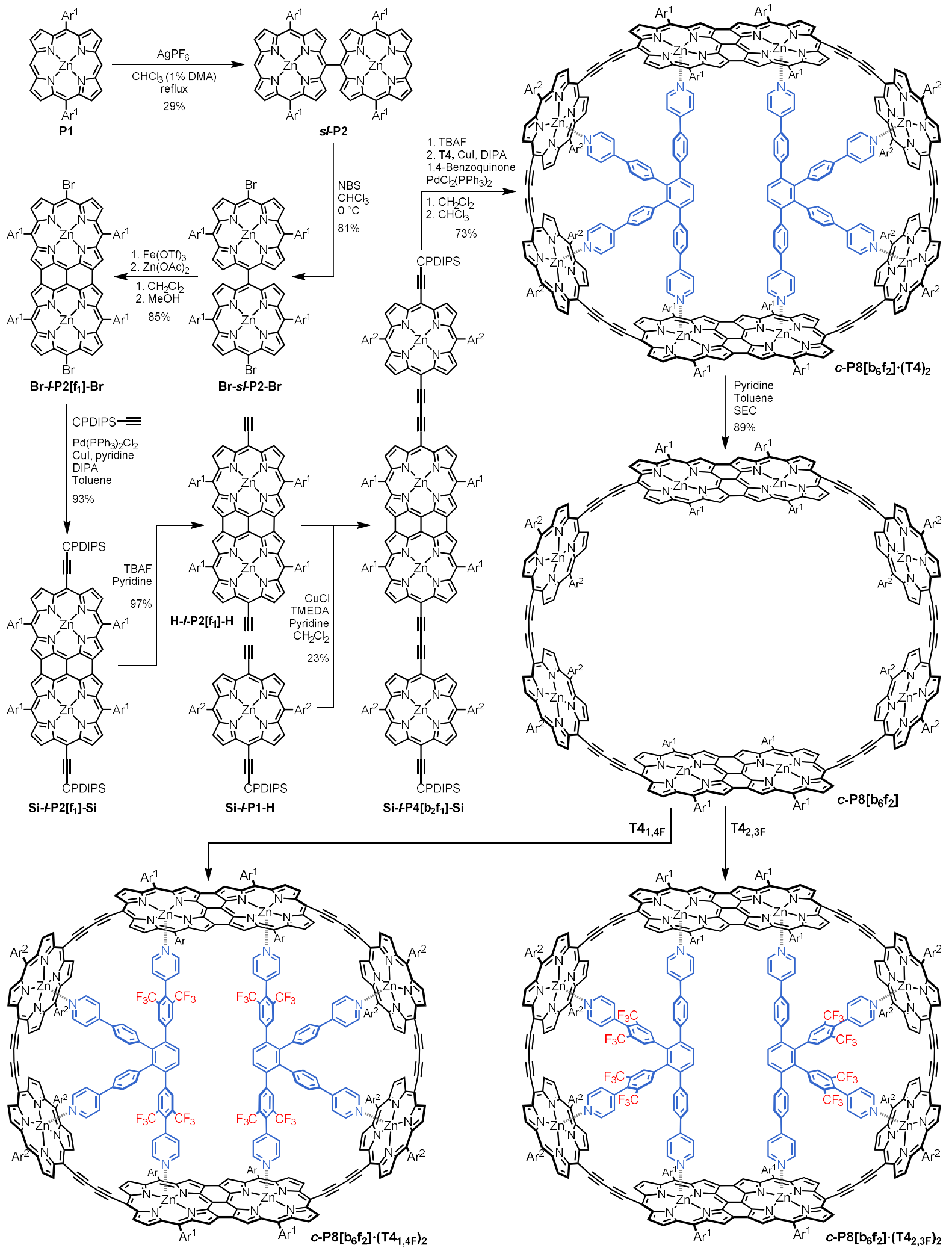

Scheme S2. Synthesis of $c-P 8\left[b_{6} f_{2}\right] \bullet(T 4)_{2}$ and free $c-P 8\left[b_{6} f_{2}\right]$, and preparation of fluorinated complexes $c-P 8\left[b_{6} f_{2}\right] \bullet\left(T 41_{1,4 F}\right)_{2}$

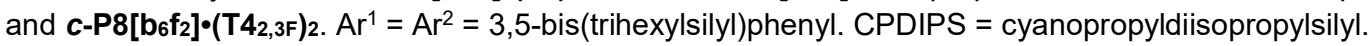




\section{Si-I-P2[f $]_{1}-\mathrm{Si}:$}

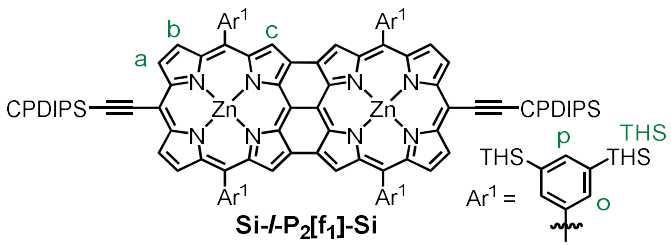

In a Schlenk flask, bromo-porphyrin dimer $\mathrm{Br}-\mathrm{I}-\mathrm{P2}\left[\mathrm{f}_{1}\right]-\mathrm{Br}\left(380 \mathrm{mg}, 0.110 \mathrm{mmol}, 1\right.$ equiv.), $\mathrm{Pd}\left(\mathrm{PPh}_{3}\right)_{2} \mathrm{Cl}_{2}(16 \mathrm{mg}$, $0.023 \mathrm{mmol})$, and Cul $(5 \mathrm{mg}, 0.026 \mathrm{mmol})$ were dissolved in toluene $(11 \mathrm{~mL}), i-\mathrm{Pr}_{2} \mathrm{NH}(2 \mathrm{~mL})$, and pyridine $(0.3$ $\mathrm{mL}$ ) and subjected to three freeze-pump-thaw cycles. Cyanopropyldiisopropylsilylacetylene $(104 \mu \mathrm{L}, 0.456$ mmol, 4 equiv.) was added and the reaction mixture heated to $50^{\circ} \mathrm{C}$. After stirring for 2 hours, the mixture was cooled to room temperature, and the volatiles were removed in vacuo. The crude mixture was purified by flash column chromatography $\left(\mathrm{SiO}_{2}\right.$; eluent: $\left.40 \% \mathrm{CH}_{2} \mathrm{Cl}_{2} / \mathrm{PE}_{40-60}\right)$ to afford the desired product $\mathbf{S i - I - P 2 [ f _ { 1 } ] - S i ~ ( 3 8 0 ~ m g , ~}$ 93\%) as a dark green solid.

${ }^{1} \mathrm{H}$ NMR $\left(500 \mathrm{MHz}, \mathrm{CDCl}_{3}, 298 \mathrm{~K}\right) \delta_{\mathrm{H}}=8.41(\mathrm{~d}, J=4.6 \mathrm{~Hz}, 4 \mathrm{H}, \mathrm{a}), 7.81(\mathrm{~s}, 4 \mathrm{H}, \mathrm{p}), 7.78(\mathrm{~s}, 8 \mathrm{H}, 0), 7.47(\mathrm{~d}, J=$ $4.6 \mathrm{~Hz}, 4 \mathrm{H}, \mathrm{b}), 7.06(\mathrm{~s}, 4 \mathrm{H}, \mathrm{c}), 2.44\left(\mathrm{t}, J=6.8 \mathrm{~Hz}, 4 \mathrm{H}, \mathrm{CPDIPS}-\mathrm{CH}_{2}\right), 2.04-1.95\left(\mathrm{~m}, 4 \mathrm{H}, \mathrm{CPDIPS}-\mathrm{CH}_{2}\right), 1.01-$ $0.97\left(\mathrm{~m}, 4 \mathrm{H}, \mathrm{CPDIPS}-\mathrm{CH}_{2}\right), 1.45-0.75\left(\mathrm{~m}, 340 \mathrm{H}\right.$, THS + CPDIPS-CH + CPDIPS-CH $\mathrm{CH}_{3} \mathrm{ppm}$. MALDI-ToF $\mathrm{m} / \mathrm{z}$ 3714.257 (calculated for $\left[\mathrm{C}_{232} \mathrm{H}_{376} \mathrm{~N}_{10} \mathrm{Si}_{10} \mathrm{Zn}_{2}\right]^{+}:$3714.604). UV-vis-NIR $\left(\mathrm{CDCl}_{3}\right) \lambda_{\max }(\log \varepsilon): 1133$ (4.60), 994 (4.42), 580 (5.28), 487 (4.76), 438 (5.20).

\section{H-I-P2[f 1 -H:}

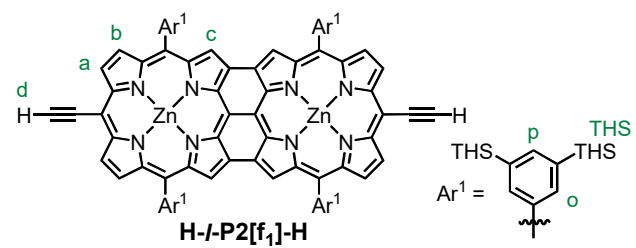

Si-I-P2[f 1 -Si (80 mg, $21.5 \mu \mathrm{mol})$ was dissolved in $\mathrm{CH}_{2} \mathrm{Cl}_{2}(10 \mathrm{~mL})$ and pyridine $(0.1 \mathrm{~mL})$. TBAF $(1.0 \mathrm{M}$ in THF, $0.25 \mathrm{~mL}, 0.25 \mathrm{mmol}$ ) was added and the reaction mixture was stirred for 25 minutes at room temperature before being passed through a pad of silica (eluent: $60 \% \mathrm{CHCl}_{3} / \mathrm{PE}_{40-60}+1 \%$ pyridine). The volatiles were removed in vacuo to afford $\mathbf{H}-\mathbf{I}-\mathbf{P} 2\left[\mathbf{f}_{1}\right]-\mathbf{H}(70 \mathrm{mg}, \mathbf{9 7 \%})$ as a green solid.

${ }^{1} \mathrm{H}$ NMR $\left(400 \mathrm{MHz}, \mathrm{CDCl}_{3}, 298 \mathrm{~K}\right) \delta_{\mathrm{H}}=8.45(\mathrm{~d}, J=4.7 \mathrm{~Hz}, 4 \mathrm{H}, \mathrm{a}), 7.81(\mathrm{~d}, J=1.2 \mathrm{~Hz}, 4 \mathrm{H}, \mathrm{p}), 7.80(\mathrm{~d}, J=1.2$ $\mathrm{Hz}, 8 \mathrm{H}, 0), 7.48$ (d, $J=4.7 \mathrm{~Hz}, 4 \mathrm{H}, \mathrm{b}), 7.08(\mathrm{~s}, 4 \mathrm{H}, \mathrm{c}), 3.77$ (s, 2H, d), 1.43-0.79 (m, 312H, THS) ppm.

\section{$\mathrm{Si}-\mathrm{I}-\mathrm{P} 4\left[\mathrm{~b}_{2} \mathrm{f}_{1}\right]-\mathrm{Si}:$}
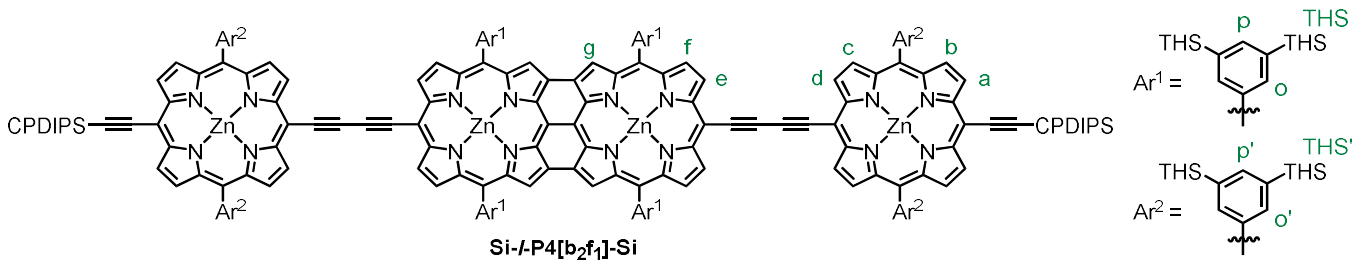

In a $500 \mathrm{~mL}$ round bottom flask, $\mathbf{H}-\mathbf{I}-\mathbf{P} 2\left[\mathbf{f}_{1}\right]-\mathbf{H}(70 \mathrm{mg}, 20.9 \mu \mathrm{mol})$ and $\mathbf{S i - I - P 1 - H ~}(240 \mathrm{mg}, 0.127 \mathrm{mmol})$ were dissolved in $\mathrm{CH}_{2} \mathrm{Cl}_{2}(10 \mathrm{~mL})$ and pyridine $(0.1 \mathrm{~mL})$. CuCl $(167 \mathrm{mg}, 1.69 \mathrm{mmol})$ and TMEDA $(0.25 \mathrm{~mL})$ were added, and the mixture was stirred vigorously under an oxygen rich atmosphere. After 35 minutes, the reaction was filtered through a pad of silica (eluent: $\mathrm{CHCl}_{3}+1 \%$ pyridine) and concentrated in vacuo. The crude residue was purified by SEC (toluene $+1 \%$ pyridine) and further purified by recycling GPC (toluene $+1 \%$ pyridine) to afford $\mathbf{S i - I - P 4}\left[\mathbf{b}_{2} \mathbf{f}_{1}\right]-\mathbf{S i}(35 \mathrm{mg}, 23 \%)$ as a green solid. 
${ }^{1} \mathrm{H}$ NMR $\left(500 \mathrm{MHz}, \mathrm{CDCl}_{3}, 298 \mathrm{~K}\right) \delta_{\mathrm{H}}=9.73(\mathrm{~d}, J=4.6 \mathrm{~Hz}, 4 \mathrm{H}, \mathrm{d}), 9.63(\mathrm{~d}, J=4.6 \mathrm{~Hz}, 4 \mathrm{H}, \mathrm{a}), 8.88(\mathrm{~d}, J=$ $4.6 \mathrm{~Hz}, 4 \mathrm{H}, \mathrm{c}$ ), 8.86 (d, J = 4.6 Hz, 4H, b), 8.59 (d, J = 4.5 Hz, 4H, e), 8.23 (s, o'), 7.99 (s, 4H, p'), 7.81 (s, 4H, p), $7.80(\mathrm{~s}, 8 \mathrm{H}, 0) 7.48(\mathrm{~d}, J=4.5 \mathrm{~Hz}, 4 \mathrm{H}, \mathrm{f}), 6.96(\mathrm{~s}, 4 \mathrm{H}, \mathrm{g}), 2.54\left(\mathrm{t}, J=6.8 \mathrm{~Hz}, 4 \mathrm{H}, \mathrm{CPDIPS}-\mathrm{CH}_{2}\right), 2.23-2.16(\mathrm{~m}$, $4 \mathrm{H}$, CPDIPS- $\left.\mathrm{CH}_{2}\right), 1.19-1.14\left(\mathrm{~m}, 4 \mathrm{H}\right.$, CPDIPS- $\left.\mathrm{CH}_{2}\right), 1.55-0.64(\mathrm{~m}, 652 \mathrm{H}, \mathrm{THS}+\mathrm{THS}+\mathrm{CPDIPS}-\mathrm{CH}+$ CPDIPS-CH $\left.{ }_{3}\right)$ ppm. ${ }^{13} \mathrm{C}$ NMR $\left(126 \mathrm{MHz}, \mathrm{CDCl}_{3}, 298 \mathrm{~K}\right) \delta \mathrm{C}=155.9,154.8,154.2,153.3,153.1,152.3,150.8$, $150.5,144.9,140.5,139.3,139.0,138.8,136.5,135.3,135.0,133.3,133.1,132.3,130.9,129.4,127.7,124.6$, 123.2, 119.9, 101.3, 33.7, 33.6, 31.8, 31.7, 31.1, 29.9, 24.2, 24.1, 22.82, 22.79, 21.8, 21.2, 18.8, 18.5, 14.3, $12.79,12.77,12.6,12.5,10.3,1.2 \mathrm{ppm}$. MALDI-ToF $\mathrm{m} / \mathrm{z} 7123.020$ (calculated for $\left[\mathrm{C}_{448} \mathrm{H}_{716} \mathrm{~N}_{18} \mathrm{Si}_{18} \mathrm{Zn}_{4}\right]^{+}$: 7121.974). UV-vis-NIR ( $\left.\mathrm{CDCl}_{3}\right) \lambda_{\max }(\log \varepsilon): 1137$ (5.08), 992 (4.78), 687 (5.16), 583 (5.27), 443 (5.73).

\section{$H-I-P 4\left[b_{2} f_{1}\right]-H:$}
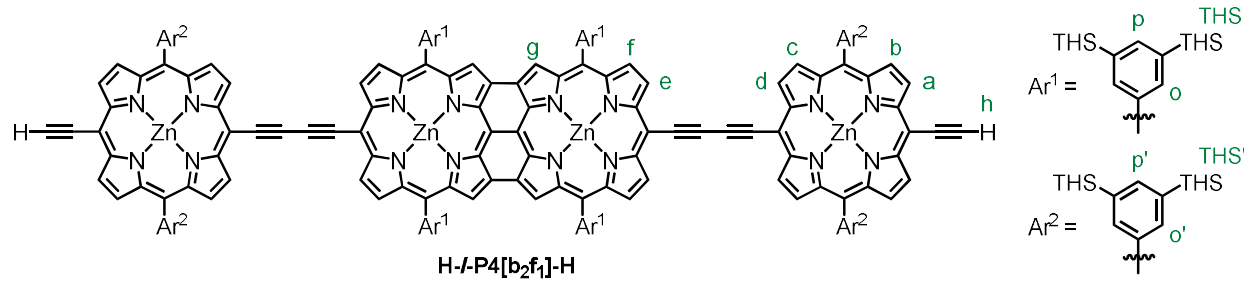

Si-I-P4[ $\left.\mathbf{b}_{2} \mathrm{f}_{1}\right]-\mathrm{Si}(5.60 \mathrm{mg}, 0.789 \mu \mathrm{mol})$ was dissolved in $\mathrm{CH}_{2} \mathrm{Cl}_{2}(2 \mathrm{~mL})$ and pyridine $(0.02 \mathrm{~mL})$. TBAF (1.0 $\mathrm{M}$ in THF, $0.08 \mathrm{~mL}, 0.08 \mathrm{mmol}$ ) was added and the reaction mixture was stirred for 25 minutes at room temperature before being passed through a pad of silica (eluent: $20 \% \mathrm{CH}_{2} \mathrm{Cl}_{2} / \mathrm{PE}_{40-60}+1 \%$ pyridine). The volatiles were removed in vacuo to afford $\mathbf{H}-\mathbf{I}-\mathbf{P} \mathbf{4}\left[\mathbf{b}_{2} \mathbf{f}_{1}\right]-\mathbf{H}(5.05 \mathrm{mg}, 95 \%)$ as a green solid.

${ }^{1} \mathrm{H} \mathrm{NMR}\left(400 \mathrm{MHz}, \mathrm{CDCl}_{3}\right) \delta \mathrm{H}=9.80(\mathrm{~d}, J=4.6 \mathrm{~Hz}, 4 \mathrm{H}, \mathrm{d}), 9.72(\mathrm{~d}, J=4.6 \mathrm{~Hz}, 4 \mathrm{H}, \mathrm{a}), 8.96(\mathrm{~d}, J=4.6 \mathrm{~Hz}, 4 \mathrm{H}$, c), $8.92(\mathrm{~d}, J=4.6 \mathrm{~Hz}, 4 \mathrm{H}, \mathrm{b}), 8.67(\mathrm{~d}, J=4.6 \mathrm{~Hz}, 4 \mathrm{H}, \mathrm{e}), 8.27$ (d, $\left.J=1.1 \mathrm{~Hz}, 8 \mathrm{H}, o^{\prime}\right), 8.01$ (t, $\left.J=1.1 \mathrm{~Hz}, 4 \mathrm{H}, \mathrm{p}^{\prime}\right)$, $7.85(\mathrm{~d}, J=1.2 \mathrm{~Hz}, 8 \mathrm{H}, 0), 7.84(\mathrm{~d}, J=1.2 \mathrm{~Hz}, 4 \mathrm{H}, \mathrm{p}), 7.57(\mathrm{~d}, J=4.6 \mathrm{~Hz}, 4 \mathrm{H}, \mathrm{f}), 7.08(\mathrm{~s}, 4 \mathrm{H}, \mathrm{h}), 4.19(\mathrm{~s}, 2 \mathrm{H}, \mathrm{h})$, $1.49-0.80(\mathrm{~m}, 624 \mathrm{H}, \mathrm{THS}+\mathrm{THS}) \mathrm{ppm}$.

\section{Complex c-P8[ $\left[b_{6} f_{2}\right] \cdot(T 4)_{2}$ :}
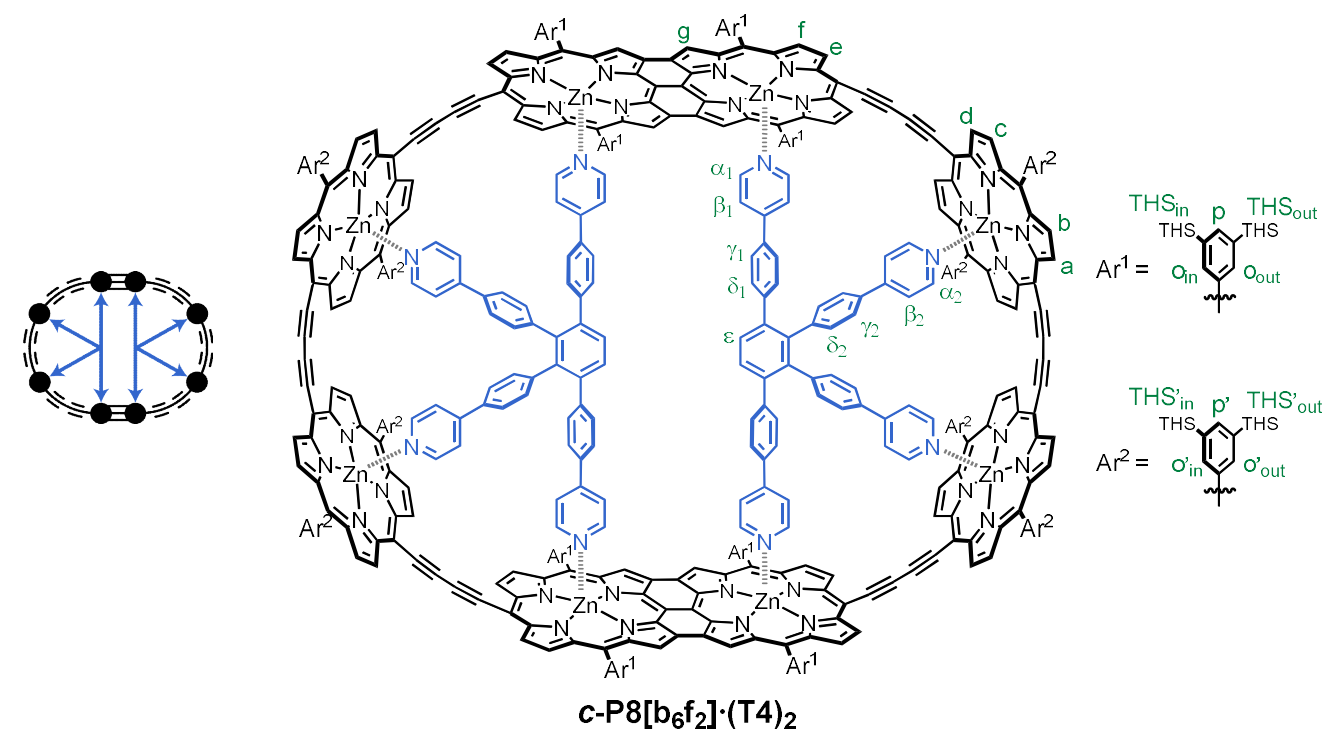

Procedure A: H-I-P4[ $\left.\mathbf{b}_{2} \mathbf{f}_{1}\right]-\mathbf{H}(5.05 \mathrm{mg}, 0.747 \mu \mathrm{mol})$ and T4 $(0.52 \mathrm{mg}, 0.753 \mu \mathrm{mol})$ were dissolved in $\mathrm{CHCl}_{3}(2$ $\mathrm{mL})$ and sonicated for 2 hours to allow for the complex formation. A catalyst mixture of $\mathrm{PdCl}_{2}\left(\mathrm{PPh}_{3}\right)_{2}(0.33 \mathrm{mg}$, $0.470 \mu \mathrm{mol})$, Cul $(0.47 \mathrm{mg}, 2.47 \mu \mathrm{mol}), 1,4$-benzoquinone $(1.08 \mathrm{mg}, 10.0 \mu \mathrm{mol})$, and $i-\mathrm{Pr}_{2} \mathrm{NH}(15 \mu \mathrm{L})$ in $\mathrm{CHCl}_{3}$ $(0.5 \mathrm{~mL})$ was added, and the reaction progress was monitored by analytical GPC (THF $+1 \%$ pyridine). After 4 hours, the mixture was passed through a pad of silica (eluent: $\mathrm{CHCl}_{3}+1 \%$ pyridine) and concentrated in vacuo. 
The resulting residue was purified by SEC (toluene $+1 \%$ pyridine) before further purification by recycling GPC (toluene $+1 \%$ pyridine) to afford $\boldsymbol{c}-\mathbf{P} 8\left[\mathbf{b}_{6} \mathbf{f}_{2}\right] \cdot(\mathbf{T 4})_{2}(4.00 \mathrm{mg}, 72 \%)$ as a brown solid and analytical amounts of $\mathbf{H}-\mathbf{I}-$ $\mathbf{P} 8\left[b_{5} f_{2}\right]-H$ as a green solid. Additional $c-P 8\left[b_{6} f_{2}\right] \cdot(T 4)_{2}$ was synthesized in two larger batches following

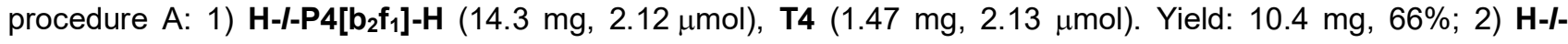
P4[ $\left.\mathbf{b}_{2} \mathrm{f}_{1}\right]-\mathbf{H}(17.4 \mathrm{mg}, 2.57 \mu \mathrm{mol}), \mathbf{T} 4(1.79 \mathrm{mg}, 2.59 \mu \mathrm{mol})$. Yield: $12.1 \mathrm{mg}, 63 \%$.

Procedure $B$ (reduced equivalents of $\mathrm{Cul}$ ): Following the general approach of procedure $\mathbf{A}, \mathbf{H}-\mathbf{I}-\mathbf{P} \mathbf{4}\left[\mathbf{b}_{\mathbf{2}} \mathbf{f}_{1}\right]-\mathbf{H}(16.3$ $\mathrm{mg}, 2.41 \mu \mathrm{mol})$ and $\mathrm{T} 4(2.34 \mathrm{mg}, 3.39 \mu \mathrm{mol})$ were reacted using an adapted catalyst mixture of $\mathrm{PdCl}_{2}\left(\mathrm{PPh}_{3}\right)_{2}$ $(1.06 \mathrm{mg}, 1.51 \mu \mathrm{mol})$, Cul $(0.54 \mathrm{mg}, 2.84 \mu \mathrm{mol}), 1,4$-benzoquinone $(3.49 \mathrm{mg}, 32.3 \mu \mathrm{mol})$, and $i-\operatorname{Pr}_{2} \mathrm{NH}(48 \mu \mathrm{L})$. The reaction was monitored by analytical GPC (THF $+1 \%$ pyridine) and stopped after 14 hours when a 1:2 ratio of $\mathbf{H}-\mathbf{I}-\mathbf{P} 8\left[\mathbf{b}_{5} \mathbf{f}_{2}\right]-\mathbf{H}$ and $\boldsymbol{c}-\mathbf{P} 8\left[\mathbf{b}_{6} \mathbf{f}_{2}\right] \cdot(\mathbf{T} 4)_{2}$ was reached. Workup and purification as described in procedure A gave $\mathbf{H}-\mathbf{I}-\mathbf{P} \mathbf{8}\left[\mathbf{b}_{5} \mathbf{f}_{2}\right]-\mathbf{H}(1.36 \mathrm{mg}, \mathbf{8} \%)$ for full characterization.

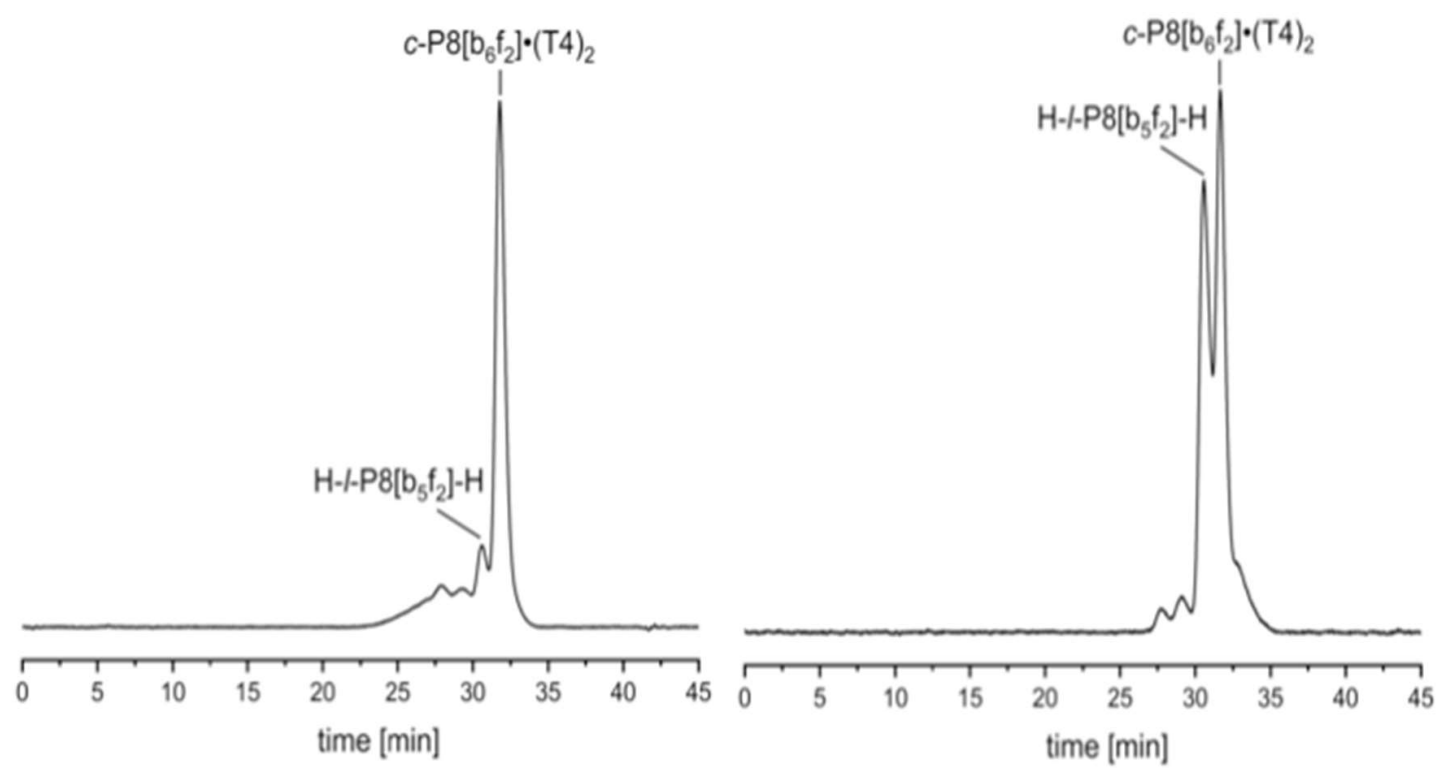

Figure S2. Analytical GPC traces (THF $+1 \%$ pyridine, $\lambda=440 \mathrm{~nm}$ ) for the synthesis of $\boldsymbol{c}-\mathbf{P} \mathbf{8}\left[\mathbf{b}_{6} \mathbf{f}_{2} \mathbf{b}_{\bullet}\left(\mathrm{T}_{4}\right)_{2}\right.$ following procedure A after 4 hours (left) and the adapted synthesis of $\mathbf{H}-\mathbf{I}-\mathbf{P} 8\left[\mathbf{b}_{5} \mathbf{f}_{2}\right]-\mathbf{H}$ following procedure $B$ after 14 hours (right).

Characterization of $c-P 8\left[b_{6} f_{2}\right] \cdot(T 4)_{2}$ :

${ }^{1} \mathrm{H}$ NMR $\left(600 \mathrm{MHz}, \mathrm{CD}_{2} \mathrm{Cl}_{2}, 298 \mathrm{~K}\right) \delta \mathrm{H}=9.58(\mathrm{~d}, J=4.3 \mathrm{~Hz}, 8 \mathrm{H}, \mathrm{a}), 9.45(\mathrm{~d}, J=4.3 \mathrm{~Hz}, 8 \mathrm{H}, \mathrm{d}), 8.78(\mathrm{~d}, J=4.3$ $\mathrm{Hz}, 8 \mathrm{H}, \mathrm{b}$ ), 8.72 (d, J = 4.3 Hz, 8H, c), 8.40 (s, 8H, o' in), 8.27 (d, J = 4.3 Hz, 8H, e), 8.02 (s, 8H, o'out), 7.99 (s,

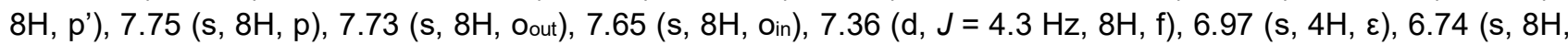
g), $6.50\left(\mathrm{~d}, J=8.7 \mathrm{~Hz}, 8 \mathrm{H}, \mathrm{Y}_{1}\right), 6.40\left(\mathrm{~d}, J=8.7 \mathrm{~Hz}, 8 \mathrm{H}, \delta_{1}\right), 6.34\left(\mathrm{~d}, J=6.4 \mathrm{~Hz}, 8 \mathrm{H}, \beta_{1}\right), 5.87(\mathrm{~d}, J=8.8 \mathrm{~Hz}, 8 \mathrm{H}$, $\left.\delta_{2}\right), 5.75\left(\mathrm{~d}, J=8.8 \mathrm{~Hz}, 8 \mathrm{H}, \mathrm{\gamma}_{2}\right), 5.59\left(\mathrm{~d}, J=6.4 \mathrm{~Hz}, 8 \mathrm{H}, \alpha_{1}\right), 5.23\left(\mathrm{~d}, J=6.2 \mathrm{~Hz}, 8 \mathrm{H}, \beta_{2}\right), 2.41(\mathrm{~d}, J=6.2 \mathrm{~Hz}, 8 \mathrm{H}$,

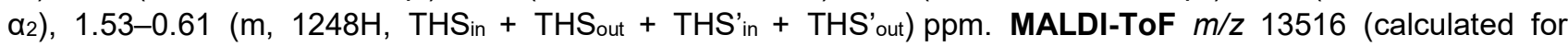
$\left[\mathrm{C}_{856} \mathrm{H}_{1352} \mathrm{~N}_{32} \mathrm{Si}_{32} \mathrm{Zn}\right]^{+}=\boldsymbol{c}-\mathbf{P 8}\left[\mathbf{b}_{6} \mathbf{f}_{2}\right]^{+}:$13513). UV-vis-NIR $\left(\mathrm{CDCl}_{3}\right) \lambda_{\max }(\log \varepsilon): 1304$ (5.49), 1254 (5.31), 1122 (5.17), 872 (5.39), 735 (5.31), 592 (5.58), 502 (5.64), 439 (5.71). 
Characterization for $\mathrm{H}-\mathrm{I}-\mathrm{P} 8\left[\mathrm{~b}_{5} \mathrm{f}_{2}\right]-\mathrm{H}$ :

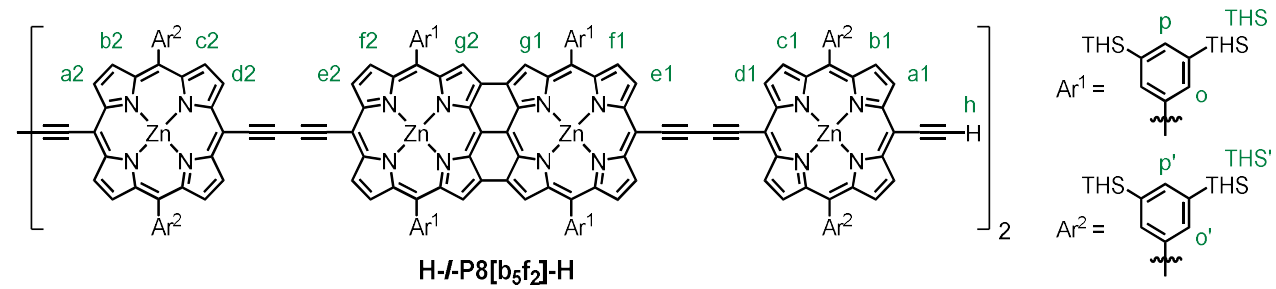

${ }^{1} \mathrm{H}$ NMR $\left(500 \mathrm{MHz}, \mathrm{CDCl}_{3}, 298 \mathrm{~K}\right) \delta \mathrm{H}=9.94(\mathrm{~d}, J=4.6 \mathrm{~Hz}, 4 \mathrm{H}, \mathrm{a} 1 / \mathrm{a} 2), 9.85-9.82(\mathrm{~m}, 4 \mathrm{H}, \mathrm{d} 1 / \mathrm{d} 2), 9.81(\mathrm{~d}, J=4.5$ $\mathrm{Hz}, 4 \mathrm{H}, \mathrm{d} 1 / \mathrm{d} 2), 9.54$ (d, $J=4.6 \mathrm{~Hz}, 4 \mathrm{H}, \mathrm{a} 1 / \mathrm{a} 2), 9.01$ (d, $J=4.6 \mathrm{~Hz}, 4 \mathrm{H}, \mathrm{b} 1 / \mathrm{b} 2), 8.99(\mathrm{~d}, J=4.5 \mathrm{~Hz}, 4 \mathrm{H}, \mathrm{c} 1 / \mathrm{c} 2)$, $8.97(\mathrm{~d}, J=4.5 \mathrm{~Hz}, 4 \mathrm{H}, \mathrm{c} 1 / \mathrm{c} 2), 8.95(\mathrm{~d}, J=4.6 \mathrm{~Hz}, \mathrm{~b} 1 / \mathrm{b} 2), 8.70-8.66(\mathrm{~m}, 8 \mathrm{H}, \mathrm{e} 1+\mathrm{e} 2), 8.32\left(\mathrm{~s}, 8 \mathrm{H}, \mathrm{Ar}^{2} \mathrm{o}^{\prime}\right), 8.28$ (s, 8H, $\left.\mathrm{Ar}^{2} \mathrm{o}^{\prime}\right), 8.04\left(\mathrm{~s}, 4 \mathrm{H}, \mathrm{Ar}^{2} \mathrm{p}^{\prime}\right), 8.01\left(\mathrm{~s}, 4 \mathrm{H}, \mathrm{Ar}^{2} \mathrm{p}^{\prime}\right), 7.88-7.83\left(\mathrm{~m}, 24 \mathrm{H}, \mathrm{Ar}^{1}\right), 7.60-7.56(\mathrm{~m}, 8 \mathrm{H}, \mathrm{f} 1+\mathrm{f} 2), 7.09$ (s, 8H, g1+g2), 3.73-3.63 (m, 2H, h), 1.56-0.69 (m, 1248H, THS + THS') ppm. MALDI-ToF m/z 13591 (calculated for $\left[\mathrm{C}_{861} \mathrm{H}_{1359} \mathrm{~N}_{33} \mathrm{Si}_{32} \mathrm{Zn}_{8}\right]^{+}=$[H-I-P8[ $\left.\mathbf{b}_{5} \mathrm{f}_{2}\right]-\mathrm{H}+$ pyridine $]^{+}:$13595). UV-vis-NIR $\left(\mathrm{CDCl}_{3}\right) \lambda_{\max }(\log \varepsilon)$ : 1140 (5.51), 993 (5.20), 719 (5.33), 673 (5.41), 582 (5.62), 440 (5.96).

\section{Free ring $c-P 8\left[b_{6} f_{2}\right]$ :}
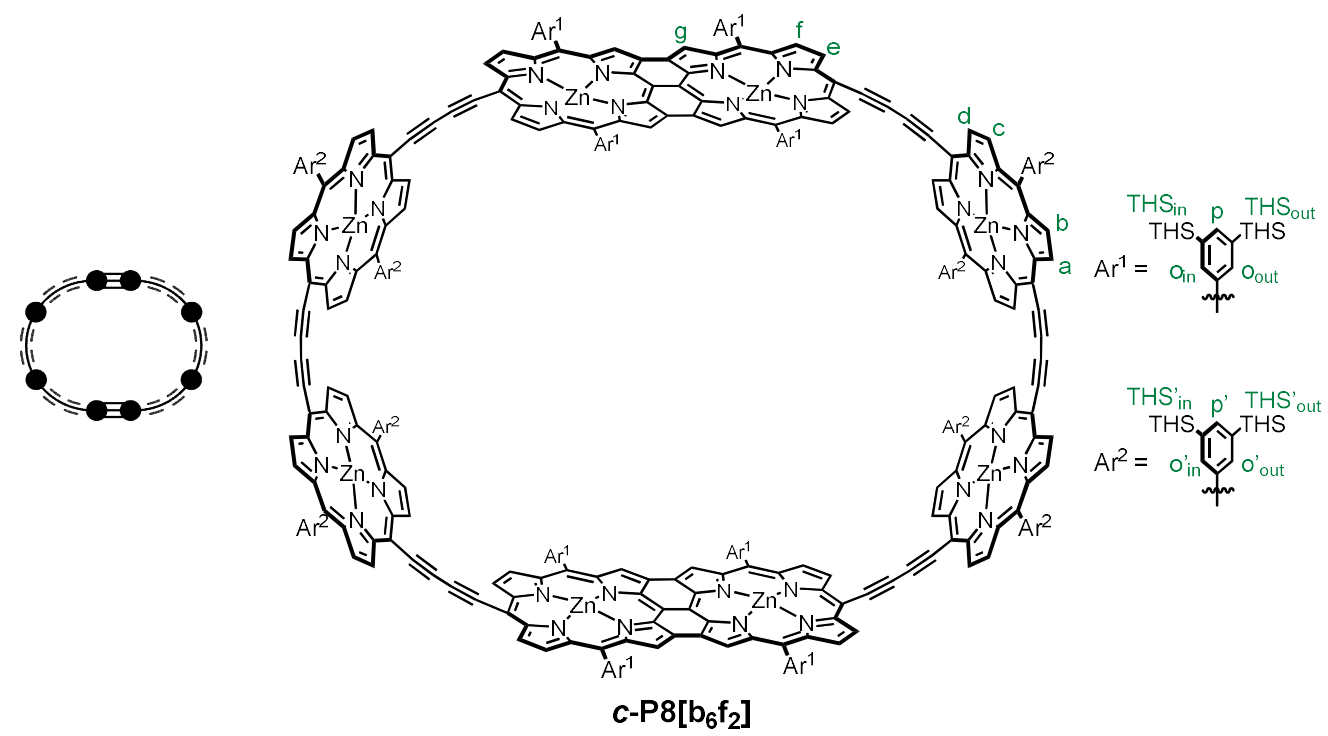

A 3.7 $\mathrm{M}(30 \%)$ solution of pyridine $(15 \mathrm{~mL})$ in toluene $(35 \mathrm{~mL})$ was eluted into a SEC column (toluene; diameter $=3.5 \mathrm{~cm}$; height $=25 \mathrm{~cm})$. A solution of the complex $c-\mathbf{P} 8\left[\mathbf{b}_{6} \mathbf{f}_{2}\right]^{\cdot}(\mathbf{T 4})_{2}(10.4 \mathrm{mg}, 0.698 \mu \mathrm{mol})$ in toluene $(5 \mathrm{~mL})$ was loaded onto the SEC column and eluted through the pyridine solution with additional toluene. The collected fraction was washed with water $(5 \times 50 \mathrm{~mL})$, dried over $\mathrm{MgSO}_{4}$, and concentrated in vacuo. The crude residue was further purified by SEC $\left(\mathrm{CHCl}_{3}\right)$ to afford free nanoring $\mathbf{c}-\mathbf{P} \mathbf{8}\left[\mathbf{b}_{6} \mathbf{f}_{2}\right](8.4 \mathrm{mg}, 89 \%)$ as a brown solid.

${ }^{1} \mathrm{H}$ NMR $\left(600 \mathrm{MHz}, \mathrm{CD}_{2} \mathrm{Cl}_{2}, 298 \mathrm{~K}\right) \delta_{\mathrm{H}}=9.72(\mathrm{~d}, J=4.5 \mathrm{~Hz}, 8 \mathrm{H}, \mathrm{a}), 9.61(\mathrm{~d}, J=4.5 \mathrm{~Hz}, 8 \mathrm{H}, \mathrm{d}), 8.85(\mathrm{~d}, J=4.5$ $\mathrm{Hz}, 8 \mathrm{H}, \mathrm{b}$ ), 8.81 (d, $J=4.5 \mathrm{~Hz}, 8 \mathrm{H}, \mathrm{c}), 8.51$ (d, $J=4.5 \mathrm{~Hz}, 8 \mathrm{H}, \mathrm{e}), 8.19\left(\mathrm{~s}, 16 \mathrm{H}, \mathrm{o}^{\prime}\right), 7.97$ (s, 8H, p'), $7.77(\mathrm{~s}, 8 \mathrm{H}$, p), $7.73(\mathrm{~s}, 16 \mathrm{H}, \mathrm{o}), 7.49(\mathrm{~d}, J=4.5 \mathrm{~Hz}, 8 \mathrm{H}, \mathrm{f}), 6.92(\mathrm{~s}, 8 \mathrm{H}, \mathrm{g}), 1.48-0.72(\mathrm{~m}, 1248 \mathrm{H}$, THS + THS') ppm. MALDIToF $\mathrm{m} / \mathrm{z} 13516$ (calculated for [ $\left.\mathrm{C}_{856} \mathrm{H}_{1352} \mathrm{~N}_{32} \mathrm{Si}_{32} \mathrm{Zn}_{8}\right]^{+}:$13513). UV-vis-NIR $\left(\mathrm{CDCl}_{3}\right) \lambda_{\max }(\log \varepsilon): 1158$ (5.32), 1009 (5.05), 782 (5.28), 691 (5.31), 585 (5.54), 491 (5.66), 435 (5.74) nm. 


\section{Complex $c-P 8\left[b_{6} f_{2}\right] \cdot\left(\mathrm{T}_{1,4 F}\right)_{2}$ :}
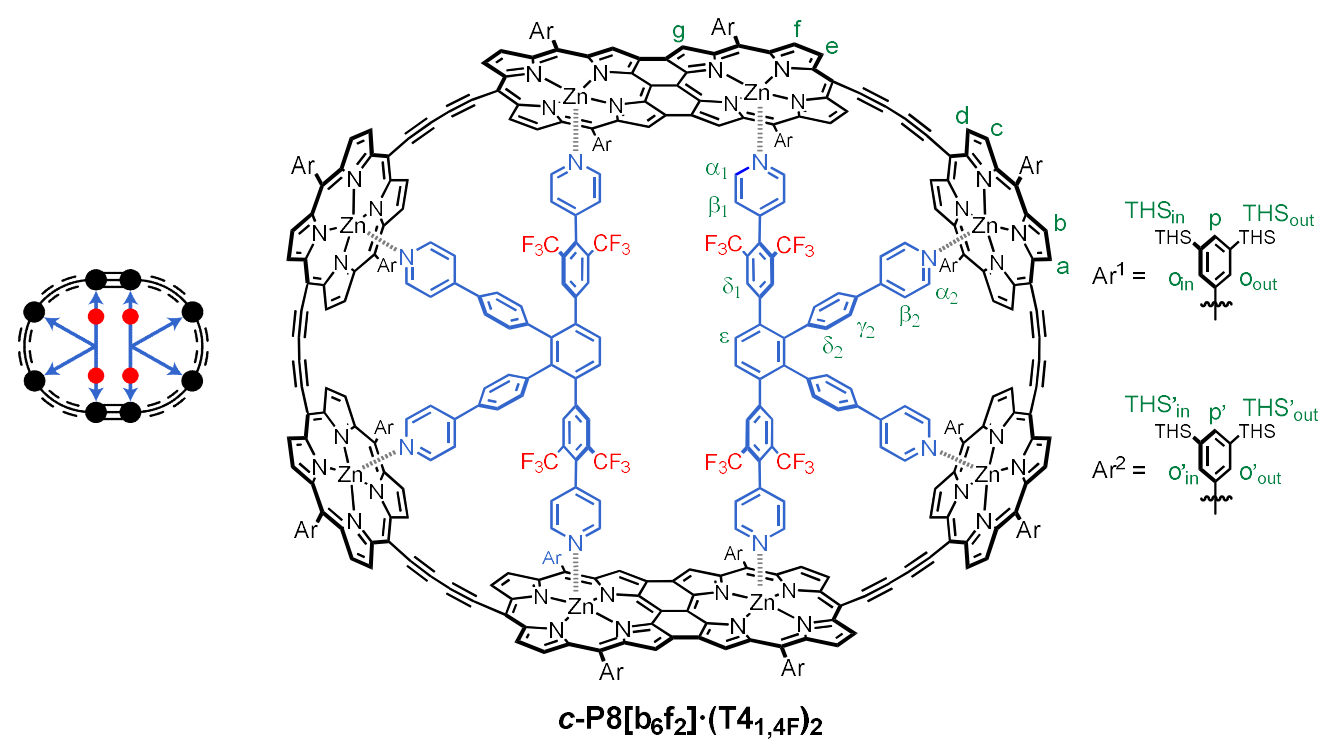

${ }^{1} \mathrm{H}$ NMR $\left(600 \mathrm{MHz}, \mathrm{CD}_{2} \mathrm{Cl}_{2}, 298 \mathrm{~K}\right) \delta_{\mathrm{H}}=9.57(\mathrm{~d}, J=4.3 \mathrm{~Hz}, 8 \mathrm{H}, \mathrm{a}), 9.49(\mathrm{~d}, J=4.4 \mathrm{~Hz}, 8 \mathrm{H}, \mathrm{d}), 8.79(\mathrm{~d}, J=4.3$ $\mathrm{Hz}, 8 \mathrm{H}, \mathrm{b}$ ), 8.75 (d, J = 4.4 Hz, 8H, c), 8.43 (s, 8H, o' in), 8.26 (d, J = 4.4 Hz, 8H, e), 8.05 (s, 8H, o'out), 8.03 (s, $\left.8 \mathrm{H}, \mathrm{p}^{\prime}\right), 7.74\left(\mathrm{~s}, 16 \mathrm{H}, \mathrm{p}+\mathrm{O}_{\text {out }}\right), 7.51\left(\mathrm{~s}, 8 \mathrm{H}, \mathrm{O}_{\text {in }}\right), 7.26(\mathrm{~d}, J=4.4 \mathrm{~Hz}, 8 \mathrm{H}, \mathrm{f}), 7.20(\mathrm{~s}, 4 \mathrm{H}, \varepsilon), 6.95\left(\mathrm{~s}, 8 \mathrm{H}, \delta_{1}\right), 6.72$ $(\mathrm{s}, 8 \mathrm{H}, \mathrm{g}), 6.07\left(\mathrm{~d}, J=6.2 \mathrm{~Hz}, 8 \mathrm{H}, \beta_{1}\right), 5.99\left(\mathrm{~d}, J=8.8 \mathrm{~Hz}, 8 \mathrm{H}, \delta_{2}\right), 5.90\left(\mathrm{~d}, J=8.8 \mathrm{~Hz}, 8 \mathrm{H}, \mathrm{\gamma}_{2}\right), 5.70(\mathrm{~d}, J=6.2$ $\left.\mathrm{Hz}, 8 \mathrm{H}, \alpha_{1}\right), 5.25\left(\mathrm{~d}, J=6.9 \mathrm{~Hz}, 8 \mathrm{H}, \beta_{2}\right), 2.51-2.46\left(\mathrm{~m}, 8 \mathrm{H}, \alpha_{2}\right), 1.64-0.55\left(\mathrm{~m}, 1248 \mathrm{H}, \mathrm{THS}_{\text {in }}+\mathrm{THS}_{\text {out }}+\mathrm{THS}_{\text {in }}+\right.$ THS' out) ppm. ${ }^{19} \mathrm{~F}$ NMR $\left(470 \mathrm{MHz}, \mathrm{CD}_{2} \mathrm{Cl}_{2}, 298 \mathrm{~K}\right) \delta \mathrm{F}=-60.63 \mathrm{ppm}$. MALDI-ToF $\mathrm{m} / \mathrm{z} 13515$ (calculated for $\left[\mathrm{C}_{856} \mathrm{H}_{1352} \mathrm{~N}_{32} \mathrm{Si}_{32} \mathrm{Zn} 8\right]^{+}=\boldsymbol{c}-\mathrm{P} 8\left[\mathrm{~b}_{6} \mathbf{f}_{2}\right]^{+}:$13513).

\section{Complex $c-P 8\left[b_{6} f_{2}\right] \cdot\left(T 4_{2,3 F}\right)_{2}$ :}
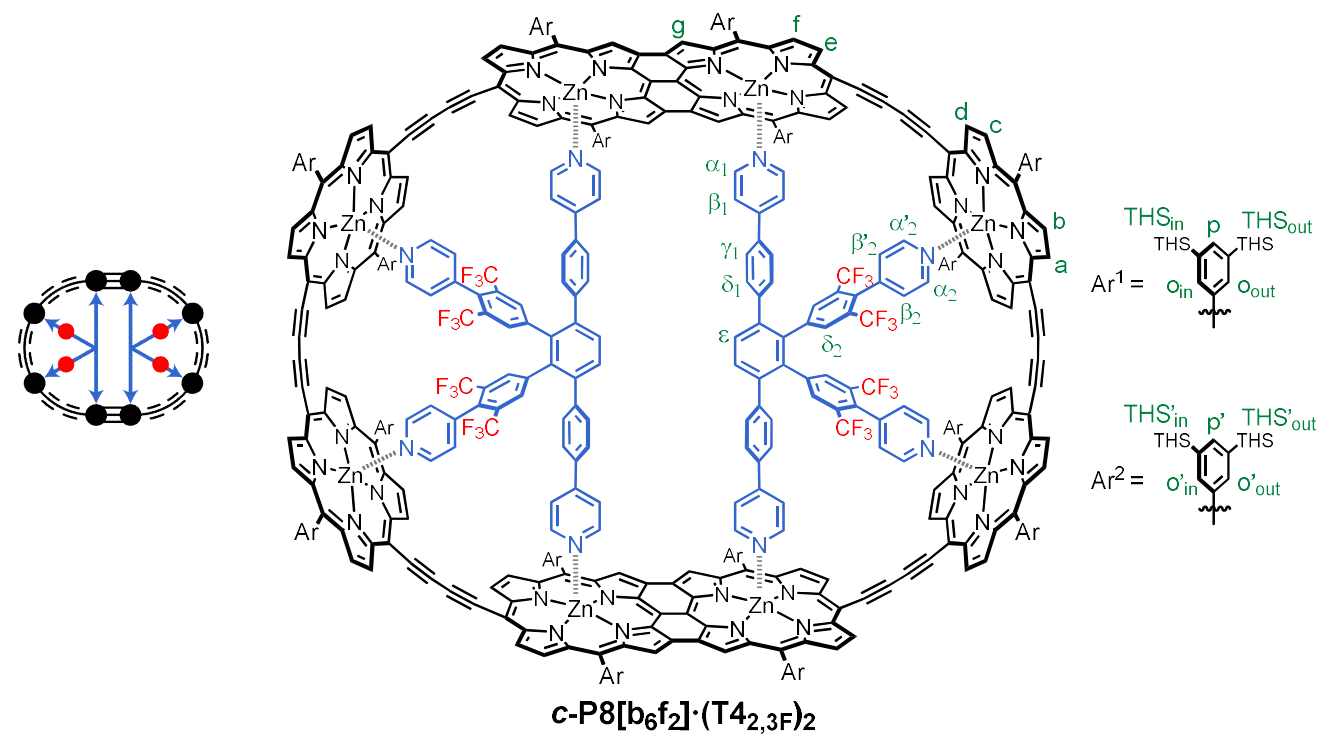

${ }^{1} \mathrm{H}$ NMR $\left(600 \mathrm{MHz}, \mathrm{CD}_{2} \mathrm{Cl}_{2}, 298 \mathrm{~K}\right) \delta_{\mathrm{H}}=9.67(\mathrm{~d}, J=4.4 \mathrm{~Hz}, 8 \mathrm{H}, \mathrm{a}), 9.46(\mathrm{~d}, J=4.3 \mathrm{~Hz}, 8 \mathrm{H}, \mathrm{d}), 8.76(\mathrm{~d}, J=4.4$ $\mathrm{Hz}, 8 \mathrm{H}, \mathrm{b}), 8.67$ (d, $J=4.3 \mathrm{~Hz}, 8 \mathrm{H}, \mathrm{c}$ ), 8.33 (d, $J=4.4 \mathrm{~Hz}, 8 \mathrm{H}, \mathrm{e}), 8.21$ (s, 8H, o' ${ }^{\prime}$ ), 8.03 (s, 8H, o' ${ }^{\prime}$ out), 7.98 (s, $\left.8 \mathrm{H}, \mathrm{p}^{\prime}\right), 7.79$ (s, 8H, p), 7.77 (s, 8H, Oout), 7.71 (s, 8H, oin), 7.38 (d, J = 4.4 Hz, f), $7.11(\mathrm{~s}, 4 \mathrm{H}, \varepsilon), 6.78$ (s, 8H, g), $6.65\left(\mathrm{~d}, J=8.4 \mathrm{~Hz}, 8 \mathrm{H}, \mathrm{v}_{1}\right), 6.47\left(\mathrm{~d}, J=8.4 \mathrm{~Hz}, 8 \mathrm{H}, \delta_{1}\right), 6.39\left(\mathrm{~d}, J=6.7 \mathrm{~Hz}, 8 \mathrm{H}, \beta_{1}\right), 6.36\left(\mathrm{~s}, 8 \mathrm{H}, \delta_{2}\right), 5.70-5.66$ $\left(\mathrm{m}, 8 \mathrm{H}, \alpha_{1}\right), 5.00\left(\mathrm{~d}, J=6.6 \mathrm{~Hz}, 4 \mathrm{H}, \beta_{2}^{\prime}\right), 4.81\left(\mathrm{~d}, J=6.5 \mathrm{~Hz}, 4 \mathrm{H}, \beta_{2}\right), 2.56-2.52\left(\mathrm{~m}, 4 \mathrm{H}, \mathrm{\alpha}_{2}\right), 2.46-2.42(\mathrm{~m}, 4 \mathrm{H}$, $\left.\alpha^{\prime}{ }_{2}\right), 1.50-0.67\left(\mathrm{~m}, 1248 \mathrm{H}, \mathrm{THS}_{\text {in }}+\mathrm{THS}_{\text {out }}+\mathrm{THS}^{\prime}\right.$ in $+\mathrm{THS}^{\prime}$ out $)$ ppm. ${ }^{19} \mathrm{~F} \mathrm{NMR}\left(470 \mathrm{MHz}, \mathrm{CD}_{2} \mathrm{Cl}_{2}, 298 \mathrm{~K}\right) \delta \mathrm{F}=-$ 61.23 ppm. MALDI-ToF $\mathrm{m} / \mathrm{z} 13515$ (calculated for [ $\left.\mathrm{C}_{856} \mathrm{H}_{1352} \mathrm{~N}_{32} \mathrm{Si}_{32} \mathrm{Zn}_{8}\right]^{+}=\boldsymbol{c}-\mathbf{P 8}\left[\mathbf{b}_{6} \mathbf{f}_{2}\right]^{+}:$13513). 


\section{Synthesis of $c-P 8\left[b_{8}\right] \cdot(T 4)_{2}, c-P 8\left[b_{8}\right] \cdot\left(T 4_{1,4 F}\right)_{2}, c-P 8\left[b_{8}\right] \cdot\left(T 4_{2,3 F}\right)_{2}$}

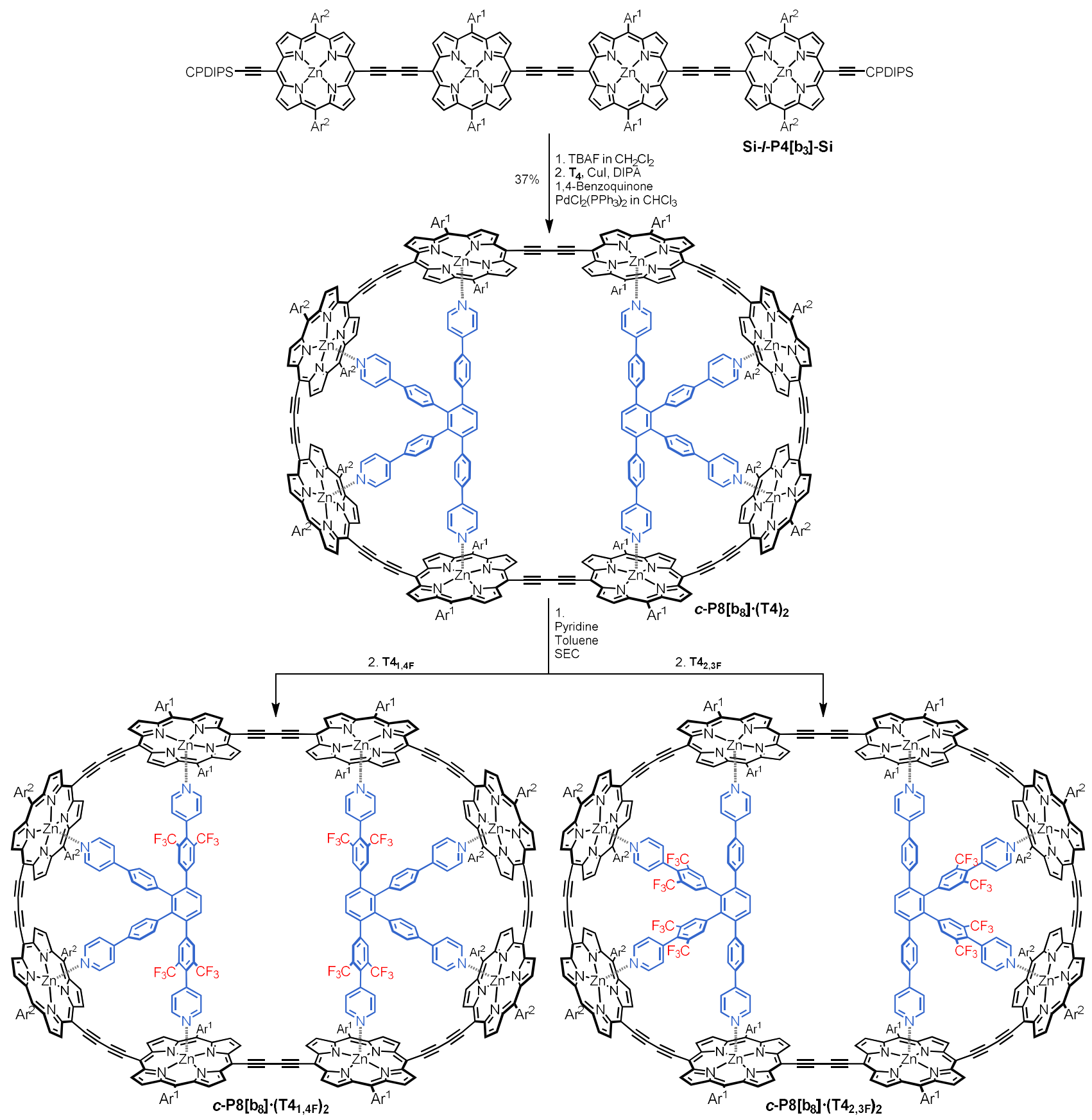

Scheme S3. Synthesis of $c-P 8\left[b_{8}\right] \cdot(T 4)_{2}$ and formation of fluorinated complexes $c-P 8\left[b_{6} f_{2}\right] \bullet\left(T 4_{1,4 F}\right)_{2}$ and $c-P 8\left[b_{6} f_{2}\right] \bullet\left(T 4_{2,3 F}\right)_{2}$. $\mathrm{Ar}^{1}=\mathrm{Ar}^{2}=3,5$-bis (trihexylsilyl)phenyl. CPDIPS = cyanopropyldiisopropylsilyl. 


\section{Complex $c-\mathrm{P} 8\left[\mathrm{~b}_{8}\right] \cdot(\mathrm{T} 4)_{2}$ :}
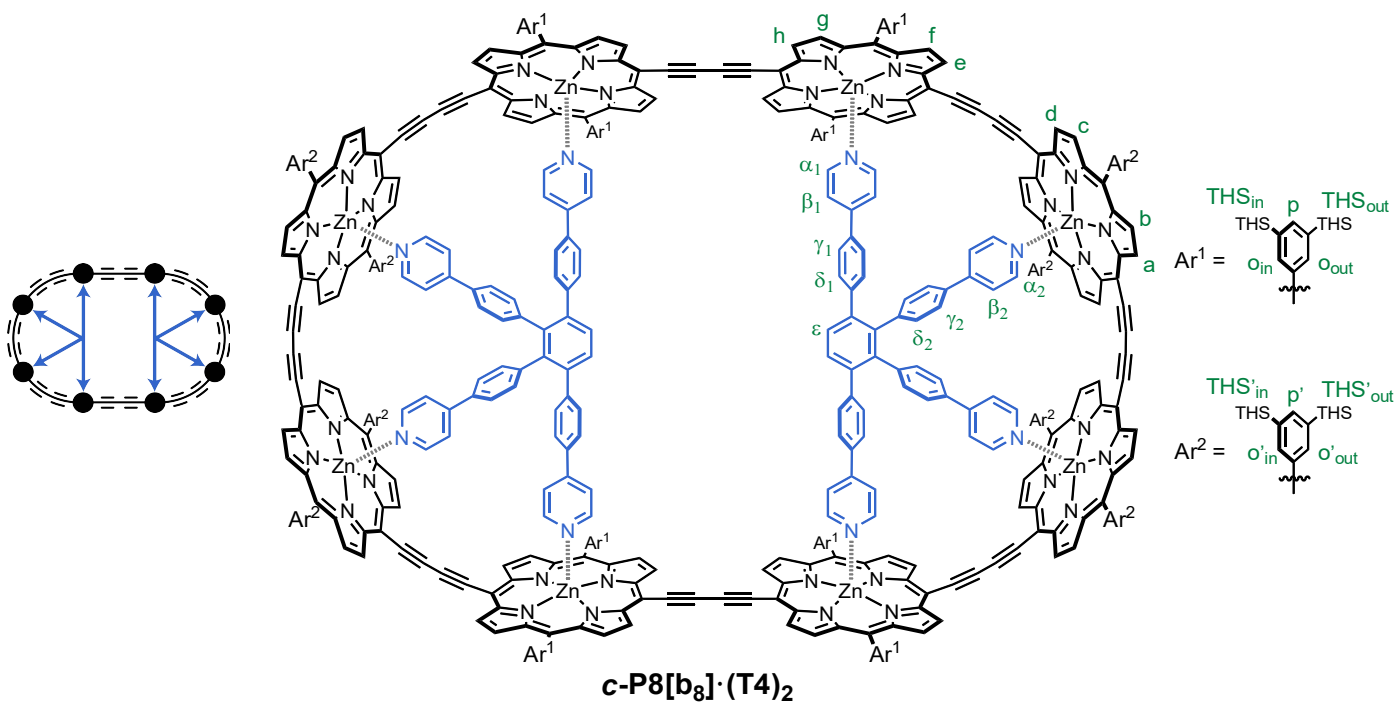

H-I-P4[ $\left.\mathbf{b}_{3}\right]-\mathbf{H}(143 \mathrm{mg}, 21.0 \mu \mathrm{mol})$ and $\mathbf{T 4}(15.9 \mathrm{mg}, 23.0 \mu \mathrm{mol})$ were dissolved in $\mathrm{CHCl}_{3}(40 \mathrm{~mL})$ and sonicated for 2 hours to allow for the complex formation. A catalyst mixture of $\mathrm{PdCl}_{2}\left(\mathrm{PPh}_{3}\right)_{2}(9.3 \mathrm{mg}, 13.3 \mu \mathrm{mol})$, Cul $(13.2$ $\mathrm{mg}, 69.3 \mu \mathrm{mol}), 1,4$-benzoquinone $(30.4 \mathrm{mg}, 281 \mu \mathrm{mol})$, and $i-\mathrm{Pr}_{2} \mathrm{NH}(0.42 \mathrm{~mL})$ in $\mathrm{CHCl}_{3}(10 \mathrm{~mL})$ was added, and the reaction progress was monitored by analytical GPC (THF $+1 \%$ pyridine). After 4 hours, the mixture was passed through a pad of silica (eluent: $\mathrm{CHCl}_{3}+1 \%$ pyridine) and concentrated in vacuo. The crude residue was purified by SEC (toluene $+1 \%$ pyridine) before further purification by recycling GPC (toluene $+1 \%$ pyridine) to afford $c-\mathbf{P} 8\left[\mathbf{b}_{8}\right] \cdot(\mathbf{T} 4)_{2}(53.2 \mathrm{mg}, 37 \%)$ as a brown solid.

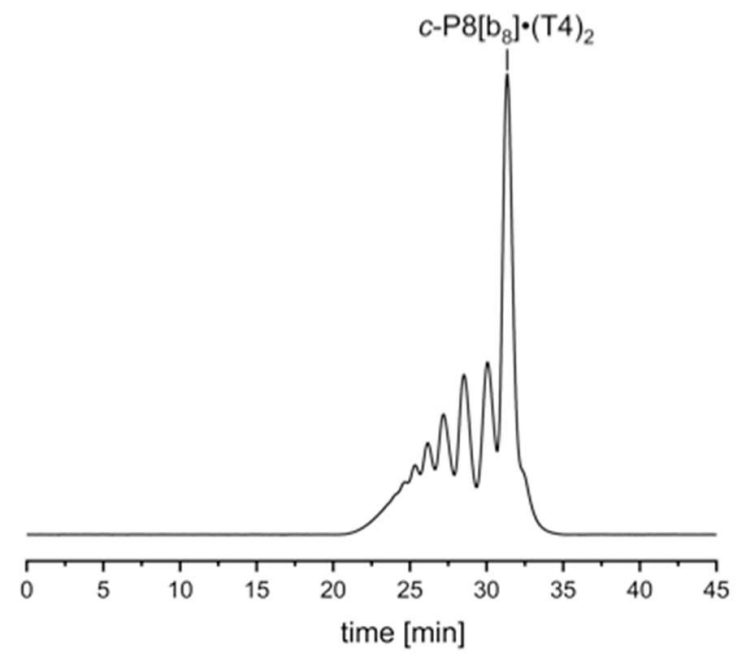

Figure S3. Analytical GPC trace (THF $+1 \%$ pyridine, $\lambda=440 \mathrm{~nm}$ ) for the synthesis of $c-\mathbf{P} 8\left[\mathbf{b}_{8}\right] \bullet \cdot\left(T_{4}\right)_{2}$ after 4 hours.

${ }^{1} \mathrm{H}$ NMR $\left(600 \mathrm{MHz}, \mathrm{CD}_{2} \mathrm{Cl}_{2}, 298 \mathrm{~K}\right) \delta_{\mathrm{H}}=9.76(\mathrm{~d}, J=4.0 \mathrm{~Hz}, 8 \mathrm{H}, \mathrm{e} / \mathrm{h}), 9.64(\mathrm{~d}, J=4.1 \mathrm{~Hz}, 8 \mathrm{H}, \mathrm{a} / \mathrm{d}), 9.63-9.60(\mathrm{~m}$, $16 \mathrm{H}, \mathrm{a} / \mathrm{d}+\mathrm{e} / \mathrm{h}), 8.87(\mathrm{~d}, J=4.0 \mathrm{~Hz}, 8 \mathrm{H}, \mathrm{f} / \mathrm{g}), 8.84-8.77(\mathrm{~m}, 24 \mathrm{H}, \mathrm{b}+\mathrm{c}+\mathrm{f} / \mathrm{g}), 8.41\left(\mathrm{~s}, 8 \mathrm{H}, \mathrm{o}^{\prime}\right.$ in), $8.30(\mathrm{~s}, 8 \mathrm{H}$, oin), 8.20 (s, 8H, Oout), 8.08 (s, 8H, o'out), 8.05 (s, 8H, p), 8.03 (s, 8H, p'), $6.68(\mathrm{~s}, 4 \mathrm{H}, \varepsilon), 6.14$ (d, J = 9.5 Hz, 8H, $\delta_{1}$ ), $6.02\left(\mathrm{~d}, J=9.5 \mathrm{~Hz}, 8 \mathrm{H}, \mathrm{y}_{1}\right), 5.70\left(\mathrm{~d}, J=8.7 \mathrm{~Hz}, 8 \mathrm{H}, \delta_{2}\right), 5.64\left(\mathrm{~d}, J=8.7 \mathrm{~Hz}, 8 \mathrm{H}, \mathrm{\gamma}_{2}\right), 5.39\left(\mathrm{~d}, J=7.3 \mathrm{~Hz}, 8 \mathrm{H}, \beta_{1}\right)$, $5.16\left(\mathrm{~d}, J=6.6 \mathrm{~Hz}, 8 \mathrm{H}, \beta_{2}\right), 2.64-2.55\left(\mathrm{~m}, 8 \mathrm{H}, \alpha_{1}\right), 2.46-2.36\left(\mathrm{~m}, 8 \mathrm{H}, \alpha_{2}\right), 1.59-0.71\left(\mathrm{~m}, 1248 \mathrm{H}, \mathrm{THS}_{\text {in }}+\mathrm{THS}_{\text {out }}+\right.$ THS' in + THS' ${ }^{\prime}$ t) ppm. UV-vis-NIR ( $\left.\mathrm{CDCl}_{3}\right) \lambda_{\max }$ (log $\left.\varepsilon\right): 860$ (5.98), 812 (5.68), 769 (5.51), 729 (5.09), 497 (5.98), 443 (5.74) nm. MALDI-ToF m/z 13615 (calculated for [C $\left.{ }_{864} \mathrm{H}_{1360} \mathrm{~N}_{32} \mathrm{Si}_{32} \mathrm{Zn}_{8}\right]^{+}=c$-P8[ $\left[\mathbf{b}_{8}\right]^{+}:$13618). 


\section{Complex $c-\mathrm{P} 8\left[\mathrm{~b}_{8}\right] \cdot\left(\mathrm{T4}_{1,4 \mathrm{~F}}\right)_{2}$ :}
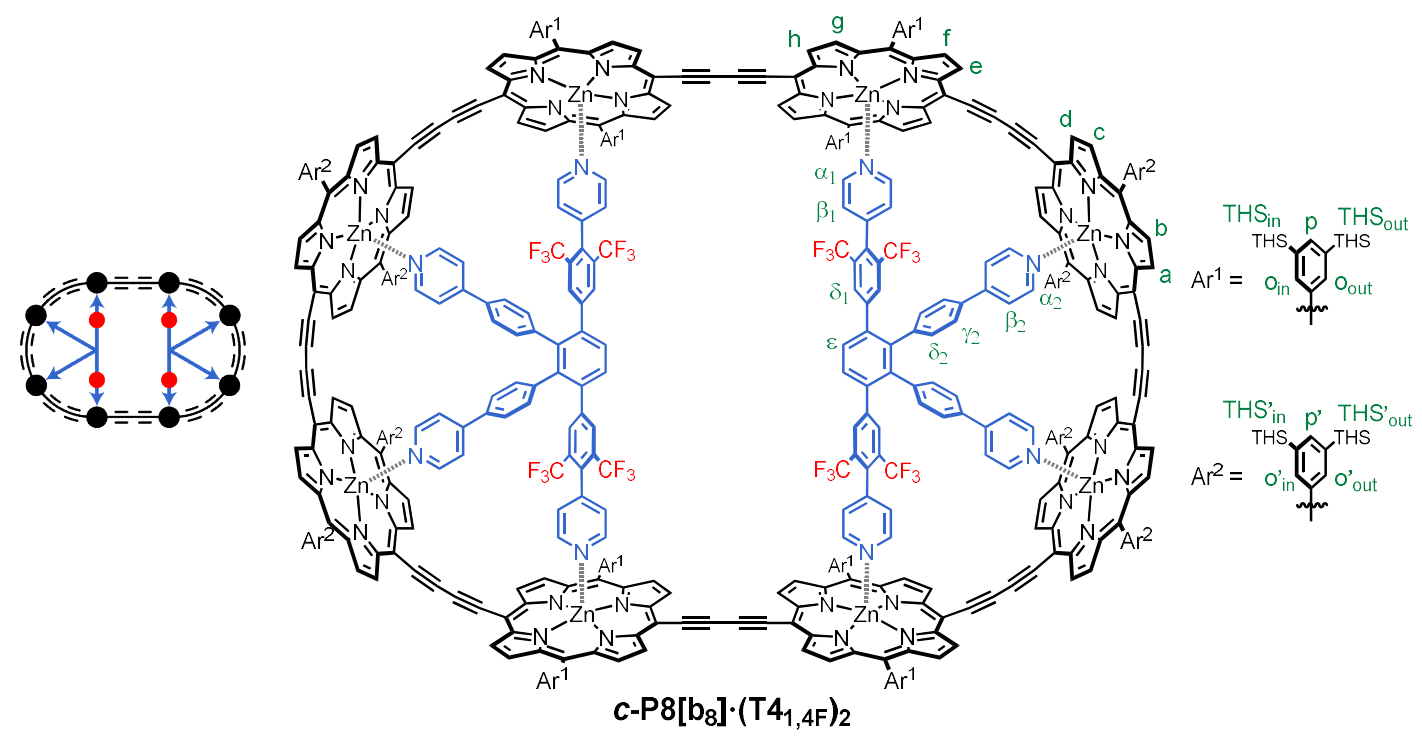

${ }^{1} \mathrm{H}$ NMR $\left(600 \mathrm{MHz}, \mathrm{CD}_{2} \mathrm{Cl}_{2}, 298 \mathrm{~K}\right) \delta_{H}=9.81(\mathrm{~d}, J=4.1 \mathrm{~Hz}, 8 \mathrm{H}, \mathrm{e} / \mathrm{h}), 9.68(\mathrm{~d}, J=4.2 \mathrm{~Hz}, 8 \mathrm{H}, \mathrm{a} / \mathrm{d}), 9.64-9.58(\mathrm{~m}$, $16 \mathrm{H}, \mathrm{a} / \mathrm{d}+\mathrm{e} / \mathrm{h}), 8.87-8.83(\mathrm{~m}, 16 \mathrm{H}, \mathrm{b} / \mathrm{c}+\mathrm{f} / \mathrm{g}), 8.82(\mathrm{~d}, J=4.2 \mathrm{~Hz}, 8 \mathrm{H}, \mathrm{b} / \mathrm{c}), 8.75(\mathrm{~d}, J=4.1 \mathrm{~Hz}, 8 \mathrm{H}, \mathrm{f} / \mathrm{g}), 8.44(\mathrm{~s}$, $8 \mathrm{H}, \mathrm{o}^{\prime}$ in), $8.22\left(\mathrm{~s}, 8 \mathrm{H}, \mathrm{O}_{\text {out }}\right), 8.13\left(\mathrm{~s}, 8 \mathrm{H}, \mathrm{O}_{\mathrm{in}}\right), 8.11\left(\mathrm{~s}, 8 \mathrm{H}, \mathrm{o}^{\prime}{ }_{\mathrm{out}}\right), 8.06\left(\mathrm{~s}, 8 \mathrm{H}, \mathrm{p}^{\prime}\right), 8.00(\mathrm{~s}, 8 \mathrm{H}, \mathrm{p}), 6.83(\mathrm{~s}, 4 \mathrm{H}, \varepsilon)$, $6.67\left(\mathrm{~s}, 8 \mathrm{H}, \delta_{1}\right), 5.82\left(\mathrm{~d}, J=8.7 \mathrm{~Hz}, 8 \mathrm{H}, \delta_{2}\right), 5.77\left(\mathrm{~d}, J=8.7 \mathrm{~Hz}, \mathrm{\gamma}_{2}\right), 5.19\left(\mathrm{~d}, J=6.6 \mathrm{~Hz}, 8 \mathrm{H}, \beta_{2}\right), 5.10(\mathrm{~d}, J=7.6$ $\left.\mathrm{Hz}, 8 \mathrm{H}, \beta_{1}\right), 2.57-2.52\left(\mathrm{~m}, 8 \mathrm{H}, \alpha_{1}\right), 2.50-2.44\left(\mathrm{~m}, 8 \mathrm{H}, \alpha_{2}\right), 1.66-0.57\left(\mathrm{~m}, 1248 \mathrm{H}, \mathrm{THS}_{\text {in }}+\mathrm{THS}_{\text {out }}+\mathrm{THS}_{\text {in }}+\right.$ THS' ${ }_{\text {out }}$ ) ppm. ${ }^{19} \mathrm{~F}$ NMR $\left(470 \mathrm{MHz}, \mathrm{CD}_{2} \mathrm{Cl}_{2}, 298 \mathrm{~K}\right) \delta \mathrm{F}=-61.05 \mathrm{ppm}$. MALDI-ToF $\mathrm{m} / \mathrm{z} 13615$ (calculated for $\left[\mathrm{C}_{864} \mathrm{H}_{1360} \mathrm{~N}_{32} \mathrm{Si}_{32} \mathrm{Zn} 8\right]^{+}=c-P 8\left[b_{8}\right]^{+}:$13618).

\section{Complex $c-\mathrm{P} 8\left[\mathrm{~b}_{8}\right] \cdot\left(\mathrm{T}_{2,3 \mathrm{~F}}\right)_{2}$ :}
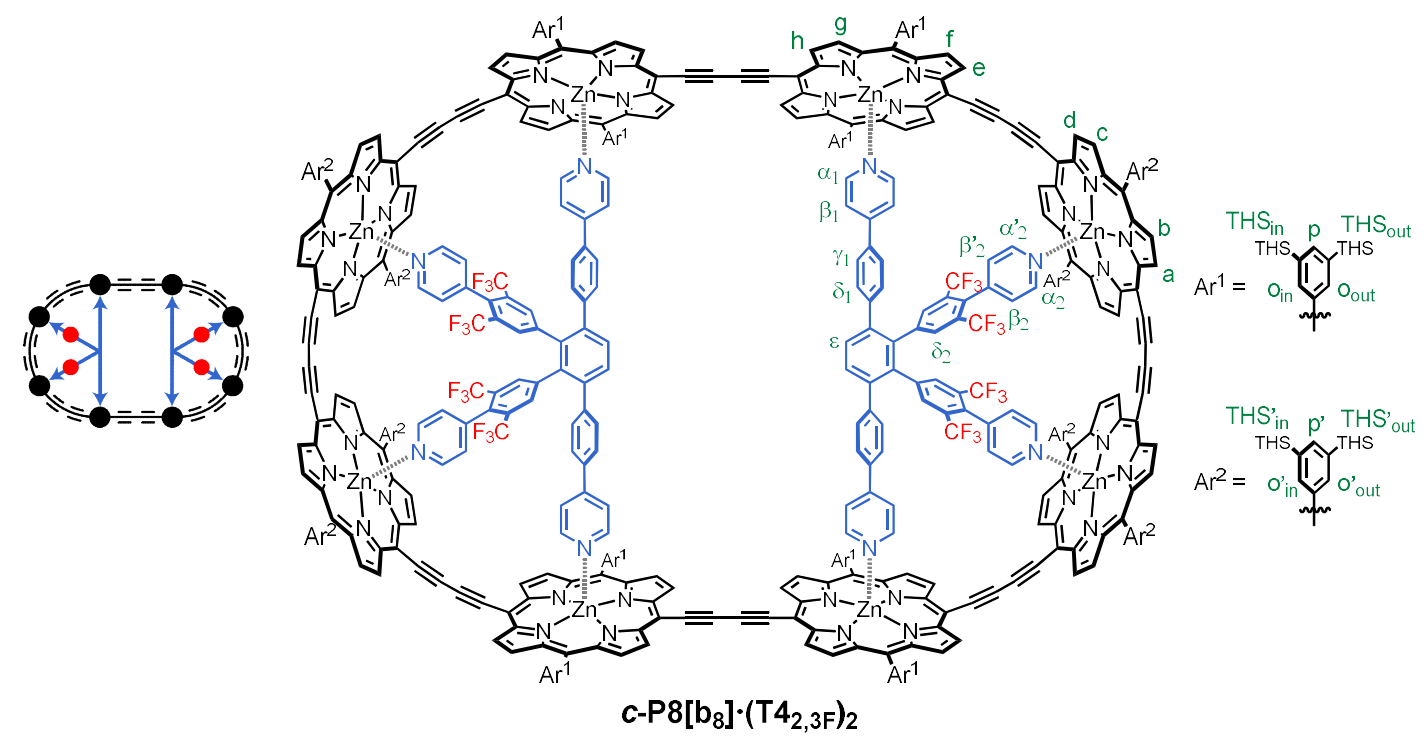

${ }^{1} \mathrm{H}$ NMR $\left(600 \mathrm{MHz}, \mathrm{CD}_{2} \mathrm{Cl}_{2}, 298 \mathrm{~K}\right) \delta \mathrm{H}=9.76(\mathrm{~d}, J=4.0 \mathrm{~Hz}, 8 \mathrm{H}, \mathrm{e} / \mathrm{h}), 9.69(\mathrm{~d}, J=4.4 \mathrm{~Hz}, 8 \mathrm{H}, \mathrm{a}), 9.68(\mathrm{~d}, J=4.0$ $\mathrm{Hz}, 8 \mathrm{H}, \mathrm{e} / \mathrm{h}$ ), $9.64(\mathrm{~d}, J=4.3 \mathrm{~Hz}, 8 \mathrm{H}, \mathrm{d}), 8.89(\mathrm{~d}, J=4.0 \mathrm{~Hz}, 8 \mathrm{H}, \mathrm{f} / \mathrm{g}), 8.85(\mathrm{~d}, J=4.0 \mathrm{~Hz}, 8 \mathrm{H}, \mathrm{f} / \mathrm{g}), 8.78(\mathrm{~d}, J=4.4$ $\mathrm{Hz}, 8 \mathrm{H}, \mathrm{b}), 8.75$ (d, J = 4.3 Hz, 8H, c), 8.37 (s, 8H, oin), 8.21 (s, 16H, o'in + Oout), 8.09 (s, 8H, o' out), 8.05 (s, 8H, p), $8.01\left(\mathrm{~s}, 8 \mathrm{H}, \mathrm{p}^{\prime}\right), 6.82(\mathrm{~s}, 4 \mathrm{H}, \varepsilon), 6.18\left(\mathrm{~d}, J=9.7 \mathrm{~Hz}, 8 \mathrm{H}, \delta_{1}\right), 6.17-6.13\left(\mathrm{~m}, 16 \mathrm{H}, \mathrm{y}_{1}+\delta_{2}\right), 5.44(\mathrm{~d}, J=7.3 \mathrm{~Hz}, 8 \mathrm{H}$, $\left.\beta_{1}\right), 4.93\left(\mathrm{~d}, J=6.3 \mathrm{~Hz}, 4 \mathrm{H}, \beta^{\prime}{ }_{2}\right), 4.73\left(\mathrm{~d}, J=6.0 \mathrm{~Hz}, 4 \mathrm{H}, \beta_{2}\right), 2.74-2.66\left(\mathrm{~m}, 8 \mathrm{H}, \alpha_{1}\right), 2.52-2.46\left(\mathrm{~m}, 4 \mathrm{H}, \alpha_{2}\right), 2.45-$ $2.41\left(\mathrm{~m}, 4 \mathrm{H}, \alpha^{\prime}\right), 1.58-0.71\left(\mathrm{~m}, 1248 \mathrm{H}, \mathrm{THS}\right.$ in $\left.+\mathrm{THS}_{\text {out }}+\mathrm{THS}^{\prime}{ }_{\text {in }}+\mathrm{THS}^{\prime}{ }_{\text {out }}\right) \mathrm{ppm} .{ }^{19} \mathrm{~F} \mathrm{NMR}\left(470 \mathrm{MHz}, \mathrm{CD}_{2} \mathrm{Cl}_{2}, 298\right.$ K) $\delta F=-61.32$ ppm. MALDI-ToF $m / z 13615$ (calculated for $\left[\mathrm{C}_{864} \mathrm{H}_{1360} \mathrm{~N}_{32} \mathrm{Si}_{32} \mathrm{Zn}_{8}\right]^{+}=\boldsymbol{c}-\mathbf{P 8}\left[\mathbf{b}_{8}\right]^{+}:$13618). 
Synthesis of templates $\mathrm{T4}, \mathrm{T} 4_{1,4 F}$, and $\mathrm{T} 4_{2,3 \mathrm{~F}}$
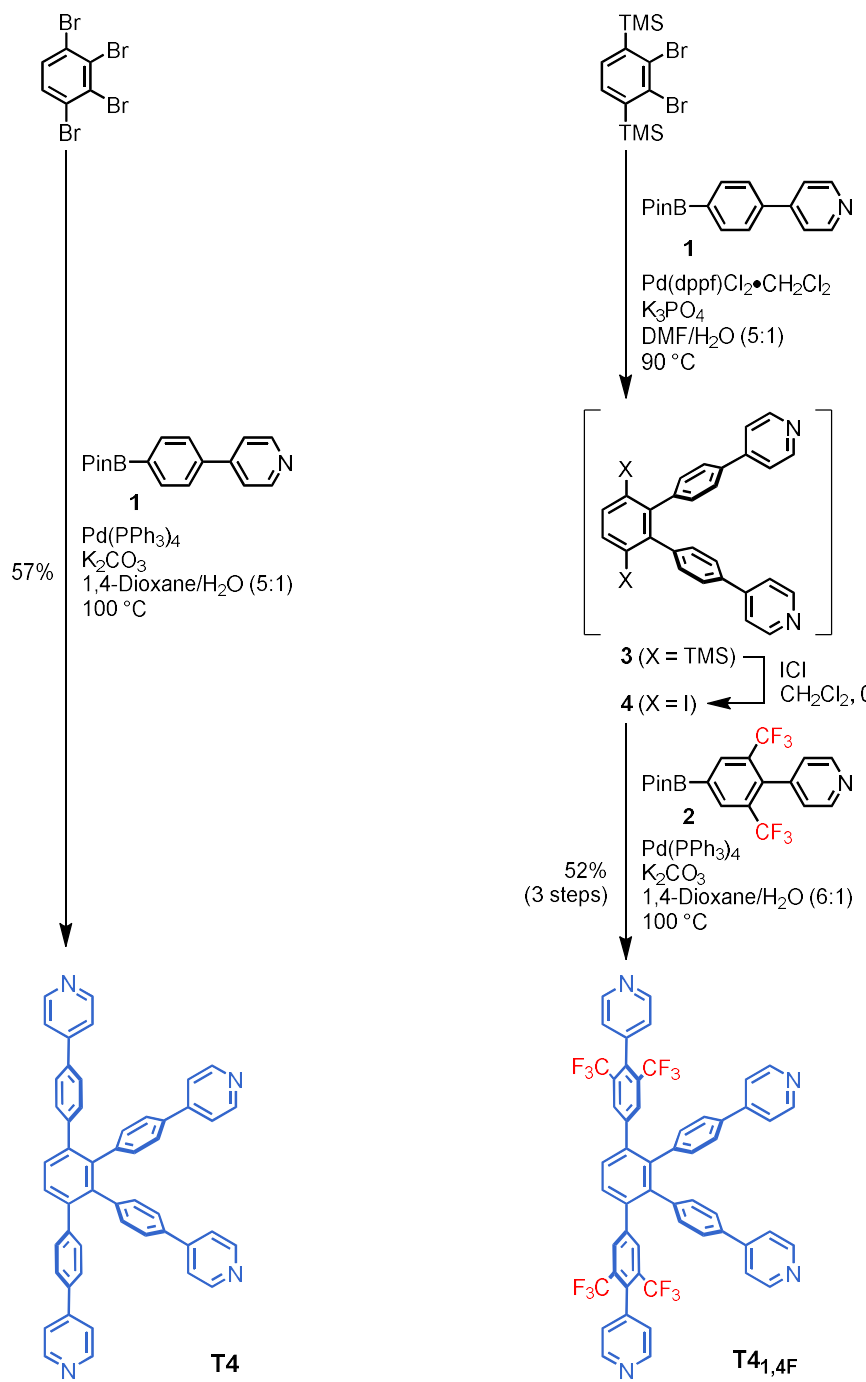

$\mathrm{M}_{\mathrm{Br}}^{\mathrm{Br}}$

TMS

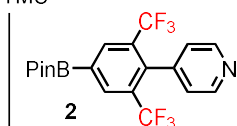

$\mathrm{Pd}(\mathrm{dppf}) \mathrm{Cl}_{2} \bullet \mathrm{CH}_{2} \mathrm{Cl}$

$\operatorname{Pd}(\mathrm{dpp}) \mathrm{Cl}$

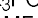

$\mathrm{DMF} / \mathrm{H}_{2} \mathrm{O}(6: 1)$
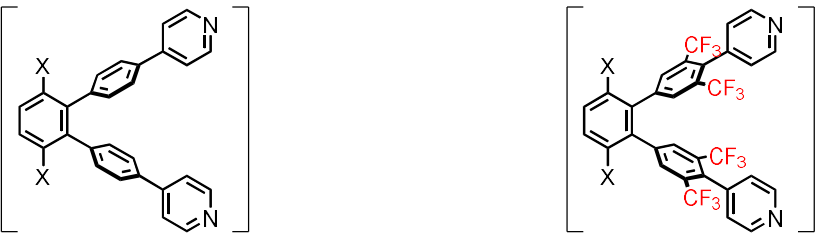

$3(\mathrm{X}=\mathrm{TMS})$

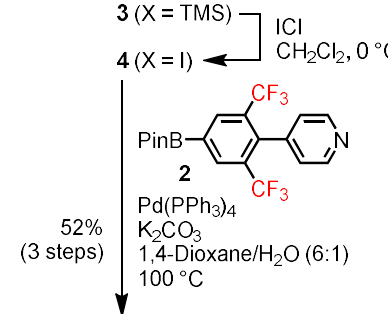

$5(X=T M S) \square, \mathrm{IC}$

$6(X=1) \longleftarrow \mathrm{CH}_{2} \mathrm{Cl}_{2}, 0^{\circ} \mathrm{C}$

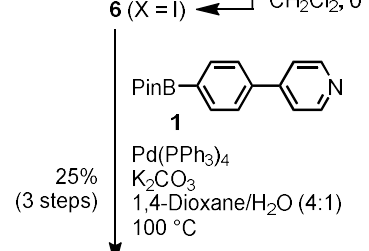

$\checkmark$

$\checkmark$
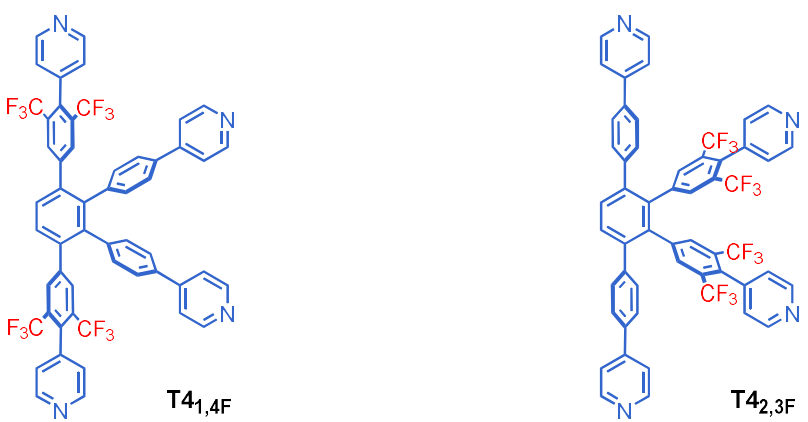

Scheme S4. Synthesis of all templates:

T4, T41,4F, and T42,3F. TMS = trimethylsilyl. dppf $=1,1^{\prime}-$ bis(diphenylphosphino)ferrocene.

\section{Template T4:}

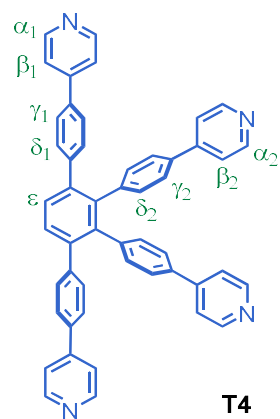

In a Schlenk flask, 1,2,3,4-tetrabromobenzene (356 mg, $0.904 \mathrm{mmol}$ ), boronic acid ester 1 (3.56 g, $12.7 \mathrm{mmol}$ ), and $\mathrm{K}_{2} \mathrm{CO}_{3}(3.90 \mathrm{~g}, 28.2 \mathrm{mmol})$ were dissolved in 1,4-dioxane $(240 \mathrm{~mL})$ and $\mathrm{H}_{2} \mathrm{O}(50 \mathrm{~mL})$ and subjected to two freeze-pump-thaw cycles. While the mixture was still frozen, $\mathrm{Pd}\left(\mathrm{PPh}_{3}\right)_{4}(406 \mathrm{mg}, 351 \mu \mathrm{mol})$ was added followed by an additional freeze-pump-thaw cycle. The mixture was heated to $100{ }^{\circ} \mathrm{C}$ for 4 days, filtered through a short pad of silica (eluent: $20 \% \mathrm{MeOH} / \mathrm{CHCl}_{3}$ ), and concentrated in vacuo. Purification by flash column 
chromatography $\left(\mathrm{SiO}_{2}\right.$, gradient elution: 0 to $\left.10 \% \mathrm{MeOH} / \mathrm{CHCl}_{3}\right)$ followed by precipitation from $\mathrm{CHCl}_{3} / \mathrm{hexane}$ afforded template T4 (355 $\mathrm{mg}, 57 \%)$ as an off-white solid.

${ }^{1} \mathrm{H}$ NMR $\left(500 \mathrm{MHz}, \mathrm{CDCl}_{3}, 298 \mathrm{~K}\right) \delta_{\mathrm{H}}=8.64-8.60\left(\mathrm{~m}, 4 \mathrm{H}, \mathrm{\alpha}_{1}\right), 8.58-8.54\left(\mathrm{~m}, 4 \mathrm{H}, \mathrm{\alpha}_{2}\right), 7.62(\mathrm{~s}, 2 \mathrm{H}, \varepsilon), 7.50(\mathrm{~d}, J=$ $\left.8.4 \mathrm{~Hz}, 4 \mathrm{H}, \mathrm{v}_{1}\right), 7.48-7.45\left(\mathrm{~m}, 4 \mathrm{H}, \beta_{1}\right), 7.39-7.36\left(\mathrm{~m}, 4 \mathrm{H}, \beta_{2}\right), 7.31\left(\mathrm{~d}, J=8.4 \mathrm{~Hz}, 4 \mathrm{H}, \mathrm{\gamma}_{2}\right), 7.27(\mathrm{~d}, J=8.4 \mathrm{~Hz}$, $\left.4 \mathrm{H}, \delta_{1}\right), 7.00\left(\mathrm{~d}, J=8.4 \mathrm{~Hz}, 4 \mathrm{H}, \delta_{2}\right) \mathrm{ppm} .{ }^{13} \mathrm{C}$ NMR $\left(126 \mathrm{MHz}, \mathrm{CDCl}_{3}, 298 \mathrm{~K}\right) \delta \mathrm{c}=150.42,150.35,147.7,147.6$, $142.5,140.8,140.7,139.8,136.3,135.5,132.4,130.7,130.1,126.5,125.9,121.5,121.3 \mathrm{ppm}$. HRMS (ESI): $\mathrm{m} / \mathrm{z}$ calcd for $\mathrm{C}_{50} \mathrm{H}_{35} \mathrm{~N}_{4}{ }^{+}\left([\mathrm{M}+\mathrm{H}]^{+}\right) 691.2856$, found 691.2856 .

\section{Template T41,4F:}

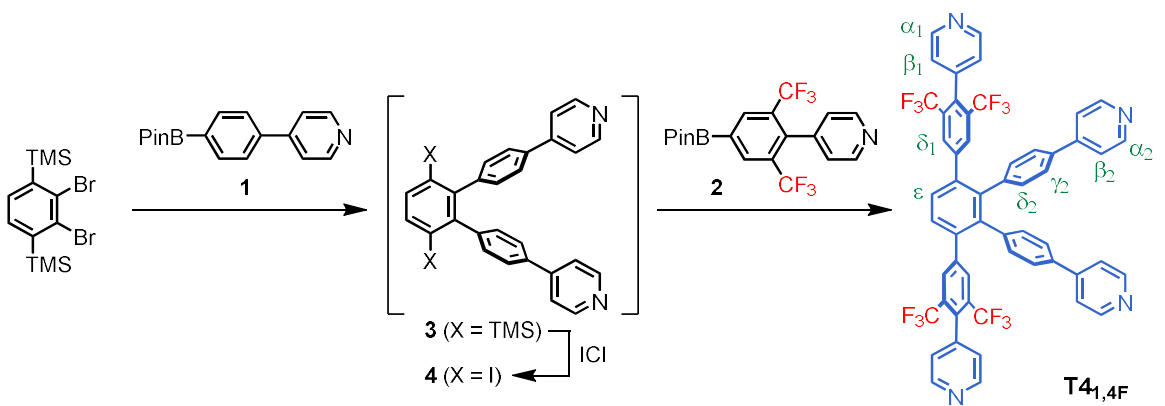

Step 1: A Schlenk flask charged with 1,4-bis(trimethylsilyl)-2,3-dibromobenzene (100 $\mathrm{mg}, 0.263 \mathrm{mmol}$ ), boronic acid ester 1 (185 mg, $0.657 \mathrm{mmol}$ ), $\mathrm{K}_{3} \mathrm{PO}_{4}\left(335 \mathrm{mg}, 1.58 \mathrm{mmol}\right.$ ), and $\mathrm{Pd}(\mathrm{dppf}) \mathrm{Cl}_{2} \cdot \mathrm{CH}_{2} \mathrm{Cl}_{2}(21.5 \mathrm{mg}, 0.026 \mathrm{mmol}$ ) in DMF $(2.5 \mathrm{~mL})$ and $\mathrm{H}_{2} \mathrm{O}(0.5 \mathrm{~mL})$ was subjected to three freeze-pump-thaw cycles and heated to $90{ }^{\circ} \mathrm{C}$. After stirring for 17 hours, the mixture was cooled to room temperature and filtered through a short pad of silica (eluent: $\left.20 \% \mathrm{MeOH} / \mathrm{CHCl}_{3}\right)$. The crude mixture was purified by flash column chromatography $\left(\mathrm{SiO}_{2}\right.$, gradient elution: $\left.1.3 / 7 \mathrm{EtOAc} / \mathrm{CHCl}_{3}, 2.3 \% \mathrm{MeOH} / \mathrm{CHCl}_{3}\right)$ to afford the bis-coupled product $3(137 \mathrm{mg}, 99 \%)$ as a pale, yellow solid containing minor impurities, presumably from desilylation. Step 2: The Suzuki-coupled product 3 (136 mg, $0.189 \mathrm{mmol}$ ) was dissolved in $\mathrm{CH}_{2} \mathrm{Cl}_{2}(3 \mathrm{~mL})$ and cooled using an ice-water bath. A solution of iodine monochloride $\left(1.13 \mathrm{~mL}, 1.13 \mathrm{mmol}, 1.0 \mathrm{M}\right.$ in $\left.\mathrm{CH}_{2} \mathrm{Cl}_{2}\right)$ was added dropwise and the resulting mixture was stirred for one hour at which point complete conversion was confirmed by TLC. The orange suspension was transferred to a separatory funnel containing a sat. aq. solution of $\mathrm{Na}_{2} \mathrm{~S}_{2} \mathrm{O}_{7}(100 \mathrm{~mL})$ and $\mathrm{CHCl}_{3}(100 \mathrm{~mL})$. The phases were thoroughly mixed and the organic phase separated. The aqueous phase was extracted once more with $\mathrm{CHCl}_{3}$ $(50 \mathrm{~mL})$ and the combined organic extracts were washed with brine $(100 \mathrm{~mL})$ and $\mathrm{H}_{2} \mathrm{O}(100 \mathrm{~mL})$, dried over $\mathrm{MgSO}_{4}$, filtered, and concentrated in vacuo. Purification by flash column chromatography $\left(\mathrm{SiO}_{2}\right.$, gradient elution: 0 to $\left.5 \% \mathrm{MeOH} / \mathrm{CHCl}_{3}\right)$ gave the doubly iodinated product $4(127 \mathrm{mg}, 78 \%)$ as a purple-grey solid containing minor impurities. Step 3: A Schlenk flask charged with doubly iodinated product 4 ( $60 \mathrm{mg}, 0.094 \mathrm{mmol}$ ), boronic acid ester 2 (98 mg, $0.236 \mathrm{mmol})$, and $\mathrm{K}_{2} \mathrm{CO}_{3}(78 \mathrm{mg}, 0.566 \mathrm{mmol})$ in 1,4-dioxane $(3 \mathrm{~mL})$ and $\mathrm{H}_{2} \mathrm{O}(0.5 \mathrm{~mL})$ was subjected to two freeze-pump-thaw cycles and while the mixture was still frozen, $\mathrm{Pd}\left(\mathrm{PPh}_{3}\right)_{4}(27 \mathrm{mg}, 0.024 \mathrm{mmol})$ was added, and three additional freeze-pump-thaw cycles were performed. The mixture was heated to $100{ }^{\circ} \mathrm{C}$ for 1.5 days, filtered through a short pad of silica (eluent: $15 \% \mathrm{MeOH} / \mathrm{CHCl}_{3}$ ), and concentrated under reduced pressure. Purification by flash column chromatography $\left(\mathrm{SiO}_{2}\right.$, gradient elution: 0 to $\left.7 \% \mathrm{MeOH} / \mathrm{CHCl}_{3}\right)$ gave the title compound $\mathbf{T 4}_{1,4 \mathrm{~F}}(62 \mathrm{mg}, 68 \%)$ as a grey, off-white solid. Yield over 3 steps: $52 \%$.

${ }^{1} \mathrm{H}$ NMR $\left(500 \mathrm{MHz}, \mathrm{CDCl}_{3}\right) \delta_{\mathrm{H}}=8.66-8.62\left(\mathrm{~m}, 4 \mathrm{H}, \mathrm{\alpha}_{1}\right), 8.62-8.59\left(\mathrm{~m}, 4 \mathrm{H}, \mathrm{\alpha}_{2}\right), 7.76\left(\mathrm{~s}, 2 \mathrm{H}, \varepsilon_{1}\right), 7.74\left(\mathrm{~s}, 4 \mathrm{H}, \delta_{1}\right)$, $7.39\left(\mathrm{~d}, J=8.2 \mathrm{~Hz}, 4 \mathrm{H}, \mathrm{\gamma}_{2}\right), 7.37-7.34\left(\mathrm{~m}, 4 \mathrm{H}, \beta_{2}\right), 7.15\left(\mathrm{br} \mathrm{d}, J=5.4 \mathrm{~Hz}, 4 \mathrm{H}, \beta_{1}\right), 7.06\left(\mathrm{~d}, J=8.2 \mathrm{~Hz}, 4 \mathrm{H}, \delta_{2}\right)$ ppm. ${ }^{19} \mathrm{~F}$ NMR $\left(470 \mathrm{MHz}, \mathrm{CDCl}_{3}\right) \delta \mathrm{F}=-60.49 \mathrm{ppm}\left(\mathrm{vs} . \mathrm{C}_{6} \mathrm{~F}_{6}, \delta_{\mathrm{F}}=-164.80 \mathrm{ppm}\right) .{ }^{13} \mathrm{C}$ NMR $\left(126 \mathrm{MHz}, \mathrm{CDCl}_{3}\right) \delta \mathrm{c}$ $=150.5,148.9,147.5,142.3,141.9,140.7,139.2,139.1,137.3,135.3,132.1,130.62$ (q, JC-F $=5.6 \mathrm{~Hz}), 130.59$ (q, JC-F $=30.3 \mathrm{~Hz}$ ), 130.1, 126.6, 124.9 (br s), 122.9 (q, JC-F $=274.8 \mathrm{~Hz}$ ), $121.5 \mathrm{ppm}$. HRMS (ESI): $\mathrm{m} / \mathrm{z}$ calcd for $\mathrm{C}_{54} \mathrm{H}_{31} \mathrm{~N}_{4} \mathrm{~F}_{12}{ }^{+}\left([\mathrm{M}+\mathrm{H}]^{+}\right)$963.2352, found 963.2346. 
Template T4,3F:

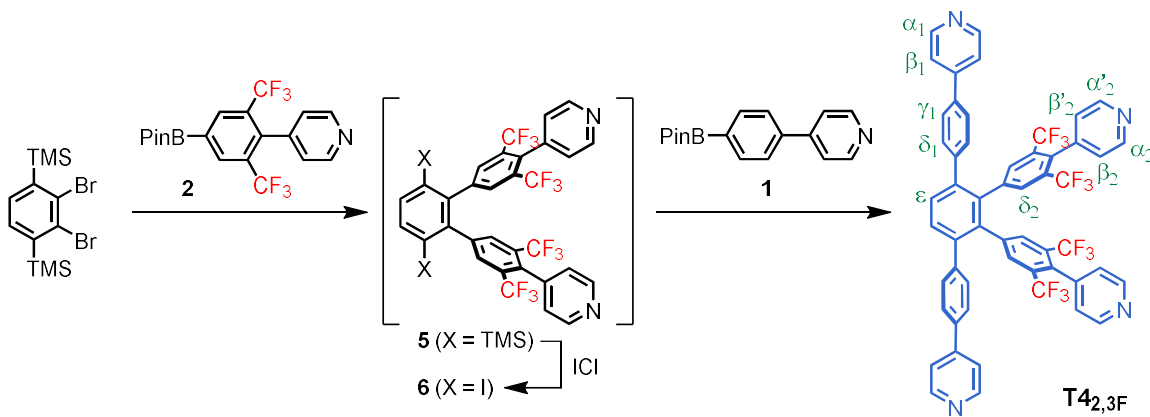

Step 1: A Schlenk flask charged with 1,4-bis(trimethylsilyl)-2,3-dibromobenzene (60 mg, $0.158 \mathrm{mmol})$, boronic acid ester $2(165 \mathrm{mg}, 0.394 \mathrm{mmol}), \mathrm{K}_{3} \mathrm{PO}_{4}(201 \mathrm{mg}, 0.947 \mathrm{mmol})$, and $\mathrm{Pd}(\mathrm{dppf}) \mathrm{Cl}_{2} \cdot \mathrm{CH}_{2} \mathrm{Cl}_{2}$ (12.9 mg, 0.016 mmol) in DMF $(3.0 \mathrm{~mL})$ and $\mathrm{H}_{2} \mathrm{O}(0.5 \mathrm{~mL})$ was subjected to four freeze-pump-thaw cycles and heated to $90{ }^{\circ} \mathrm{C}$. After stirring for 8.5 hours, the mixture was cooled to room temperature and filtered through a short pad of silica (eluent: $\left.15 \% \mathrm{MeOH} / \mathrm{CHCl}_{3}\right)$. The crude mixture was purified by flash column chromatography $\left(\mathrm{SiO}_{2}\right.$, gradient elution: 10 to 20 to $30 \%$ EtOAc/toluene) to afford the bis-coupled product 5 (48 $\mathrm{mg}, 38 \%$ ) as an off-white solid containing minor impurities, presumably from desilylation. Step 2: The Suzuki-coupled product 5 (48 mg, 0.060 mmol) was dissolved in $\mathrm{CH}_{2} \mathrm{Cl}_{2}(2 \mathrm{~mL})$ and cooled using an ice-water bath. A solution of iodine monochloride $\left(1.8 \mathrm{~mL}, 1.8 \mathrm{mmol}, 1.0 \mathrm{M}\right.$ in $\mathrm{CH}_{2} \mathrm{Cl}_{2}$ ) was added dropwise and the resulting mixture was stirred for three hours at which point complete conversion was confirmed by TLC. The mixture was diluted with $\mathrm{CHCl}_{3}(50 \mathrm{~mL})$ and washed with a sat. aq. solution of $\mathrm{Na}_{2} \mathrm{~S}_{3} \mathrm{O}_{7}(2 \times 50 \mathrm{~mL})$, brine $(100 \mathrm{~mL})$, and $\mathrm{H}_{2} \mathrm{O}(100 \mathrm{~mL})$, dried over $\mathrm{MgSO}_{4}$, filtered, and concentrated under reduced pressure. Purification by flash column chromatography $\left(\mathrm{SiO}_{2}, 3 \%\right.$ $\left.\mathrm{MeOH} / \mathrm{CHCl}_{3}\right)$ gave the doubly iodinated product $6(51 \mathrm{mg}, 94 \%)$ as an off-white solid containing minor impurities. Step 3: A Schlenk flask charged with doubly iodinated product $6(51 \mathrm{mg}, 0.056 \mathrm{mmol})$, boronic acid ester 1 (63 mg, $0.225 \mathrm{mmol})$, and $\mathrm{K}_{2} \mathrm{CO}_{3}(93 \mathrm{mg}, 0.674 \mathrm{mmol})$ in 1,4-dioxane $(2 \mathrm{~mL})$ and $\mathrm{H}_{2} \mathrm{O}(0.5 \mathrm{~mL})$ was subjected to two freeze-pump-thaw cycles, and while the mixture was still frozen, $\mathrm{Pd}\left(\mathrm{PPh}_{3}\right)_{4}(19.5 \mathrm{mg}, 0.017$ $\mathrm{mmol}$ ) was added, and three additional freeze-pump-thaw cycles were performed. The mixture was heated to $100{ }^{\circ} \mathrm{C}$ for 1.5 days, filtered through a short pad of silica (eluent: $15 \% \mathrm{MeOH} / \mathrm{CHCl}_{3}$ ), and concentrated in vacuo. Purification by flash column chromatography $\left(\mathrm{SiO}_{2}\right.$, gradient elution: 0 to $\left.7 \% \mathrm{MeOH} / \mathrm{CHCl}_{3}\right)$ followed by precipitation from $\mathrm{CHCl}_{3} /$ hexane 1:1 gave the title compound $\mathbf{T 4}_{2,3 \mathbf{F}}(38 \mathrm{mg}, 70 \%)$ as a white solid. Yield over 3 steps: $25 \%$.

${ }^{1} \mathrm{H}$ NMR $\left(500 \mathrm{MHz}, \mathrm{CDCl}_{3}\right) \delta_{\mathrm{H}}=8.71-8.65\left(\mathrm{~m}, 4 \mathrm{H}, \alpha_{1}\right), 8.62\left(\mathrm{br} \mathrm{d}, J=3.8 \mathrm{~Hz}, 4 \mathrm{H}, \alpha_{2} / \alpha_{2}{ }_{2}\right), 7.77\left(\mathrm{~s}, 2 \mathrm{H}, \varepsilon_{1}\right), 7.62$ (d, $\left.J=8.3 \mathrm{~Hz}, 4 \mathrm{H}, \mathrm{y}_{1}\right), 7.51-7.46\left(\mathrm{~m}, 4 \mathrm{H}, \beta_{1}\right), 7.41\left(\mathrm{~s}, 4 \mathrm{H}, \delta_{2}\right), 7.31\left(\mathrm{~d}, J=8.3 \mathrm{~Hz}, 4 \mathrm{H}, \delta_{1}\right), 7.10(\mathrm{br} \mathrm{d}, J=3.8 \mathrm{~Hz}$, $\left.2 \mathrm{H}, \beta_{2} / \beta^{\prime}{ }_{2}\right), 6.96\left(\mathrm{br} \mathrm{d}, J=3.8 \mathrm{~Hz}, 2 \mathrm{H}, \beta_{2} / \beta_{2}^{\prime}\right) \mathrm{ppm} .{ }^{19} \mathrm{~F}$ NMR $\left(470 \mathrm{MHz}, \mathrm{CDCl}_{3}\right) \delta \mathrm{F}=-60.70 \mathrm{ppm}\left(\mathrm{vs} . \mathrm{C}_{6} \mathrm{~F}_{6}, \delta F=\right.$ -164.80 ppm). ${ }^{13} \mathrm{C}$ NMR $\left(126 \mathrm{MHz}, \mathrm{CDCl}_{3}\right) \delta \mathrm{C}=150.6,149.1,148.8,147.5,141.9,141.2,140.7,140.4,137.7$, 137.3, 135.4, 132.6 (q, $J=5.0 \mathrm{~Hz}), 131.4,130.7,130.4$ (q, $J=30.4 \mathrm{~Hz}), 127.2,124.8,124.6,122.6$ (q, $J=275.0$ $\mathrm{Hz}), 121.7 \mathrm{ppm}$. HRMS (ESI): $\mathrm{m} / \mathrm{z}$ calcd for $\mathrm{C}_{54} \mathrm{H}_{31} \mathrm{~N}_{4} \mathrm{~F}_{12}{ }^{+}\left([\mathrm{M}+\mathrm{H}]^{+}\right)$963.2352, found 963.2344. 

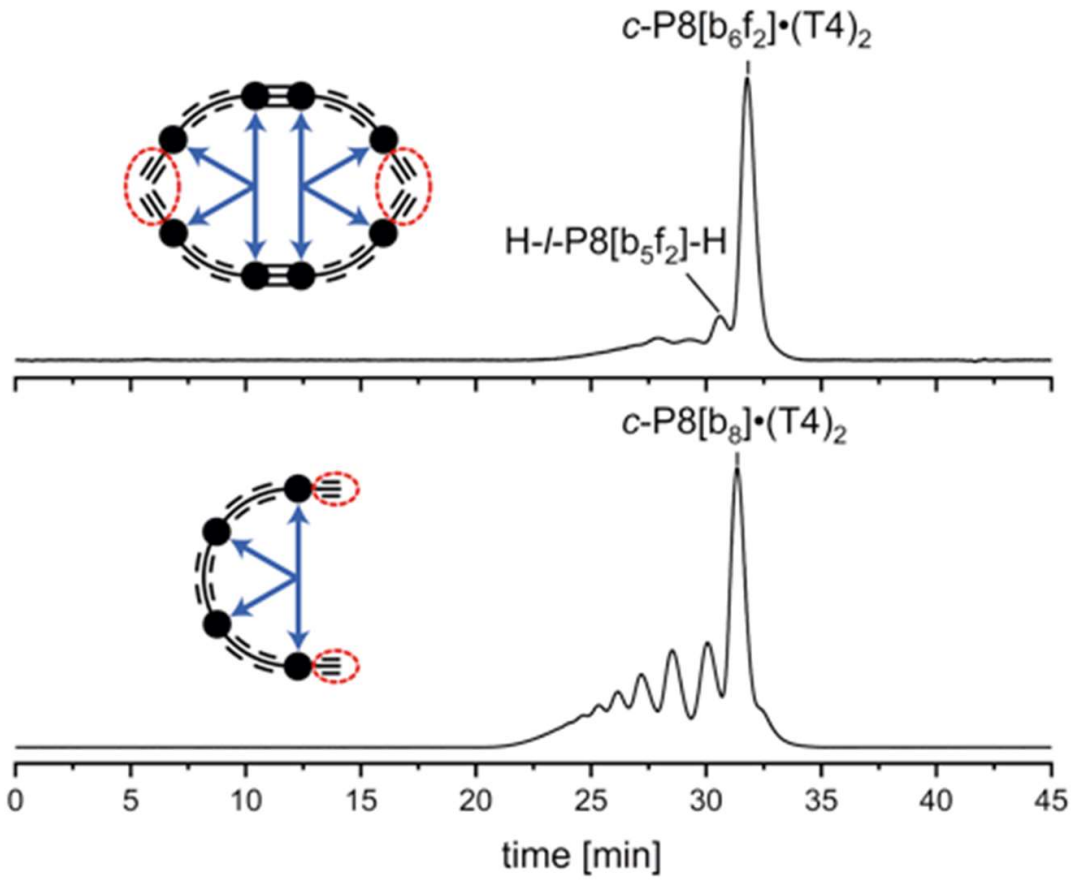

Figure S4. Comparison of the analytical GPC traces (THF $+1 \%$ pyridine, $\lambda=440 \mathrm{~nm}$ ) of the crude reaction mixtures for the synthesis of $\boldsymbol{c}-\mathbf{P} 8\left[\mathbf{b}_{6} \mathbf{f}_{2}\right] \cdot(\mathbf{T 4})_{2}$ (top) and $\boldsymbol{c}-\mathbf{P} \mathbf{8}\left[\mathbf{b}_{\mathbf{8}}\right] \cdot(\mathbf{T} 4)_{2}$ (bottom). Cartoon inserts show the preorganized complexes (H-I$\left.\mathbf{P} 4\left[b_{2} f_{1}\right]_{2}\right)_{2}(T 4)_{2}$ (top) and $\left(\mathbf{H}-/-P 4\left[b_{3}\right]\right) \cdot(T 4)$ (bottom) directing the synthesis of $c-P 8\left[b_{6} f_{2}\right]^{\bullet}(T 4)_{2}$ and $c-P 8\left[b_{8}\right]^{\bullet}(T 4)_{2}$, respectively. 


\section{4. ${ }^{1} \mathrm{H}$ NMR Assignment of Rings and Complexes}

\section{Fused ring systems}

A summary of the most important correlations used to assign fused ring $c-P 8\left[b_{6} f_{2}\right]$ and its complexes $c$ $P 8\left[b_{6} f_{2}\right] \cdot(T 4)_{2}, c-P 8\left[b_{6} f_{2}\right] \cdot\left(T 4_{1,4 F}\right)_{2}$, and $c-P 8\left[b_{6} f_{2}\right] \cdot\left(T 4_{2,3 F}\right)_{2}$ is given in Figure S5. Please confer Tables S17, $\mathbf{S} 15, \mathbf{S} 18$, and $\mathbf{S} 19$ for the complete list of NMR correlations.

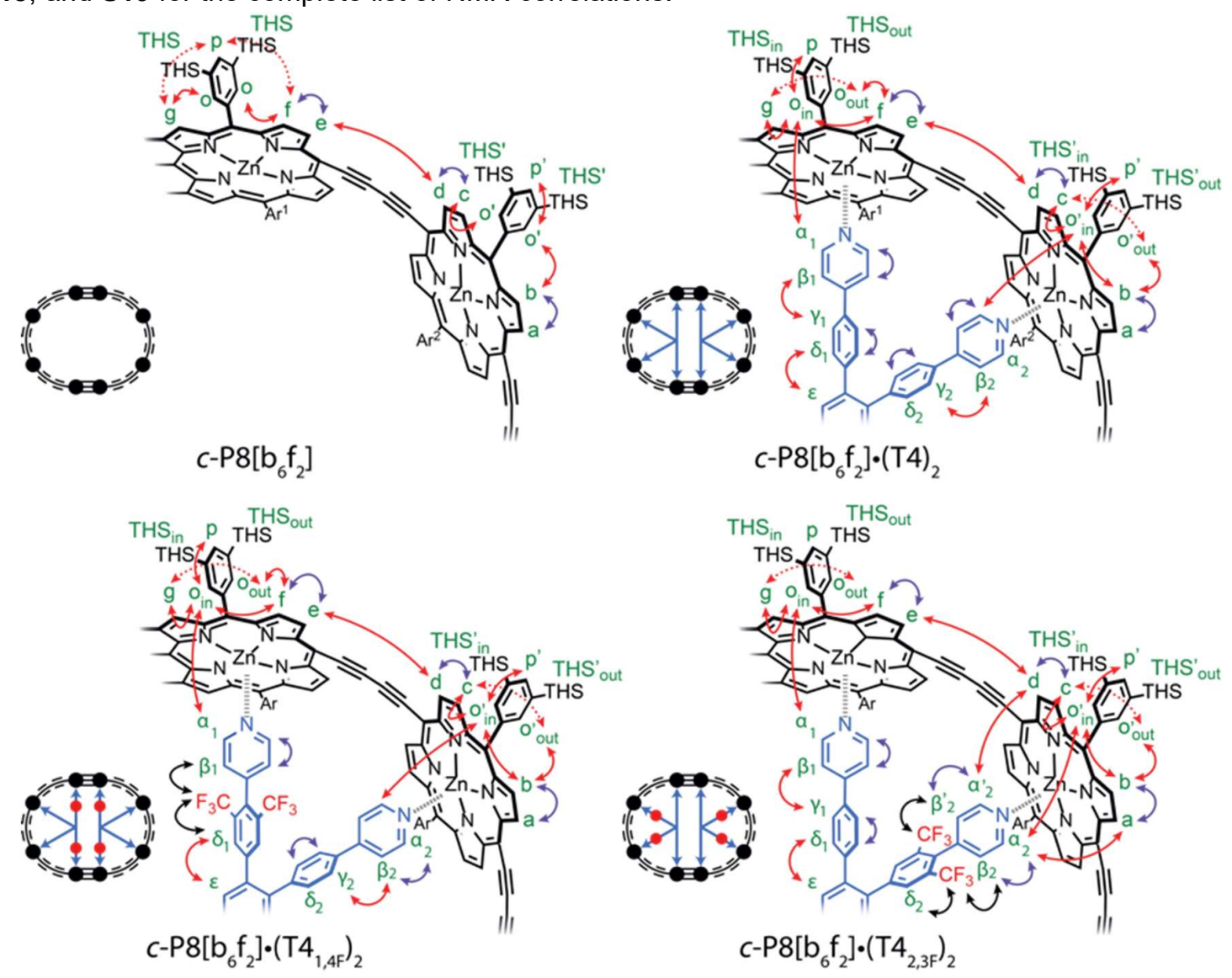

Figure S5. A summary of key NOESY (red arrows), COSY (purple arrows), and $1 \mathrm{D}{ }^{1} \mathrm{H}-{ }^{19} \mathrm{~F}$ HOESY (black arrows) correlations used in the assignment of all fused ring systems.

Template resonances in complexes $c-P 8\left[b_{6} f_{2}\right] \cdot(T 4)_{2}, \quad c-P 8\left[b_{6} f_{2}\right] \cdot\left(T 4_{1,4 F}\right)_{2}$, and $c-P 8\left[b_{6} f_{2}\right] \cdot\left(T 4_{2,3 F}\right)_{2}$ can be assigned based on NOESY, COSY, and $1 \mathrm{D}{ }^{1} \mathrm{H}-{ }^{19} \mathrm{~F}$ HOESY correlations. The $\varepsilon$ resonance is the only signal expected to present as a singlet corresponding to $4 \mathrm{H}$, and thus constitutes a reasonable starting point for the assignment. Correlations between adjacent phenylene/pyridyl rings are mainly established by NOESY (and to a minor extent HOESY), while COSY gives the correlations within each of these rings. In complexes $c$ $\mathbf{P} 8\left[b_{6} f_{2}\right] \cdot\left(T 4_{1,4 F}\right)_{2}$ and $c-P 8\left[b_{6} f_{2}\right] \cdot\left(\mathbf{T 4}_{2,3 F}\right)_{2}$, with fluorinated templates, $1 \mathrm{D}{ }^{1} \mathrm{H}-{ }^{19} \mathrm{~F}$ HOESY provides the $\delta_{1}$ and $\beta_{1}$ resonances, as these exhibit the most intense and second most intense correlations, respectively, to the $\mathrm{CF}_{3}$ groups. In addition, for complex $c-\mathbf{P} 8\left[\mathbf{b}_{6} \mathbf{f}_{2}\right] \cdot\left(\mathbf{T} \mathbf{4}_{2,3 F}\right)_{2}$, the difference in signal intensity between proton signals $\beta_{2}$ and $\beta_{2}$ in HOESY, provides a way of distinguishing these resonances. With the rotation being restricted about the fluorinated leg, on average, $\beta_{2}$ is closer than $\beta_{2}^{\prime}$ to the $\mathrm{CF}_{3}$ groups in the neighboring leg, and consequently, the $\beta_{2}$ resonance experiences a greater hOe than $\beta_{2}^{\prime}$ (Figure S6).

The inner ortho resonances of the aryl sidechains, Oin and o' in, are identified based on their NOESY correlations to the the nearest pyridyl protons ( $\alpha$ and $\beta$ ). From there on, NOESY allows identification of the outer ortho protons, Oout and o'out, as these, aside from oin and o' ${ }^{\prime}$, are the only aryl side chain resonances, with strong nOe correlations to porphyrin protons. The para resonances can be identified based on their NOESY correlations to 
the inner or outer ortho resonances within the respective aryl ring taken together with their weaker correlations to resonances within the nearest porphyrin unit.

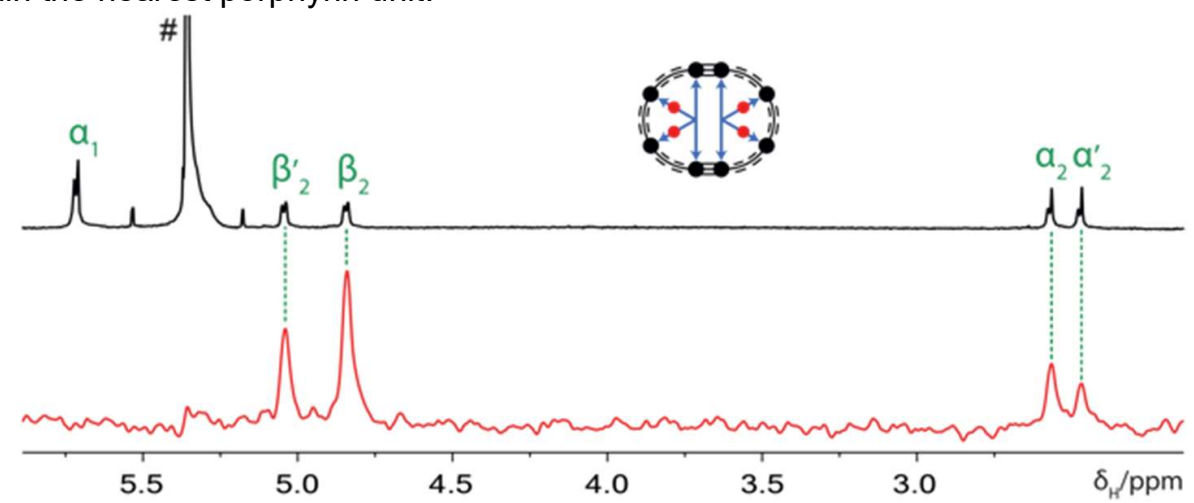

Figure S6. Region of ${ }^{1} \mathrm{H}$ (top) and $1 \mathrm{D}{ }^{1} \mathrm{H}_{-}{ }^{19} \mathrm{~F}$ HOESY (bottom, red) spectra of complex $\mathbf{c}-\mathbf{P} 8\left[\mathbf{b}_{6} \mathbf{f}_{2}\right]_{\bullet} \cdot\left(\mathbf{T 4}_{2,3}, 3\right)_{2}$ recorded in $\mathrm{CD}_{2} \mathrm{Cl}_{2}$. The differences in hOe intensities are used to assign alpha and beta resonances in the fluorinated leg of the template. Peak assigned with \# arise from $\mathrm{CHCl}_{3}$.

Porphyrin resonances of the tape unit can be distinguished from resonances of the all butadiyne-linked porphyrin unit based on chemical shift differences. In these systems, the tape resonances are in all cases located at lower chemical shift values than those of the all-butadiyne linked porphyrin unit, decreasing from resonance $e$ to $f$ to $g$ in the tape porphyrin (Figure S7). In addition, tape resonance $g$ is readily identified, as it is the only porphyrin proton expected to yield a singlet in the ${ }^{1} \mathrm{H}$ spectrum. Starting from $\mathrm{g}$, the tape and all-butadiyne linked porphyrin resonances are assigned using NOESY and COSY correlations. The NOESY correlation across the butadiyne link between e and $d$ allows for the distinction between resonances $a / d$ and $b / c$ within the all-butadiyne linked porphyrin unit. Due to splitting of the alpha protons in complex $c-\mathbf{P} 8\left[\mathbf{b}_{6} \mathbf{f}_{2}\right] \cdot\left(\mathbf{T 4}_{2,3 \mathrm{~F}}\right)_{2}$, differentiation between $\mathrm{a} / \mathrm{d}$ and $b / c$ is further supported by nOe correlations between $a$ and $\alpha_{2}$ and between $d$ and $\alpha_{2}^{\prime}$.

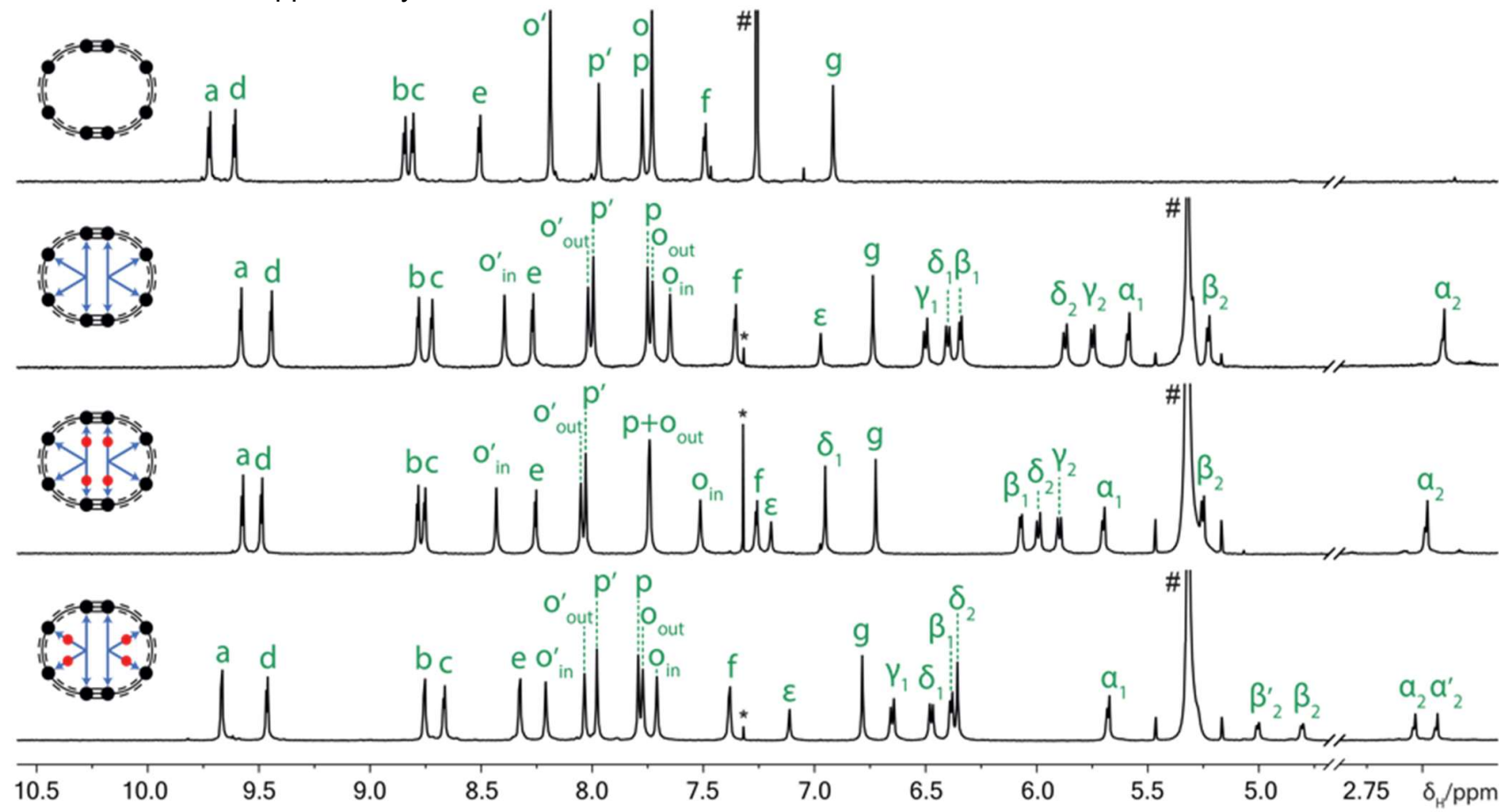

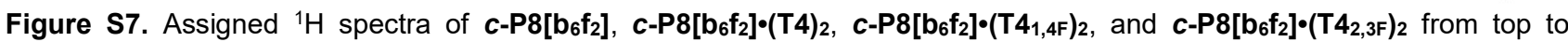
bottom recorded in $\mathrm{CDCl}_{3}$ for $\boldsymbol{c}-\mathrm{P} 8\left[\mathbf{b}_{6} \mathrm{f}_{2}\right]$ and $\mathrm{CD}_{2} \mathrm{Cl}_{2}$ for the template complexes. The THS signals at ca. $\delta_{-1}=1.7-0.5 \mathrm{ppm}$ are omitted for clarity. Peaks assigned with \# and ${ }^{*}$ arise from $\mathrm{CHCl}_{3}\left(\boldsymbol{c}-\mathbf{P} 8\left[\mathbf{b}_{6} \mathbf{f}_{2}\right]\right)$ or $\mathrm{CHDCl}_{2}\left(\boldsymbol{c}-\mathbf{P} 8\left[\mathbf{b}_{6} \mathbf{f}_{2}\right]\right.$ complexes) and neutral thianthrene, respectively. 


\section{All-butadiyne linked ring systems}

A summary of the most important correlations used to assign all-butadiyne linked ring complexes $c-\mathbf{P} 8\left[\mathbf{b}_{8}\right]_{\mathbf{0}} \cdot(\mathbf{T} 4)_{2}$, $c-P 8\left[b_{8}\right] \cdot\left(T_{1} 1_{1,4 F}\right)_{2}$, and $c-P 8\left[b_{8}\right] \cdot\left(T_{2}, 3 F\right)_{2}$ is given in Figure S8. Please confer Table S20, S21, and S22 for the complete list of NMR correlations.

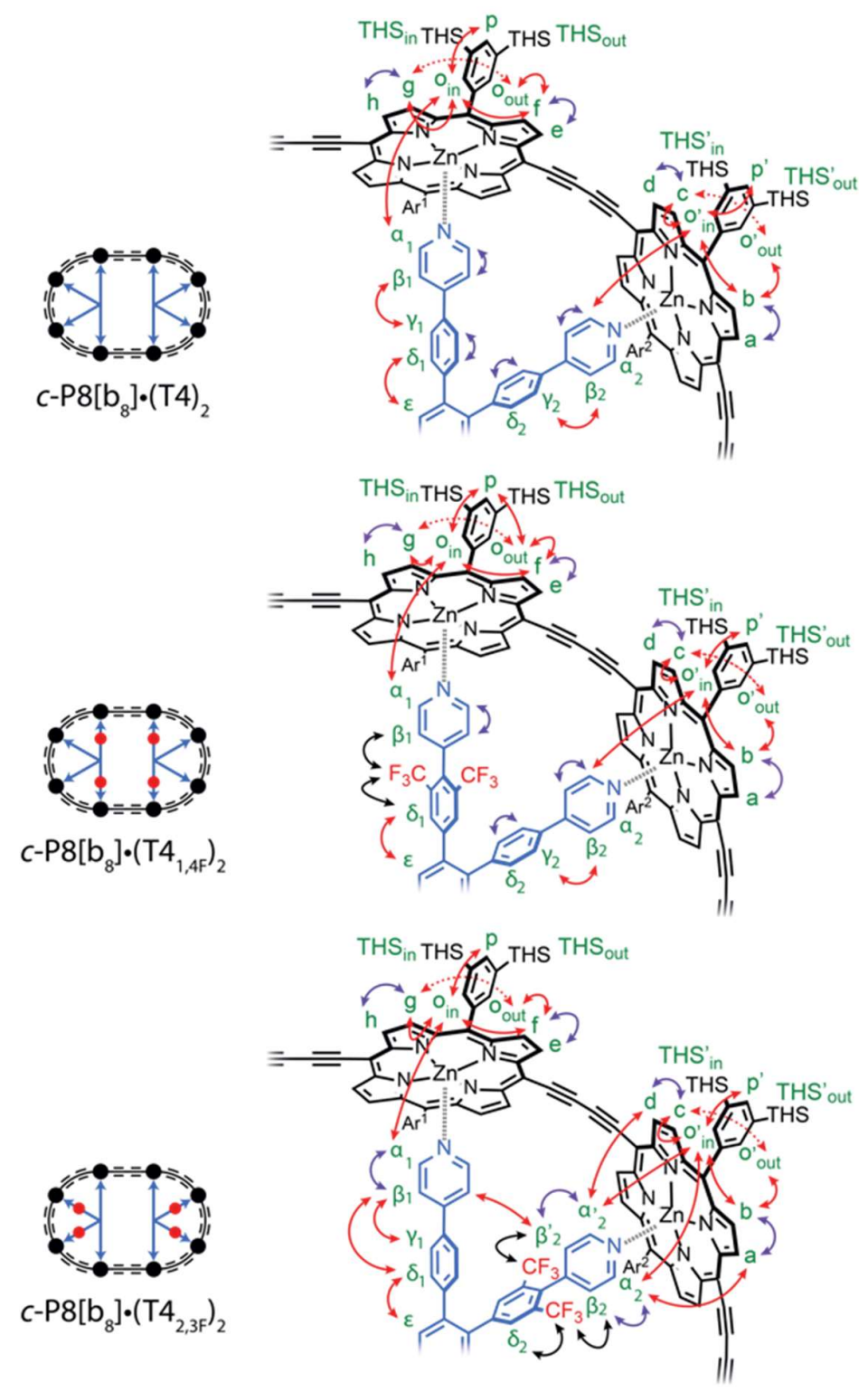

Figure S8. A summary of key NOESY (red arrows), COSY (purple arrows), and $1 \mathrm{D}{ }^{1} \mathrm{H}-{ }^{19} \mathrm{~F}$ HOESY (black arrows) correlations used in the assignment of all-butadiyne linked complexes.

The ${ }^{1} \mathrm{H}$ assignment of the butadiyne linked complexes is analogous to the approach described for the fused ring systems. Similarly, the $\varepsilon$ resonance is a good starting point, as it is the only proton expected to result in a singlet corresponding to $4 \mathrm{H}$. From $\varepsilon$, the template resonances are assigned based on NOESY and COSY correlations, as well as $1 \mathrm{D}^{1} \mathrm{H}_{-}{ }^{19} \mathrm{~F}$ HOESY in the case of fluorinated complexes $c-\mathrm{P} 8\left[\mathbf{b}_{8}\right]_{\bullet} \cdot\left(\mathbf{T 4}_{1,4 \mathrm{~F}}\right)_{2}$, and $c-\mathrm{P} 8\left[\mathbf{b}_{8}\right]_{\bullet} \cdot\left(\mathbf{T 4}_{2,3 \mathrm{~F}}\right)_{2}$. The $\delta$ and $\beta$ resonances within the same leg as the $\mathrm{CF}_{3}$ groups are readily identified via HOESY, given that these two resonances experience the most and second most intense hOes, respectively. For the fluorinated complex $c-P 8\left[b_{8}\right] \cdot\left(T_{4}, 3 F\right)_{2}$, the split alpha and beta resonances are also assigned using HOESY, once again by consideration of their relative differences in signal intensity (Figure S9). In addition, this assignment is supported by a weak NOESY correlation between beta resonances $\left(\beta_{2}^{\prime}\right.$ and $\left.\beta_{1}\right)$ in different template legs (Figure S10). 


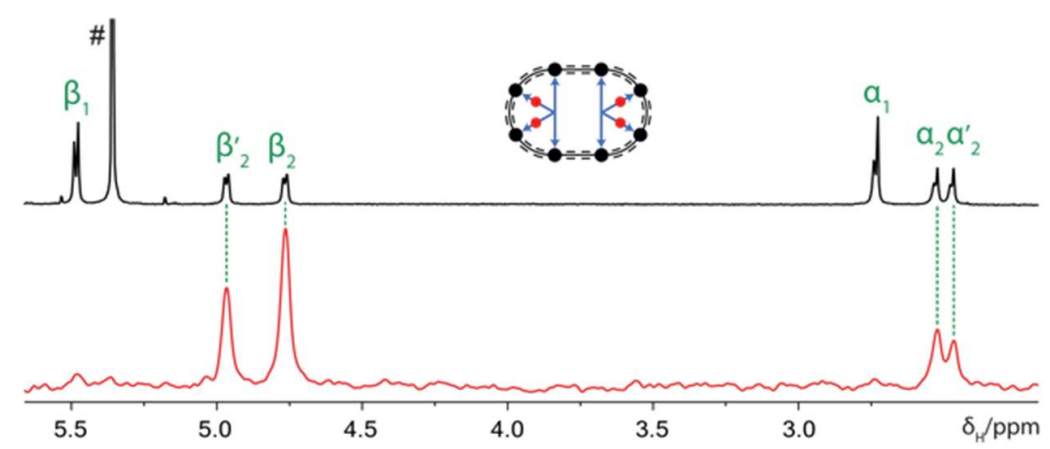

Figure S9. Region of ${ }^{1} \mathrm{H}$ (top) and $1 \mathrm{D}{ }^{1} \mathrm{H}-{ }^{19} \mathrm{~F}$ HOESY (bottom, red) spectra of complex $\mathbf{c}-\mathbf{P} 8\left[\mathbf{b}_{8}\right] \cdot\left(\mathbf{T}_{2}, 3 \mathrm{~F}\right)_{2}$ recorded in $\mathrm{CD}_{2} \mathrm{Cl}_{2}$. The differences in signal intensities in HOESY are used to assign alpha and beta resonances in the fluorinated leg of the template. Peak assigned with \# arise from $\mathrm{CHDCl}_{2}$.

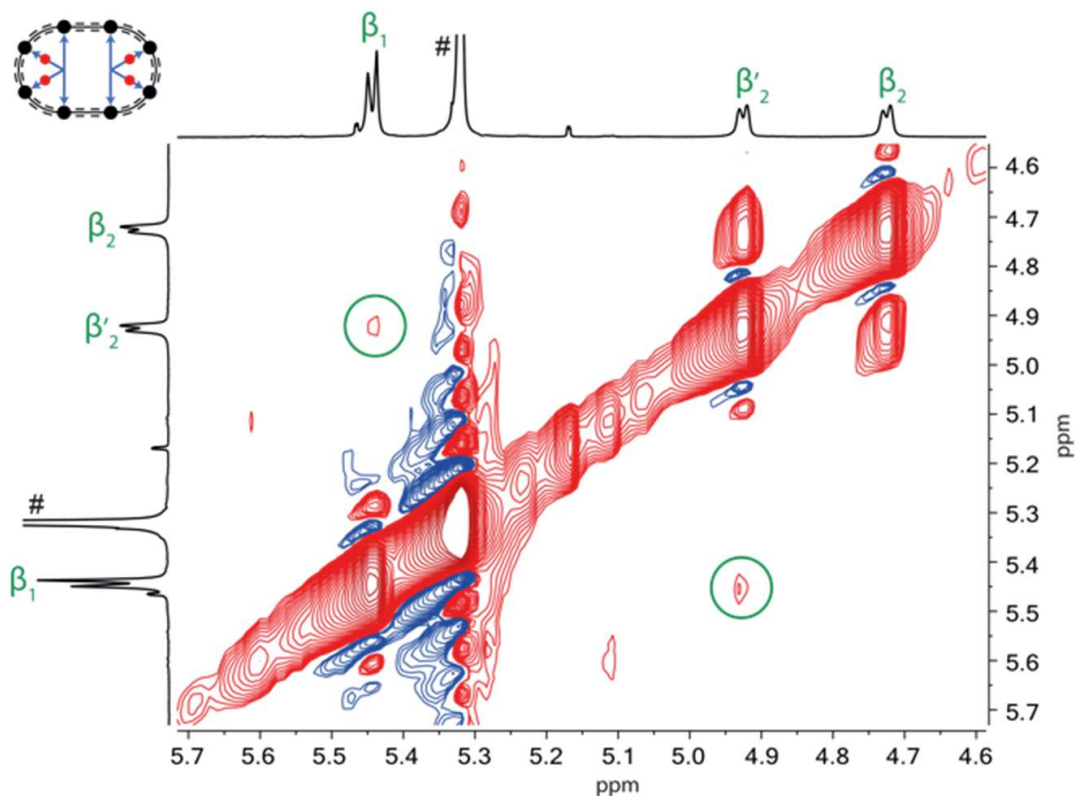

Figure S10. Region of the NOESY spectrum of complex $c-\mathbf{P} 8\left[\mathbf{b}_{8}\right] \cdot\left(\mathbf{T}_{2}, 3 \mathrm{~F}\right)_{2}$ recorded in $\mathrm{CD}_{2} \mathrm{Cl}_{2}$. The weak correlation (circled) between resonances $\beta_{1}$ and $\beta_{2}^{\prime}$ is used to assign the split beta protons in the fluorinated leg. Peaks assigned with \# arise from $\mathrm{CHDCl}_{2}$.

The inner ortho protons, Oin and o'in, are identified based on their NOESY correlations to the closest pyridyl protons (alpha and beta). All the aryl side chain resonances correlate by NOESY within the same aryl ring, and both types of ortho resonances exhibit strong NOESY correlations to porphyrin resonances, whereas the para resonances do not. This allows for the assignment of outer ortho and para resonances.

The porphyrin resonances are identified, as to which of the two porphyrin units they belong to, based on their NOESY correlations to both the nearest template pyridyl protons and side chain ortho protons. Also used, the characteristic chemical shift feature of butadiyne-linked porphyrins being that the porphyrin protons closest to the acetylenes are at higher $\delta_{\mathrm{H}}$ (usually ca. $10-9.5 \mathrm{ppm}$ ) compared to the protons sitting next to the aryl side group (usually ca. $9.0-8.5 \mathrm{ppm}$ ).

For complexes $c-\mathbf{P 8}\left[\mathbf{b}_{8}\right]^{\bullet}(\mathbf{T 4})_{2}$ and $c-\mathbf{P 8}\left[\mathbf{b}_{8}\right]_{\bullet} \cdot\left(\mathbf{T 4}_{1,4 \mathrm{~F}}\right)_{2}$, it is not possible to distinguish resonances of the same porphyrin unit that correspond to protons on directly opposite sides of the aryl side group. Hence, the proton couples: a/d, e/h, b/c, and f/g cannot be distinguished. The NOESY correlation between resonances $\mathrm{d}$ and e that would allow this distinction is absent in these complexes; likely due to the close spacing of the porphyrin signals. For complex $c-P 8\left[b_{8}\right] \cdot\left(\mathbf{T 4}_{2,3 F}\right)_{2}$, the split template alpha and beta resonances offers a way of telling the porphyrin sides apart. Thereby, the porphyrin resonances of the unit closest to the fluorinated leg can be resolved via the 
NOESY correlations between $a$ and $\alpha_{2}$ and between $d$ and $\alpha_{2}$. The assigned spectra are shown below (Figure S11).

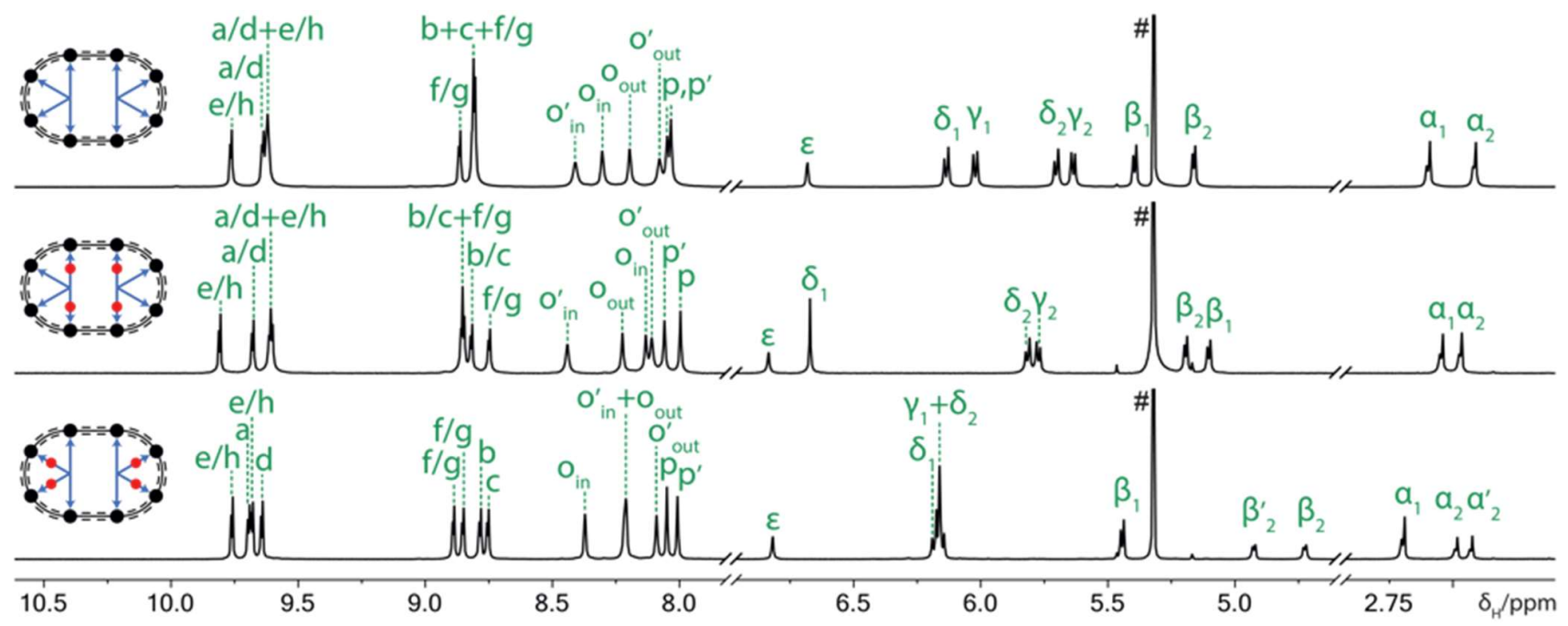

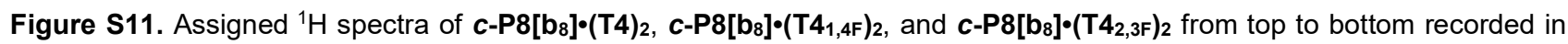
$\mathrm{CD}_{2} \mathrm{Cl}_{2}$. The THS signals at ca. $\delta_{\mathrm{H}}=1.7-0.5 \mathrm{ppm}$ are omitted for clarity. Peaks assigned with \# arise from $\mathrm{CHDCl}_{2}$. 


\section{Analysis of Global Ring Currents}

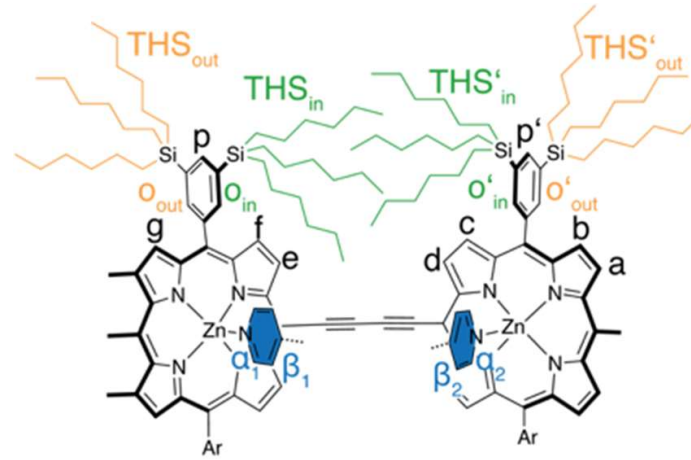

The presence and character of a global ring current around the circumference of a porphyrin nanoring complex is established based on the induced chemical shift differences of resonances inside and outside the ring. The induced magnetic field lines are focused towards the center of the ring and consequently, resonances located within the circumference of the ring will be affected to a larger extent by a global current than resonances located on the outside. The porphyrin ring complexes investigated in this work possess three distinct chemical shift environments within the circumference of the ring: 1 ) being the template resonances, in particular the $\alpha_{1 / 2}$ and $\beta_{1 / 2}$ protons on the pyridyl groups facing the porphyrin units and the $\mathrm{CF}_{3}$ groups in the fluorinated templates; 2) the inner trihexylsilyl protons, $\mathrm{THS}^{\left({ }^{(}\right)}$in on the aryl residues; and 3) the inner ortho protons, $\mathrm{o}^{\left({ }^{(}\right)}$in, in the aryl residues. The second set of trihexylsilyl protons, THS(') out and ortho resonances, $\mathrm{O}^{\left.()^{(}\right)}$out are pointing towards the outside of the porphyrin ring. The remaining porphyrin beta protons $a, b, c, d, e, f, g$, and - in the case of all butadiyne linked complexes $-h$, and the para-aryl protons $p^{(i)}$ are located on the circumference of the ring and will thus only experience small chemical shift differences resulting from an induced global ring current.

A combination of COSY, NOESY, and $1 \mathrm{D}^{1} \mathrm{H}-{ }^{19} \mathrm{~F}$ HOESY experiments were used to partially assign and identify key resonances in the spectra of each oxidation state corresponding to $c-P 8\left[b_{6} f_{2}\right]_{\bullet} \cdot(T 4)_{2}, c-P 8\left[b_{6} f_{2}\right]_{\bullet}\left(T_{4} 4_{1,4 F}\right)_{2}$, and $c-P 8\left[b_{6} f_{2}\right] \cdot\left(\mathbf{T 4}_{2,3 F}\right)_{2}$ (Figures S13-S15). The key resonances in the spectra of the oxidized complexes of $c$ -

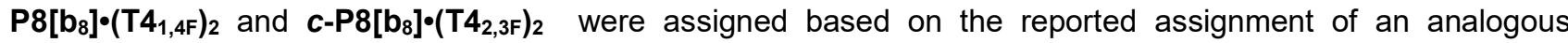
complex, $c-\mathrm{P} 8\left[\mathrm{~b}_{8}\right]^{\cdot}(\mathrm{T} 4)_{2}$ (Figures S16 + S17). ${ }^{4}$

The inner and outer THS resonances in the region between 4 and -3 ppm can be distinguished based on their chemical shift differences in all oxidation states. The inner THS resonances, THS ${ }^{\left({ }^{(}\right)}$in, are significantly affected by oxidation and an induced ring current, and are thus identified as the multiplet of protons which shifts upon oxidation. On the other hand, the outer THS resonances, THS ${ }^{\left({ }^{(}\right)}$out, remain almost at identical chemical shift in all oxidation states. This assignment is further supported by NOESY and $1 \mathrm{D}^{1} \mathrm{H}-{ }^{19} \mathrm{~F}$ HOESY correlations of template resonances to the $\mathrm{THS}^{\left({ }^{(}\right)}$in resonances, whereas none are observed to the outer, $\mathrm{THS}^{\left({ }^{(}\right)}$out resonances (Figure S12). No HSQC correlations between the template and inner THS resonances were observed in $c$ $\mathbf{P 8}\left[b_{6} f_{2}\right] \cdot(T 4)_{2}, c-P 8\left[b_{6} f_{2}\right] \cdot\left(T 4_{1,4 F}\right)_{2}$, and $c-P 8\left[b_{6} f_{2}\right]_{\bullet} \cdot\left(T 4_{2,3 F}\right)_{2}$ despite the use of long acquisition times (up to 8 hours). Given a proton line-width dependency of the HSQC experiment, this may be ascribed to signal broadening effects from the presence of open-shell species, existing between the endpoints of the oxidative titration.

Due to the similar chemical structures of complexes $c-P 8\left[b_{6} f_{2}\right] \cdot(T 4)_{2}, \quad c-P 8\left[b_{6} f_{2}\right] \cdot\left(T 4_{1,4 F}\right)_{2}$, and $c$ $\mathbf{P 8}\left[b_{6} f_{2}\right] \cdot\left(\mathbf{T 4}_{2,3 F}\right)_{2}$, we employed a cross-assignment approach for identifying resonances in each oxidation state: In the first step, resonances of the individual nanoring complex were assigned based on the respective 2D NMR experiments. Then, the assigned spectra of the three different complexes in each oxidation states were correlated, and the findings summarized in an overall assignment of the proton spectra of $c-P 8\left[b_{6} f_{2}\right] \cdot(T 4)_{2}$ (Figures S18-S20). Cross-assignment of the template resonances was directed by the correlation of the $\alpha_{1}$ and $\alpha_{2}$ resonances as they experience little change in their immediate chemical environment within templates of different fluorination patterns. The individual assignment of the non-fluorinated complex $c-P 8\left[b_{6} f_{2}\right]_{\bullet}\left(\mathbf{T}_{4}\right)_{2}$ was based on NOESY spectra of the +4 and +6 oxidation states and a combination of NOESY and COSY experiments in the +8 state. In the assignment of complexes $c-P 8\left[b_{6} f_{2}\right]_{\bullet}\left(\mathbf{T 4}_{1,4 F}\right)_{2}$, and $c-P 8\left[b_{6} f_{2}\right]_{\bullet}\left(\mathbf{T 4}_{2,3 F}\right)_{2}$, we exploited the additional information of the fluorine probes by recording $1 \mathrm{D}{ }^{1} \mathrm{H}-{ }^{19} \mathrm{~F}$ HOESY spectra of the +4 and +6 oxidation states and a combination of NOESY, COSY, and 1D ${ }^{1} \mathrm{H}-{ }^{19} \mathrm{~F}$ HOESY experiments in the +8 state. Template resonances could be readily identified via HOESY given that the $\delta$ and $\beta$ resonances within the same 
leg as the $\mathrm{CF}_{3}$ groups experience the most and second most intense hOes, respectively followed by the $\beta$ and $\alpha$ resonances. NOESY and COSY experiments highlighted the correlations within the template and beta porphyrin regions, and in the case of NOESY experiments, also correlations between the template and the porphyrin resonances.

In some cases, not all resonances could be unambiguously assigned, even after substantially extending the number of scans. These resonances have not been labeled in the different spectra.

a)

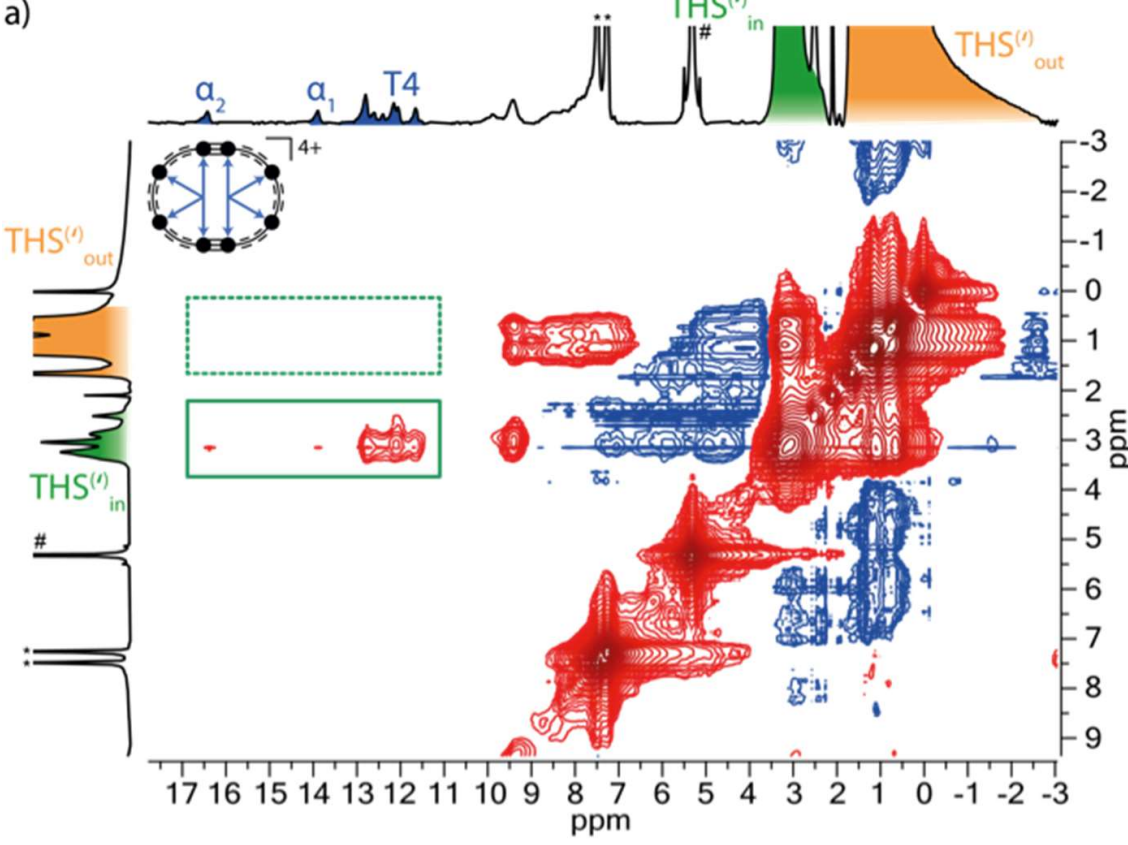

b)

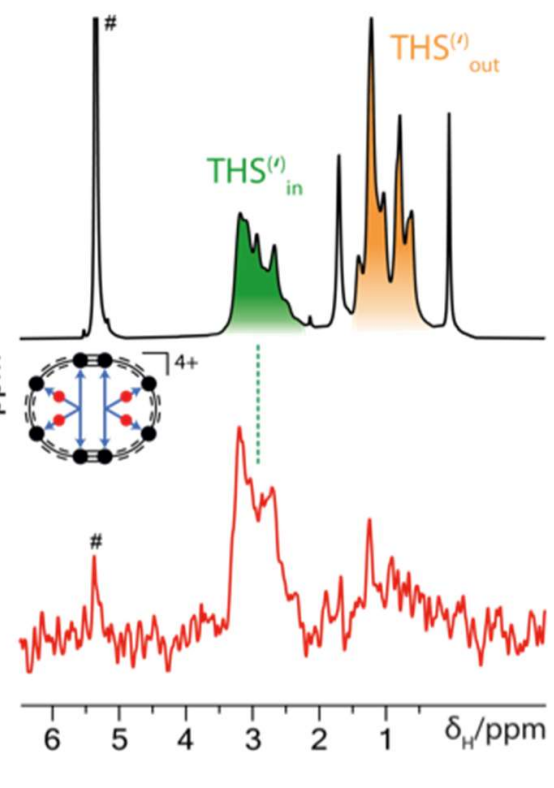

Figure S12. Representative regions of the ${ }^{1} \mathrm{H}-{ }^{1} \mathrm{H}$ NOESY spectrum of $\boldsymbol{c}-\mathbf{P} 8\left[\mathbf{b}_{6} \mathrm{f}_{2}\right]_{\bullet} \cdot\left(\mathrm{T}_{4}\right)_{2}{ }^{4+}$ in $\mathrm{CD}_{2} \mathrm{Cl}_{2}$ at $223 \mathrm{~K}$ (a) and the $1 \mathrm{D}$ ${ }^{1} \mathrm{H}-{ }^{19} \mathrm{~F}$ HOESY spectrum of $\boldsymbol{c}-\mathbf{P} 8\left[\mathbf{b}_{6} \mathbf{f}_{2}\right] \cdot\left(\mathbf{T 4}_{2}, 3 \mathrm{~F}\right)_{2}{ }^{4+}$ in $\mathrm{CD}_{2} \mathrm{Cl}_{2}$ at $223 \mathrm{~K}(\mathrm{~b})$, highlighting the correlations between the inner THS $\left(\mathrm{THS}^{\left({ }^{(}\right)}\right.$in $)$and template resonances. Peaks assigned with \# and ${ }^{*}$ arise from $\mathrm{CHDCl}_{2}$ and neutral thianthrene, respectively.

\section{Use of chemical shift differences as a measure for relative ring current strengths}

i) Following the Biot-Savart law ${ }^{11}$ and the NMR Larmor frequency definition, a direct relation between the chemical shift difference $(\Delta \delta)$ and the (anti)aromatic ring current $(I)$ can be established. The Biot-Savart law describes the magnetic field $B$ at a point in space generated by a constant flowing current $I$ as:

$$
d B=\frac{\mu_{0}}{4 \pi} I \frac{r \times d l}{r^{3}},
$$

where $\mu_{0}$ is the magnetic constant, $r$ is the distance from the electric circuit element to the point, and $d l$ is a small length element of the circuit. In the simplified case of a circular current loop with radius $a$, the solution to this differential equation reveals that the magnetic field at the center of the ring, $B_{C}$, is given as:

$$
B_{C}=\frac{\mu_{0} I}{2 a},
$$

which serves to highlight the directly proportional relationship between ring current $I$ and its induced magnetic field $B$.

ii) The Larmor frequency $v$ of a nucleus is directly proportional to the effective magnetic field strength experienced by that nucleus. The magnetic field contribution stemming from a nearby ring current, $B_{R C}$, may be isolated as a frequency difference $\Delta v$, assuming two states of that nucleus can be defined, one in which a ring current is on and the other one, where it is off:

$$
\Delta v=v_{o n}-v_{o f f}=\frac{\gamma}{2 \pi} B_{R C},
$$


Differences in the Larmor frequency are directly translated into the experimentally observed chemical shift differences according to:

$$
\Delta \delta=10^{6} \frac{\gamma}{2 \pi v_{\text {Inst }}} B_{R C},
$$

where $v_{\text {Inst }}$ denotes the operating frequency of the NMR instrument.

iii) In our analysis, we use the probe nuclei from templates ( $\alpha$ and $\mathrm{CF}_{3}$ resonances) and the inner THS chains to infer changes in ring current from changes in their chemical shifts. We define the chemical shift difference, $\Delta \delta$, as the shift difference between a state affected by the ring current and one which is not. In case of template probes, shifts corresponding to unbound template are used in order to subtract magnetic contributions inherent to the template. In case of the inner THS probe, the shift of the outer THS resonances are used to subtract magnetic contributions independent of the induced ring current.

$$
\begin{aligned}
& \Delta \delta(\text { template })=\delta_{\text {Bound }}-\delta_{\text {Unbound }}, \\
& \Delta \delta(T H S)=\delta_{T H S, \text { inner }}-\delta_{T H S, \text { outer }},
\end{aligned}
$$

According to this definition, positive chemical shift differences correspond to a paratropic ring current and an antiaromatic character, whereas negative chemical shift differences correspond to a diatropic ring current and global aromatic character of the porphyrin nanoring.

iv) The chemical shift difference ratio can be used to compare ring currents between different nanoring complexes. To compare the relative ring current strength of a partially fused nanoring complex $c$ $\mathbf{P} 8\left[\mathrm{~b}_{6} \mathrm{f}_{2}\right] \cdot\left(\mathrm{T} \mathbf{T}_{\mathrm{x}, \mathrm{YF}}\right)_{2}$ and an all-butadiyne linked nanoring complex $c-\mathrm{P} 8\left[\mathrm{~b}_{8}\right] \cdot\left(\mathrm{T} \mathbf{x}_{\mathrm{x}, \mathrm{YF}}\right)_{2}$, we use their relative shift ratio, $\varphi$, which we define as:

$$
\varphi=\frac{\Delta \delta_{X, Y}\left(\boldsymbol{c}-\boldsymbol{P 8}\left[\boldsymbol{b}_{6} f_{2}\right] \cdot\left(T 4_{X, Y}\right)_{2}\right)}{\Delta \delta_{X, Y}\left(\boldsymbol{c}-\boldsymbol{P 8}\left[b_{8}\right] \cdot\left(T 4_{X, Y}\right)_{2}\right)},
$$

with $X, Y$ denoting either a 1,4 or 2,3 substitution pattern corresponding to the two fluorinated templates.

From comparison of the relative shift ratio $\varphi$ of complexes with the same fluorination pattern, we were able to establish how the relative ring current strengths change through the oxidation states. Comparison of $\varphi$ of complexes with different fluorination patterns in the same oxidation state allowed us to establish the global nature of the induced magnetic effects. 


\section{Overview of NMR Spectra of Nanoring Complexes}

(a) neutral, local aromatic

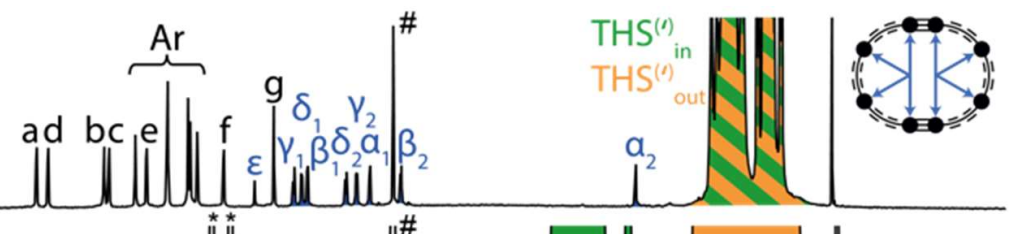

(b)

$4+$, antiaromatic

(c)

$6+$, aromatic

(d)

$8+$, antiaromatic

$\mathrm{T} 4$
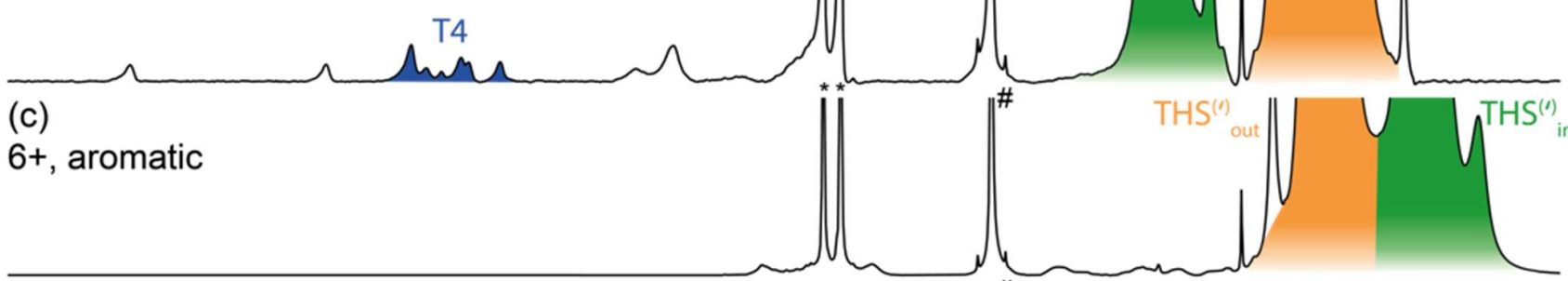

8t, antiaromatic

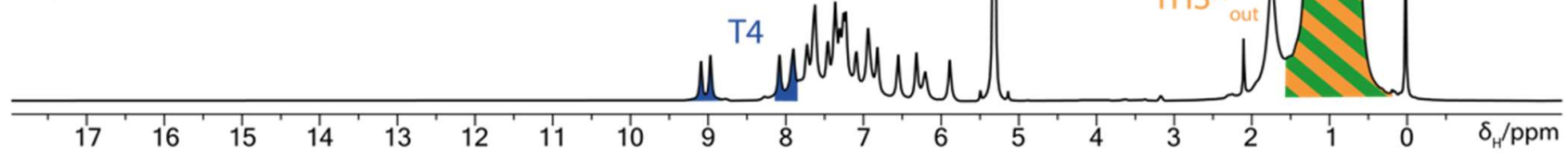

Figure S13. Summary of ${ }^{1} \mathrm{H}$ NMR $\left(500 \mathrm{MHz}, \mathrm{CD}_{2} \mathrm{Cl}_{2}\right)$ spectra of neutral (a, $\left.298 \mathrm{~K}\right)$ and oxidized (b-d, $\left.223 \mathrm{~K}\right) \boldsymbol{c}$-P8[b6f2]•(T4)2 generated by titration with $\mathrm{Thn}^{+}$. Refer to Figure $\mathbf{S 1}$ for labeling scheme. Peaks assigned with \# and * arise from $\mathrm{CHDCl}_{2}$ and neutral thianthrene, respectively. Unlabeled resonances were not unambiguously assigned.

(a)

neutral, local aromatic
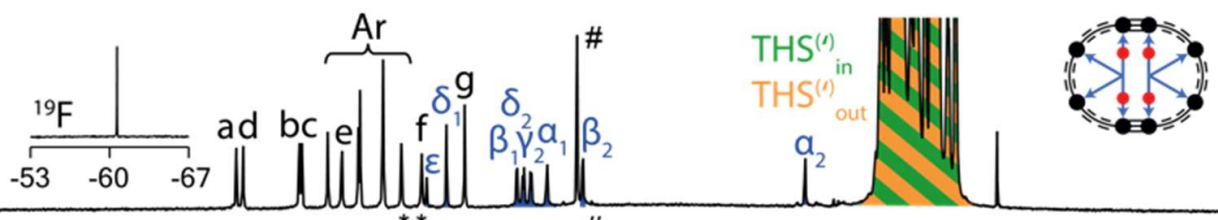

(b)

$4+$, antiaromatic

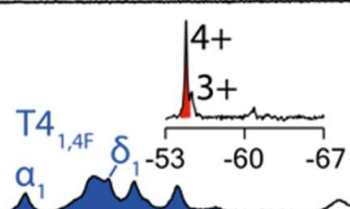

(c)

$6+$, aromatic

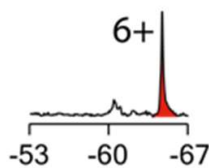

(d)

$8+$, antiaromatic
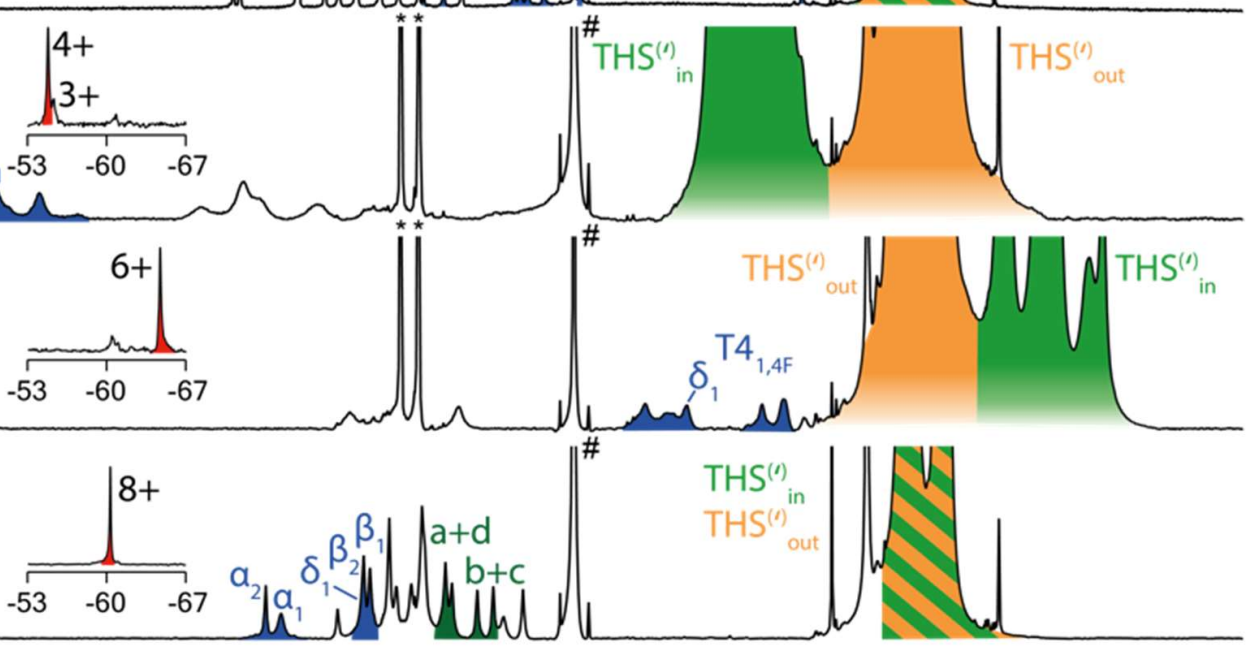

$17 \quad 16 \quad 15 \quad 14 \quad 13$

Figure S14. Summary of ${ }^{1} \mathrm{H}$ NMR (500 MHz, $\mathrm{CD}_{2} \mathrm{Cl}_{2}$ ) spectra of neutral (a, $298 \mathrm{~K}$ ) and oxidized (b-d, $223 \mathrm{~K}$ ) c$\mathbf{P} 8\left[\mathbf{b}_{6} \mathbf{f}_{2}\right] \cdot\left(\mathrm{T}_{1}, \mathbf{4} \mathrm{F}\right)_{2}$ generated by titration with $\mathrm{Thn}^{+}$. Inserts show concomitantly recorded ${ }^{19} \mathrm{~F} \mathrm{NMR}\left(471 \mathrm{MHz} \mathrm{CD} \mathrm{Cl}_{2}\right) \mathrm{spectra}$ of the $\mathrm{CF}_{3}$ probes. Refer to Figure $\mathbf{S 1}$ for labeling scheme. Peaks assigned with \# and ${ }^{*}$ arise from $\mathrm{CHDCl}_{2}$ and neutral thianthrene, respectively. Unlabeled resonances were not unambiguously assigned. 
(a) neutral, local aromatic
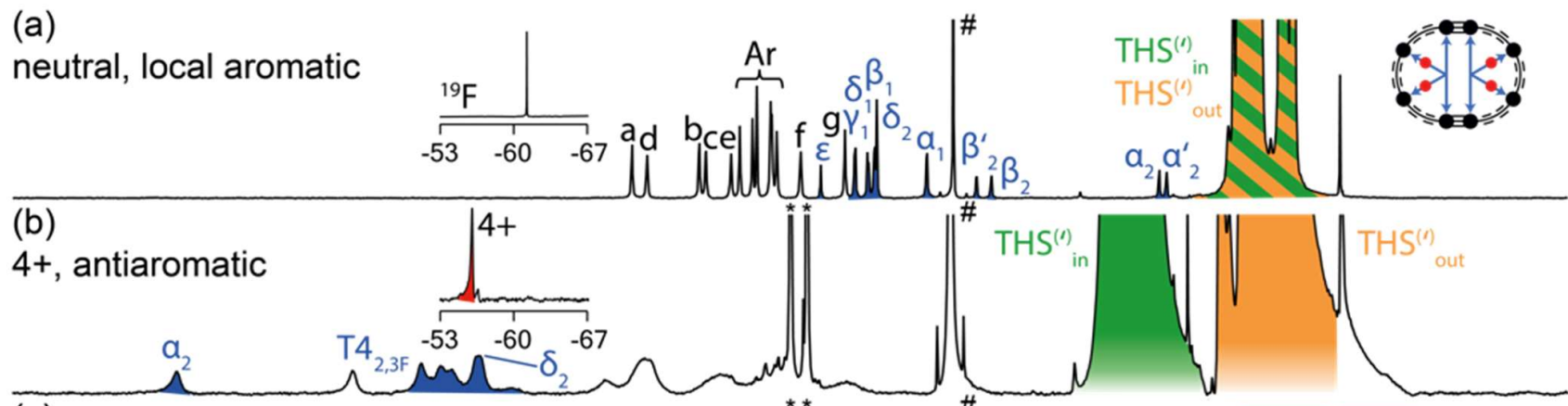

(c)

$6+$, aromatic

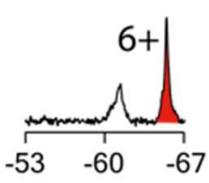

(d)

$8+$, antiaromatic
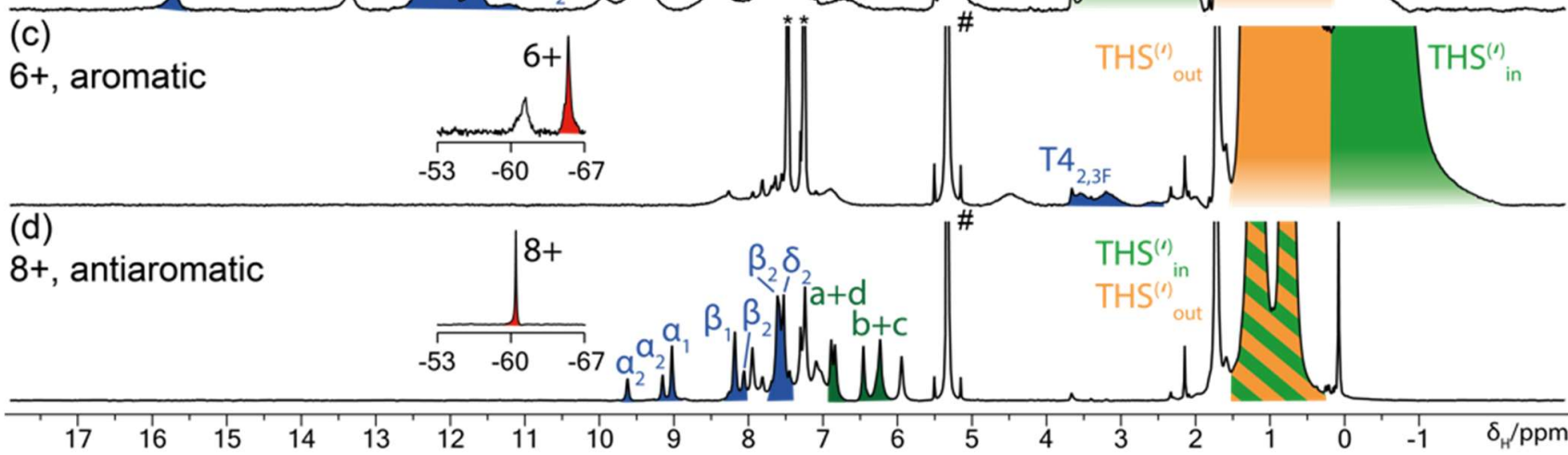

Figure S15. Summary of ${ }^{1} \mathrm{H}$ NMR $\left(500 \mathrm{MHz}, \mathrm{CD}_{2} \mathrm{Cl}_{2}\right)$ spectra of neutral $(\mathrm{a}, 298 \mathrm{~K})$ and oxidized (b-d, $\left.223 \mathrm{~K}\right) \mathrm{c}$ $\mathbf{P} 8\left[b_{6} f_{2}\right] \cdot\left(\mathrm{T4}_{2}, 3 \mathrm{~F}\right)_{2}$ generated by titration with $\mathrm{Thn}^{+}$. Inserts show concomitantly recorded ${ }^{19} \mathrm{~F} \mathrm{NMR}\left(471 \mathrm{MHz} \mathrm{CD}_{2} \mathrm{Cl}_{2}\right) \mathrm{spectra}$ of the $\mathrm{CF}_{3}$ probes. Refer to Figure $\mathbf{S} 1$ for labeling scheme. Peaks assigned with \# and * arise from $\mathrm{CHDCl}_{2}$ and neutral thianthrene, respectively. Unlabeled resonances were not unambiguously assigned.

(a)

neutral, local aromatic

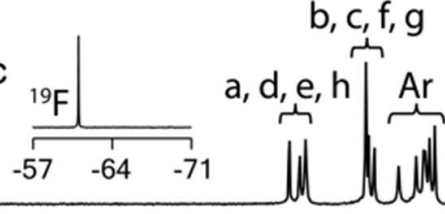

(b)

$4+$, antiaromatic

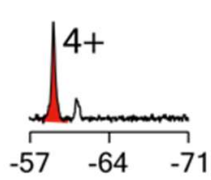

(c)

$6+$, aromatic

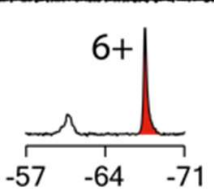

(d)

$8+$, antiaromatic
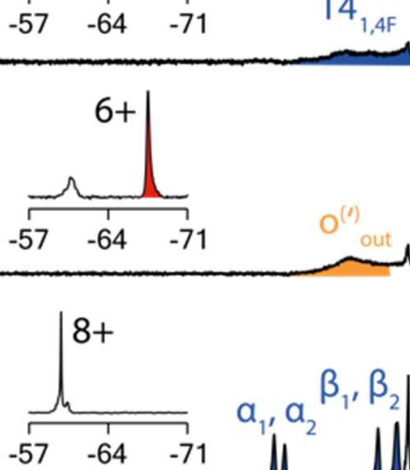
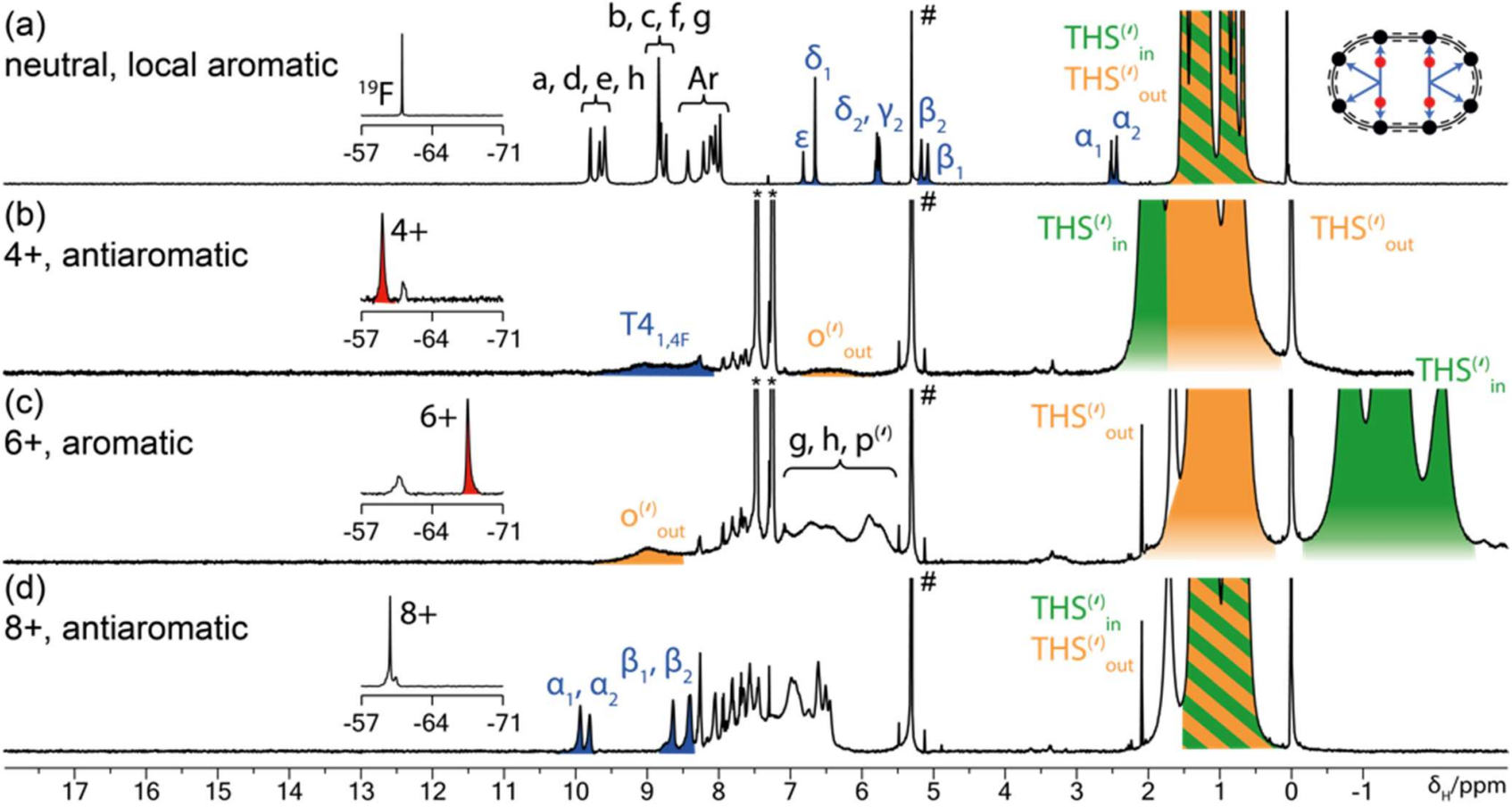

Figure S16. Summary of ${ }^{1} \mathrm{H}$ NMR $\left(500 \mathrm{MHz}, \mathrm{CD}_{2} \mathrm{Cl}_{2}\right)$ spectra of neutral $(\mathrm{a}, 298 \mathrm{~K})$ and oxidized (b-d, $\left.223 \mathrm{~K}\right) \mathrm{c}$ $\mathbf{P} 8\left[\mathbf{b}_{8}\right]^{\bullet}\left(\mathrm{T4}_{1,4 \mathrm{~F}}\right)_{2}$ generated by titration with $\mathrm{Thn}^{+}$. Inserts show concomitantly recorded ${ }^{19} \mathrm{~F}$ NMR $\left(471 \mathrm{MHz}, \mathrm{CD}_{2} \mathrm{Cl}_{2}\right) \mathrm{spectra}$ of the $\mathrm{CF}_{3}$ probes. Refer to Figure $\mathbf{S} 1$ for labeling scheme. Peaks assigned with \# and * arise from $\mathrm{CHDCl}_{2}$ and neutral thianthrene, respectively. Unlabeled resonances were not unambiguously assigned. 
(a) neutral, local aromatic
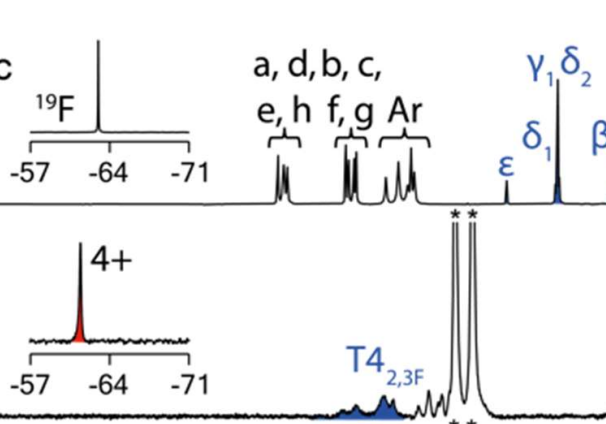

(c)

$6+$, aromatic
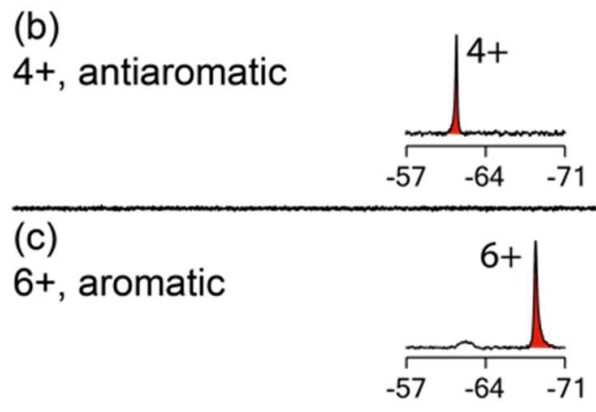

(d)

$8+$, antiaromatic
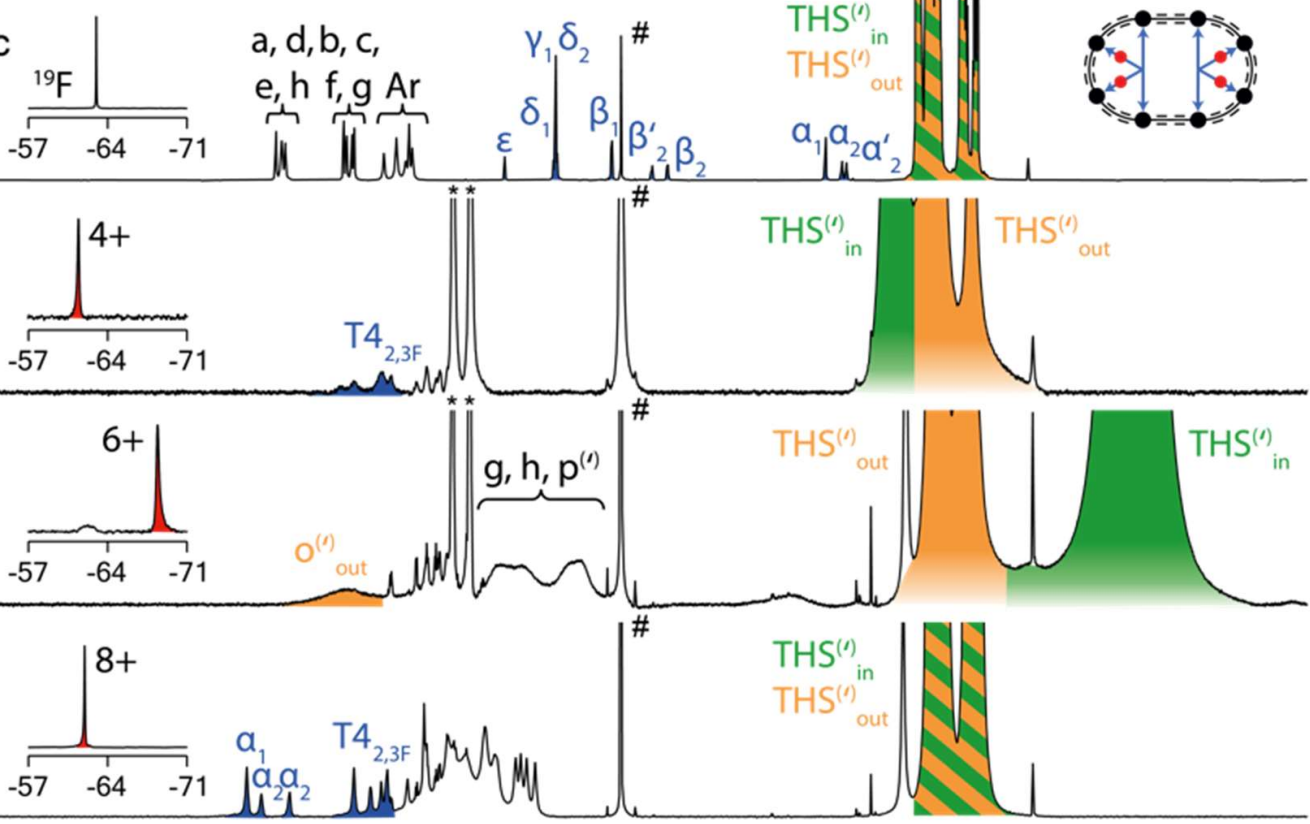

17

Figure S17. Summary of ${ }^{1} \mathrm{H}$ NMR (500 MHz, CD $2 \mathrm{Cl}_{2}$ ) spectra of neutral (a, $298 \mathrm{~K}$ ) and oxidized (b-d, $223 \mathrm{~K}$ ) c-

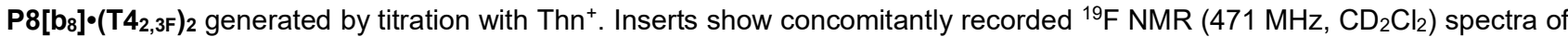
the $\mathrm{CF}_{3}$ probes. Refer to Figure $\mathbf{S 1}$ for labeling scheme. Peaks assigned with \# and * arise from $\mathrm{CHDCl}_{2}$ and neutral thianthrene, respectively. Unlabeled resonances were not unambiguously assigned.

(a) 4+, combined assignment

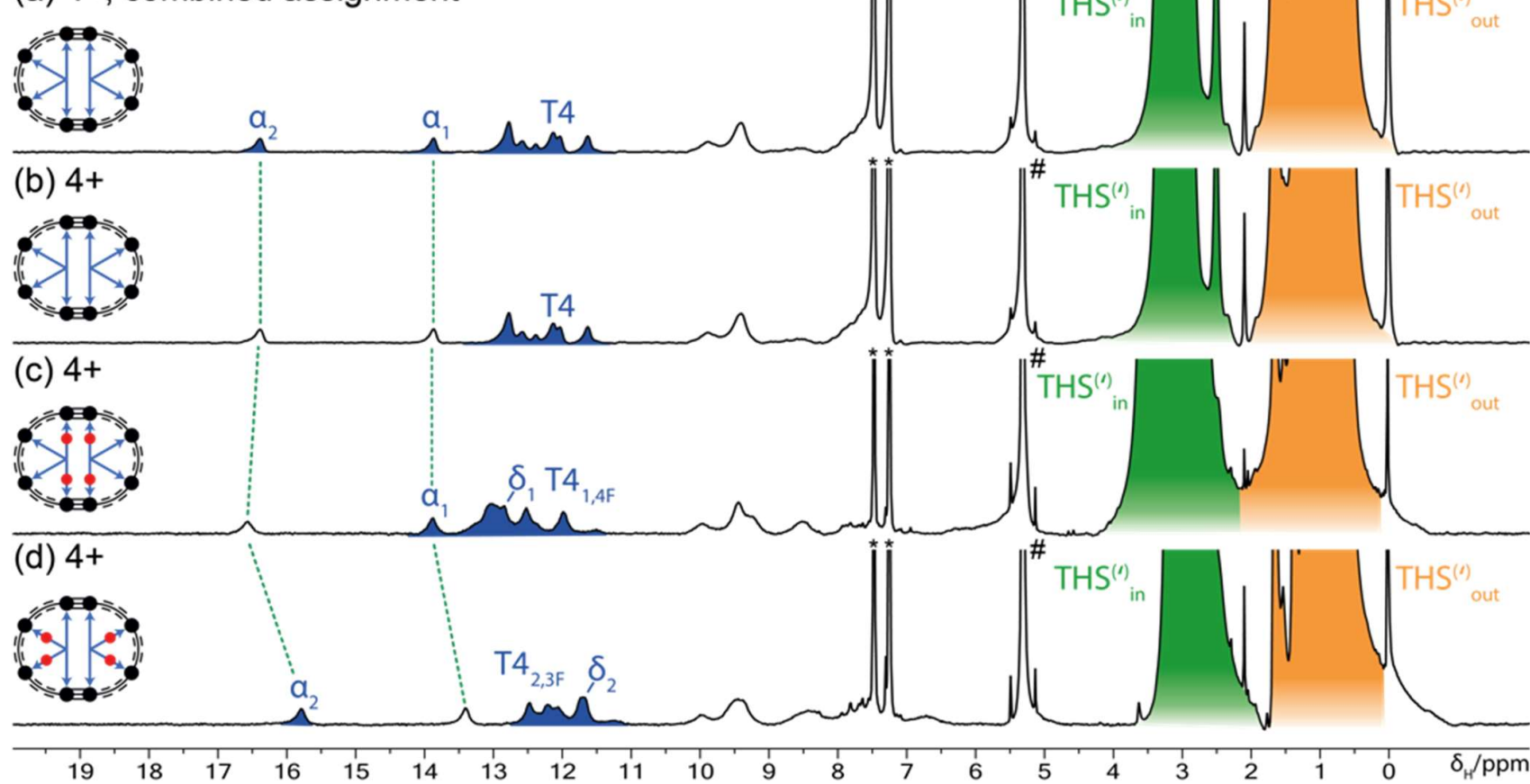

Figure S18. Cross-assigned ${ }^{1} \mathrm{H}$ NMR spectrum $\left(500 \mathrm{MHz}, \mathrm{CD}_{2} \mathrm{Cl}_{2}\right)$ of $\boldsymbol{c}-\mathbf{P} 8\left[\mathbf{b}_{6} \mathbf{f}_{2}\right]^{\bullet}\left(\mathbf{T}_{4}\right)_{2}$ in the 4+ oxidation state $(\mathrm{a}, 223 \mathrm{~K})$ and

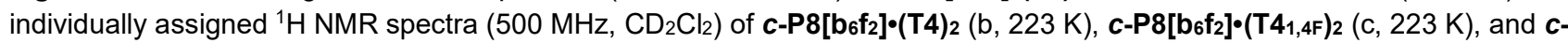
$\mathbf{P 8}\left[b_{6} f_{2}\right] \cdot\left(\mathbf{T}_{2,3 F}\right)_{2}(\mathrm{~d}, 223 \mathrm{~K})$ in their 4+ oxidation state correlated for the overall assignment of (a). Refer to Figure S1 for labelling scheme. Peaks assigned with \# and * arise from $\mathrm{CHDCl}_{2}$ and neutral thianthrene, respectively. Unlabeled resonances were not unambiguously assigned. 
(a) 6+, combined assignment
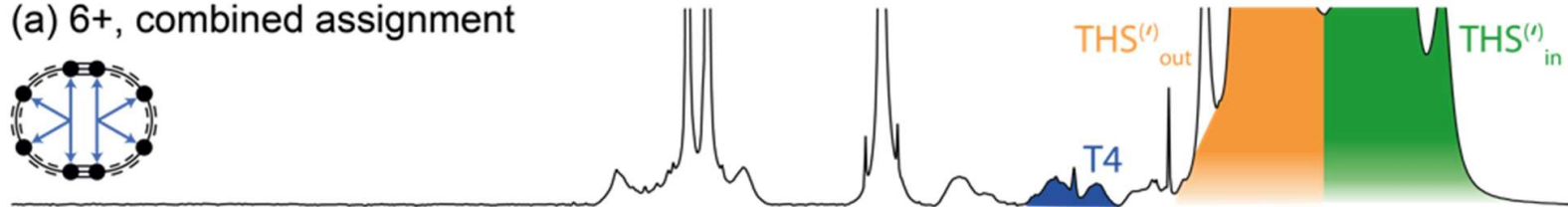

(b) $6+$
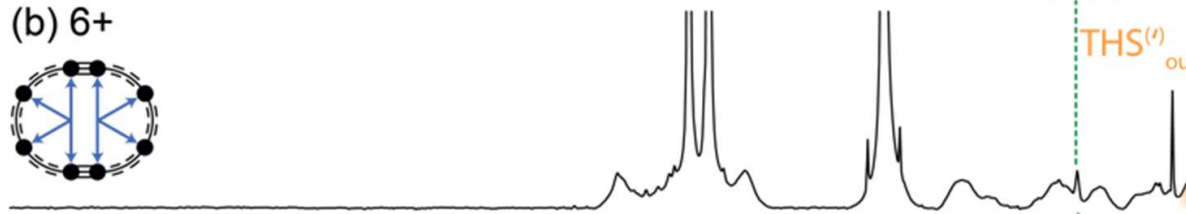

(c) $6+$
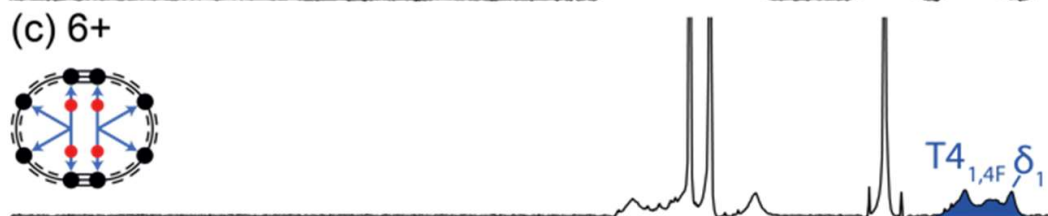

(d) $6+$
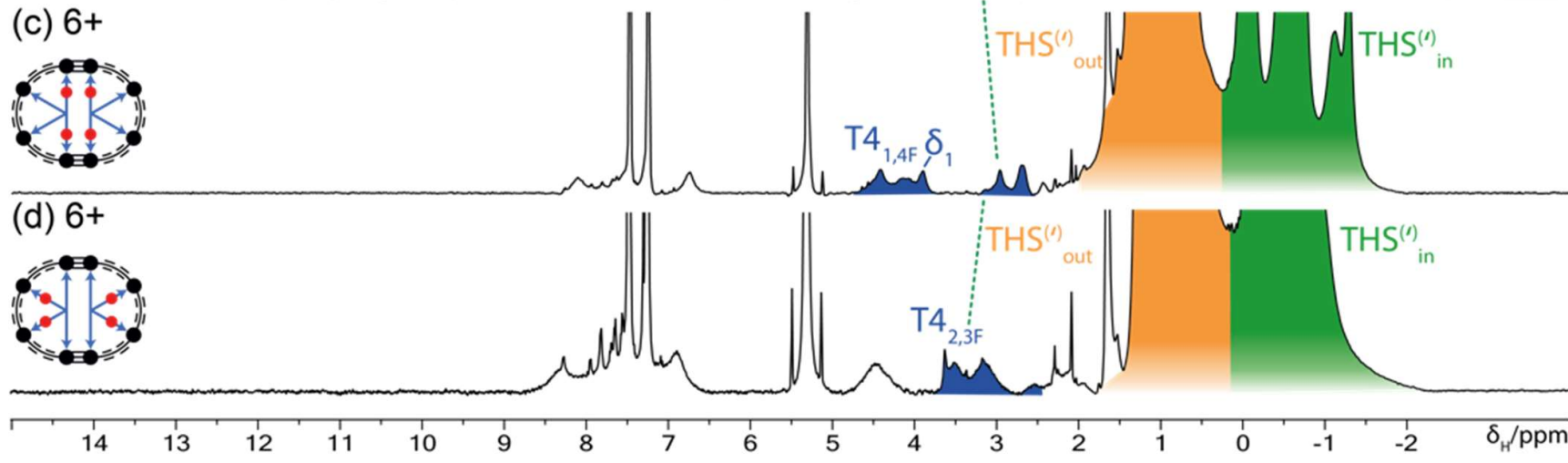

Figure S19. Cross-assigned ${ }^{1} \mathrm{H}$ NMR spectrum $\left(500 \mathrm{MHz}, \mathrm{CD}_{2} \mathrm{Cl}_{2}\right)$ of $\boldsymbol{c}-\mathbf{P} \mathbf{8}\left[\mathbf{b}_{6} \mathbf{f}_{2}\right]_{\bullet} \cdot(\mathbf{T 4})_{2}$ in the $6+$ oxidation state $(\mathrm{a}, 223 \mathrm{~K})$ and

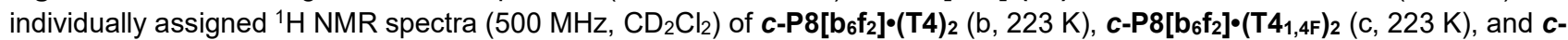
$\mathbf{P} 8\left[b_{6} f_{2}\right] \cdot\left(T 4_{2,3 F}\right)_{2}(d, 223 \mathrm{~K})$ in their $6+$ oxidation state correlated for the overall assignment of (a). Refer to Figure S1 for labelling scheme. Peaks assigned with \# and * arise from $\mathrm{CHDCl}_{2}$ and neutral thianthrene, respectively. Unlabeled resonances were not unambiguously assigned.

(a) 8+, combined assignment
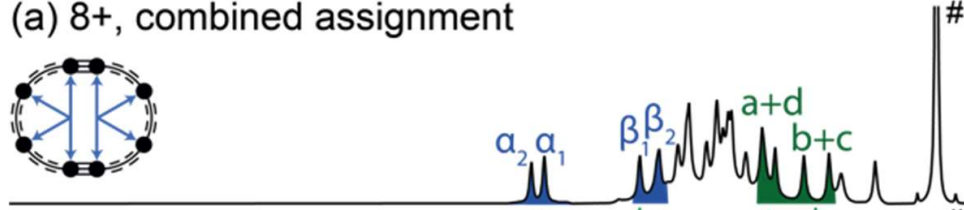

(b) $8+$

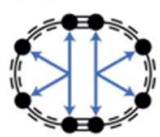

(c) $8+$

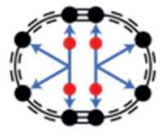

(d) $8+$

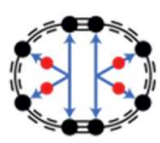

(1)
Non
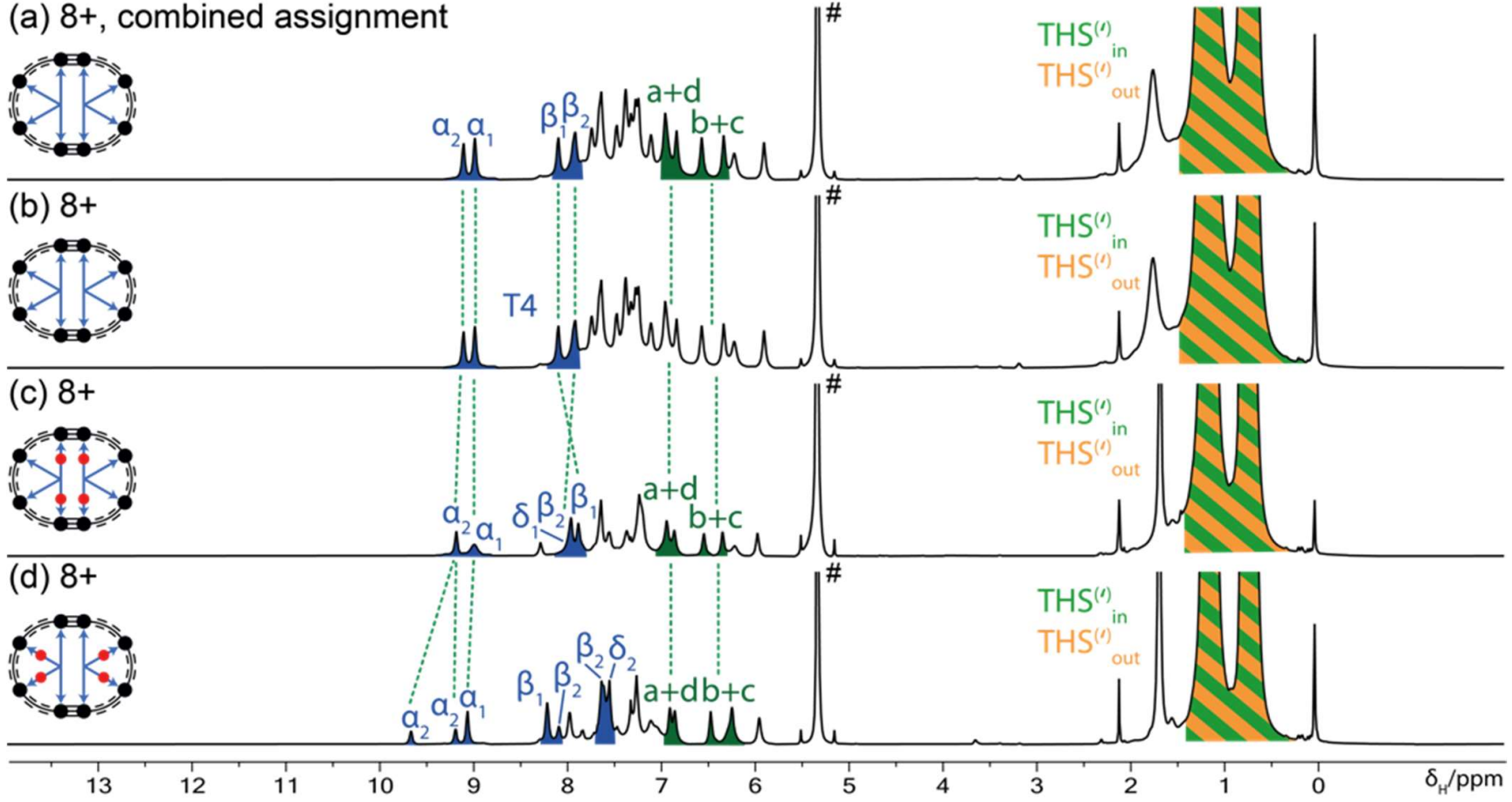

Figure S20. Cross-assigned ${ }^{1} \mathrm{H}$ NMR spectrum $\left(500 \mathrm{MHz}, \mathrm{CD}_{2} \mathrm{Cl}_{2}\right)$ of $\boldsymbol{c}-\mathbf{P} 8\left[\mathbf{b}_{6} \mathbf{f}_{2}\right]_{\bullet}\left(\mathbf{T}_{4}\right)_{2}$ in the 8+ oxidation state $(\mathrm{a}, 223 \mathrm{~K})$ and

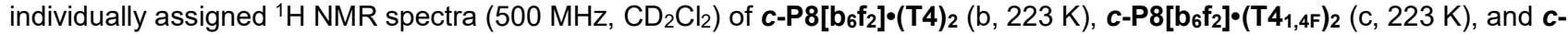
$\mathbf{P} 8\left[b_{6} f_{2}\right] \cdot\left(T_{4}, 3 F\right)_{2}(d, 223 \mathrm{~K})$ in their 8+ oxidation state correlated for the overall assignment of (a). Refer to Figure S1 for labelling scheme. Peaks assigned with \# arise from $\mathrm{CHDCl}_{2}$. Unlabeled resonances were not unambiguously assigned. 


\section{Observed NMR Shifts in Oxidation Titrations}

Table S1. ${ }^{1} \mathrm{H}$ and ${ }^{19} \mathrm{~F}$ NMR chemical shifts for oxidation states of nanoring complexes $c-P 8\left[b_{6} f_{2}\right] \bullet(T 4)_{2}, c-P 8\left[b_{6} f_{2}\right] \bullet\left(T 4_{1,4 F}\right)_{2}, c-$

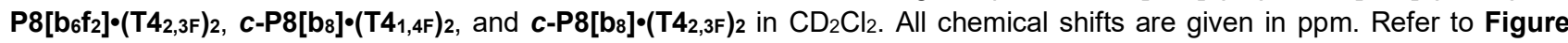
$\mathbf{S 1}$ for labeling scheme of the complexes. aresonance was assigned via a crossassignment approach as detailed in the strategy for the assignment of global ring currents; ${ }^{b}$ referenced to hexafluorobenzene $(-164.8 \mathrm{ppm})$.

\begin{tabular}{|c|c|c|c|c|c|}
\hline \multicolumn{2}{|l|}{$c-\mathrm{P} 8\left[\mathrm{~b}_{6} \mathrm{f}_{2}\right] \bullet(\mathrm{T} 4)_{2}$} & 0 / $298 \mathrm{~K}$ & $4+/ 223 \mathrm{~K}$ & $6+/ 223 \mathrm{~K}$ & $8+/ 223 \mathrm{~K}$ \\
\hline \multirow[b]{10}{*}{$c-P 8\left[b_{6} f_{2}\right] \cdot\left(T 4_{1,4 F}\right)_{2}$} & $\alpha_{1}$ & 5.59 & $13.87^{a}$ & - & $8.97^{a}$ \\
\hline & $\alpha_{2}$ & 2.41 & $16.39^{a}$ & - & $9.09^{a}$ \\
\hline & $\boldsymbol{\beta}_{1}$ & 6.34 & - & - & $8.08^{a}$ \\
\hline & $\beta_{2}$ & 5.23 & - & - & $7.90^{\mathrm{a}}$ \\
\hline & $a+d$ & $\begin{array}{l}\text { a: } 9.58 \\
\text { d: } 9.45\end{array}$ & - & - & $6.94,6.82^{\mathrm{a}}$ \\
\hline & $b+c$ & $\begin{array}{l}\text { b: } 8.78 \\
\text { c: } 8.72\end{array}$ & - & - & $6.55,6.32^{a}$ \\
\hline & T4 & - & $13.06-11.45$ & $3.79-2.68^{a}$ & - \\
\hline & $\mathrm{THS}^{()_{\text {in }}}$ & $1.53-0.61$ & $4.12-2.18$ & $0.37--1.51$ & $1.55-0.31$ \\
\hline & THS ${ }^{(')}$ out & $1.53-0.61$ & $1.91-0.14$ & $1.54-0.37$ & $1.55-0.31$ \\
\hline & & 0 / $298 \mathrm{~K}$ & $4+/ 223 \mathrm{~K}$ & $6+/ 223 \mathrm{~K}$ & $8+/ 223 \mathrm{~K}$ \\
\hline & $\alpha_{1}$ & 5.70 & 13.89 & - & 8.98 \\
\hline & $\alpha_{2}$ & $2.51-2.46$ & $16.58^{a}$ & - & 9.17 \\
\hline & $\beta_{1}$ & 6.07 & - & - & 7.87 \\
\hline & $\boldsymbol{\beta}_{2}$ & 5.25 & - & - & 7.94 \\
\hline & $\delta_{1}$ & 6.95 & 12.85 & 3.91 & 7.94 \\
\hline & $\mathrm{CF}_{3}{ }^{\mathrm{b}}$ & -60.61 & -54.76 & -64.74 & -60.30 \\
\hline & $a+d$ & $\begin{array}{l}\text { a: } 9.57 \\
\text { d: } 9.49\end{array}$ & - & - & $6.92,6.84$ \\
\hline & $b+c$ & $\begin{array}{l}\mathrm{b}: 8.79 \\
\mathrm{c}: 8.75\end{array}$ & - & - & $6.53,6.33$ \\
\hline & $T 4_{1,4 F}$ & - & $13.53-11.35$ & $\begin{array}{l}4.71-3.80 \\
3.20-2.60\end{array}$ & - \\
\hline & $\mathrm{THS}^{\left({ }^{(}\right)_{\text {in }}}$ & $1.64-0.55$ & $4.18-2.12$ & $0.27--1.62$ & $1.50-0.41$ \\
\hline & THS(') out & $1.64-0.55$ & $1.80-0.09$ & $1.59-0.27$ & $1.50-0.41$ \\
\hline
\end{tabular}

\begin{tabular}{|c|c|c|c|c|}
\hline$c-P 8\left[b_{6} f_{2}\right] \cdot\left(T 4_{2,3 F}\right)_{2}$ & 0 / $298 \mathrm{~K}$ & $4+/ 223 \mathrm{~K}$ & $6+/ 223 \mathrm{~K}$ & $8+/ 223 \mathrm{~K}$ \\
\hline$\alpha_{1}$ & $5.70-5.66$ & $13.41^{\mathrm{a}}$ & - & 9.05 \\
\hline$\alpha_{2}$ & $\begin{array}{l}\alpha_{2}: 2.56-2.52 \\
\alpha_{2}^{\prime}: 2.46-2.42\end{array}$ & 15.80 & - & $9.65,9.17$ \\
\hline$\beta_{1}$ & 6.39 & - & - & 8.20 \\
\hline$\beta_{2}$ & $\begin{array}{l}\beta_{2}: 4.81 \\
\beta_{2}^{\prime}: 5.00\end{array}$ & - & - & $8.07,7.62$ \\
\hline$\delta_{2}$ & 6.36 & 11.71 & - & 7.53 \\
\hline $\mathrm{CF}_{3}{ }^{\mathrm{b}}$ & -61.23 & -56.07 & -65.41 & -60.46 \\
\hline$a+d$ & $\begin{array}{l}\text { a: } 9.67 \\
\text { d: } 9.46\end{array}$ & - & - & $6.89,6.84$ \\
\hline$b+c$ & $\begin{array}{l}\mathrm{b}: 8.76 \\
\mathrm{c}: 8.67\end{array}$ & - & - & $6.46,6.23$ \\
\hline $\mathrm{T4}_{2,3 \mathrm{~F}}$ & - & $12.67-11.08$ & $3.70-2.44$ & - \\
\hline $\mathrm{THS}^{\left({ }^{(}\right)_{\text {in }}}$ & $1.50-0.67$ & $3.49-1.82$ & $0.13--2.05$ & $1.47-0.39$ \\
\hline THS(') out & $1.50-0.67$ & $1.72-0.07$ & $1.47-0.13$ & $1.47-0.39$ \\
\hline
\end{tabular}




\begin{tabular}{|c|c|c|c|c|c|}
\hline$c-\mathrm{P} 8\left[\mathrm{~b}_{8}\right]^{\bullet}(\mathrm{T} 41,4 \mathrm{~F}) 2$ & & $0 / 298 \mathrm{~K}$ & 4+ / $223 \mathrm{~K}$ & $6+/ 223 \mathrm{~K}$ & $8+/ 223 \mathrm{~K}$ \\
\hline & $\alpha_{1}+\alpha_{2}$ & $\begin{array}{l}\alpha_{1}: 2.57-2.52 \\
\alpha_{2}: 2.50-2.44\end{array}$ & - & - & $9.94,9.81$ \\
\hline & $\beta_{1}+\beta_{2}$ & $\begin{array}{l}\beta_{1}: 5.10 \\
\beta_{2}: 5.19\end{array}$ & - & - & $8.65,8.41$ \\
\hline & $\mathrm{CF}_{3}{ }^{\mathrm{b}}$ & -60.63 & -59.11 & -67.52 & -59.86 \\
\hline & $\mathrm{O}^{(1)}$ out & 8.11 & $6.96-5.97$ & $9.50-8.61$ & - \\
\hline & $\mathrm{T4}_{1,4 \mathrm{~F}}$ & - & $9.80-8.00$ & - & - \\
\hline & $\mathrm{THS}^{()_{\text {in }}}$ & $1.66-0.57$ & $2.51-1.78$ & $-0.24--2.51$ & $1.58-0.37$ \\
\hline & THS(') out & $1.66-0.57$ & $1.78-0.17$ & $1.57-0.35$ & $1.58-0.37$ \\
\hline
\end{tabular}

\begin{tabular}{|c|c|c|c|c|c|}
\hline$c-\mathrm{P} 8\left[\mathrm{~b}_{8}\right] \cdot\left(\mathrm{T} 4_{2,3 \mathrm{~F}}\right)_{2}$ & & 0 / 298 K & $4+/ 223 \mathrm{~K}$ & $6+/ 223 \mathrm{~K}$ & $8+/ 223 \mathrm{~K}$ \\
\hline & $\alpha_{1}$ & $2.74-2.66$ & - & - & 10.13 \\
\hline & $\alpha_{2}$ & $\begin{array}{l}\alpha_{2}: 2.52-2.46 \\
\alpha_{2}^{\prime}: 2.45-2.41\end{array}$ & - & - & $9.95,9.59$ \\
\hline & $\mathrm{CF}_{3}{ }^{\mathrm{b}}$ & -61.32 & -59.42 & -67.85 & -60.08 \\
\hline & $\mathrm{O}^{(1)_{\text {out }}}$ & 8.09 & - & $9.68-8.41$ & - \\
\hline & $\mathbf{T 4 2 , 3 \mathrm { F }}$ & - & $9.30-8.13$ & - & $8.84-8.22$ \\
\hline & $\mathrm{THS}^{()_{i n}}$ & $1.58-0.71$ & $2.22-1.56$ & $-0.11--2.61$ & $1.57-0.29$ \\
\hline & THS(') out & $1.58-0.71$ & $1.56-0.10$ & $1.55-0.40$ & $1.57-0.29$ \\
\hline
\end{tabular}




\section{Counting of $\pi$-Electrons in a Global $c-P 8\left[b_{6} f_{2}\right]$ Circuit}

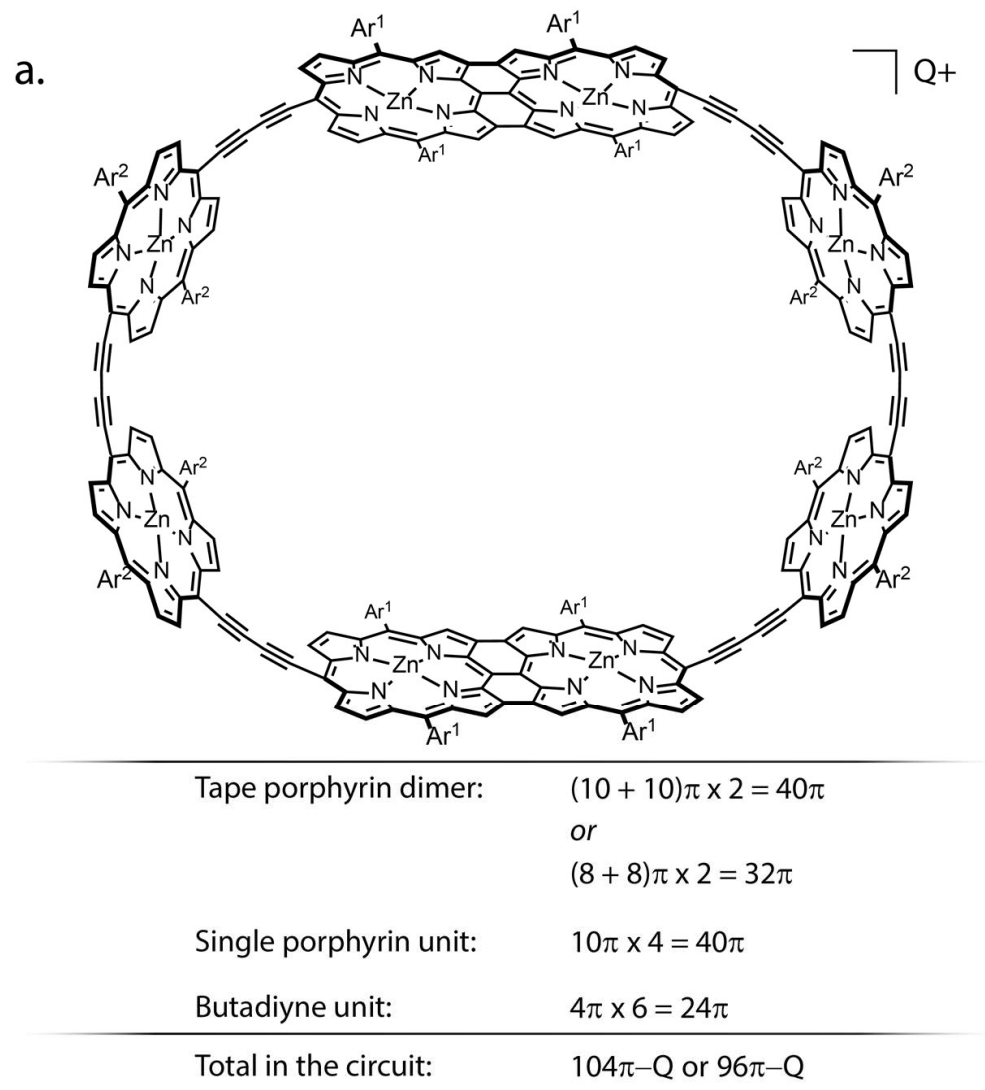

b.

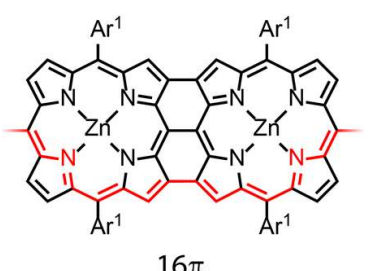

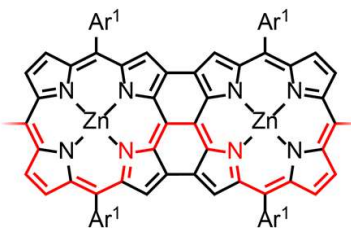

$20 \pi$

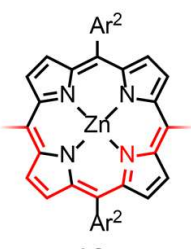

$10 \pi$

Figure S21. $\pi$-Electron count for the global ring circuit of $c$-P8 $\left[\mathbf{b}_{6} \mathbf{f}_{2}\right]$ (a) and possible delocalization pathways (in red) in the porphyrin tape dimer and single porphyrin units (b). The complete circuit consists of 2 tape dimers, 4 single porphyrin units, and 6 butadiyne links. A long and a short conjugation pathway exist for the tape dimer, contributing in total 20ח and $16 \pi$ electrons, respectively, per unit. This leads to two possible $\pi$ electron counts for the global circuit: $104 \pi-Q$ or $96 \pi-Q$, where $Q$ denotes the oxidation state of the system. $\mathrm{Ar}^{1}=\mathrm{Ar}^{2}=3,5$-bis(trihexylsilyl)phenyl. 


\section{Summary of Experimental Results and NICS Calculations}

Table S2. Summary of calculated (NICS, ppm) and experimental $(\Delta \delta, \mathrm{ppm})$ results for the study of global (anti)aromaticity in

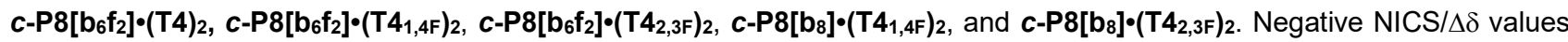
and $4 n+2$ Hückel classification correspond to aromaticity; positive NICS/ $\Delta \delta$ values and $4 n$ Hückel classification to antiaromaticity. NICS $(0)$ values were calculated in the center of the nanoring complexes using DFT (LC-whPBE/6-31G* $(\mathrm{w}=0.1))$ without template. Chemical shift differences $\Delta \delta \mathrm{THS}=\delta \mathrm{THS}\left({ }^{\prime}\right)$ in $-\delta \mathrm{THS}\left({ }^{\prime}\right)$ out were calculated using the average chemical shift of the respective multiplets. $\Delta \delta \mathrm{x}=\delta \mathrm{x}$,bound $-\delta \mathrm{x}$,unbound values describe the chemical shift differences of template resonances $X=\alpha_{1}, \alpha_{2}, \delta_{1}$, and $\delta_{2}$ in the nanoring complexes with respect to free template. $\Delta \delta_{F}=\delta_{F, b o u n d}-\delta_{F}$,unbound values describe the ${ }^{19} \mathrm{~F}$ chemical shift differences of the $\mathrm{CF}_{3}$ groups with respect to free template. Refer to Tables S23-S25 for unbound template resonances at room temperature. Chemical shift differences $\Delta \delta_{\mathrm{F}}$ for the oxidized nanoring complexes were calculated using the chemical shifts of unbound template in $\mathrm{CD}_{2} \mathrm{Cl}_{2}$ at $223 \mathrm{~K}: \delta_{\mathrm{F}}\left(\mathrm{T} 4_{1,4 \mathrm{~F}}\right)=-60.59 \mathrm{ppm} ; \delta_{\mathrm{F}}\left(\mathrm{T} 4_{2,3 \mathrm{~F}}\right)=-60.69$ ppm. NMR spectra of nanoring complexes were recorded in $\mathrm{CD}_{2} \mathrm{Cl}_{2}$. Neutral shifts: $298 \mathrm{~K}$; oxidized shifts: $223 \mathrm{~K}$. ${ }^{a}$ local aromatic current observed; ${ }^{b}$ value averaged over the respective resonance region.

\begin{tabular}{|c|c|c|c|c|c|}
\hline$c-\mathrm{P} 8\left[\mathrm{~b}_{6} \mathrm{f}_{2}\right] \cdot(\mathrm{T} 4)_{2}$ & & 0 & $4+$ & $6+$ & $8+$ \\
\hline & $n \pi \mathrm{e}^{-}$ & $\begin{array}{c}104 / \\
96\end{array}$ & $\begin{array}{c}100 / \\
92\end{array}$ & $\begin{array}{c}98 / \\
90\end{array}$ & $\begin{array}{c}96 / \\
88\end{array}$ \\
\hline & Hückel classification & $4 n \pi^{\mathrm{a}}$ & $4 n \pi$ & $4 n+2 \pi$ & $4 n \pi$ \\
\hline & $\operatorname{NICS}(0)_{z z}$ & 0.69 & 6.86 & -37.51 & 3.97 \\
\hline & $\operatorname{NICS}(0)_{\text {iso }}$ & -0.76 & 1.83 & -12.69 & 1.37 \\
\hline & $\Delta \delta$ THS & 0 & 2.12 & -1.53 & - \\
\hline & $\Delta \delta_{\alpha 1}$ & -3.03 & 5.25 & - & 0.35 \\
\hline & $\Delta \delta_{\alpha 2}$ & -6.15 & 7.83 & - & 0.53 \\
\hline
\end{tabular}

\begin{tabular}{|c|c|c|c|c|c|}
\hline$c-\mathrm{P} 8\left[\mathrm{~b}_{6} \mathrm{f}_{2}\right] \cdot\left(\mathrm{T} 4_{1,4 \mathrm{~F}}\right)_{2}$ & & 0 & 4+ & $6+$ & $8+$ \\
\hline & $n \pi \mathrm{e}^{-}$ & $\begin{array}{c}104 / \\
96\end{array}$ & $\begin{array}{c}100 / \\
92\end{array}$ & $\begin{array}{c}98 / \\
90\end{array}$ & $\begin{array}{c}96 / \\
88\end{array}$ \\
\hline & Hückel classification & $4 n \pi^{a}$ & $4 n \pi$ & $4 n+2 \pi$ & $4 n \pi$ \\
\hline & $\operatorname{NICS}(0)_{z z}$ & 0.69 & 6.86 & -37.51 & 3.97 \\
\hline & $\operatorname{NICS}(0)_{\text {iso }}$ & -0.76 & 1.83 & -12.69 & 1.37 \\
\hline & $\Delta \delta$ THS & 0 & 2.20 & -1.61 & - \\
\hline & $\Delta \delta_{\alpha 1}$ & -2.94 & 5.25 & - & 0.34 \\
\hline & $\Delta \delta_{\alpha 2}$ & $-6.12^{b}$ & 7.97 & - & 0.56 \\
\hline & $\Delta \delta_{\delta 1}$ & -0.79 & 5.11 & -3.83 & 0.20 \\
\hline & $\Delta \delta_{1,4 \mathrm{~F}}$ & -0.12 & 5.83 & -4.15 & 0.29 \\
\hline
\end{tabular}

\begin{tabular}{|c|c|c|c|c|c|}
\hline$c-\mathrm{P} 8\left[\mathrm{~b}_{6} \mathrm{f}_{2}\right] \cdot(\mathrm{T} 42,3 \mathrm{~F})_{2}$ & & 0 & 4+ & $6+$ & $8+$ \\
\hline & $n \pi \mathbf{e}^{-}$ & $\begin{array}{c}104 / \\
96\end{array}$ & $\begin{array}{c}100 / \\
92\end{array}$ & $\begin{array}{c}98 / \\
90\end{array}$ & $\begin{array}{c}96 / \\
88\end{array}$ \\
\hline & Hückel classification & $4 n \pi^{a}$ & $4 n \pi$ & $4 n+2 \pi$ & $4 n \pi$ \\
\hline & $\operatorname{NICS}(0)_{z z}$ & 0.69 & 6.86 & -37.51 & 3.97 \\
\hline & $\operatorname{NICS}(0)_{\text {iso }}$ & -0.76 & 1.83 & -12.69 & 1.37 \\
\hline & $\Delta \delta$ THS & 0 & 1.76 & -1.76 & - \\
\hline & $\Delta \delta_{\alpha 1}$ & $-3.00^{b}$ & 4.73 & - & 0.37 \\
\hline & $\Delta \delta_{\delta 2}$ & -1.05 & 4.30 & - & 0.12 \\
\hline & $\Delta \delta_{2,3 F}$ & -0.53 & 4.62 & -4.72 & 0.23 \\
\hline
\end{tabular}




\begin{tabular}{|c|c|c|c|c|c|}
\hline$c-\mathrm{P} 8\left[\mathrm{~b}_{8}\right] \bullet\left(\mathrm{T}_{1} \mathbf{1}_{1,4 \mathrm{~F}}\right)_{2}$ & & 0 & 4+ & $6+$ & $8+$ \\
\hline & $n \pi \mathrm{e}^{-}$ & 112 & 108 & 106 & 104 \\
\hline & Hückel classification & $4 n \pi^{\mathrm{a}}$ & $4 n \pi$ & $4 n+2 \pi$ & $4 n \pi$ \\
\hline & $\operatorname{NICS}(0)_{z z}$ & 0.53 & 8.64 & -39.07 & 1.84 \\
\hline & $\operatorname{NICS}(0)_{\text {iso }}$ & -0.68 & 2.12 & -13.57 & 0.40 \\
\hline & $\Delta \delta_{\text {THS }}$ & 0 & 1.17 & -2.34 & - \\
\hline & $\Delta \delta_{1,4 \mathrm{~F}}$ & -0.14 & 1.48 & -6.93 & 0.73 \\
\hline
\end{tabular}

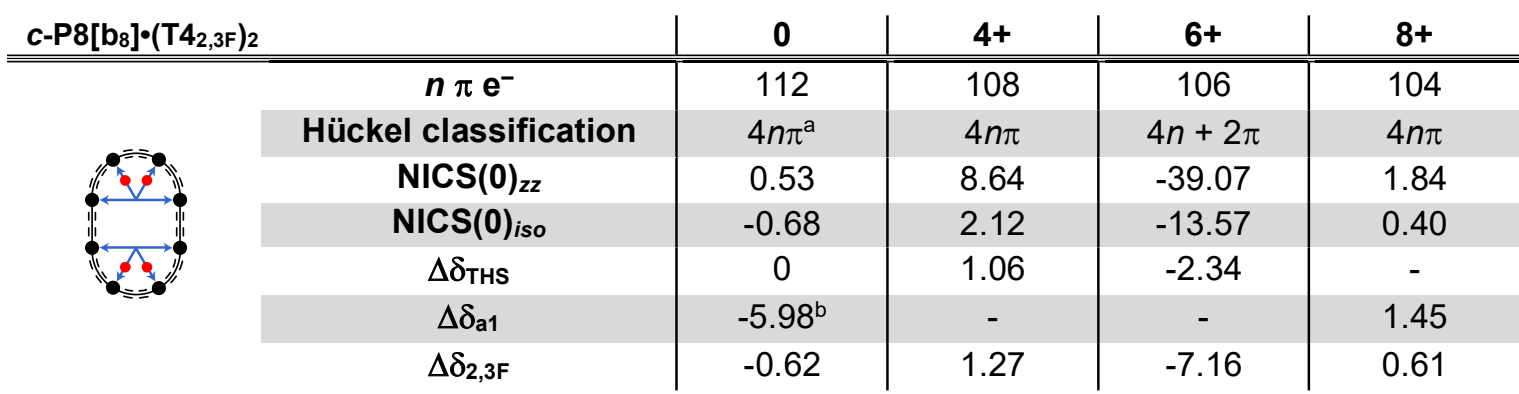




\section{Full NMR Oxidation Titrations}

\section{${ }^{1} \mathrm{H}$ NMR}

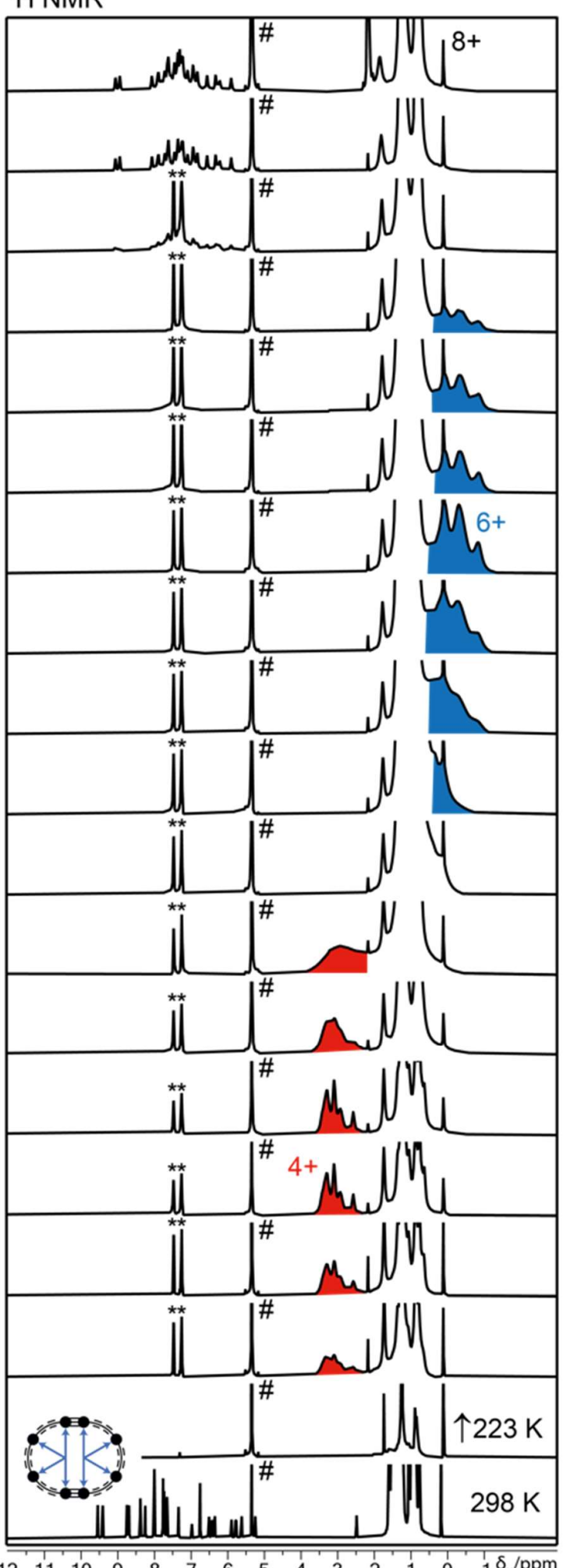

$\mathrm{V}\left(\mathrm{Thn}^{+}\right) / \mu \mathrm{L}$

70.0

66.0

62.0

56.0

52.0

50.0

45.0

42.0

40.0

36.0

34.0

30.0

28.0

26.0

25.0

24.0

22.0

0.0

0.0

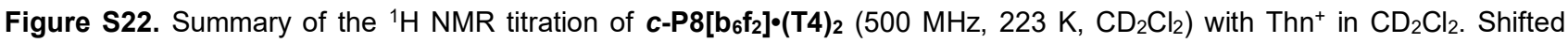
$\mathrm{THS}^{\left({ }^{(}\right)}$in resonances indicating global antiaromaticity are highlighted in red; those indicating global aromaticity are highlighted in blue. Peaks assigned with \# and * arise from $\mathrm{CHDCl}_{2}$ and neutral thianthrene, respectively. 


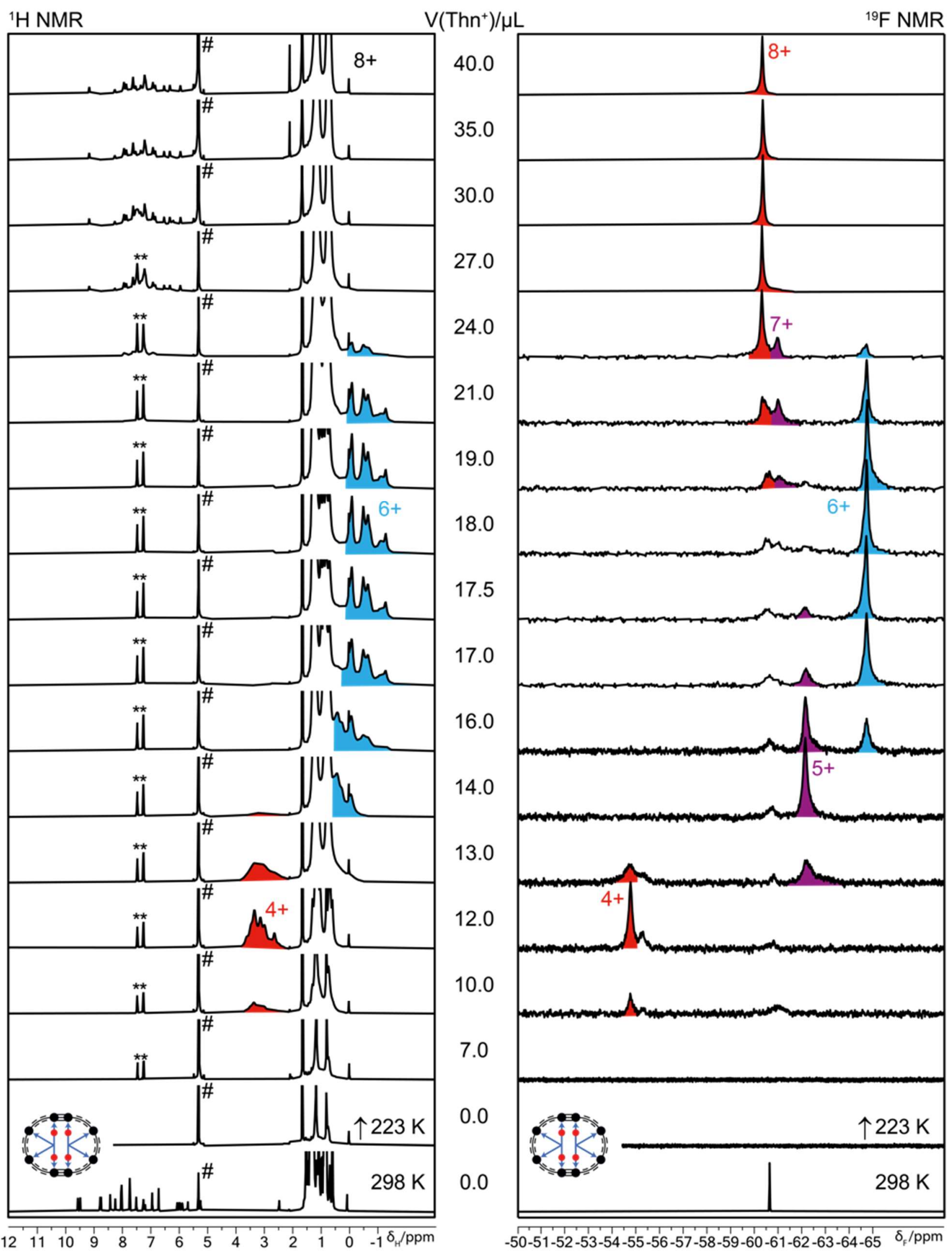

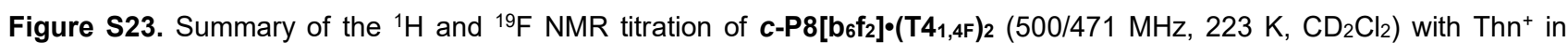
$\mathrm{CD}_{2} \mathrm{Cl}_{2}$. Shifted $\mathrm{THS}^{\left({ }^{(}\right)}$in and $\mathrm{CF}_{3}$ resonances indicating global antiaromaticity are highlighted in red; those indicating global aromaticity highlighted in blue. Odd-numbered oxidation states are highlighted in purple in the ${ }^{19} \mathrm{~F}$ NMR spectrum. Peaks assigned with \# and * arise from $\mathrm{CHDCl}_{2}$ and neutral thianthrene, respectively. 


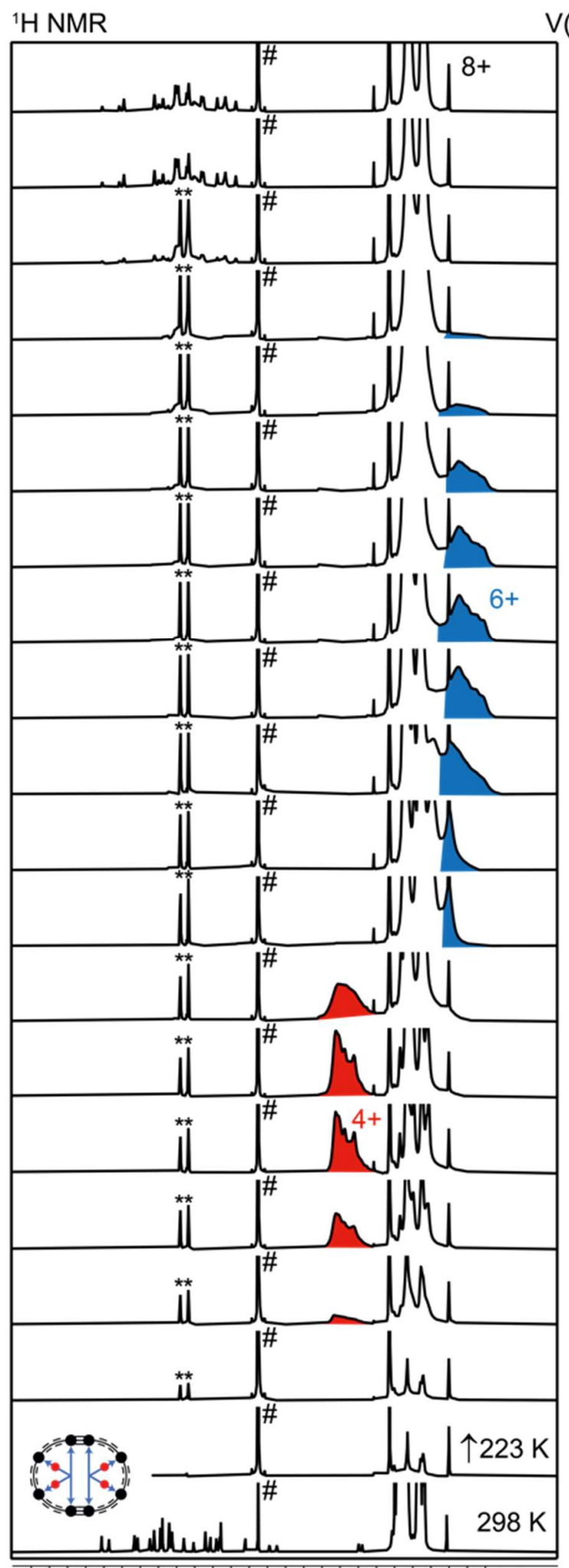

$\mathrm{V}\left(\mathrm{Thn}^{+}\right) / \mu \mathrm{L}$

${ }^{19} \mathrm{~F}$ NMR
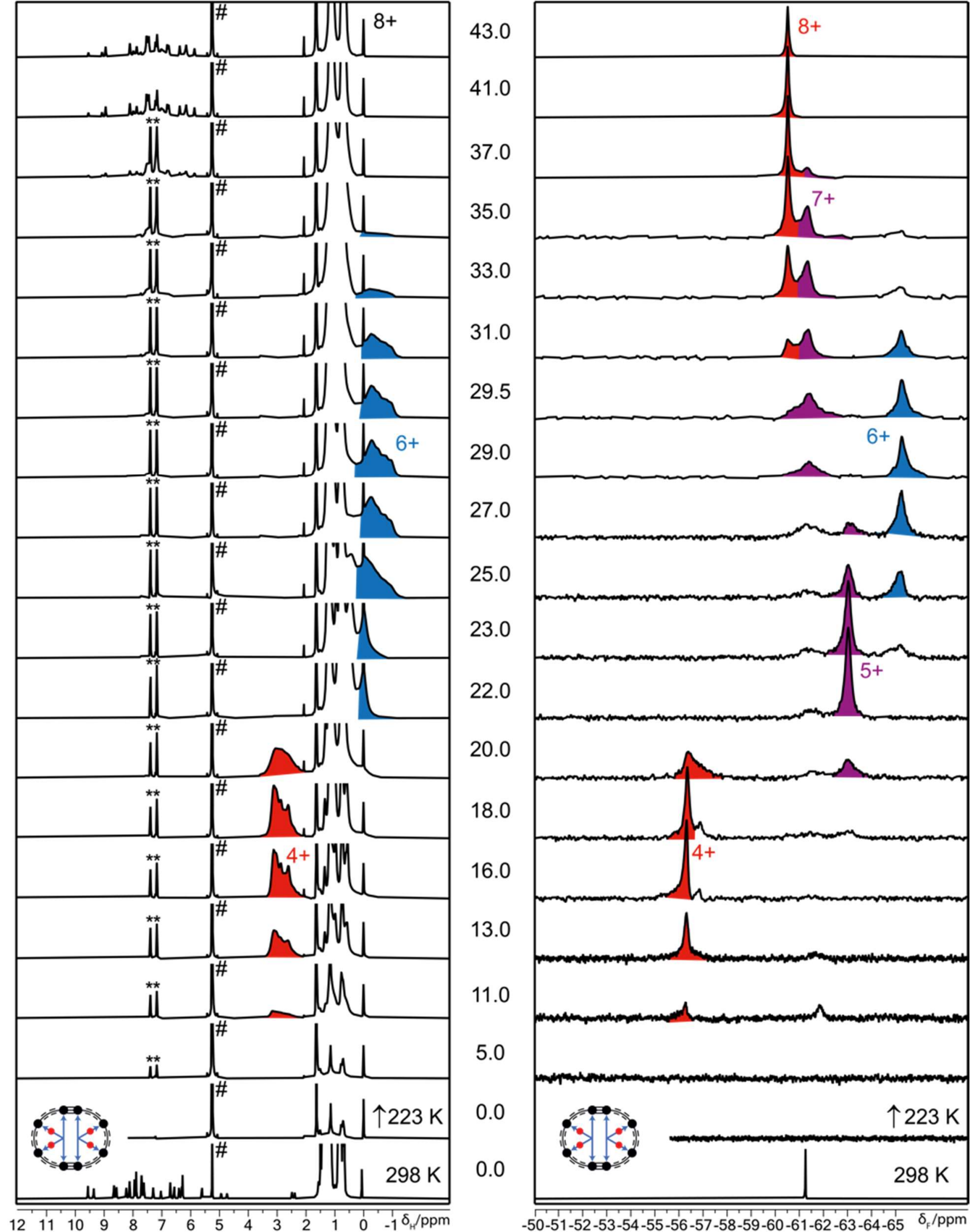

$-50-51-52-53-54-55-56-57-58-59-60-61-62-63-64-65 \quad \delta_{F} / p p m$

Figure S24. Summary of the ${ }^{1} \mathrm{H}$ and ${ }^{19} \mathrm{~F}$ NMR titration of $\boldsymbol{c}-\mathbf{P} 8\left[\mathbf{b}_{6} \mathbf{f}_{2}\right] \cdot\left(\mathbf{T 4}_{2,3} \mathbf{F}\right)_{2}\left(500 / 471 \mathrm{MHz}, 223 \mathrm{~K}, \mathrm{CD}_{2} \mathrm{Cl}_{2}\right)$ with $\mathrm{Thn}^{+}$in $\mathrm{CD}_{2} \mathrm{Cl}_{2}$. Shifted $\mathrm{THS}^{\left({ }^{(}\right)}$in and $\mathrm{CF}_{3}$ resonances indicating global antiaromaticity are highlighted in red; those indicating global aromaticity highlighted in blue. Odd-numbered oxidation states are highlighted in purple in the ${ }^{19} \mathrm{~F}$ NMR spectrum. Peaks assigned with \# and * arise from $\mathrm{CHDCl}_{2}$ and neutral thianthrene, respectively. 


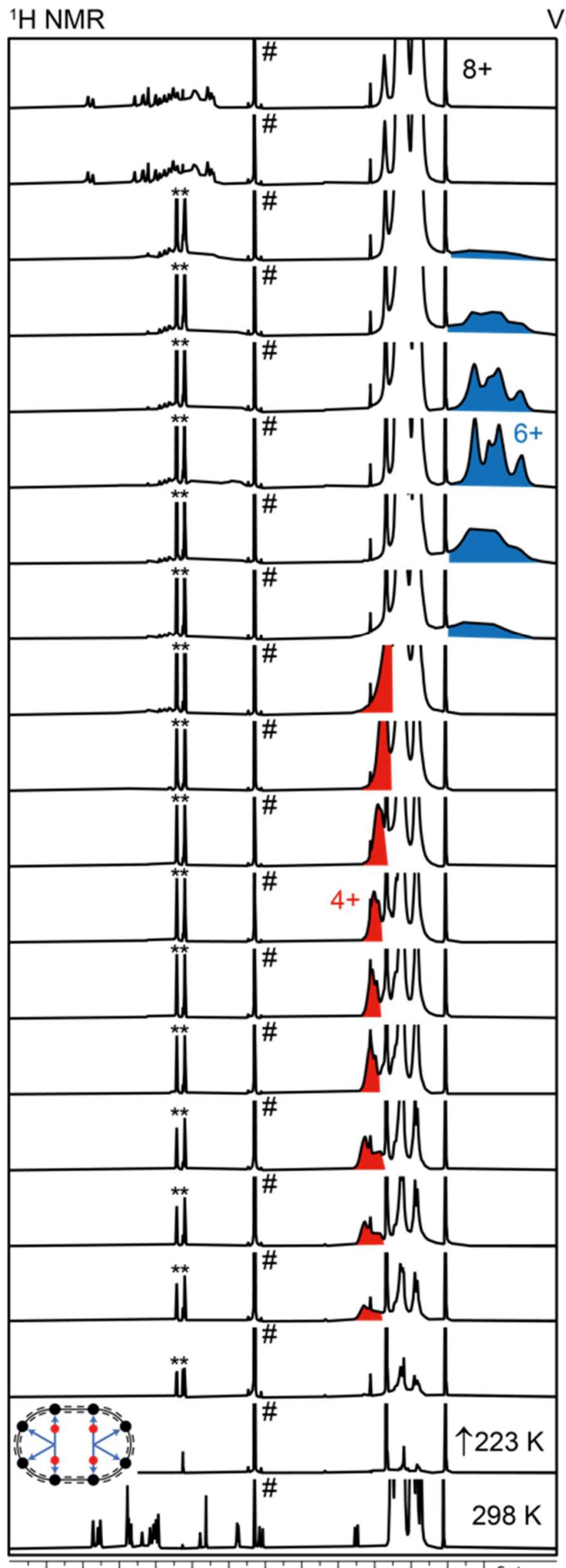

$\mathrm{V}\left(\mathrm{Thn}^{+}\right) / \mu \mathrm{L}$

${ }^{19} \mathrm{~F}$ NMR

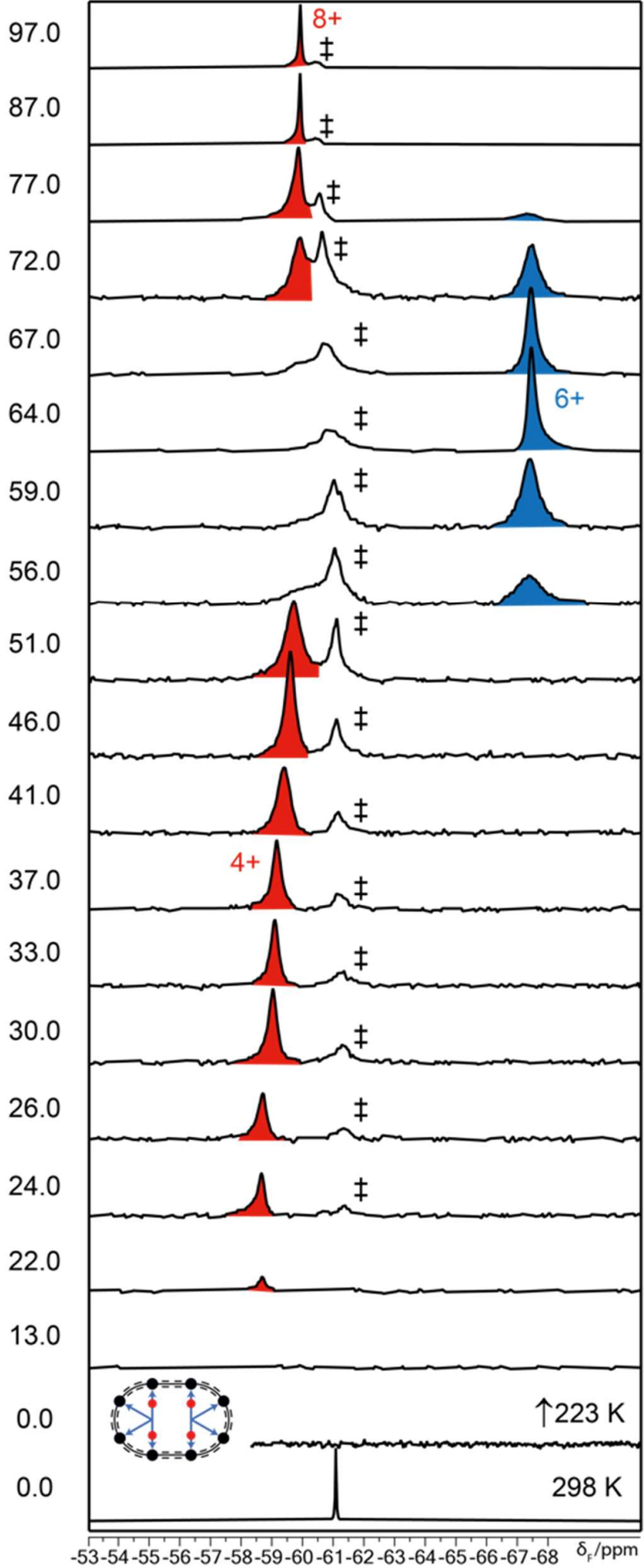

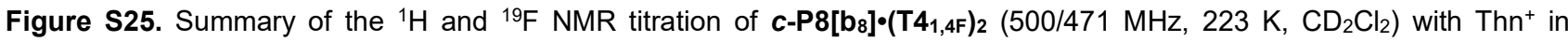
$\mathrm{CD}_{2} \mathrm{Cl}_{2}$. Shifted $\mathrm{THS}^{\left({ }^{(}\right)}$in and $\mathrm{CF}_{3}$ resonances indicating global antiaromaticity are highlighted in red; those indicating global aromaticity are highlighted in blue. Peaks assigned with \# and * arise from $\mathrm{CHDCl}_{2}$ and neutral thianthrene, respectively. Residual ${ }^{19} \mathrm{~F}$ resonances assigned with $\ddagger$ indicate decomposed nanoring. 
${ }^{1} \mathrm{H}$ NMR

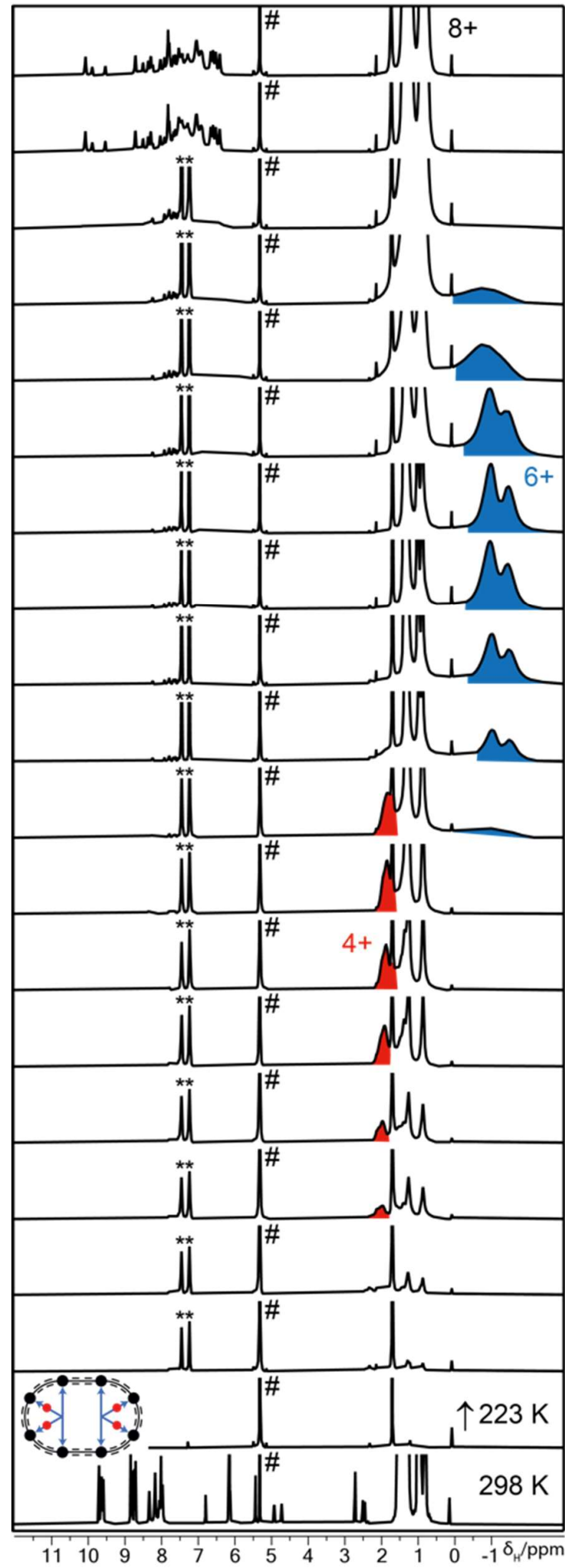

$\mathrm{V}\left(\mathrm{Thn}^{+}\right) / \mu \mathrm{L}$

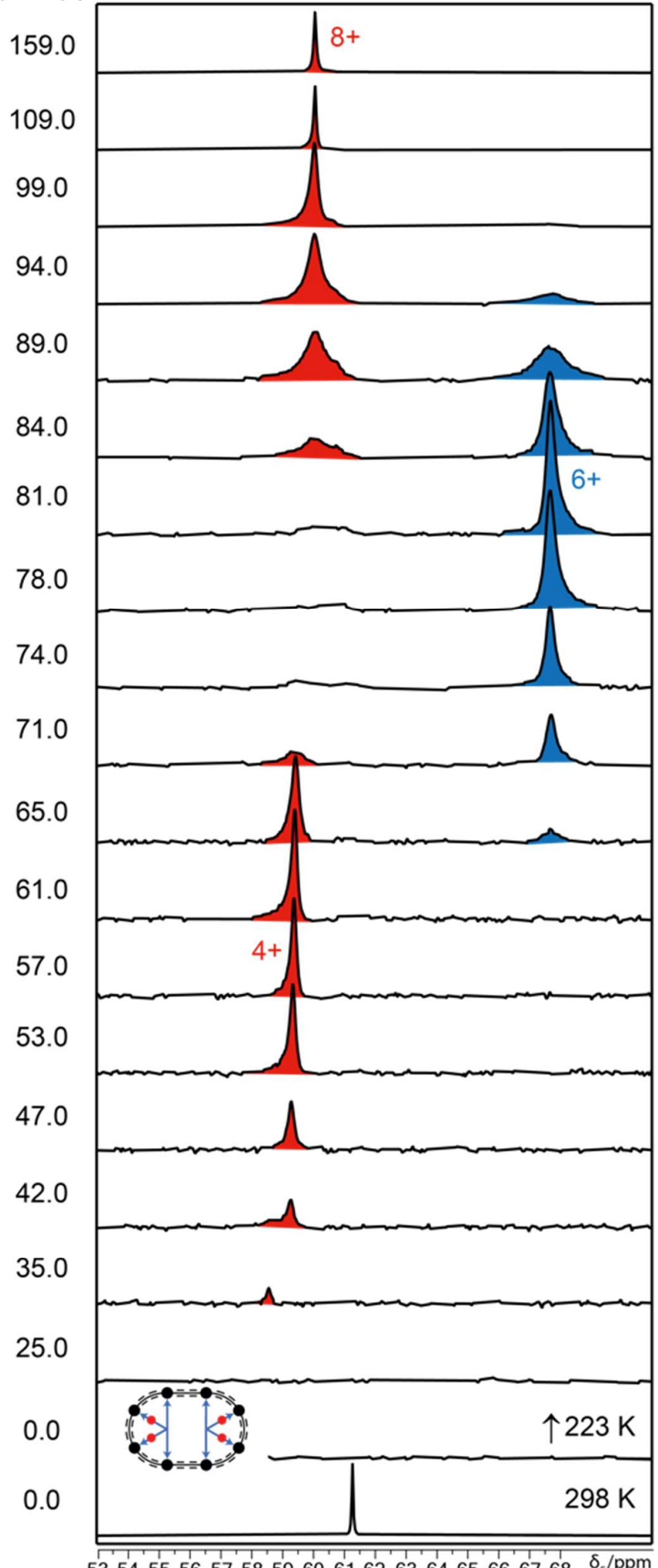

$-53-54-55-56-57-58-59-60-61-62-63-64-65-66-67-68 \quad \delta_{\mathrm{F}} / \mathrm{ppm}$

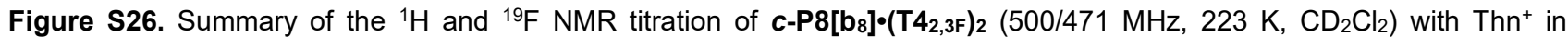
$\mathrm{CD}_{2} \mathrm{Cl}_{2}$. Shifted $\mathrm{THS}^{\left({ }^{(}\right)}$in and $\mathrm{CF}_{3}$ resonances indicating global antiaromaticity are highlighted in red; those indicating global aromaticity are highlighted in blue. Peaks assigned with \# and * arise from $\mathrm{CHDCl}_{2}$ and neutral thianthrene, respectively. 


\section{Computational Chemistry Methods}

Molecular models were built in HyperChem ${ }^{\mathrm{TM}}$ 8.0 using the $\mathrm{MM}+$ forcefield with parameters modified for the description of porphyrins. ${ }^{12-15}$ The porphyrin meso aryl groups were replaced with $\mathrm{H}$ for all calculations. The resulting geometries were subjected to further optimization in MOPAC2016 using the PM7 level of theory and in the absence of symmetry. ${ }^{16}$ The optimized structures were subjected for DFT calculations. DFT geometry optimizations of nanorings $c-\mathbf{P} 8\left[b_{6} f_{2}\right] \cdot(T 4)_{2}$ and $c-P 8\left[b_{8}\right]_{\bullet}\left(T_{4}\right)_{2}\left(D_{2}\right.$ initial guess), and linear oligomers $\mathbf{H}-\mathbf{l}-\mathbf{P} 2\left[f_{1}\right]-$ $\mathbf{H}, \mathbf{H}-\boldsymbol{I}-\mathbf{P} 2\left[\mathbf{b}_{1}\right]-\mathbf{H}, \mathbf{H}-\boldsymbol{I}-\mathbf{P} 4\left[\mathbf{b}_{2} \mathbf{f}_{1}\right]-\mathbf{H}$ and $\mathbf{H}-\boldsymbol{I}-\mathbf{P} \mathbf{8}\left[\mathbf{b}_{5} \mathbf{f}_{2}\right]-\mathbf{H}\left(D_{2 h}\right.$ initial guess) were first performed using Gaussian 16/A.03 with the B3LYP/6-31G* functional/basis set. ${ }^{17-21}$ The minimized structures (converged to $D_{2}$ symmetry for nanorings and $D_{2 \mathrm{~h}}$ for linear oligomers) were subjected to frequency calculations, revealing no imaginary frequencies. After that, the structures were further optimized for every oxidation state using the LC-whPBE/6$31 G^{*}(\omega=0.1)$ functional/basis set, ${ }^{22-25}$ and the resulting structures were used for NICS, ACID and TD-DFT calculations.

NICS/susceptibility calculations were performed using the GIAO method, as implemented in Gaussian16/A.03

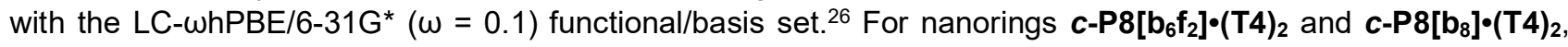
NICS grids were calculated with $1 \AA$ resolution on a $51 \AA \times 41 \AA$ grid. For linear oligomers $\mathbf{H}-\mathbf{I}-\mathbf{P} 2\left[\mathbf{f}_{1}\right]-\mathbf{H}$ and $\mathbf{H}-\mathbf{l}-$ P2[ $\left.\mathbf{b}_{1}\right]-\mathbf{H}$, NICS grids were calculated with $0.25 \AA$ resolution on a $21 \AA \times 11 \AA$ grid.

ACID calculations were conducted using the CSGT method, as implemented in Gaussian09/D.01 with the LC$\omega P B E / 6-31 G^{*}(\omega=0.1)$ functional/basis set. ${ }^{26}$ Version 2.0 of the ACID program (external to Gaussian) was used to generate the ACID results, ${ }^{27}$ and the results were visualized using POV-Ray. Templates were removed prior to NICS and ACID calculations.

TD-DFT calculations were conducted for the first 64 excited states employing Gaussian16/A.03 with the LC$\omega P B E / 6-31 G^{*}(\omega=0.1)$ functional/basis set. ${ }^{29}$ Natural transition orbitals (NTOs) were calculated for the excited states $S_{1}$ and $S_{2}$ for $c-P 8\left[b_{6} f_{2}\right] \cdot(T 4)_{2}$ and $c-P 8\left[b_{8}\right] \cdot(T 4)_{2}, S_{2}$ for $\mathbf{H}-I-P 4\left[b_{2} f_{1}\right]-H$, as well as $S_{3}$ for $\mathbf{H}-I-P 8\left[b_{5} f_{2}\right]-H .{ }^{30}$ 


\section{Time-Dependent Density Functional Theory}

Table S3. TD-DFT excitation energies and oscillator strengths of the $c-P 8\left[\mathbf{b}_{6} \mathbf{f}_{2}\right]^{\cdot}\left(\mathrm{T}_{4}\right)_{2}$ calculated at LC- $\omega \mathrm{hPBE} / 6-31 \mathrm{G}^{*}(\omega=$ 0.1 ) level of energy.

\begin{tabular}{|c|c|c|c|c|c|c|c|}
\hline $\begin{array}{l}\text { excited } \\
\text { state }\end{array}$ & $\mathrm{nm}$ & $\mathrm{eV}$ & $f$ & $\begin{array}{c}\text { excited } \\
\text { state }\end{array}$ & $\mathrm{nm}$ & $\mathrm{eV}$ & $f$ \\
\hline 1 & 1347.79 & 0.9199 & 0 & 33 & 628.9 & 1.9714 & 0 \\
\hline 2 & 1175.31 & 1.0549 & 2.2972 & 34 & 625.31 & 1.9828 & 0.0307 \\
\hline 3 & 1030.26 & 1.2034 & 0.0003 & 35 & 612.53 & 2.0241 & 0 \\
\hline 4 & 1030.25 & 1.2034 & 0 & 36 & 607.62 & 2.0405 & 0.0058 \\
\hline 5 & 898.68 & 1.3796 & 2.6932 & 37 & 600.02 & 2.0663 & 0 \\
\hline 6 & 859.78 & 1.442 & 0.0001 & 38 & 574.85 & 2.1568 & 0 \\
\hline 7 & 749.26 & 1.6547 & 0 & 39 & 573.1 & 2.1634 & 0 \\
\hline 8 & 711.07 & 1.7436 & 1.7492 & 40 & 572.82 & 2.1645 & 0.0777 \\
\hline 9 & 709.94 & 1.7464 & 0 & 41 & 572.47 & 2.1658 & 0.0036 \\
\hline 10 & 706.44 & 1.7551 & 0.0946 & 42 & 572 & 2.1676 & 0.0001 \\
\hline 11 & 705.96 & 1.7563 & 0.4364 & 43 & 571.97 & 2.1677 & 0.0721 \\
\hline 12 & 704.02 & 1.7611 & 0.0088 & 44 & 571.43 & 2.1697 & 0 \\
\hline 13 & 699.89 & 1.7715 & 0 & 45 & 569.83 & 2.1758 & 0.0002 \\
\hline 14 & 684.03 & 1.8126 & 0.3936 & 46 & 565.55 & 2.1923 & 0 \\
\hline 15 & 680.35 & 1.8224 & 0.0099 & 47 & 565.29 & 2.1933 & 0 \\
\hline 16 & 677.06 & 1.8312 & 0 & 48 & 554.47 & 2.2361 & 0.0001 \\
\hline 17 & 676.5 & 1.8327 & 0.0009 & 49 & 553.47 & 2.2401 & 0.0012 \\
\hline 18 & 675.35 & 1.8359 & 0 & 50 & 548.25 & 2.2615 & 0.8856 \\
\hline 19 & 670.92 & 1.848 & 0.0032 & 51 & 545.36 & 2.2734 & 0 \\
\hline 20 & 669.68 & 1.8514 & 0 & 52 & 533.99 & 2.3218 & 0.067 \\
\hline 21 & 667.91 & 1.8563 & 0.0031 & 53 & 533.92 & 2.3221 & 0.0166 \\
\hline 22 & 660.27 & 1.8778 & 0.0373 & 54 & 533.47 & 2.3241 & 0.4247 \\
\hline 23 & 657.85 & 1.8847 & 0 & 55 & 524.3 & 2.3647 & 0.0013 \\
\hline 24 & 651.62 & 1.9027 & 0.0024 & 56 & 524.28 & 2.3649 & 0 \\
\hline 25 & 651.54 & 1.9029 & 0.0243 & 57 & 522.47 & 2.3731 & 0.0004 \\
\hline 26 & 649.06 & 1.9102 & 0.0001 & 58 & 522.4 & 2.3733 & 0.0192 \\
\hline 27 & 646.13 & 1.9189 & 0.0019 & 59 & 522.24 & 2.3741 & 0 \\
\hline 28 & 645.3 & 1.9214 & 0.0002 & 60 & 518.93 & 2.3892 & 0.0008 \\
\hline 29 & 640.78 & 1.9349 & 0 & 61 & 517.16 & 2.3974 & 1.9387 \\
\hline 30 & 640.49 & 1.9358 & 0.0366 & 62 & 509.88 & 2.4316 & 0.0001 \\
\hline 31 & 636.49 & 1.9479 & 0.0002 & 63 & 509.84 & 2.4318 & 0 \\
\hline 32 & 636.44 & 1.9481 & 0.0005 & 64 & 509.39 & 2.434 & 0.0204 \\
\hline
\end{tabular}
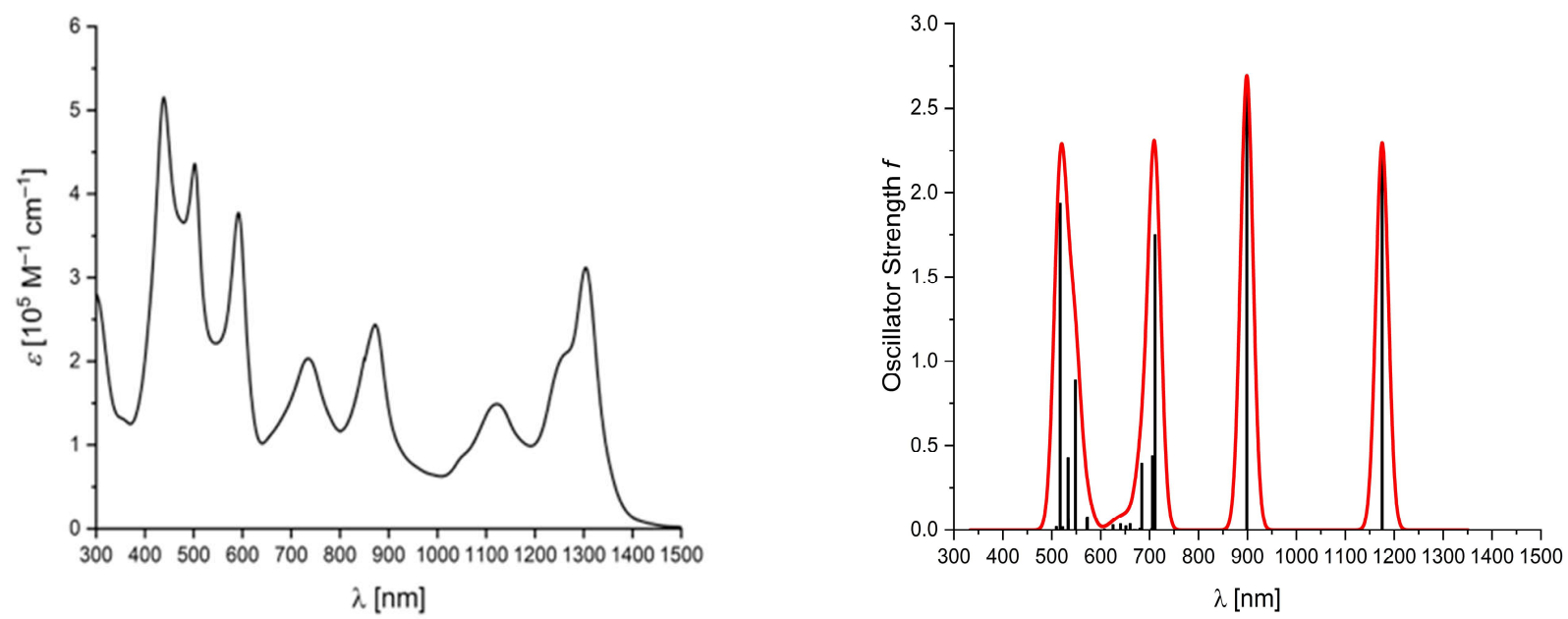

Figure S27. (Left) Experimental UV-Vis-NIR of $\boldsymbol{c}-\mathbf{P 8}\left[\mathbf{b}_{6} \mathbf{f}_{2}\right]_{\bullet}\left(\mathbf{T}_{4}\right)_{2}$ measured in $\mathrm{CHCl}_{3}$ at $298 \mathrm{~K}$. (Right) (black bars) Calculated wavelength vs. oscillator strength of $c-P 8\left[b_{6} f_{2}\right]_{\bullet}\left(T_{4}\right)_{2}$. (red) Simulated absorption spectrum assuming a Gaussian line-shape for each transition, with width $50 \mathrm{~nm}$. Calculated at the LC- $\omega \mathrm{hPBE} / 6-31 \mathrm{G}^{*}(\omega=0.1)$ level of energy for the first 64 excited states. 
Table S4. TD-DFT excitation energies and oscillator strengths of the $\boldsymbol{c}-\mathbf{P} 8\left[\mathbf{b}_{\mathbf{8}}\right]_{\mathbf{\bullet}}(\mathbf{T} \mathbf{4})_{2}$ calculated at LC- $\omega \mathrm{hPBE} / 6-31 \mathrm{G}^{*}(\omega=$ $0.1)$ level of energy.

\begin{tabular}{|c|c|c|c|c|c|c|c|}
\hline $\begin{array}{l}\text { excited } \\
\text { state }\end{array}$ & $\mathrm{nm}$ & $\mathrm{eV}$ & $f$ & $\begin{array}{l}\text { excited } \\
\text { state }\end{array}$ & $\mathrm{nm}$ & $\mathrm{eV}$ & $f$ \\
\hline 1 & 1053.31 & 1.1771 & 0 & 33 & 562.11 & 2.2057 & 0 \\
\hline 2 & 893.97 & 1.3869 & 2.9308 & 34 & 556.87 & 2.2264 & 0 \\
\hline 3 & 865.05 & 1.4333 & 6.1074 & 35 & 556.52 & 2.2278 & 0.0009 \\
\hline 4 & 720.83 & 1.72 & 0.0003 & 36 & 556.1 & 2.2295 & 0 \\
\hline 5 & 719.74 & 1.7226 & 0.0013 & 37 & 555.53 & 2.2318 & 0 \\
\hline 6 & 681.35 & 1.8197 & 0.0048 & 38 & 554.65 & 2.2354 & 0 \\
\hline 7 & 680.96 & 1.8207 & 0.0018 & 39 & 524.21 & 2.3652 & 0.0015 \\
\hline 8 & 671.44 & 1.8465 & 0.0161 & 40 & 520.75 & 2.3809 & 0.0051 \\
\hline 9 & 670.7 & 1.8486 & 0.0002 & 41 & 511.27 & 2.425 & 0.1629 \\
\hline 10 & 650.43 & 1.9062 & 0.0005 & 42 & 509.66 & 2.4327 & 0.0016 \\
\hline 11 & 650.32 & 1.9065 & 0.0002 & 43 & 508.85 & 2.4366 & 0.0038 \\
\hline 12 & 650.09 & 1.9072 & 0.0003 & 44 & 507.43 & 2.4434 & 0.0028 \\
\hline 13 & 649.62 & 1.9086 & 0.0001 & 45 & 506.63 & 2.4472 & 0.0009 \\
\hline 14 & 649.18 & 1.9099 & 0.0001 & 46 & 506.18 & 2.4494 & 0.0132 \\
\hline 15 & 647.25 & 1.9156 & 0.0017 & 47 & 506.17 & 2.4495 & 0.001 \\
\hline 16 & 644.72 & 1.9231 & 0.0021 & 48 & 505.34 & 2.4535 & 0.0008 \\
\hline 17 & 643.98 & 1.9253 & 0.003 & 49 & 504.62 & 2.457 & 0.2523 \\
\hline 18 & 643.71 & 1.9261 & 0 & 50 & 503.62 & 2.4618 & 0.0214 \\
\hline 19 & 643.44 & 1.9269 & 0.0004 & 51 & 503.22 & 2.4638 & 0.0019 \\
\hline 20 & 642.67 & 1.9292 & 0.0007 & 52 & 503.05 & 2.4646 & 0.0062 \\
\hline 21 & 631.19 & 1.9643 & 0.0046 & 53 & 503.03 & 2.4647 & 0.0072 \\
\hline 22 & 623.74 & 1.9878 & 0.0248 & 54 & 502.96 & 2.4651 & 0.0107 \\
\hline 23 & 623.17 & 1.9896 & 0.0139 & 55 & 502.27 & 2.4685 & 0.2279 \\
\hline 24 & 614.13 & 2.0189 & 0.0002 & 56 & 499.04 & 2.4845 & 0.0066 \\
\hline 25 & 613.96 & 2.0194 & 0.0001 & 57 & 498.65 & 2.4864 & 0.0036 \\
\hline 26 & 600.8 & 2.0637 & 0.0002 & 58 & 495.07 & 2.5044 & 0.0288 \\
\hline 27 & 590.38 & 2.1001 & 0 & 59 & 494.02 & 2.5097 & 0.0027 \\
\hline 28 & 573.96 & 2.1602 & 0.0001 & 60 & 493.8 & 2.5108 & 0.0007 \\
\hline 29 & 573.63 & 2.1614 & 0.0001 & 61 & 493.52 & 2.5123 & 0.0014 \\
\hline 30 & 573.35 & 2.1624 & 0.0001 & 62 & 493.08 & 2.5145 & 0.0047 \\
\hline 31 & 571.1 & 2.171 & 0.0001 & 63 & 490.5 & 2.5277 & 0.0047 \\
\hline 32 & 563.96 & 2.1985 & 0 & 64 & 489.54 & 2.5327 & 0.0094 \\
\hline
\end{tabular}
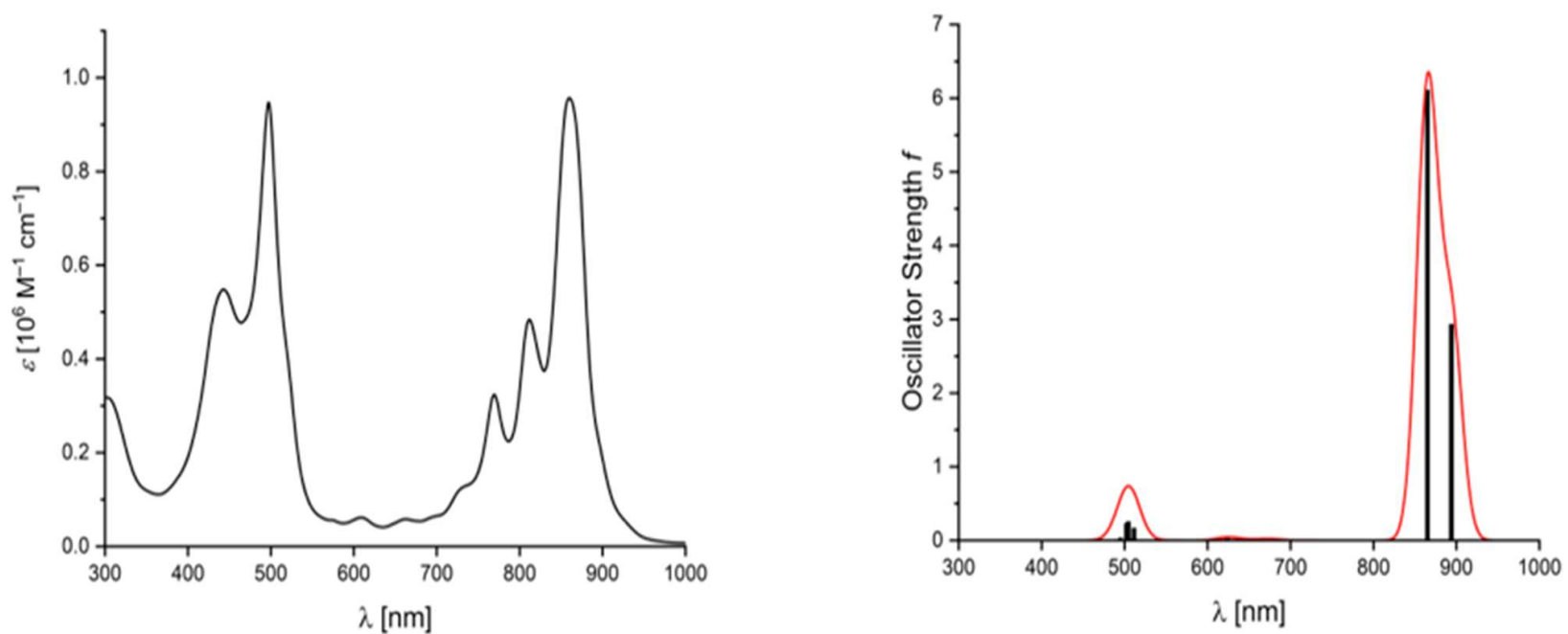

Figure S28. (Left) Experimental UV-Vis-NIR of $\boldsymbol{c}-\mathbf{P 8}$ [b8]•(T4)2 measured in $\mathrm{CHCl}_{3}$ at $298 \mathrm{~K}$. (Right) (black bars) Calculated wavelength vs. oscillator strength of $\mathbf{c}-\mathbf{P 8}\left[\mathbf{b}_{8}\right]^{\bullet}(\mathbf{T} 4)_{2}$. (red) Simulated absorption spectrum assuming a Gaussian line-shape for each transition, with width $50 \mathrm{~nm}$. Calculated at the LC- $\omega \mathrm{hPBE} / 6-31 \mathrm{G}^{*}(\omega=0.1)$ level of energy for the first 64 excited states. 
Table S5. TD-DFT excitation energies and oscillator strengths of the $\mathbf{H}-\mathbf{I}-\mathbf{P} 8\left[\mathbf{b}_{5} \mathbf{f}_{2}\right]-\mathbf{H}$ calculated at LC- $\omega \mathrm{hPBE} / 6-31 \mathrm{G}^{*}(\omega=$ $0.1)$ level of energy.

\begin{tabular}{|c|c|c|c|c|c|c|c|}
\hline $\begin{array}{l}\text { excited } \\
\text { state }\end{array}$ & $\mathrm{nm}$ & $\mathrm{eV}$ & $f$ & $\begin{array}{c}\text { excited } \\
\text { state }\end{array}$ & $\mathrm{nm}$ & $\mathrm{eV}$ & $f$ \\
\hline 1 & 1070.3 & 1.1584 & 6.1995 & 33 & 530.13 & 2.3388 & 0 \\
\hline 2 & 1020.2 & 1.2153 & 0 & 34 & 529.1 & 2.3433 & 0.2737 \\
\hline 3 & 1003.23 & 1.2358 & 0 & 35 & 526.26 & 2.356 & 2.9716 \\
\hline 4 & 1003.23 & 1.2358 & 0 & 36 & 514.64 & 2.4091 & 0 \\
\hline 5 & 778.23 & 1.5931 & 2.2381 & 37 & 514.64 & 2.4092 & 0.0248 \\
\hline 6 & 682.49 & 1.8166 & 0 & 38 & 511.62 & 2.4234 & 0 \\
\hline 7 & 675.07 & 1.8366 & 2.4317 & 39 & 507.92 & 2.441 & 0 \\
\hline 8 & 660.97 & 1.8758 & 0 & 40 & 507.92 & 2.441 & 0.0001 \\
\hline 9 & 660.82 & 1.8762 & 0 & 41 & 497.83 & 2.4905 & 0 \\
\hline 10 & 660.82 & 1.8762 & 0 & 42 & 495.28 & 2.5033 & 0 \\
\hline 11 & 633.39 & 1.9575 & 0 & 43 & 494.04 & 2.5096 & 0.0684 \\
\hline 12 & 633.38 & 1.9575 & 0.0394 & 44 & 488.99 & 2.5355 & 0 \\
\hline 13 & 632.63 & 1.9598 & 0 & 45 & 488.99 & 2.5355 & 0 \\
\hline 14 & 632.63 & 1.9598 & 0.0012 & 46 & 481.12 & 2.577 & 1.0396 \\
\hline 15 & 629.93 & 1.9682 & 0 & 47 & 478.32 & 2.5921 & 0 \\
\hline 16 & 629.93 & 1.9682 & 0 & 48 & 477.58 & 2.5961 & 0 \\
\hline 17 & 623.32 & 1.9891 & 0.3605 & 49 & 476.2 & 2.6036 & 0.1893 \\
\hline 18 & 618.97 & 2.0031 & 0.002 & 50 & 475.18 & 2.6092 & 0 \\
\hline 19 & 618.06 & 2.006 & 0 & 51 & 475.18 & 2.6092 & 0.1118 \\
\hline 20 & 610.48 & 2.0309 & 0 & 52 & 474.11 & 2.6151 & 0 \\
\hline 21 & 598.26 & 2.0724 & 0 & 53 & 474.11 & 2.6151 & 0 \\
\hline 22 & 598.26 & 2.0724 & 0.0038 & 54 & 472.07 & 2.6264 & 0 \\
\hline 23 & 592.96 & 2.0909 & 0.1376 & 55 & 472.07 & 2.6264 & 0 \\
\hline 24 & 589.57 & 2.103 & 0 & 56 & 471.04 & 2.6321 & 0.1145 \\
\hline 25 & 574.7 & 2.1574 & 0 & 57 & 470.4 & 2.6357 & 0 \\
\hline 26 & 566.28 & 2.1895 & 0.1628 & 58 & 470.36 & 2.636 & 0.2346 \\
\hline 27 & 552.08 & 2.2458 & 0 & 59 & 469.53 & 2.6406 & 0.2666 \\
\hline 28 & 552.03 & 2.246 & 0 & 60 & 467.38 & 2.6528 & 0 \\
\hline 29 & 548.56 & 2.2602 & 0.4922 & 61 & 457.17 & 2.712 & 0 \\
\hline 30 & 547.05 & 2.2664 & 0 & 62 & 457.17 & 2.712 & 0.0206 \\
\hline 31 & 542.45 & 2.2856 & 0 & 63 & 453.75 & 2.7324 & 0 \\
\hline 32 & 542.45 & 2.2856 & 0 & 64 & 453.73 & 2.7326 & 0.2833 \\
\hline
\end{tabular}
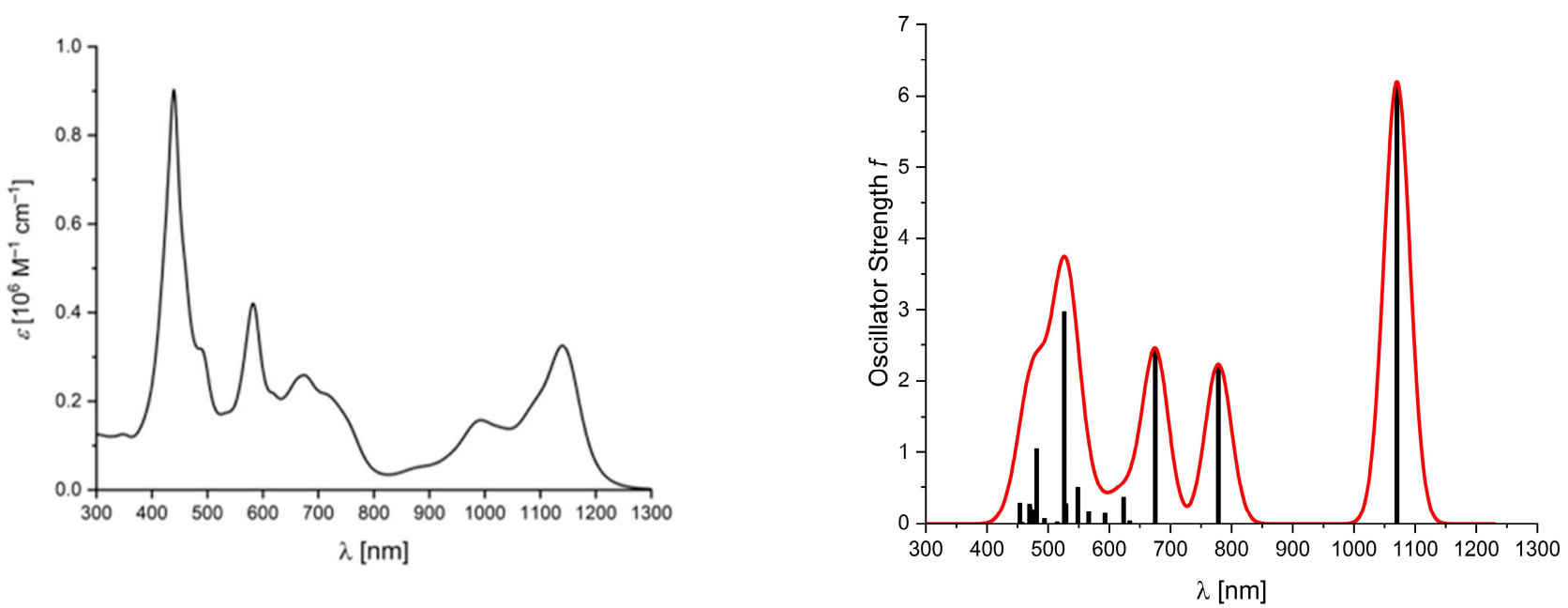

Figure S29. (Left) Experimental UV-Vis-NIR of $\mathbf{H}-\mathbf{I - P 8}\left[\mathbf{b}_{5} \mathbf{f}_{2}\right]-\mathbf{H}$ measured in $\mathrm{CHCl}_{3}$ at $298 \mathrm{~K}$. (Right) (black bars) Calculated wavelength vs. oscillator strength of $\mathbf{H}-\mathbf{I}-\mathbf{P} \mathbf{8}\left[\mathbf{b}_{5} \mathbf{f}_{2}\right]-\mathbf{H}$. (red) Simulated absorption spectrum assuming a Gaussian line-shape for each transition, with width $50 \mathrm{~nm}$. Calculated at the LC- $\omega \mathrm{hPBE} / 6-31 \mathrm{G}^{*}(\omega=0.1)$ level of energy for the first 64 excited states. 
Table S6. TD-DFT excitation energies and oscillator strengths of the $\mathbf{H}-\mathbf{I}-\mathbf{P} 4\left[\mathbf{b}_{2} \mathbf{f}_{1}\right]-\mathbf{H}$ calculated at LC- $\omega \mathrm{hPBE} / 6-31 \mathrm{G}^{*}(\omega=$ $0.1)$ level of energy.

\begin{tabular}{|c|c|c|c|c|c|c|c|}
\hline $\begin{array}{l}\text { excited } \\
\text { state }\end{array}$ & $\mathrm{nm}$ & $\mathrm{eV}$ & $f$ & $\begin{array}{c}\text { excited } \\
\text { state }\end{array}$ & $\mathrm{nm}$ & $\mathrm{eV}$ & $f$ \\
\hline 1 & 1027.16 & 1.2071 & 2.0243 & 33 & 436.58 & 2.8399 & 0 \\
\hline 2 & 1002.11 & 1.2372 & 0 & 34 & 436.57 & 2.84 & 0 \\
\hline 3 & 682.33 & 1.8171 & 0 & 35 & 436.51 & 2.8404 & 0.0027 \\
\hline 4 & 663.44 & 1.8688 & 2.5494 & 36 & 435.27 & 2.8484 & 0 \\
\hline 5 & 660.35 & 1.8775 & 0 & 37 & 435.22 & 2.8488 & 0.1914 \\
\hline 6 & 633.08 & 1.9584 & 0.02 & 38 & 434.23 & 2.8553 & 0.3032 \\
\hline 7 & 632.82 & 1.9592 & 0 & 39 & 431.3 & 2.8747 & 0 \\
\hline 8 & 629.52 & 1.9695 & 0 & 40 & 431.16 & 2.8756 & 0 \\
\hline 9 & 601.31 & 2.0619 & 0 & 41 & 421.76 & 2.9397 & 0 \\
\hline 10 & 598.26 & 2.0724 & 0.0037 & 42 & 418.08 & 2.9655 & 0.0129 \\
\hline 11 & 598.26 & 2.0724 & 0 & 43 & 412.02 & 3.0092 & 0 \\
\hline 12 & 588.42 & 2.1071 & 0.2045 & 44 & 411.01 & 3.0166 & 0 \\
\hline 13 & 550.7 & 2.2514 & 0 & 45 & 407.61 & 3.0417 & 0 \\
\hline 14 & 542.26 & 2.2864 & 0 & 46 & 407.26 & 3.0444 & 1.1945 \\
\hline 15 & 542.26 & 2.2864 & 0 & 47 & 403.48 & 3.0729 & 0 \\
\hline 16 & 539.16 & 2.2996 & 0.4288 & 48 & 403.23 & 3.0748 & 0.0074 \\
\hline 17 & 516.68 & 2.3996 & 1.6909 & 49 & 403.23 & 3.0748 & 0 \\
\hline 18 & 511.08 & 2.4259 & 0.019 & 50 & 401.78 & 3.0859 & 0 \\
\hline 19 & 507.48 & 2.4431 & 0 & 51 & 400.53 & 3.0955 & 0.0244 \\
\hline 20 & 489.07 & 2.5351 & 0 & 52 & 399.99 & 3.0997 & 0.0563 \\
\hline 21 & 488.35 & 2.5389 & 0 & 53 & 397.18 & 3.1216 & 0 \\
\hline 22 & 481.83 & 2.5732 & 0 & 54 & 397.15 & 3.1219 & 0.2179 \\
\hline 23 & 474.16 & 2.6148 & 0 & 55 & 391.08 & 3.1703 & 0.0013 \\
\hline 24 & 474.16 & 2.6148 & 0 & 56 & 390.02 & 3.1789 & 0.0688 \\
\hline 25 & 474.03 & 2.6155 & 0 & 57 & 389.98 & 3.1792 & 0 \\
\hline 26 & 474.03 & 2.6155 & 0.1238 & 58 & 389.98 & 3.1792 & 0 \\
\hline 27 & 469.26 & 2.6421 & 0 & 59 & 388.84 & 3.1886 & 0 \\
\hline 28 & 466.37 & 2.6585 & 0.0142 & 60 & 388.49 & 3.1914 & 0 \\
\hline 29 & 456.95 & 2.7133 & 0.1722 & 61 & 385.25 & 3.2183 & 0 \\
\hline 30 & 454.58 & 2.7274 & 0.1167 & 62 & 385.15 & 3.2191 & 0.5197 \\
\hline 31 & 452.34 & 2.741 & 0 & 63 & 380.26 & 3.2605 & 0.0152 \\
\hline 32 & 447.1 & 2.7731 & 0 & 64 & 380.18 & 3.2612 & 0.0199 \\
\hline
\end{tabular}
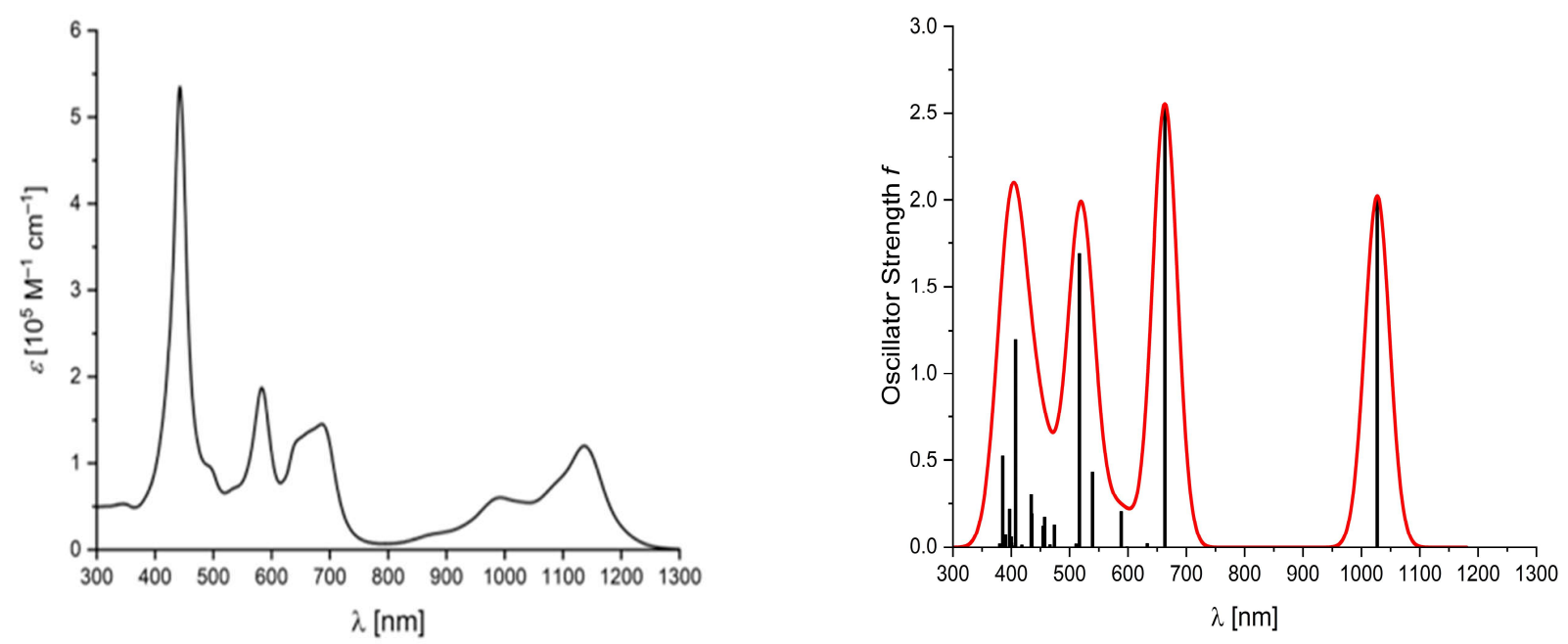

Figure S30. (Left) Experimental UV-Vis-NIR of Si-I-P4[ $\left.\mathbf{b}_{2} \mathbf{f}_{1}\right]-\mathrm{Si}$ measured in $\mathrm{CHCl}_{3}$ at $298 \mathrm{~K}$. (Right) (black bars) Calculated wavelength vs. oscillator strength of $\mathbf{H}-\mathbf{I}-\mathbf{P} 4\left[\mathbf{b}_{2} \mathbf{f}_{1}\right]-\mathbf{H}$. (red) Simulated absorption spectrum assuming a Gaussian line-shape for each transition, with width $50 \mathrm{~nm}$. Calculated at the LC- $\omega \mathrm{hPBE} / 6-31 \mathrm{G}^{*}(\omega=0.1)$ level of energy for the first 64 excited states. 


\section{Natural Transition Orbital Pair Calculations}

Table S7. Natural transition orbital pairs for the $S_{0} \rightarrow S_{1}$ excitation $(1347.79 \mathrm{~nm}, 0.92 \mathrm{eV}, f=0.0000)$ of $\boldsymbol{c}-\mathbf{P} 8\left[\mathbf{b}_{6} \mathrm{f}_{2}\right] \cdot(\mathbf{T 4})_{2}$ calculated at the LC-whPBE/6-31G* $(w=0.1)$ level of theory. The eigenvalue associated with the natural transition orbital pair is $\lambda$.

Hole

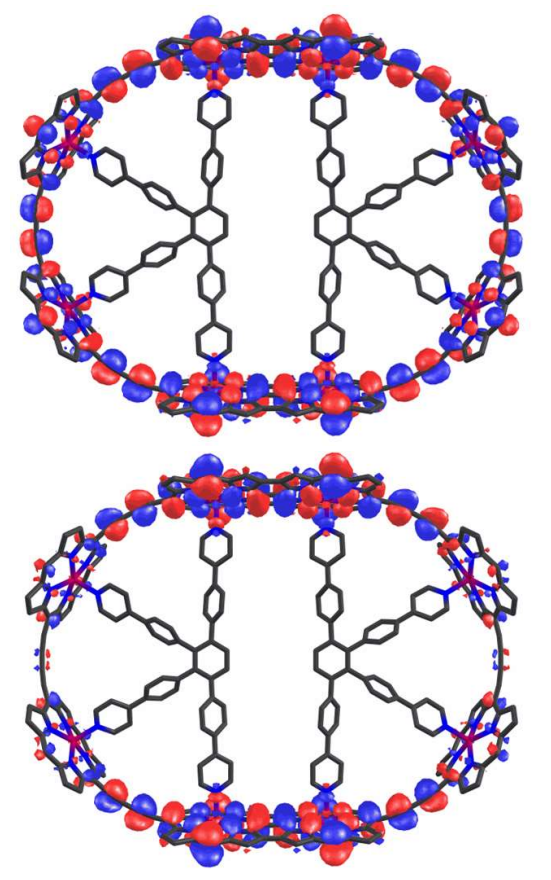

Electron
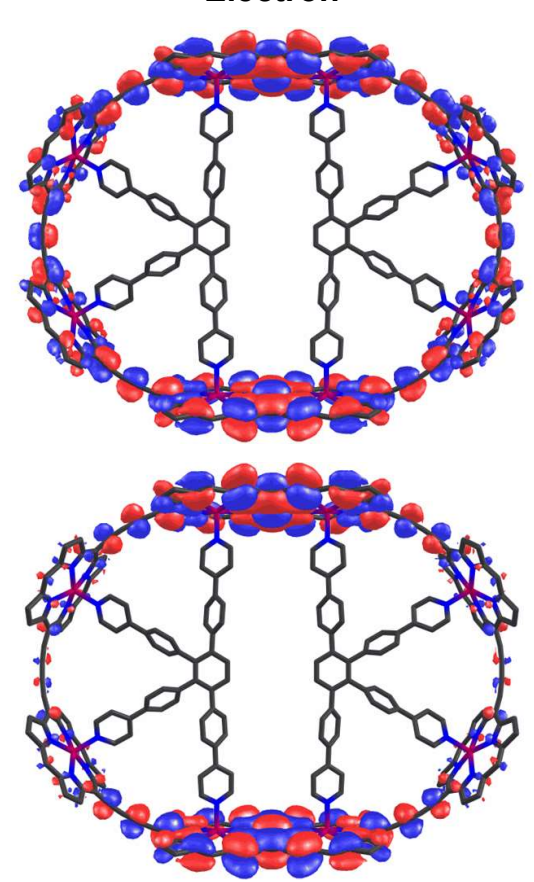

$\lambda$

0.5356

0.3223

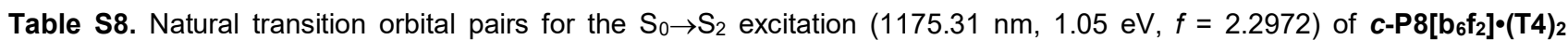
calculated at the LC-whPBE/6-31G* $(w=0.1)$ level of theory. The eigenvalue associated with the natural transition orbital pairs is $\lambda$.
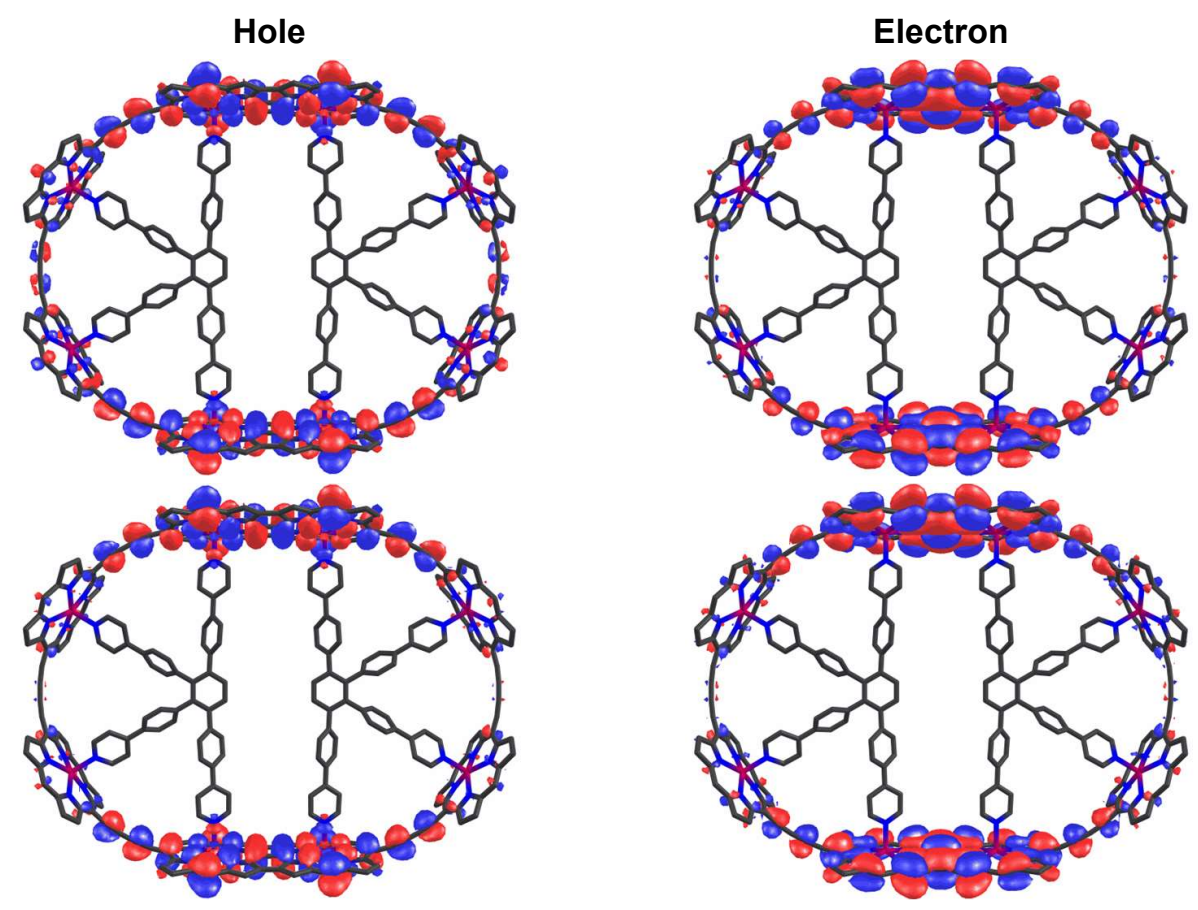

$\lambda$

0.4743

0.4623 
Table S9. Natural transition orbital pairs for the $S_{0} \rightarrow S_{1}$ excitation $(1053.31 \mathrm{~nm}, 1.18 \mathrm{eV}, f=0.0000)$ of $\boldsymbol{c}-\mathbf{P 8}\left[\mathbf{b}_{8}\right] \cdot(\mathbf{T 4})_{2}$ calculated at the LC-whPBE/6-31G* $(w=0.1)$ level of theory. The eigenvalue associated with the natural transition orbital pair is $\lambda$.

Hole
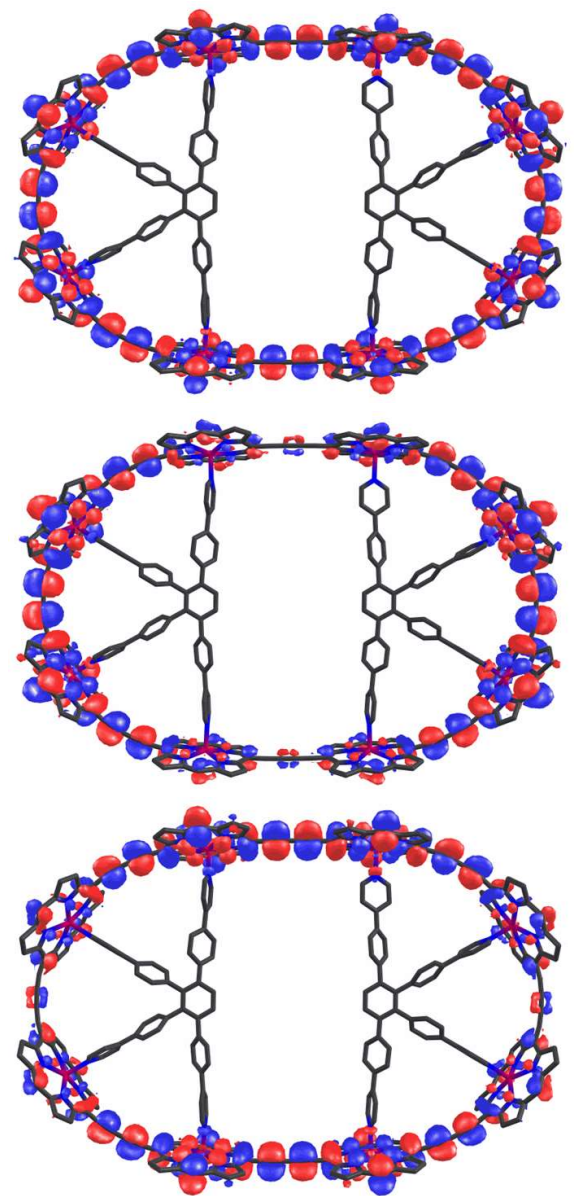

Electron
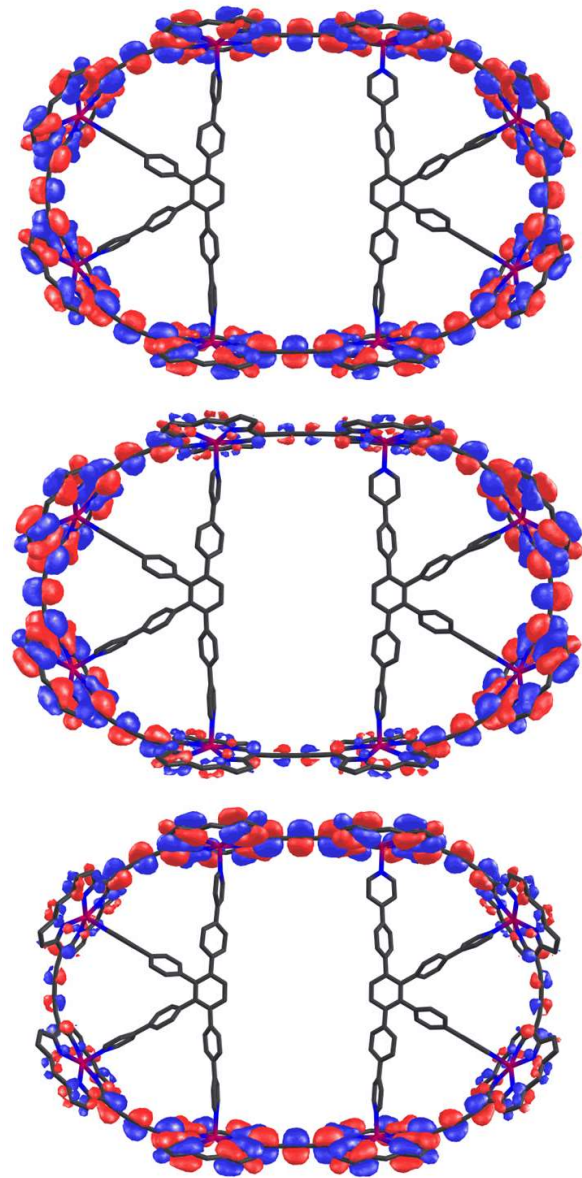

0.4715

0.2193

0.1887

Table S10. Natural transition orbital pairs for the $S_{0} \rightarrow S_{2}$ excitation $(893.97 \mathrm{~nm}, 1.39 \mathrm{eV}, f=2.9308)$ of $c-\mathbf{P}_{8}\left[\mathbf{b}_{8}\right]^{\circ}(\mathrm{T} 4)_{2}$ calculated at the LC-whPBE/6-31G* $(w=0.1)$ level of theory. The eigenvalue associated with the natural transition orbital pair is $\lambda$.

Hole
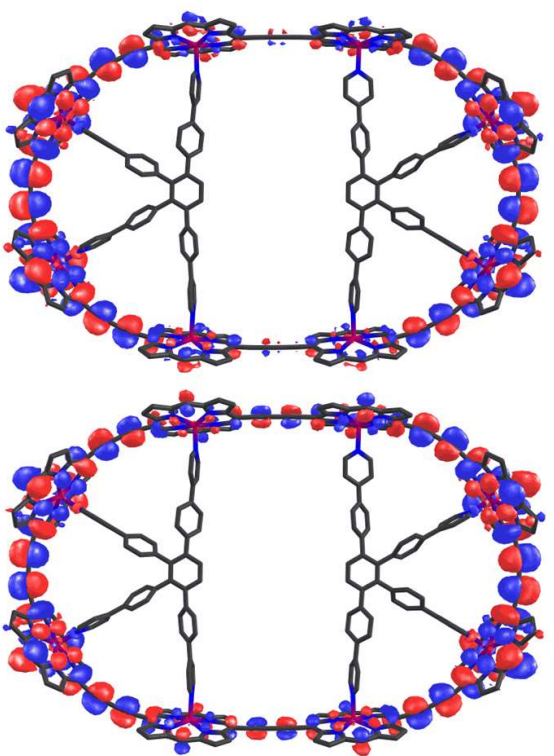

Electron
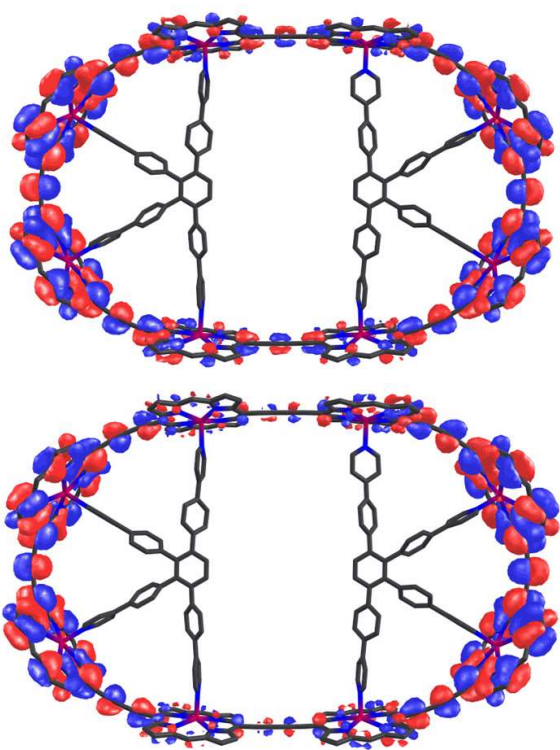

S47 $\lambda$

0.4207

0.4155 
Table S11. Natural transition orbital pairs for the $S_{0} \rightarrow S_{1}$ excitation $(1027.16 \mathrm{~nm}, 1.21 \mathrm{eV}, f=2.2043)$ of $\mathbf{H}-\mathbf{I}-\mathbf{P} 4\left[\mathbf{b}_{2} \mathbf{f}_{1}\right]-\mathbf{H}$ calculated at the LC-whPBE/6-31G* $(w=0.1)$ level of theory. The eigenvalue associated with the natural transition orbital pair is $\lambda$.

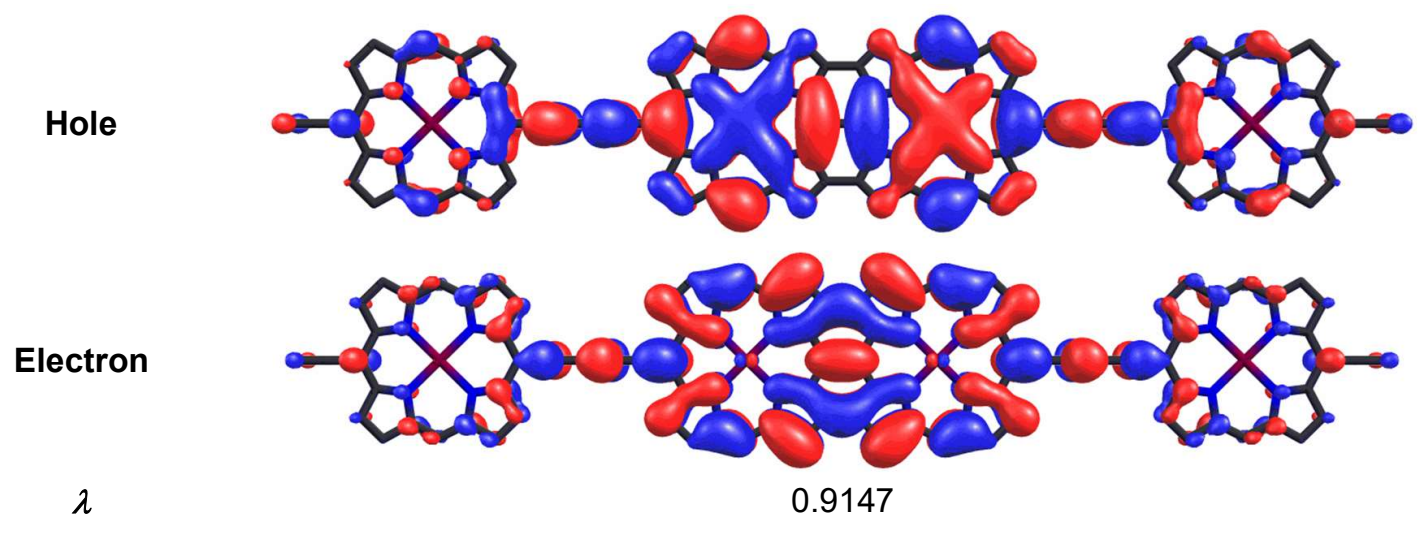

Table S12. Natural transition orbital pairs for the $S_{0} \rightarrow S_{1}$ excitation $(1070.30 \mathrm{~nm}, 1.16 \mathrm{eV}, f=6.1995)$ of $\mathbf{H}-\mathbf{I}-\mathbf{P} 8\left[\mathbf{b}_{5} \mathbf{f}_{2}\right]-\mathbf{H}$ calculated at the LC-whPBE/6-31G* $(w=0.1)$ level of theory. The eigenvalue associated with the natural transition orbital pair is $\lambda$.

Hole

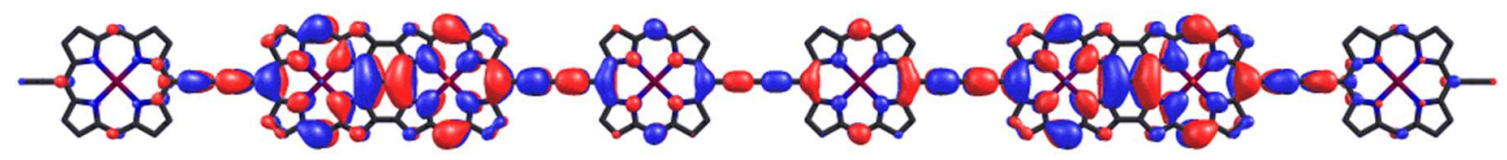

Electron

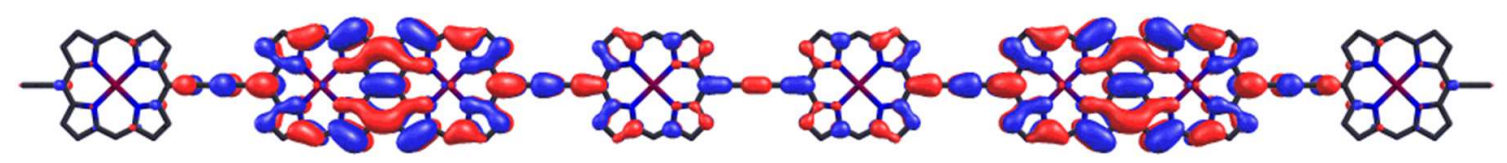
$\lambda$

0.4835

Hole

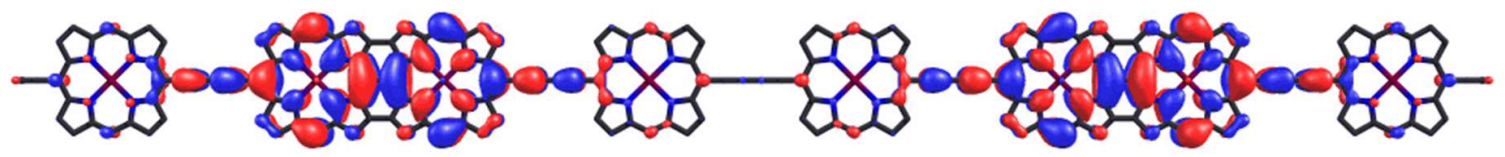

Electron

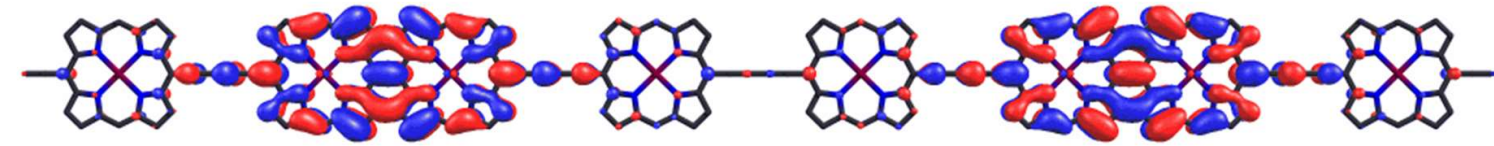




\section{NICS and ACID calculations}

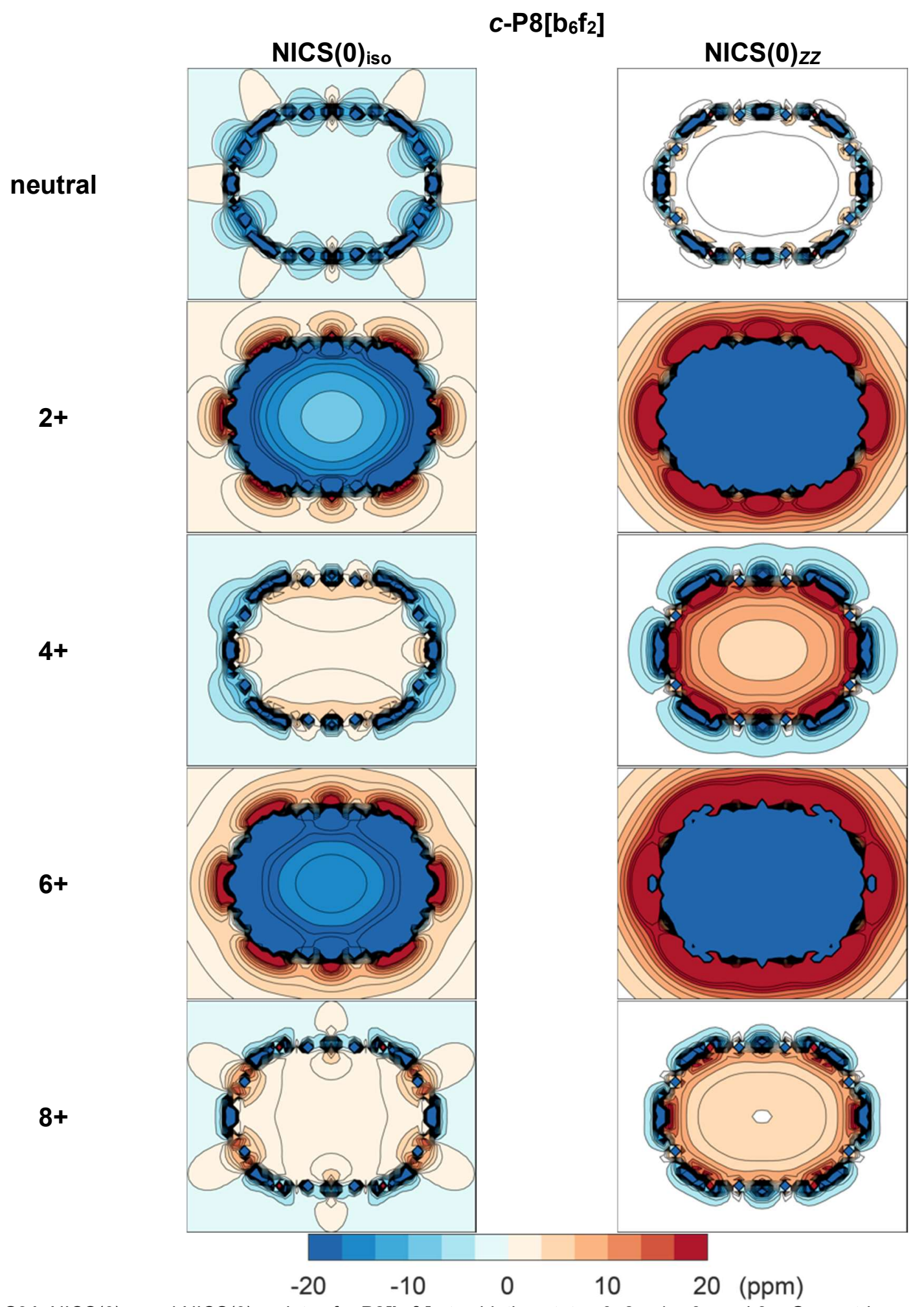

Figure S31. NICS $(0)_{\text {iso }}$ and $\mathrm{NICS}(0)_{z z}$ plots of $\boldsymbol{c}-\mathbf{P} 8\left[\mathbf{b}_{6} \mathbf{f}_{2}\right]$ at oxidation states $0,2+, 4+, 6+$ and $8+$. Geometries were optimized using LC- $\omega \mathrm{hPBE} / 6-31 \mathrm{G}^{*}(\omega=0.1)$ at every oxidation state with the templates. NICS were calculated in the absence of template on a planar grid bisecting the $\mathrm{Zn}$ atoms $(51 \AA \times 41 \AA$, spacing $1 \AA$ ). The color axis is truncated left (blue) and right (red) -20 ppm and 20 ppm, respectively. Contours are drawn every 3.3 ppm, from -20 to 20 ppm. 


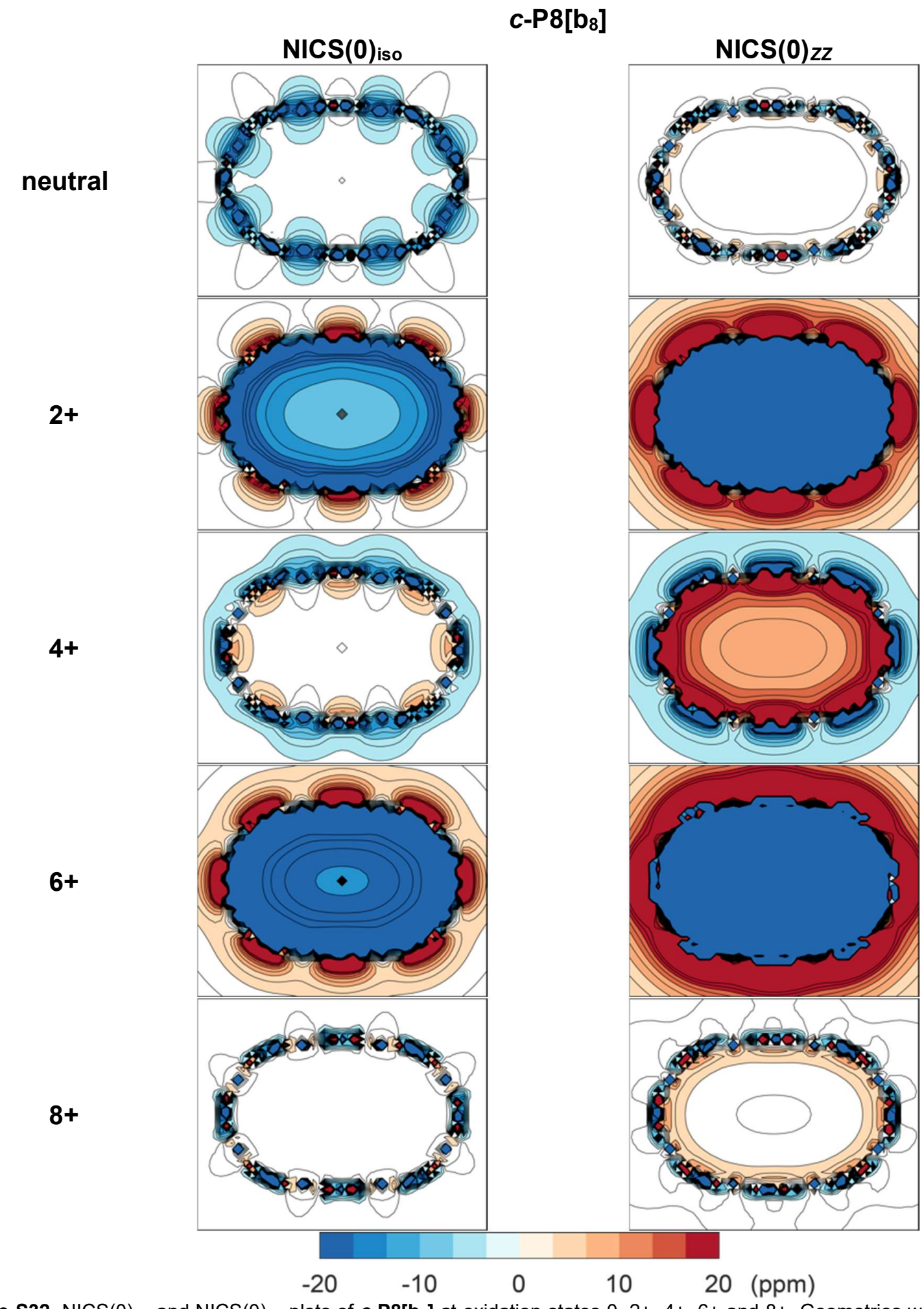

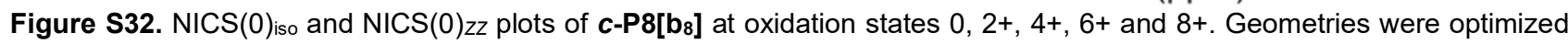
using LC-whPBE/6-31G* $(\omega=0.1)$ at every oxidation state with the templates. NICS were calculated in the absence of template on a planar grid bisecting the $\mathrm{Zn}$ atoms $(51 \AA \times 41 \AA$, spacing $1 \AA$ ). The color axis is truncated left (blue) and right (red) -20 ppm and 20 ppm, respectively. Contours are drawn every 3.3 ppm, from -20 to 20 ppm. 


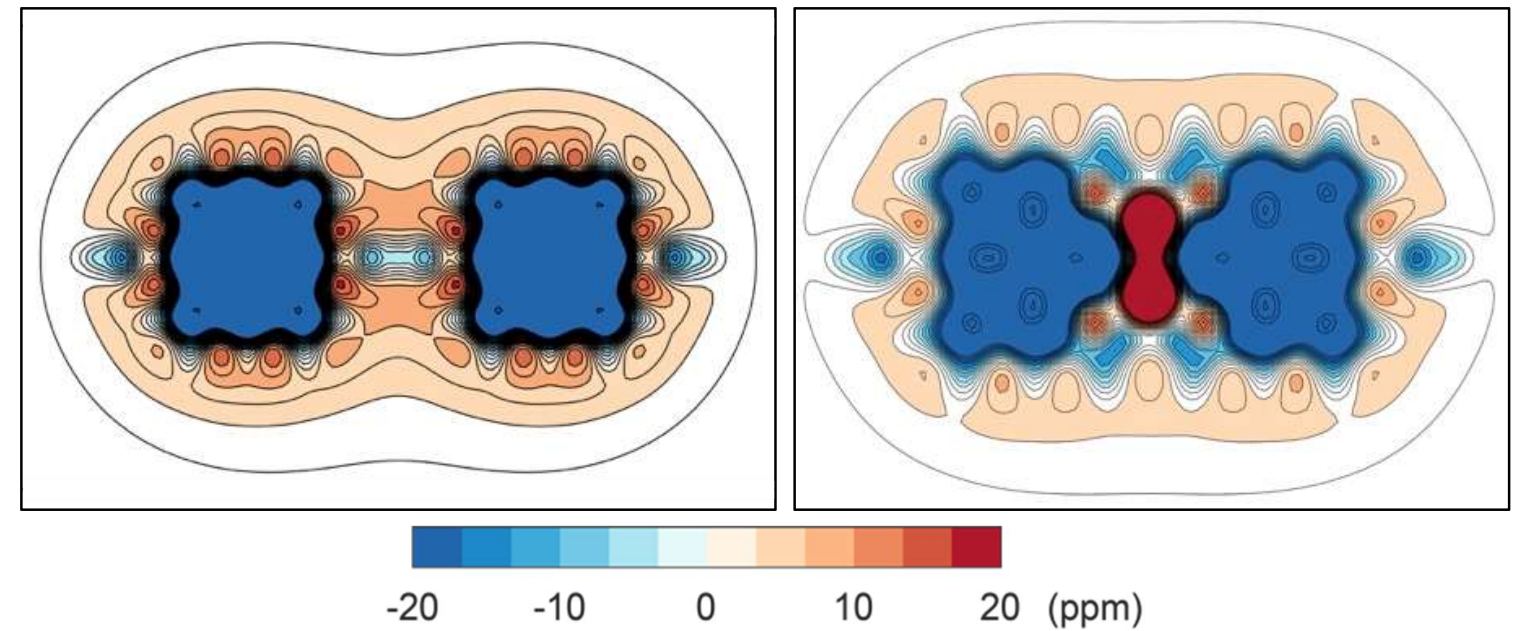

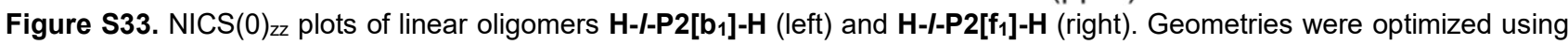
LC-whPBE/6-31G* $(\omega=0.1)$ and NICS grids were calculated with $0.25 \AA$ resolution on a $21 \AA \times 11 \AA$ grid. The color axis is truncated left (blue) and right (red) -20 ppm and 20 ppm, respectively. 


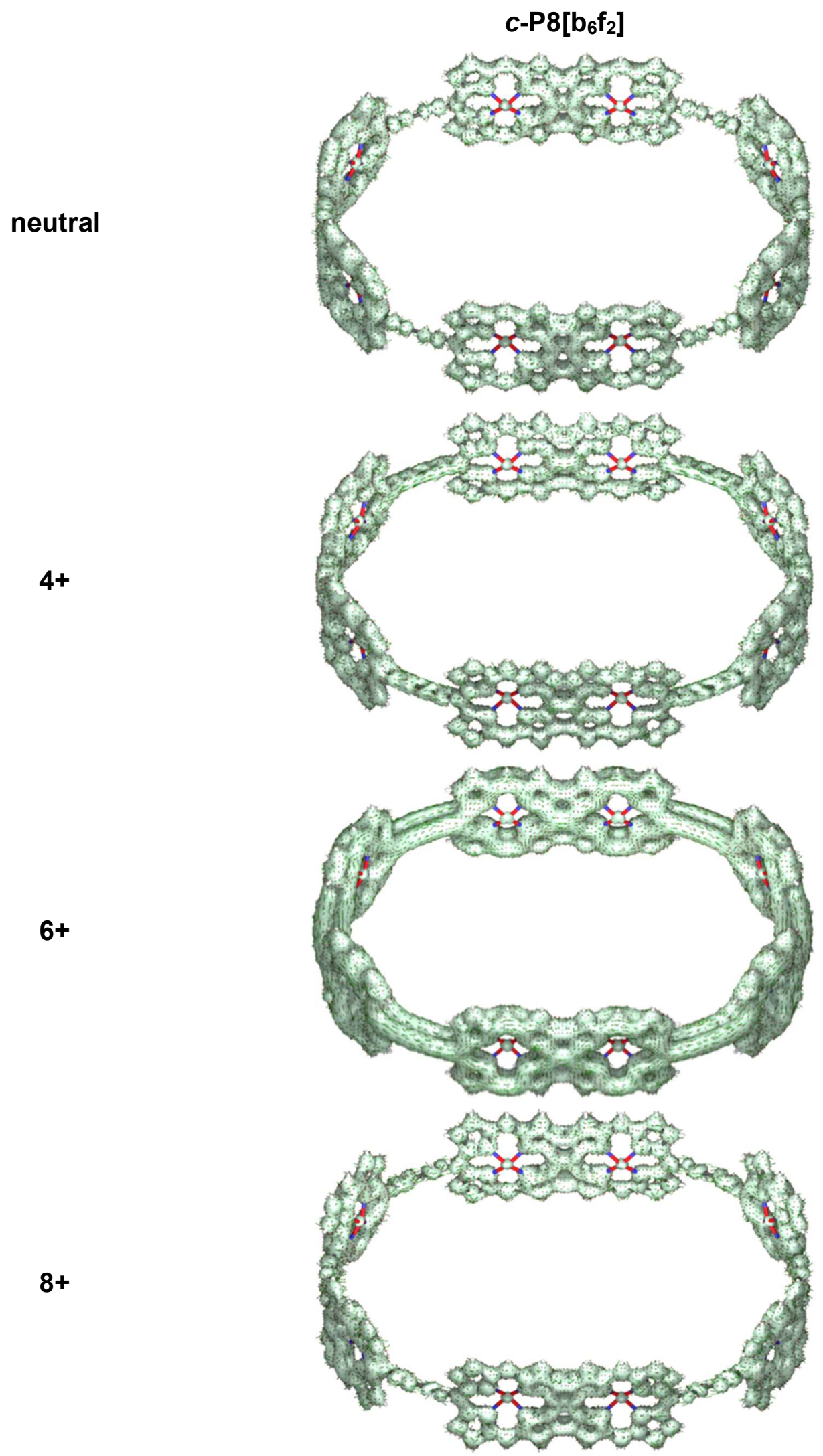

Figure S34. ACID plots of $c-P 8\left[b_{6} f_{2}\right]$ (top view at an angle). 


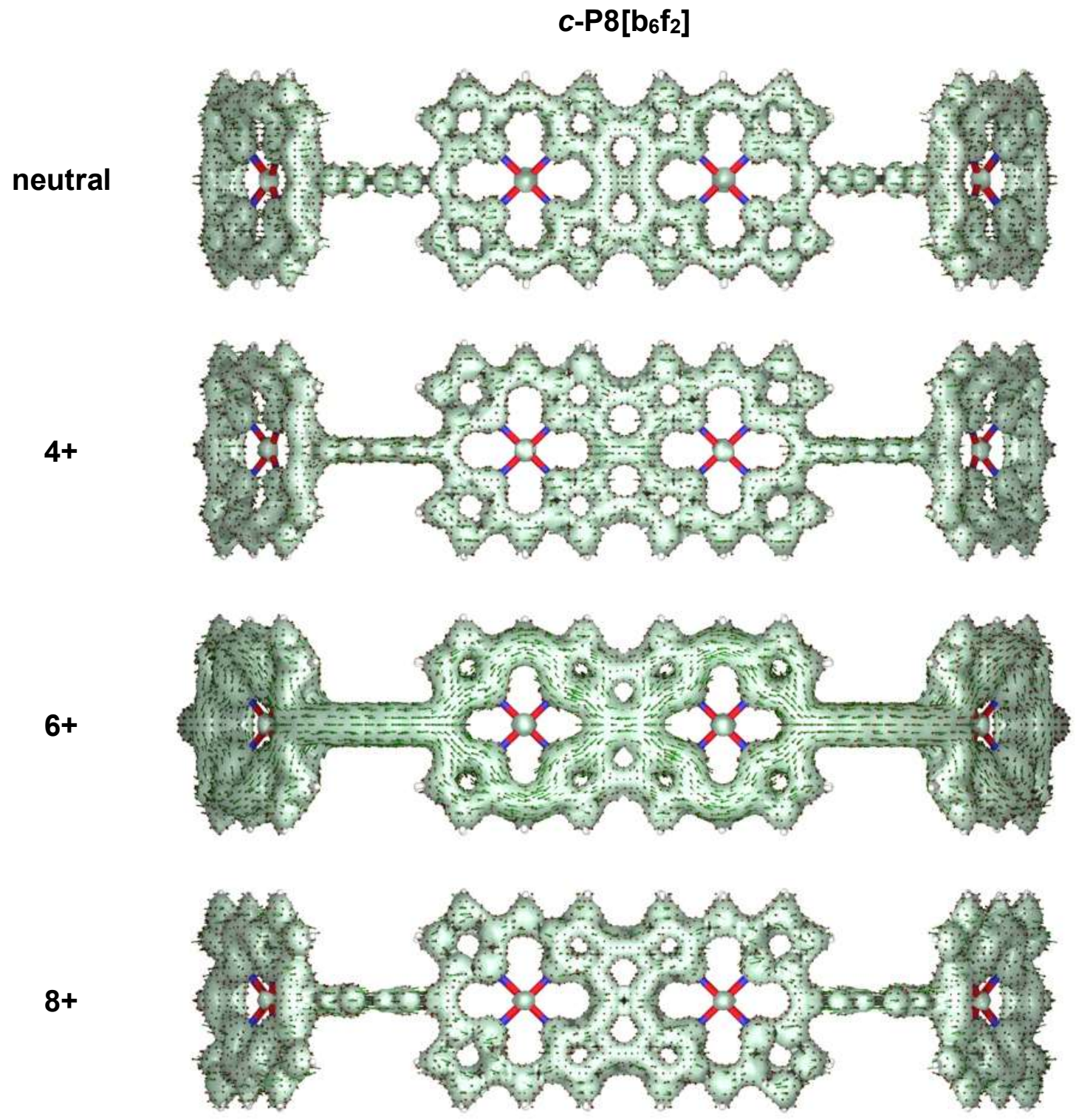

Figure S35. ACID plots of $c-P 8\left[b_{6} f_{2}\right]$ (porphyrin tape region). 


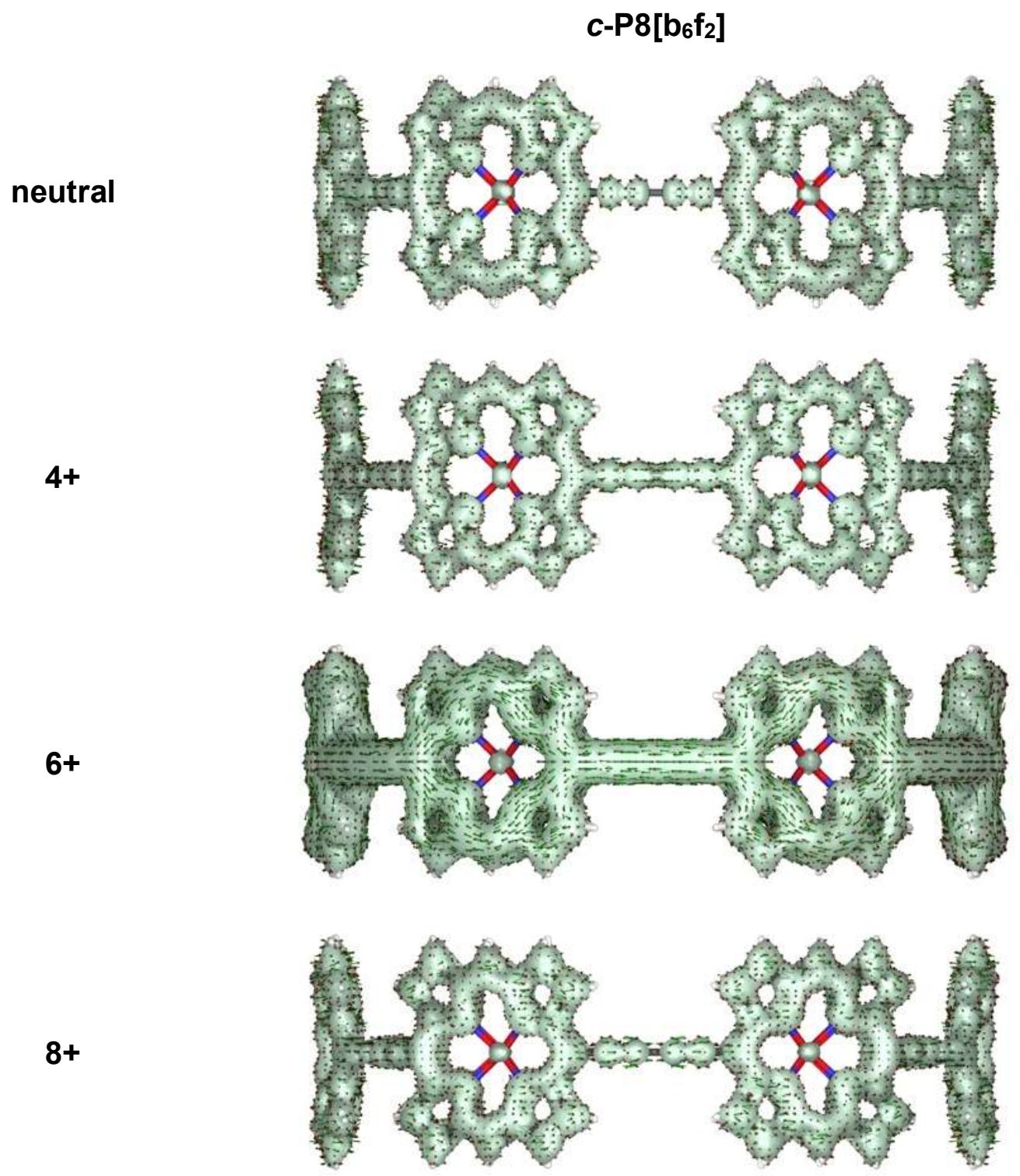

Figure S36. ACID plots of $c-\mathbf{P} 8\left[b_{6} f_{2}\right]$ (butadiyne porphyrin region). 


\section{NMR and Mass Spectra of Novel Compounds}

\section{$\mathrm{Si}-\mathrm{I}-\mathrm{P} 2\left[\mathrm{f}_{1}\right]-\mathrm{Si}:$}
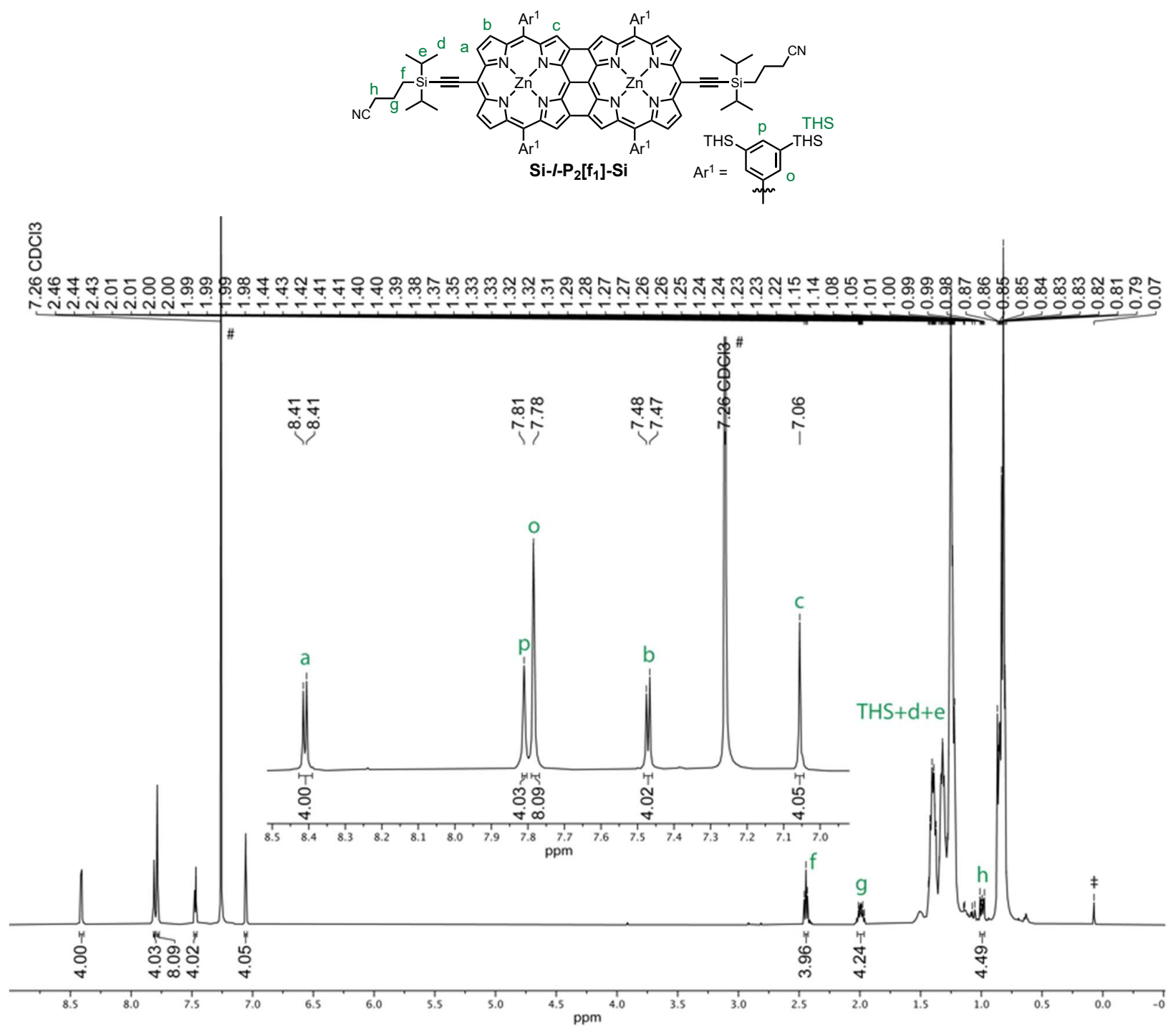

Figure S37. Labelled structure and ${ }^{1} \mathrm{H}$ NMR spectrum of $\mathbf{S i}-\mathrm{I}-\mathbf{P 2}\left[\mathrm{f}_{1}\right]-\mathrm{Si}\left(500 \mathrm{MHz}, \mathrm{CDCl}_{3}, 298 \mathrm{~K}\right)$. \#= $\mathrm{CHCl}_{3} ; \ddagger=$ silicon grease.

Table S13. NMR assignment and correlations for Si-I-P2[ $\left.\mathbf{f}_{1}\right]-\mathbf{S i}$.

\begin{tabular}{|c|c|c|c|c|c|c|}
\hline \# & Assign. & ${ }^{1} \mathrm{H}$ & $\begin{array}{l}\text { Mult. } \\
J(H z)\end{array}$ & $\begin{array}{l}{ }^{1} \mathrm{H}-{ }^{1} \mathrm{H} \\
\text { COSY }\end{array}$ & ${ }^{1} \mathrm{H}-{ }^{1} \mathrm{H}$ NOESY ${ }^{+}$ & ${ }^{1} \mathrm{H}-{ }^{13} \mathrm{CHSQC}+{ }^{13} \mathrm{C}$ \\
\hline 1 & $a$ & $8.41(4 \mathrm{H})$ & $d, J=4.6$ & 4 & $s: 4 ; w: 3$ & 129.8 \\
\hline 2 & $\mathrm{p}$ & $7.81(4 \mathrm{H})$ & s & - & m: 9 & 139.4 \\
\hline 3 & o & $7.78(8 \mathrm{H})$ & $\mathrm{s}$ & - & $\begin{array}{c}\text { w: } 1 ; \mathrm{s}: 4,5 ; \mathrm{m}: \\
9\end{array}$ & 138.6 \\
\hline 4 & b & $7.47(4 \mathrm{H})$ & $\mathrm{d}, J=4.6$ & 1 & $\mathrm{~s}: 1,3 ; \mathrm{m}: 9$ & 132.2 \\
\hline 5 & c & $7.06(4 \mathrm{H})$ & s & - & $\mathrm{s}: 3 ; \mathrm{m}: 9$ & 127.8 \\
\hline 6 & $f$ & $2.44(4 \mathrm{H})$ & $\mathrm{t}, J=6.8$ & 7 & - & 21.1 \\
\hline 7 & g & $2.04-1.95(4 \mathrm{H})$ & $\mathrm{m}$ & 6,8 & - & 21.6 \\
\hline 8 & $\mathrm{~h}$ & $1.01-0.97(4 \mathrm{H})$ & $\mathrm{m}$ & 7 & - & 10.1 \\
\hline 9 & THS+d+e & $1.45-0.75(340 \mathrm{H})$ & $\mathrm{m}$ & 9 & $m: 2,3,4,5$ & $\begin{array}{c}12.2,12.8,14.3,18.3,18.6,22.6 \\
22.8,24.1,29.9,31.7,33.6\end{array}$ \\
\hline
\end{tabular}

${ }^{\dagger}$ Relative correlation intensities are designated as: $\mathrm{s}=$ strong, $\mathrm{m}=$ medium, $\mathrm{w}=$ weak. 


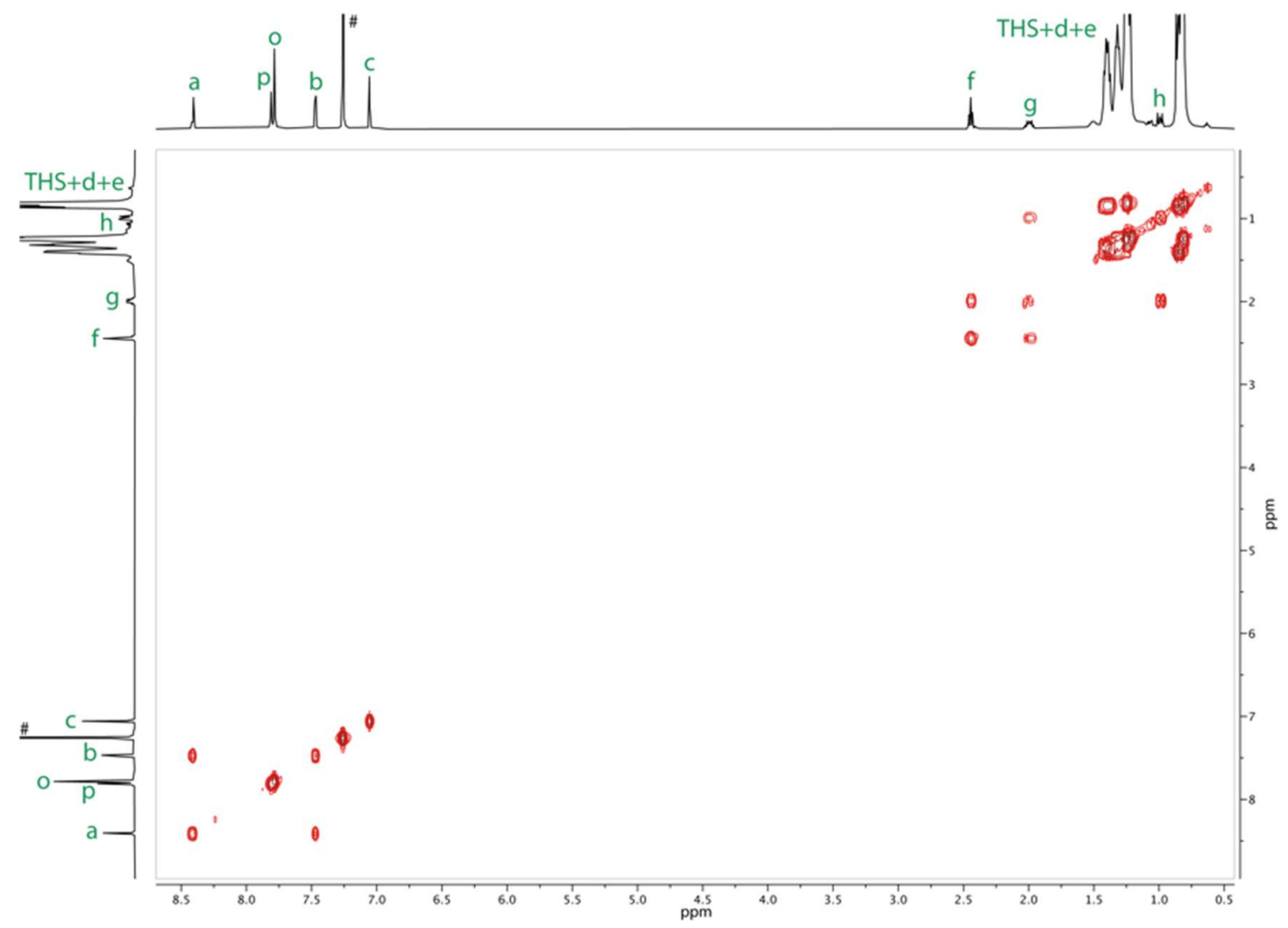

Figure S38. ${ }^{1} \mathrm{H}-{ }^{1} \mathrm{H}$ COSY spectrum of Si-I-P2[f $\left.\mathbf{f}_{1}\right]-\mathbf{S i}\left(500 \mathrm{MHz}, \mathrm{CDCl}_{3}, 298 \mathrm{~K}\right)$.

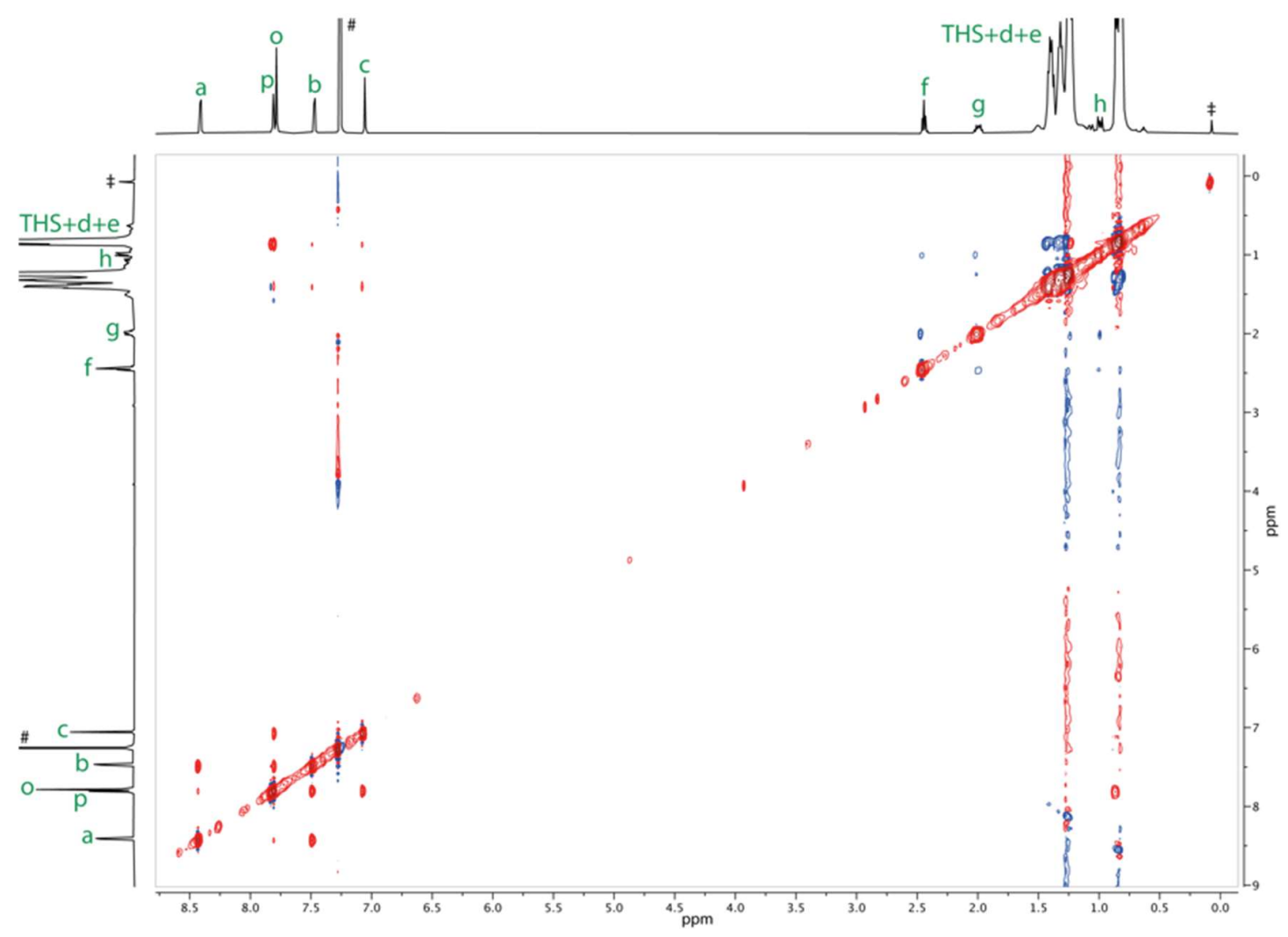

Figure S39. ${ }^{1} \mathrm{H}^{-1} \mathrm{H}$ NOESY spectrum of $\mathbf{S i - I - P 2}\left[\mathbf{f}_{1}\right]-\mathrm{Si}\left(500 \mathrm{MHz}, \mathrm{CDCl}_{3}, 298 \mathrm{~K}\right)$. 


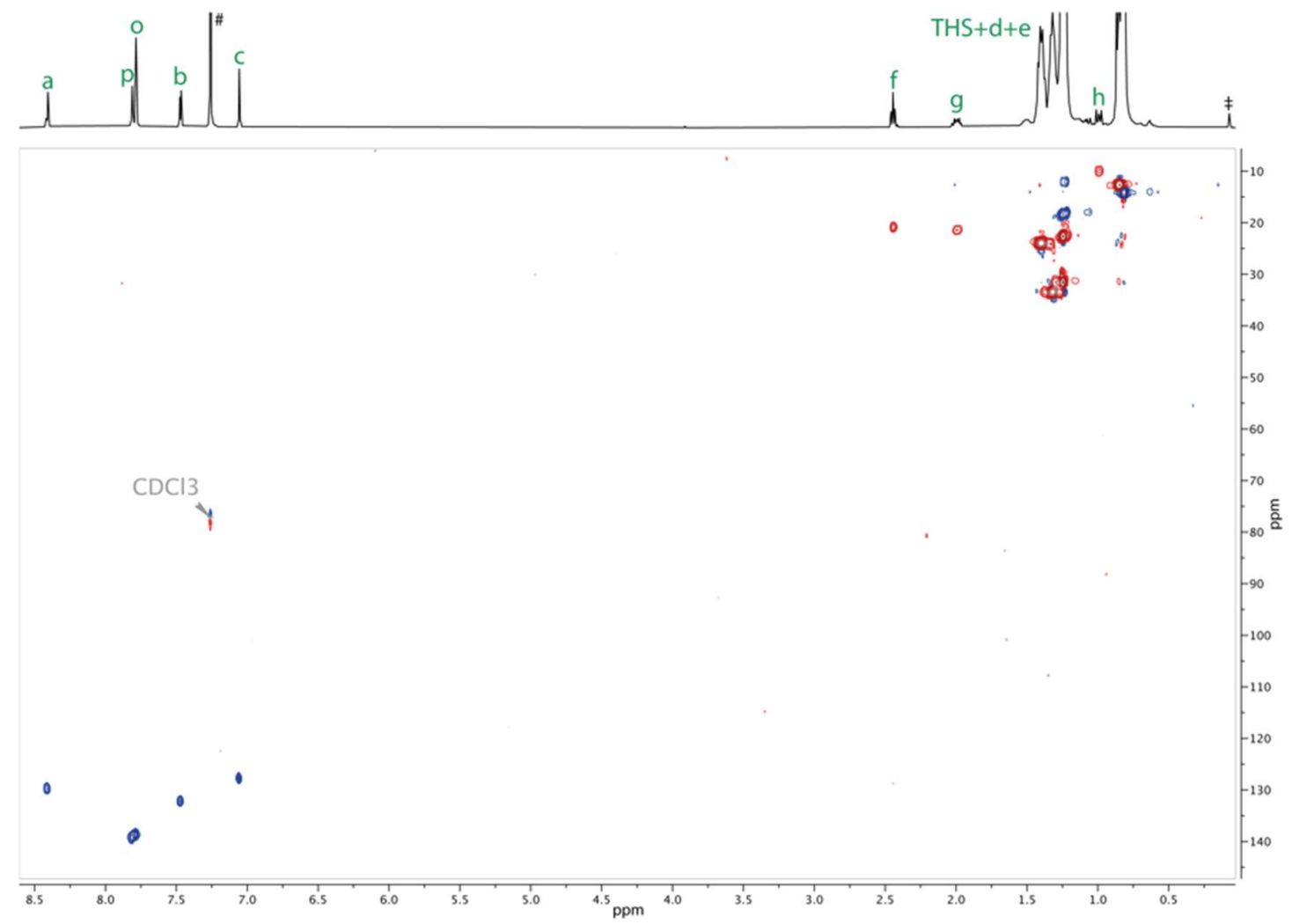

Figure S40. ${ }^{1} \mathrm{H}-{ }^{13} \mathrm{C}$ HSQC spectrum of Si-I-P2[ $\left.\mathrm{f}_{1}\right]-\mathrm{Si}\left(500 \mathrm{MHz}, \mathrm{CDCl}_{3}, 298 \mathrm{~K}\right)$.

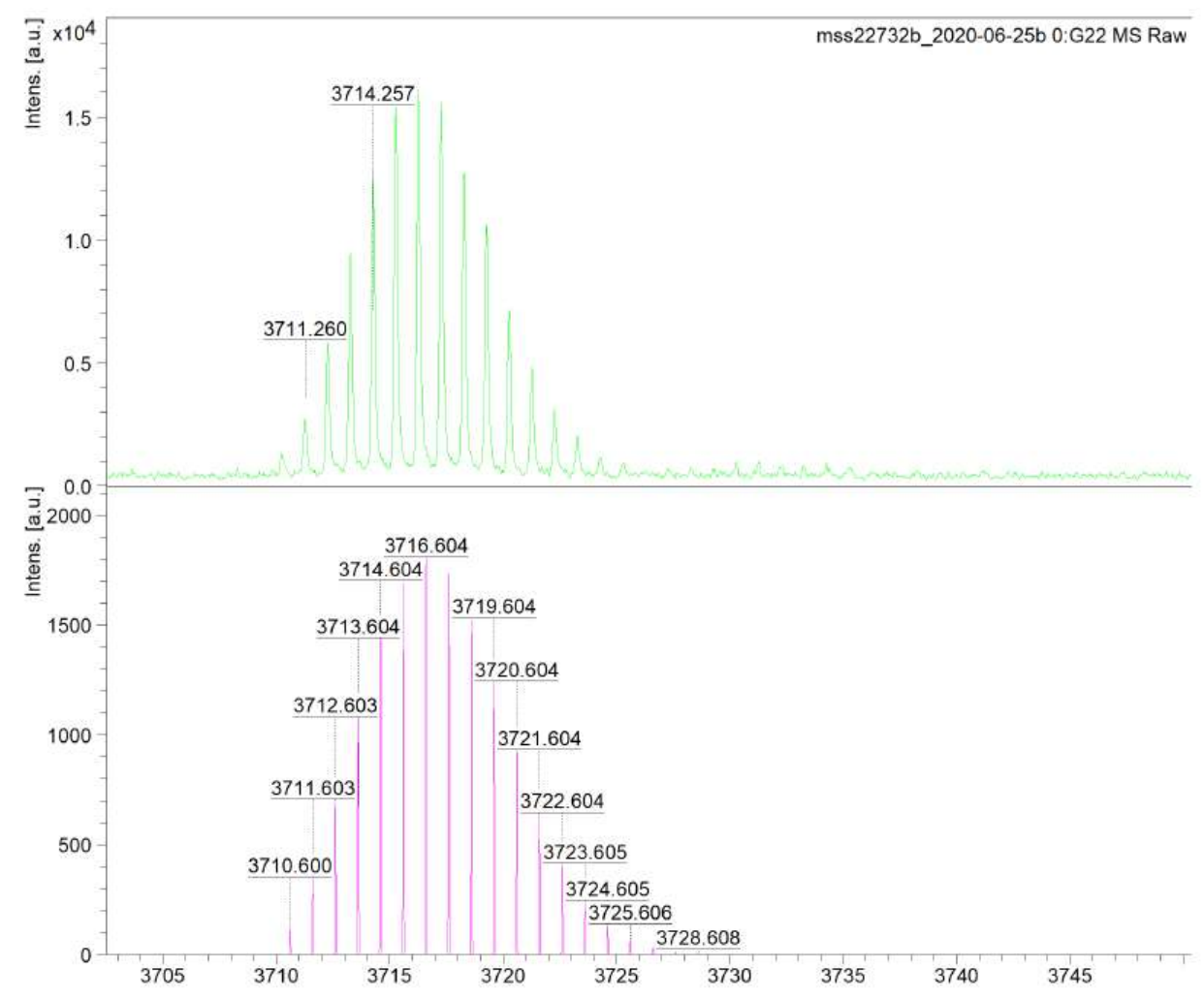

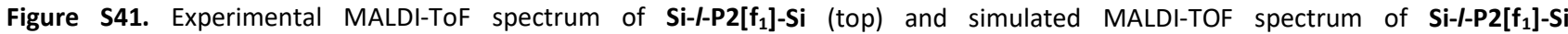
$\left[\mathrm{C}_{232} \mathrm{H}_{376} \mathrm{~N}_{10} \mathrm{Si}_{10} \mathrm{Zn}_{2}\right]^{+}$(bottom). 


\section{$H-I-P 2\left[f_{1}\right]-H:$}
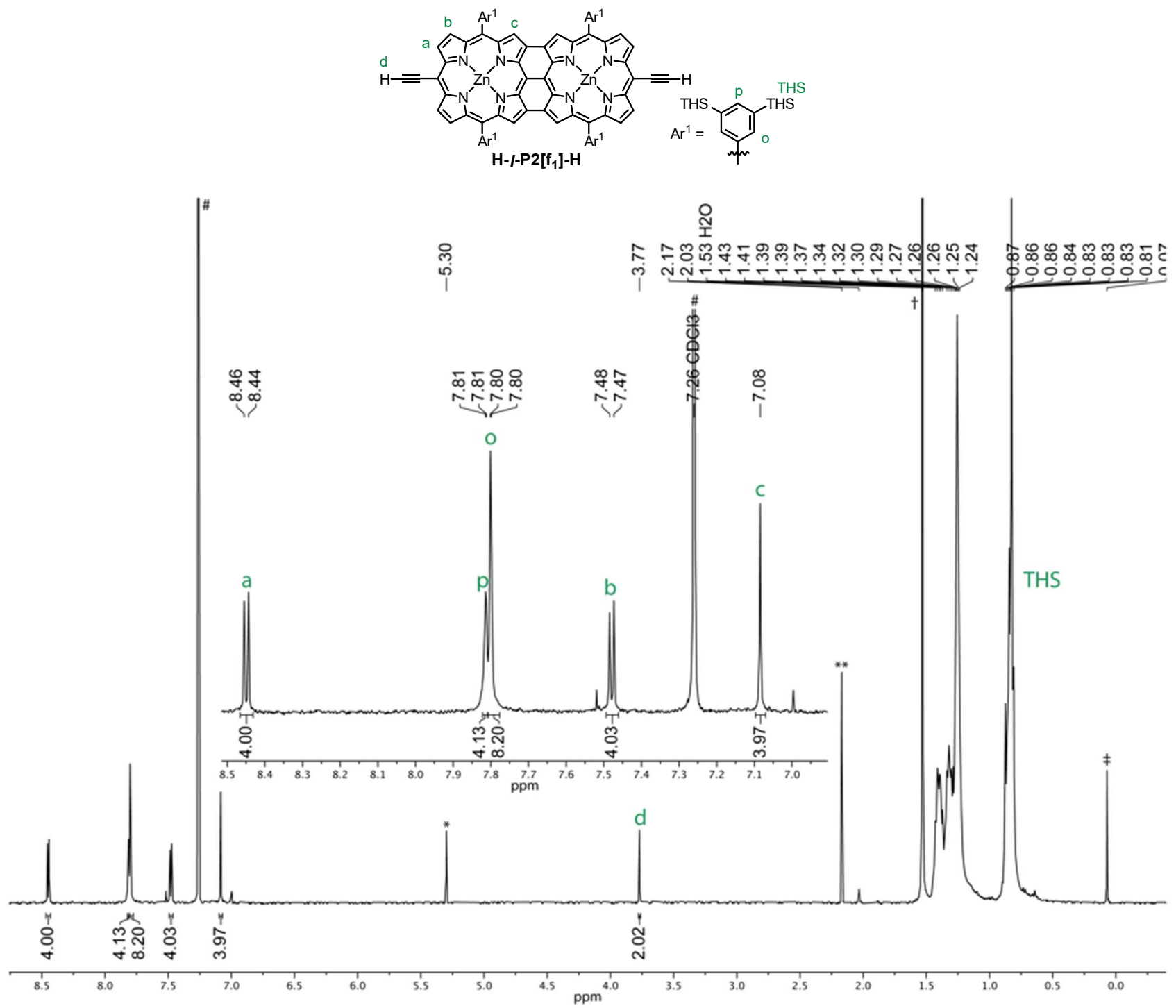

Figure S42. Labelled structure and ${ }^{1} \mathrm{H}$ NMR spectrum of $\mathbf{H}-\mathrm{I}-\mathbf{P 2}\left[\mathrm{f}_{1}\right]-\mathbf{H}\left(400 \mathrm{MHz}, \mathrm{CDCl}_{3}, 298 \mathrm{~K}\right)$. \#= $\mathrm{CHCl}_{3} ;{ }^{*}=\mathrm{CH}_{2} \mathrm{Cl}_{2} ; * *=$ acetone; ${ }^{*}=$ water; $\ddagger$ = silicon grease. 


\section{$\mathrm{Si}-\mathrm{I}-\mathrm{P} 4\left[\mathrm{~b}_{2} \mathrm{f}_{1}\right]-\mathrm{Si}$ :}
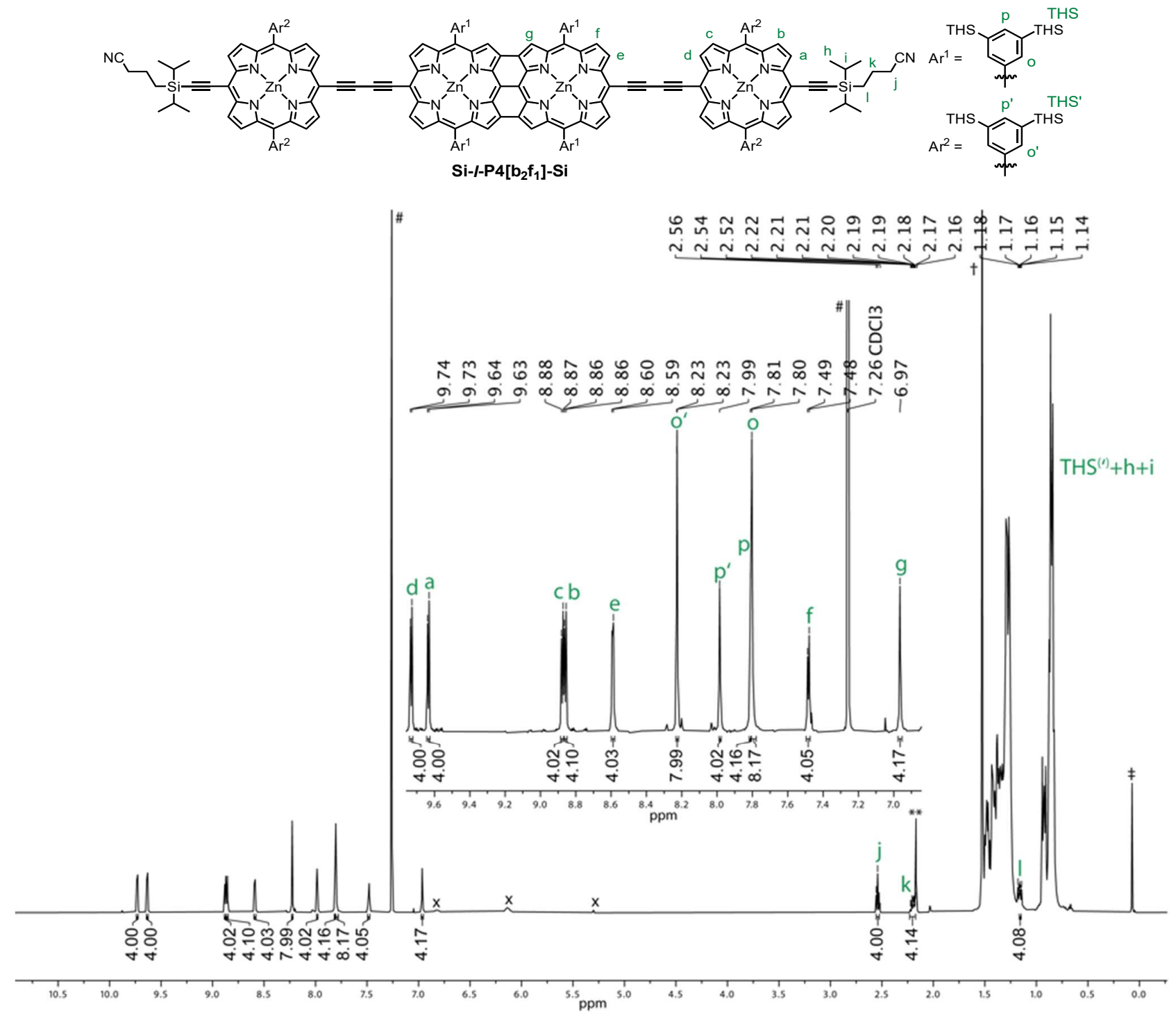

Figure S43. Labelled structure and ${ }^{1} \mathrm{H}$ NMR spectrum of Si-I-P4 $\left[\mathbf{b}_{2} \mathbf{f}_{1}\right]-\mathrm{Si}\left(500 \mathrm{MHz}, \mathrm{CDCl}_{3}, 298 \mathrm{~K}\right) . \#=\mathrm{CHCl}_{3} ; \mathrm{x}=$ pyridine; ${ }^{* *}=$ acetone; $\dagger=$ water; $\ddagger$ = silicon grease. 
Table S14. NMR assignment and correlations for tetramer Si-I-P4[ $\left.\mathbf{b}_{2} \mathbf{f}_{1}\right]-\mathbf{S i}$.

\begin{tabular}{|c|c|c|c|c|c|c|}
\hline$\#$ & Assign. & ${ }^{1} \mathrm{H}$ & $\begin{array}{l}\text { Mult. } \\
J(\mathrm{~Hz})\end{array}$ & $\begin{array}{l}{ }^{1} \mathrm{H}-{ }^{1} \mathrm{H} \\
\mathrm{COSY}\end{array}$ & $\begin{array}{c}{ }^{1} \mathrm{H}-{ }^{1} \mathrm{H} \\
\text { ROESY }^{+}\end{array}$ & ${ }^{1} \mathrm{H}-{ }^{13} \mathrm{CHSQC}+{ }^{13} \mathrm{C}$ \\
\hline 1 & $d$ & $9.73(4 \mathrm{H})$ & $\mathrm{d}, J=4.6$ & 3 & $s: 3 ; w: 5,15$ & 130.89 \\
\hline 2 & a & $9.63(4 \mathrm{H})$ & $\mathrm{d}, J=4.6$ & 4 & s: 4; m: 15 & 130.89 \\
\hline 3 & c & $8.88(4 \mathrm{H})$ & $d, J=4.6$ & 1 & $\mathrm{~s}: 1,6 ; \mathrm{m}: 15$ & 133.30 \\
\hline 4 & $b$ & $8.86(4 \mathrm{H})$ & $\mathrm{d}, J=4.6$ & 2 & $\mathrm{~s}: 2,6 ; \mathrm{m}: 15$ & 133.11 \\
\hline 5 & e & $8.59(4 \mathrm{H})$ & $\mathrm{d}, J=4.5$ & 10 & $\begin{array}{c}\mathrm{s}: 10 ; \mathrm{m}: 15 \\
\text { w: } 1\end{array}$ & 129.43 \\
\hline 6 & $\mathrm{o}^{\prime}$ & $8.23(8 \mathrm{H})$ & $\mathrm{s}$ & 7 & $s: 3,4,15$ & 140.52 \\
\hline 7 & $p^{\prime}$ & $7.99(4 \mathrm{H})$ & s & 6 & s: 15 & 139.31 \\
\hline 8 & $\mathrm{p}$ & $7.81(4 \mathrm{H})$ & s & - & s: 15 & 139.00 \\
\hline 9 & 0 & $7.80(8 \mathrm{H})$ & s & - & $s: 10,11,15$ & 138.79 \\
\hline 10 & $f$ & $7.48(4 \mathrm{H})$ & $\mathrm{d}, J=4.5$ & 5 & s: 5, 9; w: 15 & 132.32 \\
\hline 11 & $\mathrm{~g}$ & $6.96(4 \mathrm{H})$ & $s$ & - & s: 9,15 & 127.67 \\
\hline 12 & j & $2.54(4 \mathrm{H})$ & $\mathrm{t}, J=6.82$ & 13 & w: 13,14 & 21.19 \\
\hline 13 & $\mathrm{k}$ & $2.23-2.16(4 \mathrm{H})$ & $\mathrm{m}$ & 12,14 & w: $12,14,15$ & 21.77 \\
\hline 14 & 1 & $1.19-1.14(4 \mathrm{H})$ & $\mathrm{m}$ & 13 & $w: 12,13,15$ & 10.30 \\
\hline 15 & $T H S+T H S^{\prime}+h+i$ & $1.55-0.64(652 \mathrm{H})$ & $\mathrm{m}$ & 15 & $\begin{array}{c}\mathrm{s}: 6,7,8,9 \\
11 ; \mathrm{m}: 2,3,4 \\
5,10 ; \mathrm{w}: 1 \\
13,14\end{array}$ & $\begin{array}{c}12.46,12.58,12.77,12.79,14.30, \\
18.50,18.76,22.79,22.82,24.14, \\
24.17,29.86,31.71,31.75,33.63, \\
33.66\end{array}$ \\
\hline
\end{tabular}

${ }^{\dagger}$ Relative correlation intensities are designated as: $\mathrm{s}=$ strong, $\mathrm{m}=$ medium, $\mathrm{w}=$ weak.

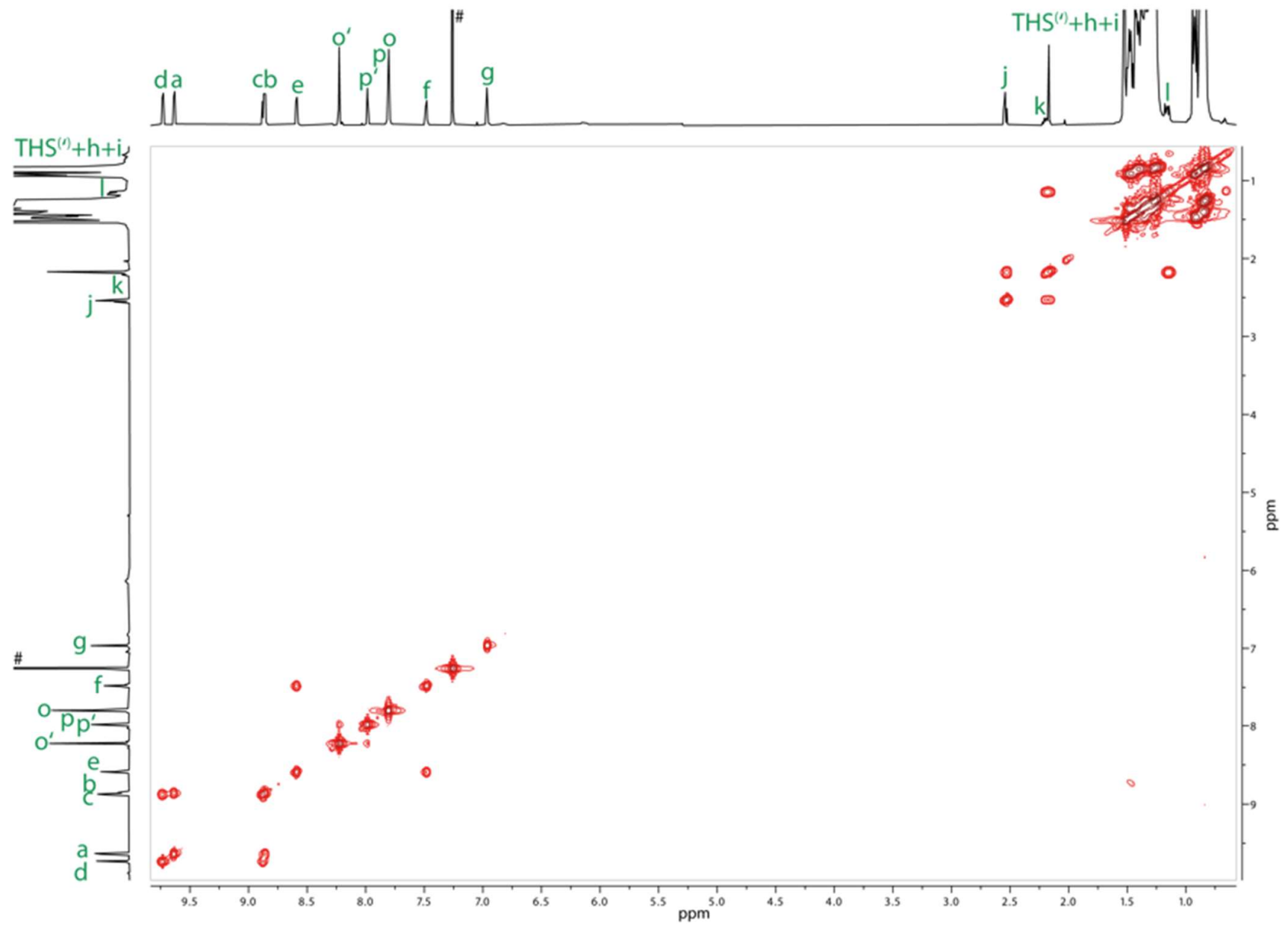

Figure S44. ${ }^{1} \mathrm{H}-{ }^{1} \mathrm{H}$ COSY spectrum of Si-I-P4 $\left[\mathbf{b}_{2} \mathbf{f}_{1}\right]-\mathbf{S i}\left(500 \mathrm{MHz}, \mathrm{CDCl}_{3}, 298 \mathrm{~K}\right)$. 


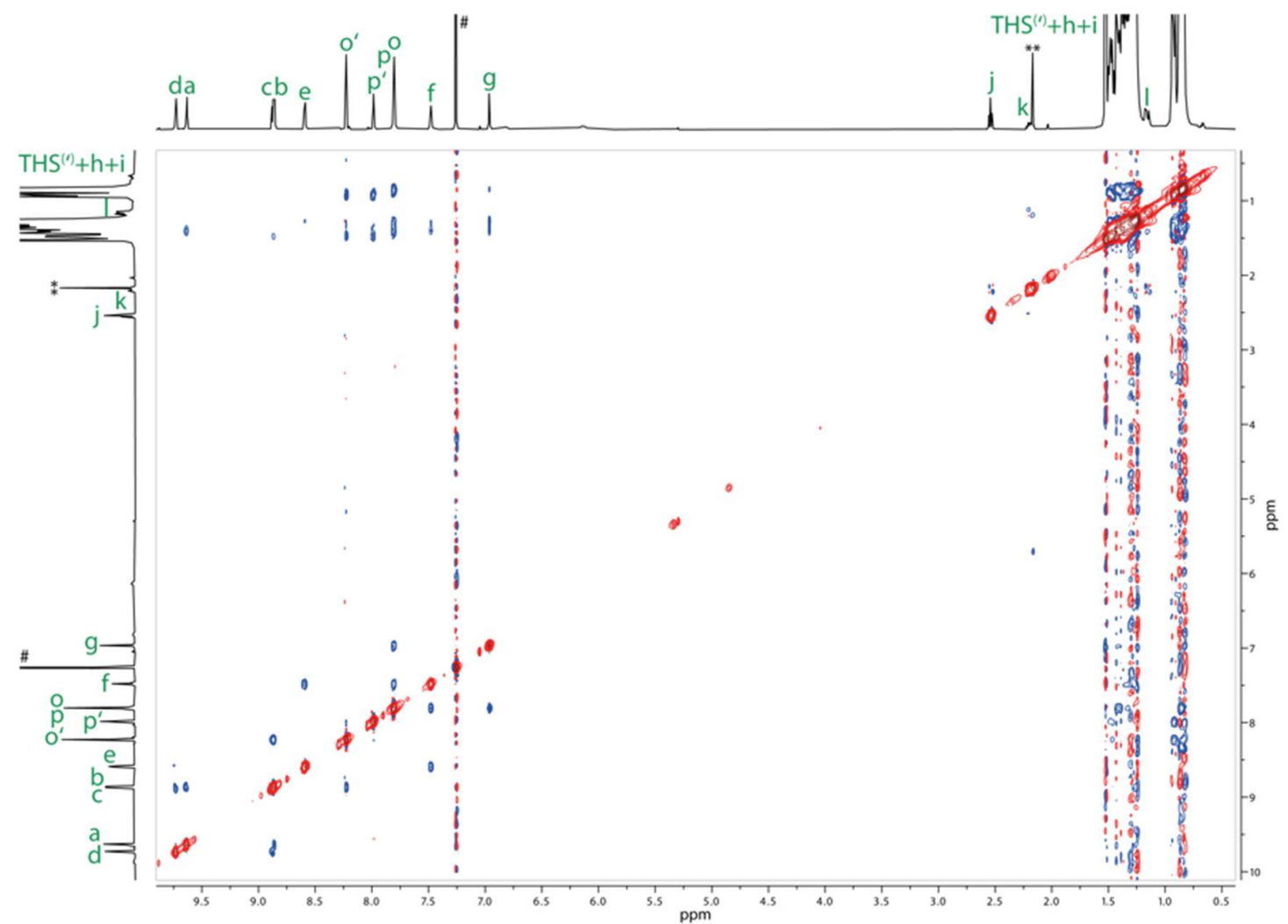

Figure S45. ${ }^{1} \mathrm{H}-{ }^{1} \mathrm{H}$ ROESY spectrum of Si-I-P4[ $\left[\mathbf{b}_{2} \mathbf{f}_{1}\right]-\mathrm{Si}\left(500 \mathrm{MHz}, \mathrm{CDCl}_{3}, 298 \mathrm{~K}\right)$.

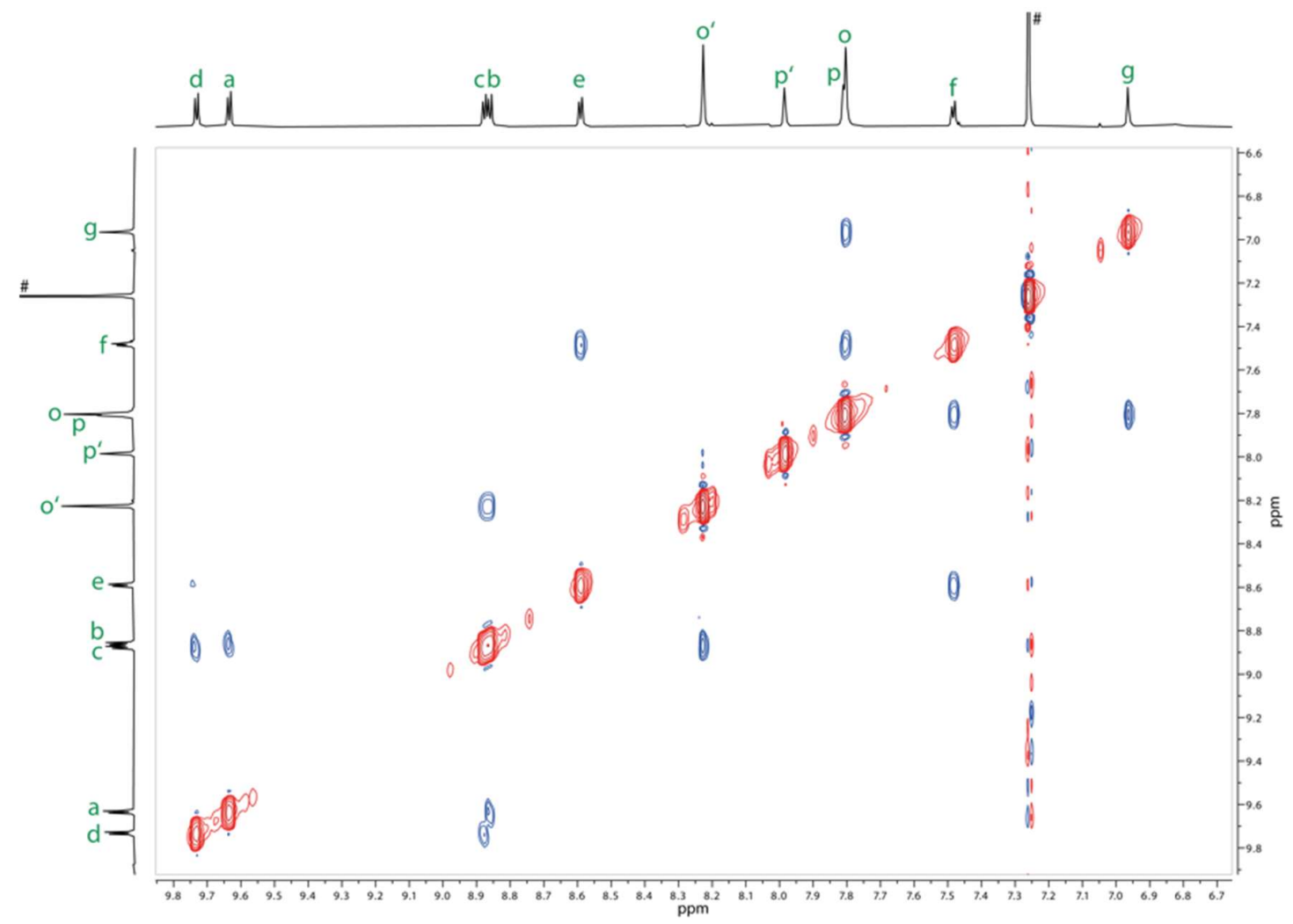

Figure S46. Enlarged region of the ROESY spectrum of $\mathbf{S i - I - P 4}\left[\mathbf{b}_{2} \mathbf{f}_{\mathbf{1}}\right]-\mathbf{S i}\left(500 \mathrm{MHz}, \mathrm{CDCl}_{3}, 298 \mathrm{~K}\right)$. 


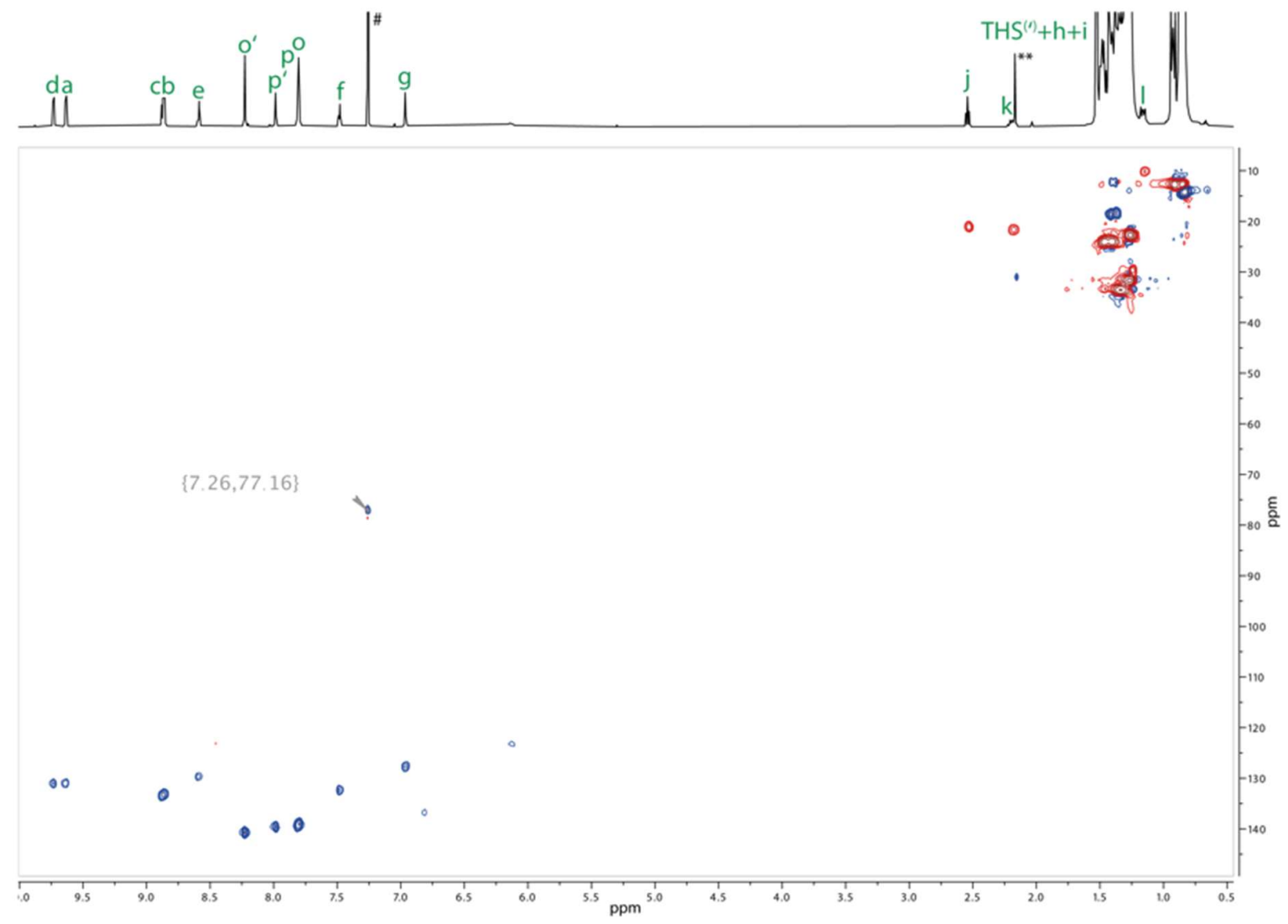

Figure S47. ${ }^{1} \mathrm{H}^{-13} \mathrm{C} \mathrm{HSQC}$ spectrum of Si-I-P4[ $\left.\mathbf{b}_{2} \mathbf{f}_{1}\right]-\mathrm{Si}\left(500 \mathrm{MHz}, \mathrm{CDCl}_{3}, 298 \mathrm{~K}\right)$.

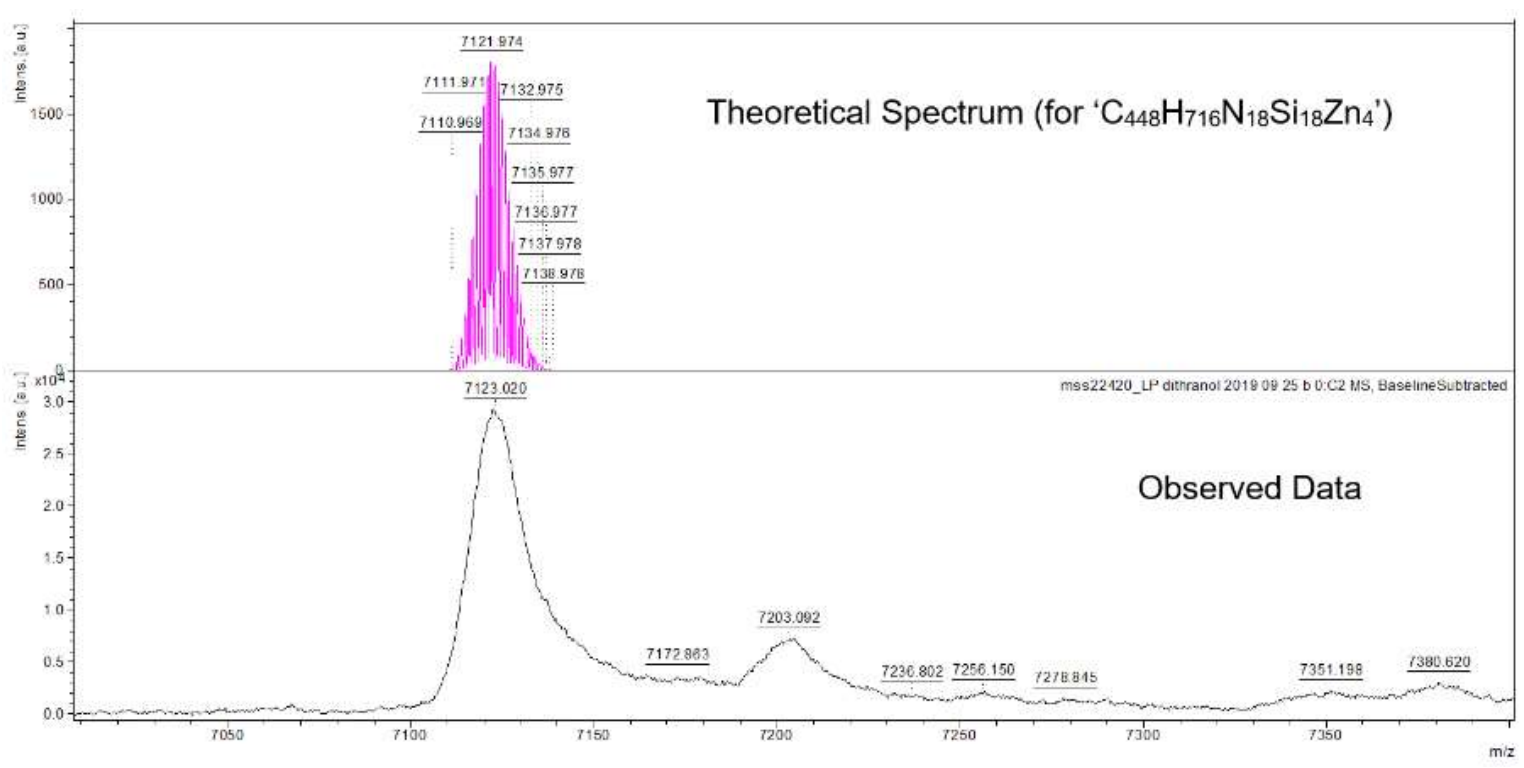

Figure S48. Experimental MALDI-ToF spectrum of Si-I-P4 $\left[\mathbf{b}_{2} \mathbf{f}_{\mathbf{1}}\right]-\mathbf{S i}$ (bottom) and simulated MALDI-TOF spectrum of $\mathbf{S i - I - P 4}\left[\mathbf{b}_{2} \mathbf{f}_{1}\right]-\mathbf{S i}^{+}$ $\left[\mathrm{C}_{448} \mathrm{H}_{716} \mathrm{~N}_{18} \mathrm{Si}_{18} \mathrm{Zn}_{4}\right]^{+}$(top). 
$H-I-P 4\left[b_{2} f_{1}\right]-H:$
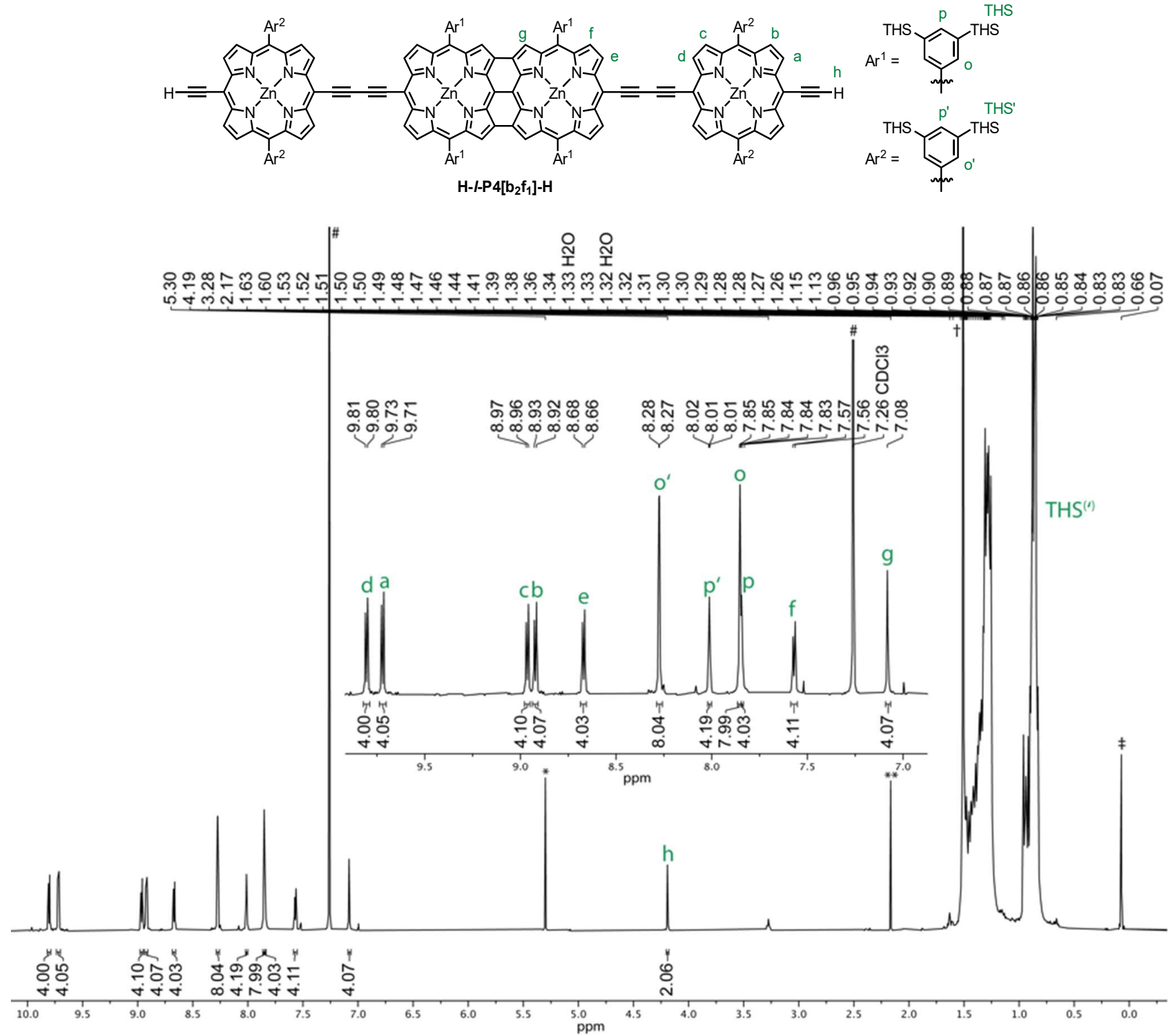

Figure S49. Labelled structure and ${ }^{1} \mathrm{H}$ NMR spectrum of $\mathbf{H}-\mathbf{I}-\mathbf{P} 4\left[\mathbf{b}_{2} \mathbf{f}_{1}\right]-\mathbf{H}\left(400 \mathrm{MHz}, \mathrm{CDCl}_{3}, 298 \mathrm{~K}\right) . \#=\mathrm{CHCl}_{3} ; *=\mathrm{CH}_{2} \mathrm{Cl}_{2} ; * *=\mathrm{acetone}^{*}+=$ water; $¥=$ silicon grease. 

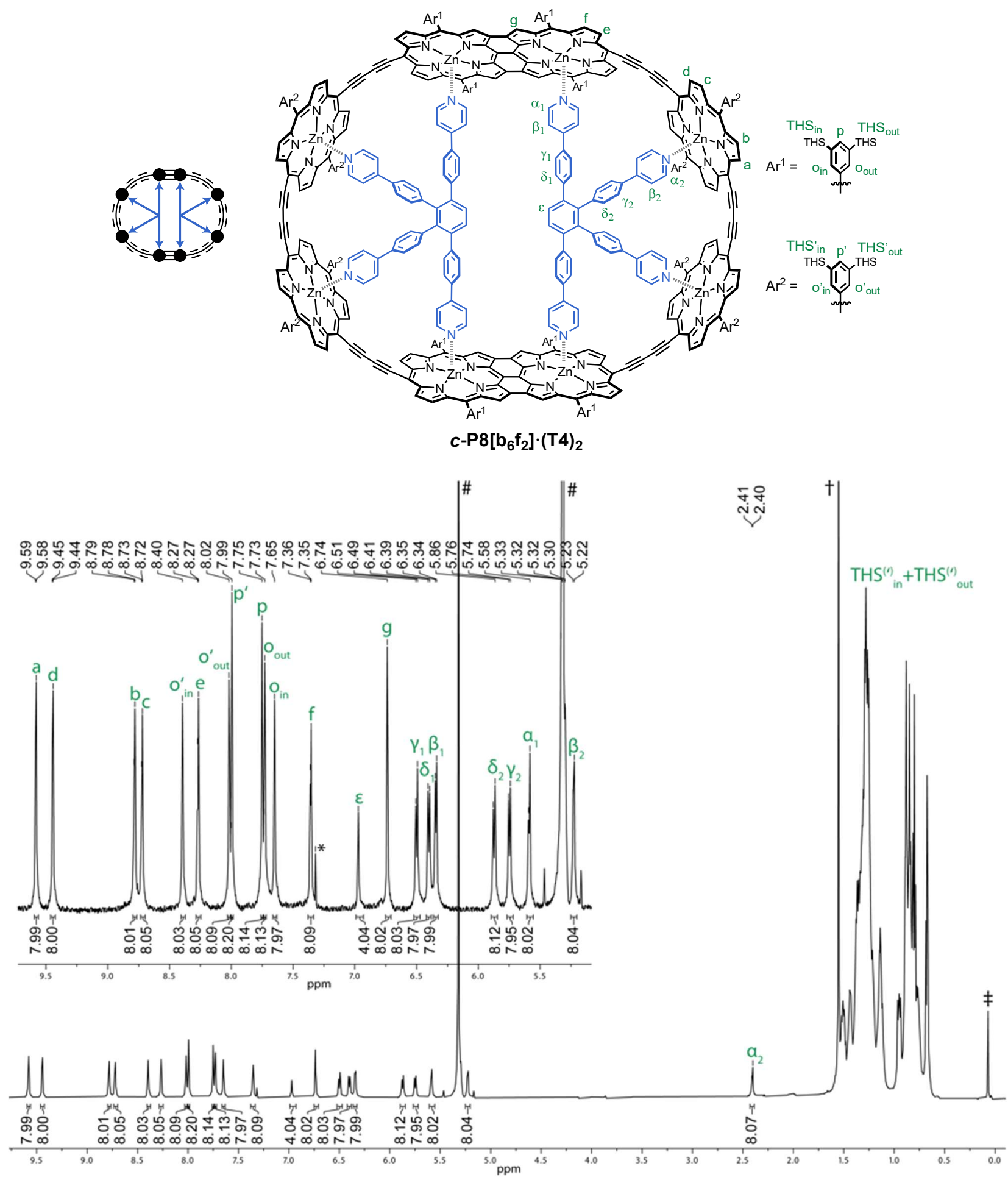

Figure S50. Assigned structure and ${ }^{1} \mathrm{H}$ NMR spectrum of $c-\mathbf{P} 8\left[\mathbf{b}_{6} \mathrm{f}_{2}\right] \bullet(\mathrm{T} 4)_{2}\left(600 \mathrm{MHz}, \mathrm{CD}_{2} \mathrm{Cl}_{2}, 298 \mathrm{~K}\right) . \#=\mathrm{CHDCl}_{2} ;{ }^{*}=\mathrm{CHCl}_{3} ; \dagger=$ water; $\neq=$ silicon grease. 
Table S15. Complete ${ }^{1} \mathrm{H}$ NMR assignment and correlations for complex $c-P 8\left[b_{b} f_{2}\right] \bullet(T 4)_{2}$.

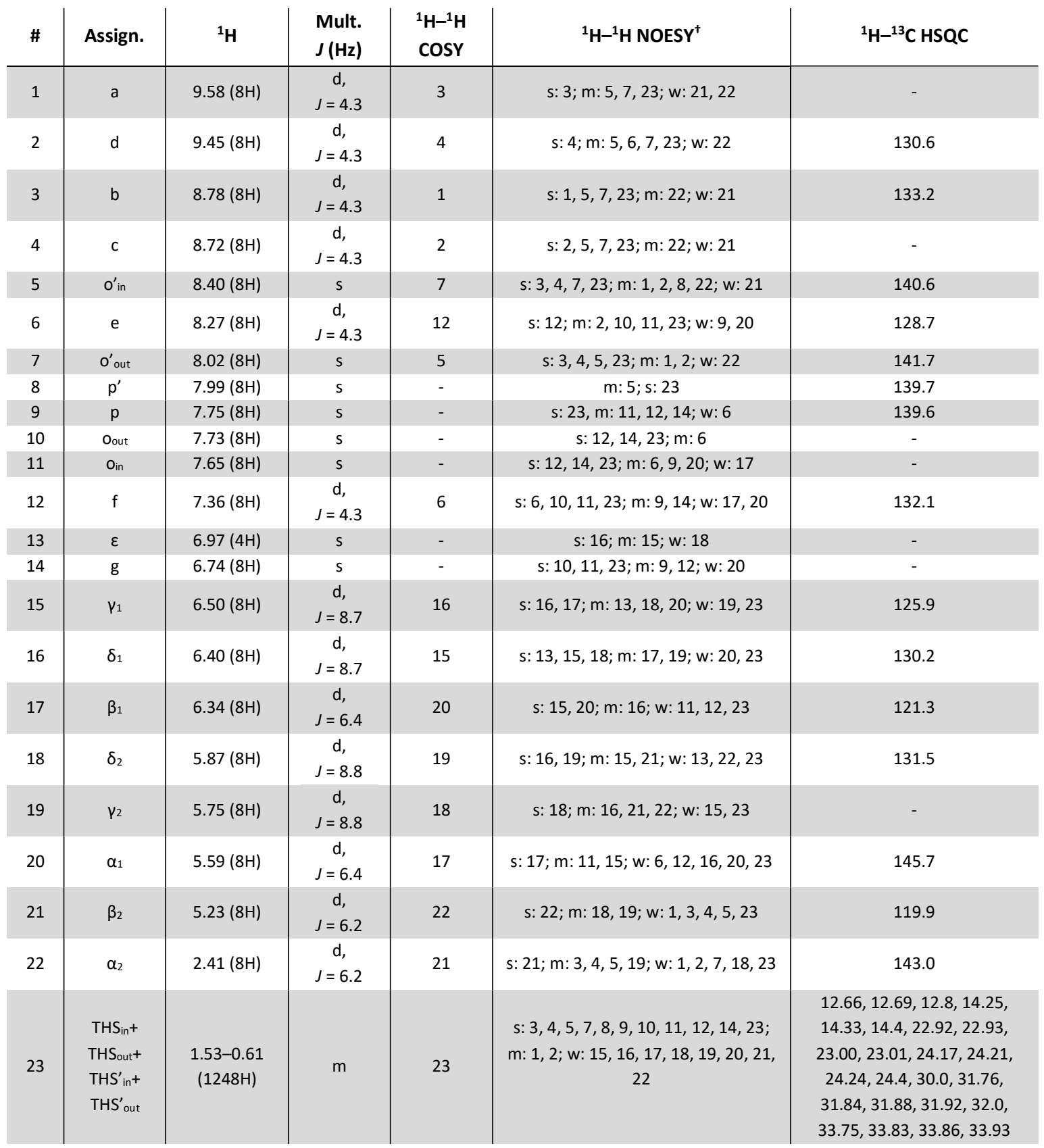

${ }^{\dagger}$ Relative correlation intensities are designated as: $\mathrm{s}=$ strong, $\mathrm{m}=$ medium, $\mathrm{w}=$ weak. 


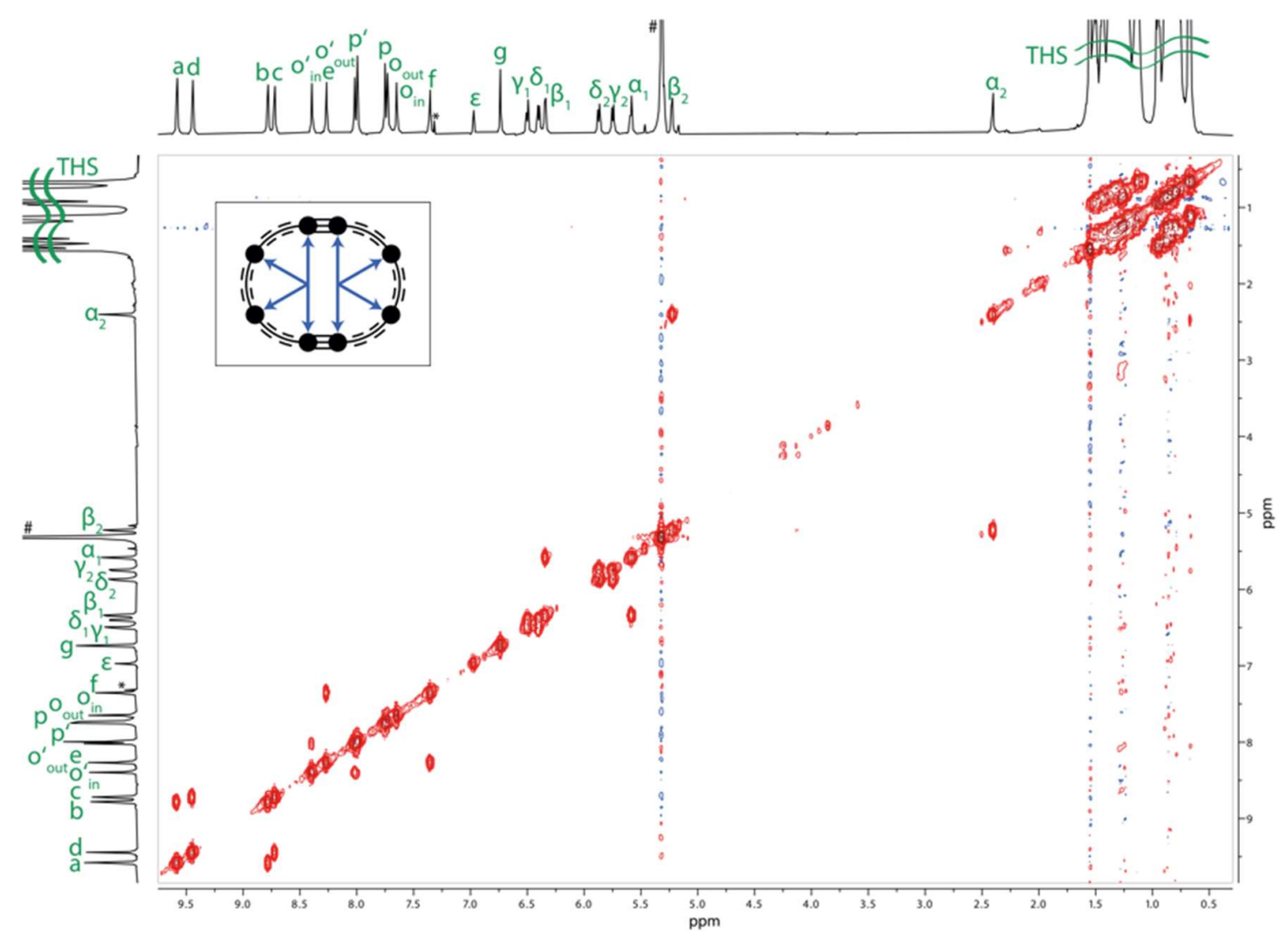

Figure S51. ${ }^{1} \mathrm{H}-{ }^{1} \mathrm{H}$ COSY spectrum of $c-\mathbf{P} 8\left[\mathbf{b}_{6} \mathbf{f}_{2}\right] \bullet(T 4)_{2}\left(600 \mathrm{MHz}, \mathrm{CD}_{2} \mathrm{Cl}_{2}, 298 \mathrm{~K}\right)$.

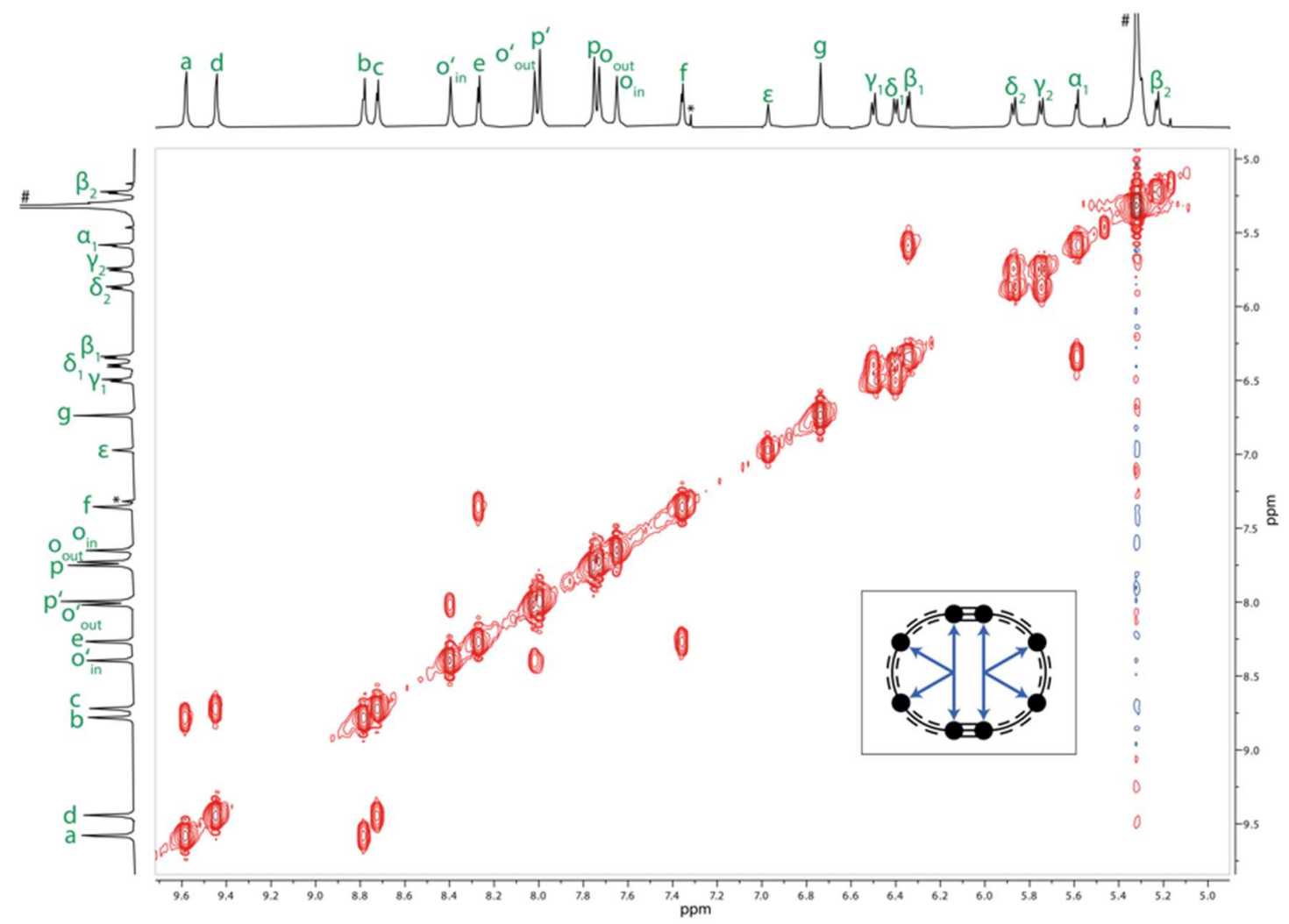

Figure S52. Enlarged region of the COSY spectrum of $\boldsymbol{c}-\mathbf{P 8}\left[\mathbf{b}_{6} \mathbf{f}_{2}\right] \bullet(T 4)_{2}\left(600 \mathrm{MHz}, \mathrm{CD}_{2} \mathrm{Cl}_{2}, 298 \mathrm{~K}\right)$. 


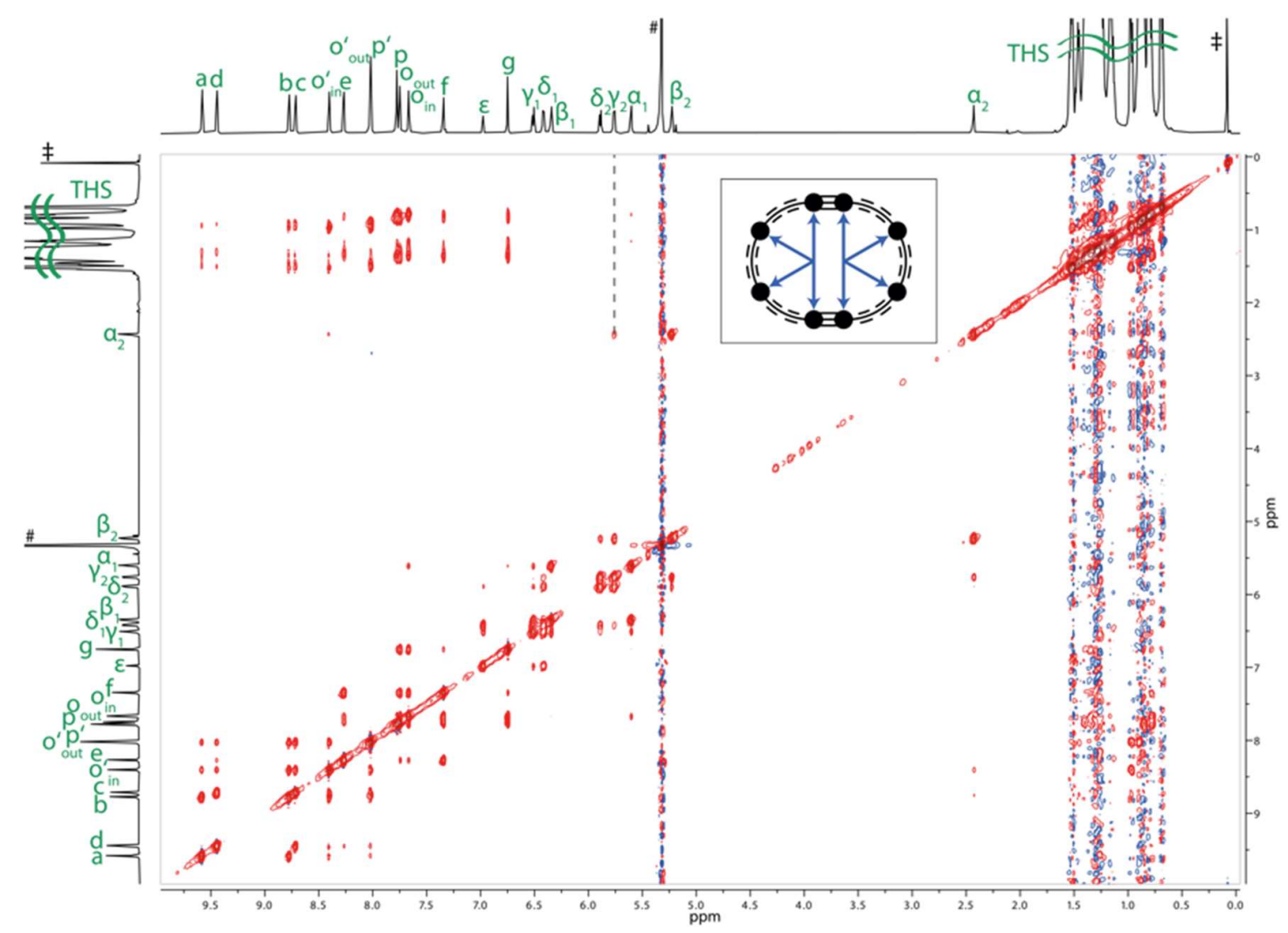

Figure S53. ${ }^{1} \mathrm{H}-{ }^{1} \mathrm{H}$ NOESY spectrum of $c-\mathrm{P} 8\left[\mathbf{b}_{6} \mathbf{f}_{2}\right] \bullet(\mathrm{T} 4)_{2}\left(600 \mathrm{MHz}, \mathrm{CD}_{2} \mathrm{Cl}_{2}, 298 \mathrm{~K}\right)$.

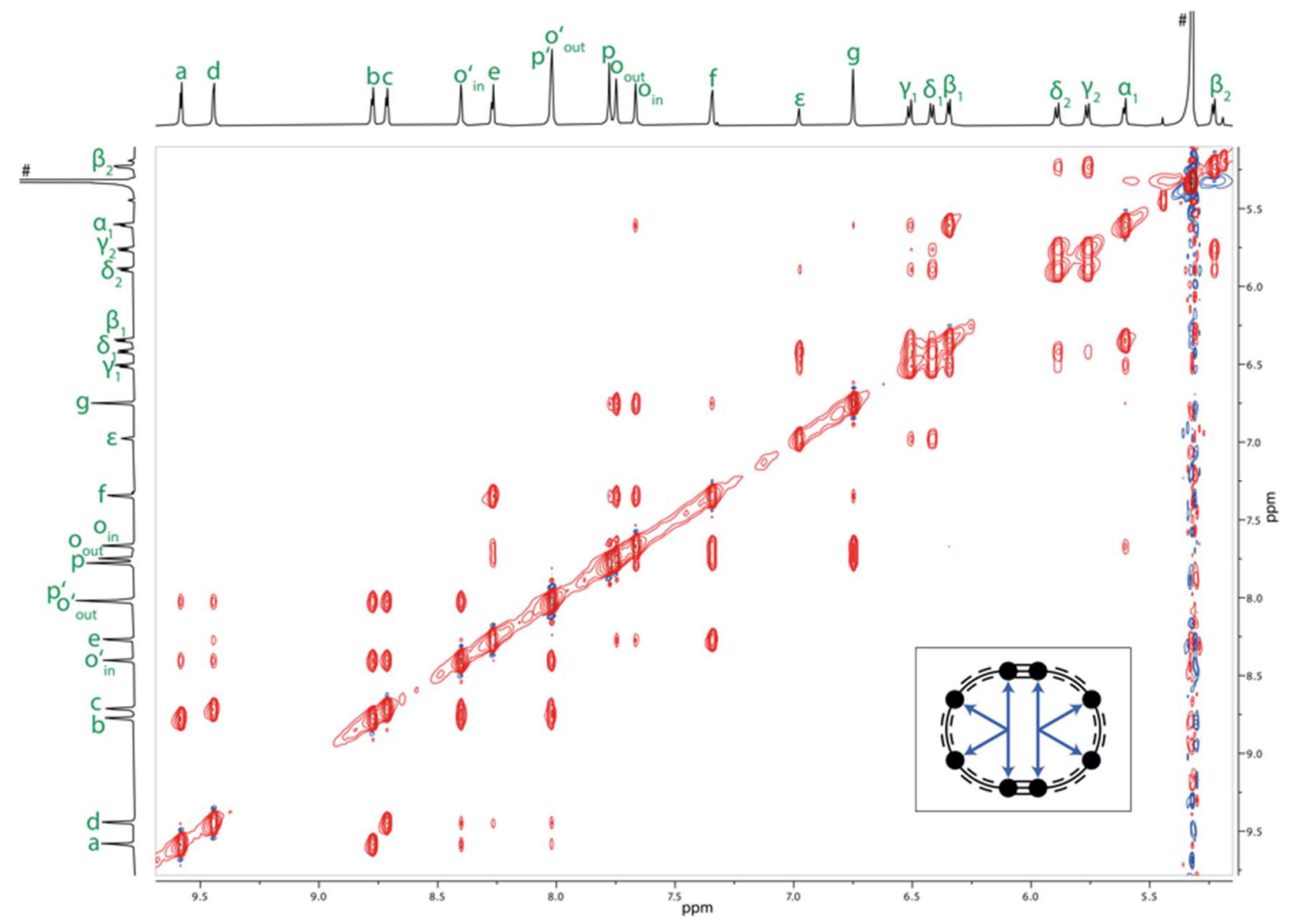

Figure S54. Enlarged region of the NOESY spectrum of $c-\mathbf{P 8}\left[\mathbf{b}_{6} \mathbf{f}_{2}\right] \bullet(T 4)_{2}\left(600 \mathrm{MHz}, \mathrm{CD}_{2} \mathrm{Cl}_{2}, 298 \mathrm{~K}\right)$. 


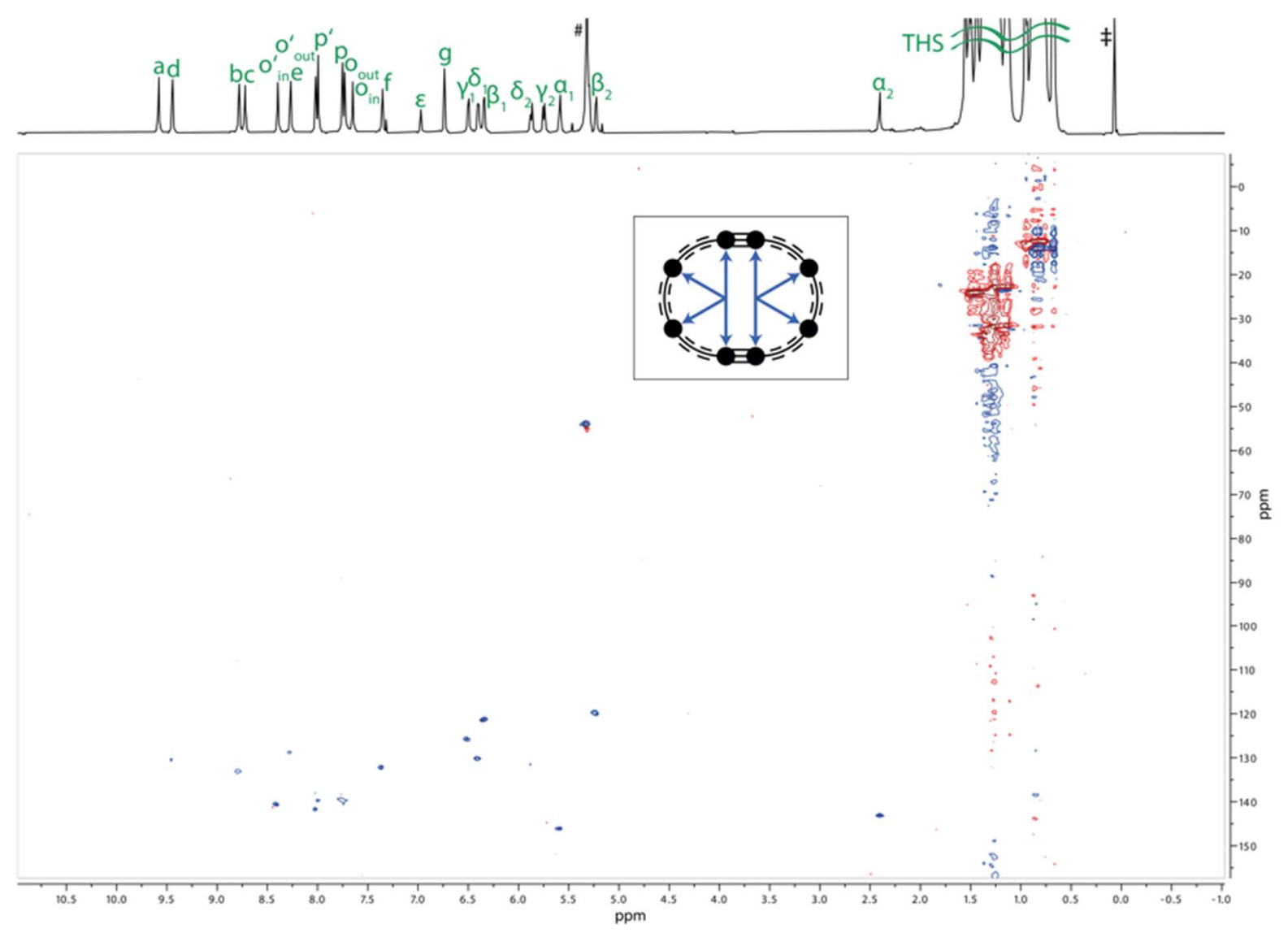

Figure S55. ${ }^{1} \mathrm{H}^{-13} \mathrm{C}$ HSQC spectrum of $\boldsymbol{c}-\mathbf{P} 8\left[\mathbf{b}_{6} \mathrm{f}_{2}\right] \bullet(\mathrm{T} 4)_{2}\left(600 \mathrm{MHz}, \mathrm{CD}_{2} \mathrm{Cl}_{2}, 298 \mathrm{~K}\right)$.

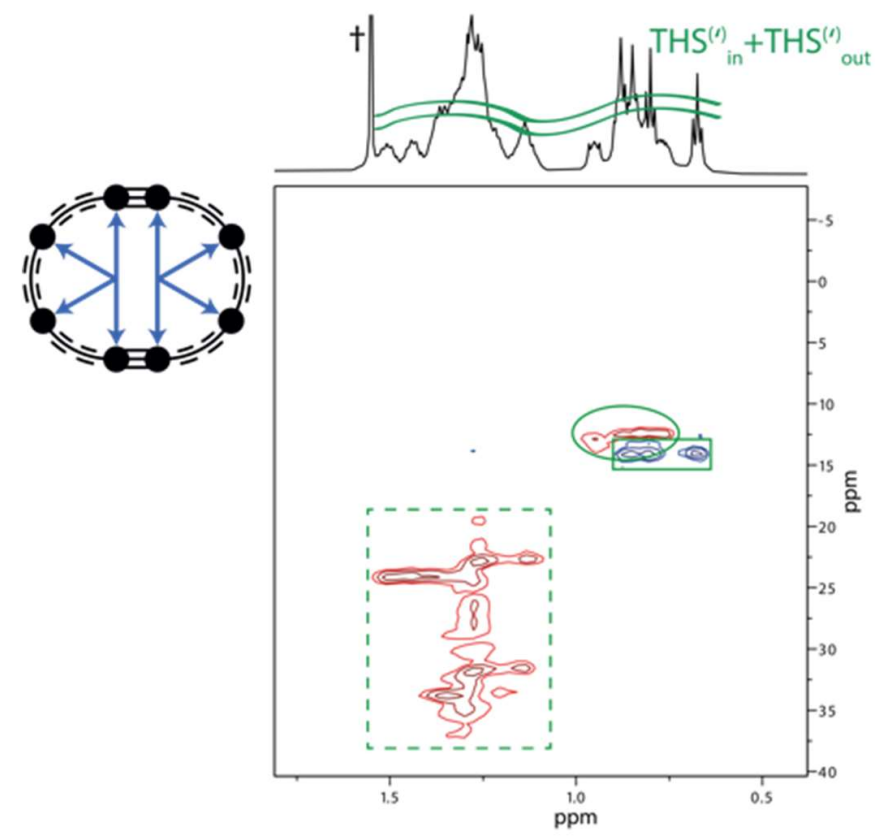

Figure S56. THS region of the ${ }^{1} \mathrm{H}-{ }^{13} \mathrm{C}$ HSQC spectrum of $c-\mathbf{P} 8\left[\mathbf{b}_{6} \mathbf{f}_{2}\right] \bullet\left(\mathrm{T}_{4}\right)_{2}\left(600 \mathrm{MHz}, \mathrm{CD}_{2} \mathrm{Cl}_{2}, 298 \mathrm{~K}\right)$. Si-R- $\mathrm{CH}_{3}$ resonances are indicated with a solid box, $\mathrm{Si}-\mathrm{CH}_{2}-\mathrm{R}$ resonances with a solid circle, and $\mathrm{Si}-\mathrm{CH}_{2}-\mathrm{C}_{4} \mathrm{H}_{8}-\mathrm{CH}_{3}$ resonances with a dashed box. 


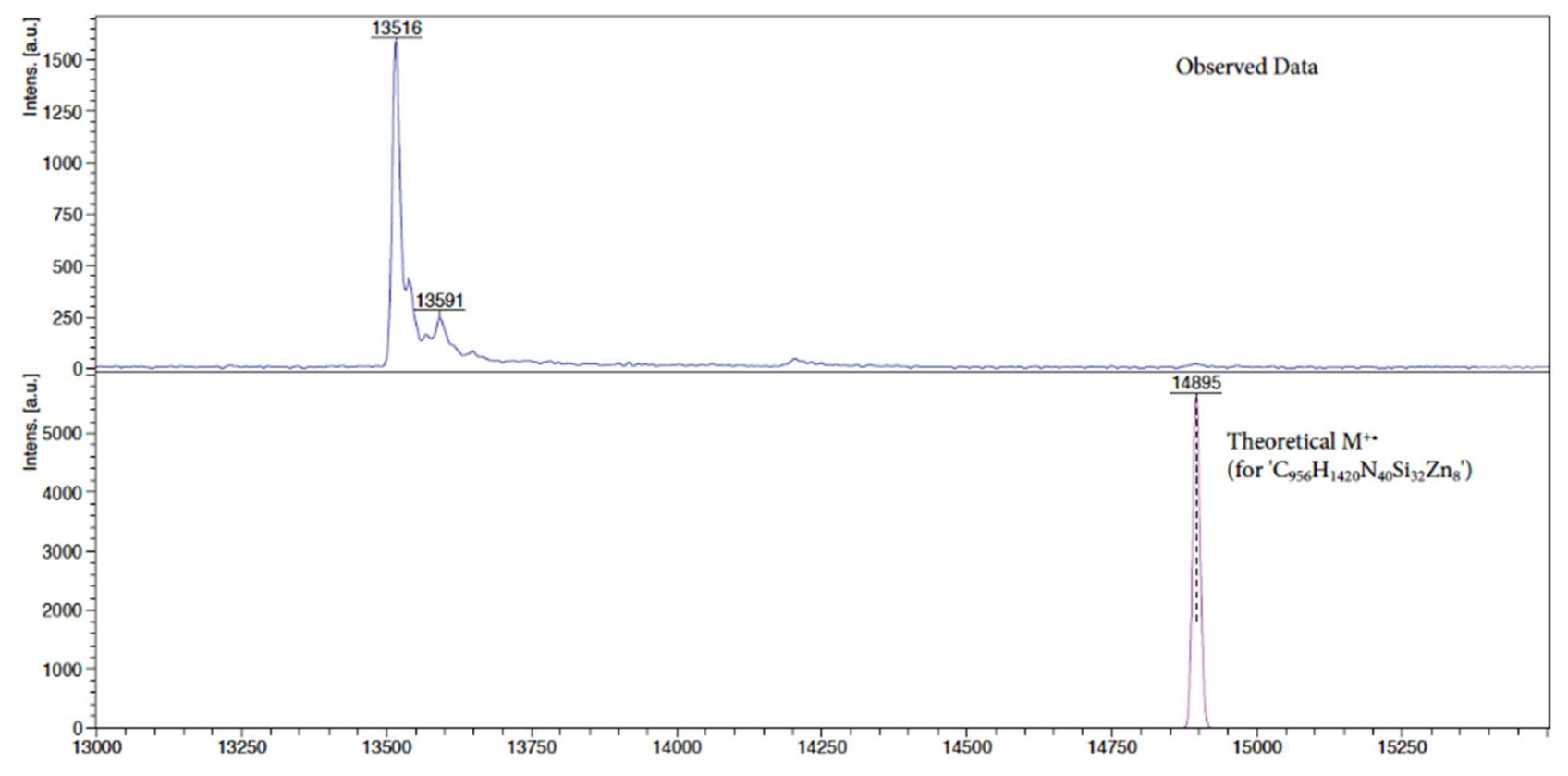

Figure S57. Experimental MALDI-ToF spectrum of $c-P 8\left[b_{6} f_{2}\right] \bullet(T 4)_{2}$ (top) and simulated MALDI-TOF spectrum of $c-P 8\left[b_{6} f_{2}\right] \bullet(T 4)_{2}{ }^{+}$ $\left[\mathrm{C}_{956} \mathrm{H}_{1420} \mathrm{~N}_{40} \mathrm{Si}_{32} \mathrm{Zn}_{8}\right]^{+}$(bottom). ${ }^{\dagger}$ and $\ddagger$ indicate residual signals of $\boldsymbol{c}-\mathbf{P 8}\left[\mathbf{b}_{6} \mathbf{f}_{2}\right] \bullet(\mathbf{T 4})_{2}{ }^{+}$and $\boldsymbol{c}-\mathbf{P 8}\left[\mathbf{b}_{6} \mathbf{f}_{2}\right] \bullet(\mathbf{T} 4)^{+}$before and after onefold fragmentation, respectively.

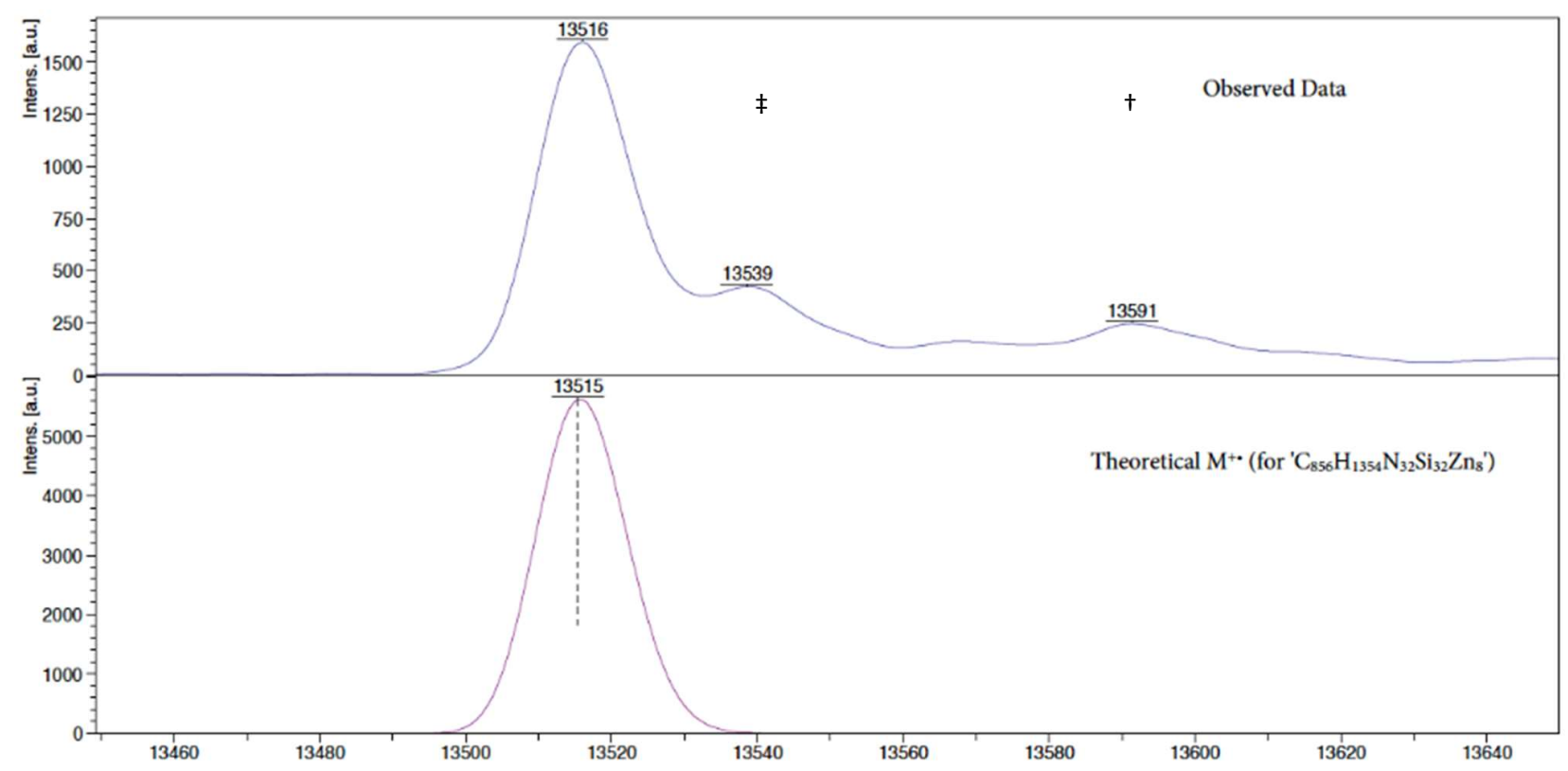

Figure S58. Enlarged region of the experimental MALDI-ToF spectrum of $\boldsymbol{c}-\mathbf{P 8}\left[\mathbf{b}_{6} \mathbf{f}_{\mathbf{2}}\right]_{\bullet}(\mathbf{T} 4)_{2}\left(\right.$ top) and simulated spectrum of $\boldsymbol{c}-\mathbf{P 8}\left[\mathbf{b}_{6} \mathrm{f}_{2}\right]+\mathbf{2} \mathrm{H}^{+}$ $\left[\mathrm{C}_{856} \mathrm{H}_{1352} \mathrm{~N}_{32} \mathrm{Si}_{32} \mathrm{Zn}_{8}+2 \mathrm{H}\right]^{+}$(bottom). 
$H-I-P 8\left[b_{5} f_{2}\right]-H:$
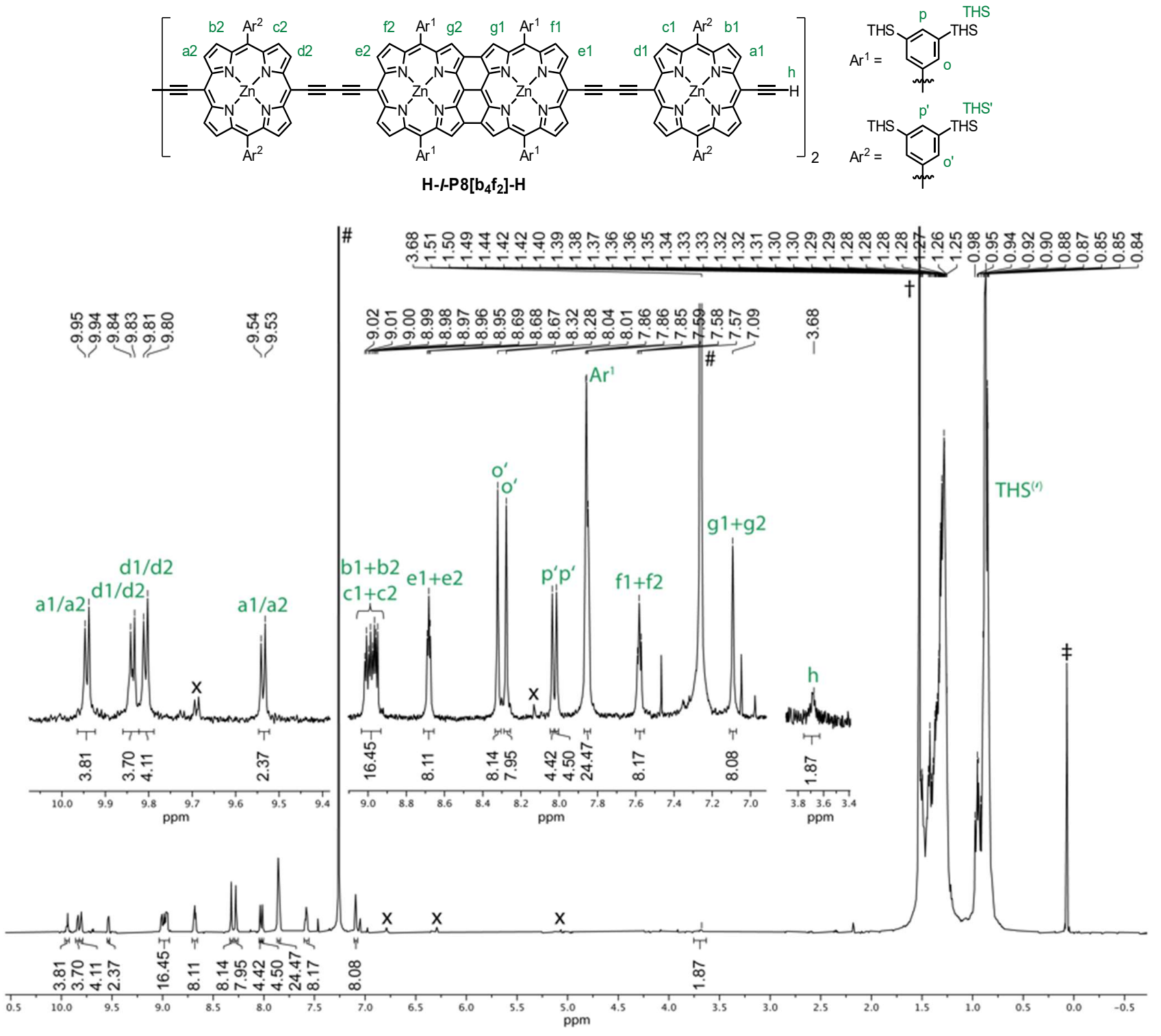

Figure S59. Assigned structure and ${ }^{1} \mathrm{H}$ NMR spectrum of $\mathbf{H}-\mathbf{I}-\mathbf{P} 8\left[\mathbf{b}_{5} \mathbf{f}_{2}\right]-\mathbf{H}\left(500 \mathrm{MHz}, \mathrm{CDCl}_{3}, 298 \mathrm{~K}\right) . \#=\mathrm{CHCl}_{3} ; \dagger=$ water; $\neq=$ silicon grease; $\mathrm{x}$ $=$ decomposition products. 
Table S16. Complete ${ }^{1} \mathbf{H}$ NMR assignment and correlations for complex $\mathbf{H}-\mathbf{I}-\mathbf{P} 8\left[\mathbf{b}_{5} \mathbf{f}_{2}\right]-\mathbf{H}$.

\begin{tabular}{|c|c|c|c|c|c|}
\hline$\#$ & Assign. & ${ }^{1} \mathbf{H}$ & $\begin{array}{l}\text { Mult. } \\
J(H z)\end{array}$ & ${ }^{1} \mathrm{H}-{ }^{1} \mathrm{H} \cos Y$ & ${ }^{1} \mathrm{H}-{ }^{1} \mathrm{H}$ NOESY ${ }^{+}$ \\
\hline 1 & $\mathrm{a} 1 / \mathrm{a} 2$ & $9.94(4 \mathrm{H})$ & $\mathrm{d}, J=4.6$ & 5 & s: 5; m: 10; w:18 \\
\hline 2 & $\mathrm{~d} 1 / \mathrm{d} 2$ & $9.85-9.82(4 \mathrm{H})$ & $\mathrm{m}$ & 6 & s:6; m: 11; w: 9 \\
\hline 3 & $\mathrm{~d} 1 / \mathrm{d} 2$ & $9.81(4 \mathrm{H})$ & $d, J=4.5$ & 7 & s: $7 ; m: 10 ; w: 9,18$ \\
\hline 4 & a1/a2 & $9.54(4 \mathrm{H})$ & $\mathrm{d}, J=4.6$ & 8 & s: 8; w: 11 \\
\hline 5 & $\mathrm{~b} 1 / \mathrm{b} 2$ & $9.01(4 \mathrm{H})$ & $\mathrm{d}, J=4.6$ & 1 & $\mathrm{~s}: 1,10,11 ; \mathrm{m}: 18$ \\
\hline 6 & $\mathrm{c} 1 / \mathrm{c} 2$ & $8.99(4 \mathrm{H})$ & $\mathrm{d}, J=4.5$ & 2 & $\mathrm{~s}: 2,10,11 ; \mathrm{m}: 18$ \\
\hline 7 & $\mathrm{c} 1 / \mathrm{c} 2$ & $8.97(4 \mathrm{H})$ & $\mathrm{d}, J=4.5$ & 3 & $\mathrm{~s}: 3,10,11 ; \mathrm{m}: 18$ \\
\hline 8 & b1/b2 & $8.95(4 \mathrm{H})$ & $\mathrm{d}, J=4.6$ & 4 & $\mathrm{~s}: 4,10,11 ; \mathrm{m}: 18$ \\
\hline 9 & $\mathrm{e} 1+\mathrm{e} 2$ & $8.70-8.66(8 \mathrm{H})$ & $\mathrm{m}$ & 15 & $\mathrm{~s}: 15,18 ; \mathrm{m}: 14 ; \mathrm{w}: 2,3,16$ \\
\hline 10 & $\mathrm{Ar}^{2}, \mathrm{o}^{\prime}$ & $8.32(8 \mathrm{H})$ & s & 12 & $\mathrm{~s}: 5,6,7,8,18 ; \mathrm{m}: 1,3 ; \mathrm{w}: 12$ \\
\hline 11 & $\mathrm{Ar}^{2}, \mathrm{o}^{\prime}$ & $8.28(8 \mathrm{H})$ & s & 13 & $\mathrm{~s}: 5,6,7,8,18 ; \mathrm{m}: 2 ; \mathrm{w}: 4,13$ \\
\hline 12 & $\mathrm{Ar}^{2}, \mathrm{p}^{\prime}$ & $8.04(4 \mathrm{H})$ & s & 10 & s: $18 ; w: 10$ \\
\hline 13 & $A r^{2}, p^{\prime}$ & $8.01(4 \mathrm{H})$ & s & 11 & s: 18; w: 11 \\
\hline 14 & $\operatorname{Ar}^{1}$ & $7.88-7.83(24 \mathrm{H})$ & $\mathrm{m}$ & - & $\mathrm{s}: 15,16,18 ; \mathrm{m}: 9$ \\
\hline 15 & $f 1+f 2$ & $7.60-7.56(8 \mathrm{H})$ & $\mathrm{m}$ & 9 & s: 14,$18 ; \mathrm{m:} 16$ \\
\hline 16 & $g 1+g 2$ & $7.09(8 \mathrm{H})$ & s & - & s: 14, 18; m: 15; w: 9 \\
\hline 17 & $\mathrm{~h}$ & $3.73-3.63(2 \mathrm{H})$ & $\mathrm{m}$ & - & - \\
\hline 18 & THS+THS' & $1.56-0.69(1248 \mathrm{H})$ & $\mathrm{m}$ & 18 & $\begin{array}{c}\mathrm{s}: 9,10,11,12,13,14,15,16 ; \\
\mathrm{m}: 5,6,7,8 ; \mathrm{w}: 1,3\end{array}$ \\
\hline
\end{tabular}

${ }^{\dagger}$ Relative correlation intensities are designated as: $\mathrm{s}=$ strong, $\mathrm{m}=$ medium, $\mathrm{w}=$ weak.

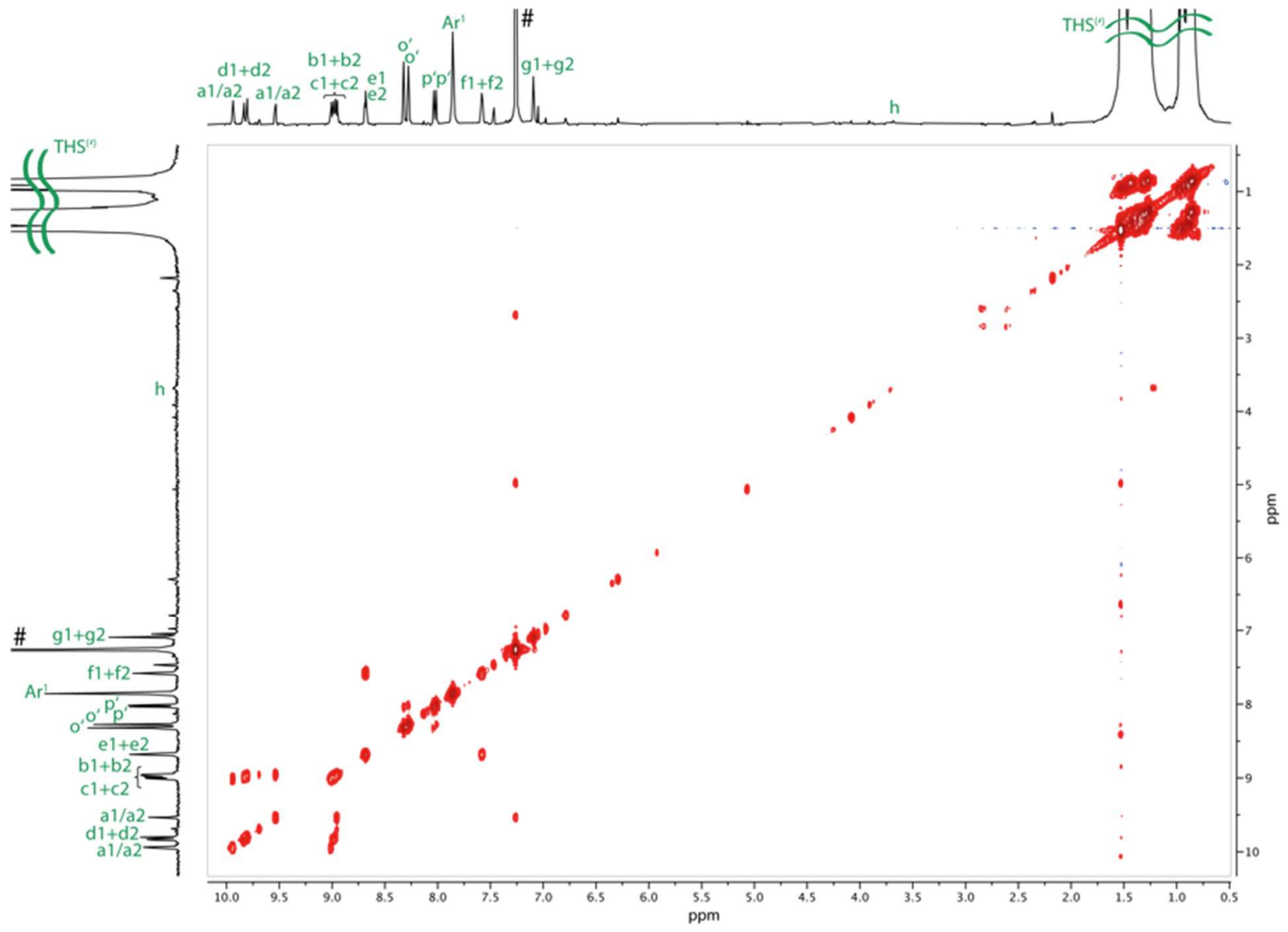

Figure S60. ${ }^{1} \mathrm{H}-{ }^{1} \mathrm{H}$ COSY spectrum of $\mathbf{H}-\mathbf{I}-\mathbf{P} 8\left[\mathbf{b}_{5} \mathbf{f}_{2}\right]-\mathbf{H}\left(500 \mathrm{MHz}, \mathrm{CDCl}_{3}, 298 \mathrm{~K}\right)$. 


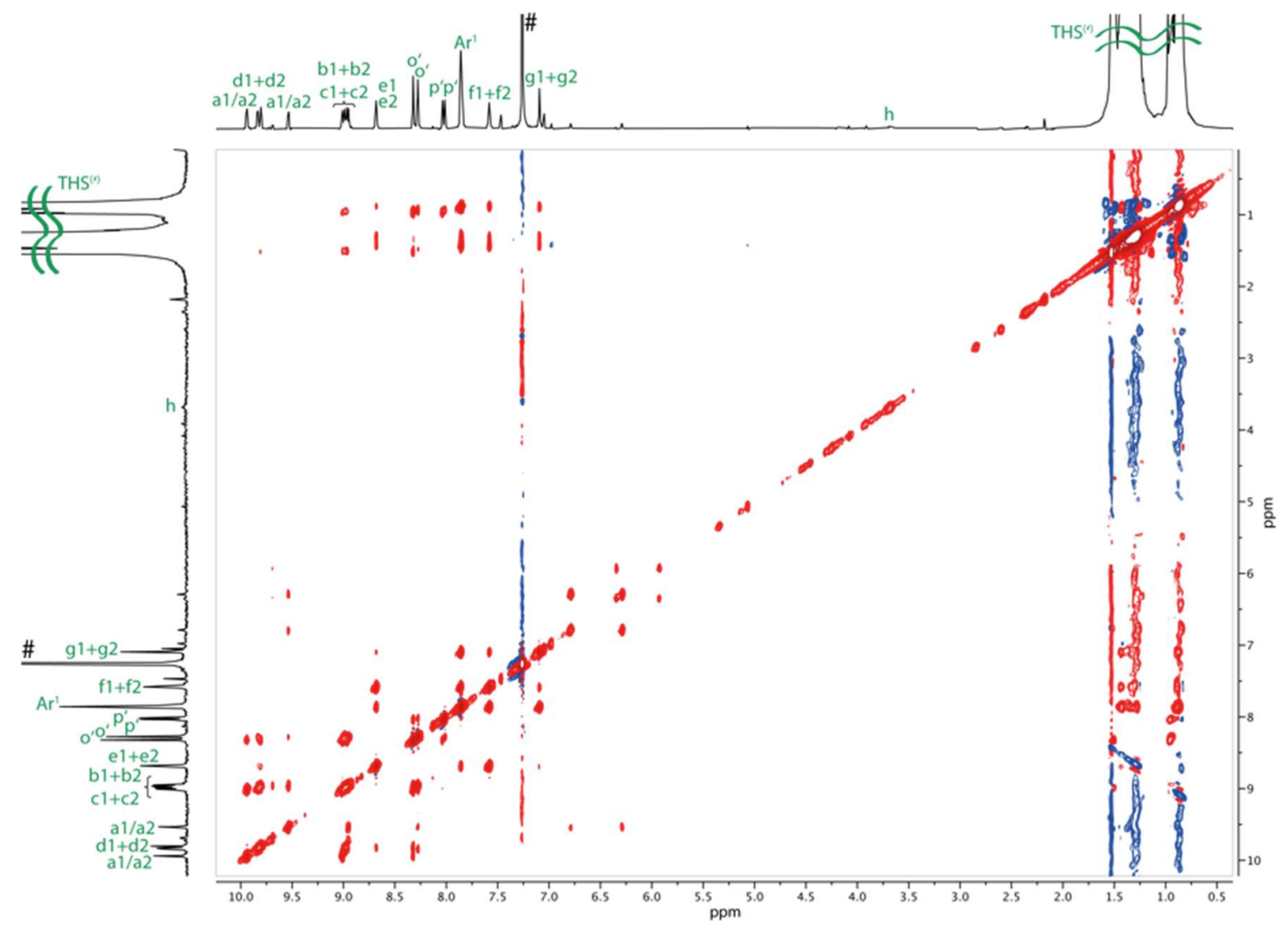

Figure S61. ${ }^{1} \mathrm{H}-{ }^{1} \mathrm{H}$ NOESY spectrum of $\mathbf{H}-\mathrm{I}-\mathbf{P} 8\left[\mathbf{b}_{5} \mathbf{f}_{2}\right]-\mathbf{H}\left(500 \mathrm{MHz}, \mathrm{CDCl}_{3}, 298 \mathrm{~K}\right)$.

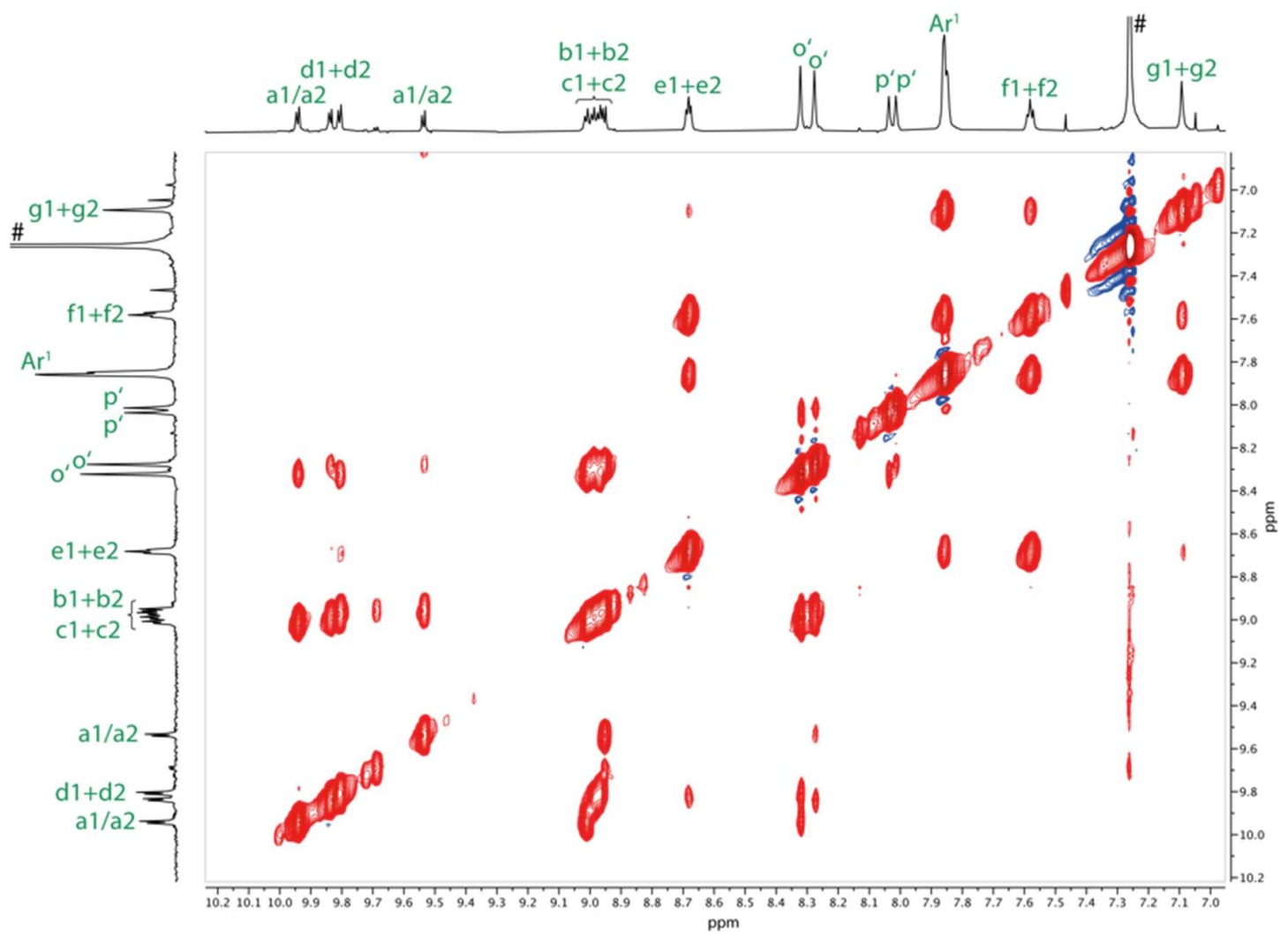

Figure S62. Enlarged region of the NOESY spectrum of $\mathbf{H}-\mathbf{I}-\mathbf{P} 8\left[\mathbf{b}_{5} \mathbf{f}_{2}\right]-\mathbf{H}\left(500 \mathrm{MHz}, \mathrm{CDCl}_{3}, 298 \mathrm{~K}\right)$. 


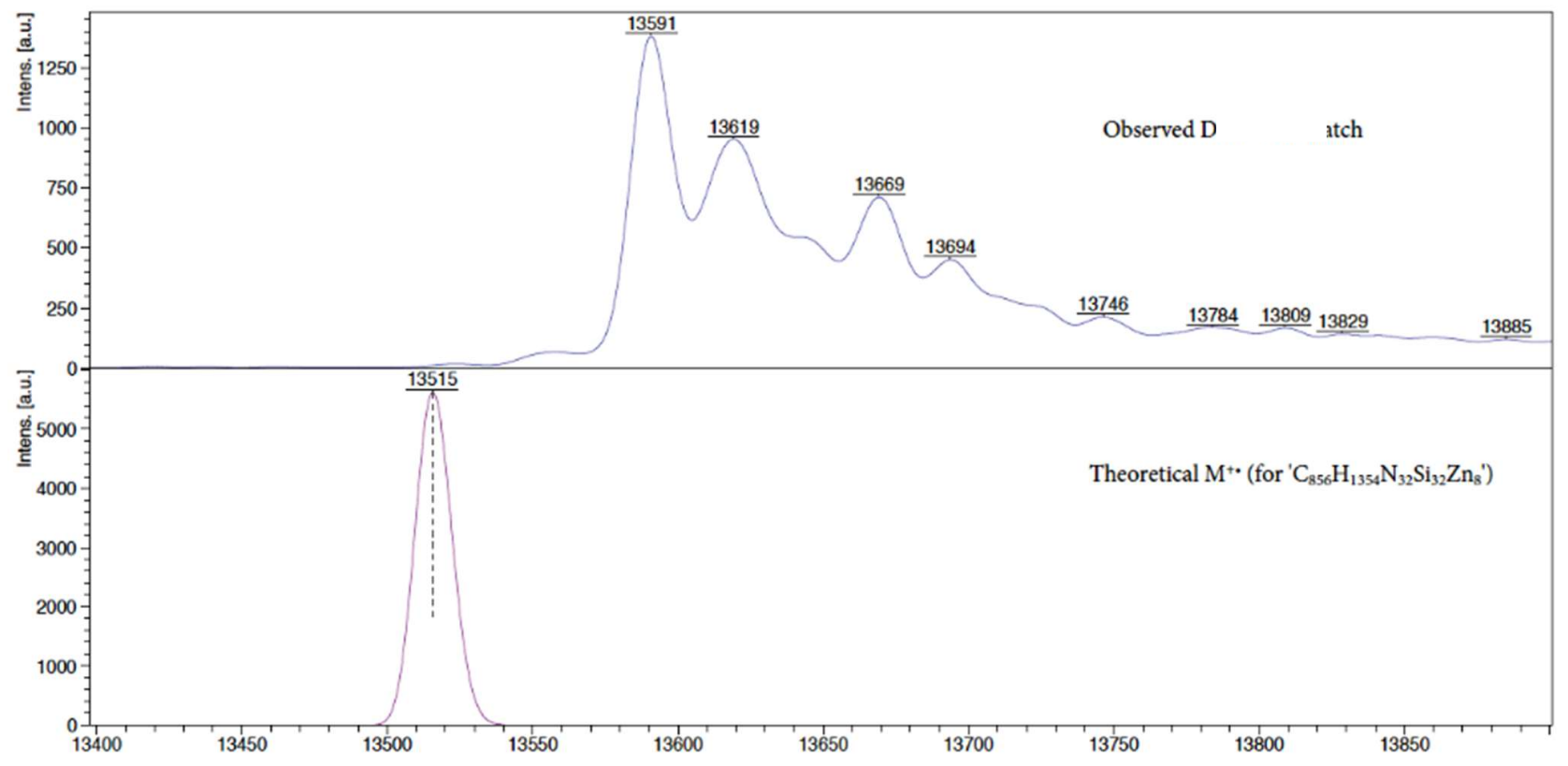

Figure S63. Experimental MALDI-ToF spectrum of $\mathbf{H}-\mathbf{I}-\mathbf{P} 8\left[\mathbf{b}_{5} \mathbf{f}_{2}\right]-\mathbf{H}$ (top) and simulated MALDI-TOF spectrum of $\mathbf{H}-\mathbf{I}-\mathbf{P} 8\left[\mathbf{b}_{5} \mathbf{f}_{2}\right]-\mathbf{H}^{+}$ $\left[\mathrm{C}_{856} \mathrm{H}_{1354} \mathrm{~N}_{32} \mathrm{Si}_{32} \mathrm{Zn}_{8}\right]^{+}$(bottom). The observed signal in the experimental spectrum corresponds to $\left[\mathrm{H}-\mathrm{I}-\mathbf{P} 8\left[\mathbf{b}_{5} \mathrm{f}_{2}\right]-\mathbf{H}+\mathbf{p y r i d i n e}\right]^{+}$with a theoretical $m / z$ value for $\left[\mathrm{C}_{861} \mathrm{H}_{1359} \mathrm{~N}_{33} \mathrm{Si}_{32} \mathrm{Zn}_{8}\right]^{+}=13595$. 


\section{Free ring $c-P 8\left[b_{6} f_{2}\right]$ :}
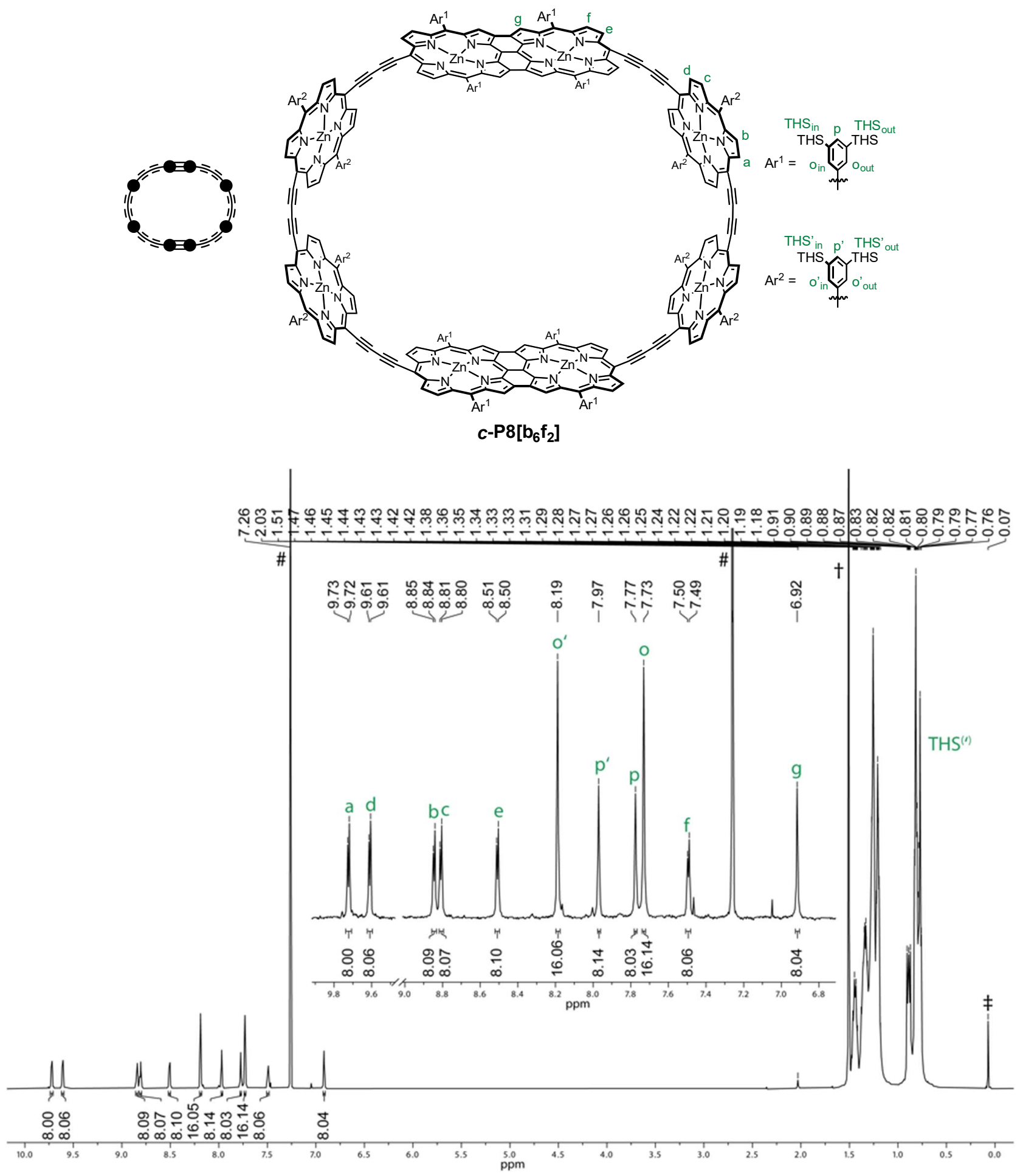

Figure S64. Assigned structure and ${ }^{1} \mathrm{H}$ NMR spectrum of $c-\mathbf{P} 8\left[\mathbf{b}_{6} \mathrm{f}_{2}\right]\left(500 \mathrm{MHz}, \mathrm{CDCl}_{3}, 298 \mathrm{~K}\right) . \#=\mathrm{CHCl}_{3} ; \dagger=$ water; $\ddagger=$ silicon grease. 
Table S17. Complete ${ }^{1} \mathrm{H}$ NMR assignment and correlations for $\mathbf{c}-\mathbf{P} 8\left[\mathbf{b}_{\mathbf{b}} \mathbf{f}_{2}\right]$

\begin{tabular}{|c|c|c|c|c|c|c|}
\hline$\#$ & Assign. & ${ }^{1} \mathrm{H}$ & $\begin{array}{l}\text { Mult. } \\
J(H z)\end{array}$ & $\begin{array}{l}{ }^{1} \mathrm{H}-{ }^{1} \mathrm{H} \\
\text { cosY }\end{array}$ & ${ }^{1} \mathrm{H}-{ }^{1} \mathrm{H} \mathrm{NOESY}^{+}$ & ${ }^{1} \mathrm{H}-{ }^{13} \mathrm{C}$ HSQC \\
\hline 1 & a & $9.72(8 \mathrm{H})$ & $\mathrm{d}, J=4.5$ & 3 & $\mathrm{~s}: 3 ; \mathrm{m}: 6,12$ & 131.3 \\
\hline 2 & d & $9.61(8 \mathrm{H})$ & $\mathrm{d}, J=4.5$ & 4 & $s: 4 ; m: 6,12 ; w: 5$ & 131.3 \\
\hline 3 & b & $8.85(8 \mathrm{H})$ & $\mathrm{d}, J=4.5$ & 1 & $\mathrm{~s}: 1,6 ; \mathrm{m}: 12 ; \mathrm{w}: 7$ & 133.6 \\
\hline 4 & c & $8.81(8 \mathrm{H})$ & $\mathrm{d}, J=4.5$ & 2 & $\mathrm{~s}: 2,6 ; \mathrm{m}: 12 ; \mathrm{w}: 7$ & 133.6 \\
\hline 5 & e & $8.51(8 \mathrm{H})$ & $\mathrm{d}, J=4.5$ & 10 & s: $10 ; \mathrm{m:}$ 9, 12; w: 2, 11 & 129.4 \\
\hline 6 & $\mathrm{o}^{\prime}$ & $8.19(16 \mathrm{H})$ & s & 7 & $\mathrm{~s}: 3,4,12 ; \mathrm{m}: 1,2,7$ & 140.5 \\
\hline 7 & $p^{\prime}$ & $7.97(8 \mathrm{H})$ & s & 6 & $\mathrm{~s}: 12 ; \mathrm{m}: 6 ; \mathrm{w}: 3,4$ & 139.5 \\
\hline 8 & $\mathrm{p}$ & $7.77(8 \mathrm{H})$ & s & - & s: 12; m: 10, 11 & 139.4 \\
\hline 9 & 0 & $7.73(16 \mathrm{H})$ & $s$ & - & $\mathrm{s}: 10,11 ; 12 ; \mathrm{m}: 5$ & 138.7 \\
\hline 10 & $f$ & $7.49(8 \mathrm{H})$ & $\mathrm{d}, J=4.5$ & 5 & $\mathrm{~s}: 5,9 ; \mathrm{m}: 8,11,12$ & 132.4 \\
\hline 11 & g & $6.92(8 \mathrm{H})$ & s & - & $\mathrm{s}: 9,12 ; \mathrm{m}: 8,10 ; \mathrm{w}: 5$ & 128.0 \\
\hline 12 & THS+THS' & $\begin{array}{c}1.48-0.72 \\
(1248 \mathrm{H})\end{array}$ & $\mathrm{m}$ & 12 & $\begin{array}{c}\mathrm{s}: 6,7,8,9,11 ; \mathrm{m}: 1,2,3 \\
4,5,10\end{array}$ & $\begin{array}{c}12.7,12.8,14.2,14.3,22.76 \\
22.77,24.1,24.2,29.9,31.66 \\
31.73,33.57,33.63\end{array}$ \\
\hline
\end{tabular}

${ }^{\dagger}$ Relative correlation intensities are designated as: $s=$ strong, $m=$ medium, $w=$ weak.

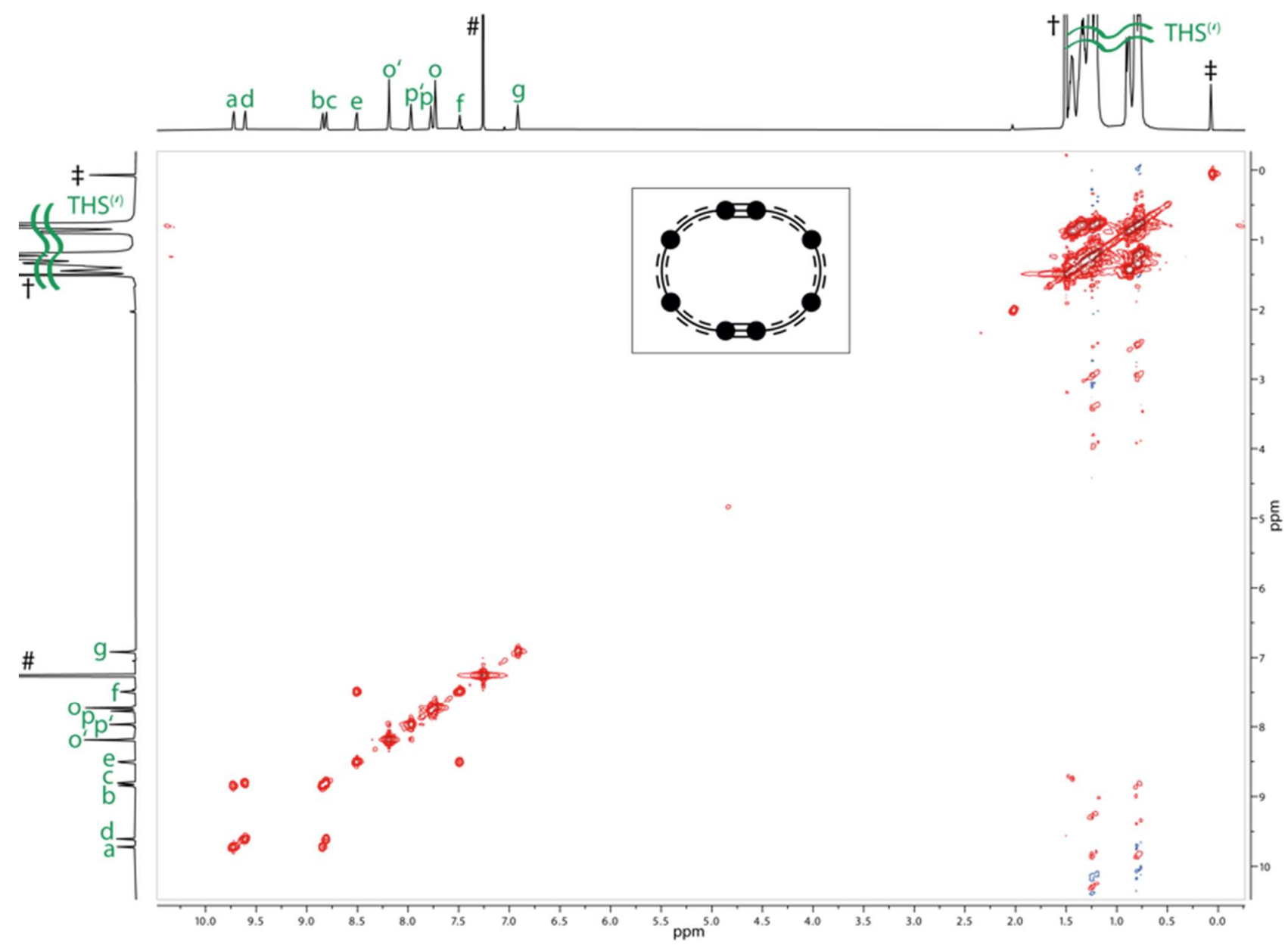

Figure S65. ${ }^{1} \mathrm{H}-{ }^{1} \mathrm{H}$ COSY spectrum of $c-\mathrm{P} 8\left[\mathbf{b}_{6} \mathrm{f}_{2}\right]\left(500 \mathrm{MHz}, \mathrm{CDCl}_{3}, 298 \mathrm{~K}\right)$. 


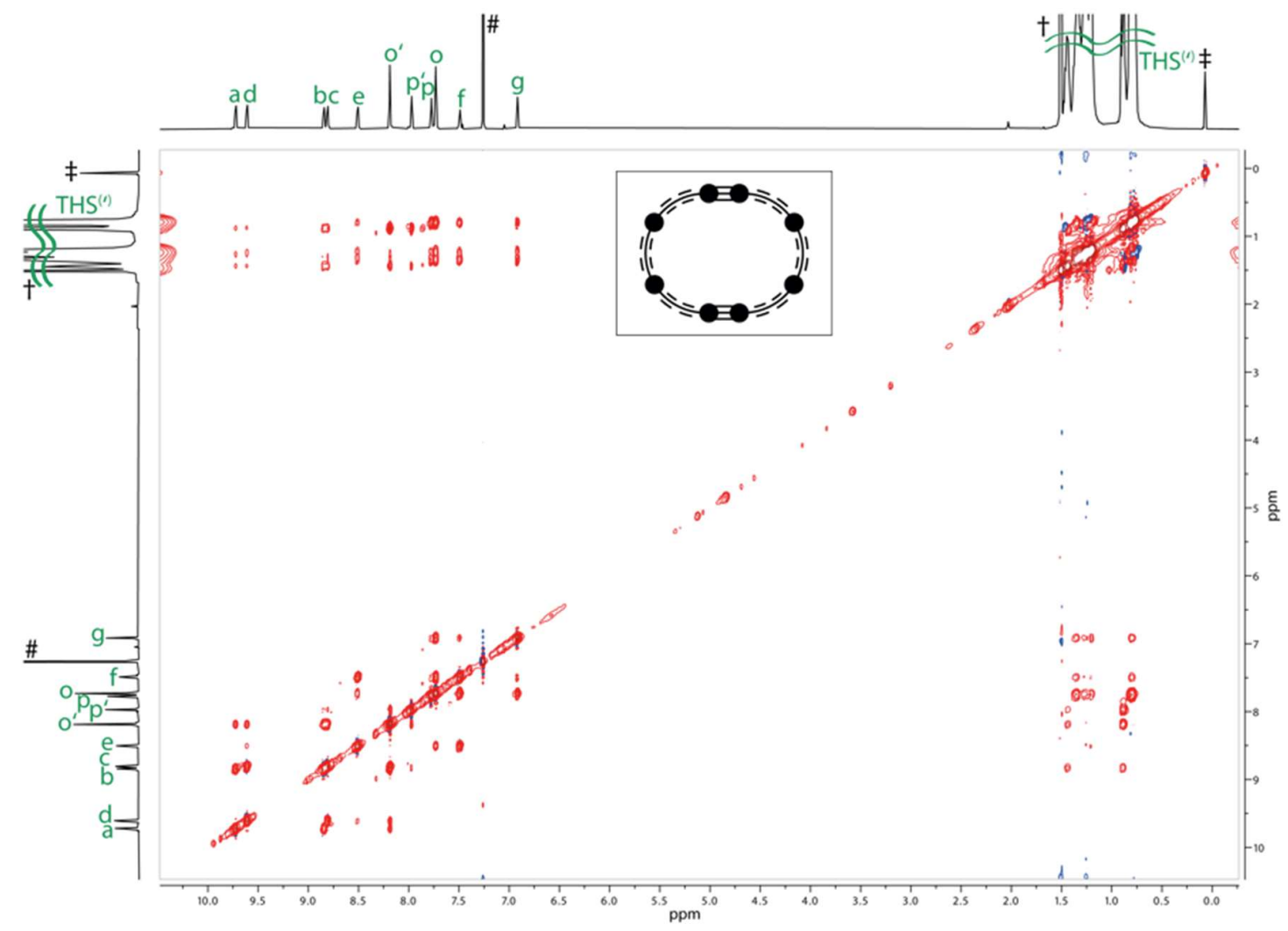

Figure S66. ${ }^{1} \mathrm{H}-{ }^{1} \mathrm{H}$ NOESY spectrum of $\boldsymbol{c}-\mathbf{P} 8\left[\mathbf{b}_{6} \mathbf{f}_{2}\right]\left(500 \mathrm{MHz}, \mathrm{CDCl}_{3}, 298 \mathrm{~K}\right)$.

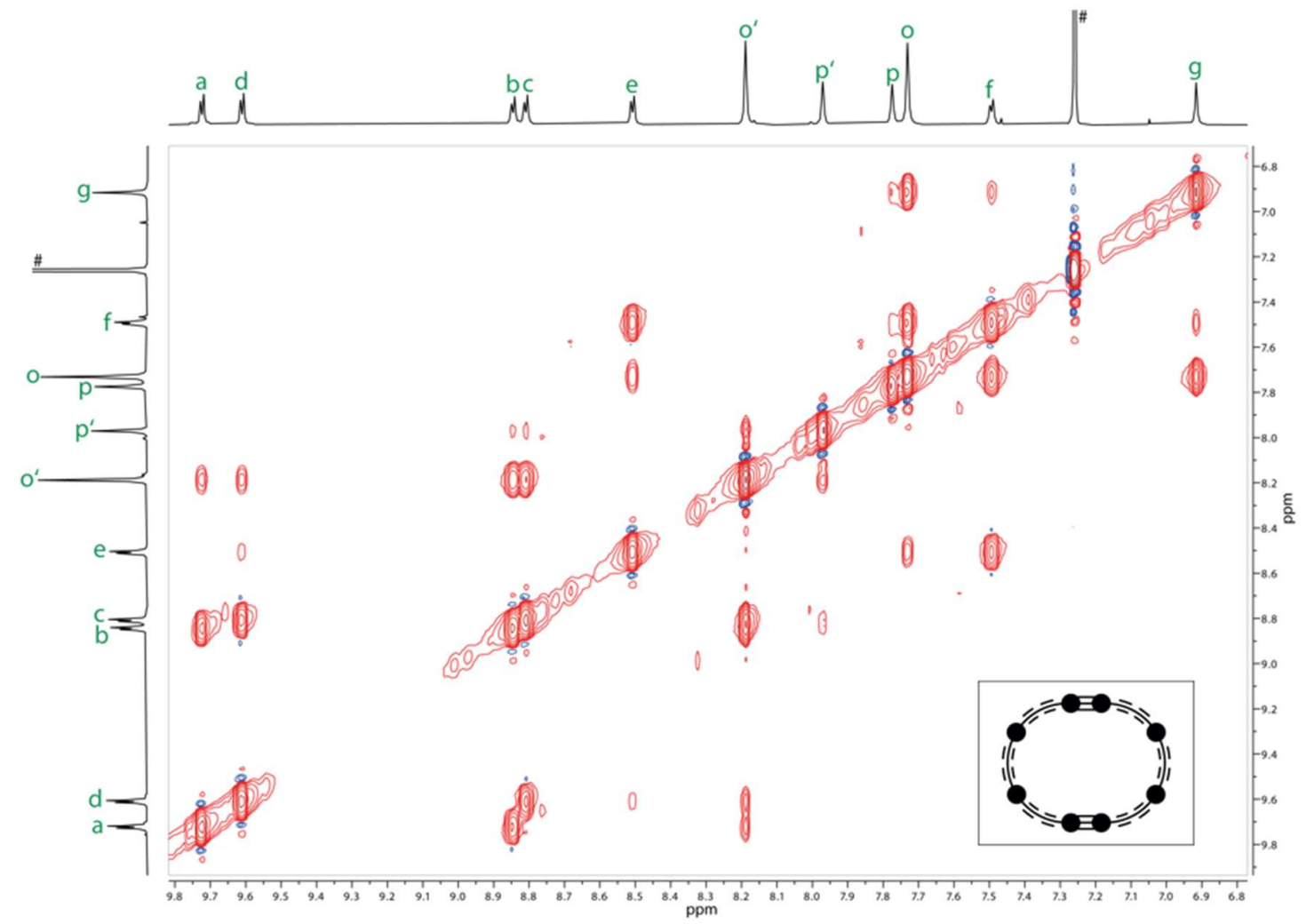

Figure $\mathbf{S 6 7}$. Enlarged region of the NOESY spectrum of $\boldsymbol{c}-\mathbf{P} 8\left[\mathbf{b}_{6} \mathbf{f}_{2}\right]\left(500 \mathrm{MHz}, \mathrm{CDCl}_{3}, 298 \mathrm{~K}\right)$. 


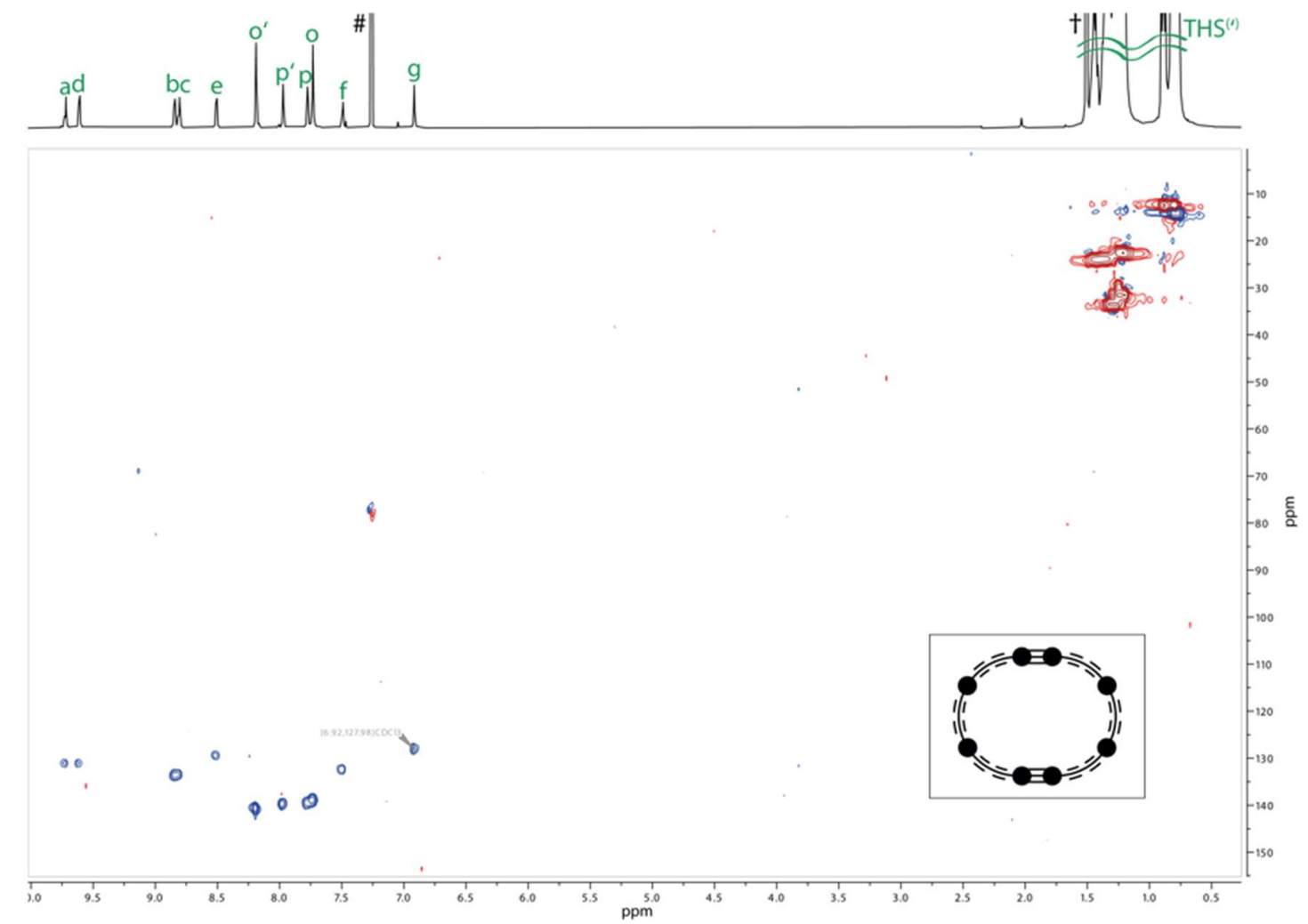

Figure S68. ${ }^{1} \mathrm{H}_{-}{ }^{13} \mathrm{C} \mathrm{HSQC}$ spectrum of $\boldsymbol{c}-\mathbf{P} 8\left[\mathbf{b}_{6} \mathbf{f}_{2}\right]\left(500 \mathrm{MHz}, \mathrm{CDCl}_{3}, 298 \mathrm{~K}\right)$.

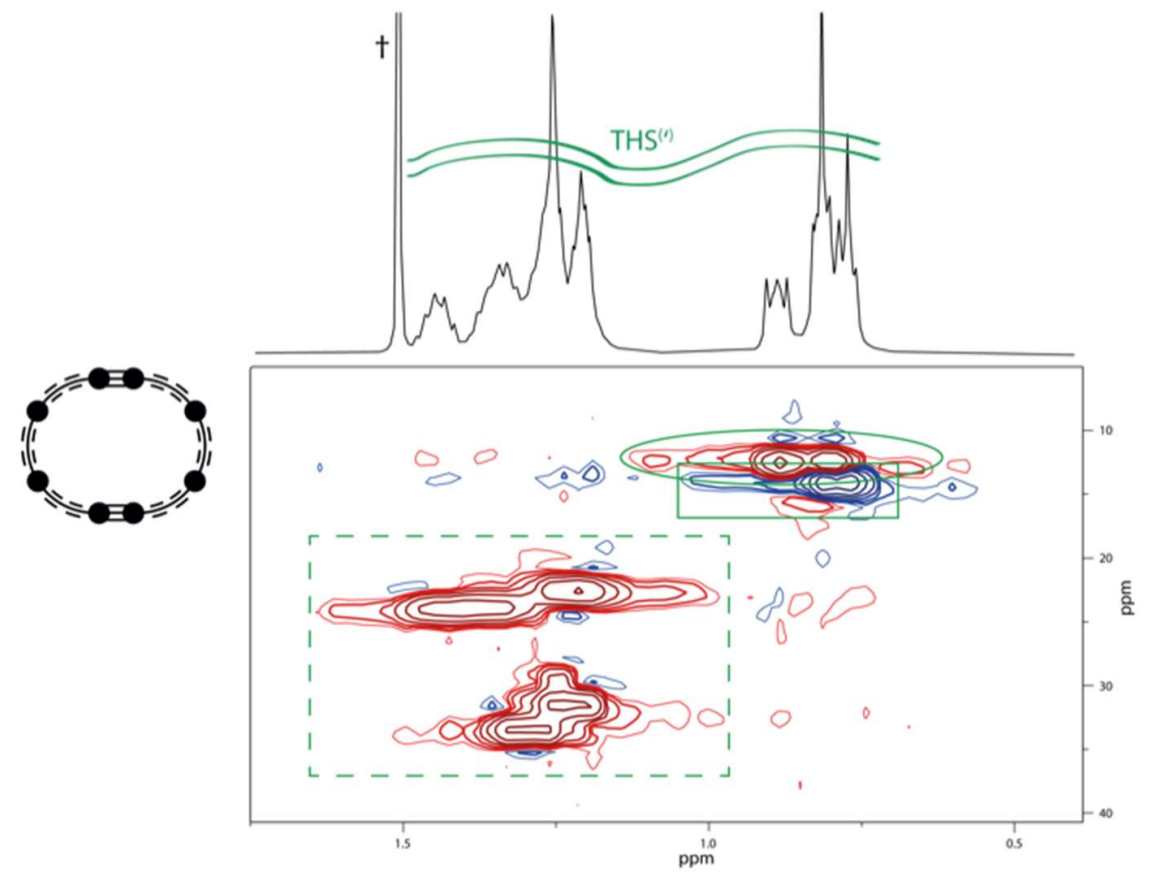

Figure S69. THS region of the ${ }^{1} \mathrm{H}-{ }^{13} \mathrm{C}$ HSQC spectrum of $\boldsymbol{c}-\mathbf{P} 8\left[\mathbf{b}_{6} \mathbf{f}_{2}\right]\left(500 \mathrm{MHz}, \mathrm{CD}_{2} \mathrm{Cl}_{2}, 298 \mathrm{~K}\right)$. Si-R-CH resonances are indicated with a solid box, $\mathrm{Si}-\mathrm{CH}_{2}-\mathrm{R}$ resonances with a solid circle, and $\mathrm{Si}-\mathrm{CH}_{2}-\mathrm{C}_{4} \mathrm{H}_{8}-\mathrm{CH}_{3}$ resonances with a dashed box. 


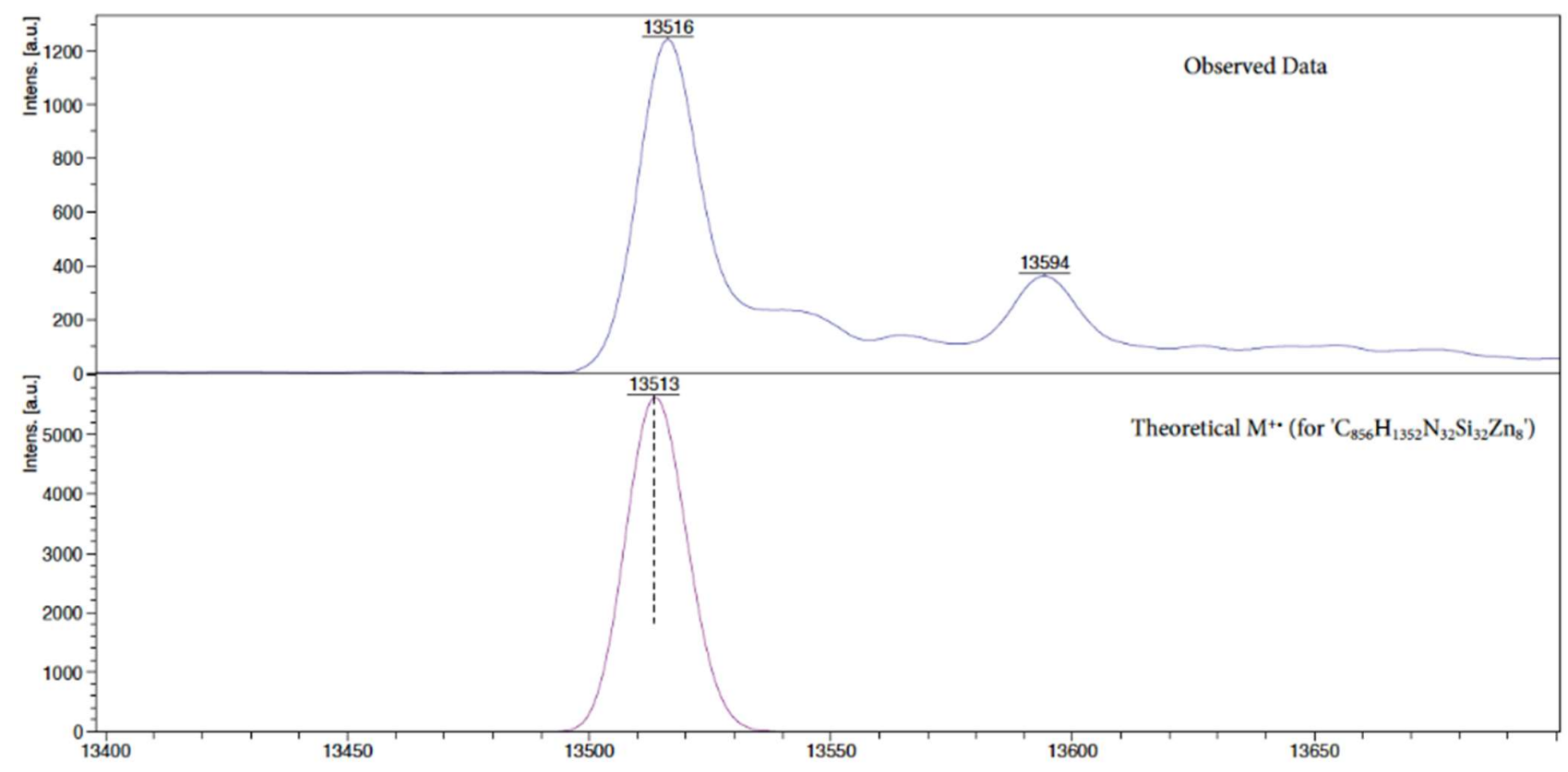

Figure S70. Experimental MALDI-ToF spectrum of $\boldsymbol{c}-\mathbf{P 8}\left[\mathbf{b}_{6} \mathbf{f}_{2}\right]$ (top) and simulated MALDI-TOF spectrum of $\boldsymbol{c}-\mathbf{P 8}\left[\mathbf{b}_{6} \mathbf{f}_{2}\right]^{+}$ $\left[\mathrm{C}_{856} \mathrm{H}_{1352} \mathrm{~N}_{32} \mathrm{Si}_{32} \mathrm{Zn}_{8}\right]^{+}$(bottom). 

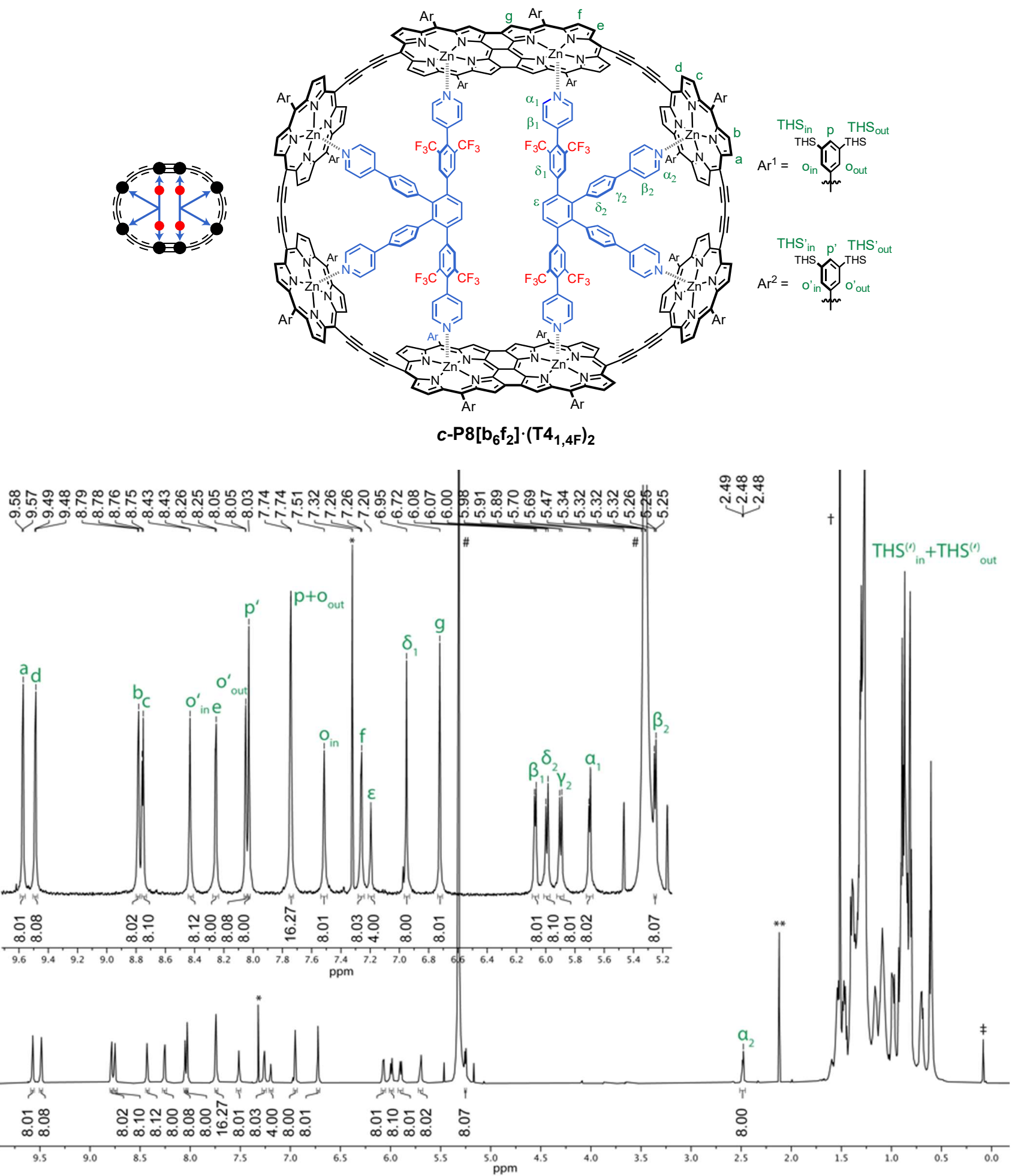

Figure S71. Labelled structure and ${ }^{1} \mathrm{H}$ NMR spectrum of $\boldsymbol{c}-\mathbf{P} 8\left[\mathbf{b}_{6} \mathbf{f}_{2}\right] \bullet\left(\mathbf{T 4}_{1,4 \mathrm{~F}}\right)_{2}\left(600 \mathrm{MHz}, \mathrm{CD}_{2} \mathrm{Cl}_{2}, 298 \mathrm{~K}\right)$. \#= $\mathrm{CHDCl}_{2} ; *=\mathrm{CHCl}_{3} ; * *=$ acetone; $\dagger=$ water; $\ddagger$ = silicon grease . 
Table S18. Complete ${ }^{1} \mathrm{H}$ NMR assignment and correlations for complex $c-\mathbf{P} 8\left[\mathbf{b}_{\mathbf{b}} \mathbf{f}_{2}\right] \bullet\left(\mathbf{T 4}_{\mathbf{1}, 4 \mathrm{~F}}\right)_{\mathbf{2}}$

\begin{tabular}{|c|c|c|c|c|c|c|c|}
\hline$\#$ & Assign. & ${ }^{1} \mathbf{H}$ & $\begin{array}{c}\text { Mult. J } \\
(\mathrm{Hz})\end{array}$ & $\begin{array}{l}{ }^{1} \mathrm{H}-{ }^{1} \mathrm{H} \\
\text { COSY }\end{array}$ & ${ }^{1} \mathrm{H}-{ }^{1} \mathrm{H} \mathrm{NOESY}^{+}$ & $\begin{array}{c}{ }^{1} \mathbf{H}-^{19} \mathbf{F} \\
\text { HOESY }\end{array}$ & ${ }^{1} \mathrm{H}-{ }^{13} \mathrm{C}$ HSQC \\
\hline 1 & $\mathrm{a}$ & $9.57(8 \mathrm{H})$ & $\mathrm{d}, J=4.3$ & 3 & $s: 3 ; w: 5,7,20,21$ & - & 130.5 \\
\hline 2 & $d$ & $9.49(8 \mathrm{H})$ & $\mathrm{d}, J=4.4$ & 4 & $\begin{array}{c}\text { s: } 4 ; w: 5,6,7,20 \\
21\end{array}$ & - & 130.8 \\
\hline 3 & $b$ & $8.79(8 \mathrm{H})$ & $\mathrm{d}, J=4.3$ & 1 & $\begin{array}{c}\mathrm{s}: 1,5,7 ; \mathrm{m}: 21, \mathrm{w}: \\
20\end{array}$ & - & 133.7 \\
\hline 4 & c & $8.75(8 \mathrm{H})$ & $\mathrm{d}, J=4.4$ & 2 & $\begin{array}{c}\mathrm{s}: 2,5,7 ; \mathrm{m}: 21 ; \mathrm{w}: \\
20\end{array}$ & - & 133.7 \\
\hline 5 & $o_{\text {in }}^{\prime}$ & $8.43(8 \mathrm{H})$ & s & 7 & $\begin{array}{c}\mathrm{s}: 3,4,7,8,21 ; \mathrm{w}: \\
1,2,20\end{array}$ & - & 140.8 \\
\hline 6 & e & $8.26(8 \mathrm{H})$ & $\mathrm{d}, J=4.4$ & 11 & $\begin{array}{c}\mathrm{s}: 11 ; \mathrm{m}: 21 ; \mathrm{w}: 2 \\
9,10,18\end{array}$ & - & - \\
\hline 7 & $\mathrm{o}_{\text {out }}^{\prime}$ & $8.05(8 \mathrm{H})$ & s & 5 & $\begin{array}{c}s: 3,4,5,21 ; w: 1 \\
2\end{array}$ & - & 141.8 \\
\hline 8 & $p^{\prime}$ & $8.03(8 \mathrm{H})$ & s & - & s: 5,21 & - & 139.8 \\
\hline 9 & $p+O_{\text {out }}$ & $7.74(16 \mathrm{H})$ & s & 10 & $\begin{array}{c}\mathrm{s}: 11,14,21 ; \mathrm{m}: \\
10 ; \mathrm{w}: 6\end{array}$ & - & 139.5 \\
\hline 10 & Oin & $7.51(8 \mathrm{H})$ & s & 9 & $\begin{array}{c}\text { s: } 9,14,21 ; m: 11 ; \\
\text { w: } 6,18\end{array}$ & - & 138.9 \\
\hline 11 & $f$ & $7.26(8 \mathrm{H})$ & $\mathrm{d}, J=4.4$ & 6 & $\begin{array}{c}\mathrm{s}: 6,9,10,21 ; \mathrm{w}: \\
14\end{array}$ & - & 132.4 \\
\hline 12 & $\varepsilon$ & $7.20(4 \mathrm{H})$ & s & - & s: 13; w: 16 & w & - \\
\hline 13 & $\delta_{1}$ & $6.95(8 \mathrm{H})$ & $\mathrm{s}$ & - & $\begin{array}{c}\text { s: } 12 ; \mathrm{m}: 16 ; \mathrm{w}: \\
17,21\end{array}$ & s & 130.5 \\
\hline 14 & g & $6.72(8 \mathrm{H})$ & s & - & $\begin{array}{c}\mathrm{s}: 9,10,21 ; \mathrm{w}: 11 \\
18\end{array}$ & - & 127.6 \\
\hline 15 & $\beta_{1}$ & $6.07(8 \mathrm{H})$ & $\mathrm{d}, J=6.2$ & 18 & $\mathrm{~s}: 18 ; \mathrm{m}: 21$ & $\mathrm{~m}$ & 125.0 \\
\hline 16 & $\delta_{2}$ & $5.99(8 \mathrm{H})$ & $\mathrm{d}, J=8.8$ & 17 & $\begin{array}{c}\mathrm{s}: 17 ; \mathrm{m}: 13 ; \mathrm{w}: \\
12,19\end{array}$ & $\mathrm{vw}$ & 131.4 \\
\hline 17 & $\gamma_{2}$ & $5.90(8 \mathrm{H})$ & $\mathrm{d}, J=8.8$ & 16 & $\begin{array}{c}\mathrm{s}: 16 ; \mathrm{m}: 19 ; \mathrm{w}: \\
13,20\end{array}$ & - & 126.0 \\
\hline 18 & $\alpha_{1}$ & $5.70(8 \mathrm{H})$ & $\mathrm{d}, J=6.2$ & 15 & $\begin{array}{c}\mathrm{s}: 15 ; \mathrm{m}: 21 ; \mathrm{w}: 6 \\
10,14\end{array}$ & w & 145.0 \\
\hline 19 & $\beta_{2}$ & $5.25(8 \mathrm{H})$ & $d, J=6.9$ & 20 & s: $20 ; \mathrm{m}: 17 ; \mathrm{w}: 16$ & - & 120.5 \\
\hline 20 & $\alpha_{2}$ & $\begin{array}{c}2.51-2.46 \\
(8 \mathrm{H})\end{array}$ & $\mathrm{m}$ & 19 & $\begin{array}{c}\text { s: } 19 ; \text { w: } 1,2,3,4 \\
5,17\end{array}$ & - & 143.4 \\
\hline 21 & $\begin{array}{c}\mathrm{THS}_{\text {in }}+\mathrm{THS}_{\text {out }} \\
+\mathrm{THS}^{\prime}{ }_{\text {in }}+ \\
\mathrm{THS}_{\text {out }}^{\prime}\end{array}$ & $\begin{array}{c}1.64-0.55 \\
(1248 \mathrm{H})\end{array}$ & $\mathrm{m}$ & 21 & $\begin{array}{c}\mathrm{s}: 5,7,8,9,10,11 \\
14 ; \mathrm{m}: 3,4,6,15, \\
18 ; \mathrm{w}: 1,2,13\end{array}$ & vw & $\begin{array}{c}12.8,13.0,13.1,14.2, \\
14.37,14.40,22.9,23.1, \\
24.3,24.38,24.41,24.5, \\
30.1,31.9,32.00,32.04, \\
32.1,33.8,33.90,33.94, \\
34.0\end{array}$ \\
\hline
\end{tabular}

${ }^{+}$Relative correlation intensities are designated as: $s=$ strong, $m=$ medium, $w=$ weak, $v w=$ very weak. 


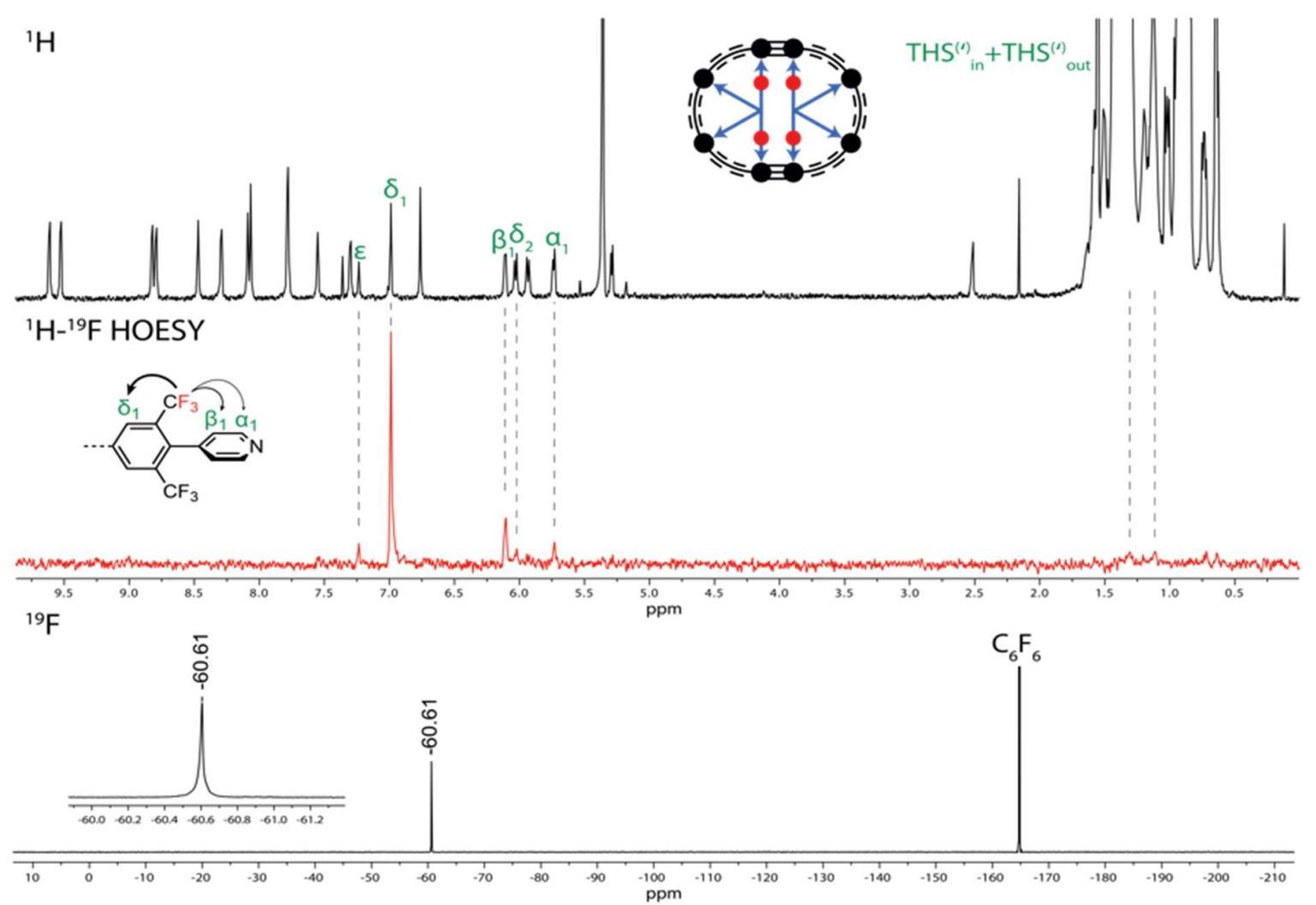

Figure S72. Combined ${ }^{1} \mathrm{H}$ (top), $1 \mathrm{D}^{1} \mathrm{H}^{-19} \mathrm{~F}$ HOESY (middle, red), and ${ }^{19} \mathrm{~F}$ (bottom) spectra of $\boldsymbol{c}$-P8[ $\left.\mathbf{b}_{6} \mathrm{f}_{2}\right] \bullet\left(\mathrm{T4}_{1,4 \mathrm{~F}}\right)_{2}\left(500 \mathrm{MHz}, \mathrm{CD}_{2} \mathrm{Cl}_{2}, 298 \mathrm{~K}\right)$.

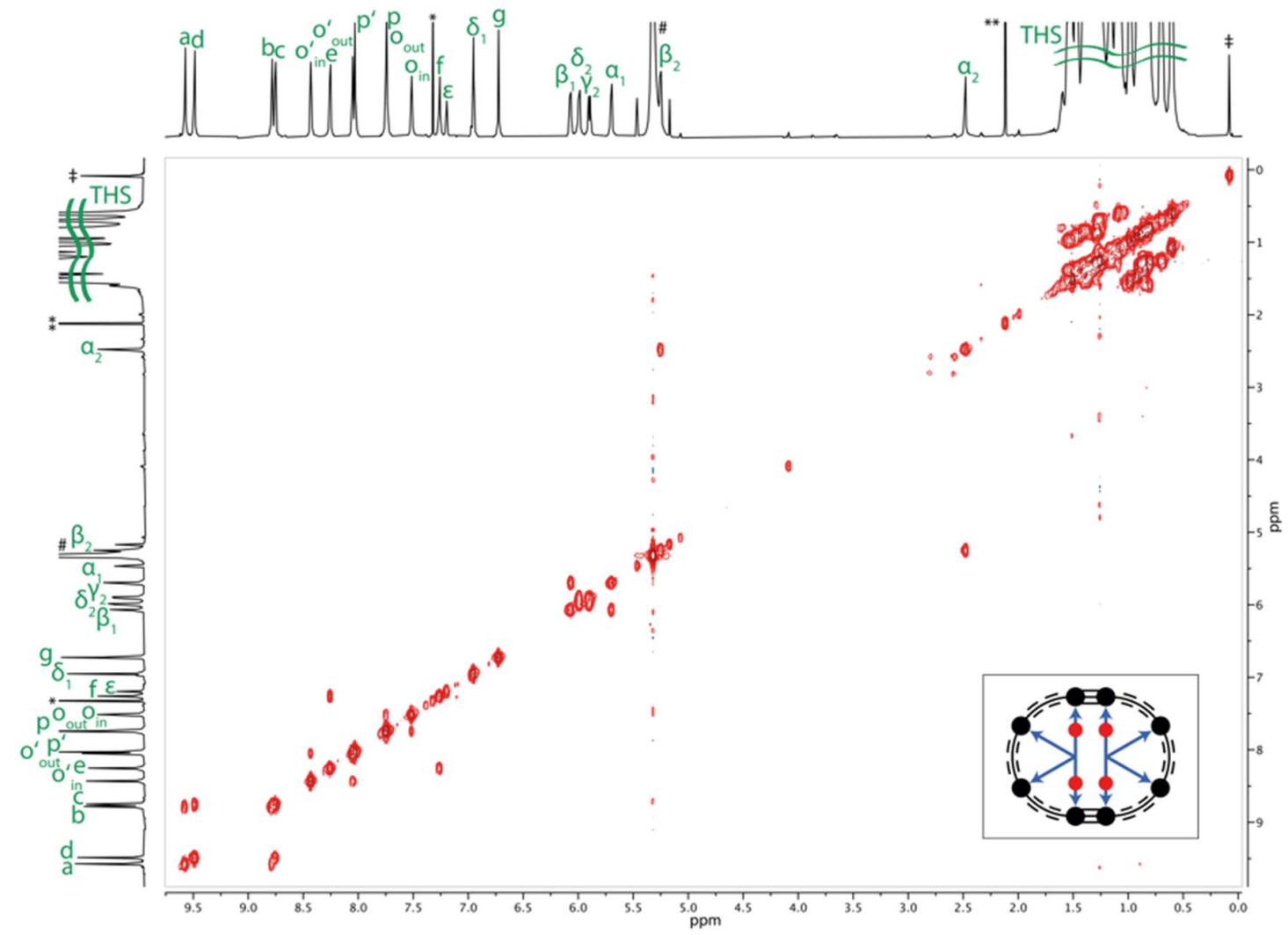

Figure S73. ${ }^{1} \mathrm{H}-{ }^{1} \mathrm{H}$ COSY spectrum of $c-\mathrm{P} 8\left[\mathrm{~b}_{6} \mathrm{f}_{2}\right] \bullet\left(\mathrm{T4}_{1,4 \mathrm{~F}}\right)_{2}\left(600 \mathrm{MHz}, \mathrm{CD}_{2} \mathrm{Cl}_{2}, 298 \mathrm{~K}\right)$. 


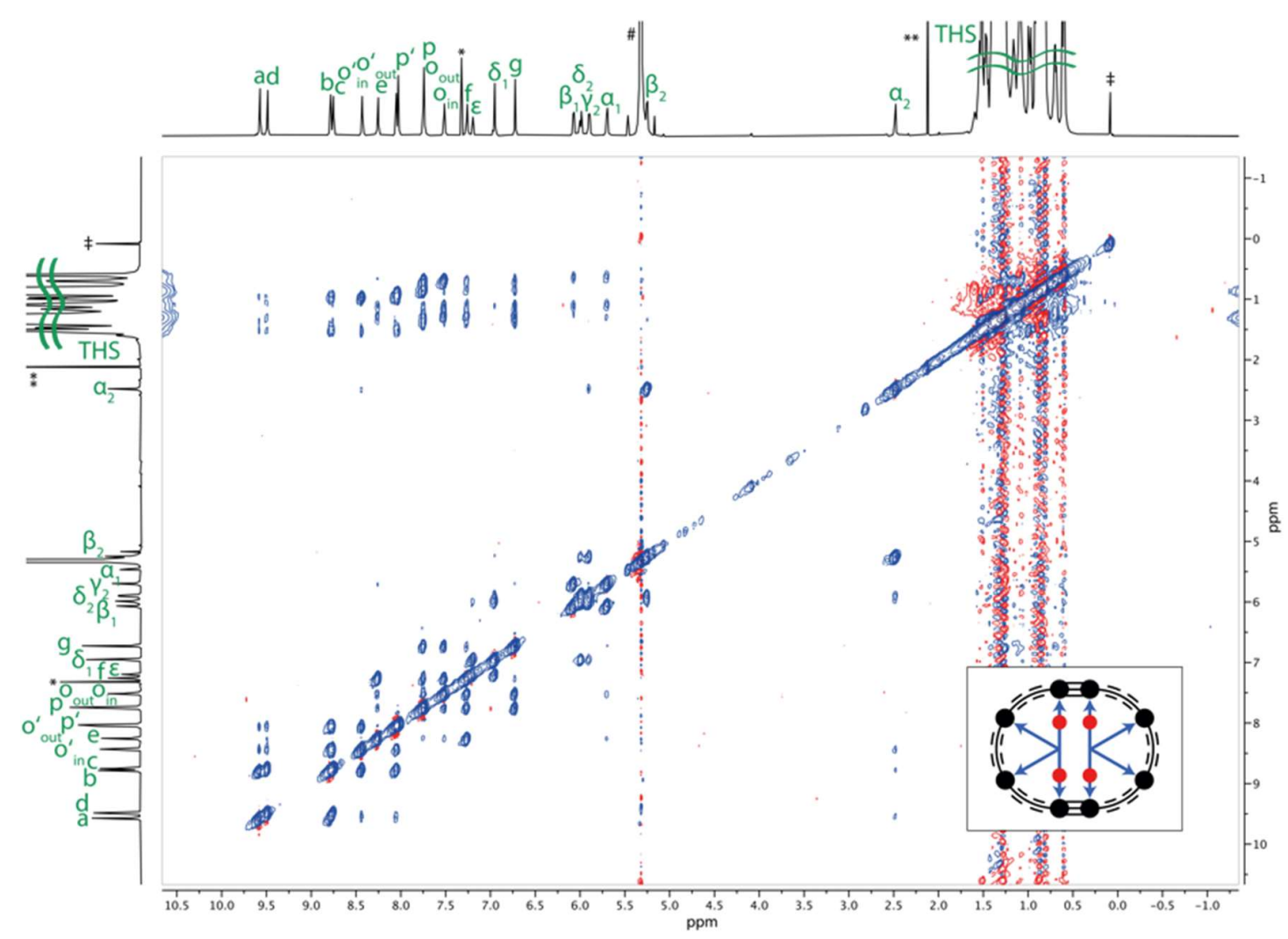

Figure S74. ${ }^{1} \mathrm{H}-{ }^{1} \mathrm{H}$ NOESY spectrum of $\boldsymbol{c}-\mathbf{P 8}\left[\mathrm{b}_{6} \mathrm{f}_{2}\right] \bullet\left(\mathrm{T4}_{1,4 \mathrm{~F}}\right)_{2}\left(600 \mathrm{MHz}, \mathrm{CD}_{2} \mathrm{Cl}_{2}, 298 \mathrm{~K}\right)$.

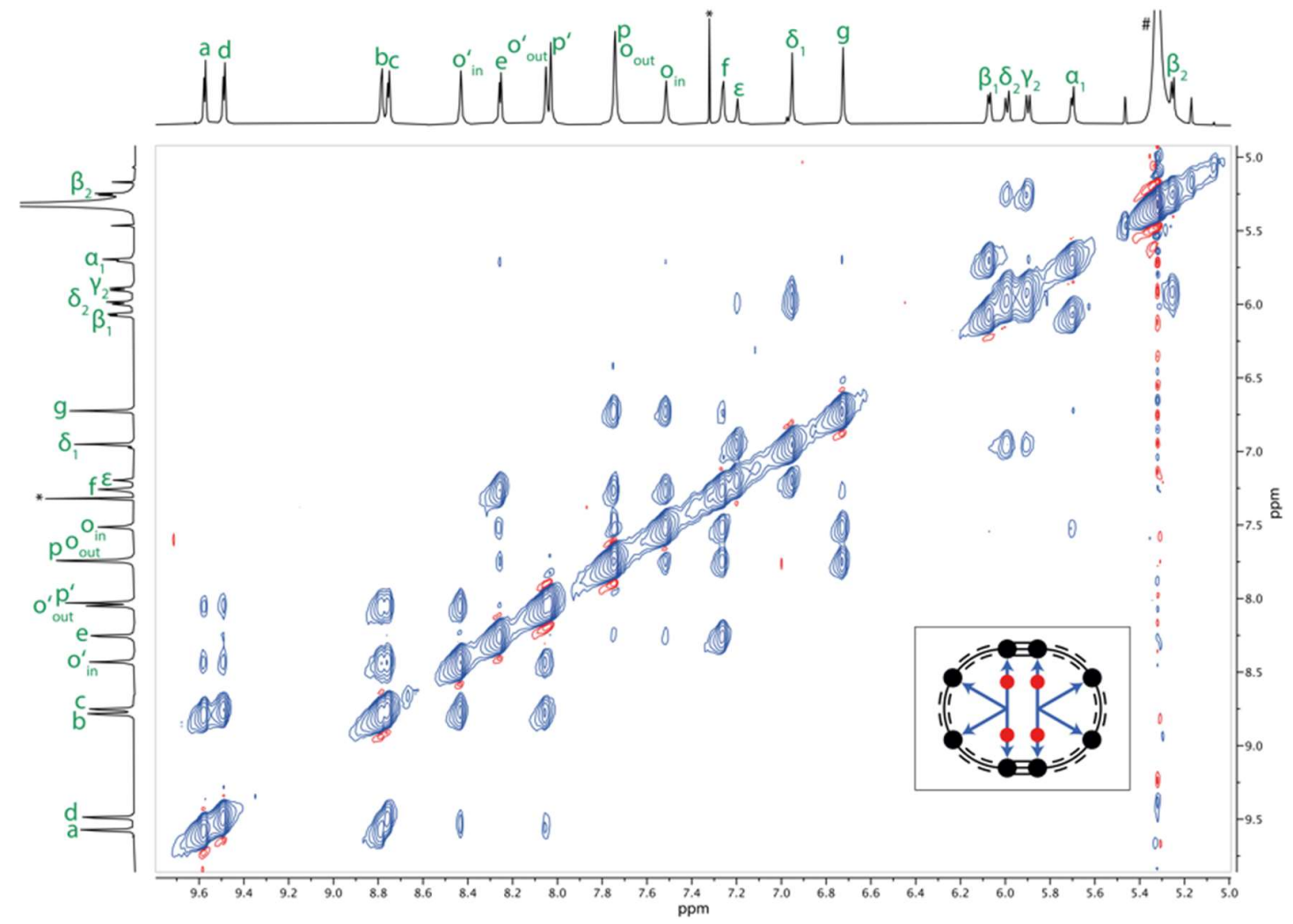

Figure S75. Enlarged region of the NOESY spectrum of $\boldsymbol{c}-\mathbf{P} 8\left[\mathbf{b}_{\mathbf{6}} \mathbf{f}_{2}\right] \bullet\left(\mathbf{T 4}_{1,4 \mathrm{~F}}\right)_{2}\left(600 \mathrm{MHz}, \mathrm{CD}_{2} \mathrm{Cl}_{2}, 298 \mathrm{~K}\right)$. 


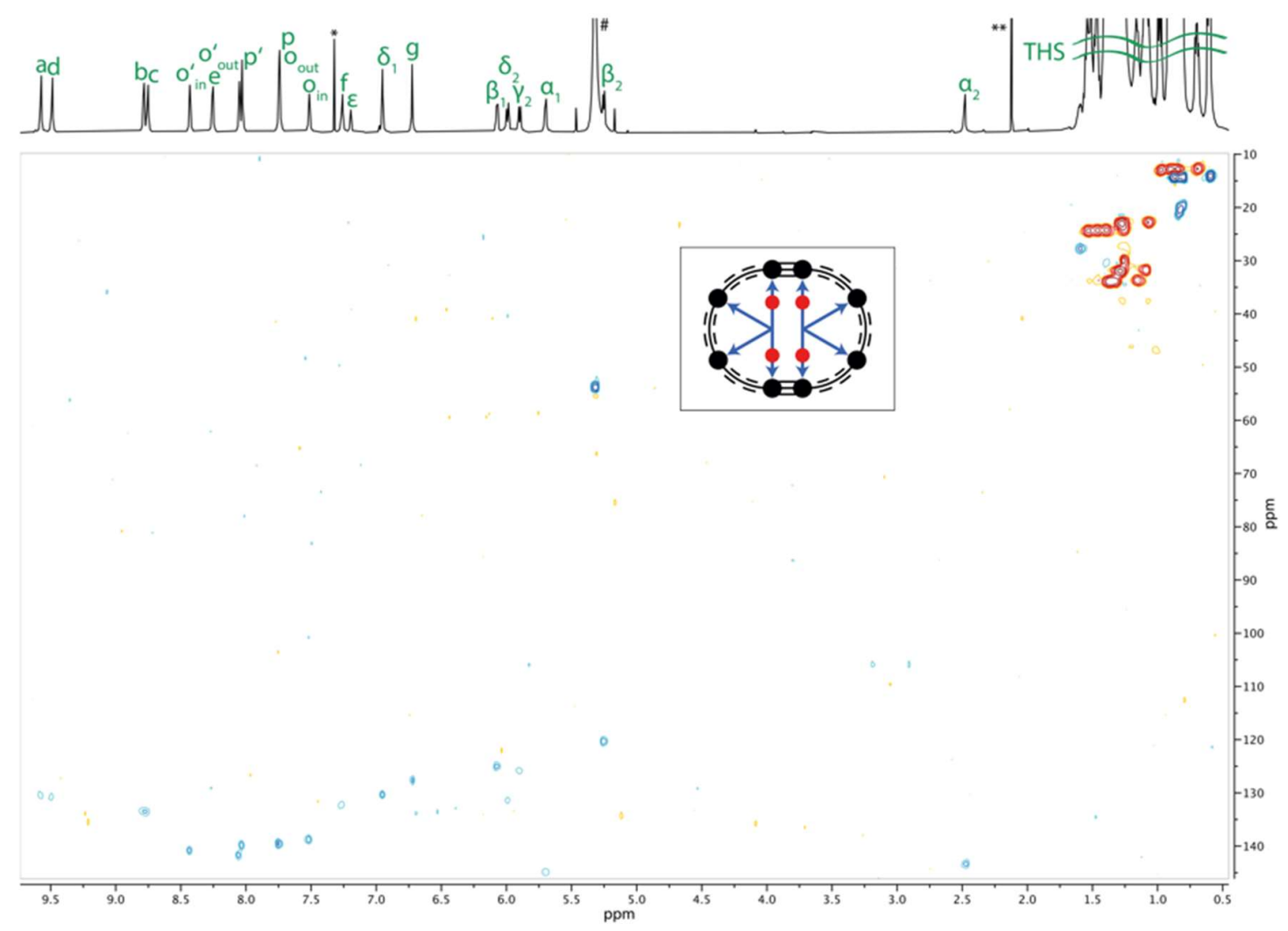

Figure S76. ${ }^{1} \mathrm{H}^{-13} \mathrm{C} \mathrm{HSQC}$ spectrum of $c-\mathbf{P 8}\left[\mathbf{b}_{6} \mathbf{f}_{2}\right] \bullet\left(\mathbf{T 4}_{1,4 \mathrm{~F}}\right)_{2}\left(600 \mathrm{MHz}, \mathrm{CD}_{2} \mathrm{Cl}_{2}, 298 \mathrm{~K}\right)$.

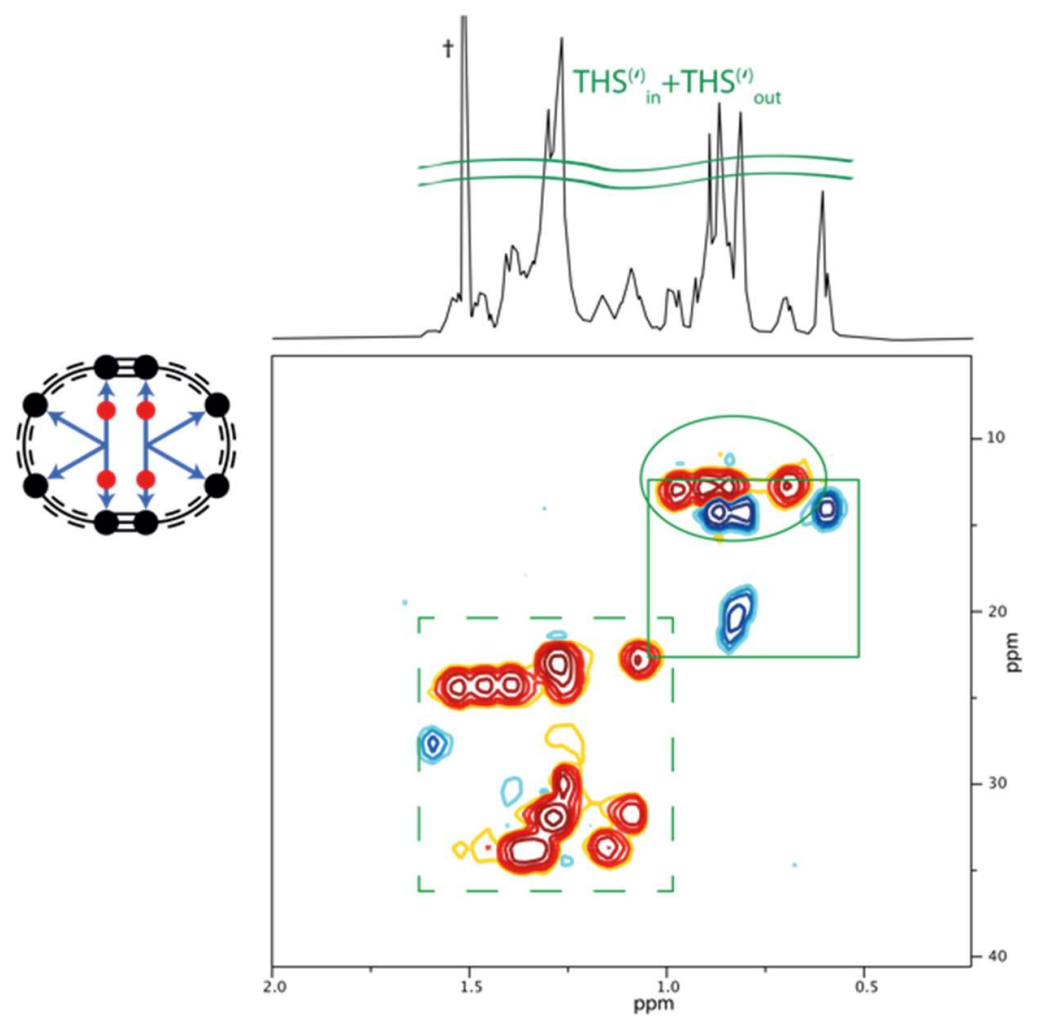

Figure S77. THS region of the ${ }^{1} \mathrm{H}-{ }^{13} \mathrm{C}$ HSQC spectrum of $\boldsymbol{c}-\mathbf{P} \mathbf{8}\left[\mathbf{b}_{6} \mathbf{f}_{2}\right] \bullet\left(\mathbf{T 4}_{1,4 \mathrm{~F}}\right)_{\mathbf{2}}\left(600 \mathrm{MHz}, \mathrm{CD}_{2} \mathrm{Cl}_{2}, 298 \mathrm{~K}\right)$. Si-R-CH resonances are indicated with a solid box, $\mathrm{Si}-\mathrm{CH}_{2}-\mathrm{R}$ resonances with a solid circle, and $\mathrm{Si}-\mathrm{CH}_{2}-\mathrm{C}_{4} \mathrm{H}_{8}-\mathrm{CH}_{3}$ resonances with a dashed box. 


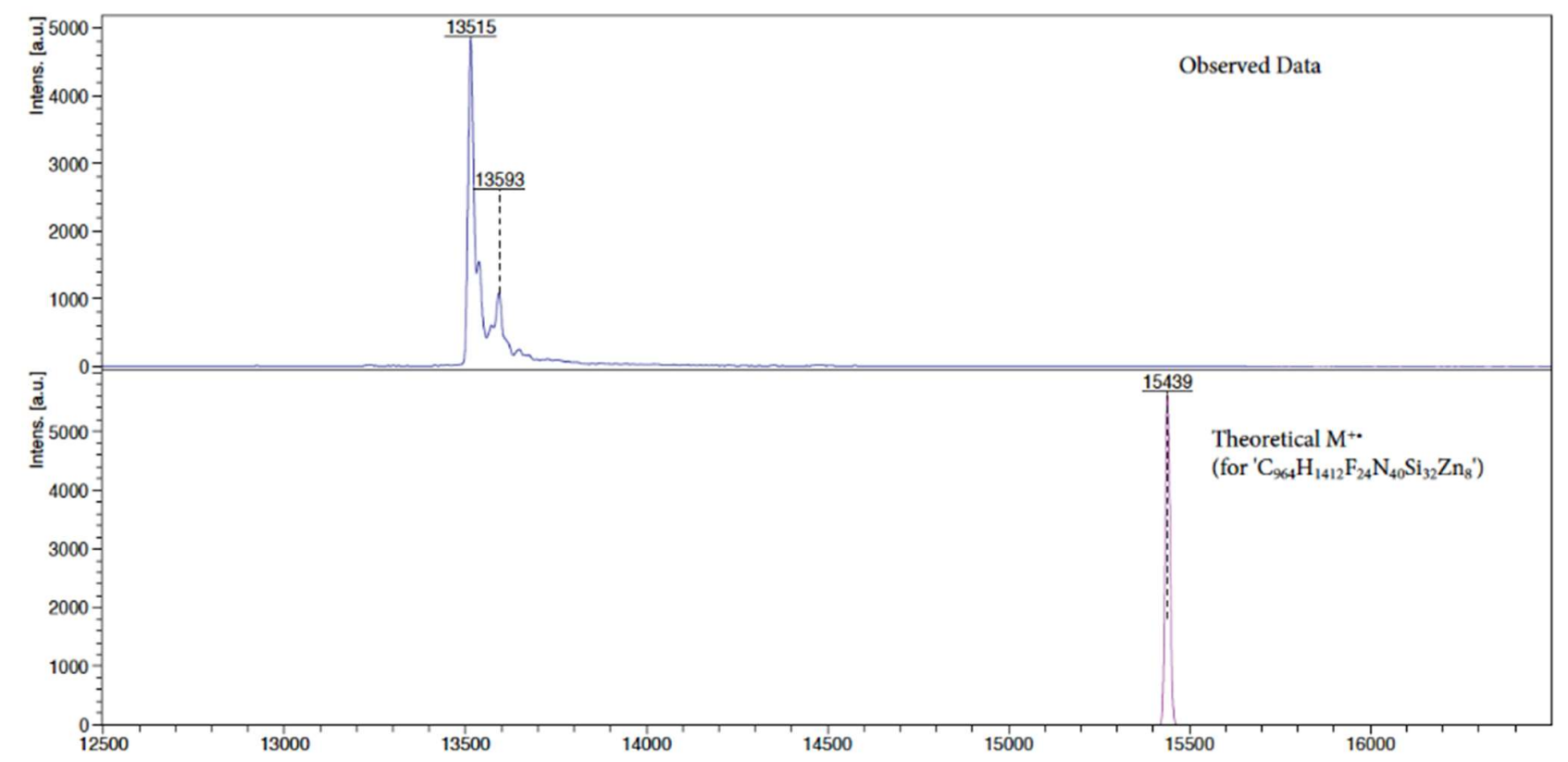

Figure S78. Experimental MALDI-ToF spectrum of $c-P 8\left[b_{6} f_{2}\right] \bullet\left(\mathbf{T 4}_{1,4 \mathrm{~F}}\right)_{2}$ (top) and simulated MALDI-TOF spectrum of $c-P 8\left[\mathbf{b}_{6} \mathbf{f}_{2}\right] \bullet\left(\mathbf{T 4}_{1,4 \mathrm{~F}}\right)_{2}^{+}$ $\left[\mathrm{C}_{964} \mathrm{H}_{1412} \mathrm{~F}_{24} \mathrm{~N}_{40} \mathrm{Si}_{32} \mathrm{Zn}_{8}\right]^{+}$(bottom).

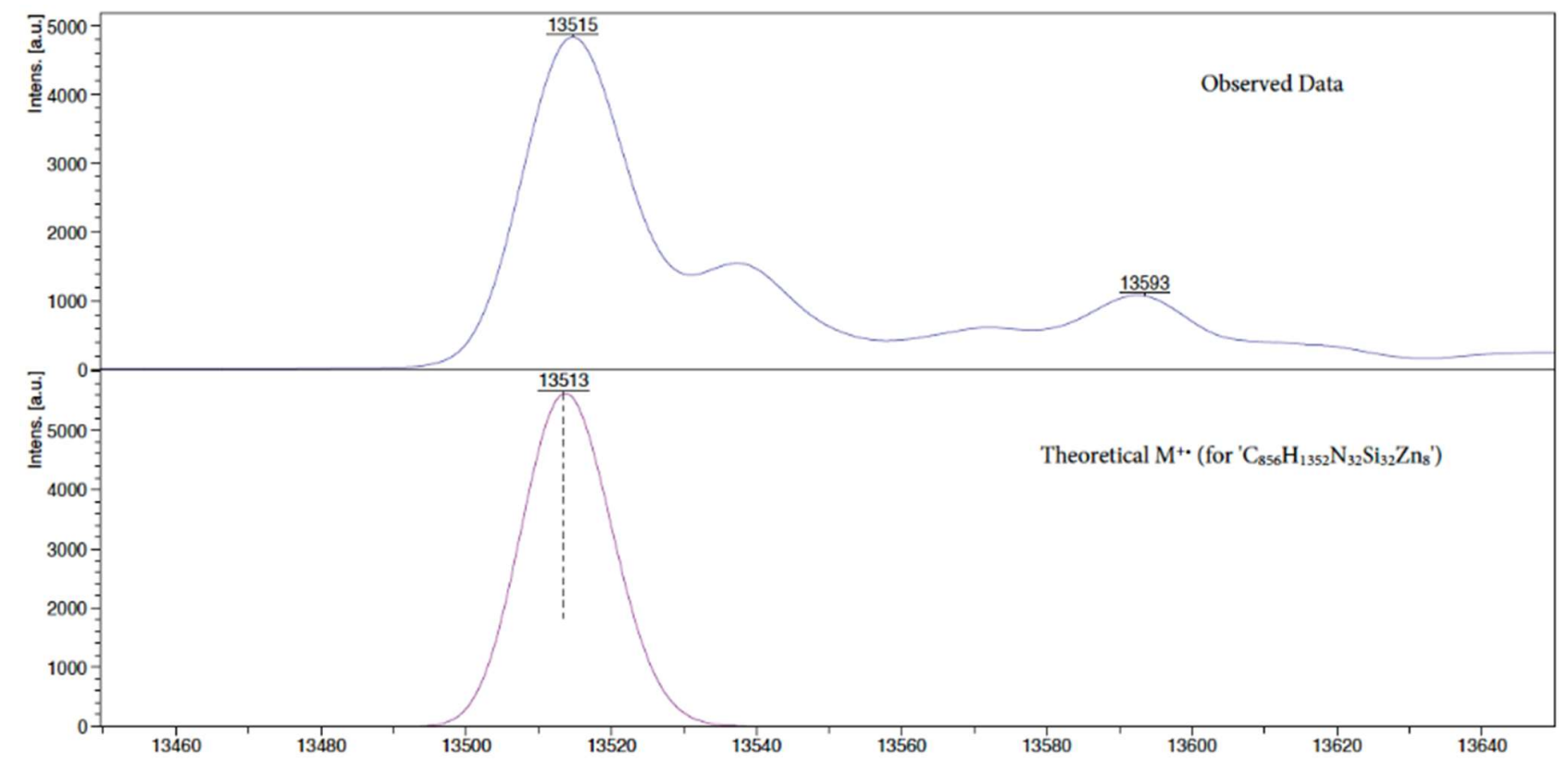

Figure S79. Enlarged region of the experimental MALDI-ToF spectrum of $c-P 8\left[b_{6} f_{2}\right] \bullet\left(T 4_{1,4 F}\right)_{2}$ (top) and simulated spectrum of $c-P 8\left[b_{6} f_{2}\right]^{+}$ $\left[\mathrm{C}_{856} \mathrm{H}_{1352} \mathrm{~N}_{32} \mathrm{Si}_{32} \mathrm{Zn}_{8}\right]^{+}$(bottom). 

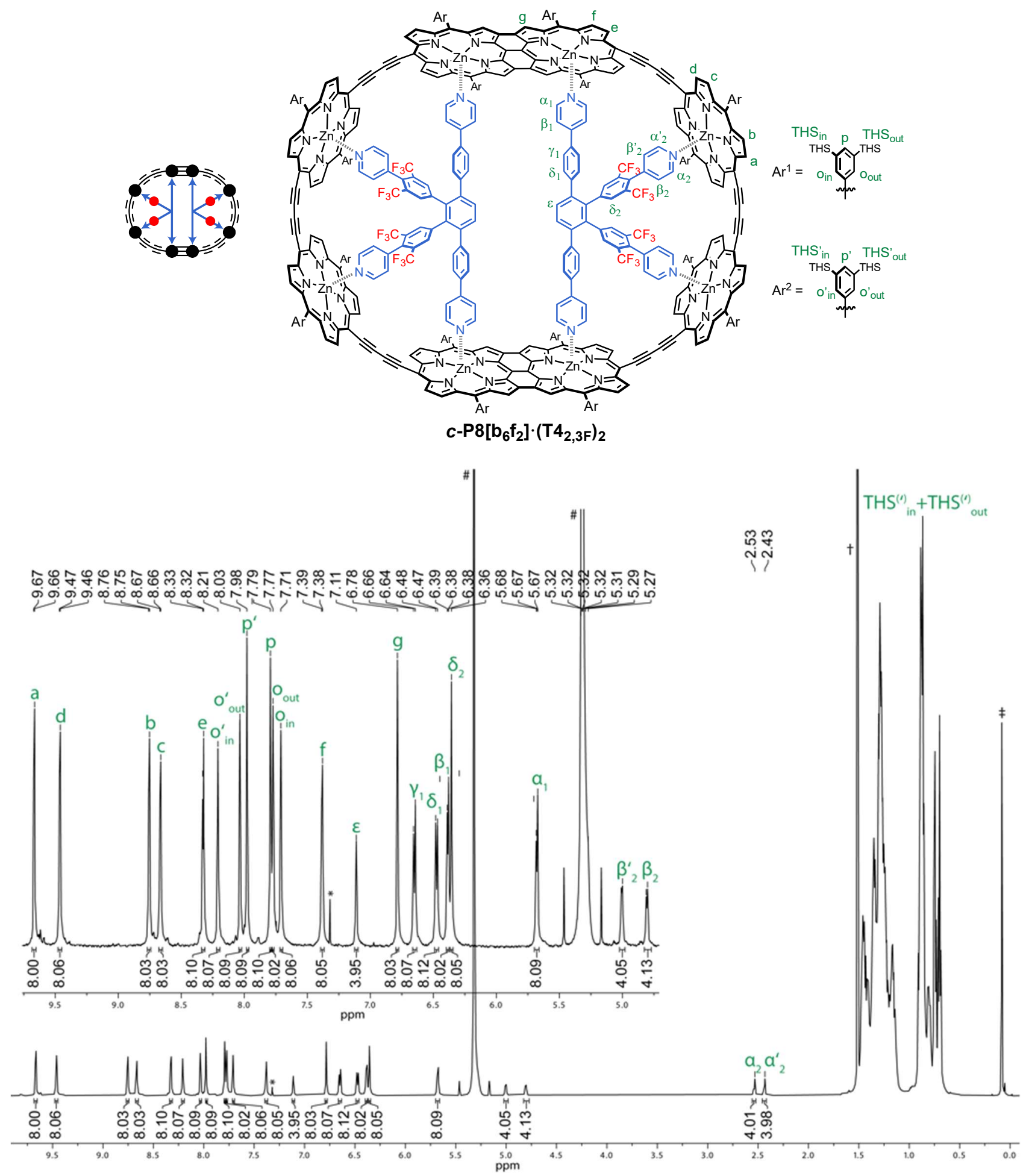

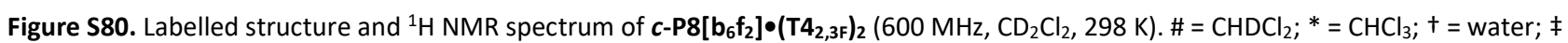
= silicon grease . 
Table S19. Complete ${ }^{1} \mathrm{H}$ NMR assignment and correlations for complex $c-\mathbf{P 8}\left[\mathbf{b}_{b} \mathbf{f}_{2}\right] \bullet\left(\mathbf{T 4}_{2,3 F}\right)_{2}$.

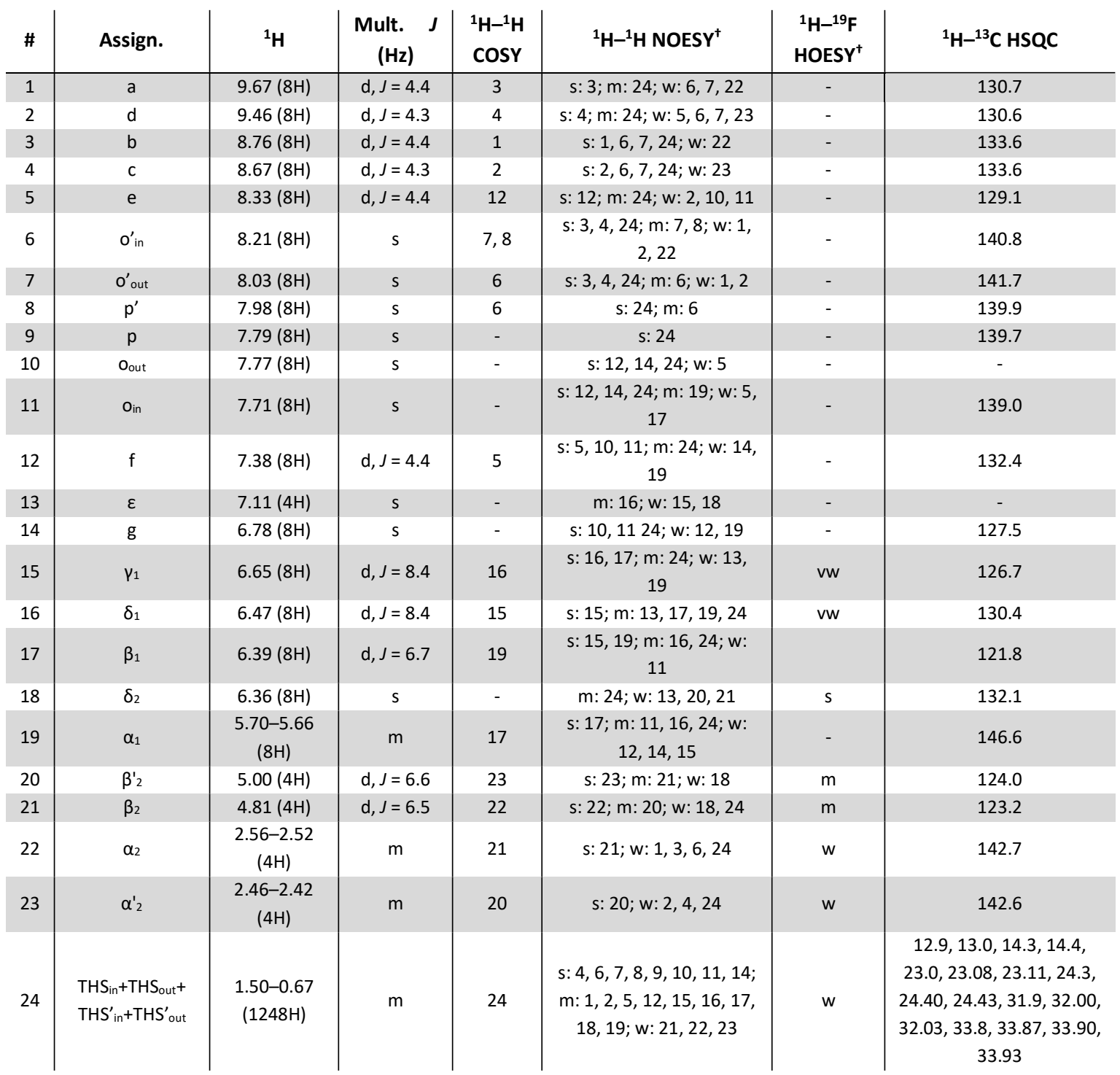

${ }^{+}$Relative correlation intensities are designated as: $s=$ strong, $m=$ medium, $w=$ weak, $v w=$ very weak. 


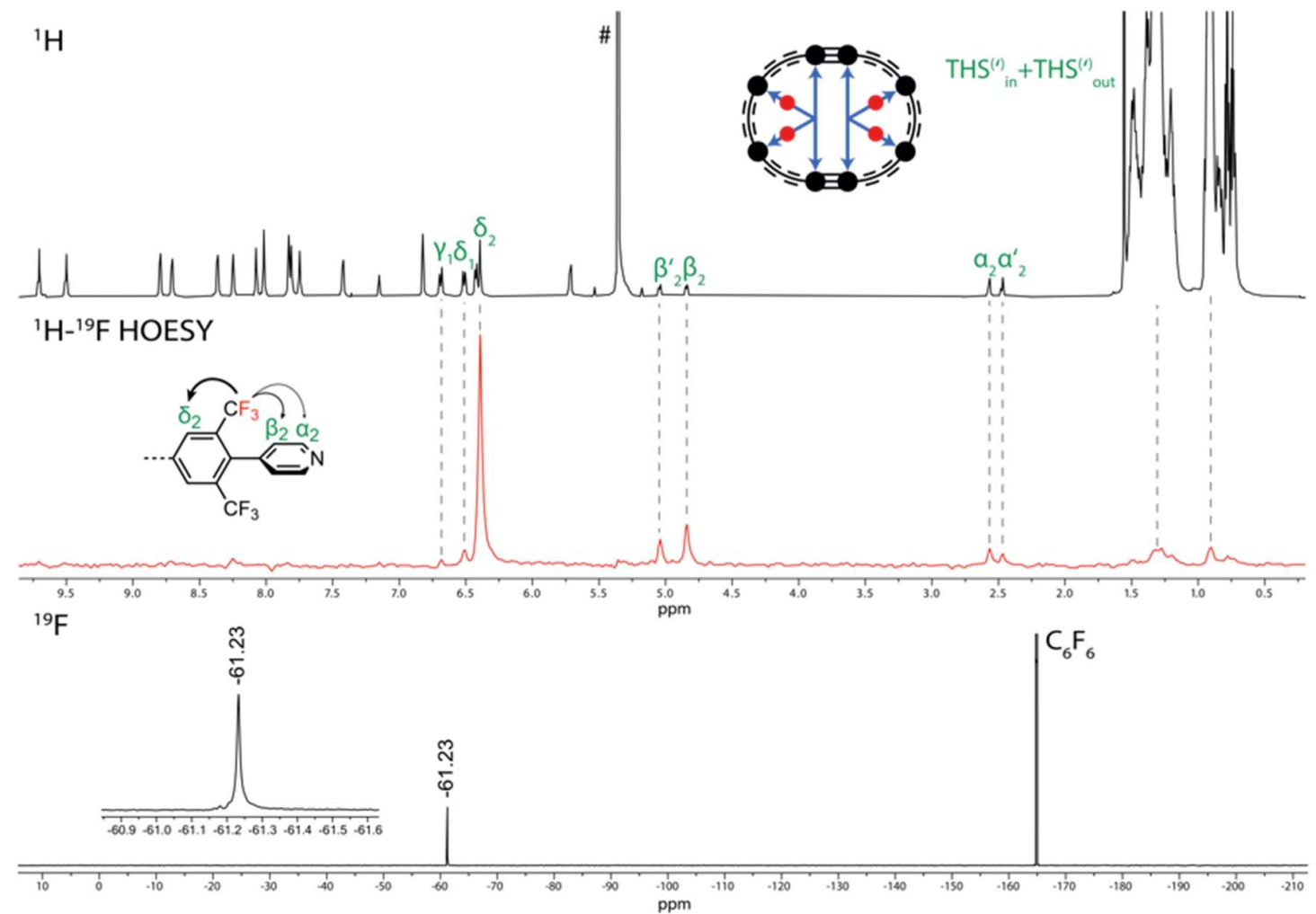

Figure S81. Combined ${ }^{1} \mathrm{H}$ (top), $1 \mathrm{D}^{1} \mathrm{H}^{-19} \mathrm{~F}$ HOESY (middle, red), and ${ }^{19} \mathrm{~F}$ (bottom) spectra of $\boldsymbol{c}$-P8 $\left[\mathbf{b}_{6} \mathbf{f}_{2}\right] \bullet\left(\mathrm{T4}_{2,3 \mathrm{~F}}\right)_{2}\left(500 \mathrm{MHz}, \mathrm{CD}_{2} \mathrm{Cl}_{2}, 298 \mathrm{~K}\right)$.

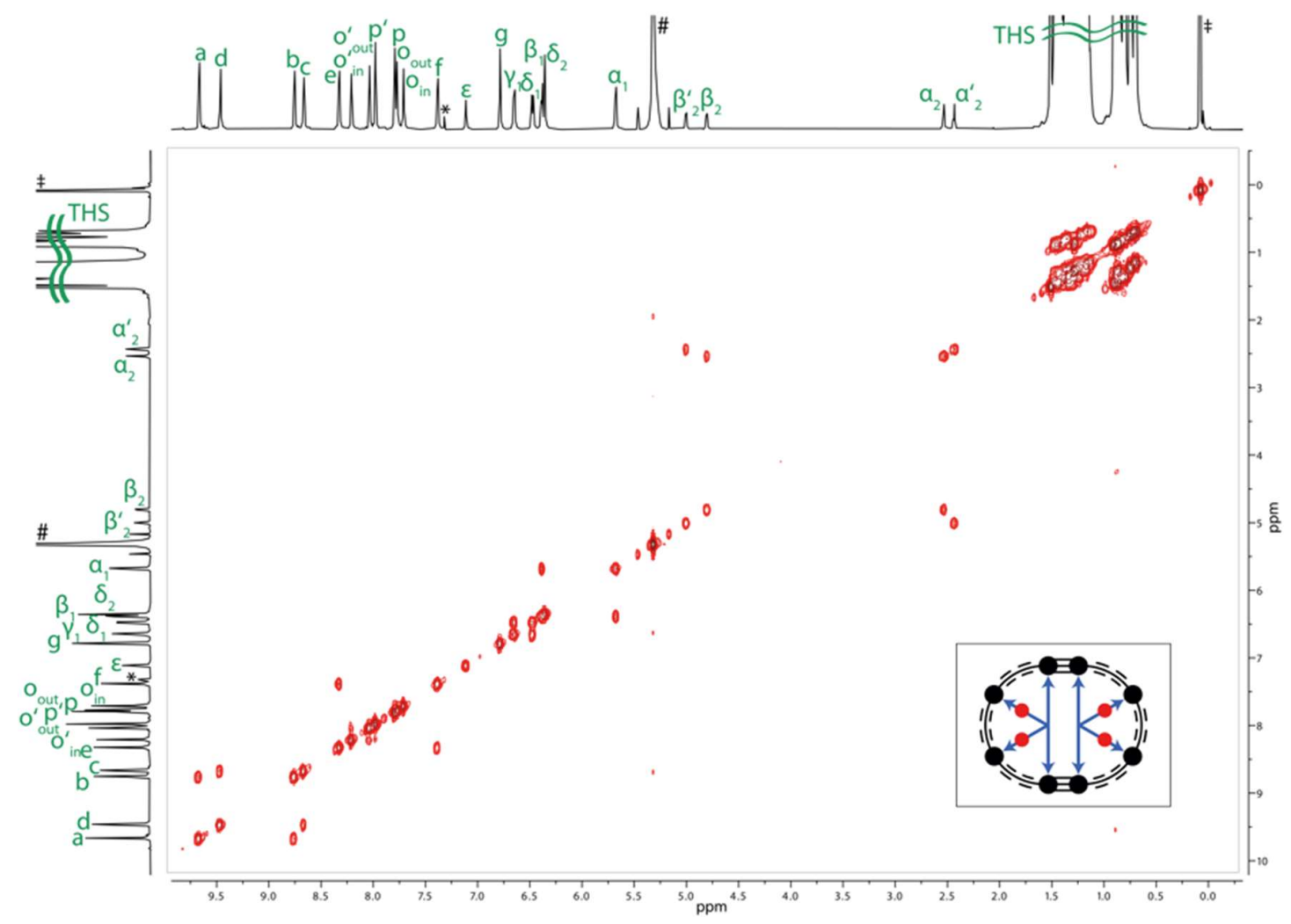

Figure S82. ${ }^{1} \mathrm{H}-{ }^{1} \mathrm{H}$ COSY spectrum of $\boldsymbol{c}-\mathbf{P} 8\left[\mathbf{b}_{6} \mathrm{f}_{2}\right] \bullet\left(\mathrm{T4}_{2,3 \mathrm{~F}}\right)_{2}\left(600 \mathrm{MHz}, \mathrm{CD}_{2} \mathrm{Cl}_{2}, 298 \mathrm{~K}\right)$. 


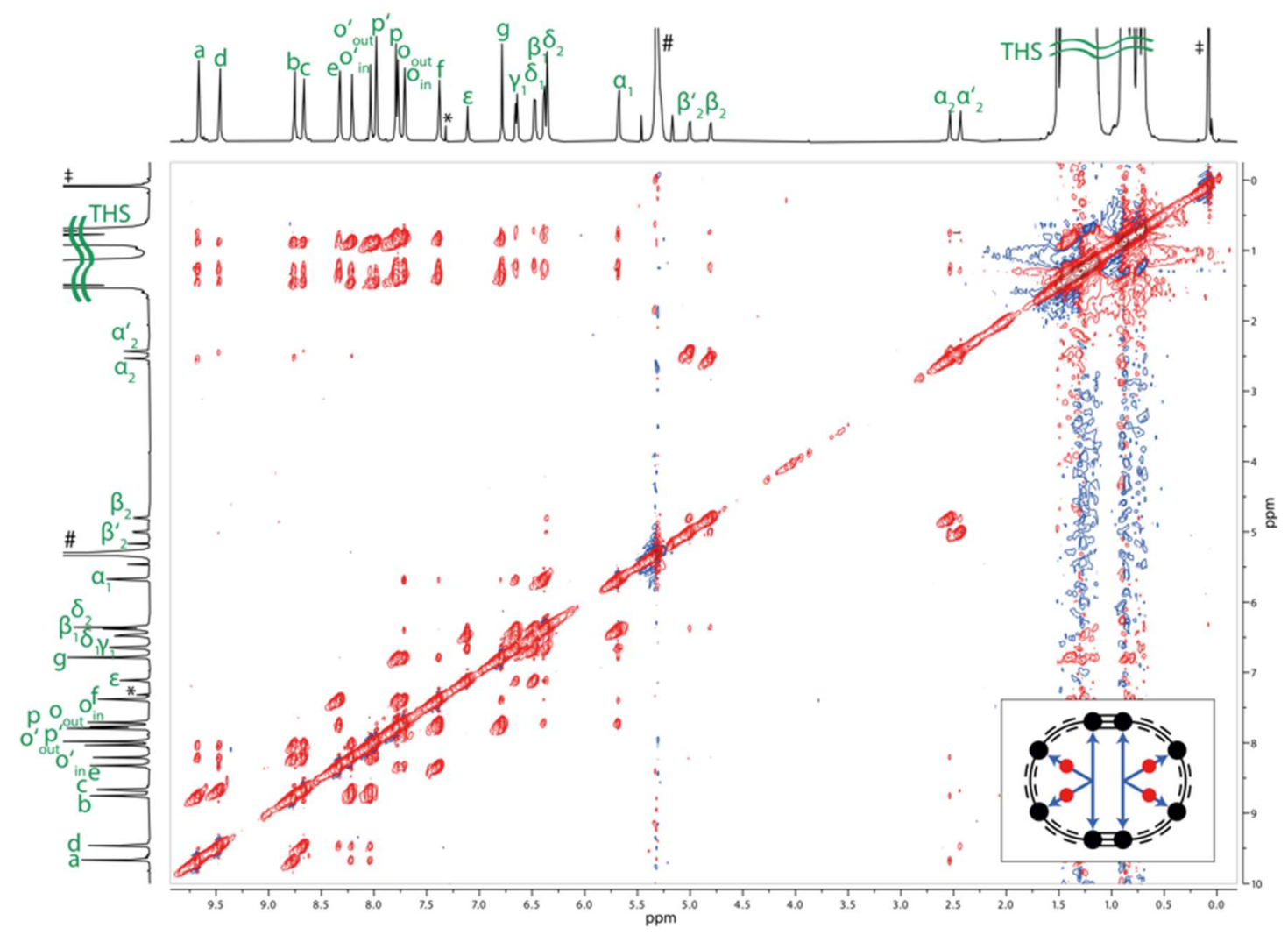

Figure S83. ${ }^{1} \mathrm{H}-{ }^{1} \mathrm{H}$ NOESY spectrum of $c-P 8\left[b_{6} f_{2}\right] \bullet\left(\mathbf{T 4}_{2,3 F}\right)_{2}\left(600 \mathrm{MHz}, \mathrm{CD}_{2} \mathrm{Cl}_{2}, 298 \mathrm{~K}\right)$.

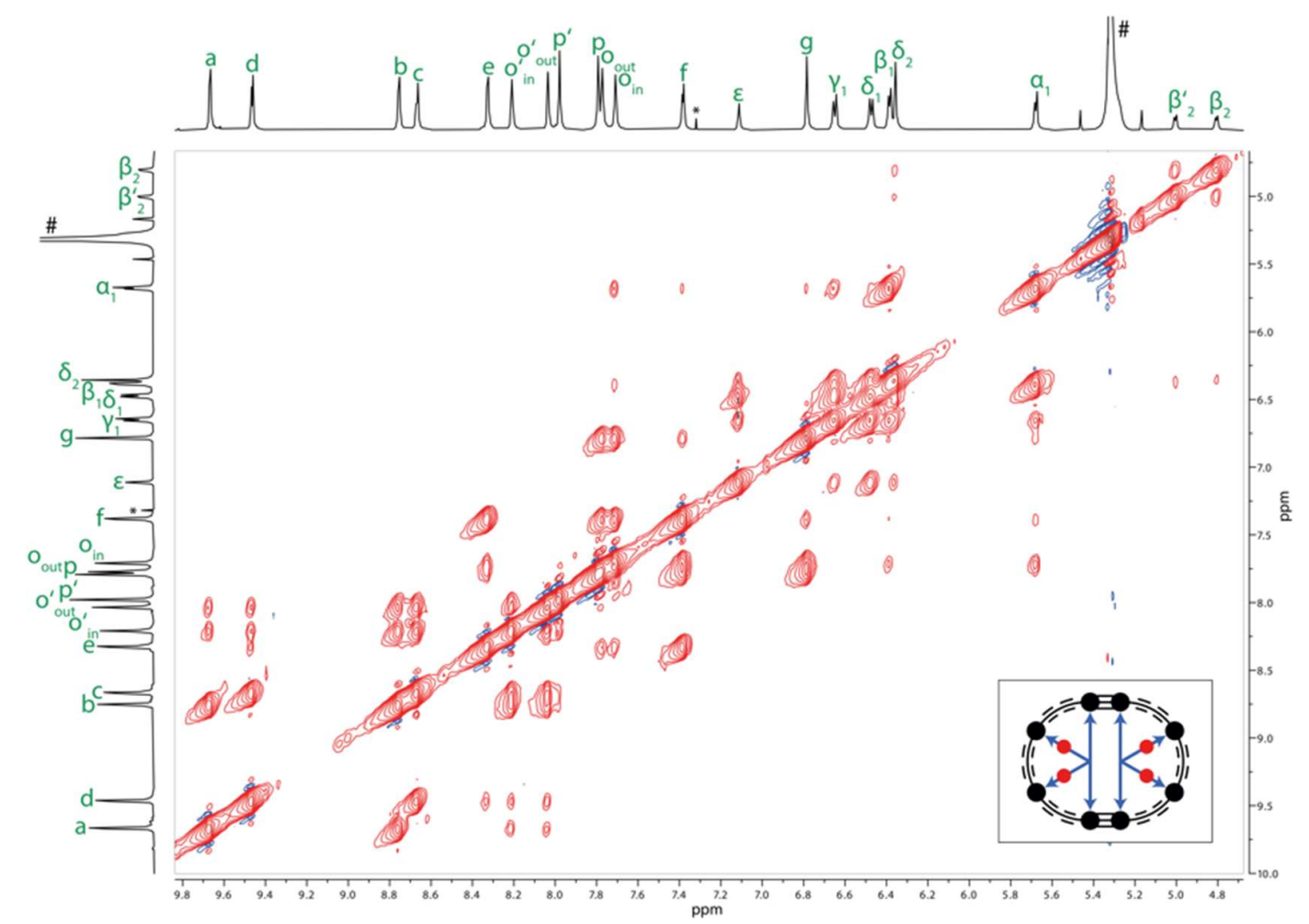

Figure S84. Enlarged region of the NOESY spectrum of $\boldsymbol{c}-\mathbf{P 8}\left[\mathbf{b}_{\mathbf{6}} \mathbf{f}_{\mathbf{2}}\right] \bullet\left(\mathbf{T 4}_{2,3 \mathrm{~F}}\right)_{2}\left(600 \mathrm{MHz}, \mathrm{CD}_{2} \mathrm{Cl}_{2}, 298 \mathrm{~K}\right)$. 


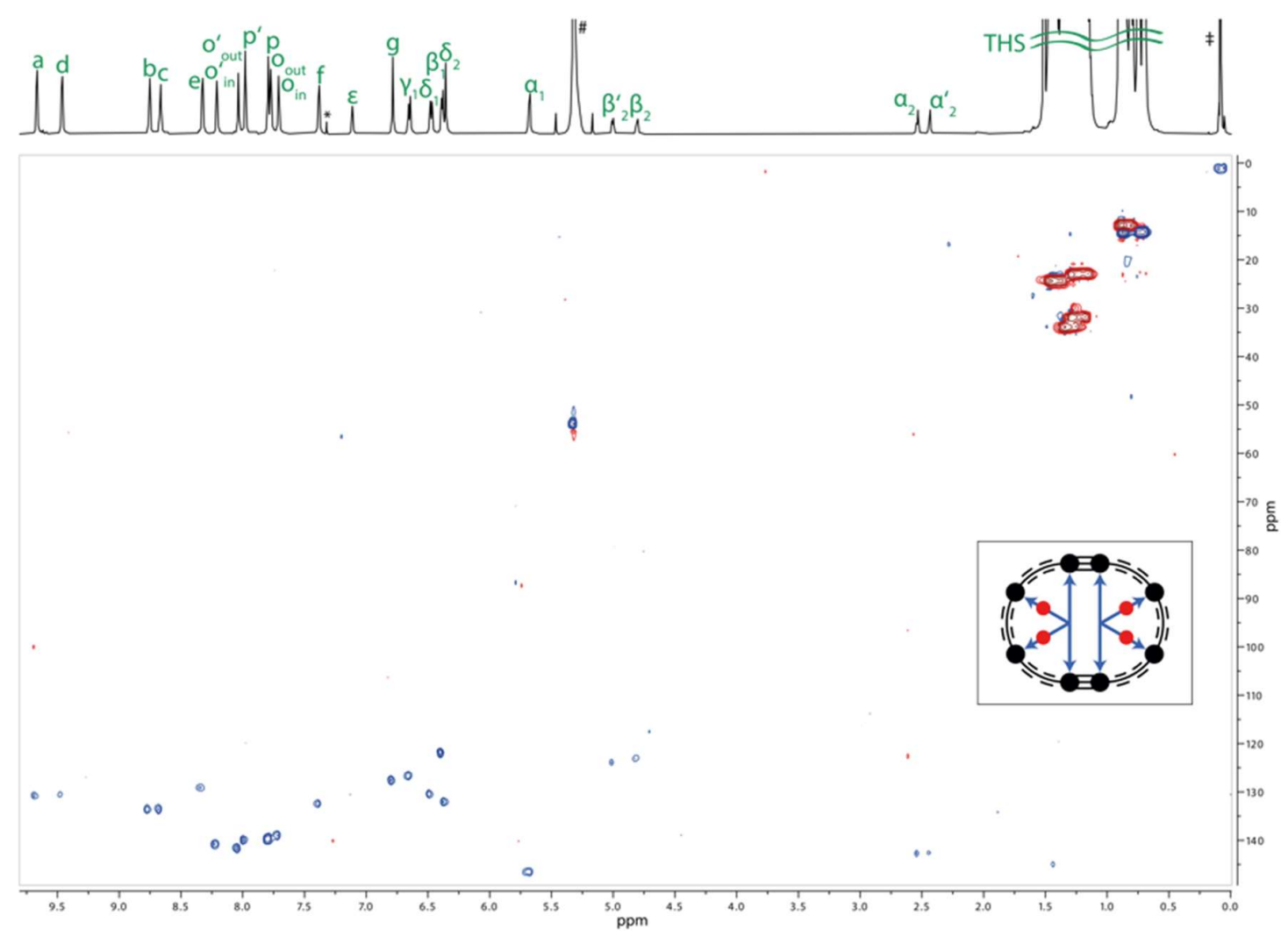

Figure S85. ${ }^{1} \mathrm{H}-{ }^{13} \mathrm{C} \mathrm{HSQC}$ spectrum of $c-\mathbf{P 8}\left[\mathbf{b}_{6} \mathrm{f}_{2}\right] \bullet\left(\mathbf{T 4}_{2,3 \mathrm{~F}}\right)_{2}\left(600 \mathrm{MHz}, \mathrm{CD}_{2} \mathrm{Cl}_{2}, 298 \mathrm{~K}\right)$.

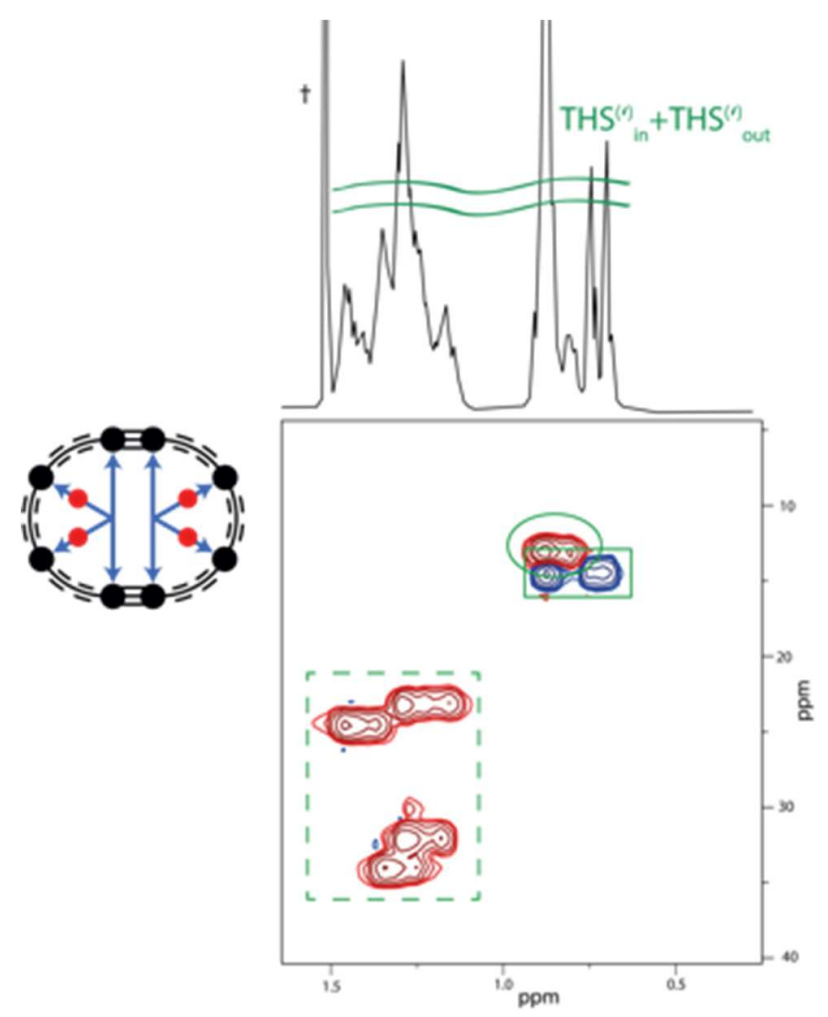

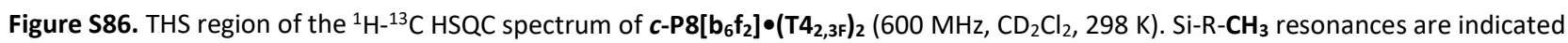
with a solid box, $\mathrm{Si}-\mathrm{CH}_{2}-\mathrm{R}$ resonances with a solid circle, and $\mathrm{Si}-\mathrm{CH}_{2}-\mathrm{C}_{4} \mathrm{H}_{8}-\mathrm{CH}_{3}$ resonances with a dashed box. 


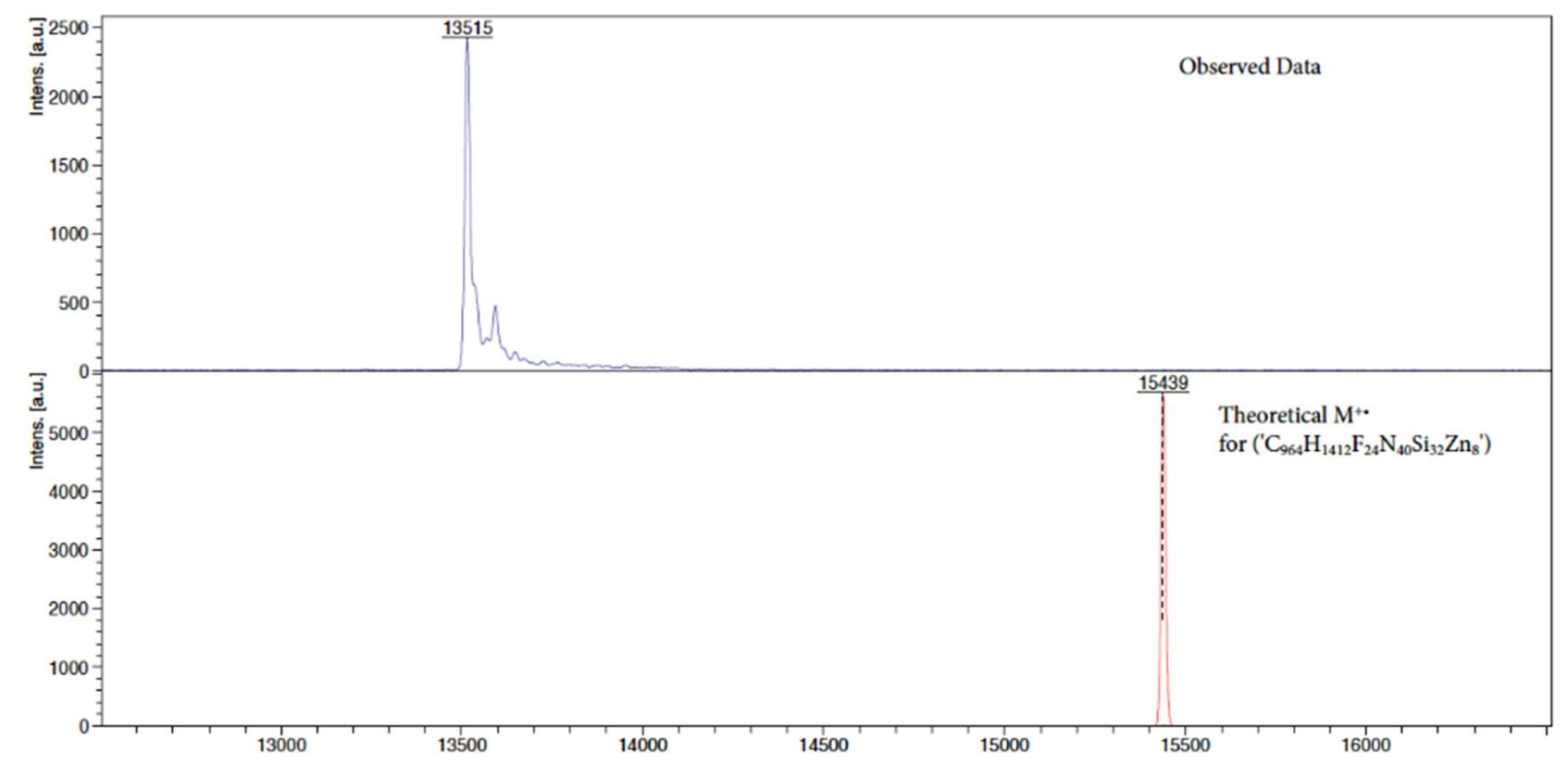

Figure S87. Experimental MALDI-ToF spectrum of $c-P 8\left[b_{6} f_{2}\right] \bullet\left(T 4_{2,3 F}\right)_{2}$ (top) and simulated MALDI-TOF spectrum of $c-P 8\left[b_{6} f_{2}\right] \bullet\left(T 4_{2,3 F}\right)_{2}{ }^{+}$ $\left[\mathrm{C}_{964} \mathrm{H}_{1412} \mathrm{~F}_{24} \mathrm{~N}_{40} \mathrm{Si}_{32} \mathrm{Zn}_{8}\right]^{+}$(bottom).

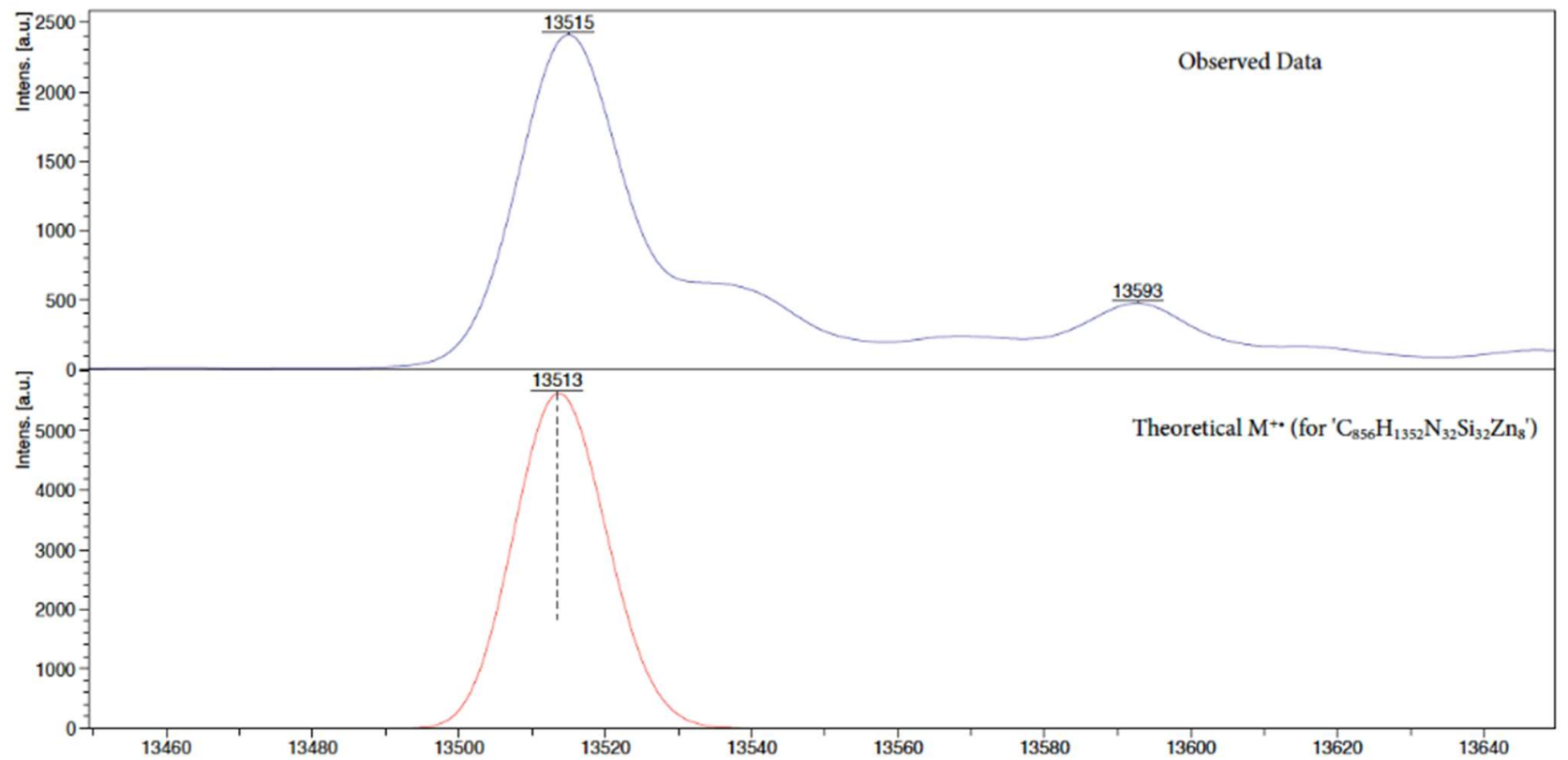

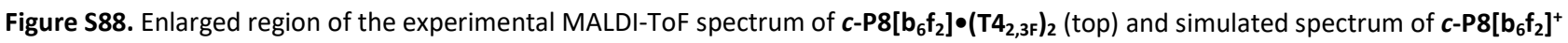
$\left[\mathrm{C}_{856} \mathrm{H}_{1352} \mathrm{~N}_{32} \mathrm{Si}_{32} \mathrm{Zn}_{8}\right]^{+}$(bottom). 

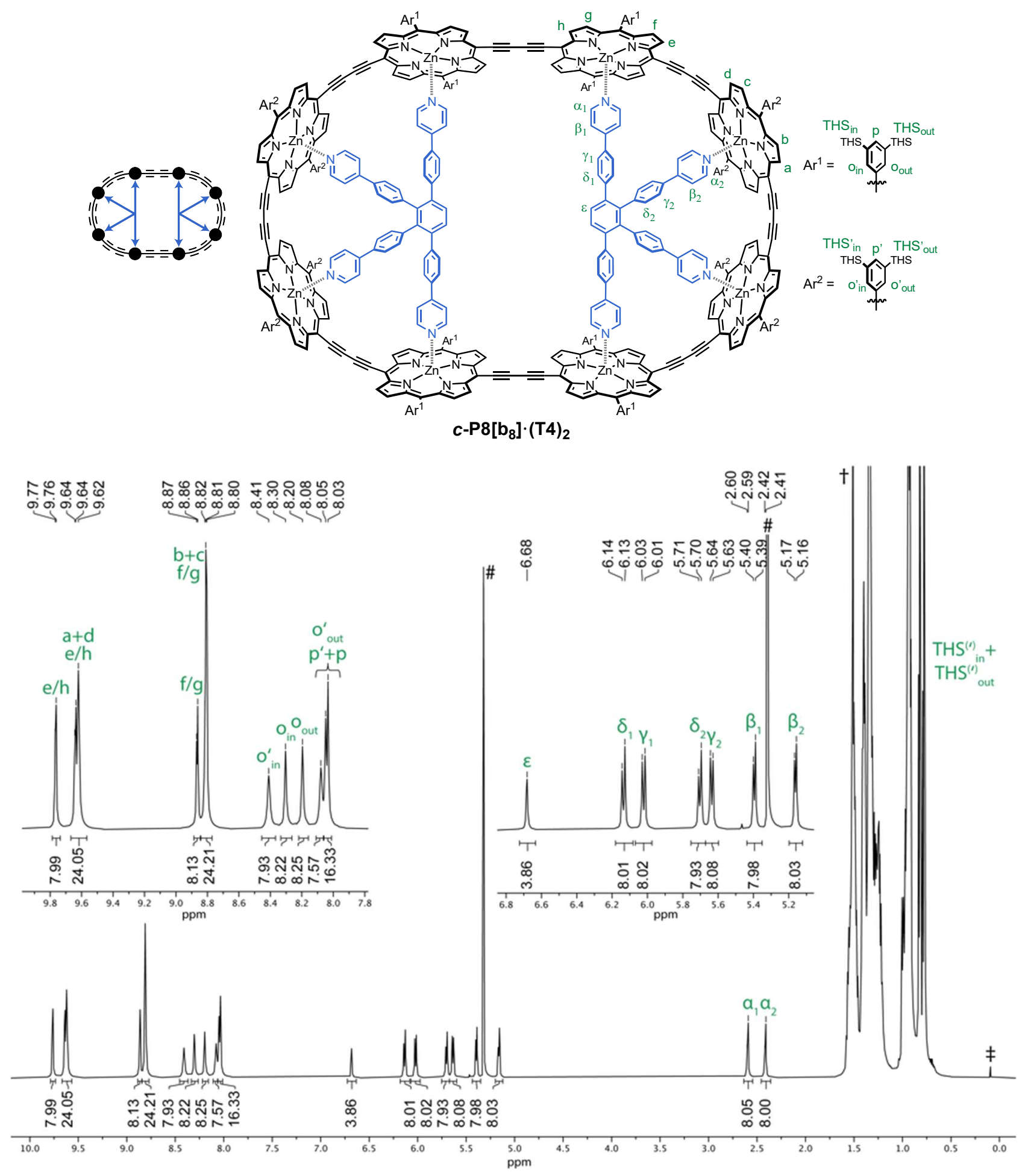

Figure S89. Assigned structure and ${ }^{1} \mathrm{H}$ NMR spectrum of $\boldsymbol{c}-\mathbf{P 8}\left[\mathbf{b}_{8}\right] \bullet(T 4)_{2}\left(600 \mathrm{MHz}, \mathrm{CD}_{2} \mathrm{Cl}_{2}, 298 \mathrm{~K}\right)$. \#= $\mathrm{CHDCl}_{2} ; \dagger=$ water; $\neq=$ silicon grease. 
Table S20. Complete ${ }^{1} \mathrm{H}$ NMR assignment and correlations for complex $c-\mathbf{P 8}\left[\mathbf{b}_{\mathbf{8}}\right] \bullet(\mathbf{T} 4)_{2}$.

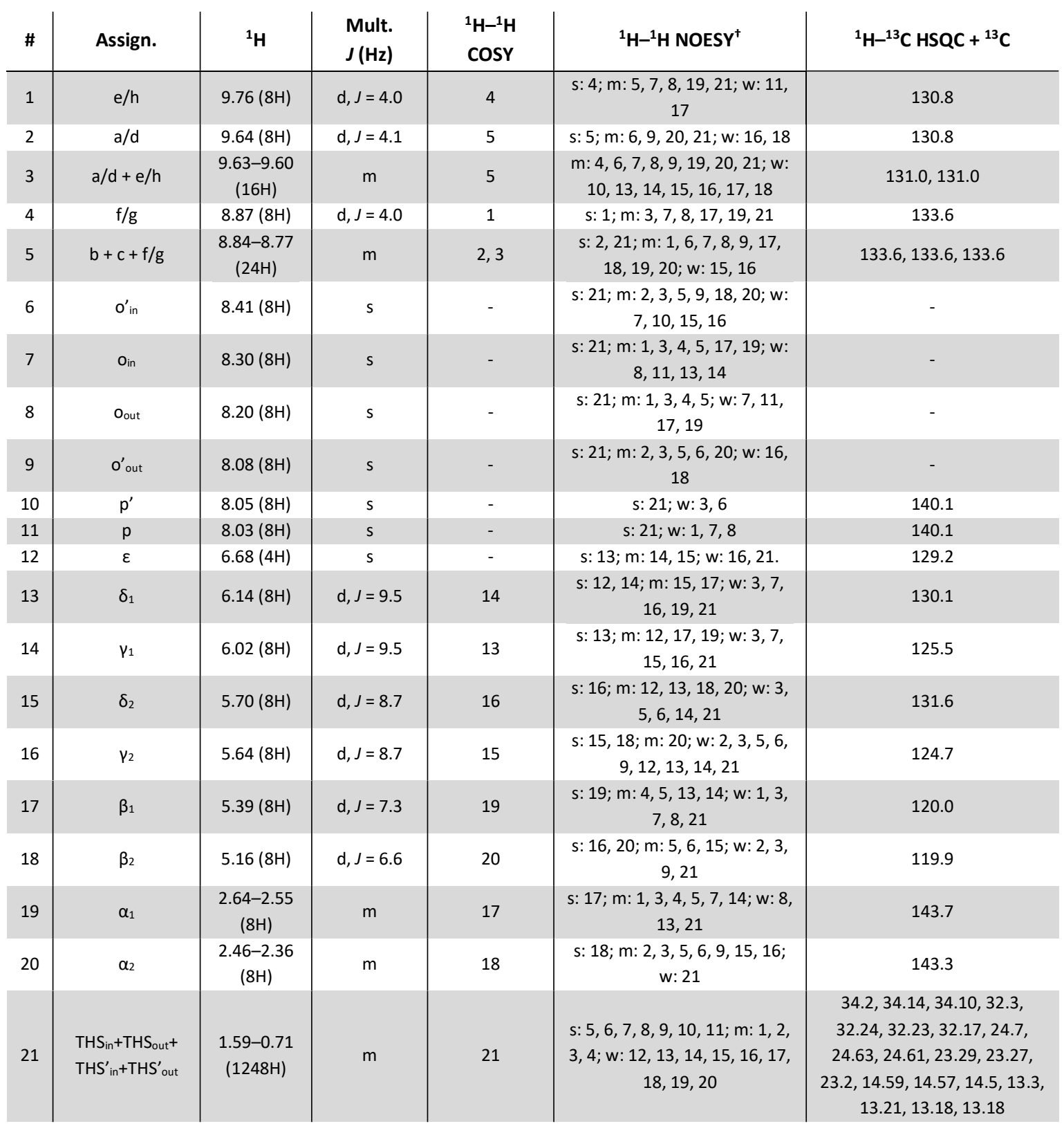

${ }^{\dagger}$ Relative correlation intensities are designated as: $\mathrm{s}=$ strong, $\mathrm{m}=$ medium, $\mathrm{w}=$ weak. 


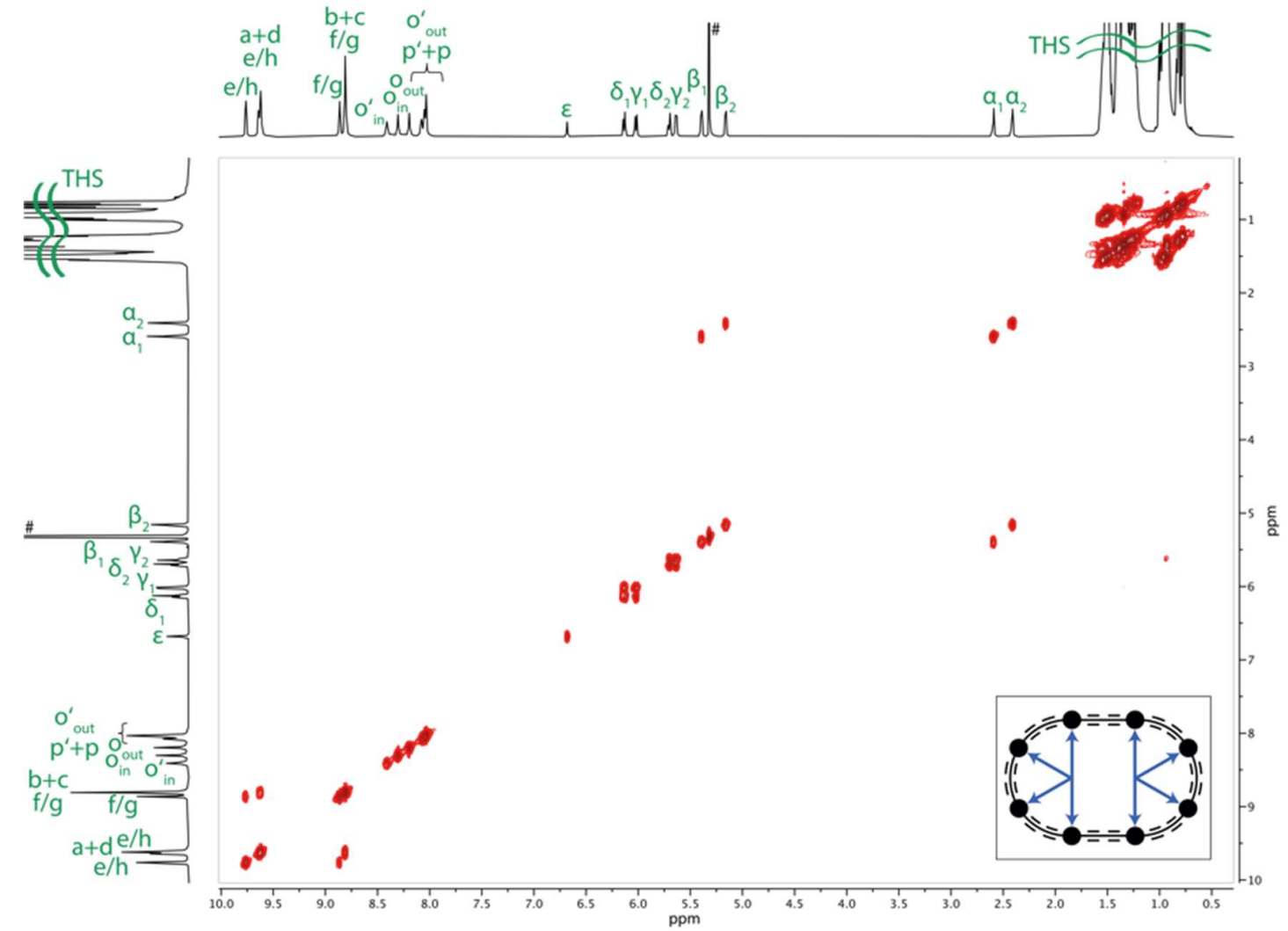

Figure S90. ${ }^{1} \mathrm{H}^{1}{ }^{1} \mathrm{H}$ COSY spectrum of $c-P 8\left[b_{8}\right] \bullet(T 4)_{2}\left(600 \mathrm{MHz}, \mathrm{CD}_{2} \mathrm{Cl}_{2}, 298 \mathrm{~K}\right)$.

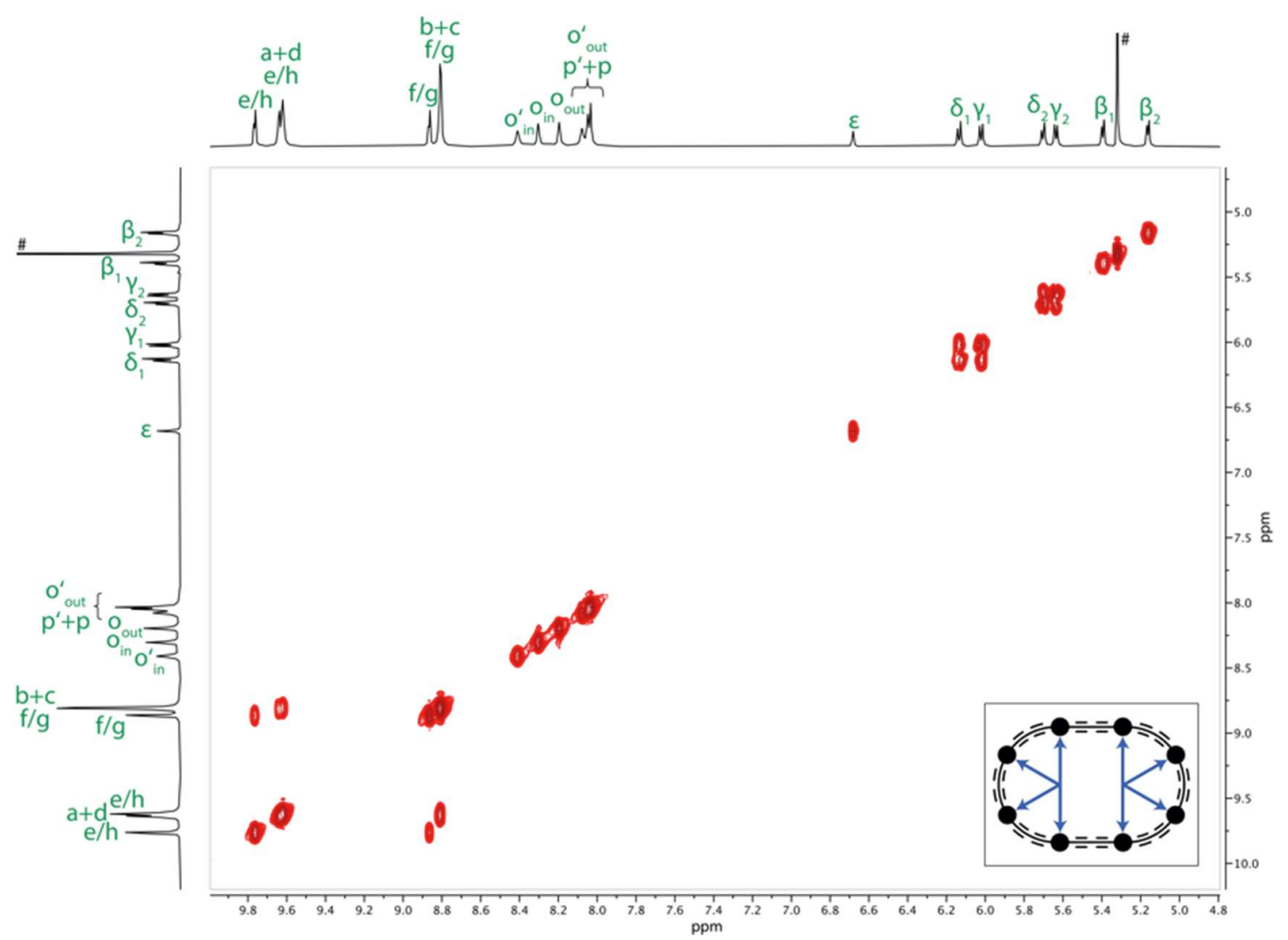

Figure S91. Enlarged region of the COSY spectrum of $c-\mathbf{P 8}\left[\mathbf{b}_{8}\right] \bullet\left(\mathrm{T}_{4}\right)_{2}\left(600 \mathrm{MHz}, \mathrm{CD}_{2} \mathrm{Cl}_{2}, 298 \mathrm{~K}\right)$. 


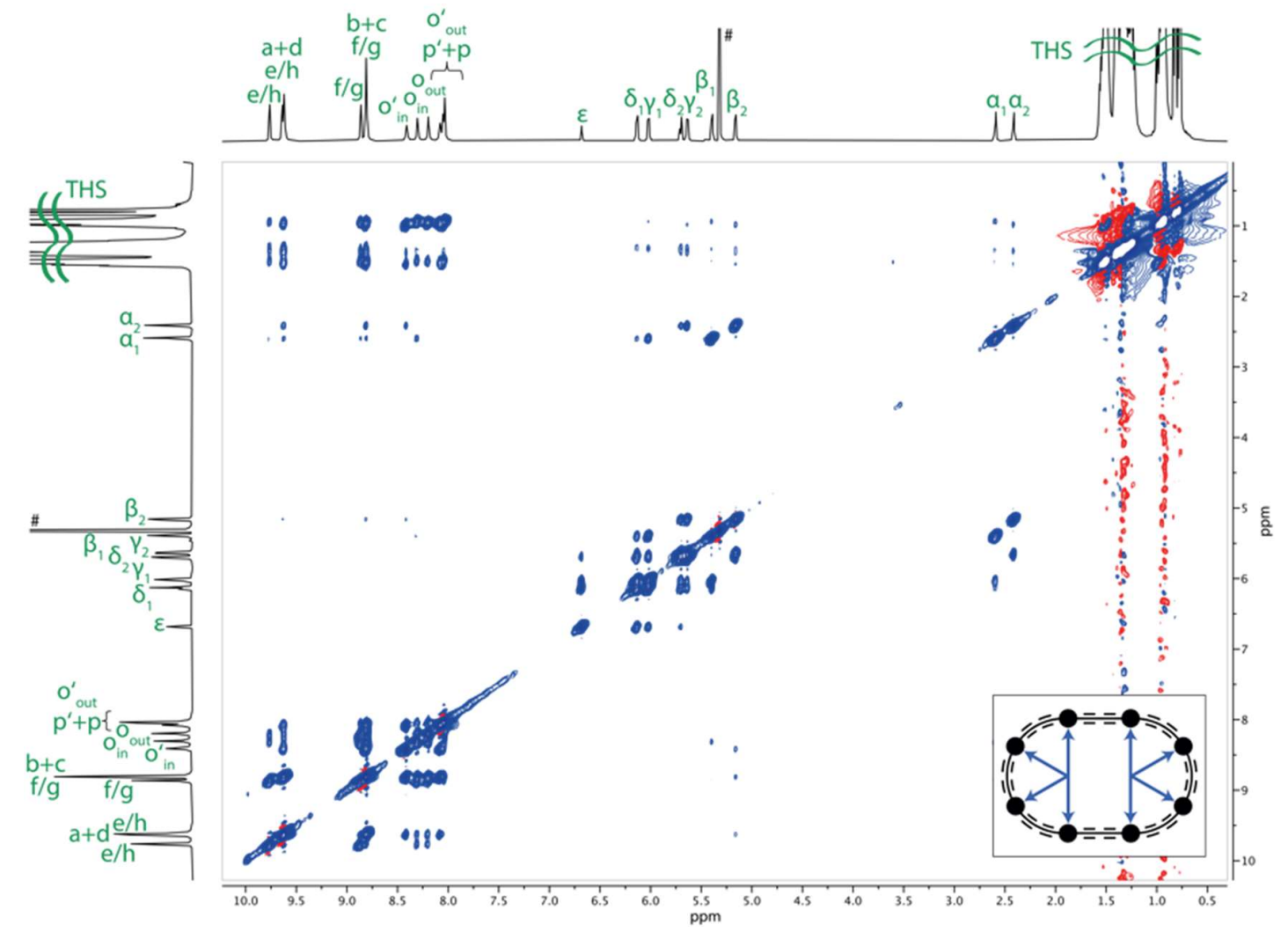

Figure S92. ${ }^{1} \mathrm{H}-{ }^{1} \mathrm{H}$ NOESY spectrum of $c-\mathrm{P} 8\left[\mathrm{~b}_{8}\right] \bullet(\mathrm{T} 4)_{2}\left(600 \mathrm{MHz}, \mathrm{CD}_{2} \mathrm{Cl}_{2}, 298 \mathrm{~K}\right)$.

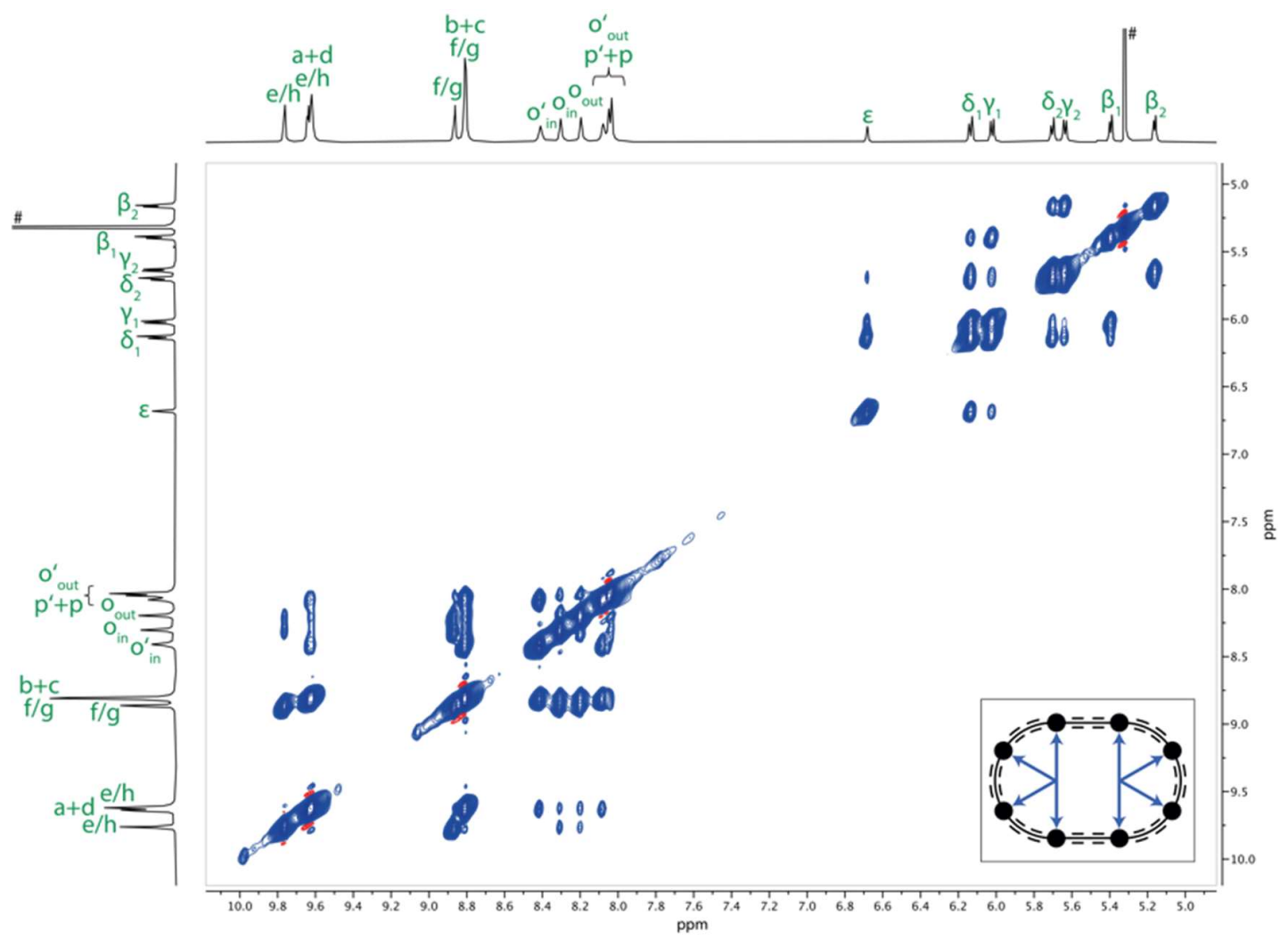

Figure S93. Enlarged region of the NOESY spectrum of $c-\mathbf{P 8}\left[\mathbf{b}_{\mathbf{8}}\right] \bullet\left(\mathrm{T}_{4}\right)_{\mathbf{2}}\left(600 \mathrm{MHz}, \mathrm{CD}_{2} \mathrm{Cl}_{2}, 298 \mathrm{~K}\right)$. 


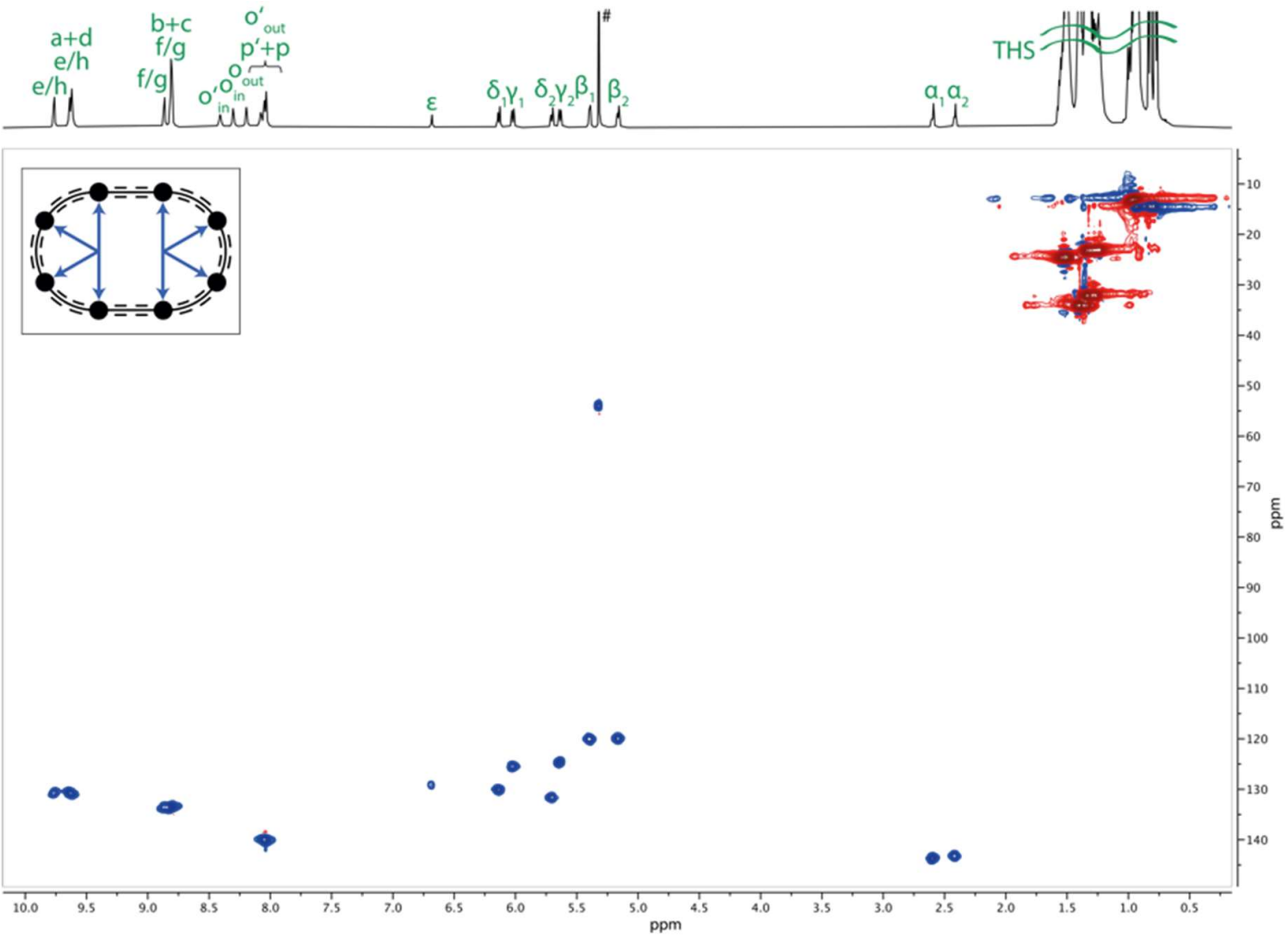

Figure S94. ${ }^{1} \mathrm{H}_{-}{ }^{13} \mathrm{C}$ HSQC spectrum of $c-\mathrm{P} 8\left[\mathrm{~b}_{8}\right] \bullet(\mathrm{T} 4)_{2}\left(600 \mathrm{MHz}, \mathrm{CD}_{2} \mathrm{Cl}_{2}, 298 \mathrm{~K}\right)$.

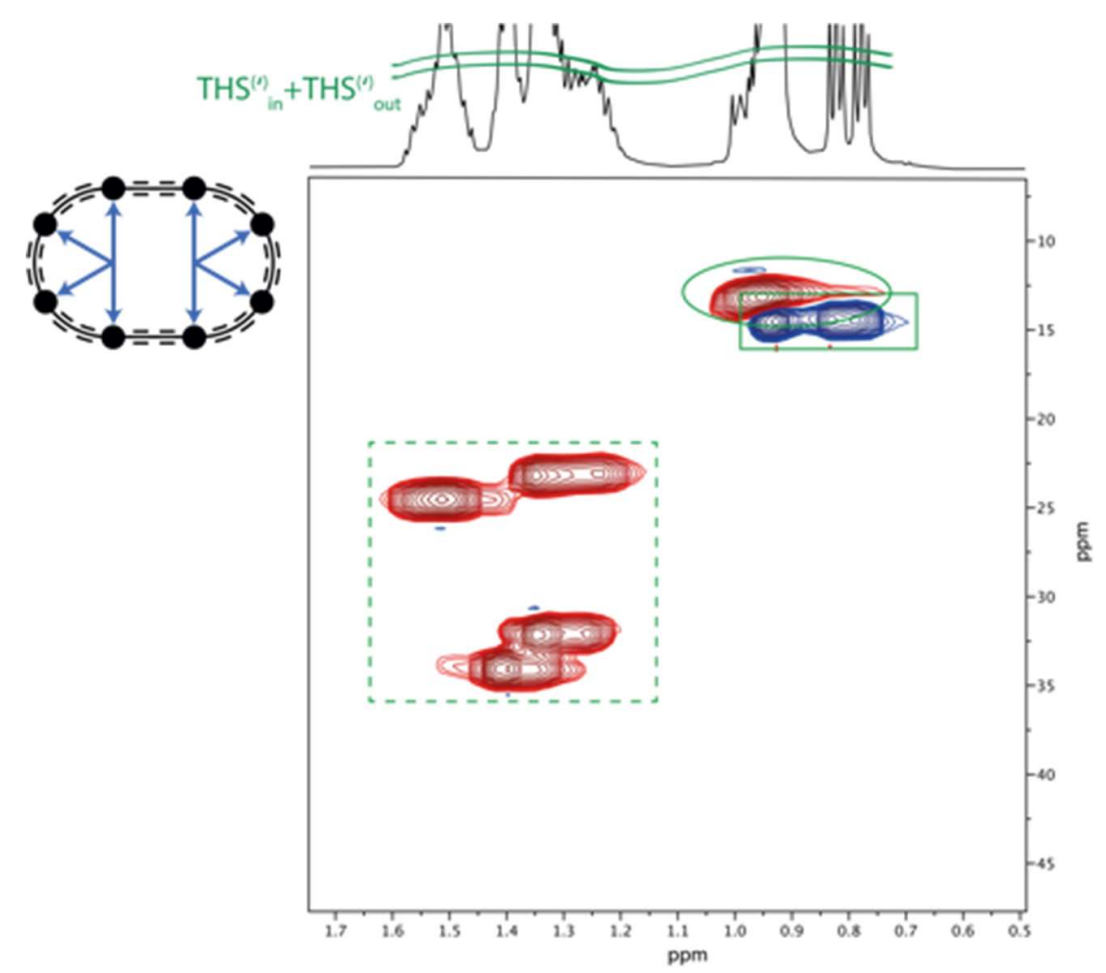

Figure S95. THS region of the ${ }^{1} \mathrm{H}_{-}{ }^{13} \mathrm{C} \mathrm{HSQC}$ spectrum of $\boldsymbol{c}-\mathbf{P 8}\left[\mathbf{b}_{8}\right] \bullet\left(\mathrm{T}_{4}\right)_{2}\left(600 \mathrm{MHz}, \mathrm{CD}_{2} \mathrm{Cl}_{2}, 298 \mathrm{~K}\right)$. $\mathrm{Si}-\mathrm{R}-\mathrm{CH}_{3}$ resonances are indicated with a solid box, $\mathrm{Si}-\mathrm{CH}_{2}-\mathrm{R}$ resonances with a solid circle, and $\mathrm{Si}-\mathrm{CH}_{2}-\mathrm{C}_{4} \mathrm{H}_{8}-\mathrm{CH}_{3}$ resonances with a dashed box. 


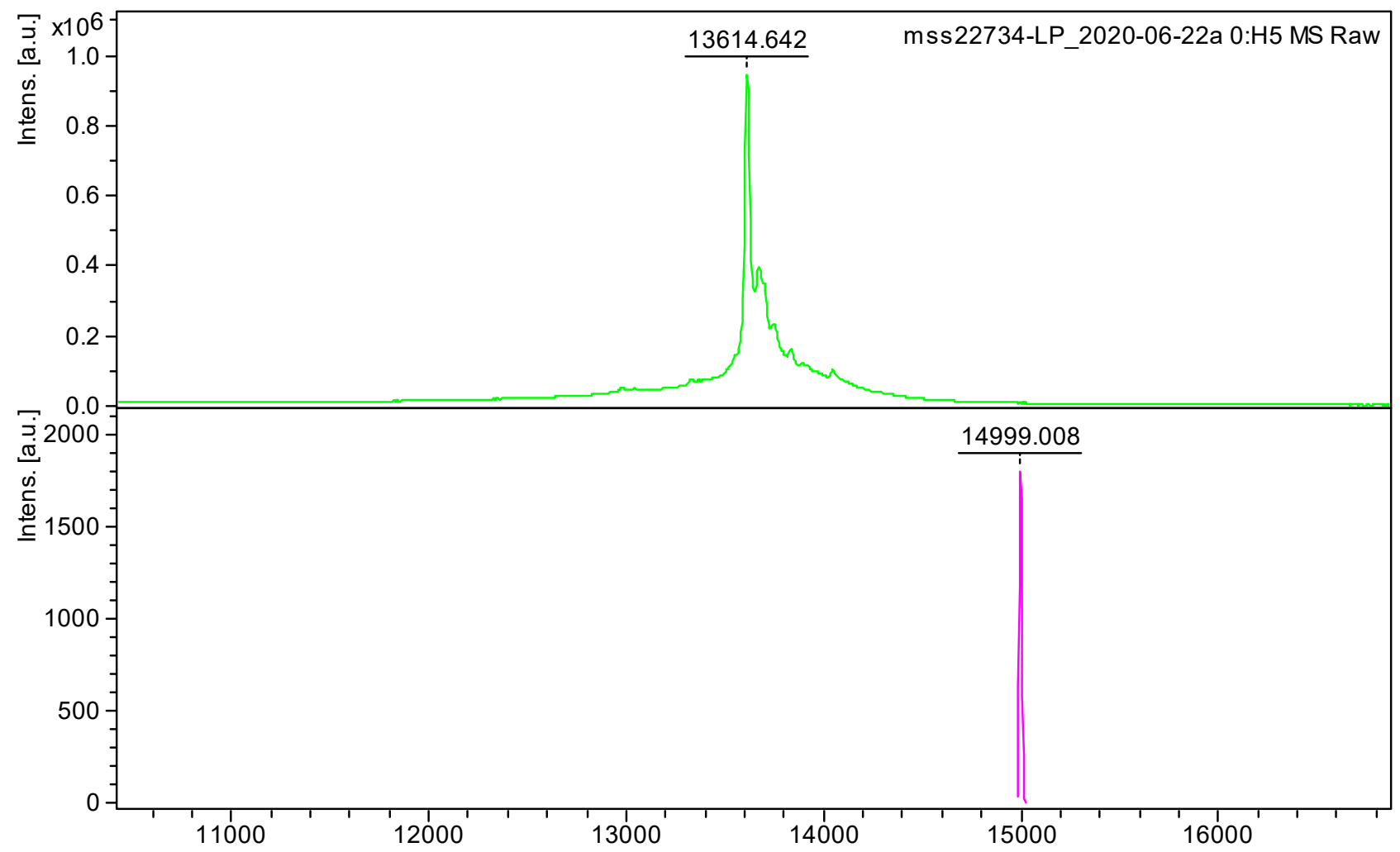

Figure S96. Experimental MALDI-ToF spectrum of $c-\mathbf{P 8}\left[\mathbf{b}_{8}\right] \bullet(T 4)_{2}$ (top) and simulated MALDI-TOF spectrum of $c-P 8\left[b_{8}\right] \bullet(T 4)_{2}{ }^{+}$

$\left[\mathrm{C}_{964} \mathrm{H}_{1412} \mathrm{~F}_{24} \mathrm{~N}_{40} \mathrm{Si}_{32} \mathrm{Zn}_{8}\right]^{+}$(bottom). Major peak corresponds to free $\boldsymbol{c}-\mathbf{P 8}\left[\mathbf{b}_{8}\right]^{+}\left[\mathrm{C}_{864} \mathrm{H}_{1360} \mathrm{~N}_{32} \mathrm{Si}_{32} \mathrm{Zn}_{8}\right]^{+}$(calculated: 13618). 

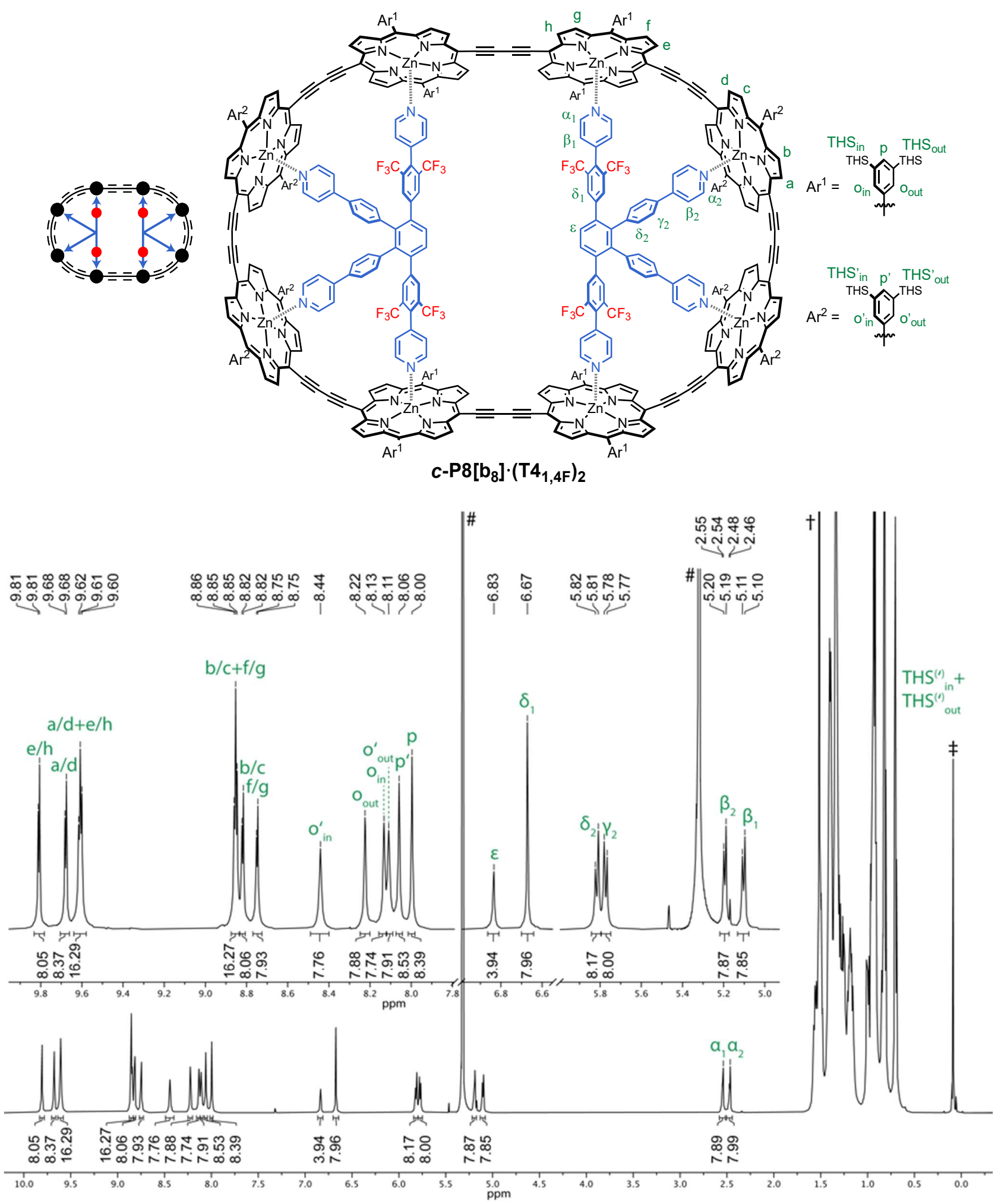

Figure S97. Labelled structure and ${ }^{1} \mathrm{H}$ NMR spectrum of $c-\mathbf{P 8}\left[\mathbf{b}_{8}\right] \bullet\left(\mathrm{T4}_{1,4 \mathrm{~F}}\right)_{2}\left(600 \mathrm{MHz}, \mathrm{CD}_{2} \mathrm{Cl}_{2}, 298 \mathrm{~K}\right)$. $\#=\mathrm{CHDCl}_{2} ; \dagger=$ water; $\neq=$ silicon grease. 
Table S21. Complete ${ }^{1} \mathrm{H}$ NMR assignment and correlations for complex $c-\mathbf{P 8}\left[\mathbf{b}_{8}\right] \bullet\left(\mathbf{T 4}_{1,4 \mathrm{~F}}\right)_{2}$.

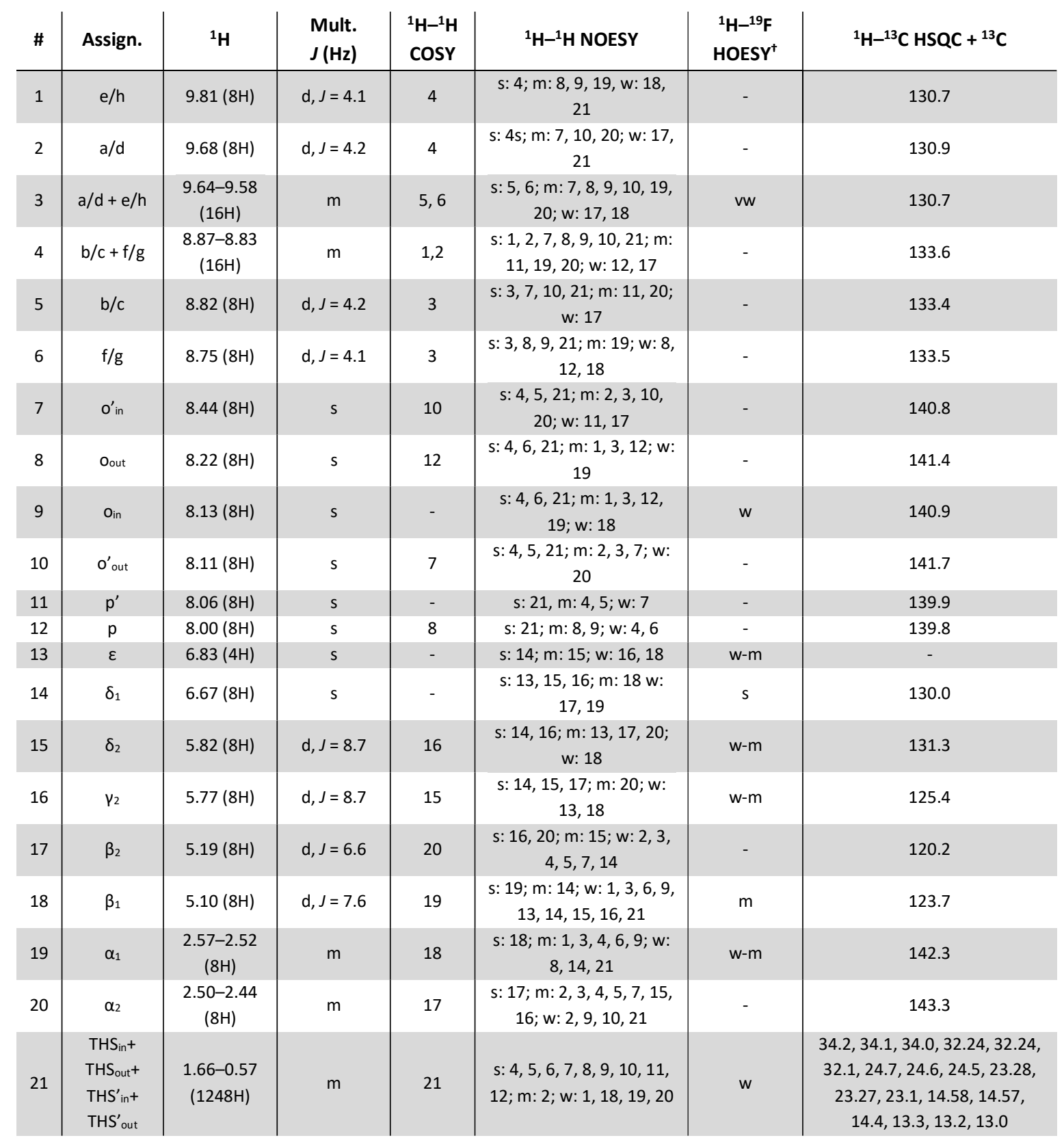

${ }^{\dagger}$ Relative correlation intensities are designated as: $\mathrm{s}=$ strong, $\mathrm{m}=$ medium, $\mathrm{w}=$ weak, $\mathrm{vw}=$ very weak. 


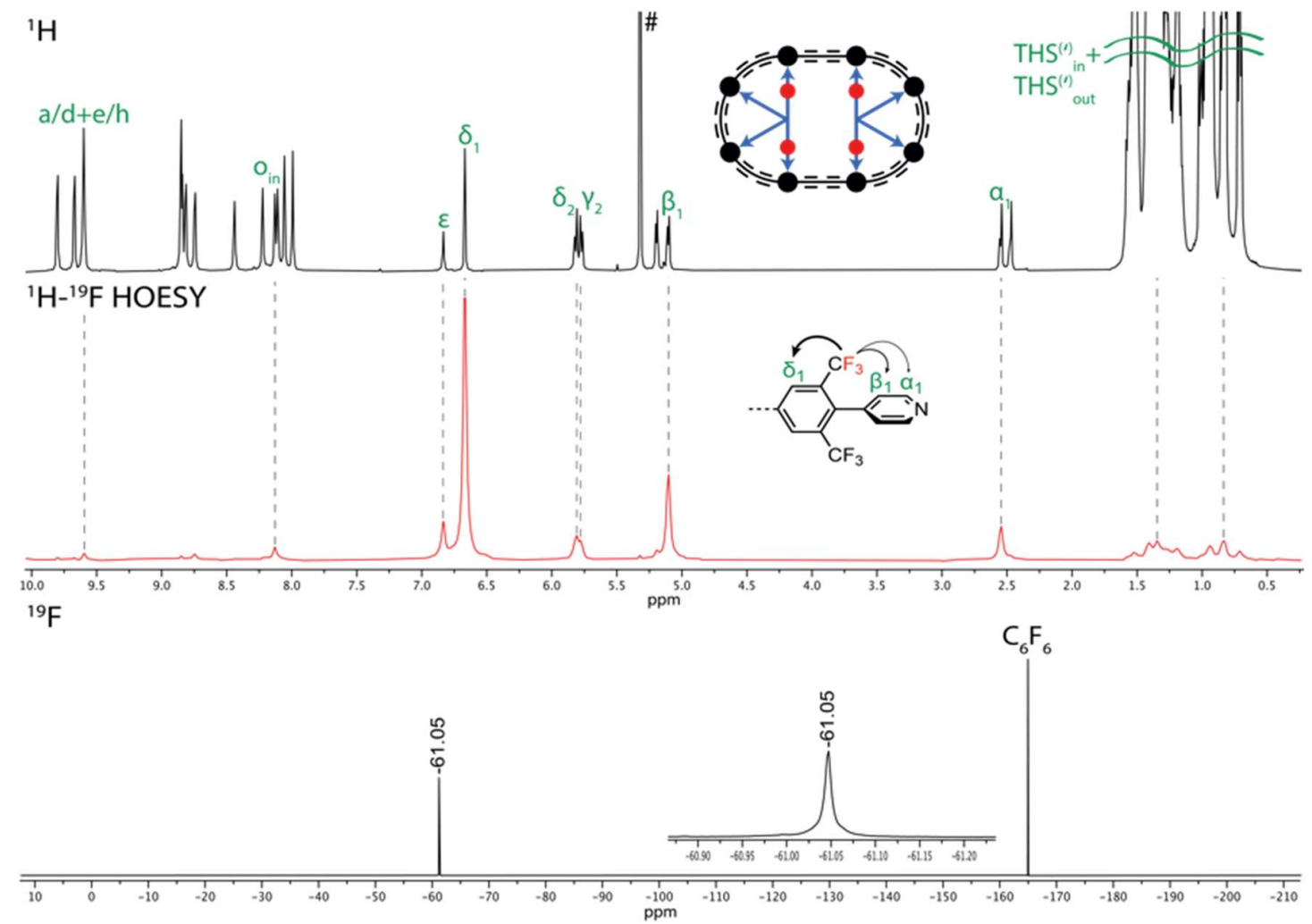

Figure S98. Combined ${ }^{1} \mathrm{H}$ (top), $1 \mathrm{D}^{1} \mathrm{H}^{-19} \mathrm{~F}$ HOESY (middle, red), and ${ }^{19} \mathrm{~F}$ (bottom) spectra of $\boldsymbol{c}$ - $\mathbf{P 8}\left[\mathbf{b}_{\mathbf{8}}\right] \bullet \cdot\left(\mathrm{T4}_{1,4 \mathrm{~F}}\right)_{2}\left(500 \mathrm{MHz}, \mathrm{CD}_{2} \mathrm{Cl}_{2}, 298 \mathrm{~K}\right)$.

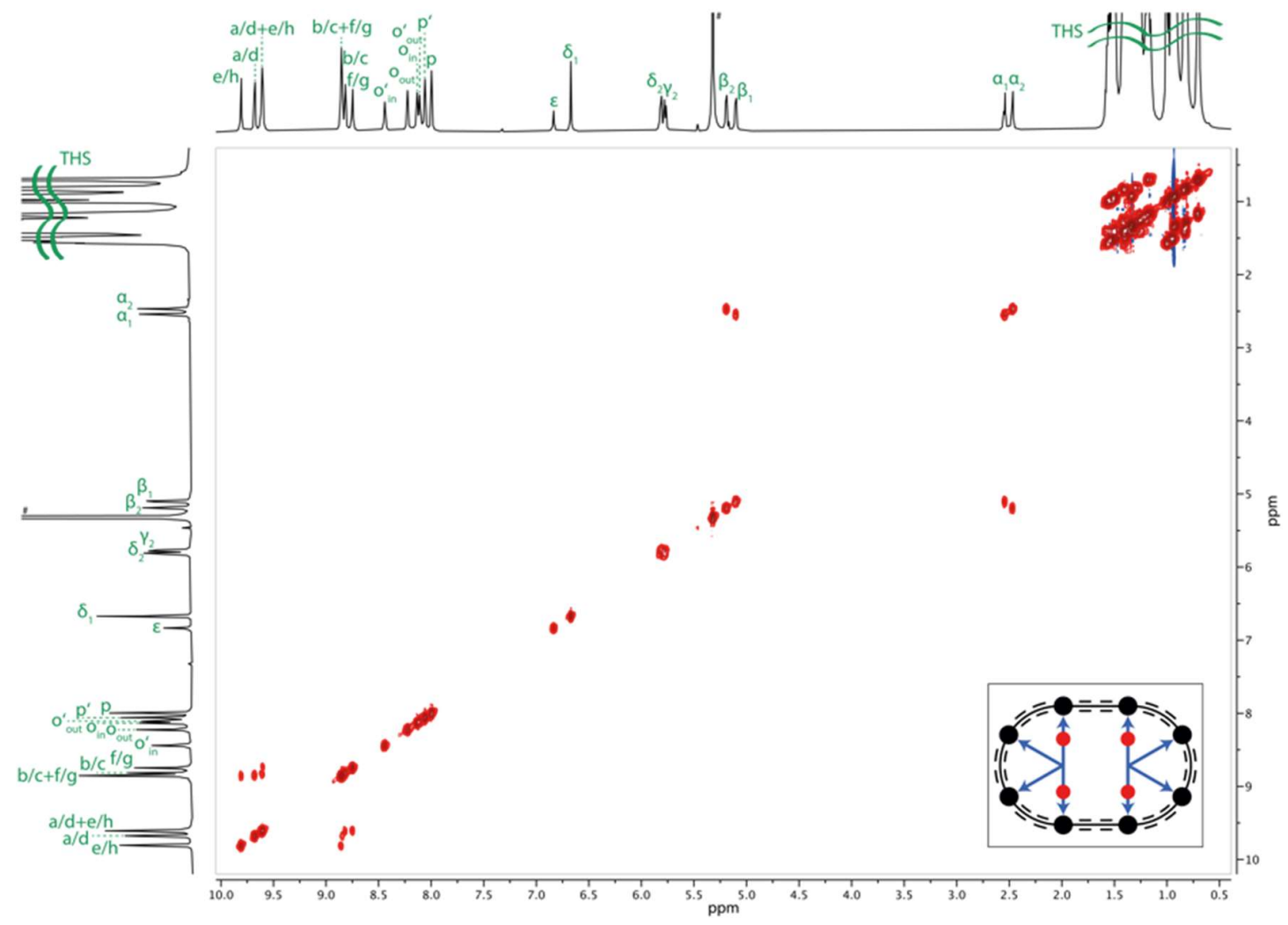

Figure S99. ${ }^{1} \mathrm{H}-{ }^{1} \mathrm{H}$ COSY spectrum of $c-P 8\left[b_{8}\right] \bullet\left(\mathrm{Tu}_{1,4 \mathrm{~F}}\right)_{2}\left(600 \mathrm{MHz}, \mathrm{CD}_{2} \mathrm{Cl}_{2}, 298 \mathrm{~K}\right)$. 


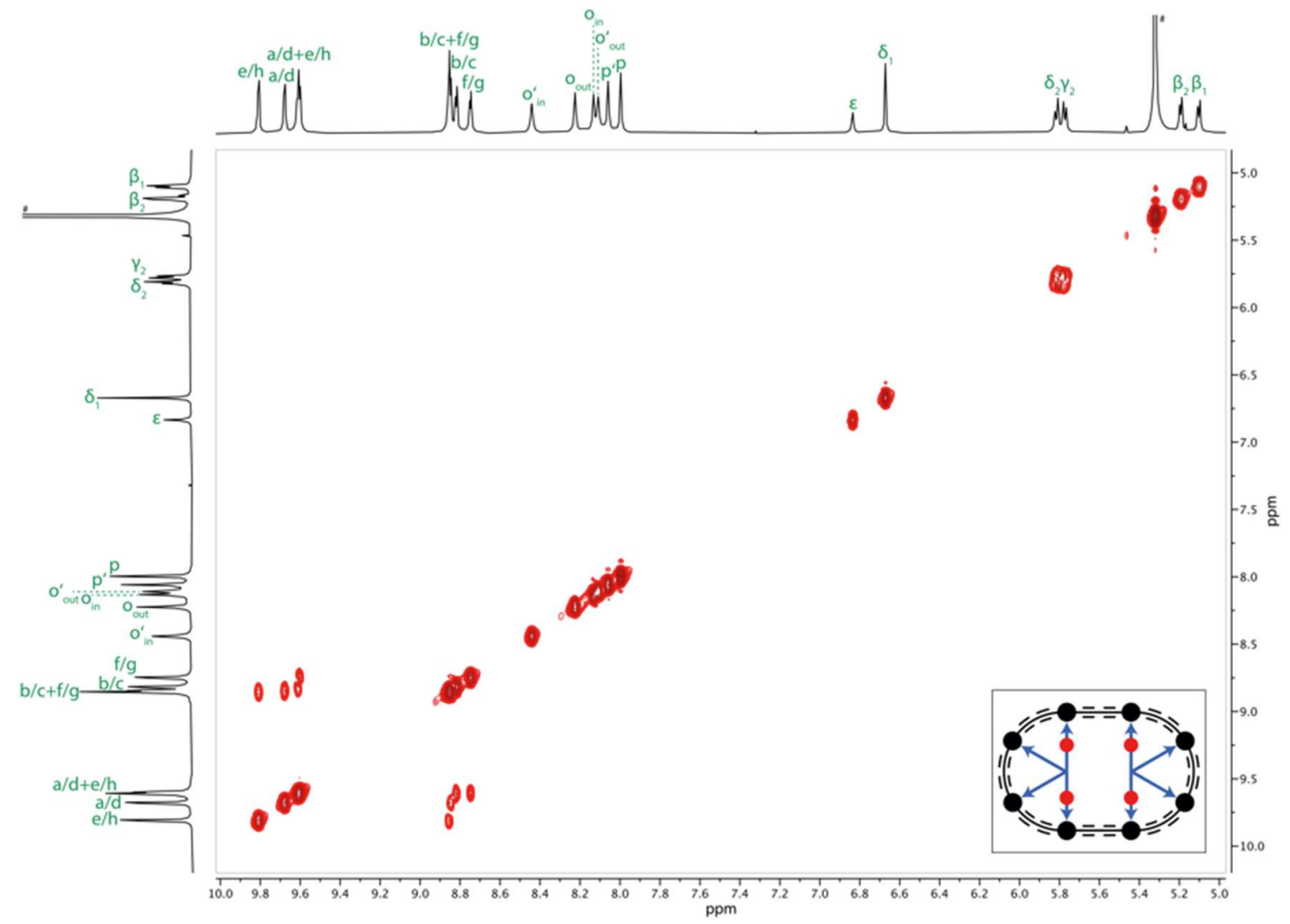

Figure S100. Enlarged region of the COSY spectrum of $\boldsymbol{c}-\mathbf{P 8}\left[\mathbf{b}_{\mathbf{8}}\right] \bullet\left(\mathbf{T 4}_{1,4 \mathrm{~F}}\right)_{\mathbf{2}}\left(600 \mathrm{MHz}, \mathrm{CD}_{2} \mathrm{Cl}_{2}, 298 \mathrm{~K}\right)$.

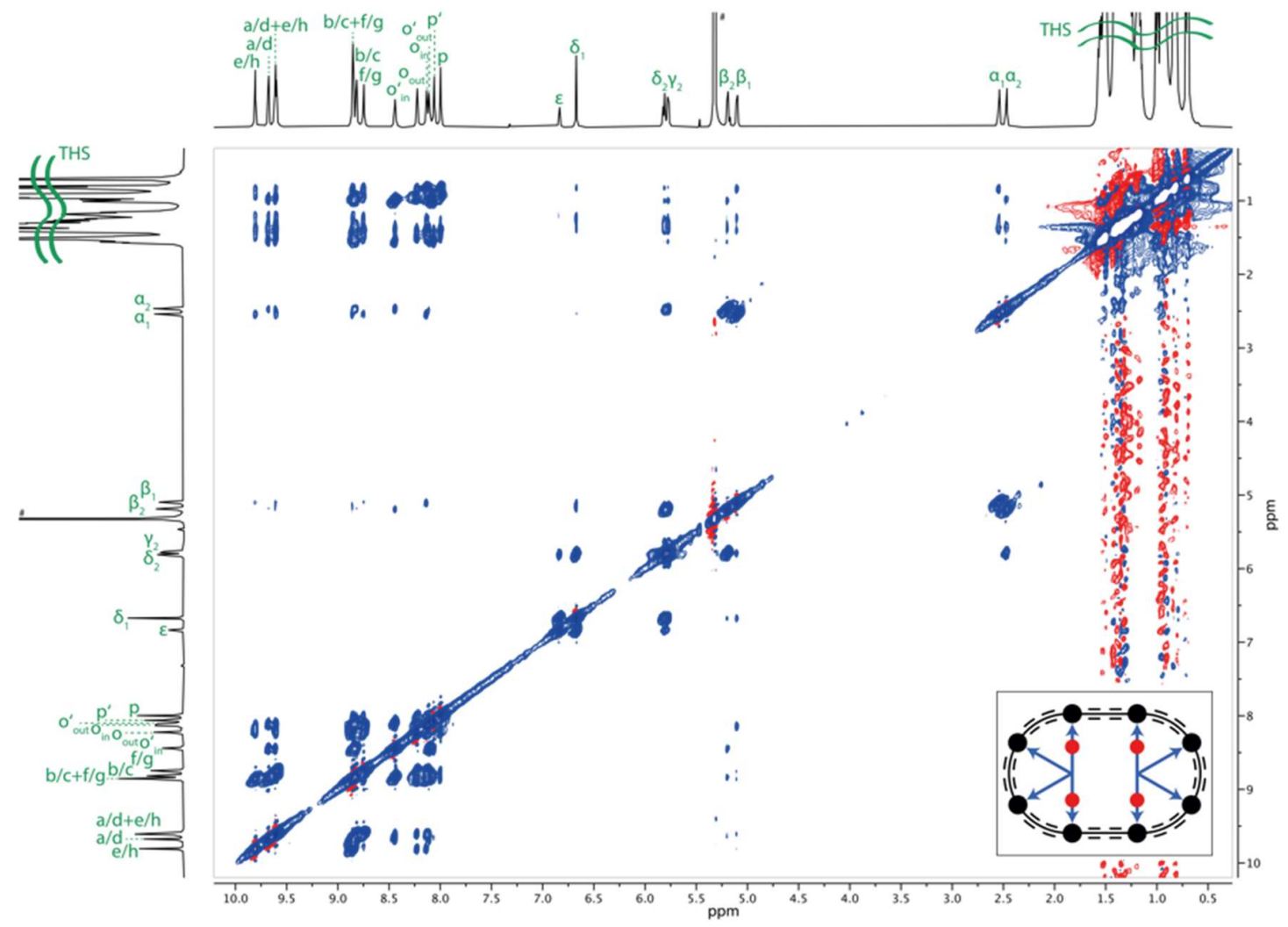

Figure S101. ${ }^{1} \mathrm{H}-{ }^{1} \mathrm{H}$ NOESY spectrum of $c-\mathrm{P} 8\left[\mathbf{b}_{8}\right] \bullet\left(\mathrm{T4}_{1,4 \mathrm{~F}}\right)_{2}\left(600 \mathrm{MHz}, \mathrm{CD}_{2} \mathrm{Cl}_{2}, 298 \mathrm{~K}\right)$. 


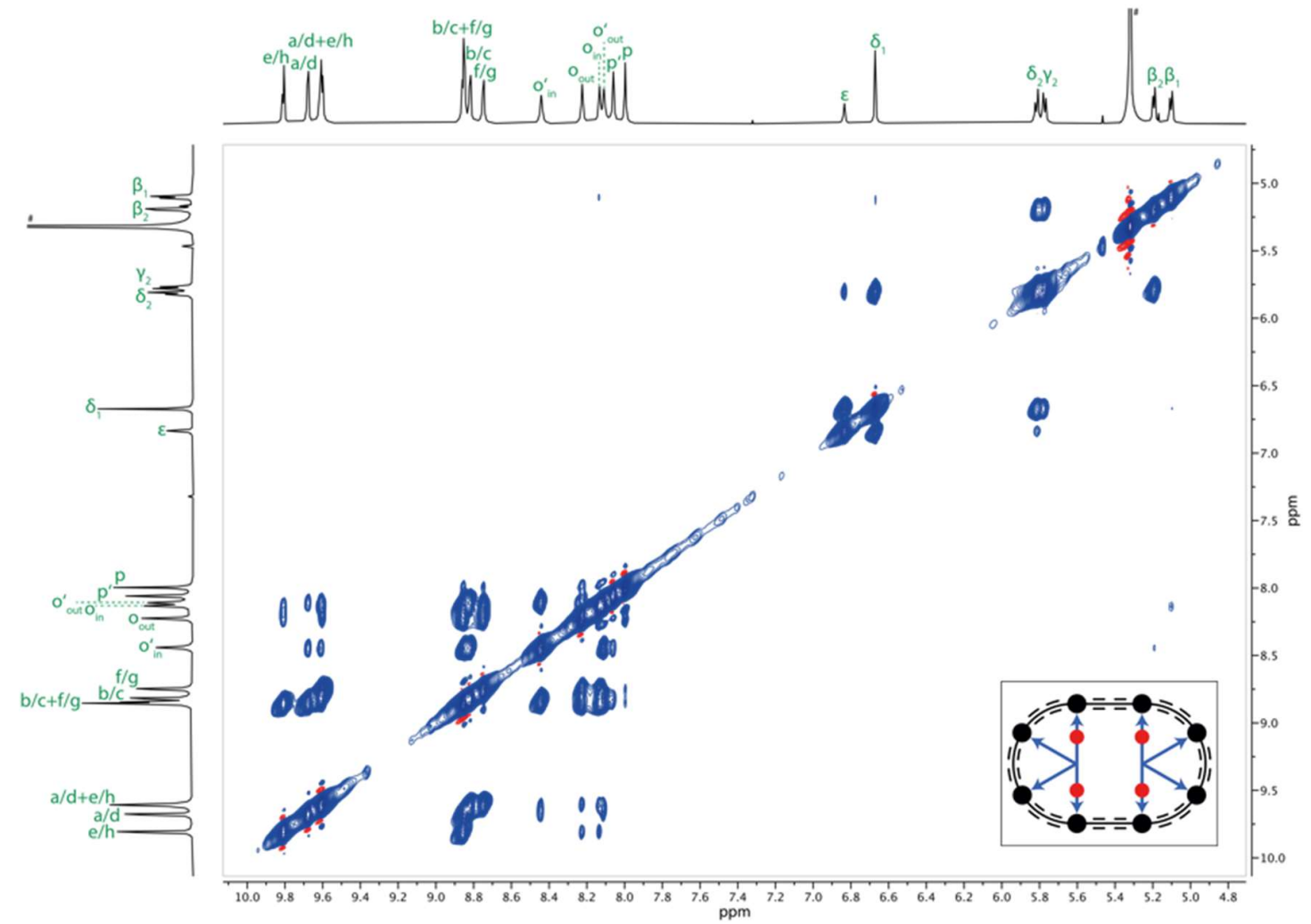

Figure S102. Enlarged region of the NOESY spectrum of $c-\mathbf{P 8}\left[\mathbf{b}_{8}\right] \bullet\left(\mathrm{Tu}_{1,4 \mathrm{~F}}\right)_{2}\left(600 \mathrm{MHz}, \mathrm{CD}_{2} \mathrm{Cl}_{2}, 298 \mathrm{~K}\right)$.

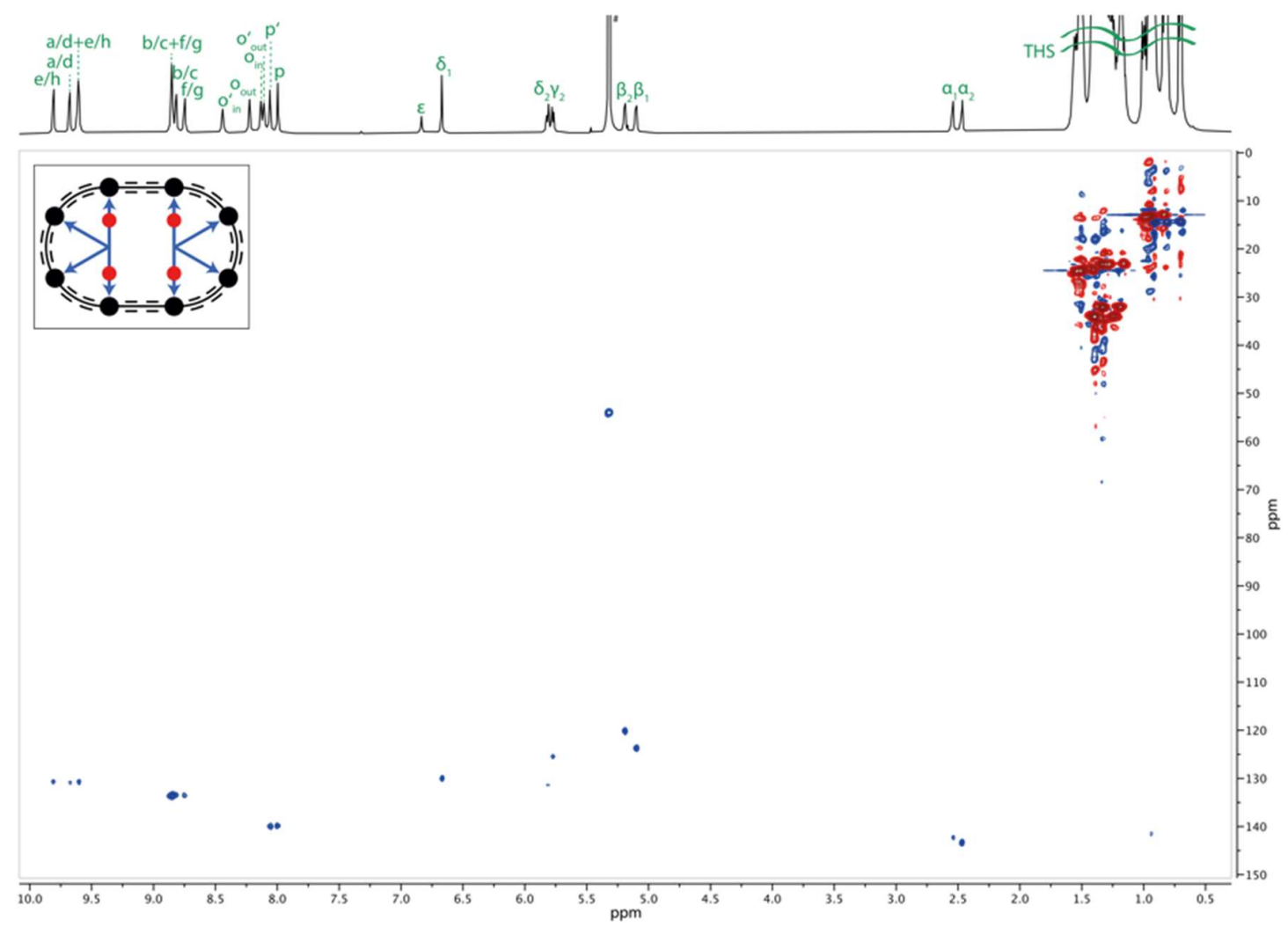

Figure S103. ${ }^{1} \mathrm{H}-{ }^{13} \mathrm{C}$ HSQC spectrum of $c-\mathrm{P} 8\left[\mathrm{~b}_{8}\right] \bullet\left(\mathrm{T4}_{1,4 \mathrm{~F}}\right)_{2}\left(600 \mathrm{MHz}, \mathrm{CD}_{2} \mathrm{Cl}_{2}, 298 \mathrm{~K}\right)$. 


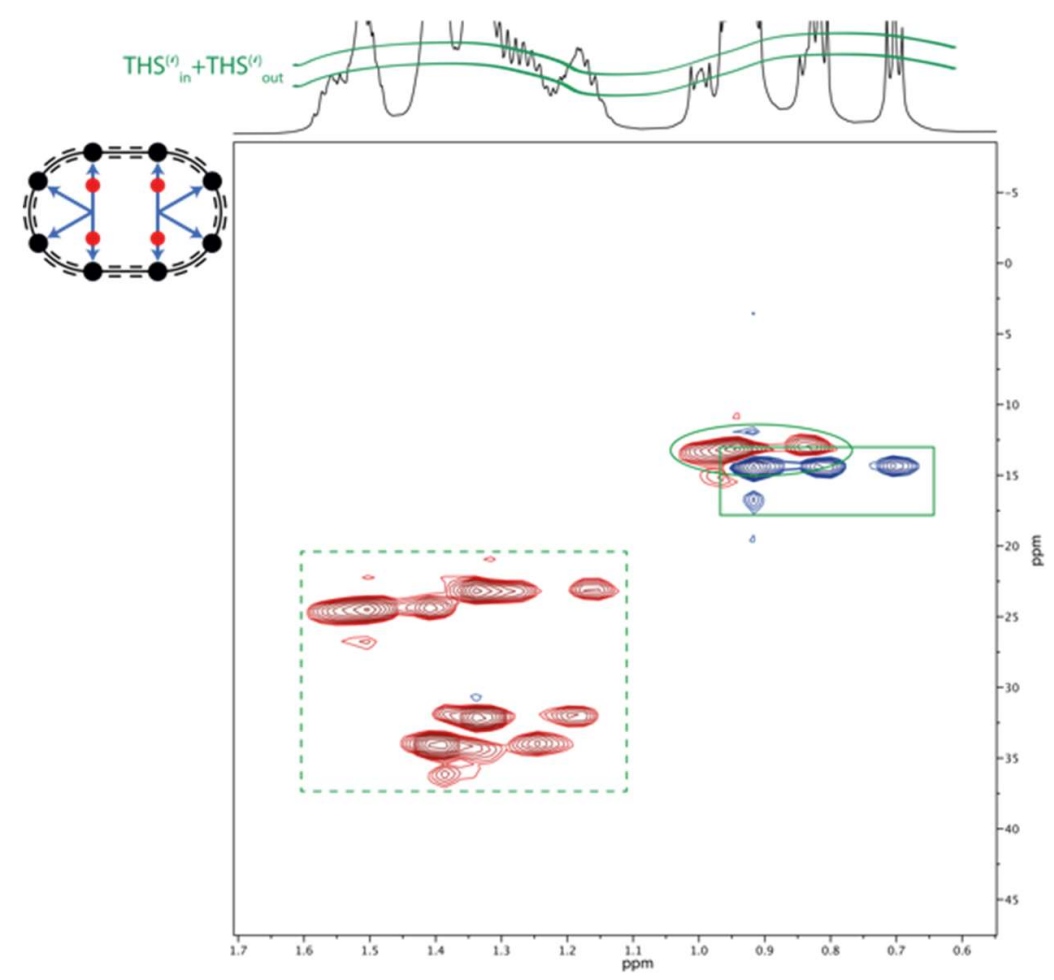

Figure S104. THS region of the ${ }^{1} \mathrm{H}-{ }^{13} \mathrm{C} \mathrm{HSQC}$ spectrum of $\boldsymbol{c}-\mathbf{P 8}\left[\mathbf{b}_{8}\right] \bullet\left(\mathrm{T4}_{1,4 \mathrm{~F}}\right)_{2}\left(600 \mathrm{MHz}, \mathrm{CD}_{2} \mathrm{Cl}_{2}, 298 \mathrm{~K}\right)$. Si-R-CH resonances are indicated with a solid box, $\mathrm{Si}-\mathrm{CH}_{2}-\mathrm{R}$ resonances with a solid circle, and $\mathrm{Si}-\mathrm{CH}_{2}-\mathrm{C}_{4} \mathrm{H}_{8}-\mathrm{CH}_{3}$ resonances with a dashed box.

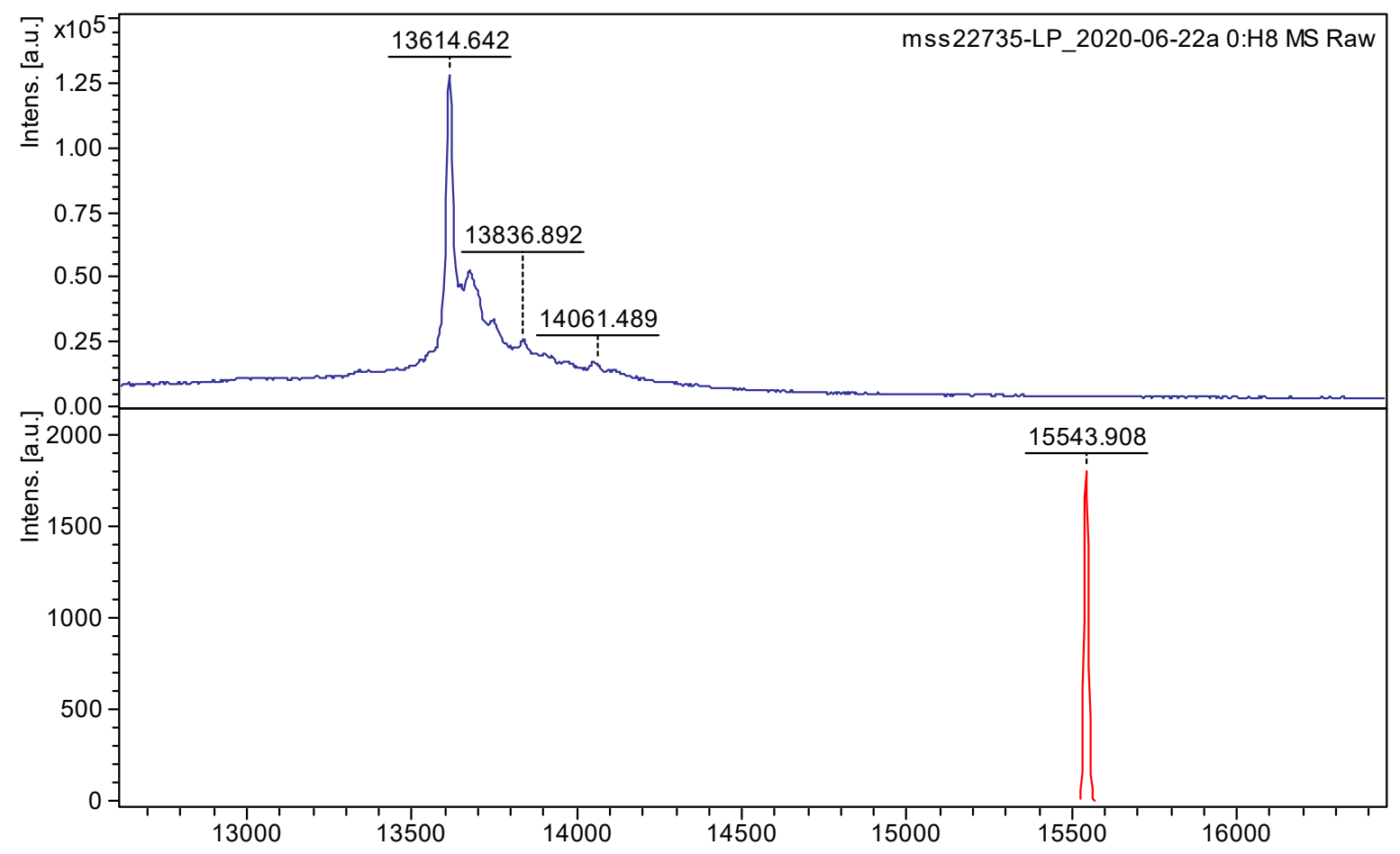

Figure S105. Experimental MALDI-ToF spectrum of $c-\mathbf{P 8}\left[\mathbf{b}_{\mathbf{8}}\right] \bullet\left(\mathbf{T 4}_{1,4 \mathrm{~F}}\right)_{2}$ (top) and simulated MALDI-TOF spectrum of $c-\mathbf{P 8}\left[\mathbf{b}_{\mathbf{8}}\right] \bullet\left(\mathbf{T 4}_{1,4 \mathrm{~F}}\right)_{2}$ $\left[\mathrm{C}_{972} \mathrm{H}_{1420} \mathrm{~F}_{24} \mathrm{~N}_{40} \mathrm{Si}_{32} \mathrm{Zn}_{8}\right]^{+}$(bottom). Major peak corresponds to free $\boldsymbol{c}-\mathbf{P 8}\left[\mathbf{b}_{8}\right]^{+}\left[\mathrm{C}_{864} \mathrm{H}_{1360} \mathrm{~N}_{32} \mathrm{Si}_{32} \mathrm{Zn}_{8}\right]^{+}$(calculated: 13618). 

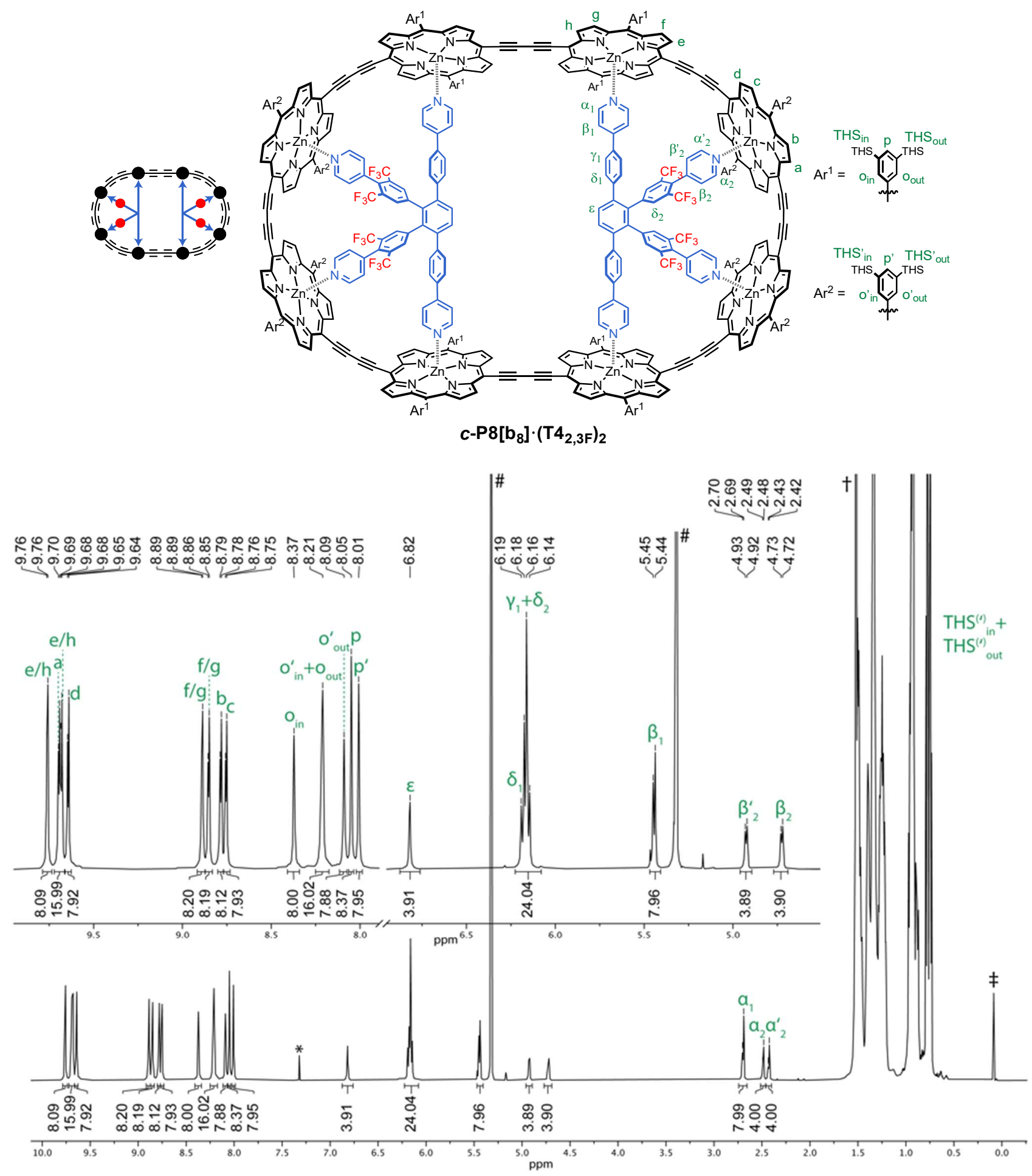

Figure S106. Labelled structure and ${ }^{1} \mathrm{H}$ NMR spectrum of $c-\mathbf{P 8}\left[\mathbf{b}_{8}\right] \bullet\left(\mathbf{T 4}_{2,3 \mathrm{~F}}\right)_{2}\left(600 \mathrm{MHz}, \mathrm{CD}_{2} \mathrm{Cl}_{2}, 298 \mathrm{~K}\right)$. \#= $\mathrm{CHDCl}_{2} ;{ }^{*}=\mathrm{CHCl}_{3} ; \dagger=$ water; $\neq=$ silicon grease. 
Table 22. Complete ${ }^{1} \mathrm{H}$ NMR assignment and correlations for complex $c-\mathbf{P 8}\left[\mathbf{b}_{8}\right] \bullet\left(\mathbf{T 4}_{2,3 \mathrm{~F}}\right)_{2}$.

\begin{tabular}{|c|c|c|c|c|c|c|c|}
\hline$\#$ & Assign. & ${ }^{1} \mathrm{H}$ & $\begin{array}{l}\text { Mult. } \\
J(\mathrm{~Hz})\end{array}$ & $\begin{array}{l}{ }^{1} \mathrm{H}-{ }^{1} \mathrm{H} \\
\text { COSY }\end{array}$ & ${ }^{1} \mathrm{H}-{ }^{1} \mathrm{H}$ NOESY ${ }^{+}$ & $\begin{array}{l}{ }^{1} \mathrm{H}-{ }^{19} \mathrm{~F} \\
\text { HOESY }\end{array}$ & ${ }^{1} \mathrm{H}-{ }^{13} \mathrm{CHSQC}+{ }^{13} \mathrm{C}$ \\
\hline 1 & $\mathrm{e} / \mathrm{h}$ & $9.76(8 \mathrm{H})$ & $\mathrm{d}, J=4.0$ & 5 & s: $5 ; \mathrm{m}: 9,10,20 ; \mathrm{w}: 17,12$ & - & 130.8 \\
\hline 2 & a & $9.69(8 \mathrm{H})$ & $\mathrm{d}, J=4.4$ & 7 & $\begin{array}{c}\mathrm{s}: 7 ; \mathrm{m:} \text { 10, } 11,21 ; \mathrm{w:} \text { 19, } \\
23\end{array}$ & - & 130.7 \\
\hline 3 & $e / h$ & $9.68(8 \mathrm{H})$ & $\mathrm{d}, J=4.0$ & 6 & $\begin{array}{c}\mathrm{s}: 6 ; \mathrm{m:}: 9,10,20 ; w: 15 \\
17,23\end{array}$ & - & 130.7 \\
\hline 4 & $d$ & $9.64(8 \mathrm{H})$ & $\mathrm{d}, \mathrm{J}=4.3$ & 8 & $\mathrm{~s}: 8 ; \mathrm{m}: 10,11,22 ; \mathrm{w}: 18$ & - & 130.7 \\
\hline 5 & $f / g$ & $8.89(8 \mathrm{H})$ & $\mathrm{d}, J=4.0$ & 1 & $\begin{array}{c}\mathrm{s}: 1 ; \mathrm{m:}: 9,10,20,23 ; \mathrm{w}: \\
12,17\end{array}$ & - & 133.6 \\
\hline 6 & $f / g$ & $8.85(8 \mathrm{H})$ & $\mathrm{d}, J=4.0$ & 3 & $\begin{array}{c}\mathrm{s}: 3 ; \mathrm{m}: 9,10,20,23 ; \mathrm{w}: \\
12,17\end{array}$ & - & 133.6 \\
\hline 7 & $b$ & $8.78(8 \mathrm{H})$ & $\mathrm{d}, J=4.4$ & 2 & $\begin{array}{c}\mathrm{s}: 2 ; \mathrm{m}: 10,11,21,22,23 ; \\
\mathrm{w}: 9,13,18,19\end{array}$ & vw & 133.5 \\
\hline 8 & c & $8.75(8 \mathrm{H})$ & $\mathrm{d}, J=4.3$ & 4 & $\begin{array}{c}\text { s: } 4 ; \mathrm{m}: 10,11,21,22,23 \\
\text { w: } 9,13,18,19\end{array}$ & vw & 133.5 \\
\hline 9 & Oin & $8.37(8 \mathrm{H})$ & s & 10 & $\begin{array}{c}s: 10,23 ; m: 1,3,5,6,12 \\
20 ; w: 7,8,16,17\end{array}$ & - & 140.8 \\
\hline 10 & $\mathrm{O}_{\text {in }}^{\prime}+\mathrm{O}_{\text {out }}$ & $8.21(16 \mathrm{H})$ & s & 9,11 & $\begin{array}{c}\mathrm{s}: 9,23 ; \mathrm{m}: 1,2,3,4,5,6 \\
7,8,11,21,22 ; \mathrm{w}: 12,13 \\
18,19,20\end{array}$ & vw & $141.3,141.3$ \\
\hline 11 & o'out & $8.09(8 \mathrm{H})$ & s & 10 & $\begin{array}{c}\mathrm{s}: 23 ; \mathrm{m}: 2,4,7,8,10 ; \mathrm{w}: \\
21\end{array}$ & - & 141.4 \\
\hline 12 & $p$ & $8.05(8 \mathrm{H})$ & s & - & $s: 23, m: 9, w: 1,5,6,10$ & - & 139.9 \\
\hline 13 & $p^{\prime}$ & $8.01(8 \mathrm{H})$ & s & - & $s: 23 ; w: 7,8,10$ & - & 139.8 \\
\hline 14 & $\varepsilon$ & $6.82(4 \mathrm{H})$ & $\mathrm{s}$ & - & s: 15; w: 17 & - & 130.5 \\
\hline 15 & $\delta_{1}$ & $6.18(8 \mathrm{H})$ & $d, J=9.7$ & - & s: $14 ; m: 17 ; w: 3$ & - & 129.9 \\
\hline 16 & $\gamma_{1}+\delta_{2}$ & $\begin{array}{c}6.17-6.13 \\
(16 \mathrm{H})\end{array}$ & $\mathrm{m}$ & - & $\begin{array}{c}\mathrm{s}: 17 ; \mathrm{m}: 20 ; \mathrm{w}: 9,18,19 \\
21,22,23\end{array}$ & s & $131.7,126.1$ \\
\hline 17 & $\beta_{1}$ & $5.44(8 \mathrm{H})$ & $\mathrm{d}, J=7.3$ & 20 & $\begin{array}{c}\mathrm{s}: 16,20 ; \mathrm{m}: 15 ; \mathrm{w}: 1,3,5 \\
6,9,14,18\end{array}$ & - & 120.4 \\
\hline 18 & $\beta_{2}^{\prime}$ & $4.93(4 \mathrm{H})$ & $\mathrm{d}, J=6.3$ & 22,19 & $\begin{array}{c}\mathrm{s}: 21,22 ; \mathrm{m}: 19 ; \mathrm{w}: 4,7,8 \\
10,16,17\end{array}$ & $w-m$ & 123.8 \\
\hline 19 & $\beta_{2}$ & $4.73(4 \mathrm{H})$ & $\mathrm{d}, J=6.0$ & 21,18 & $\begin{array}{c}\mathrm{s}: 21,22 ; \mathrm{m}: 18 ; \mathrm{w}: 2,7,8 \\
10,16\end{array}$ & $\mathrm{~m}$ & 123.0 \\
\hline 20 & $\alpha_{1}$ & $\begin{array}{c}2.74-2.66 \\
(8 \mathrm{H})\end{array}$ & $\mathrm{m}$ & 17 & $\mathrm{~s}: 17 ; \mathrm{m:} 1,3,5,6,9 ; \mathrm{w:} 10$ & - & 143.8 \\
\hline 21 & $\alpha_{2}$ & $\begin{array}{c}2.52-2.46 \\
\quad(4 \mathrm{H})\end{array}$ & $\mathrm{m}$ & 19 & $\begin{array}{c}\mathrm{s}: 18,19 ; \mathrm{m}: 2,7,8,10 ; \mathrm{w}: \\
11\end{array}$ & w & 142.6 \\
\hline 22 & $\alpha_{2}^{\prime}$ & $\begin{array}{c}2.45-2.41 \\
(4 \mathrm{H})\end{array}$ & $\mathrm{m}$ & 18 & $\mathrm{~s}: 18,19 ; \mathrm{m}: 4,7,8,10$ & w & 142.2 \\
\hline 23 & $\begin{array}{l}\mathrm{THS}_{\text {in }}+ \\
\mathrm{THS}_{\text {out }}+ \\
\mathrm{THS}_{\text {in }}+ \\
\mathrm{THS}_{\text {out }}^{\prime}\end{array}$ & $\begin{array}{c}1.58-0.71 \\
(1248 \mathrm{H})\end{array}$ & $\mathrm{m}$ & - & $\begin{array}{c}\mathrm{s}: 9,10,11,12,13 ; \mathrm{m}: 5,6 \\
7,8 ; \mathrm{w}: 2,3,16\end{array}$ & w & $\begin{array}{c}34.13,34.10,34.0,32.3, \\
32.23,32.16,24.62,24.61, \\
24.60,23.3,23.19,23.18, \\
14.58,14.57,14.49,14.47, \\
13.21,13.17,13.1 .\end{array}$ \\
\hline
\end{tabular}

${ }^{\dagger}$ Relative correlation intensities are designated as: $\mathrm{s}=$ strong, $\mathrm{m}=$ medium, $\mathrm{w}=$ weak, $\mathrm{vw}=$ very weak. 


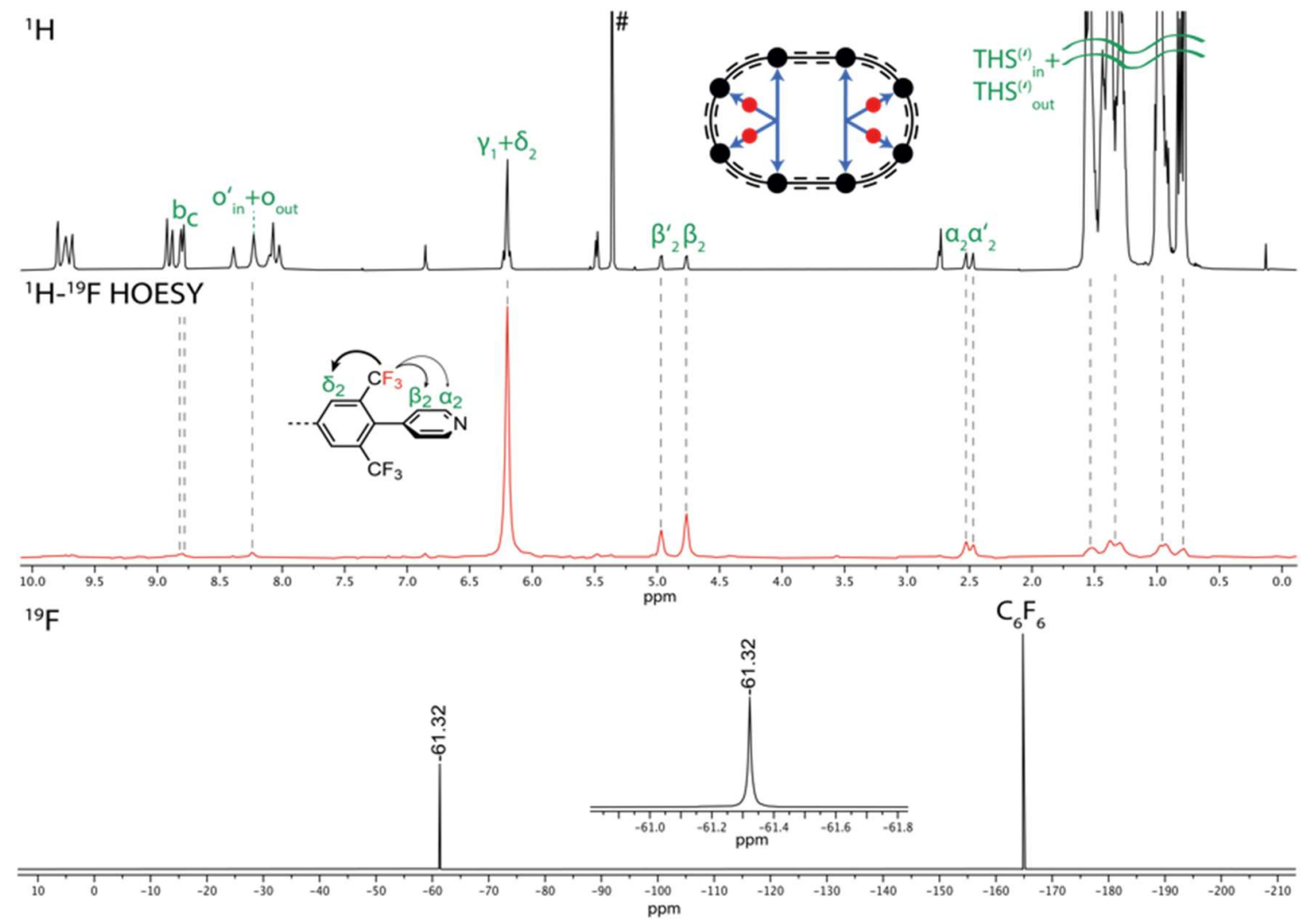

Figure S107. Combined ${ }^{1} \mathrm{H}$ (top), $1 \mathrm{D}^{1} \mathrm{H}_{-}{ }^{19} \mathrm{~F}$ HOESY (middle, red), and ${ }^{19} \mathrm{~F}$ (bottom) spectra of $\boldsymbol{c}-\mathbf{P} 8\left[\mathbf{b}_{8}\right] \bullet\left(\mathrm{T4}_{2,3 \mathrm{~F}}\right)_{2}\left(500 \mathrm{MHz}, \mathrm{CD}_{2} \mathrm{Cl}{ }_{2}, 298 \mathrm{~K}\right)$.

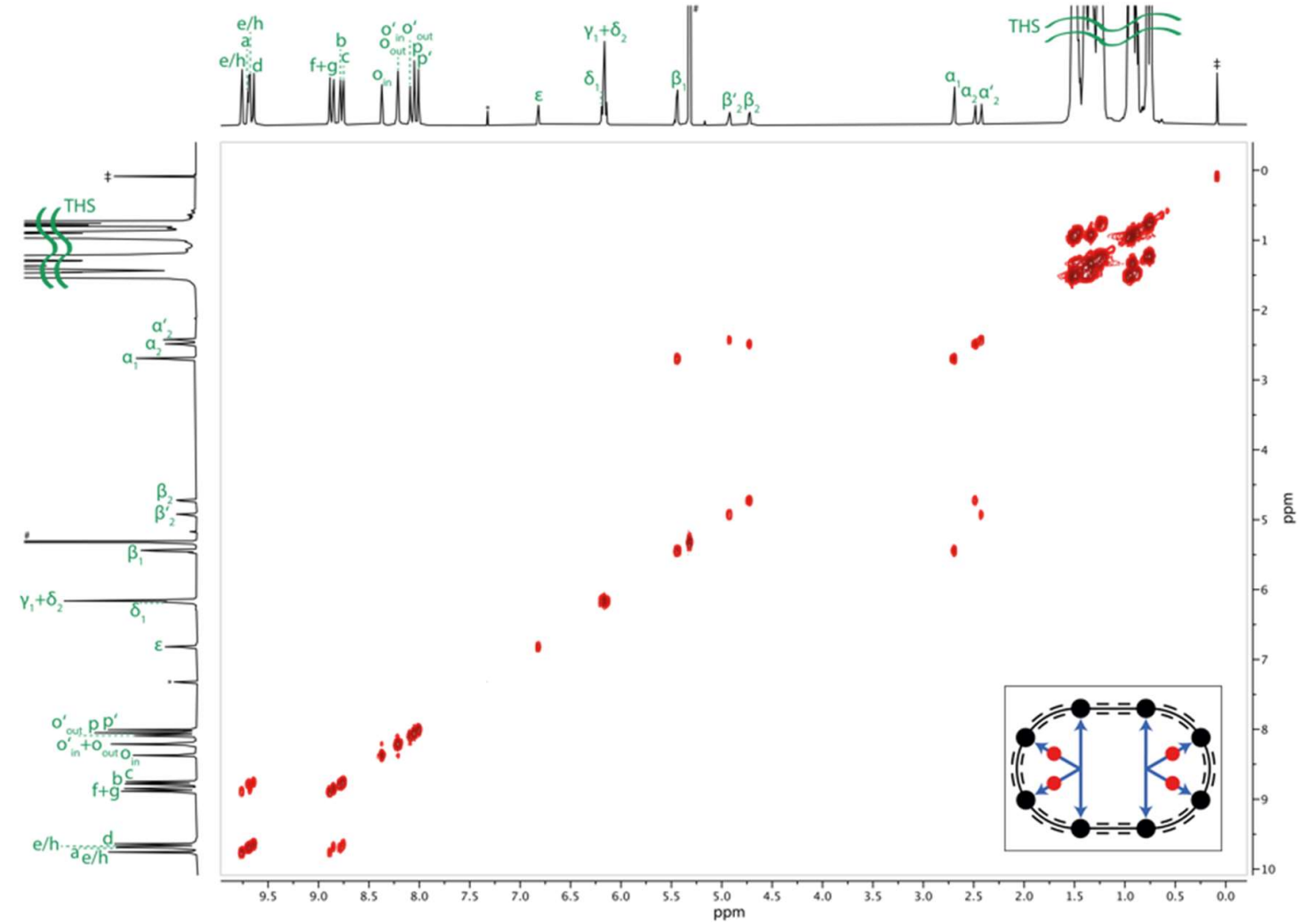

Figure S108. ${ }^{1} \mathrm{H}-{ }^{1} \mathrm{H}$ COSY spectrum of $c-\mathrm{P} 8\left[\mathrm{~b}_{8}\right] \bullet\left(\mathrm{T4}_{2,3 \mathrm{~F}}\right)_{2}\left(600 \mathrm{MHz}, \mathrm{CD}_{2} \mathrm{Cl}_{2}, 298 \mathrm{~K}\right)$. 


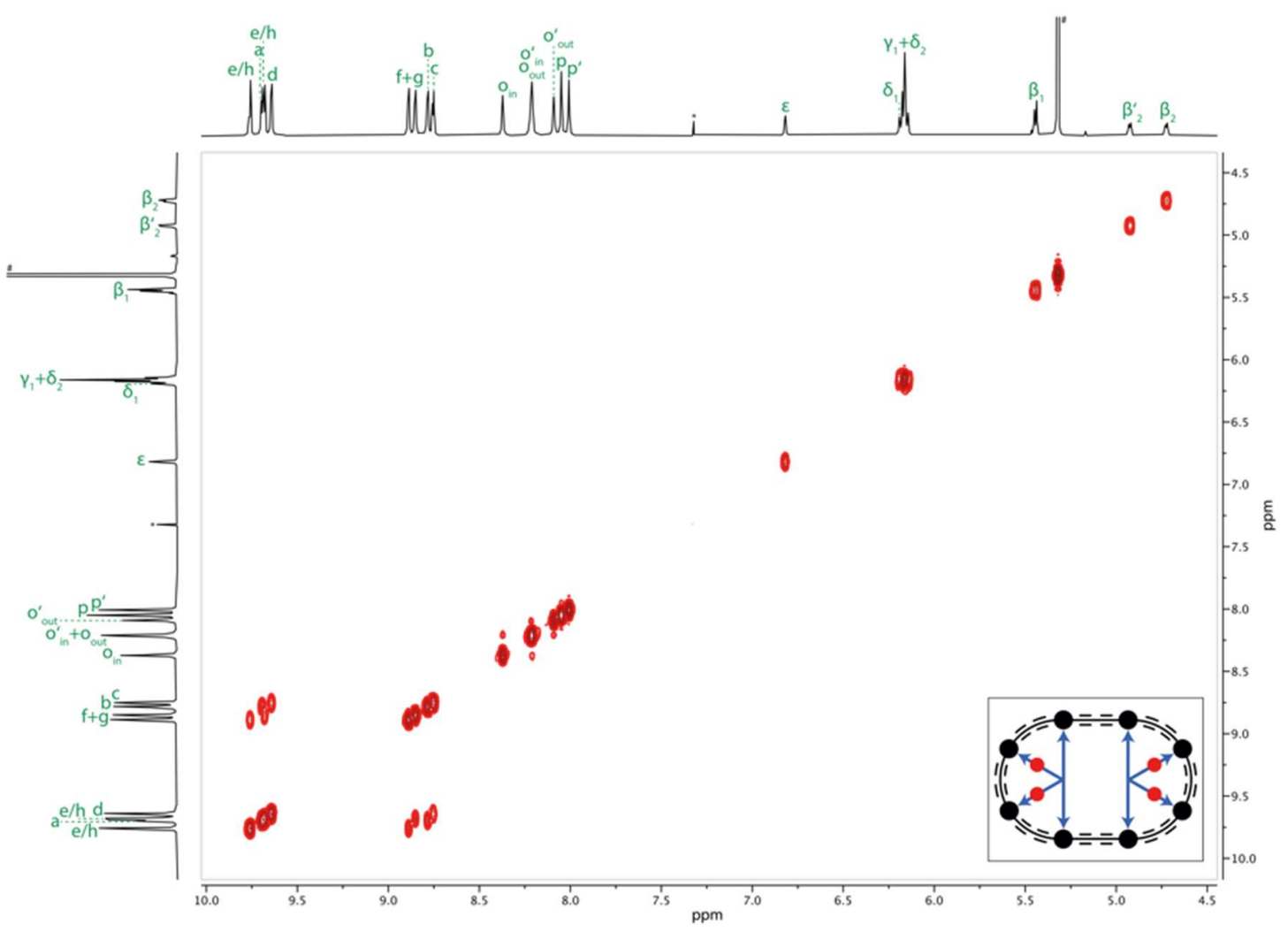

Figure S109. Enlarged region of the COSY spectrum of $c-\mathbf{P 8}\left[\mathbf{b}_{8}\right] \bullet\left(\mathrm{T4}_{2,3 \mathrm{~F}}\right)_{2}\left(600 \mathrm{MHz}, \mathrm{CD}_{2} \mathrm{Cl}_{2}, 298 \mathrm{~K}\right)$.

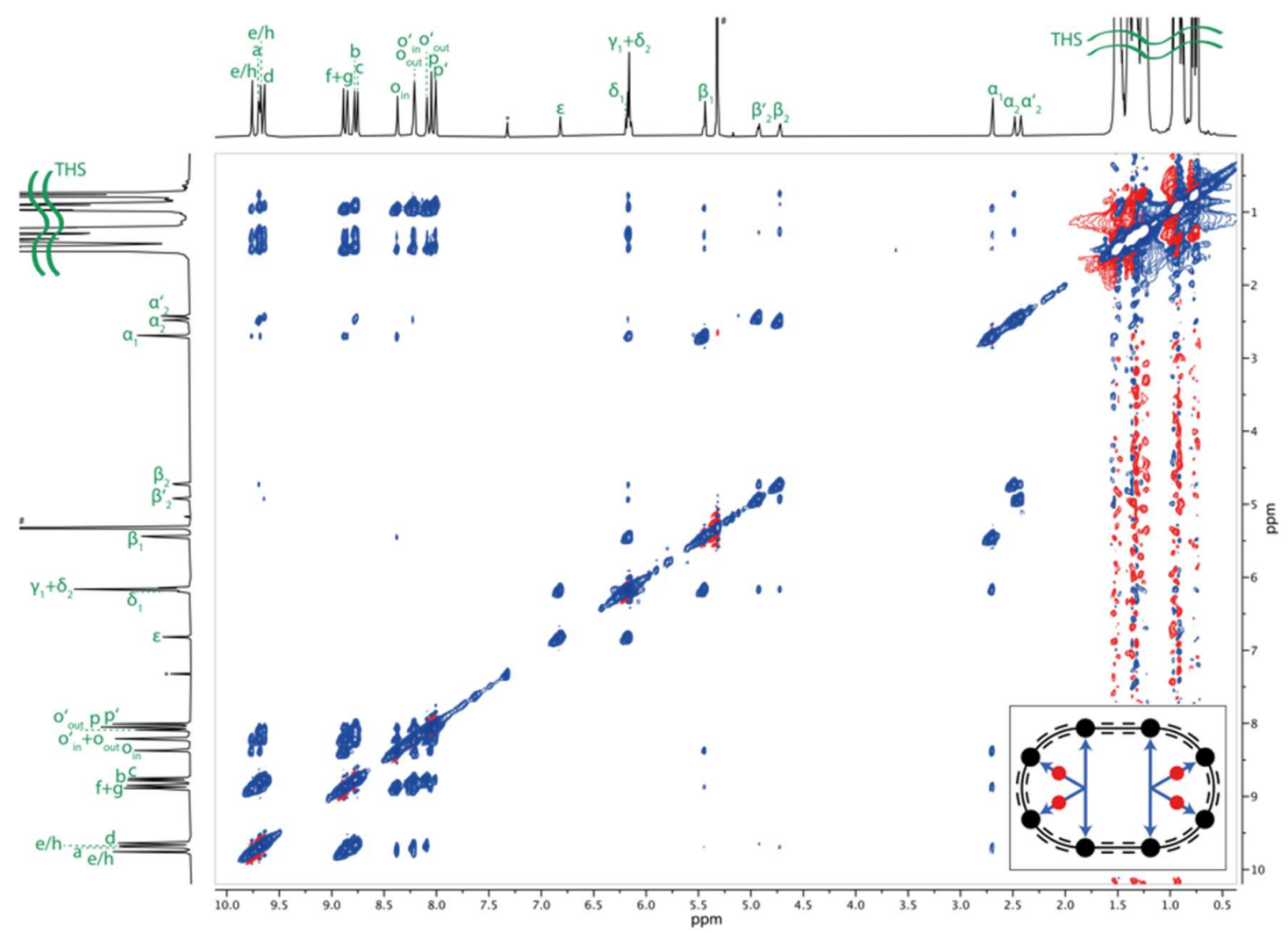

Figure S110. ${ }^{1} \mathrm{H}-{ }^{1} \mathrm{H}$ NOESY spectrum of $\boldsymbol{c}-\mathbf{P 8}\left[\mathbf{b}_{8}\right] \bullet\left(\mathrm{T4}_{\mathbf{2}, 3 \mathrm{~F}}\right)_{\mathbf{2}}\left(600 \mathrm{MHz}, \mathrm{CD}_{2} \mathrm{Cl}_{2}, 298 \mathrm{~K}\right)$. 


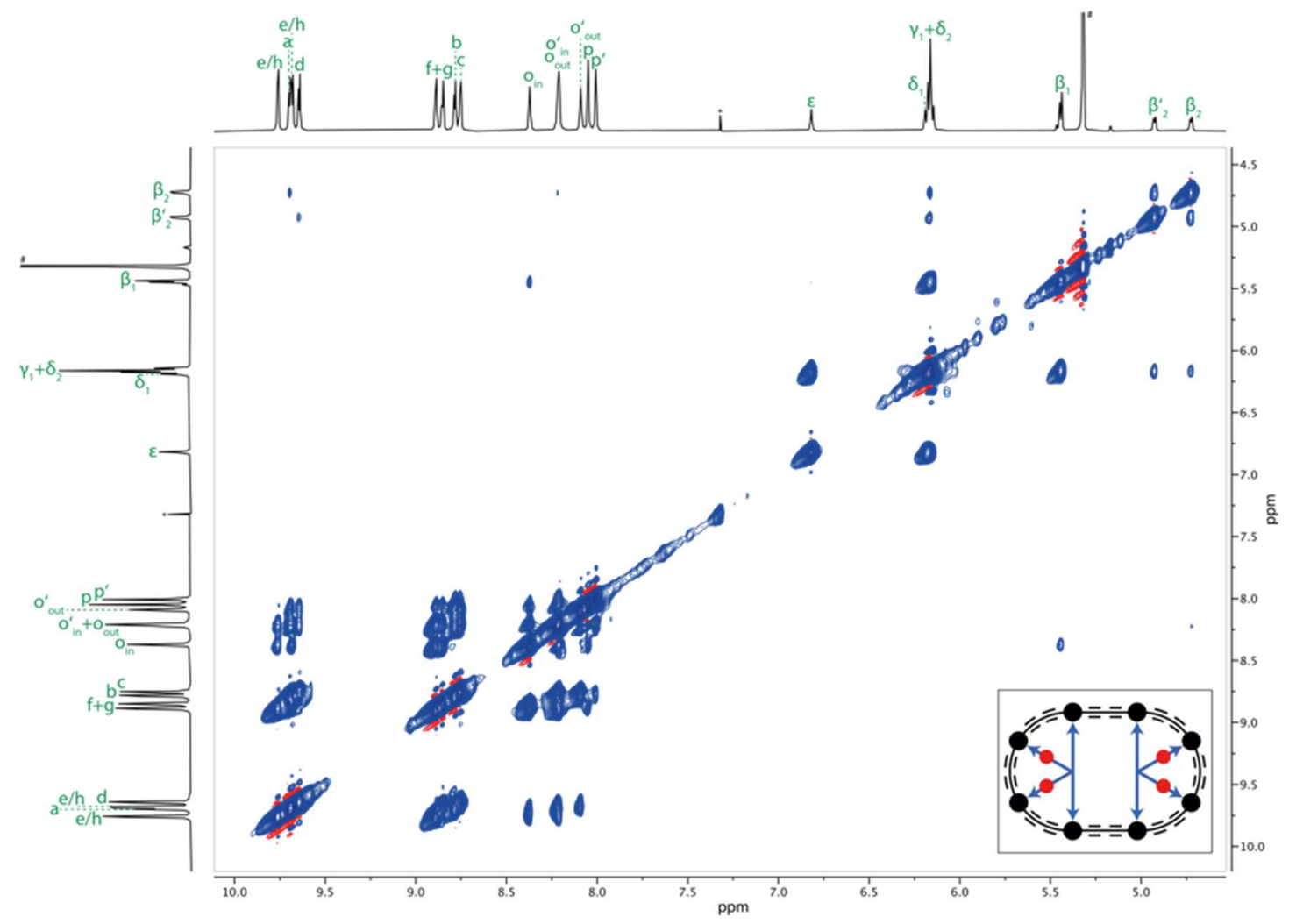

Figure S111. Enlarged region of the NOESY spectrum of $\boldsymbol{c}-\mathbf{P 8}\left[\mathbf{b}_{\mathbf{8}}\right] \bullet \cdot\left(\mathbf{T 4}_{\mathbf{2}, 3 \mathrm{~F}}\right)_{\mathbf{2}}\left(600 \mathrm{MHz}, \mathrm{CD}_{2} \mathrm{Cl}_{2}, 298 \mathrm{~K}\right)$.

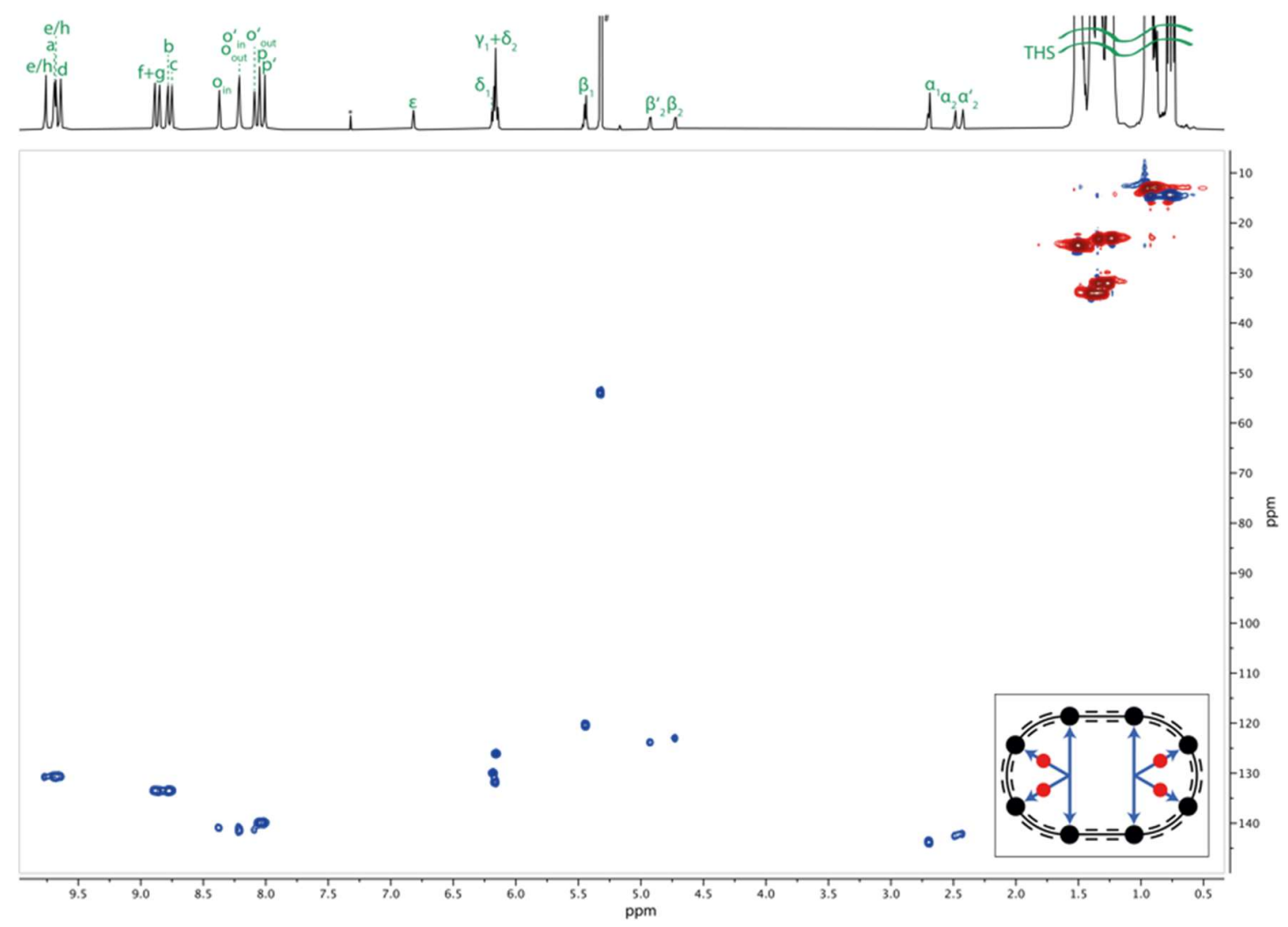

Figure S112. ${ }^{1} \mathrm{H}_{-}{ }^{13} \mathrm{C}$ HSQC spectrum of $c-\mathbf{P 8}\left[\mathbf{b}_{8}\right] \bullet\left(\mathbf{T 4}_{2,3 \mathrm{~F}}\right)_{2}\left(600 \mathrm{MHz}, \mathrm{CD}_{2} \mathrm{Cl}_{2}, 298 \mathrm{~K}\right)$. 


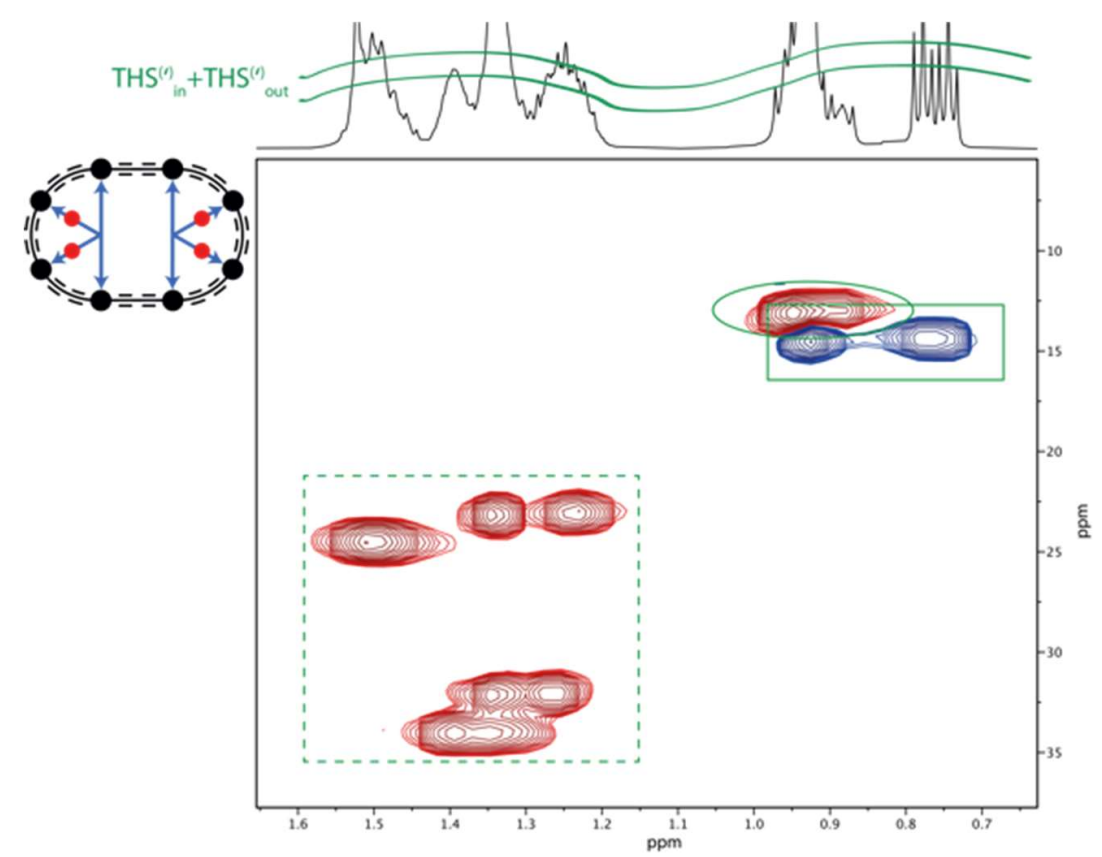

Figure S113. THS region of the ${ }^{1} \mathrm{H}_{-}{ }^{13} \mathrm{C}$ HSQC spectrum of $\boldsymbol{c}-\mathbf{P 8}\left[\mathrm{b}_{8}\right] \bullet\left(\mathrm{T4}_{2,3 \mathrm{~F}}\right)_{2}\left(600 \mathrm{MHz}, \mathrm{CD}_{2} \mathrm{Cl}_{2}, 298 \mathrm{~K}\right)$. Si-R-CH resonances are indicated with a solid box, $\mathrm{Si}-\mathrm{CH}_{2}-\mathrm{R}$ resonances with a solid circle, and $\mathrm{Si}-\mathrm{CH}_{2}-\mathrm{C}_{4} \mathrm{H}_{8}-\mathrm{CH}_{3}$ resonances with a dashed box.

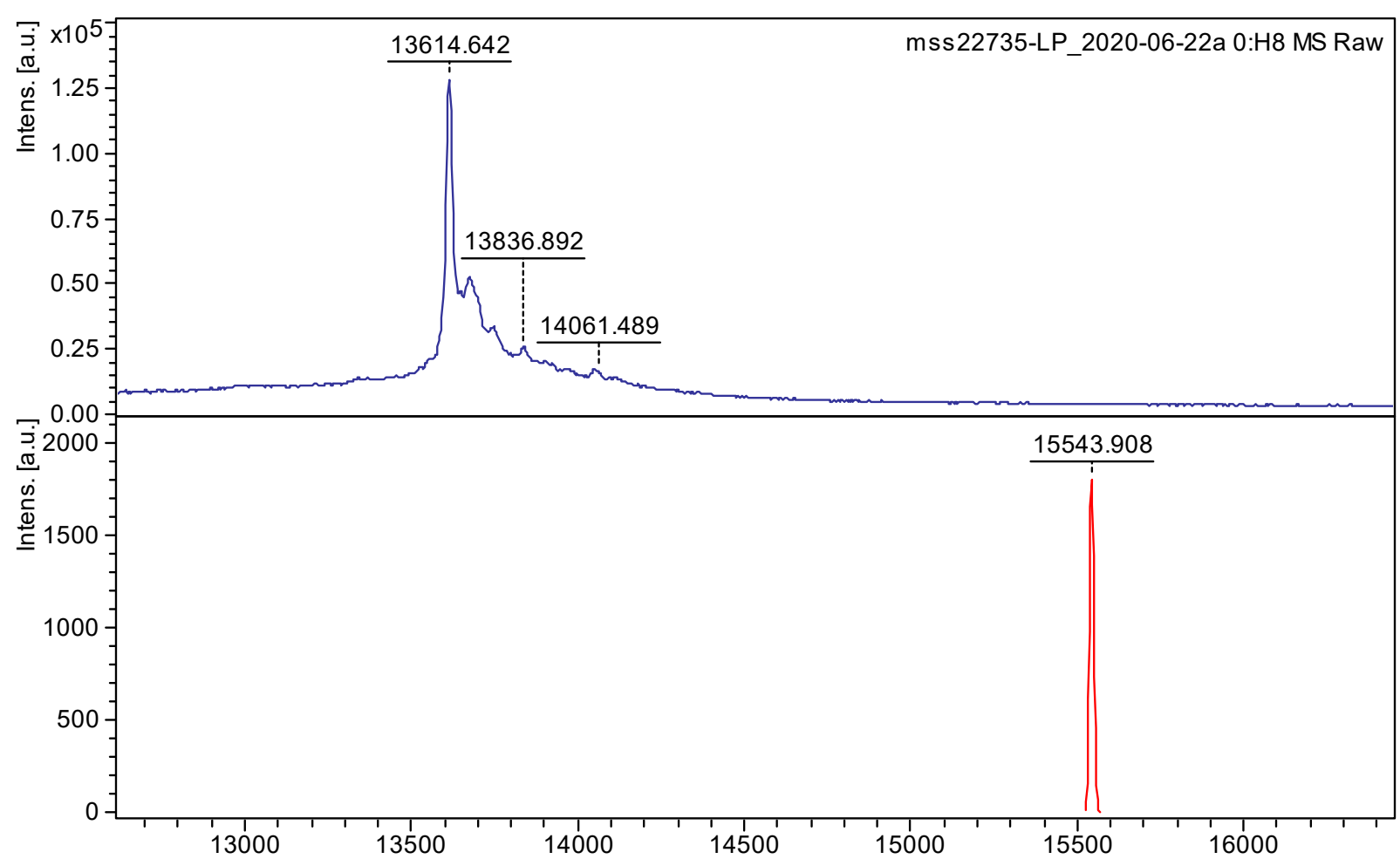

Figure S114. Experimental MALDI-ToF spectrum of $c-\mathbf{P 8}\left[\mathbf{b}_{\mathbf{8}}\right] \bullet\left(\mathbf{T 4}_{2,3 \mathrm{~F}}\right)_{2}$ (top) and simulated MALDI-TOF spectrum of $c-\mathbf{P 8}\left[\mathbf{b}_{\mathbf{8}}\right] \bullet\left(\mathbf{T 4 _ { 2 , 3 F }}\right)_{2}$ $\left[\mathrm{C}_{972} \mathrm{H}_{1420} \mathrm{~F}_{24} \mathrm{~N}_{40} \mathrm{Si}_{32} \mathrm{Zn}_{8}\right]^{+}$(bottom). Major peak corresponds to free $\boldsymbol{c}-\mathbf{P 8}\left[\mathbf{b}_{8}\right]^{+}\left[\mathrm{C}_{864} \mathrm{H}_{1360} \mathrm{~N}_{32} \mathrm{Si}_{32} \mathrm{Zn}_{8}\right]^{+}$(calculated: 13618). 
Template T4:

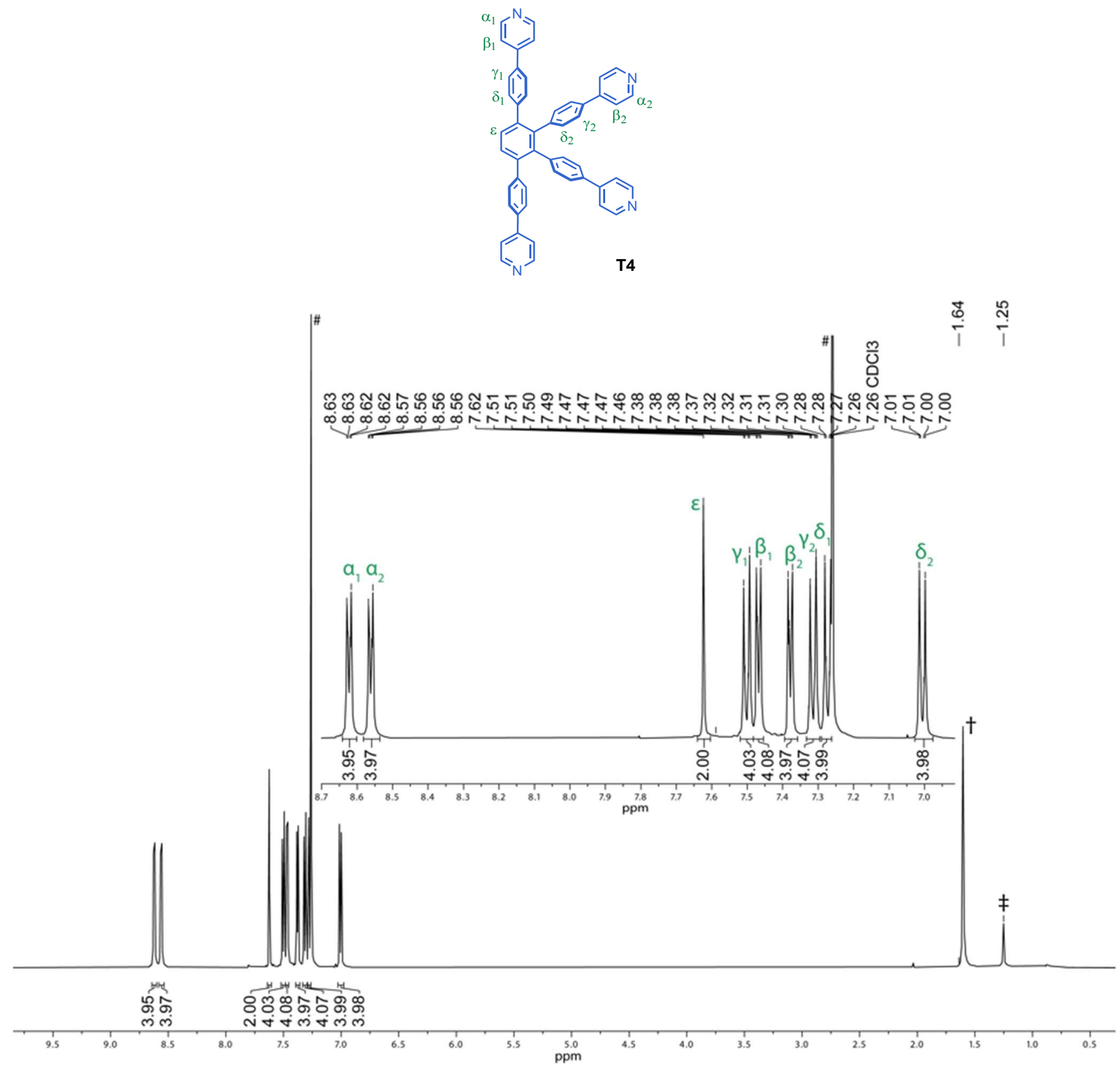

Figure S115. Assigned structure and ${ }^{1} \mathrm{H}$ NMR spectrum of T4 $\left(500 \mathrm{MHz}, \mathrm{CDCl}_{3}, 298 \mathrm{~K}\right)$. \#= $\mathrm{CHCl}_{3} ;{ }^{\dagger}=$ water; $\ddagger$ = silicon grease. 
Table S23. ${ }^{1} \mathrm{H}$ NMR assignment and correlations for template T4.

\begin{tabular}{c|c|c|c|c|c|c|c}
$\#$ & Assign. & ${ }^{1} \mathbf{H}$ & $\begin{array}{c}\text { Mult. } \\
\boldsymbol{J}(\mathbf{H z})\end{array}$ & $\begin{array}{c}{ }^{1} \mathbf{H}-{ }^{1} \mathbf{H} \\
\mathbf{C O S Y}\end{array}$ & $\begin{array}{c}{ }^{1} \mathbf{H}-{ }^{1} \mathbf{H} \\
\mathbf{N O E S Y}\end{array}$ & ${ }^{{ }^{1} \mathbf{H}-{ }^{13} \mathbf{C} \mathbf{H S Q C}}$ & ${ }^{{ }^{1} \mathbf{H}-{ }^{13} \mathbf{C H M B C}^{+}}$ \\
\hline 1 & $\alpha_{1}$ & $\begin{array}{c}8.64-8.60 \\
(4 \mathrm{H})\end{array}$ & $\mathrm{m}$ & 5 & 5 & 150.4 & $121.5,147.7,150.4$ \\
2 & $\alpha_{2}$ & $\begin{array}{c}8.58-8.54 \\
(4 \mathrm{H})\end{array}$ & $\mathrm{m}$ & 6 & 6 & 150.4 & $121.3,147.6,150.4$ \\
3 & $\varepsilon$ & $7.62(2 \mathrm{H})$ & $\mathrm{s}$ & - & 8 & 130.1 & $140.7 / 140.8,142.5$ \\
4 & $\gamma_{1}$ & $7.50(4 \mathrm{H})$ & $\mathrm{d}, J=8.4$ & 8 & 8 & 126.5 & $126.5,142.5,147.7$ \\
5 & $\beta_{1}$ & $\begin{array}{c}7.48-7.45 \\
(4 \mathrm{H})\end{array}$ & $\mathrm{m}$ & 1 & 1 & 121.5 & $121.5,136.3,150.4$ \\
6 & $\beta_{2}$ & $\begin{array}{c}7.39-7.36 \\
(4 \mathrm{H})\end{array}$ & $\mathrm{m}$ & 2 & 2 & 121.3 & $121.3,135.5,150.4$ \\
7 & $\gamma_{2}$ & $7.31(4 \mathrm{H})$ & $\mathrm{d}, J=8.4$ & 9 & 9 & 125.9 & $125.9,140.7 / 140.8$, \\
8 & $\delta_{1}$ & $7.27(4 \mathrm{H})$ & $\mathrm{d}, J=8.4$ & 4 & $9,4,3$ & $147.6 / 147.7$ \\
9 & $\delta_{2}$ & $7.00(4 \mathrm{H})$ & $\mathrm{d}, J=8.4$ & 7 & 7 & 130.7 & $126.5,130.7,136.3$ \\
$140.7 / 140.8$
\end{tabular}

'When signals are separated by / this should be interpreted as 'or' since these signals where too close to distinguish.

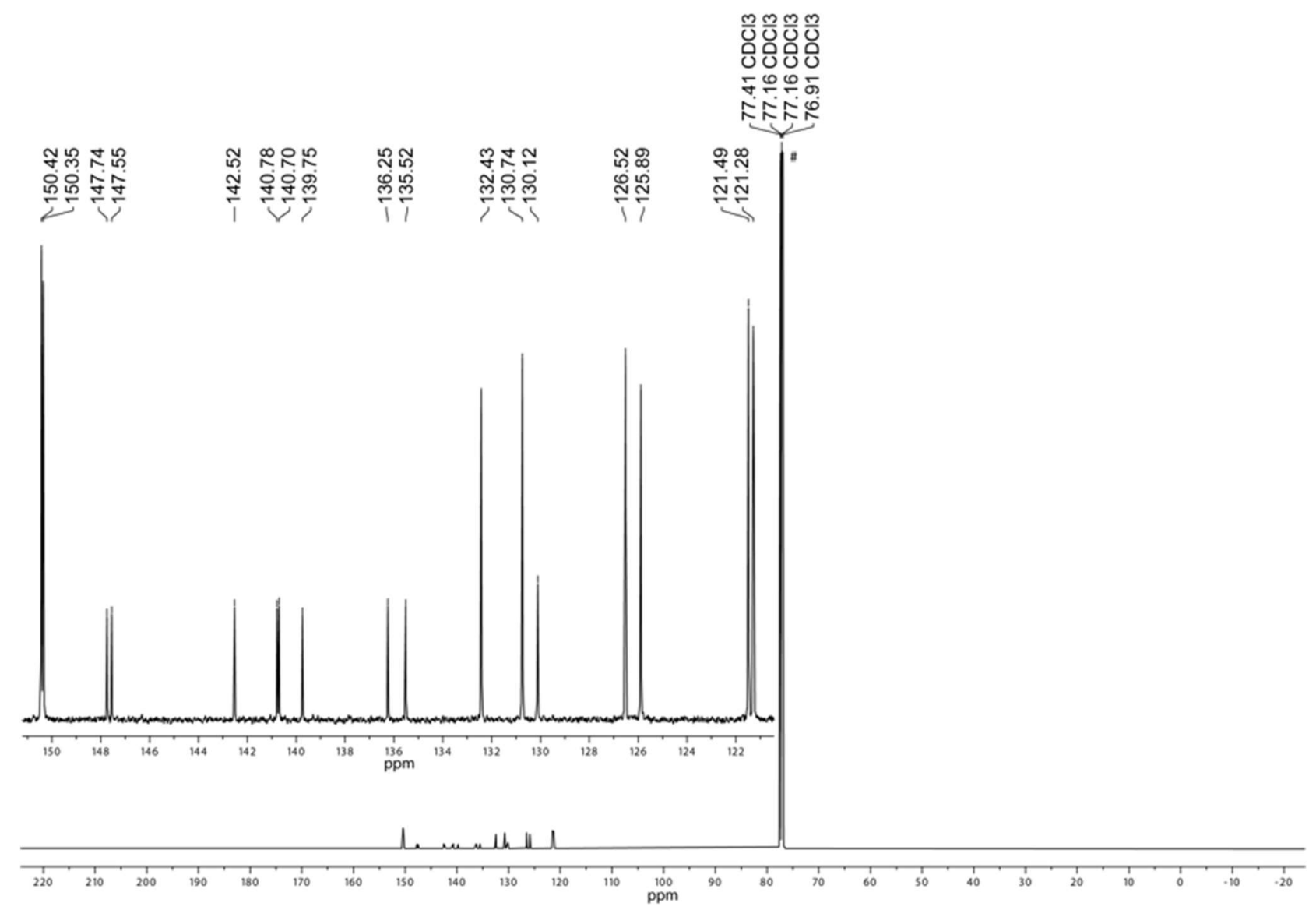

Figure S116. ${ }^{13} \mathrm{C} \mathrm{NMR} \mathrm{spectrum} \mathrm{of} \mathrm{T4}\left(500 \mathrm{MHz}, \mathrm{CDCl}_{3}, 298 \mathrm{~K}\right) . \#=\mathrm{CHCl}_{3}$. 


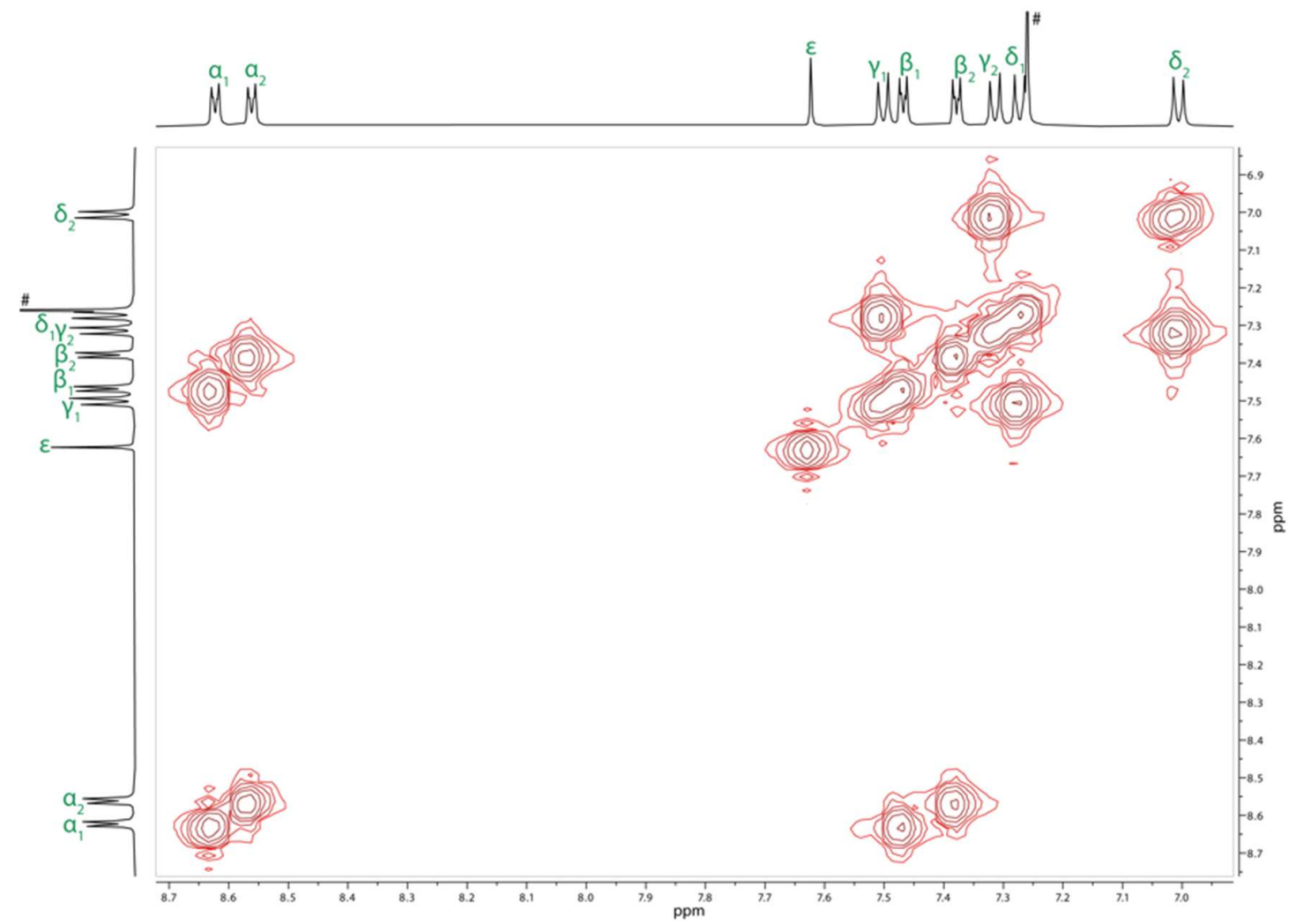

Figure S117. ${ }^{1} \mathrm{H}-{ }^{1} \mathrm{H}$ COSY spectrum of T4 $\left(500 \mathrm{MHz}, \mathrm{CDCl}_{3}, 298 \mathrm{~K}\right)$.

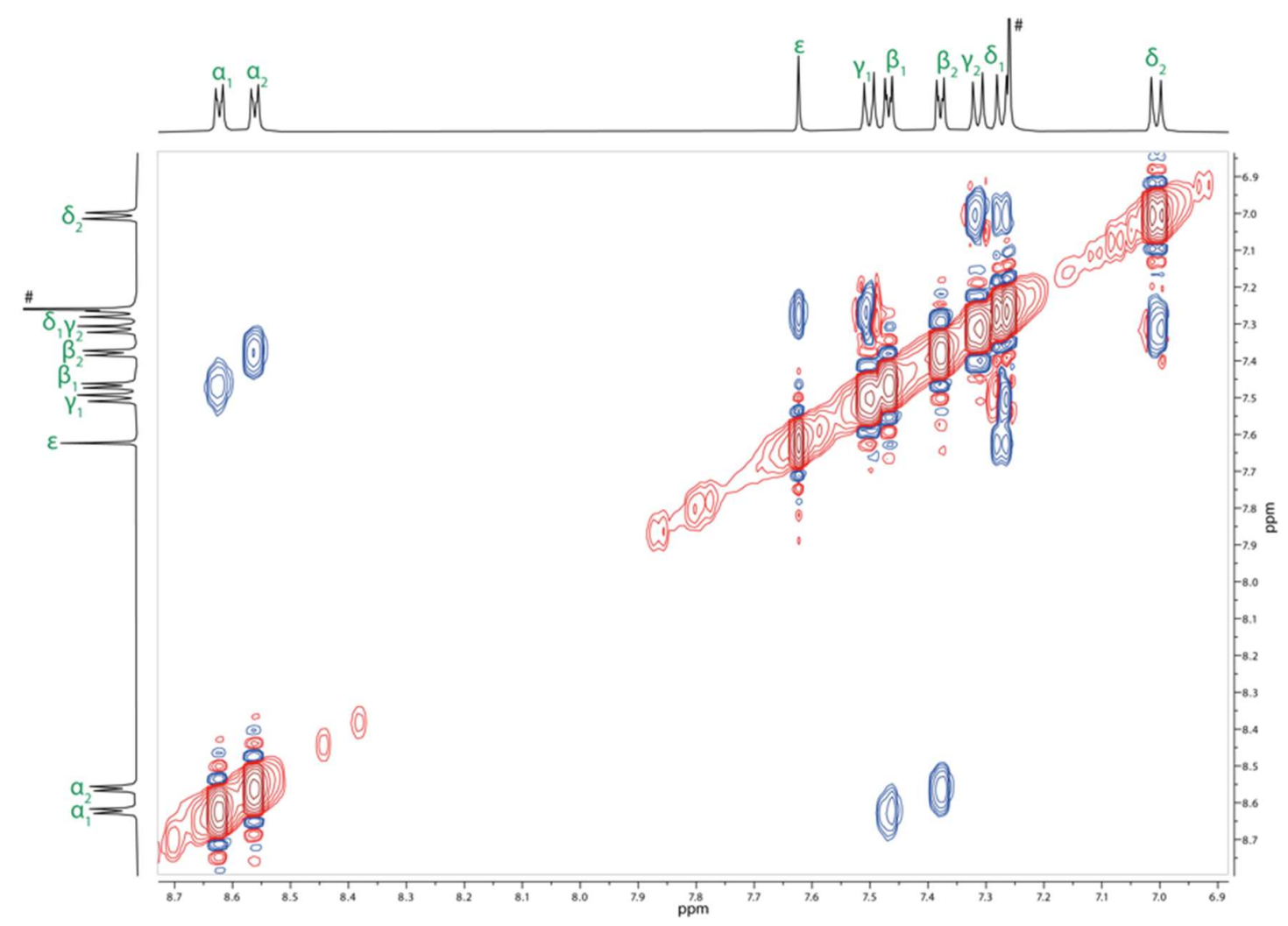

Figure S118. ${ }^{1} \mathrm{H}^{1}{ }^{1} \mathrm{H}$ NOESY spectrum of T4 $\left(500 \mathrm{MHz}, \mathrm{CDCl}_{3}, 298 \mathrm{~K}\right)$. 


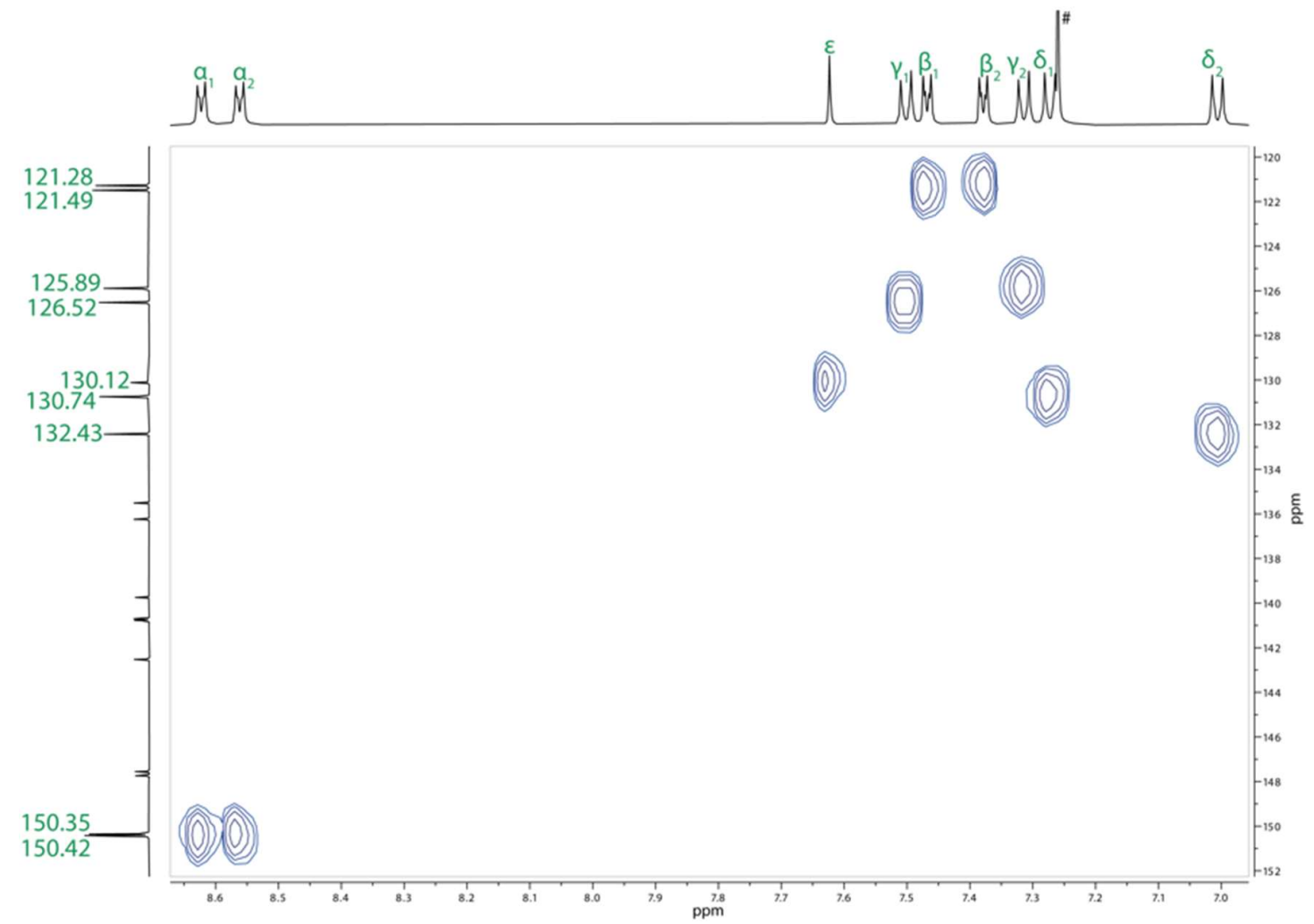

Figure S119. ${ }^{1} \mathrm{H}^{13} \mathrm{C}$ HSQC spectrum of T4 $\left(500 \mathrm{MHz}, \mathrm{CDCl}_{3}, 298 \mathrm{~K}\right)$.

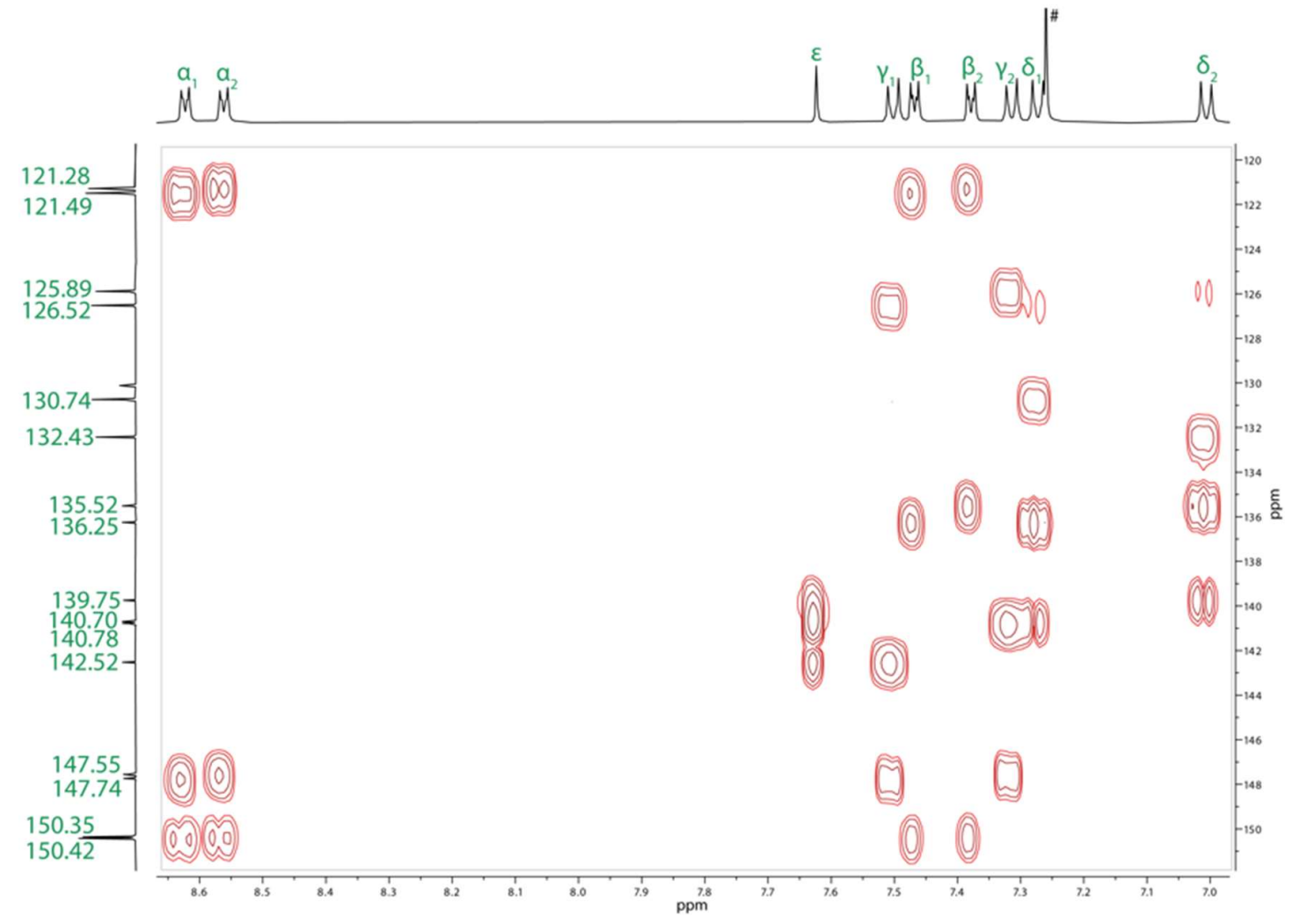

Figure S120. ${ }^{1} \mathrm{H}-{ }^{13} \mathrm{C} \mathrm{HMBC}$ spectrum of $\mathrm{T4}\left(500 \mathrm{MHz}, \mathrm{CDCl}_{3}, 298 \mathrm{~K}\right)$. 

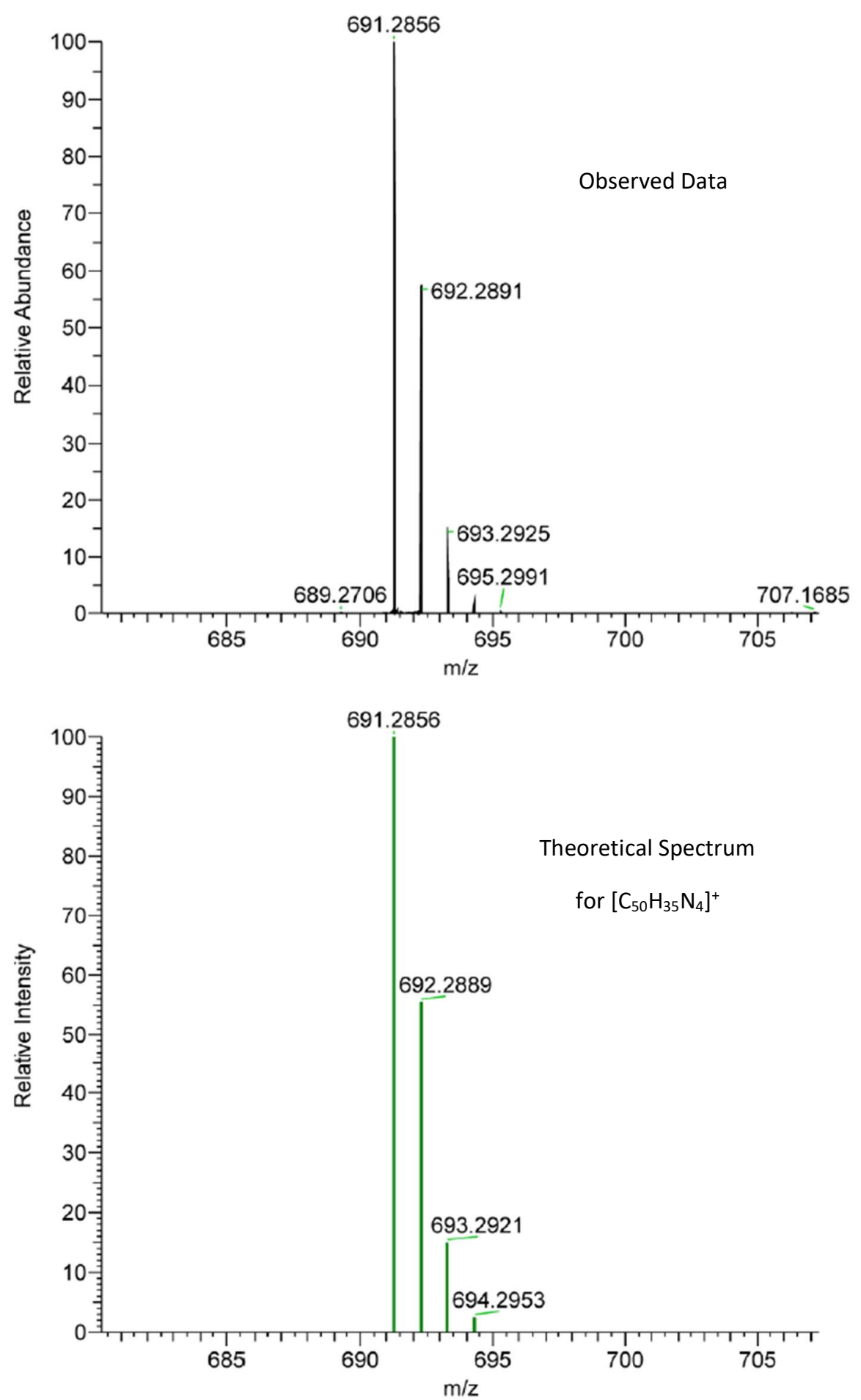

Figure S121. Experimental HR-ESI spectrum of T4 (top) and simulated HR-ESI spectrum of $[\mathrm{T4}+\mathrm{H}]^{+}\left[\mathrm{C}_{50} \mathrm{H}_{35} \mathrm{~N}_{4}\right]^{+}$(bottom). 


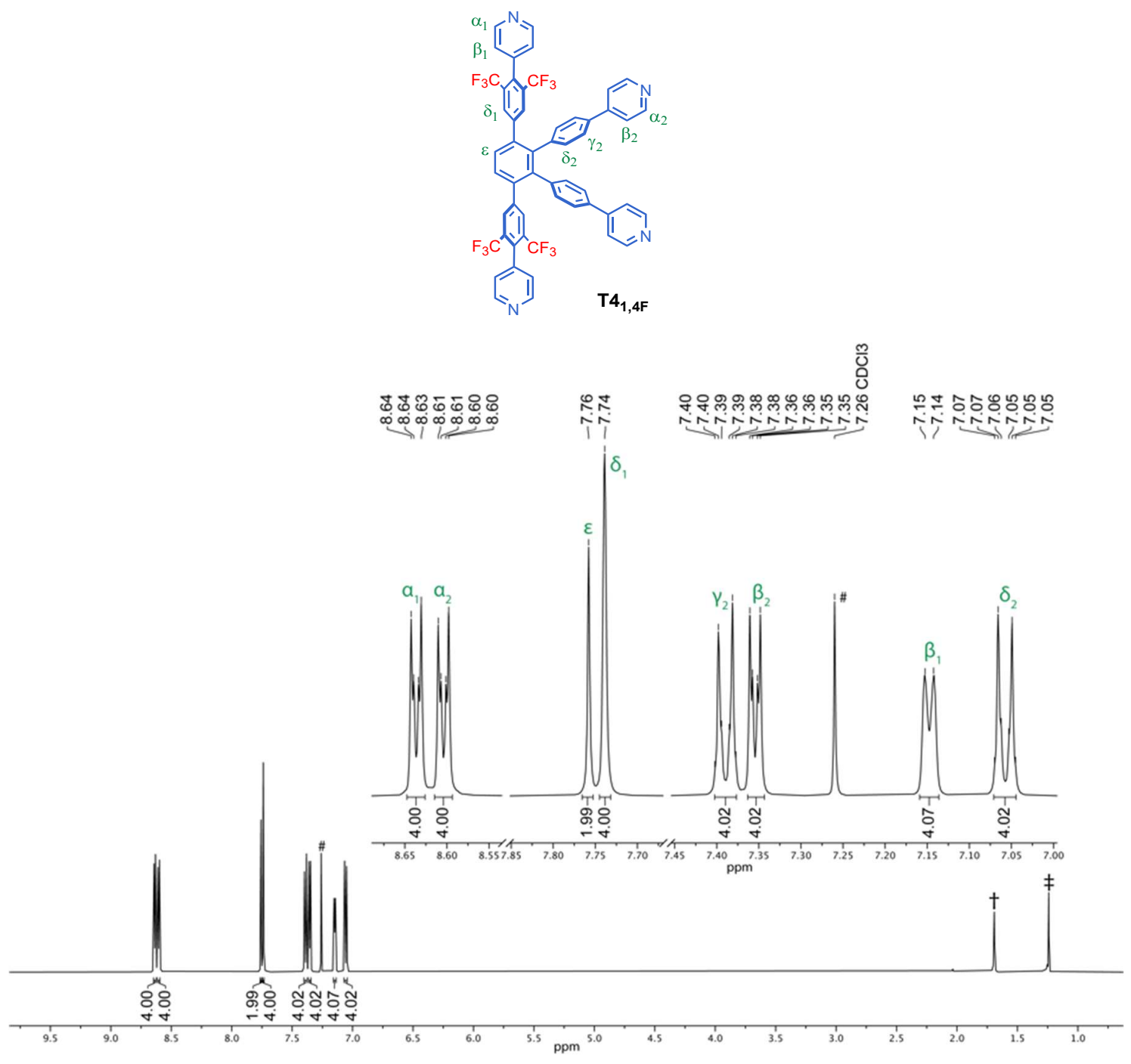

Figure S122. Assigned structure and ${ }^{1} \mathrm{H}$ NMR spectrum of $\mathrm{T4}_{1,4 \mathrm{~F}}\left(500 \mathrm{MHz}, \mathrm{CDCl}_{3}, 298 \mathrm{~K}\right)$. \#= $\mathrm{CHCl}_{3} ; \dagger=$ water; $¥=$ silicon grease.

Table S24. ${ }^{1} \mathrm{H}$ NMR assignment and correlations for template $\mathbf{T} \mathbf{4}_{1,4 F}$.

\begin{tabular}{|c|c|c|c|c|c|c|c|c|}
\hline$\#$ & Assign. & ${ }^{1} \mathrm{H}$ & $\begin{array}{l}\text { Mult. } \\
J(H z)\end{array}$ & $\begin{array}{l}{ }^{1} \mathrm{H}-{ }^{1} \mathrm{H} \\
\mathrm{COSY}\end{array}$ & $\begin{array}{l}{ }^{1} \mathrm{H}-{ }^{1} \mathrm{H} \\
\text { NOESY }\end{array}$ & $\begin{array}{c}{ }^{1} \mathrm{H}-{ }^{19} \mathbf{F} \\
\text { HOESY }\end{array}$ & $\begin{array}{l}{ }^{1} \mathrm{H}-{ }^{13} \mathrm{C} \\
\mathrm{HSQC}\end{array}$ & $\begin{array}{l}{ }^{1} \mathrm{H}-{ }^{13} \mathrm{C} \\
\mathrm{HMBC}^{\ddagger}\end{array}$ \\
\hline 1 & $\alpha_{1}$ & $8.66-8.62(4 \mathrm{H})$ & $\mathrm{m}$ & 7 & 7 & w & 148.9 & $148.9,142.3,124.9$ \\
\hline 2 & $\alpha_{2}$ & $8.62-8.59(4 \mathrm{H})$ & $\mathrm{m}$ & 6 & 6 & - & 150.5 & $150.5,147.5,121.5$ \\
\hline 3 & $\varepsilon_{1}$ & $7.76(2 \mathrm{H})$ & s & - & - & $(v w)$ & 130.1 & $141.9,139.2 / 139.1$ \\
\hline 4 & $\delta_{1}$ & $7.74(4 \mathrm{H})$ & $\mathrm{s}$ & - & 8 & $\mathrm{~s}$ & 130.6 & $\begin{array}{c}\text { 139.2/139.1, 135.3 } \\
130.62 / 130.59,122.9\end{array}$ \\
\hline 5 & $\gamma_{2}$ & $7.39(4 \mathrm{H})$ & $\begin{array}{c}d \\
J=8.2\end{array}$ & 8 & 8 & vw & 126.6 & $147.5,139.1,126.6$ \\
\hline 6 & $\beta_{2}$ & 7.37-7.34 (4H) & m & 2 & 2 & vw & 121.5 & $150.5,137.3,121.5$ \\
\hline 7 & $\beta_{1}$ & $7.15(4 \mathrm{H})$ & $\begin{array}{l}\text { br d } \\
J=5.4\end{array}$ & 1 & 1 & $\mathrm{~m}$ & 124.9 & $148.9,135.3,124.9$ \\
\hline 8 & $\delta_{2}$ & $7.06(4 \mathrm{H})$ & $\begin{array}{c}d \\
J=8.2\end{array}$ & 5 & 4,5 & $\mathrm{vw}$ & 132.1 & $140.7,137.3,132.1$ \\
\hline
\end{tabular}

${ }^{\dagger}$ Relative correlation intensities are classified as: $\mathrm{s}=$ strong, $\mathrm{m}=$ medium, $\mathrm{w}=$ weak, $\mathrm{vw}=$ very weak. ${ }^{\ddagger}$ When signals are separated by / this should be interpreted as 'or' since these signals where too close to distinguish. 


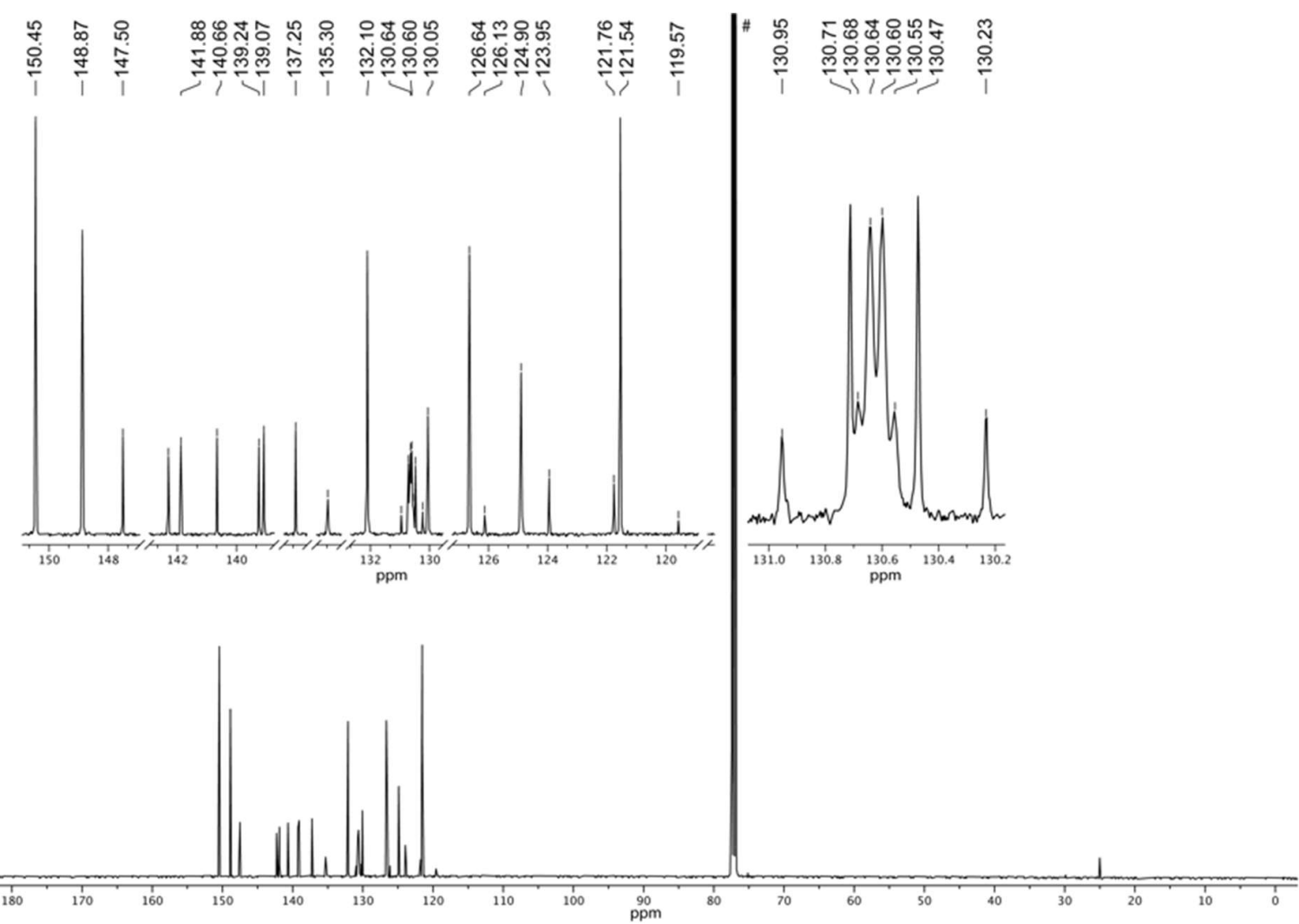

Figure S123. ${ }^{13} \mathrm{C}$ NMR spectrum of $\mathrm{T4}_{1,4 \mathrm{~F}}\left(500 \mathrm{MHz}, \mathrm{CDCl}_{3}, 298 \mathrm{~K}\right) . \#=\mathrm{CHCl}_{3}$.

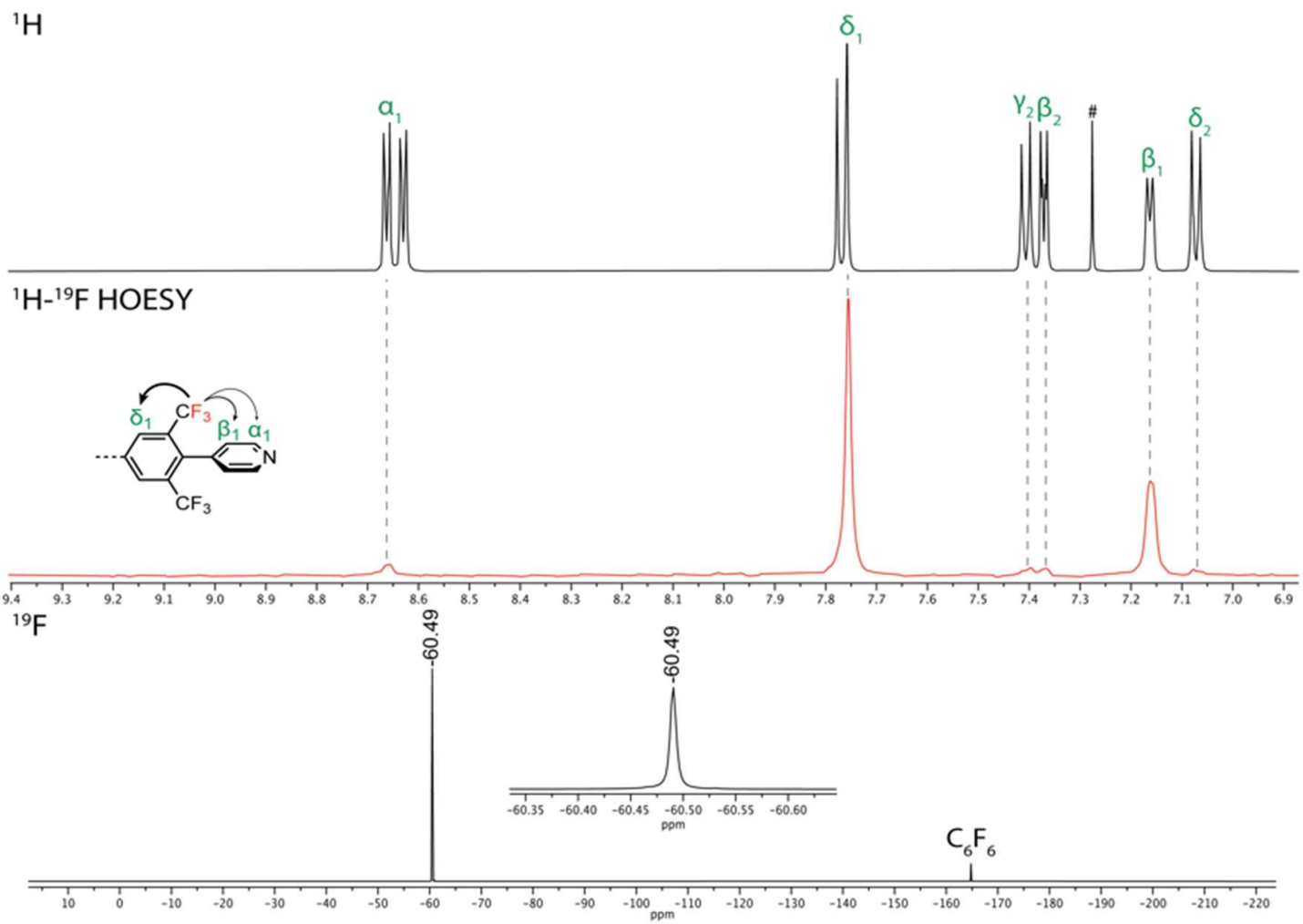

Figure S124. Combined ${ }^{1} \mathrm{H}$ (top), $1 \mathrm{D}^{1} \mathrm{H}_{-}{ }^{19} \mathrm{~F}$ HOESY (middle, red), and ${ }^{19} \mathrm{~F}$ (bottom) spectra of $\mathrm{T4}_{1,4 \mathrm{~F}}\left(500 \mathrm{MHz}, \mathrm{CDCl}_{3}, 298 \mathrm{~K}\right)$. 


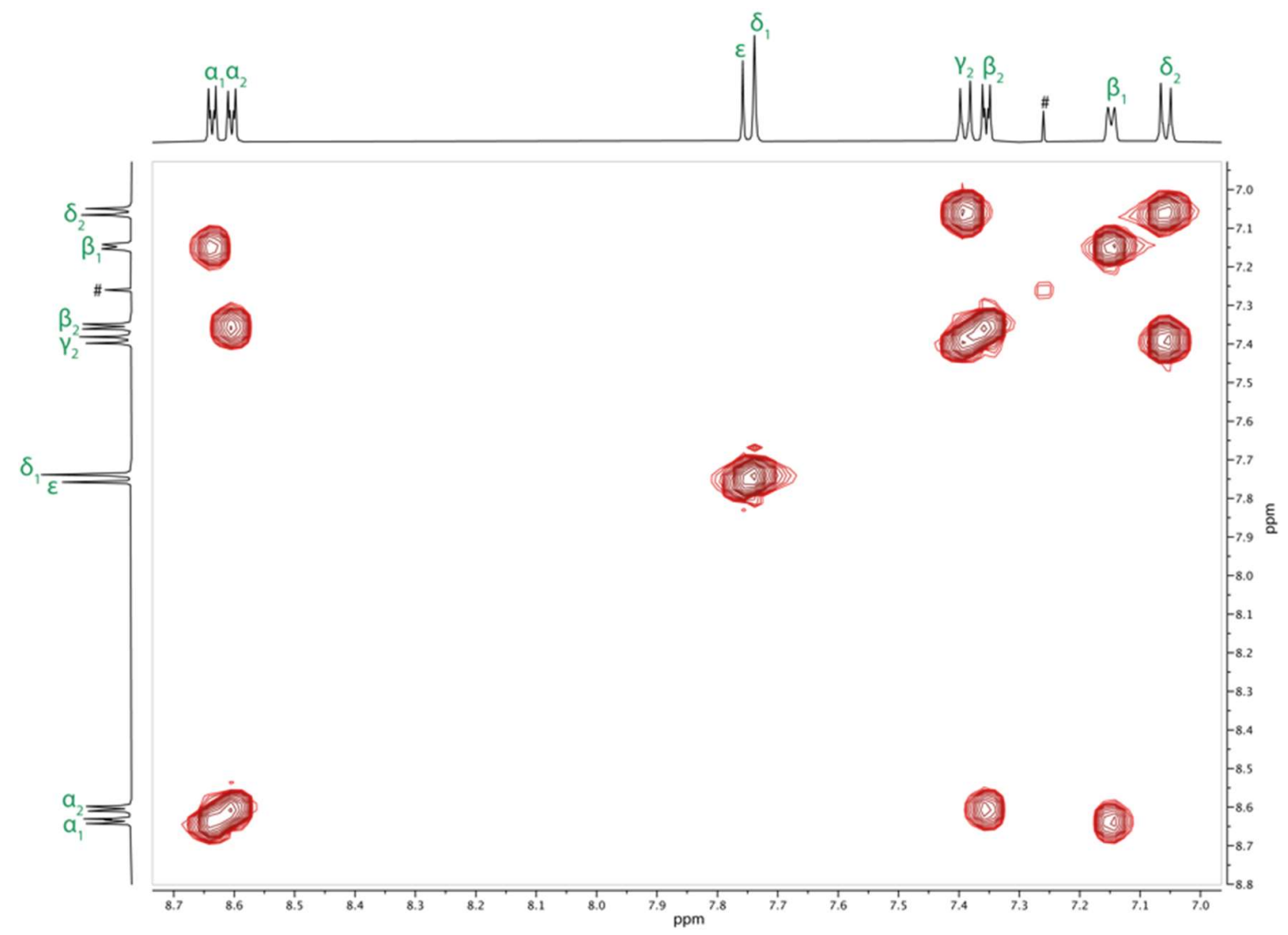

Figure S125. ${ }^{1} \mathrm{H}-{ }^{1} \mathrm{H}$ COSY spectrum of $\mathrm{T4}_{1,4 \mathrm{~F}}\left(500 \mathrm{MHz}, \mathrm{CDCl}_{3}, 298 \mathrm{~K}\right)$.

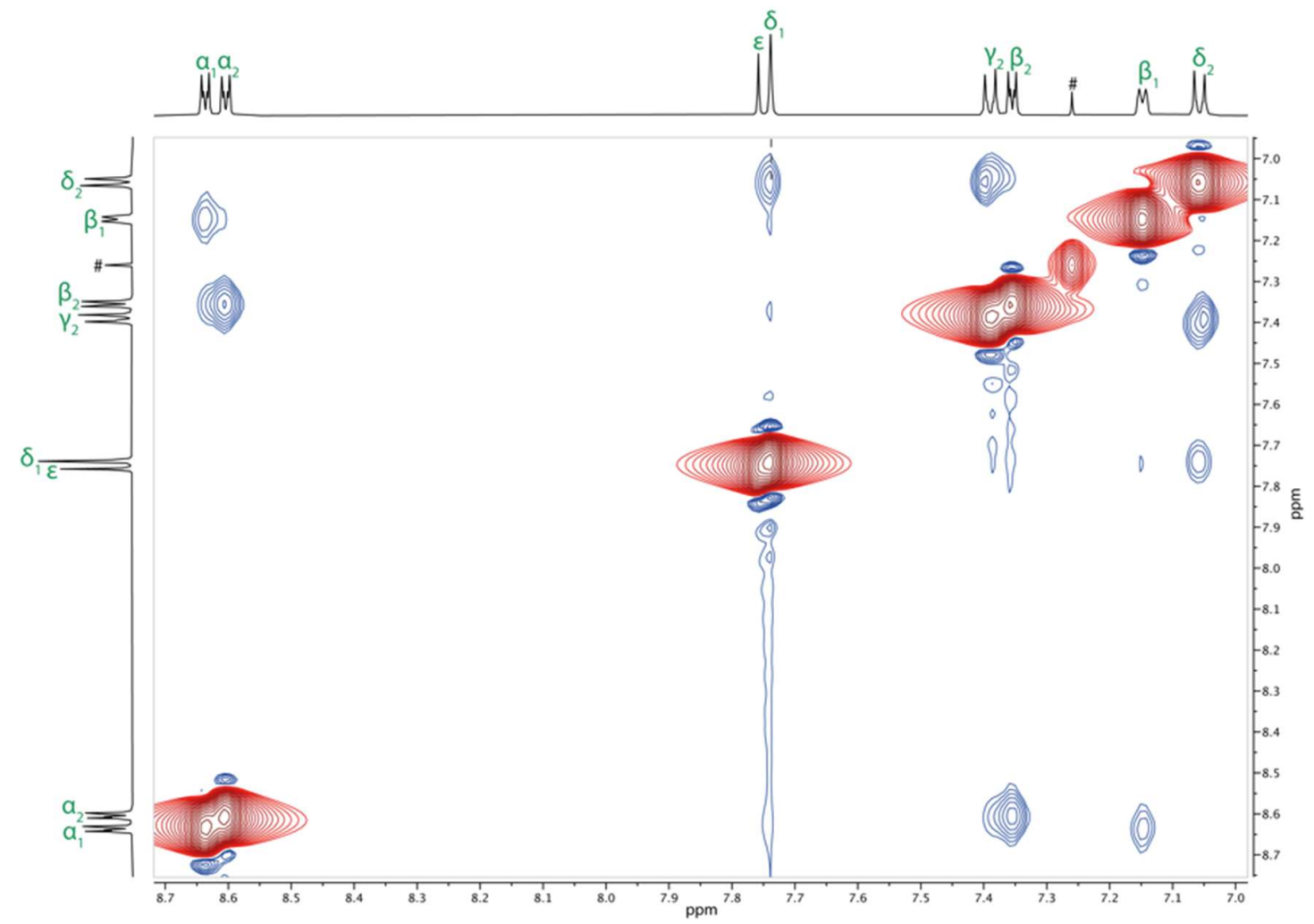

Figure S126. ${ }^{1} \mathrm{H}-{ }^{1} \mathrm{H}$ NOESY spectrum of $\mathrm{T4}_{1,4 \mathrm{~F}}\left(500 \mathrm{MHz}, \mathrm{CDCl}_{3}, 298 \mathrm{~K}\right)$. 


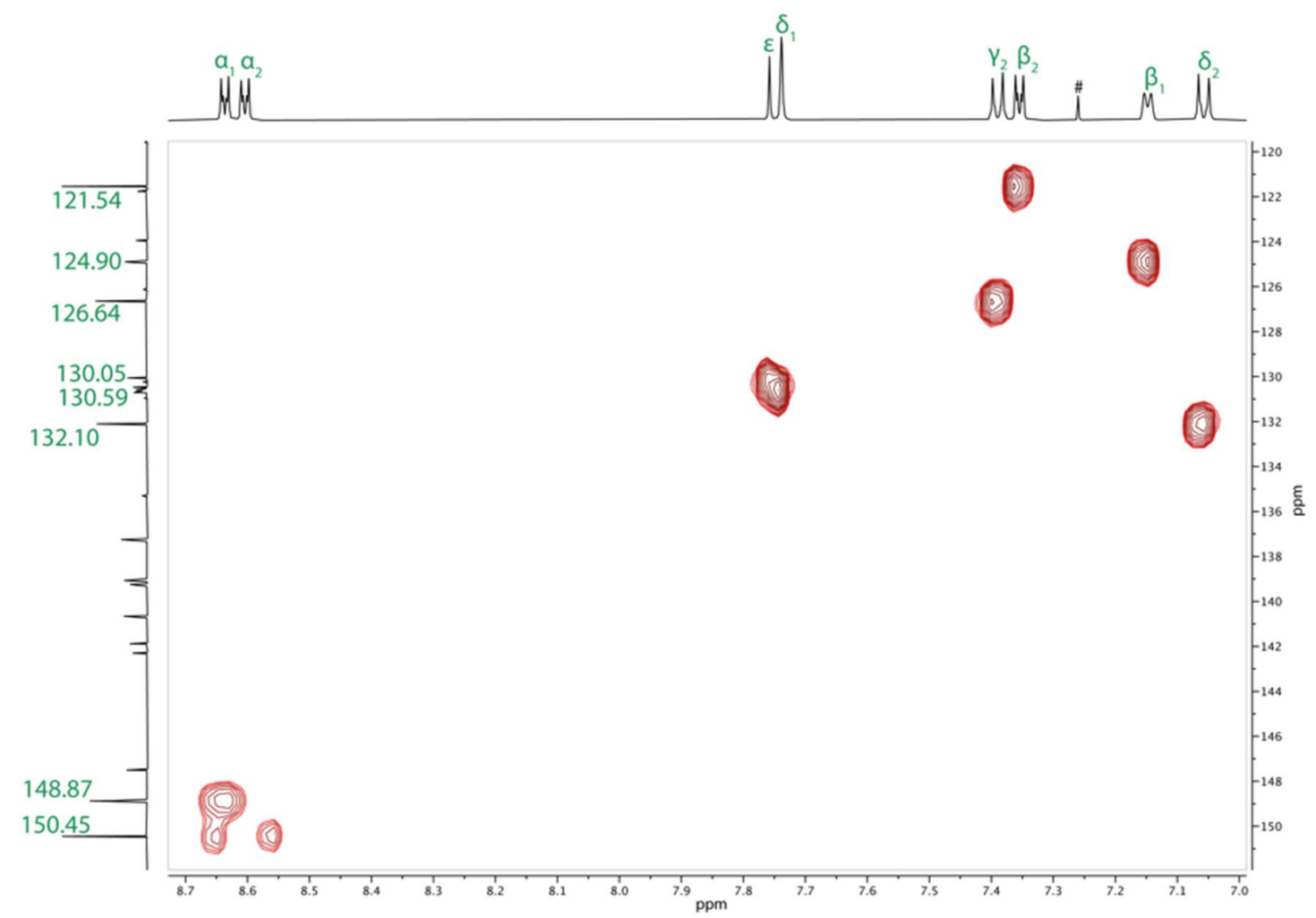

Figure S127. ${ }^{1} \mathrm{H}_{-}{ }^{13} \mathrm{C}$ HSQC spectrum of $\mathrm{T4}_{1,4 \mathrm{~F}}\left(500 \mathrm{MHz}, \mathrm{CDCl}_{3}, 298 \mathrm{~K}\right)$.

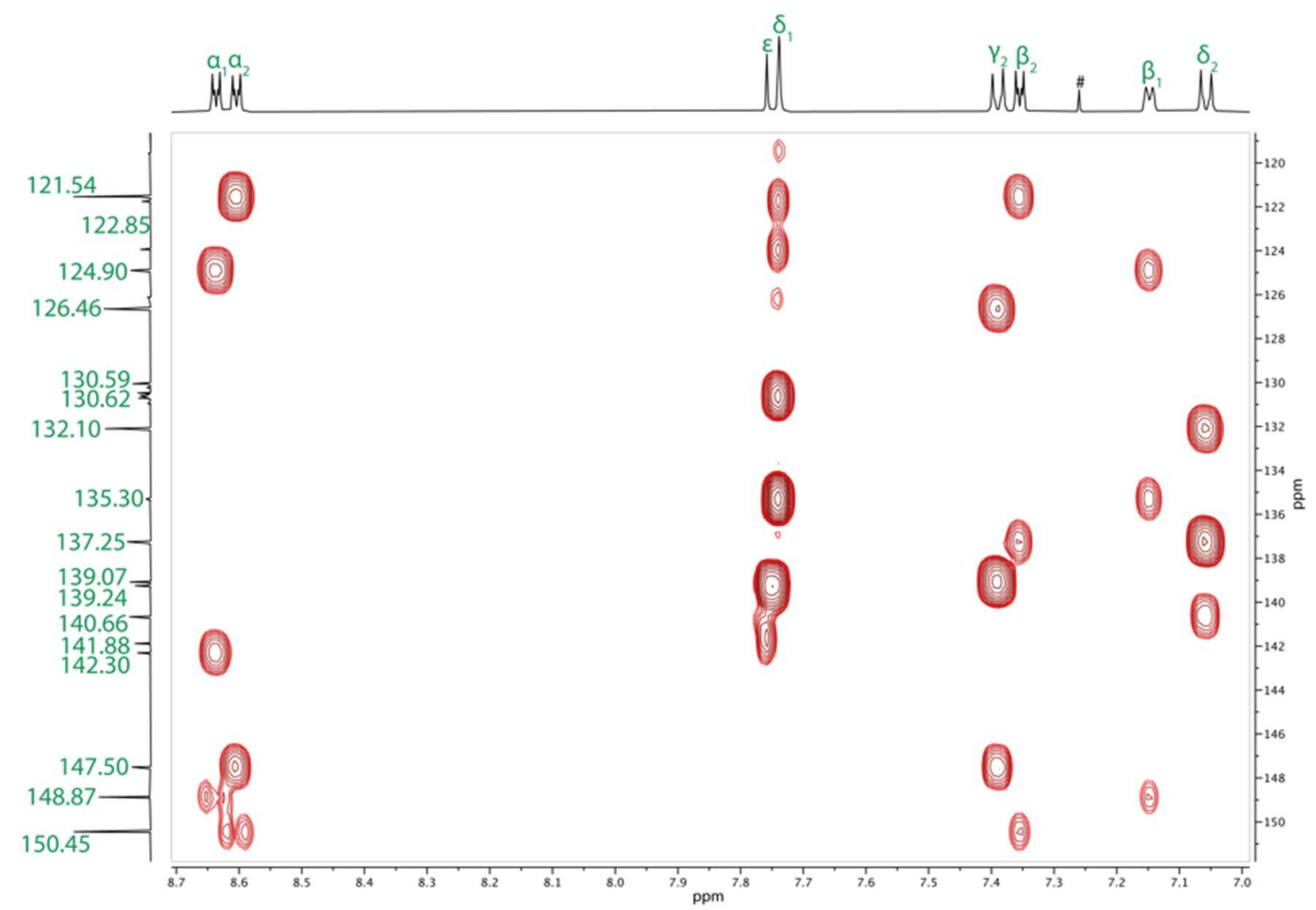

Figure S128. ${ }^{1} \mathrm{H}^{-13} \mathrm{C}$ HMBC spectrum of $\mathbf{T 4}_{1,4 \mathrm{~F}}\left(500 \mathrm{MHz}, \mathrm{CDCl}_{3}, 298 \mathrm{~K}\right)$. 

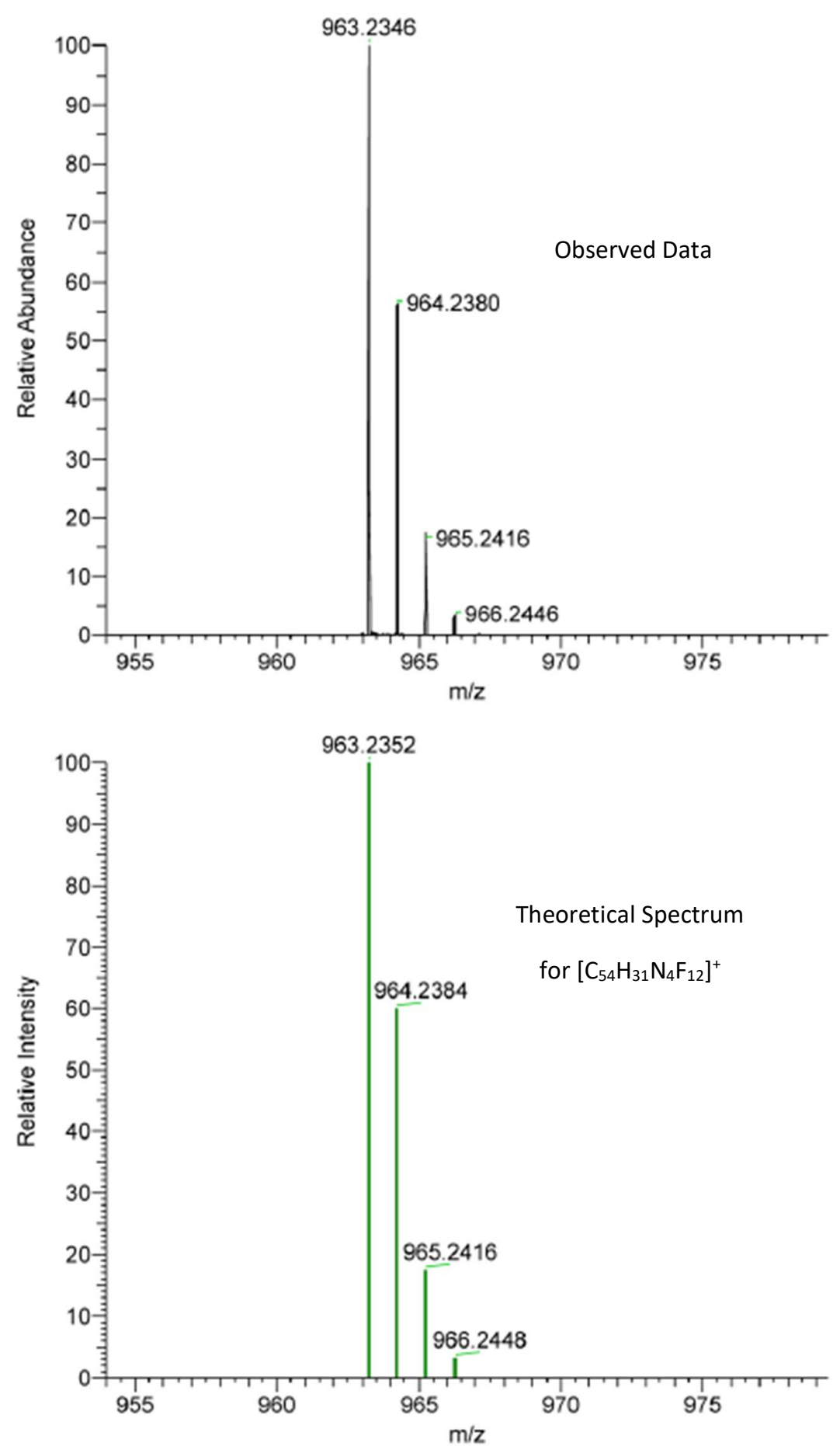

Figure S129. Experimental HR-ESI spectrum of $\mathbf{T} \mathbf{4}_{1,4 \mathrm{~F}}$ (top) and simulated HR-ESI spectrum of $\left[\mathbf{T 4}_{1,4 \mathrm{~F}}+\mathrm{H}\right]^{+}\left[\mathrm{C}_{54} \mathrm{H}_{31} \mathrm{~N}_{4} \mathrm{~F}_{12}\right]^{+}$(bottom). 


\section{Template $\mathbf{T 4}_{2,3 \mathrm{~F}}$ :}

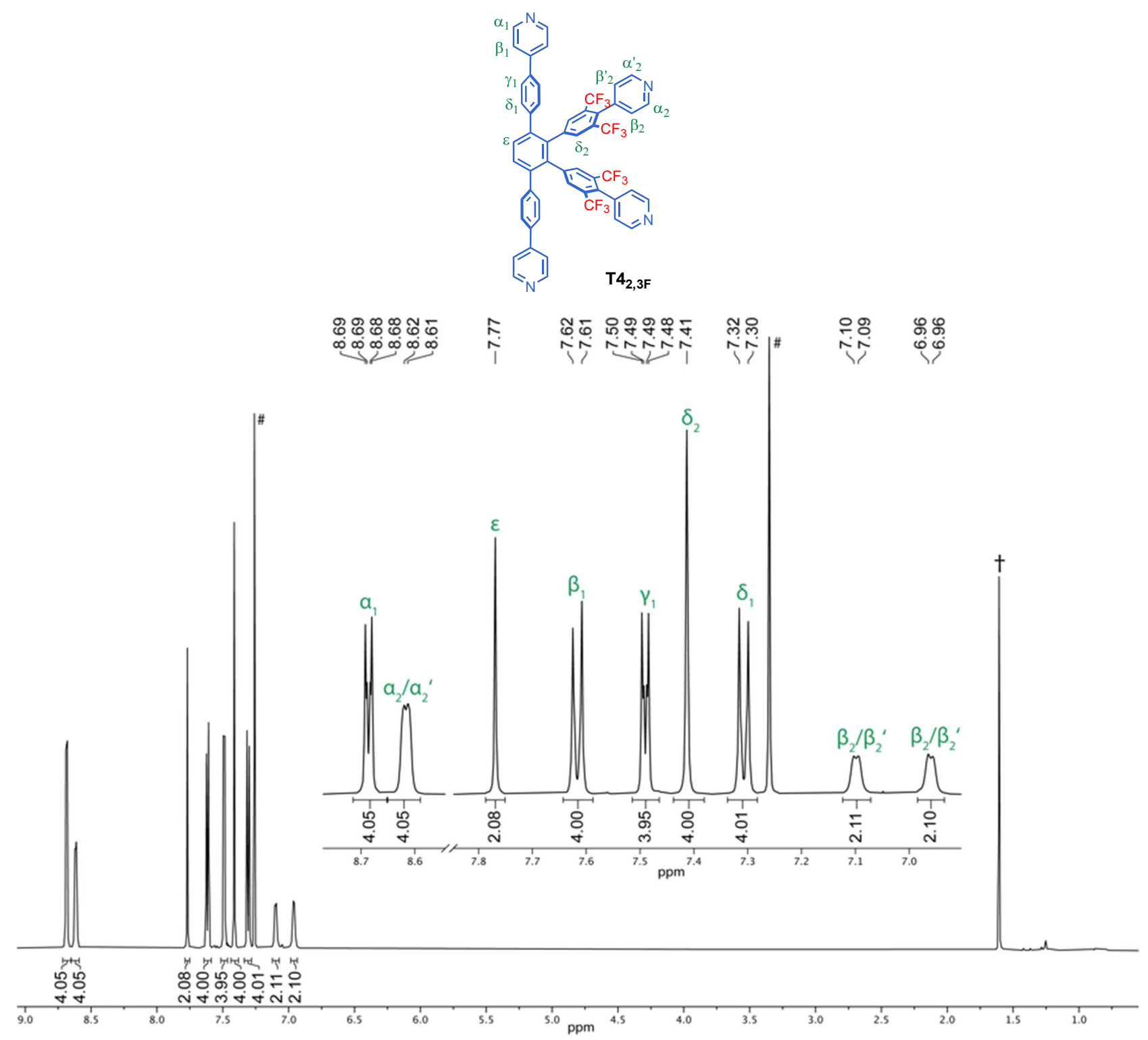

Figure S130. Assigned structure and ${ }^{1} \mathrm{H}$ NMR spectrum of $\mathrm{T4}_{2,3 \mathrm{~F}}\left(500 \mathrm{MHz}, \mathrm{CDCl}_{3}, 298 \mathrm{~K}\right)$. $\#=\mathrm{CHCl}_{3} ;{ }^{\dagger}=$ water. 
Table S25. ${ }^{1} \mathrm{H}$ NMR assignment and correlations for template T42,3F.

\begin{tabular}{|c|c|c|c|c|c|c|c|c|}
\hline \# & Assign. & ${ }^{1} \mathbf{H}$ & $\begin{array}{l}\text { Mult. } \\
J(\mathrm{~Hz})\end{array}$ & $\begin{array}{l}{ }^{1} \mathrm{H}-{ }^{1} \mathrm{H} \\
\text { COSY }\end{array}$ & $\begin{array}{c}{ }^{1} \mathrm{H}-{ }^{1} \mathrm{H} \\
\text { NOESY }\end{array}$ & $\begin{array}{c}{ }^{1} \mathrm{H}-{ }^{19} \mathrm{~F} \\
\text { HOESY }\end{array}$ & $\begin{array}{l}{ }^{1} \mathrm{H}-{ }^{13} \mathrm{C} \\
\mathrm{HSQC}\end{array}$ & $\begin{array}{l}{ }^{1} \mathrm{H}-{ }^{13} \mathrm{C} \\
\mathrm{HMBC}^{\ddagger}\end{array}$ \\
\hline 1 & $\alpha_{1}$ & $8.71-8.65(4 \mathrm{H})$ & $\mathrm{m}$ & 5 & 5 & - & 150.6 & $150.6,147.5,121.7$ \\
\hline 2 & $\alpha_{2} / \alpha_{2}^{\prime}$ & $8.62(4 \mathrm{H})$ & $\begin{array}{c}\text { brd } \\
J=3.8\end{array}$ & 8,9 & 8,9 & w & $149.1 / 148.8$ & $\begin{array}{c}149.1 / 148.8,141.9 \\
124.8,124.6\end{array}$ \\
\hline 3 & $\varepsilon_{1}$ & $7.77(2 \mathrm{H})$ & $\mathrm{s}$ & - & 7 & - & 131.4 & $141.2,137.3$ \\
\hline 4 & $\gamma_{1}$ & $7.62(4 \mathrm{H})$ & $\begin{array}{c}d \\
J=8.3\end{array}$ & 7 & 5,7 & - & 127.2 & $\begin{array}{c}147.5,140.7,127.2 \\
130.7\end{array}$ \\
\hline 5 & $\beta_{1}$ & $7.51-7.46(4 \mathrm{H})$ & $\mathrm{m}$ & 1 & 1,4 & - & 121.7 & $150.6,137.7,121.7$ \\
\hline 6 & $\delta_{2}$ & $7.41(4 \mathrm{H})$ & s & - & - & s & 132.6 & $\begin{array}{c}141.9,140.4,137.3, \\
135.4,132.6,130.4, \\
122.6\end{array}$ \\
\hline 7 & $\delta_{1}$ & $7.31(4 \mathrm{H})$ & $\begin{array}{c}d \\
J=8.3\end{array}$ & 4 & 3,4 & vw & 130.7 & $\begin{array}{c}141.2,137.7,130.7 \\
127.2\end{array}$ \\
\hline 8 & $\beta_{2} / \beta_{2}^{\prime}$ & $7.10(2 \mathrm{H})$ & $\begin{array}{c}\text { brd } \\
J=3.8\end{array}$ & 2 & 2 & $\mathrm{~m}$ & 124.8 & $135.4,124.6$ \\
\hline 9 & $\beta_{2} / \beta_{2}^{\prime}$ & $6.96(2 \mathrm{H})$ & $\begin{array}{c}\text { brd } \\
J=3.8\end{array}$ & 2 & 2 & $\mathrm{~m}$ & 124.6 & $135.4,124.8$ \\
\hline
\end{tabular}

${ }^{\dagger}$ Relative correlation intensities are classified as: $\mathrm{s}=$ strong, $\mathrm{m}=$ medium, $\mathrm{w}=$ weak, $\mathrm{vw}=$ very weak. ${ }^{\ddagger} \mathrm{When}$ signals are separated by / this should be interpreted as 'or' since these signals where too close to distinguish.

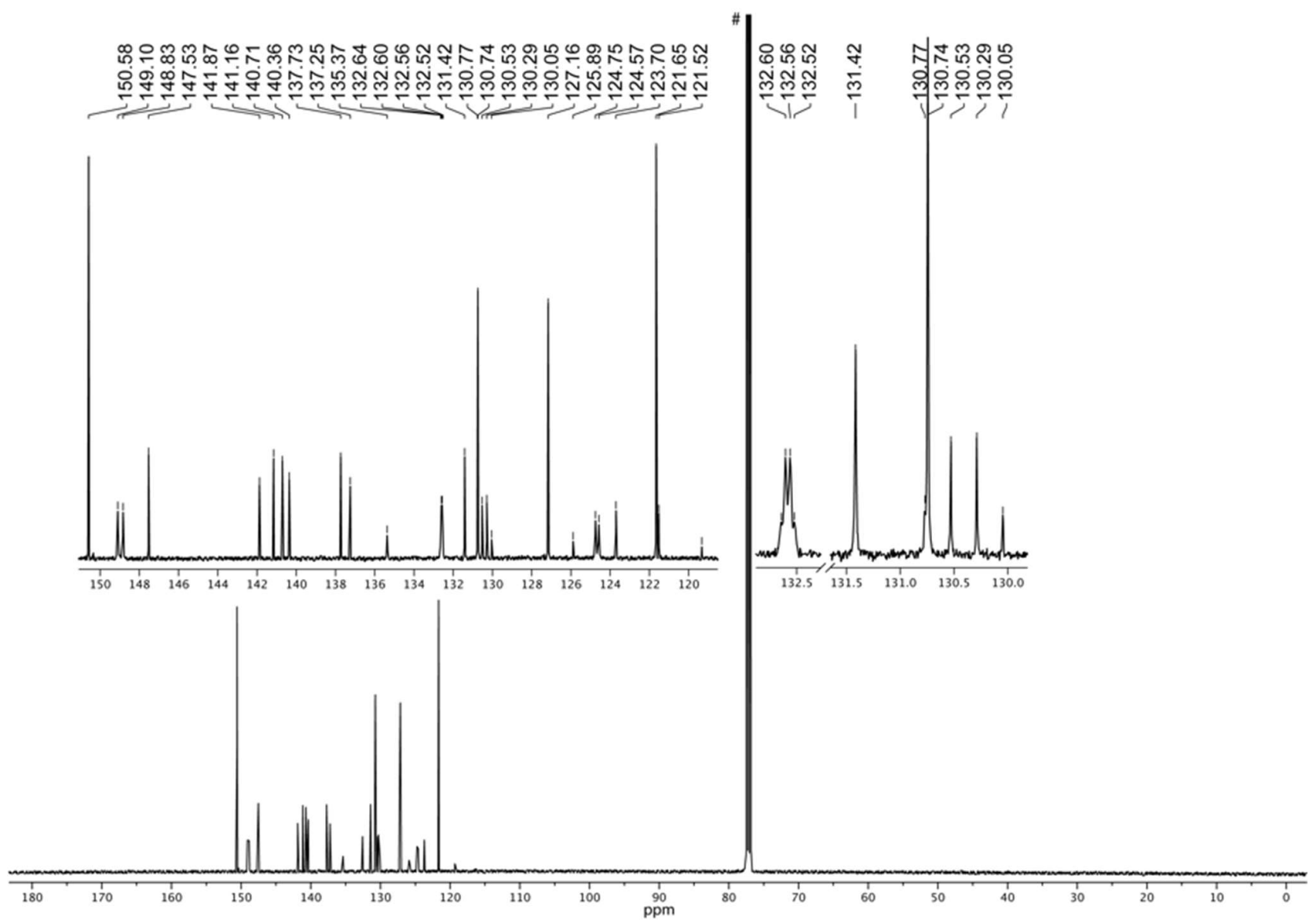

Figure S131. ${ }^{13} \mathrm{C}$ NMR spectrum of $\mathbf{T 4}_{2,3 \mathrm{~F}}\left(500 \mathrm{MHz}, \mathrm{CDCl}_{3}, 298 \mathrm{~K}\right)$. $\#=\mathrm{CHCl}_{3}$. 


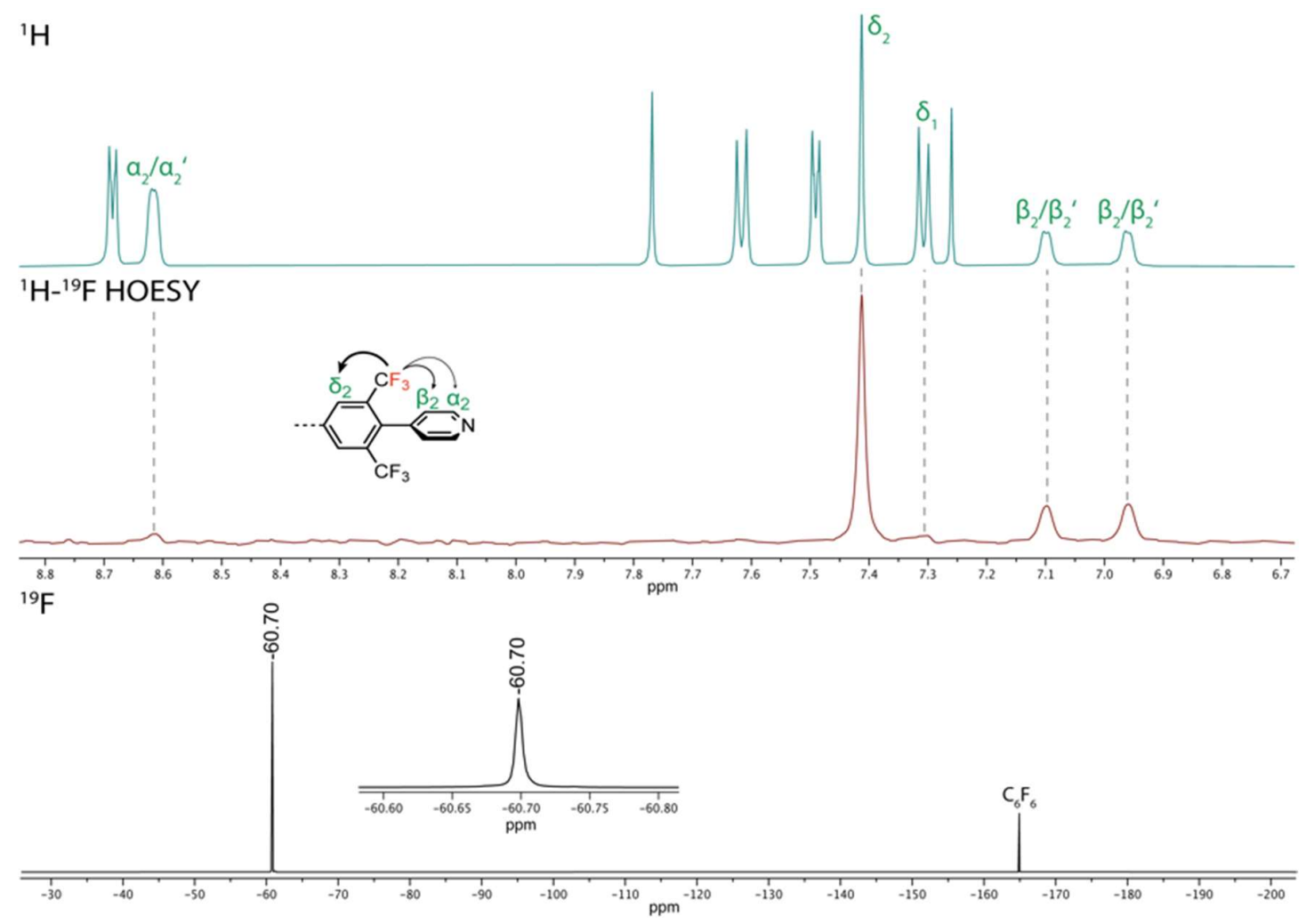

Figure S132. Combined ${ }^{1} \mathrm{H}$ (top), $1 \mathrm{D}^{1} \mathrm{H}^{-19} \mathrm{~F}$ HOESY (middle, red), and ${ }^{19} \mathrm{~F}$ (bottom) spectra of $\mathrm{T4}_{2,3 \mathrm{~F}}\left(500 \mathrm{MHz}, \mathrm{CDCl}_{3}, 298 \mathrm{~K}\right)$.

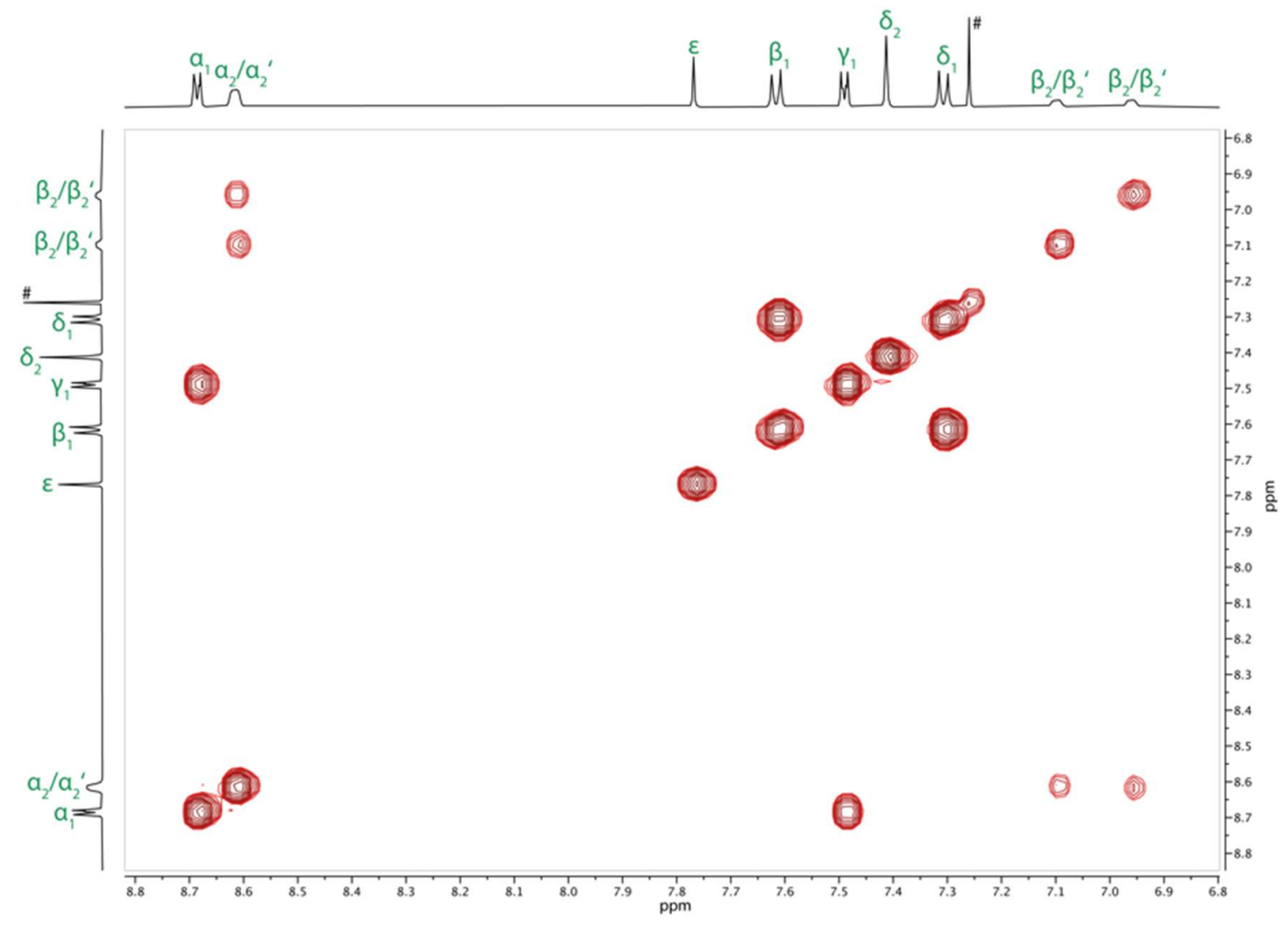

Figure S133. ${ }^{1} \mathrm{H}-{ }^{1} \mathrm{H}$ COSY spectrum of $\mathbf{T 4}_{2,3 \mathbf{F}}\left(500 \mathrm{MHz}, \mathrm{CDCl}_{3}, 298 \mathrm{~K}\right)$. 


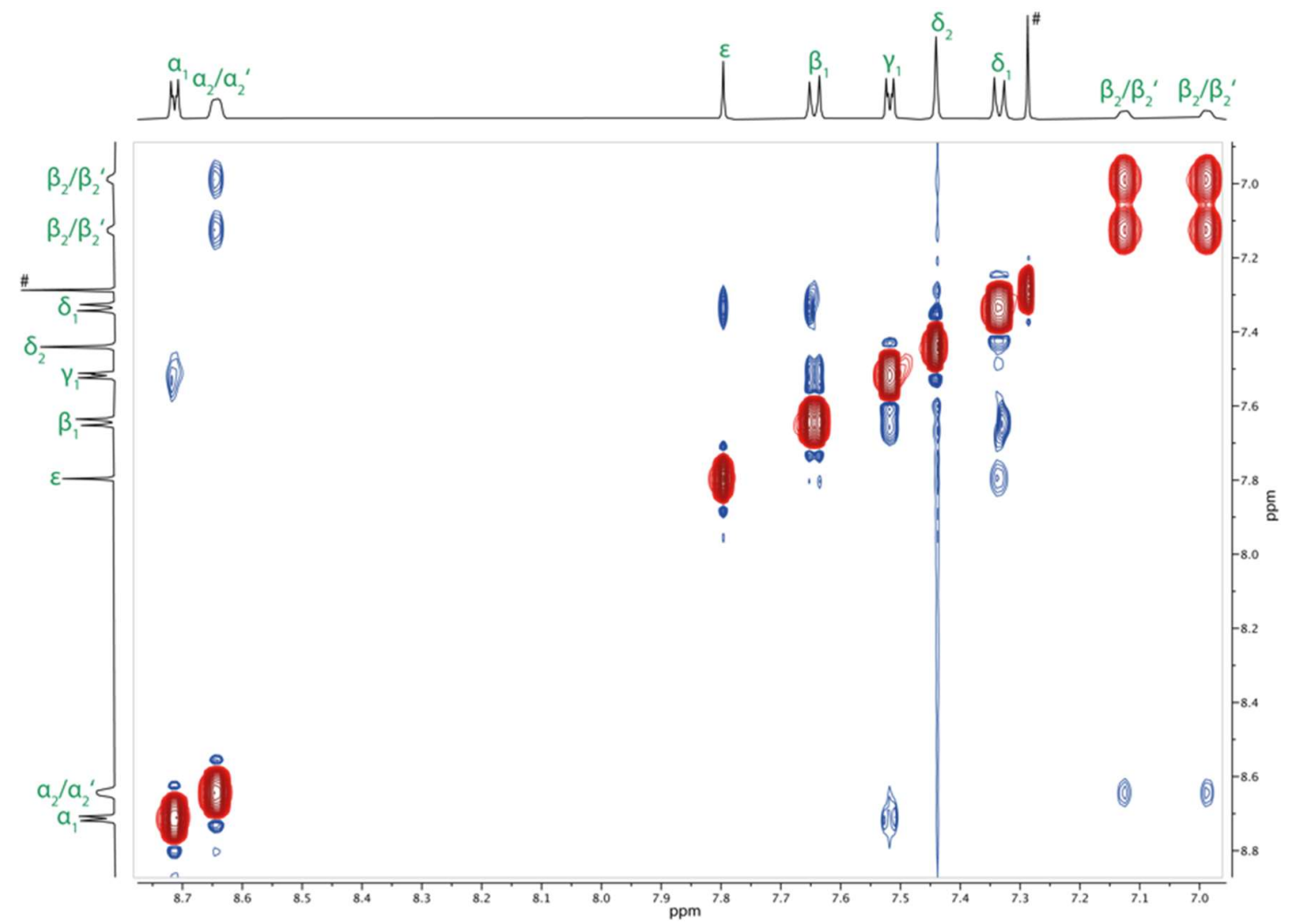

Figure S134. ${ }^{1} \mathrm{H}^{-1} \mathrm{H}$ NOESY spectrum of $\mathbf{T 4}_{2,3 \mathrm{~F}}\left(500 \mathrm{MHz}, \mathrm{CDCl}_{3}, 298 \mathrm{~K}\right)$.

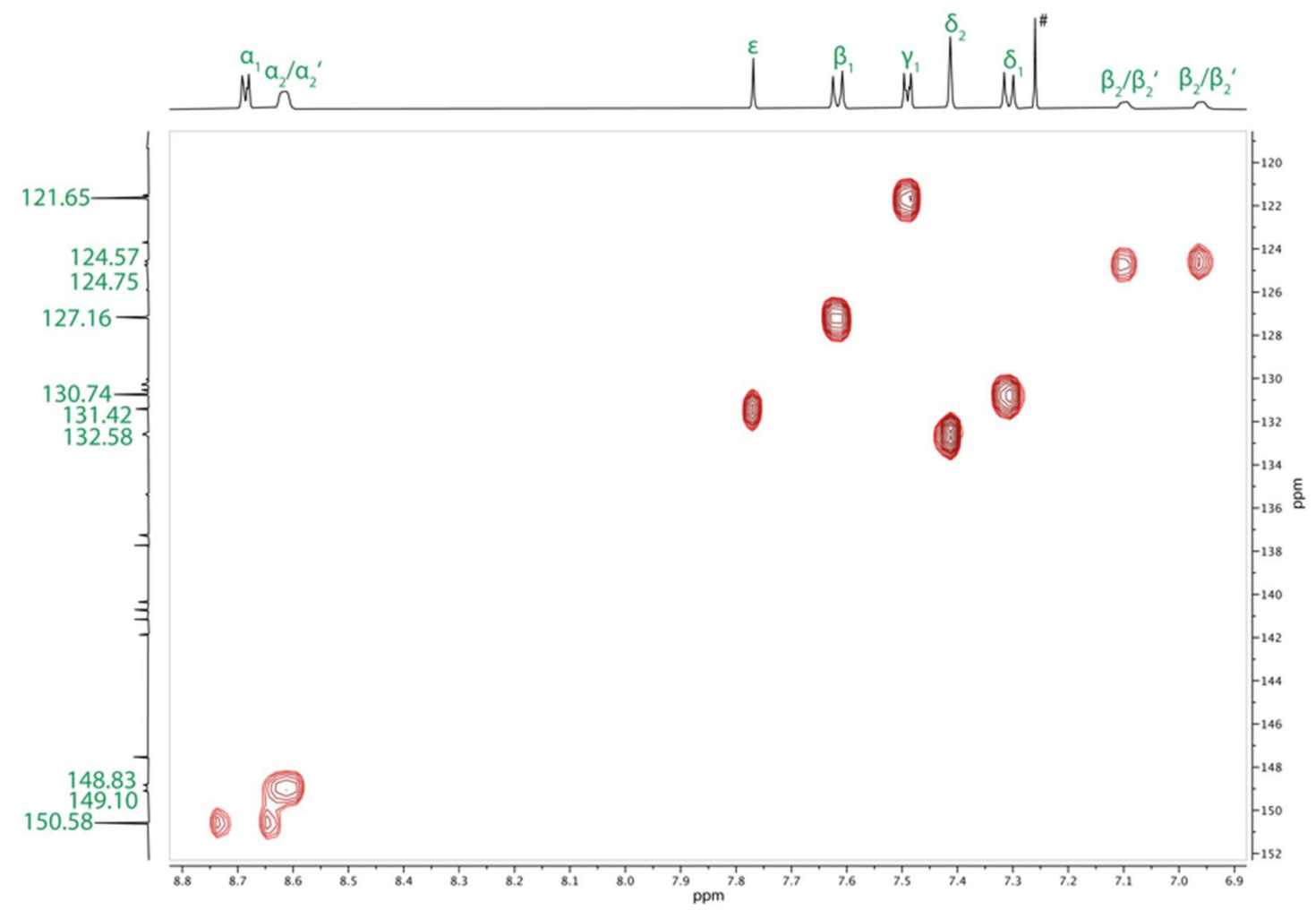

Figure S135. ${ }^{1} \mathrm{H}_{-}{ }^{13} \mathrm{C}$ HSQC spectrum of $\mathbf{T 4}_{2,3 \mathrm{~F}}\left(500 \mathrm{MHz}, \mathrm{CDCl}_{3}, 298 \mathrm{~K}\right)$. 


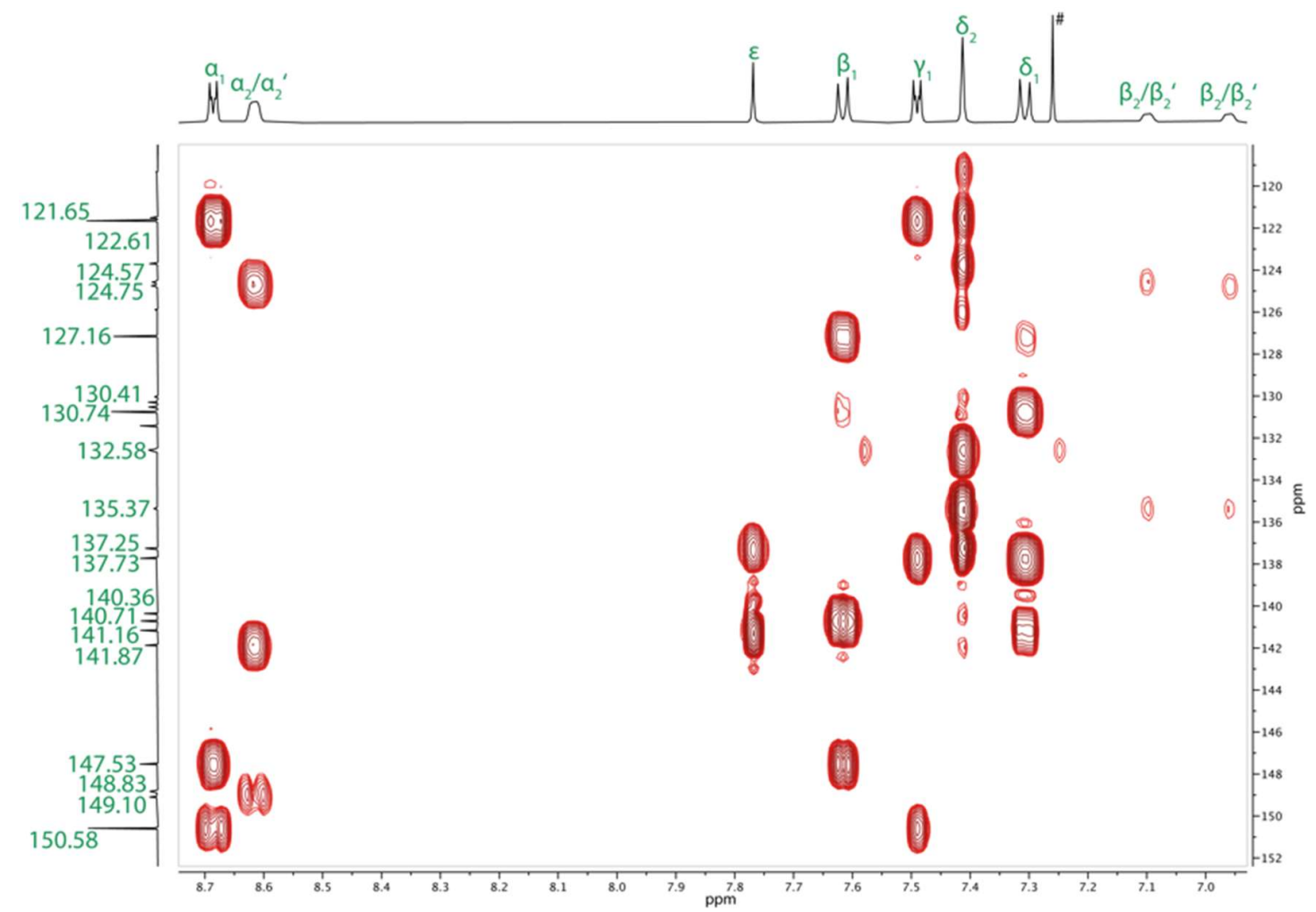

Figure S136. ${ }^{1} \mathrm{H}^{-13} \mathrm{C}$ HMBC spectrum of $\mathbf{T 4}_{2,3 \mathrm{~F}}\left(500 \mathrm{MHz}, \mathrm{CDCl}_{3}, 298 \mathrm{~K}\right)$. 

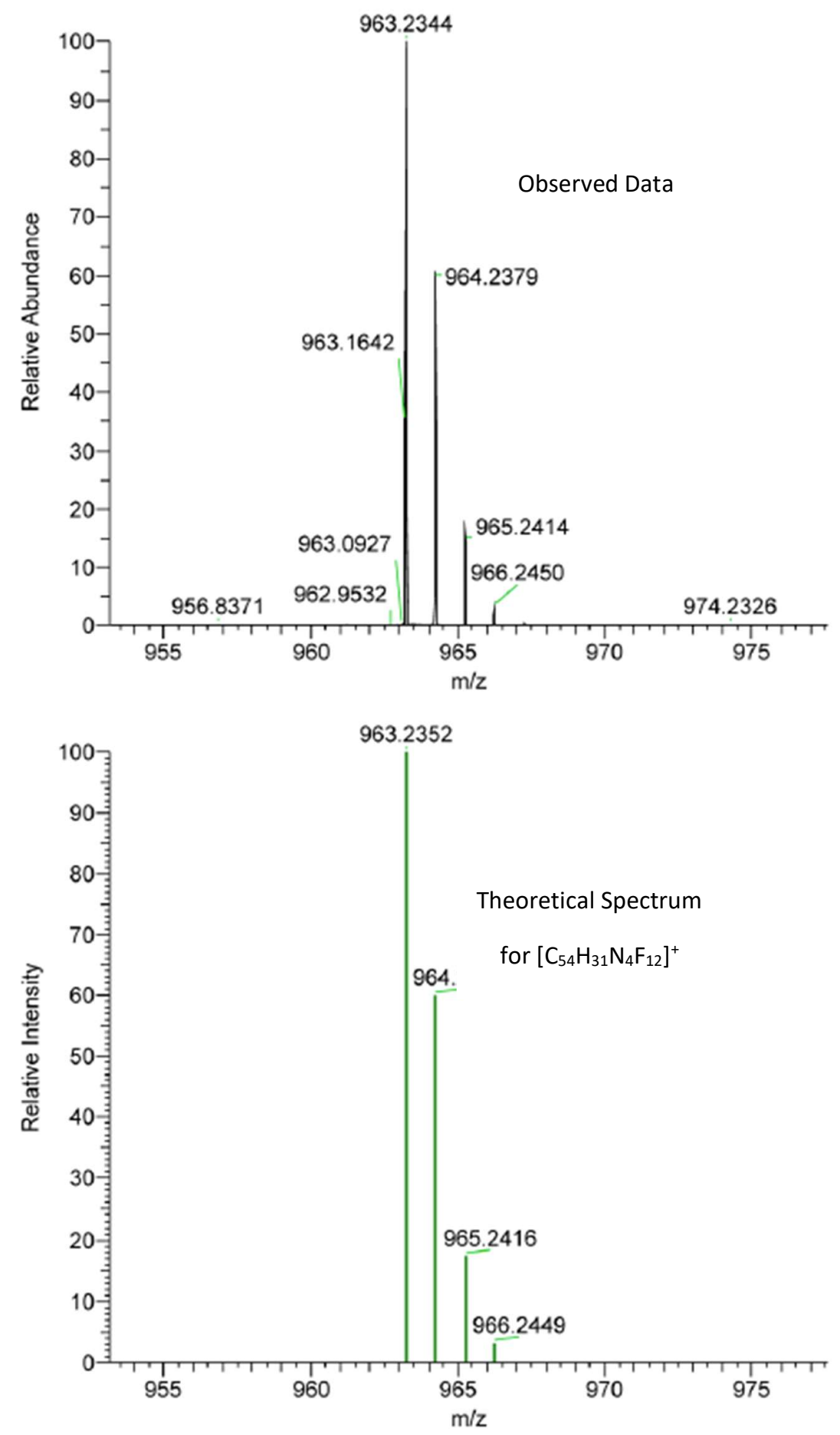

Figure S137. Experimental HR-ESI spectrum of $\mathbf{T 4}_{2,3 \mathrm{~F}}$ (top) and simulated HR-ESI spectrum of $\left[\mathrm{T4}_{2,3 \mathrm{~F}}+\mathrm{H}\right]^{+}\left[\mathrm{C}_{54} \mathrm{H}_{31} \mathrm{~N}_{4} \mathrm{~F}_{12}\right]^{+}$(bottom). 


\section{NMR Spectra of Oxidation States}

$c-P 8\left[b_{6} f_{2}\right] \bullet(T 4)_{2}:$

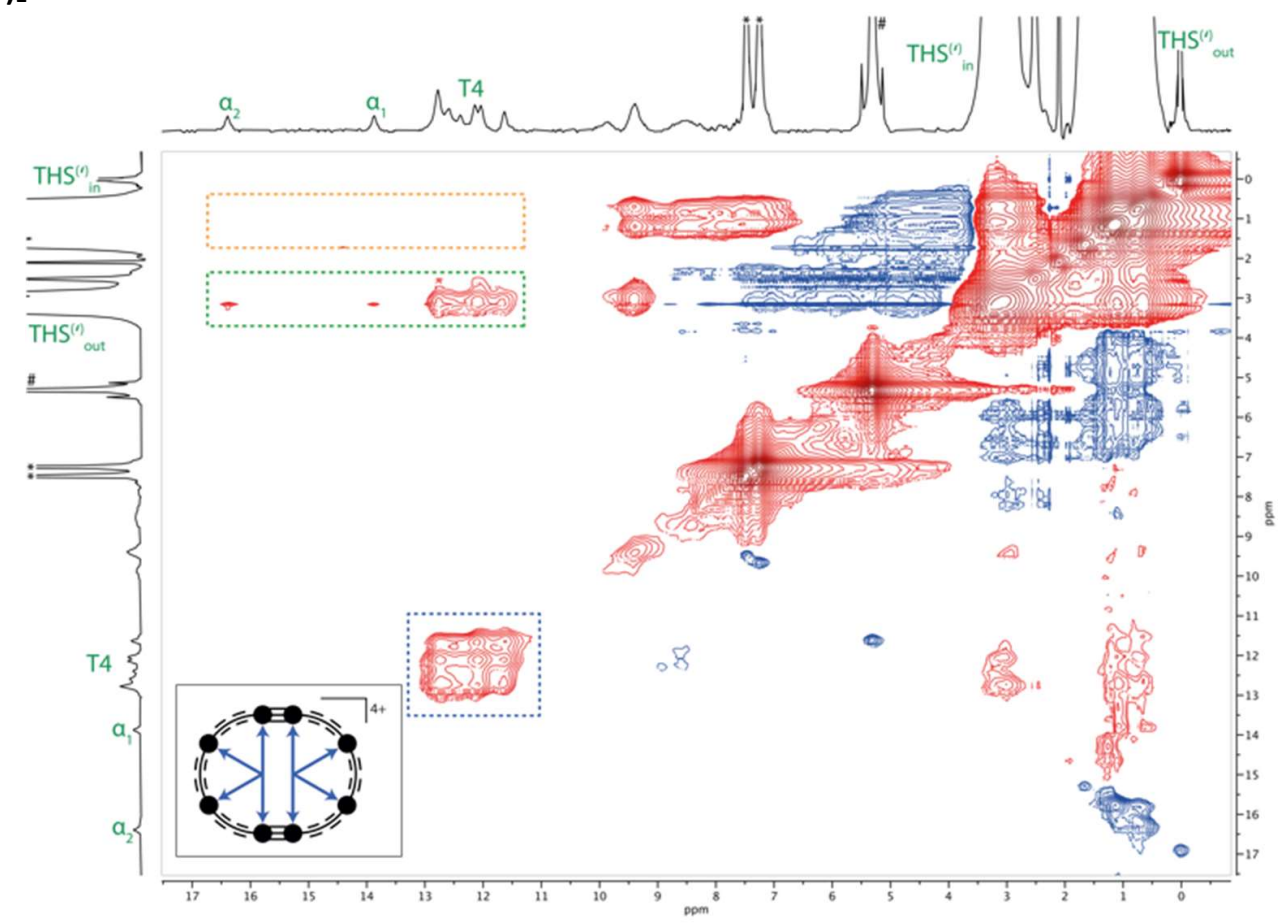

Figure S138. ${ }^{1} \mathrm{H}^{-1} \mathrm{H}$ NOESY spectrum of $\boldsymbol{c}-\mathbf{P 8}\left[\mathbf{b}_{6} \mathbf{f}_{2}\right] \bullet\left(\mathbf{T 4}_{4}\right)_{2}{ }^{4+}\left(500 \mathrm{MHz}, \mathrm{CD}_{2} \mathrm{Cl}_{2}, 223 \mathrm{~K}\right)$. Key correlations are highlighted with dashed boxes:

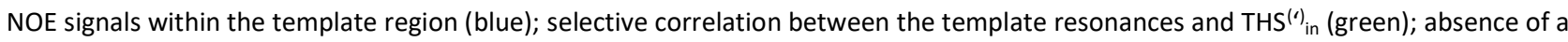
correlation between the template and $\mathrm{THS}^{\left({ }^{()}\right.}$out (orange). Peaks assigned with \# and * arise from $\mathrm{CHDCl}_{2}$ and neutral thianthrene, respectively.

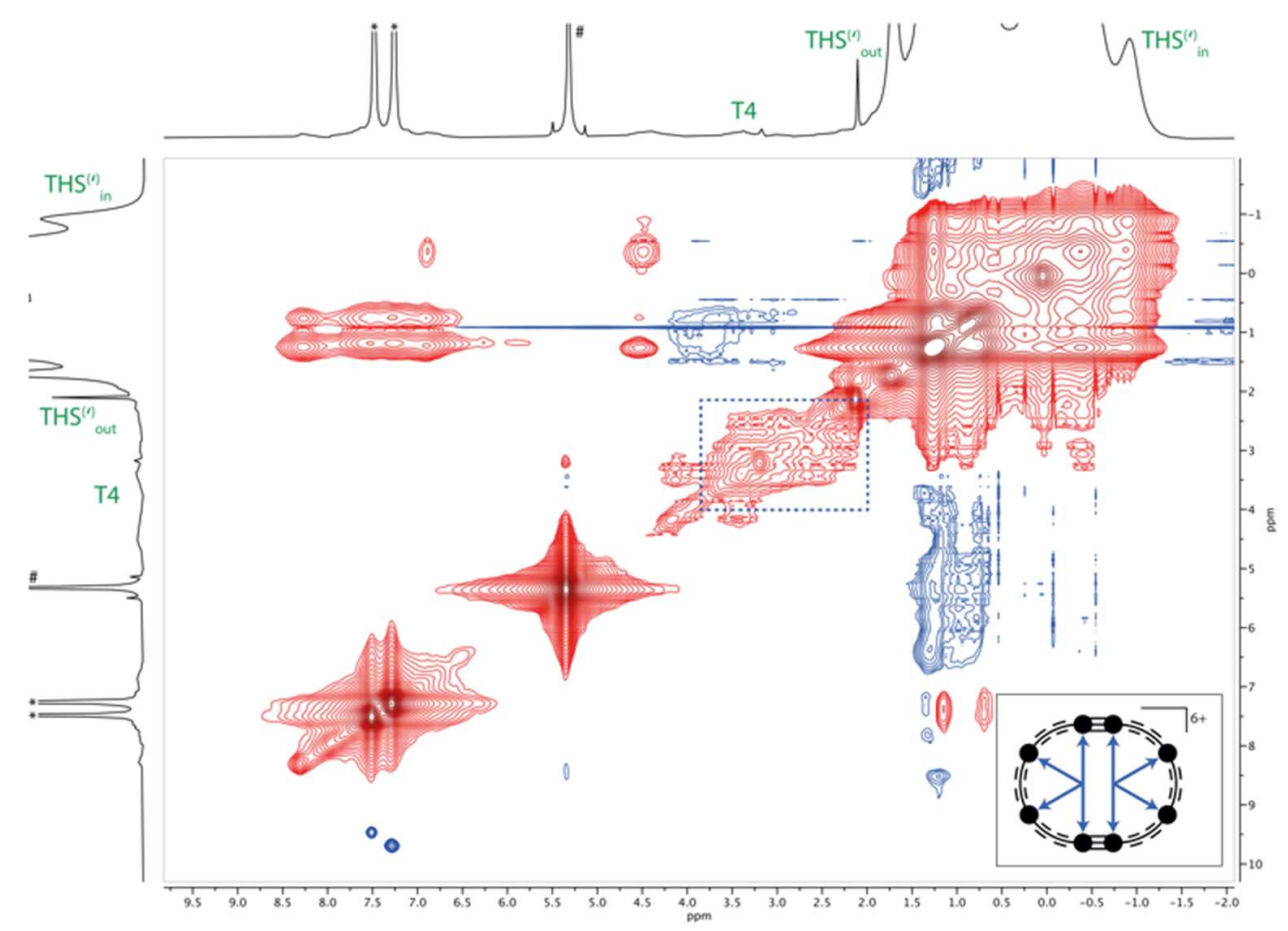

Figure S139. ${ }^{1} \mathrm{H}-{ }^{1} \mathrm{H}$ NOESY spectrum of $c-\mathbf{P 8}\left[\mathrm{b}_{6} \mathrm{f}_{2}\right] \bullet\left(\mathrm{T}_{4}\right)_{2}{ }^{6+}\left(500 \mathrm{MHz}, \mathrm{CD}_{2} \mathrm{Cl}_{2}, 223 \mathrm{~K}\right)$. Correlations within the template region are highlighted with a dashed box (blue). Peaks assigned with \# and * arise from $\mathrm{CHDCl}_{2}$ and neutral thianthrene, respectively. 


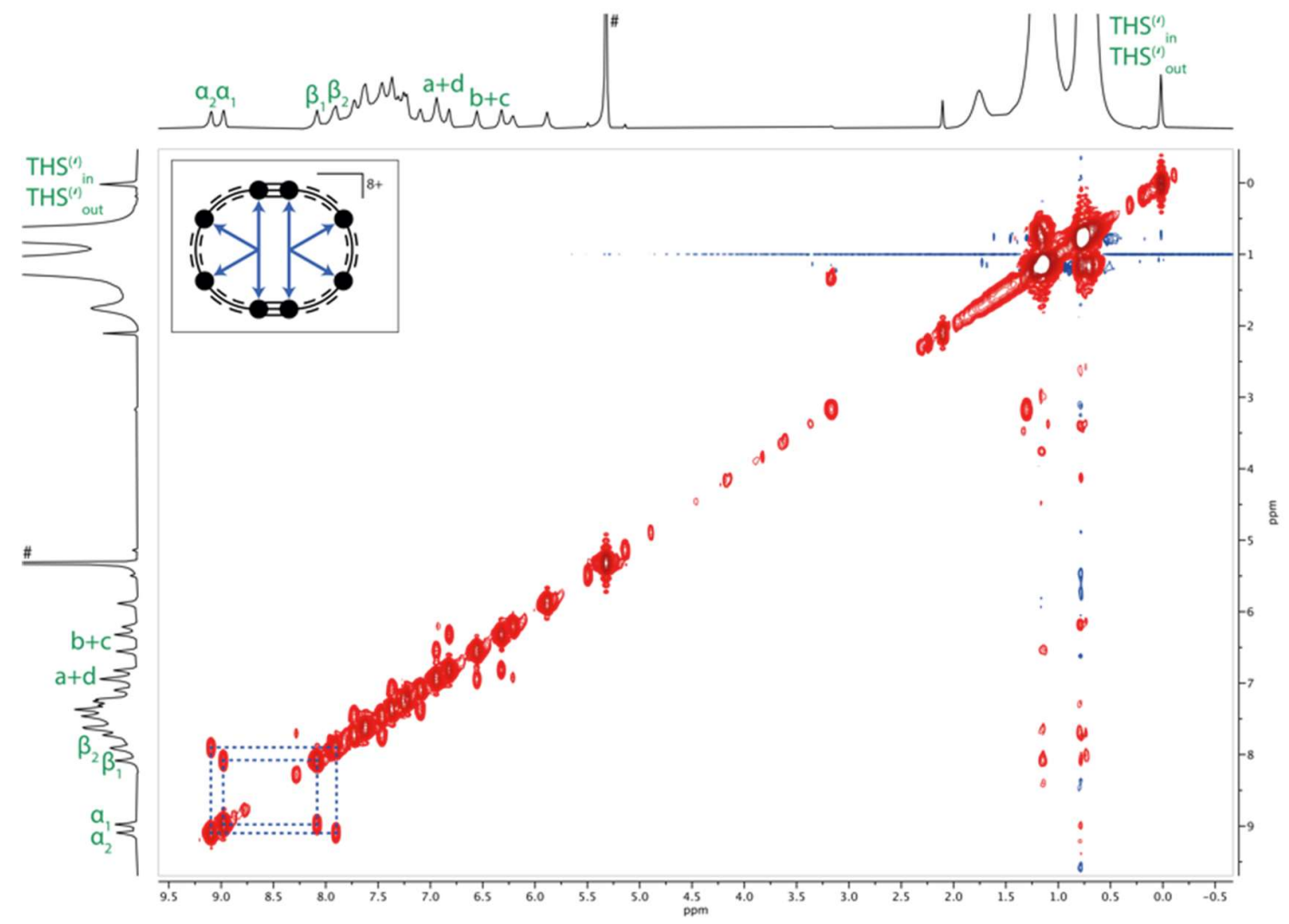

Figure S140. ${ }^{1} \mathrm{H}-{ }^{1} \mathrm{H}$ COSY spectrum of $\boldsymbol{c}-\mathbf{P 8}\left[\mathbf{b}_{6} \mathbf{f}_{2}\right] \bullet(\mathbf{T 4})_{2}{ }^{8+}\left(500 \mathrm{MHz}, \mathrm{CD}_{2} \mathrm{Cl}_{2}, 223 \mathrm{~K}\right)$. Correlations between $\alpha$ and $\beta$ resonances are highlighted in blue. Peaks assigned with \# arise from $\mathrm{CHDCl}_{2}$.

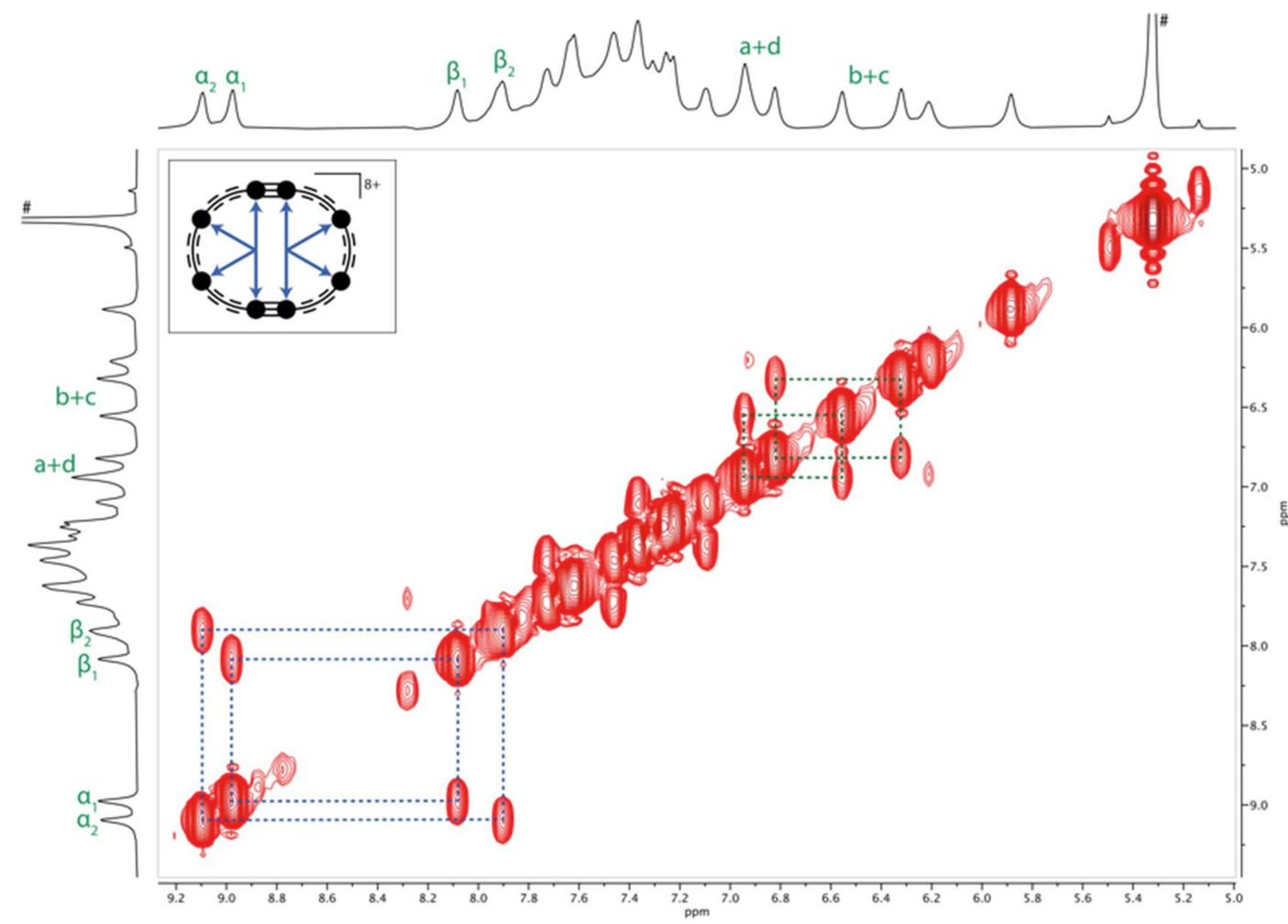

Figure S141. Enlarged region of the COSY spectrum of $c-\mathbf{P 8}\left[\mathbf{b}_{6} \mathbf{f}_{2}\right] \bullet(T 4)_{2}{ }^{8+}\left(500 \mathrm{MHz}, \mathrm{CD}_{2} \mathrm{Cl}_{2}, 223 \mathrm{~K}\right)$. Correlations between $\alpha$ and $\beta$ resonances are highlighted in blue; those between beta porphyrin resonances in green. Peaks assigned with \# arise from $\mathrm{CHDCl}_{2}$. 


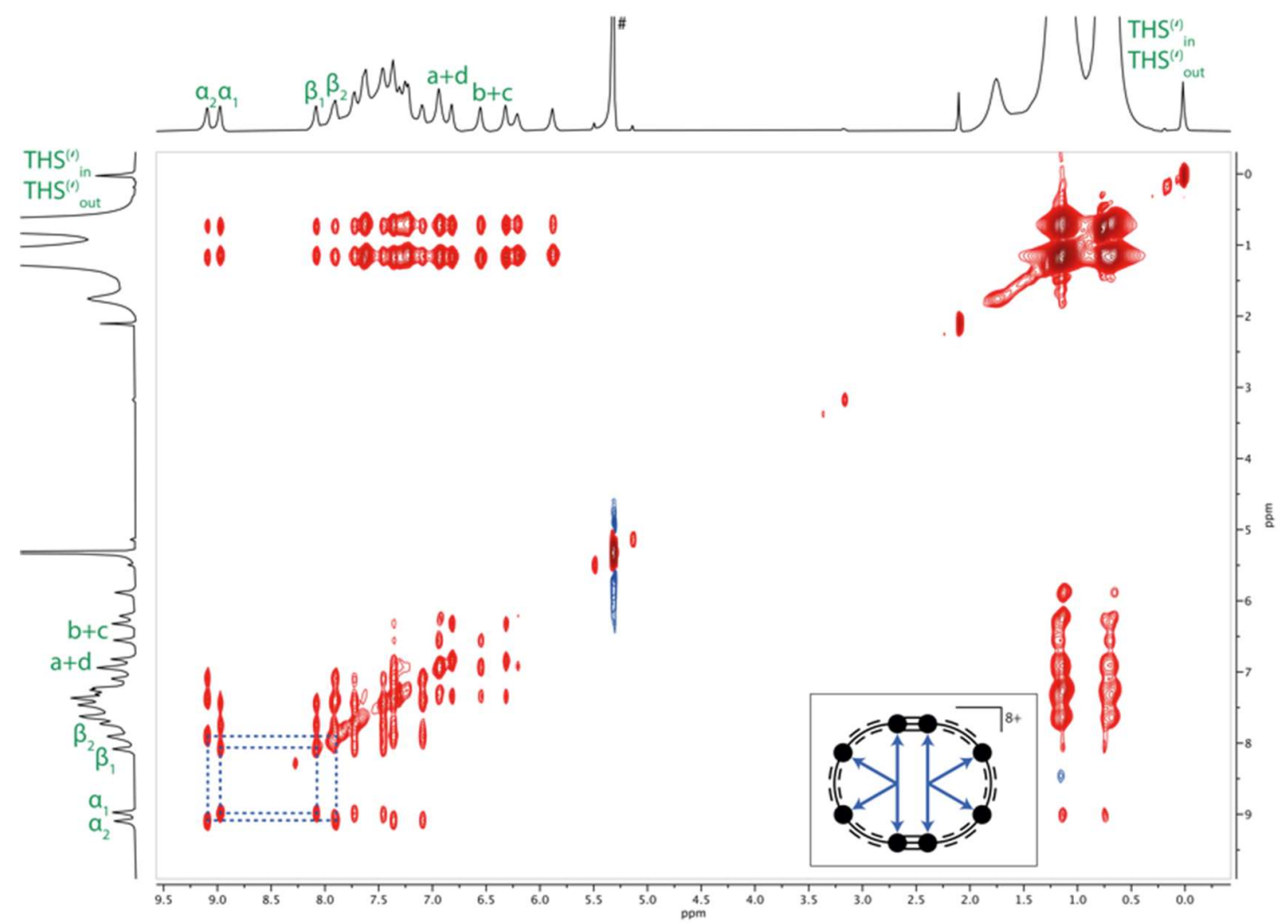

Figure S142. ${ }^{1} \mathrm{H}-{ }^{1} \mathrm{H}$ NOESY spectrum of $c-\mathrm{P8}\left[\mathrm{b}_{6} \mathrm{f}_{2}\right] \bullet(\mathrm{T4})_{2}{ }^{8+}\left(500 \mathrm{MHz}, \mathrm{CD}_{2} \mathrm{Cl}_{2}, 223 \mathrm{~K}\right)$. Correlations between $\alpha$ and $\beta$ resonances are highlighted in blue. Peaks assigned with \# arise from $\mathrm{CHDCl}_{2}$. 
$c-P 8\left[b_{6} f_{2}\right] \bullet\left(T 4_{1,4 F}\right)_{2}:$

${ }^{1} \mathrm{H}$

Figure S143. Combined ${ }^{1} \mathrm{H}$ (top) and $1 \mathrm{D}^{1} \mathrm{H}^{-19}{ }^{19} \mathrm{HOESY}$ (bottom, red) spectra of $\boldsymbol{c}-\mathrm{P} 8\left[\mathbf{b}_{6} \mathrm{f}_{2}\right] \bullet\left(\mathrm{Tu}_{1,4 \mathrm{~F}}\right)_{2}{ }^{4+}\left(500 \mathrm{MHz}, \mathrm{CD}_{2} \mathrm{Cl}_{2}, 223 \mathrm{~K}\right)$. Peaks assigned with \# and ${ }^{*}$ arise from $\mathrm{CHDCl}_{2}$ and neutral thianthrene, respectively. $\dagger$ indicates artefacts in the $1 \mathrm{D}^{1} \mathrm{H}^{1}{ }^{19} \mathrm{~F} \mathrm{HOESY}$ spectrum.

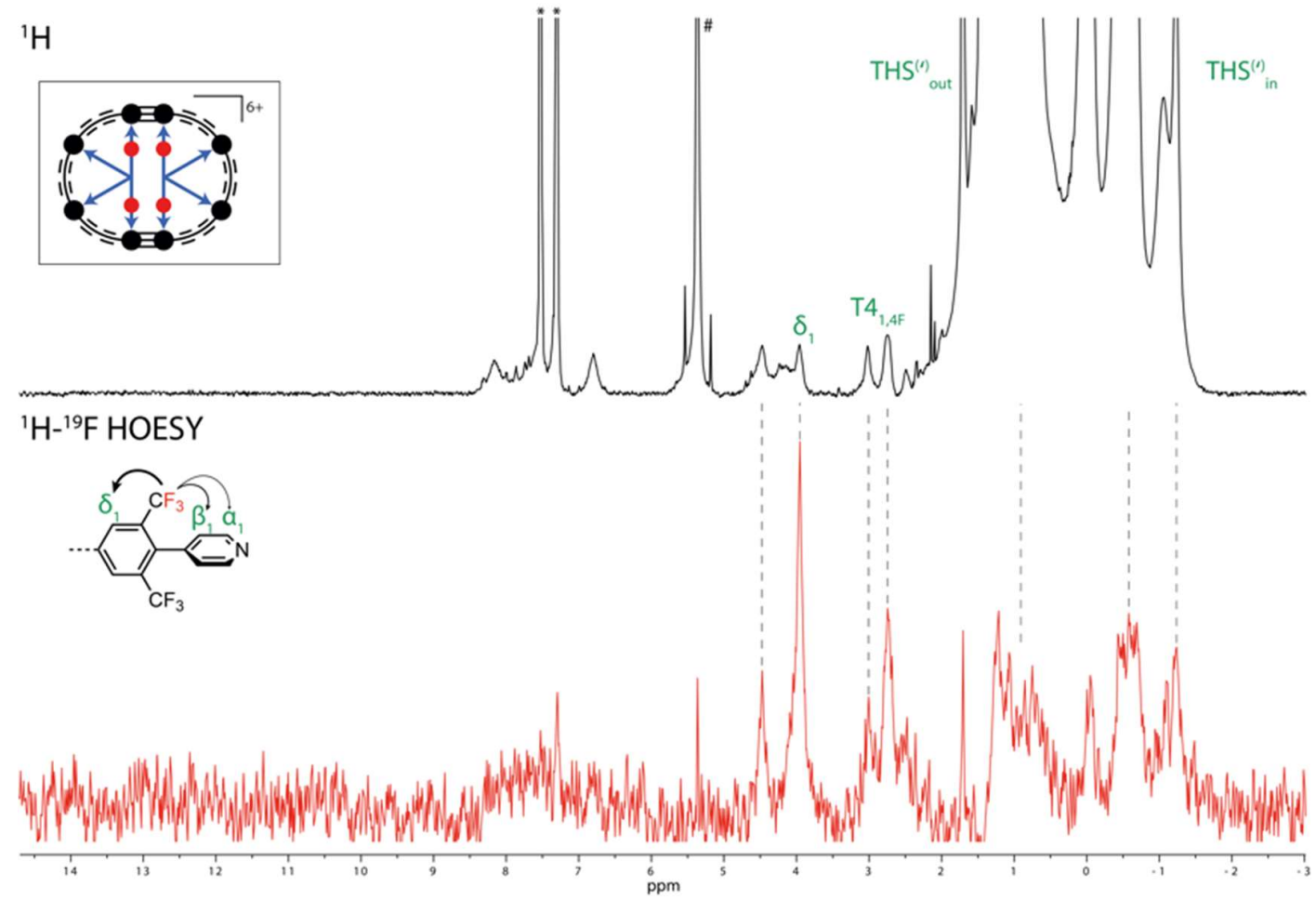

Figure S144. Combined ${ }^{1} \mathrm{H}$ (top) and $1 \mathrm{D}^{1} \mathrm{H}_{-}{ }^{19} \mathrm{~F}$ HOESY (bottom, red) spectra of $\boldsymbol{c}-\mathbf{P} 8\left[\mathbf{b}_{6} \mathrm{f}_{2}\right] \bullet-\left(\mathrm{Tu}_{1,4 \mathrm{~F}}\right)_{2}{ }^{6+}\left(500 \mathrm{MHz}, \mathrm{CD}_{2} \mathrm{Cl}_{2}, 223 \mathrm{~K}\right)$. Peaks assigned with \# and * arise from $\mathrm{CHDCl}_{2}$ and neutral thianthrene, respectively. 


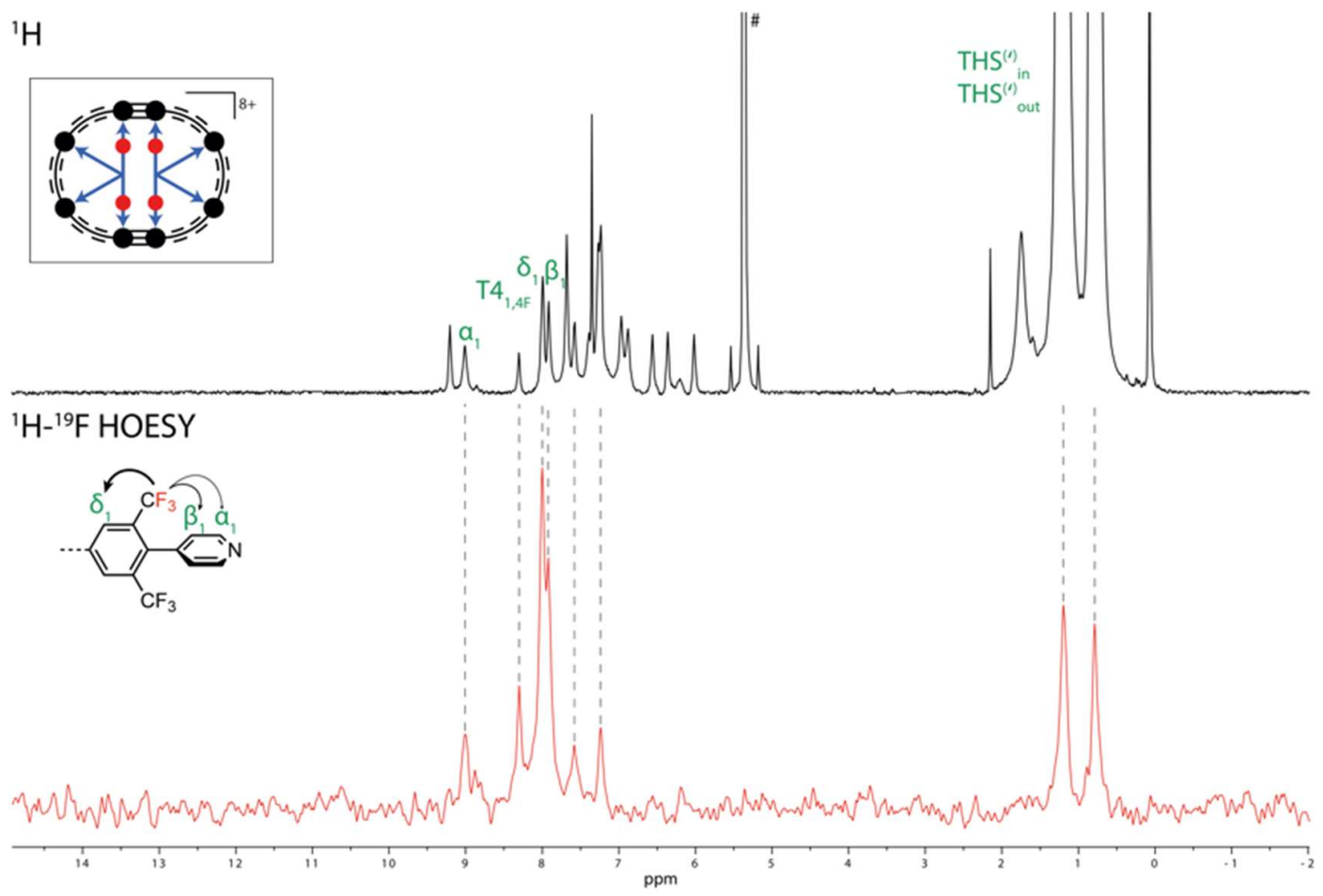

Figure S145. Combined ${ }^{1} \mathrm{H}$ (top) and $1 \mathrm{D}^{1} \mathrm{H}_{-}{ }^{19} \mathrm{~F}$ HOESY (bottom, red) spectra of $\boldsymbol{c}-\mathbf{P} 8\left[\mathbf{b}_{6} \mathrm{f}_{2}\right] \bullet\left(\mathrm{Tu}_{1,4 \mathrm{~F}}\right)_{2}{ }^{8+}\left(500 \mathrm{MHz}, \mathrm{CD}_{2} \mathrm{Cl}_{2}, 223 \mathrm{~K}\right) . \mathrm{Peak}$ assigned with \# arises from $\mathrm{CHDCl}_{2}$.

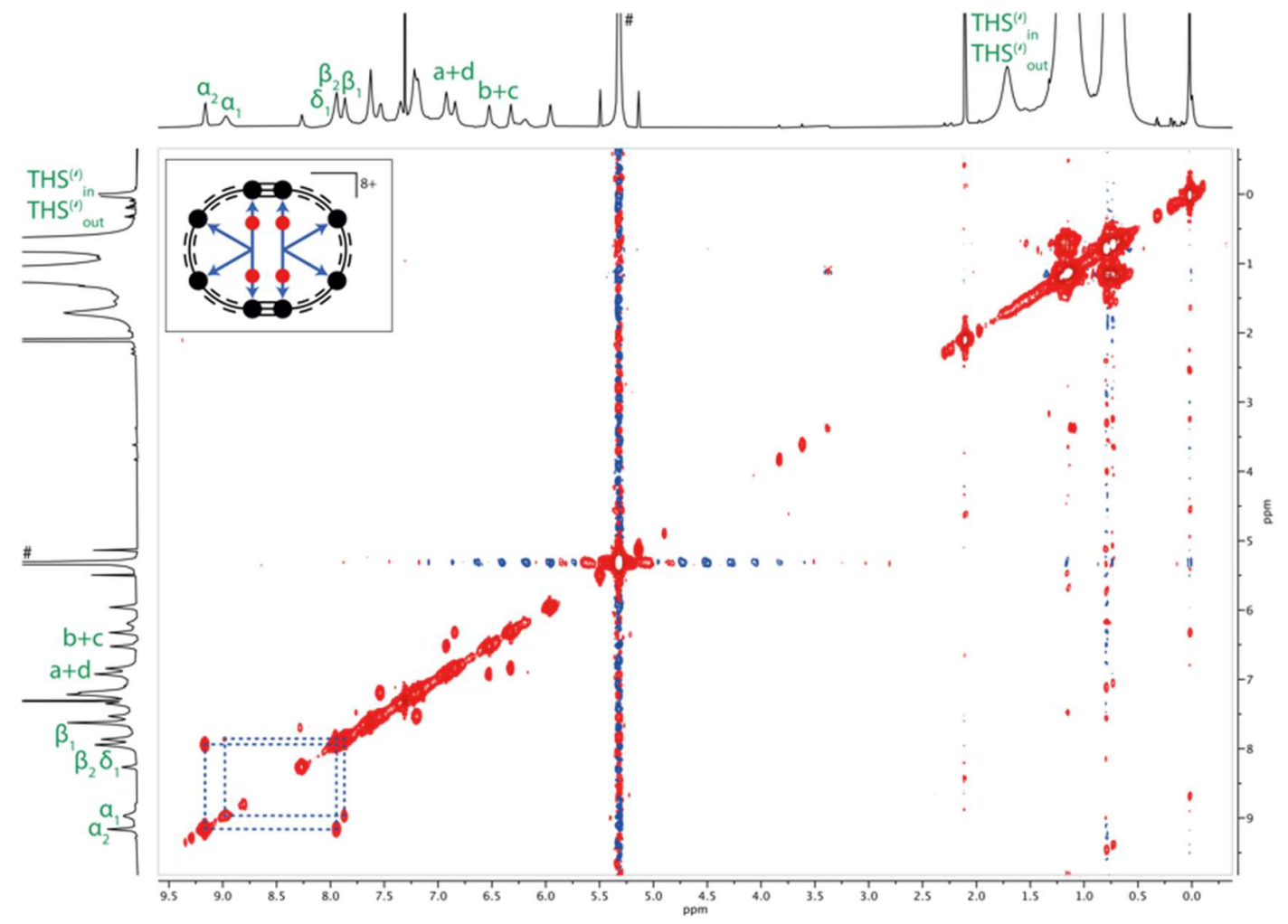

Figure S146. ${ }^{1} \mathrm{H}-{ }^{1} \mathrm{H}$ COSY spectrum of $c-\mathbf{P 8}\left[\mathrm{b}_{6} \mathrm{f}_{2}\right] \bullet\left(\mathrm{T4}_{1,4 \mathrm{~F}}\right)_{2}{ }^{8+}\left(500 \mathrm{MHz}, \mathrm{CD}_{2} \mathrm{Cl}_{2}, 223 \mathrm{~K}\right)$. Correlations between $\alpha$ and $\beta$ resonances are highlighted in blue. Peaks assigned with \# arise from $\mathrm{CHDCl}_{2}$. 


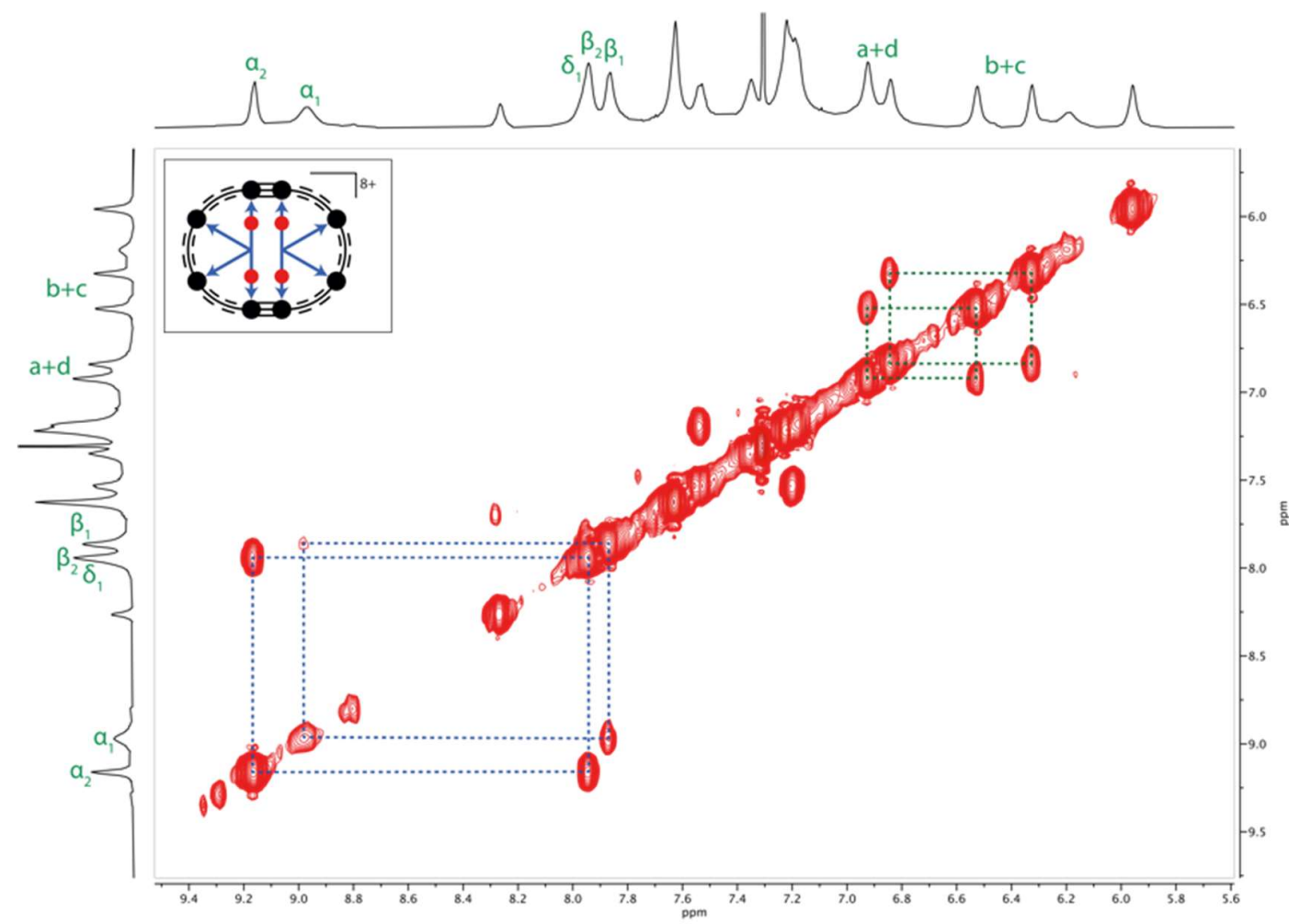

Figure S147. Enlarged region of the COSY spectrum of $c-\mathbf{P 8}\left[\mathbf{b}_{6} \mathrm{f}_{2}\right] \bullet\left(\mathrm{T4}_{1,4 \mathrm{~F}}\right)_{2}{ }^{8+}\left(500 \mathrm{MHz}, \mathrm{CD}_{2} \mathrm{Cl}_{2}, 223 \mathrm{~K}\right)$. Correlations between $\alpha$ and $\beta$ resonances are highlighted in blue; those between beta porphyrin resonances in green.

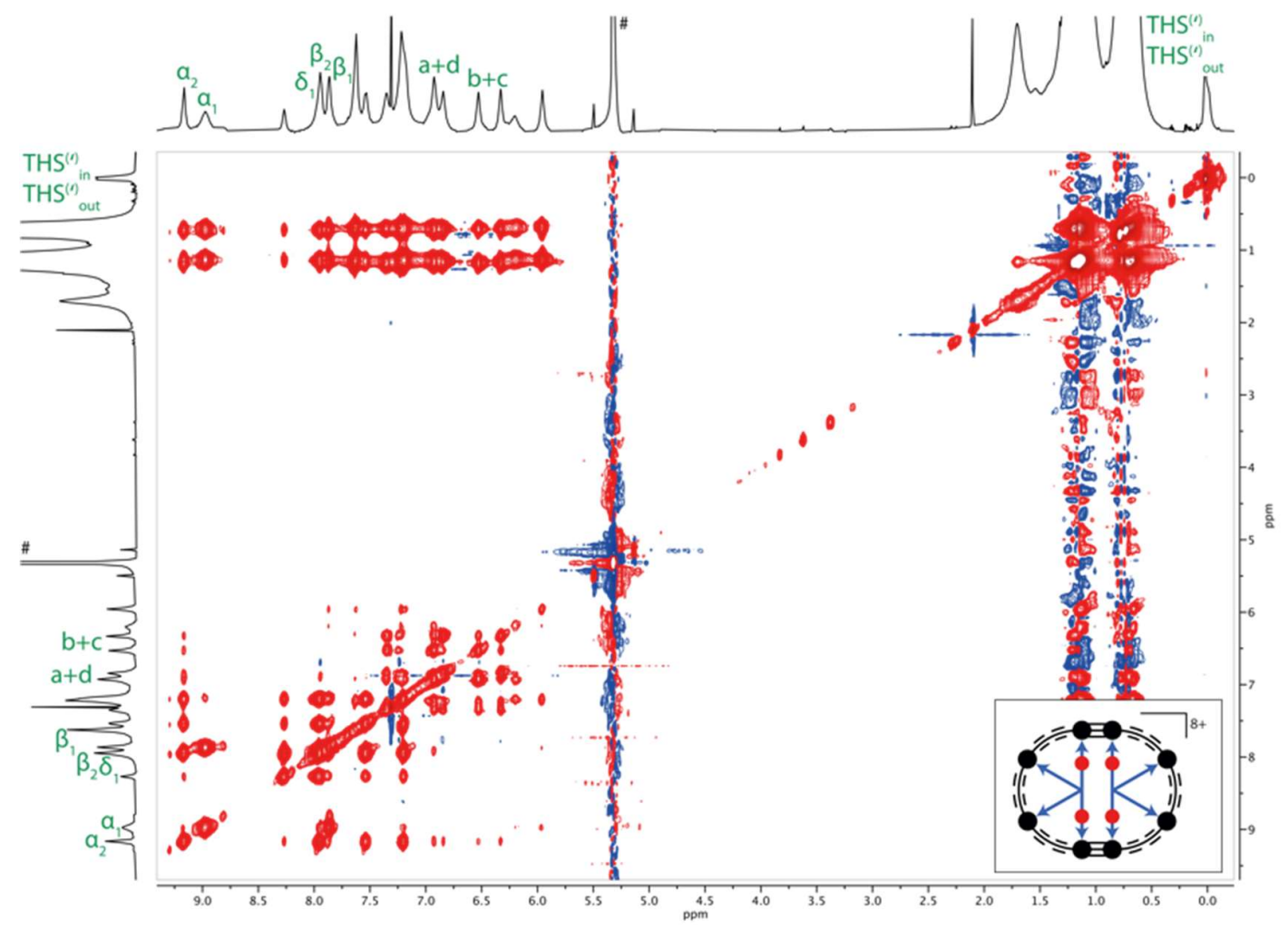

Figure S148. ${ }^{1} \mathrm{H}-{ }^{1} \mathrm{H}$ NOESY spectrum of $c-\mathrm{P8}\left[\mathrm{b}_{6} \mathrm{f}_{2}\right] \bullet\left(\mathrm{T4}_{1,4 \mathrm{~F}}\right)_{2}{ }^{8+}\left(500 \mathrm{MHz}, \mathrm{CD}_{2} \mathrm{Cl}_{2}, 223 \mathrm{~K}\right)$. Peaks assigned with \# arise from $\mathrm{CHDCl}_{2}$. 


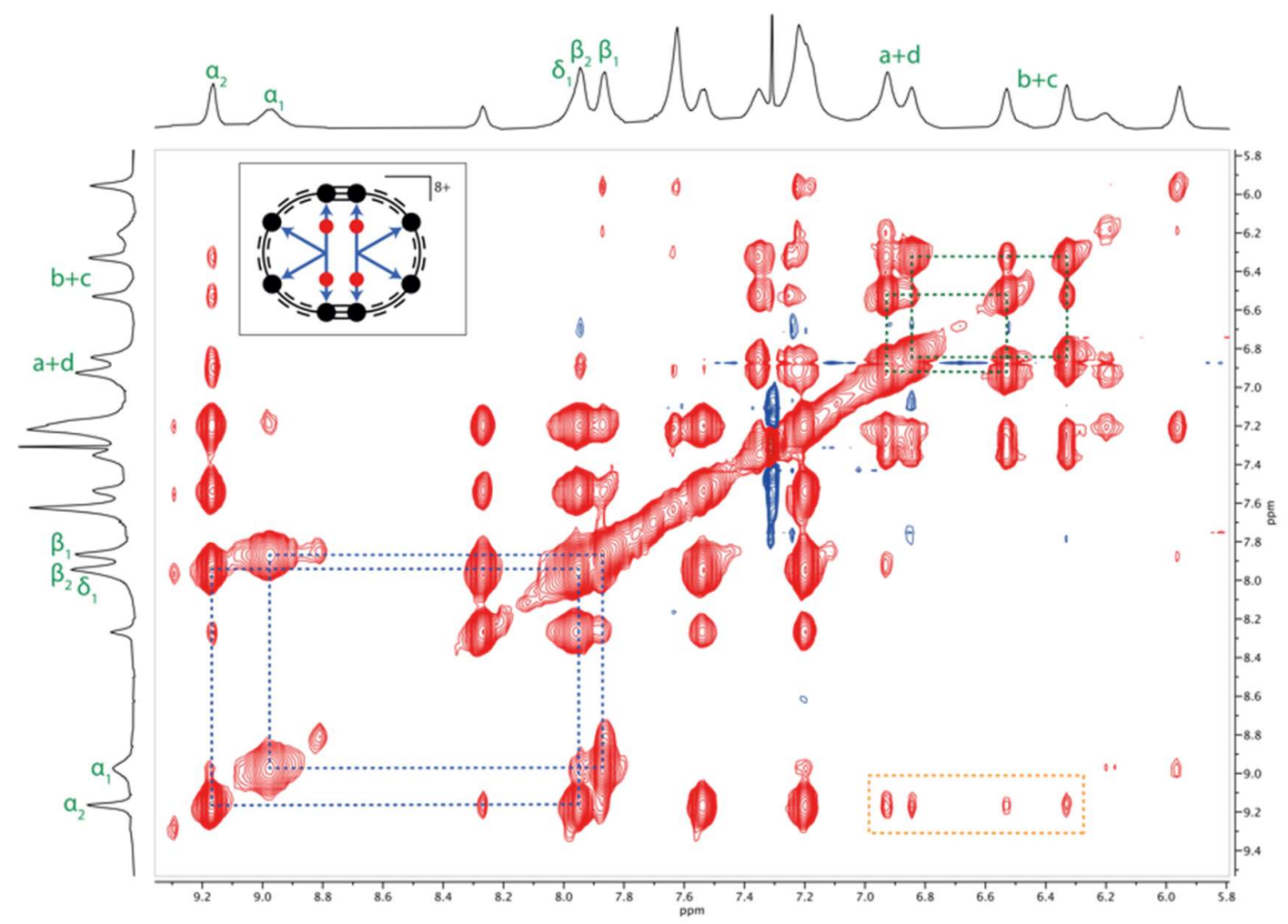

Figure S149. Enlarged region of the NOESY spectrum of $c-\mathbf{P 8}\left[\mathbf{b}_{6} \mathbf{f}_{2}\right] \bullet\left(\mathbf{T 4}_{1,4 \mathrm{~F}}\right)_{2}{ }^{8+}\left(500 \mathrm{MHz}, \mathrm{CD}_{2} \mathrm{Cl}_{2}, 223 \mathrm{~K}\right)$. Correlations between $\alpha$ and $\beta$ resonances are highlighted in blue; those between beta porphyrin resonances in green. Selective correlations between $\alpha_{2}$ and beta porphyrin resonances are highlighted with a dashed box (orange). 
$c-P 8\left[b_{6} f_{2}\right] \bullet\left(T 4_{2,3 F}\right)_{2}:$

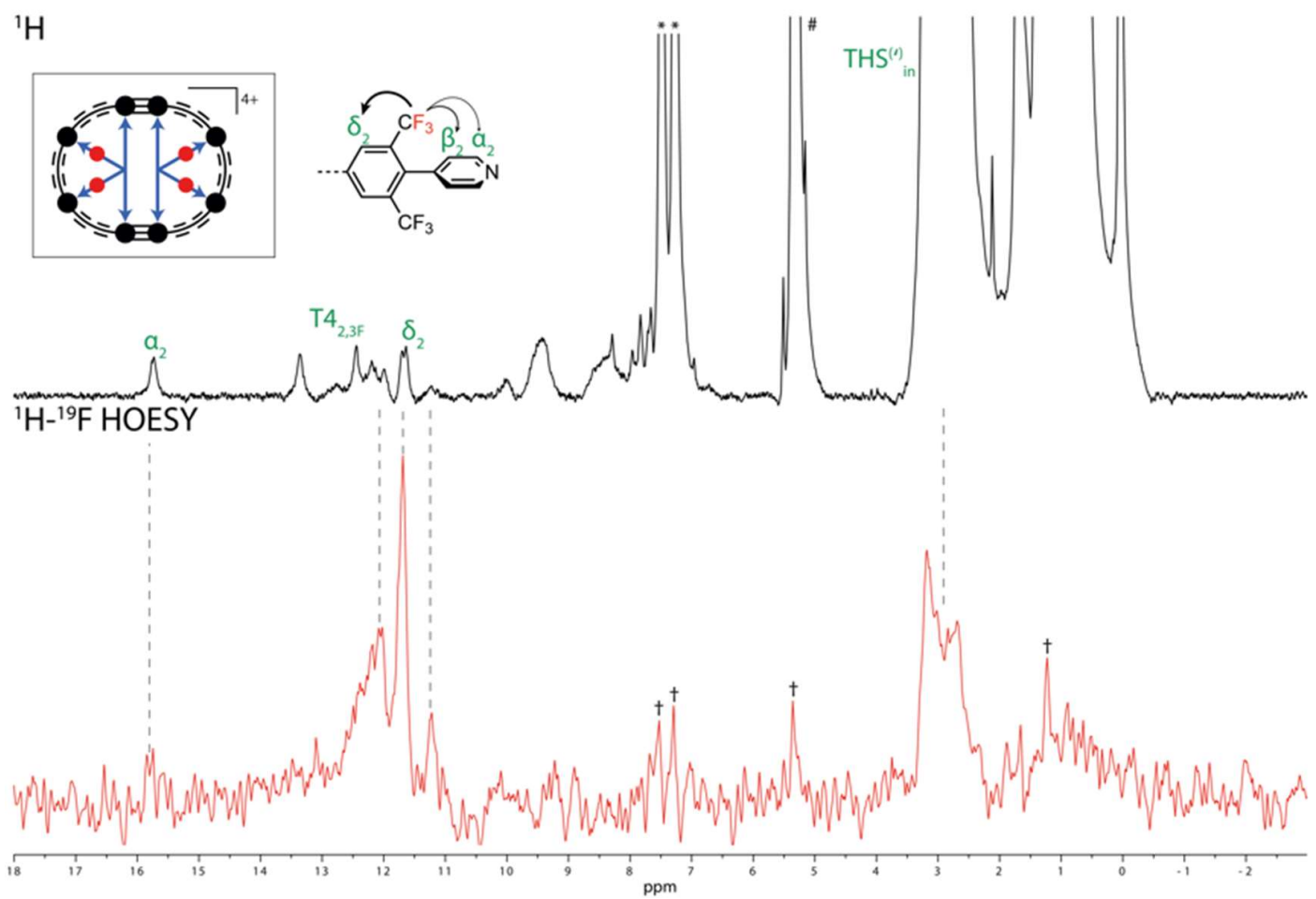

Figure S150. Combined ${ }^{1} \mathrm{H}$ (top) and $1 \mathrm{D}^{1} \mathrm{H}^{-19} \mathrm{~F}$ HOESY (bottom, red) spectra of $\boldsymbol{c}$-P8 $\left[\mathbf{b}_{6} \mathbf{f}_{2}\right] \bullet\left(\mathrm{T4}_{2,3 \mathrm{~F}}\right)_{2} \mathbf{4}^{4+}\left(500 \mathrm{MHz}, \mathrm{CD}_{2} \mathrm{Cl}_{2}, 223 \mathrm{~K}\right)$. Peaks assigned with \# and * arise from $\mathrm{CHDCl}_{2}$ and neutral thianthrene, respectively. + indicates artefacts in the $1 \mathrm{D}^{1} \mathrm{H}^{1}{ }^{19} \mathrm{~F}$ HOESY spectrum.

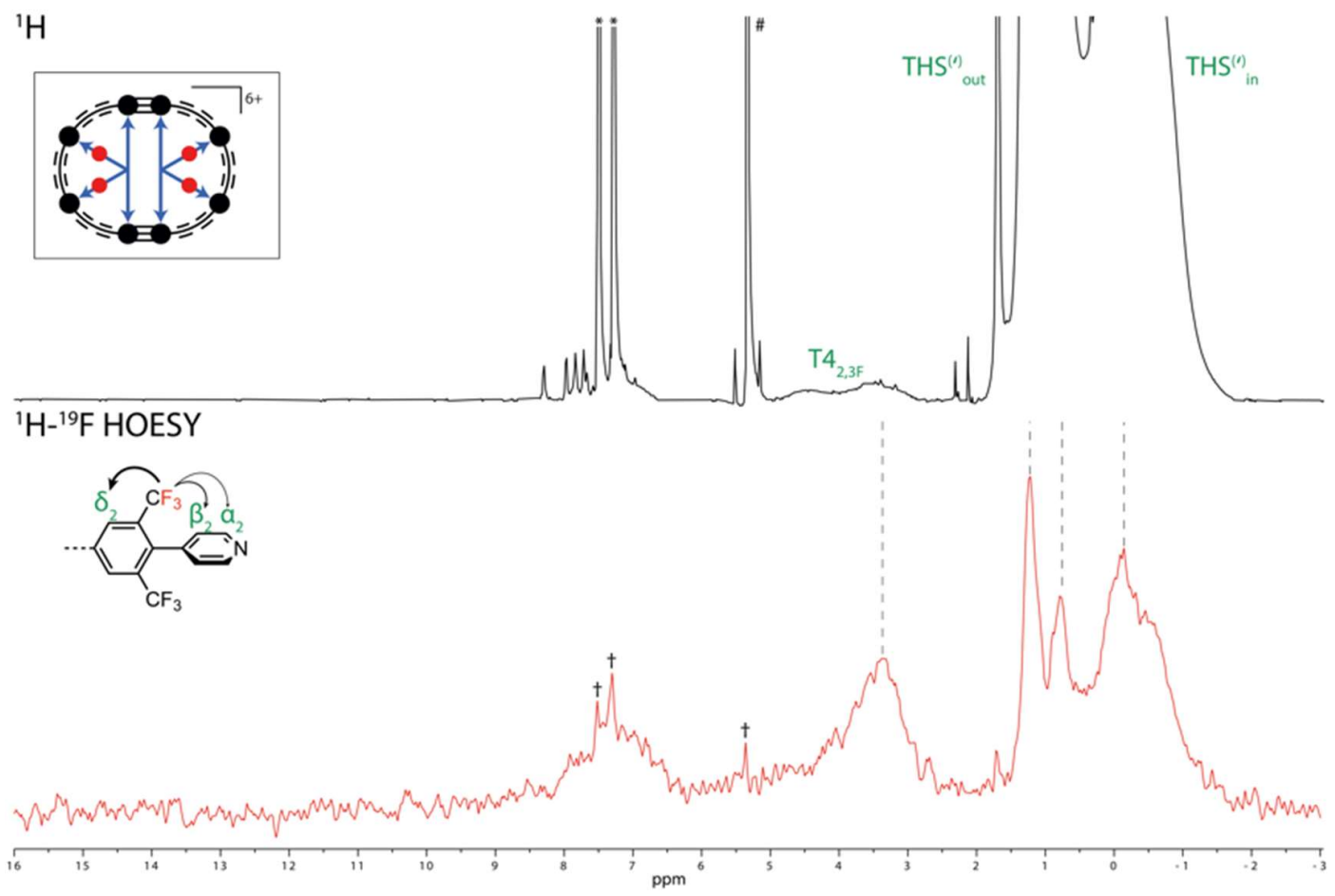

Figure S151. Combined ${ }^{1} \mathrm{H}$ (top) and $1 \mathrm{D}^{1}{ }^{\mathrm{H}-}{ }^{19} \mathrm{~F}$ HOESY (bottom, red) spectra of $\boldsymbol{c}$-P8 $\left[\mathrm{b}_{6} \mathrm{f}_{2}\right] \bullet\left(\mathrm{Tu}_{2,3 \mathrm{~F}}\right)_{2}{ }^{6+}\left(500 \mathrm{MHz}, \mathrm{CD}_{2} \mathrm{Cl}_{2}, 223 \mathrm{~K}\right.$ ). Peaks assigned with \# and ${ }^{*}$ arise from $\mathrm{CHDCl}_{2}$ and neutral thianthrene, respectively. ${ }^{+}$indicates artefacts in the $1 \mathrm{D}^{1} \mathrm{H}_{-}{ }^{19} \mathrm{~F}$ HOESY spectrum. 


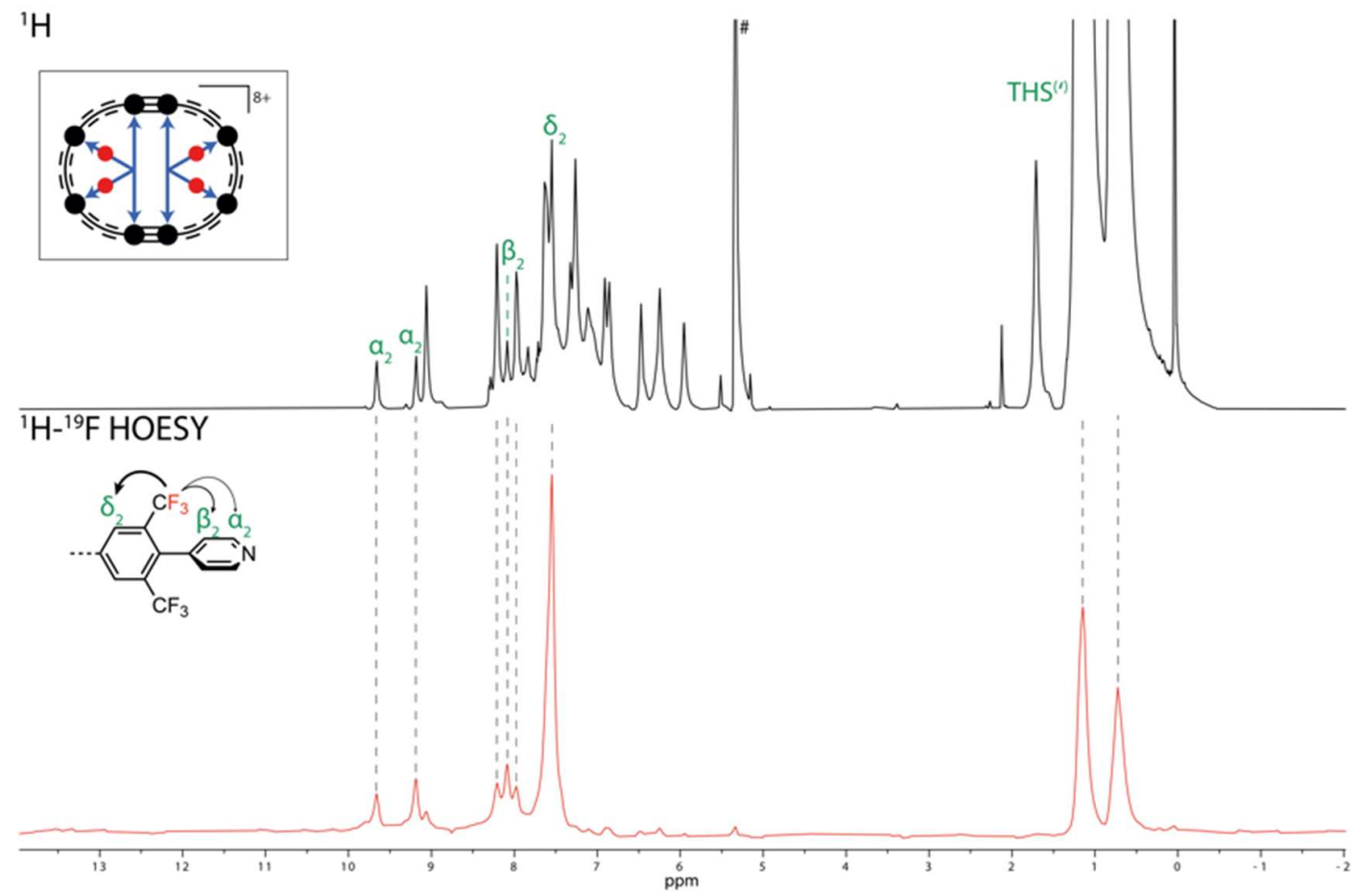

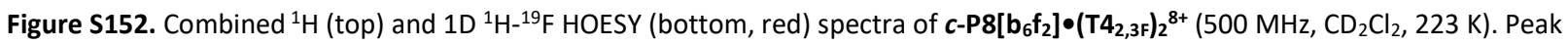
assigned with \# arises from $\mathrm{CHDCl}_{2}$.

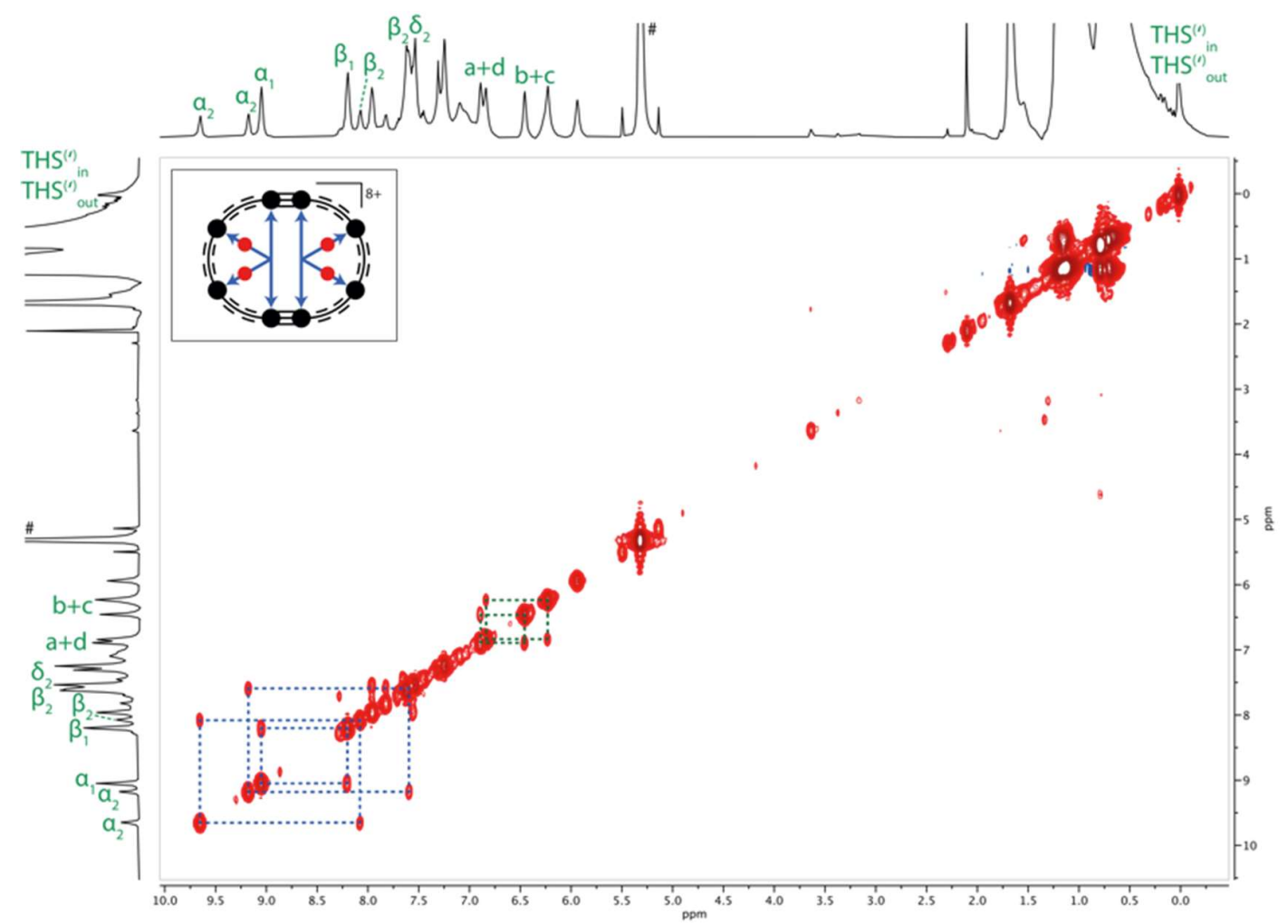

Figure S153. ${ }^{1} \mathrm{H}-{ }^{1} \mathrm{H}$ COSY spectrum of $c-\mathbf{P 8}\left[\mathrm{b}_{6} \mathrm{f}_{2}\right] \bullet\left(\mathrm{T4}_{2,3 \mathrm{~F}}\right)_{2}{ }^{8+}\left(500 \mathrm{MHz}, \mathrm{CD}_{2} \mathrm{Cl}_{2}, 223 \mathrm{~K}\right)$. Correlations between $\alpha$ and $\beta$ resonances are highlighted in blue; those between beta porphyrin resonances in green. Peaks assigned with \# arise from $\mathrm{CHDCl}_{2}$. 


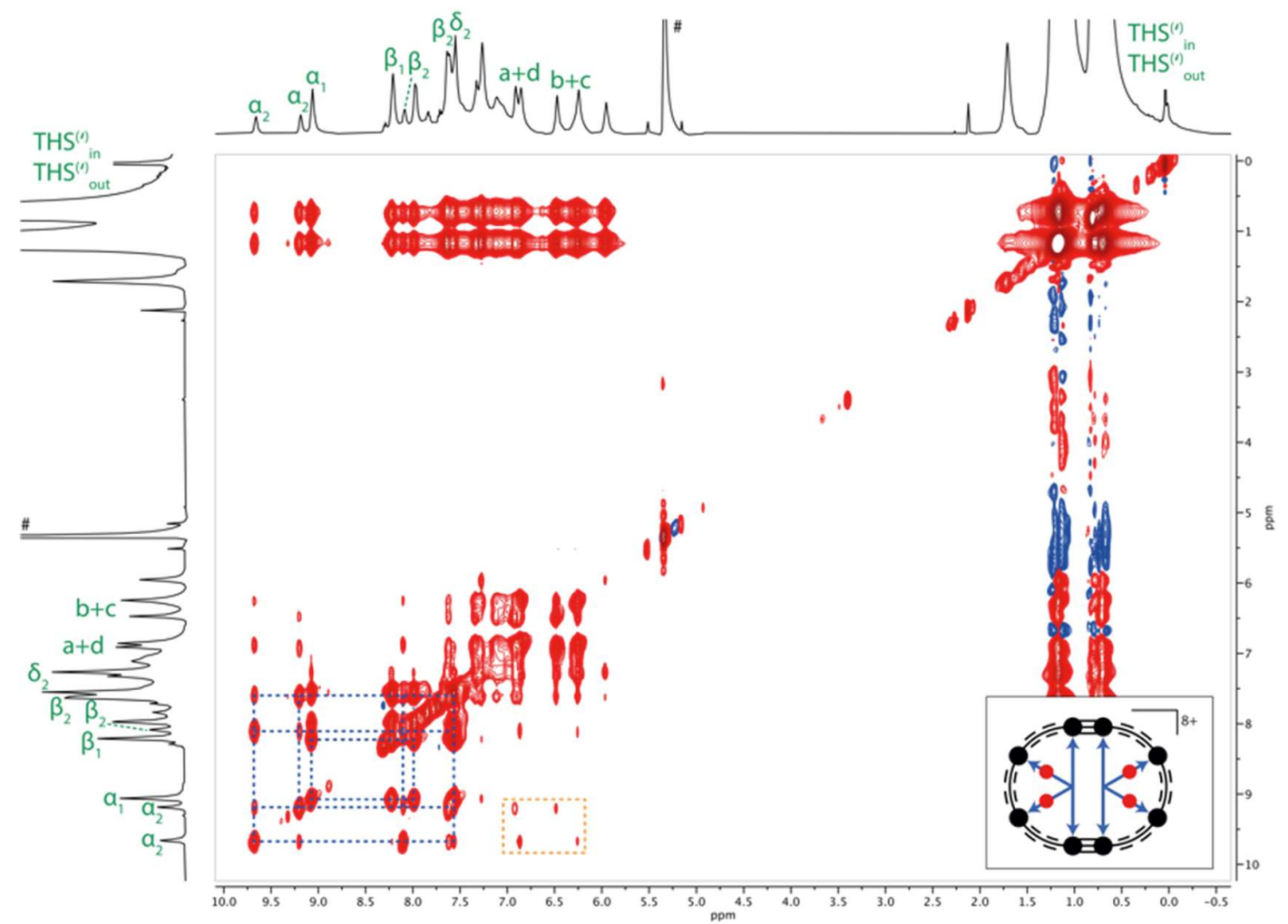

Figure S154. ${ }^{1}{ }^{-}-{ }^{1} \mathrm{H}$ NOESY spectrum of $c-\mathbf{P 8}\left[\mathrm{b}_{6} \mathrm{f}_{2}\right] \bullet\left(\mathrm{T4}_{2,3 \mathrm{~F}}\right)_{2}{ }^{8+}\left(500 \mathrm{MHz}, \mathrm{CD}_{2} \mathrm{Cl}_{2}, 223 \mathrm{~K}\right)$. Correlations between $\alpha$ and $\beta$ resonances are highlighted in blue. Selective correlations between $\alpha_{2}$ and beta porphyrin resonances are highlighted with a dashed box (orange). Peaks assigned with \# arise from $\mathrm{CHDCl}_{2}$. 


\section{DOSY Analysis of the Self-assembly Complexes}

We investigated the size difference between the self-assembly complexes of Si-I-P4[ $\left.\mathbf{b}_{2} \mathbf{f}_{1}\right]-\mathbf{S i}$ and $\mathbf{S i - I - P 4}\left[\mathbf{b}_{3}\right]-\mathbf{S i}$ with T4 by ${ }^{1} \mathrm{H}$ DOSY NMR spectroscopy. The complexes were formed by the incremental addition of a solution of $\mathbf{T} 4$ in $\mathrm{CDCl}_{3}$ to a solution of Si-I-P4[ $\left.\mathbf{b}_{2} \mathbf{f}_{1}\right]-\mathrm{Si}$ or $\mathbf{S i - I - P 4}\left[\mathbf{b}_{3}\right]-\mathbf{S i}$ in $\mathrm{CDCl}_{3}$. The endpoint of the full complex formation was determined by the complete disappearance of the proton resonances of the unbound porphyrin tetramer and a broadening of the bound template resonances, which indicates a fast exchange between unbound and complexed T4 (Figures S155 and S158). ${ }^{1} \mathrm{H}$ DOSY spectroscopy of the self-assembly product shows the clean formation of a single complex for Si-I-P4[ $\left.\mathbf{b}_{2} \mathbf{f}_{1}\right]-\mathbf{S i}$ and T4 and Si-I-P4[ $\left.\mathbf{b}_{3}\right]$-Si and T4 (Figures $\mathrm{S} 156$ and S159). Fitting of the diffusion decay curves to the Stejskal-Tanner equation ${ }^{31}$ gives a mean diffusion coefficient of $1.86 \pm 0.09 \times 10^{-10} \mathrm{~m}^{2} \mathrm{~s}^{-1}$ and $2.14 \pm 0.11 \times 10^{-10} \mathrm{~m}^{2} \mathrm{~s}^{-1}$ for the self-assembly complexes of Si-I$\mathbf{P 4}\left[\mathbf{b}_{2} \mathbf{f}_{1}\right]-\mathbf{S i}$ and T4 and Si-I-P4[ $\left.\mathbf{b}_{3}\right]-\mathbf{S i}$ and T4, respectively (Figures S157 and S160). The significant difference in the diffusion coefficients suggest an about $15 \%$ larger hydrodynamic radius for the self-assembly complex of $\mathbf{S i - I - P 4}\left[\mathbf{b}_{2} \mathbf{f}_{1}\right]-\mathbf{S i}$ and T4 compared to the self-assembly complex of Si-I-P4[ $\left.\mathbf{b}_{3}\right]-\mathbf{S i}$ and T4 under the assumption of a spherical shape of the complexes in the Stokes-Einstein relationship. ${ }^{32}{ }^{1} \mathrm{H}$ DOSY analysis of $\left.\boldsymbol{c}-\mathbf{P} 8 \mathbf{b}_{\mathbf{8}}\right]^{\bullet} \cdot(\mathbf{T 4})_{2}$ and $c-P 8\left[b_{6} f_{2}\right]_{\bullet}(T 4)_{2}$ gives a mean diffusion coefficient of $1.72 \pm 0.02 \times 10^{-10} \mathrm{~m}^{2} \mathrm{~s}^{-1}$ and $1.55 \pm 0.21 \times 10^{-10} \mathrm{~m}^{2} \mathrm{~s}^{-1}$, respectively (Figures S161-166), which was used as reference for the magnitude of the diffusion coefficient expected for a 2:2 complex. These findings suggest the predominant formation of the 2:2 complex (Si-I-P4[ $\left.\mathbf{b}_{2} \mathbf{f}_{1}\right]$ $\mathbf{S i})_{2_{2}} \cdot(\mathbf{T} 4)_{2}$ in the self-assembly of $\mathbf{S i - I - P 4}\left[\mathbf{b}_{2} \mathbf{f}_{1}\right]-\mathbf{S i}$ and $\mathbf{T 4}$, and the formation of the 1:1 complex (Si-I-P4[ $\left.\mathbf{b}_{3}\right]-$ $\mathbf{S i}) \cdot(\mathbf{T} 4)$ in the assembly of Si-I-P4$\left[\mathbf{b}_{3}\right]-\mathrm{Si}$ and T4. ${ }^{33,34}$

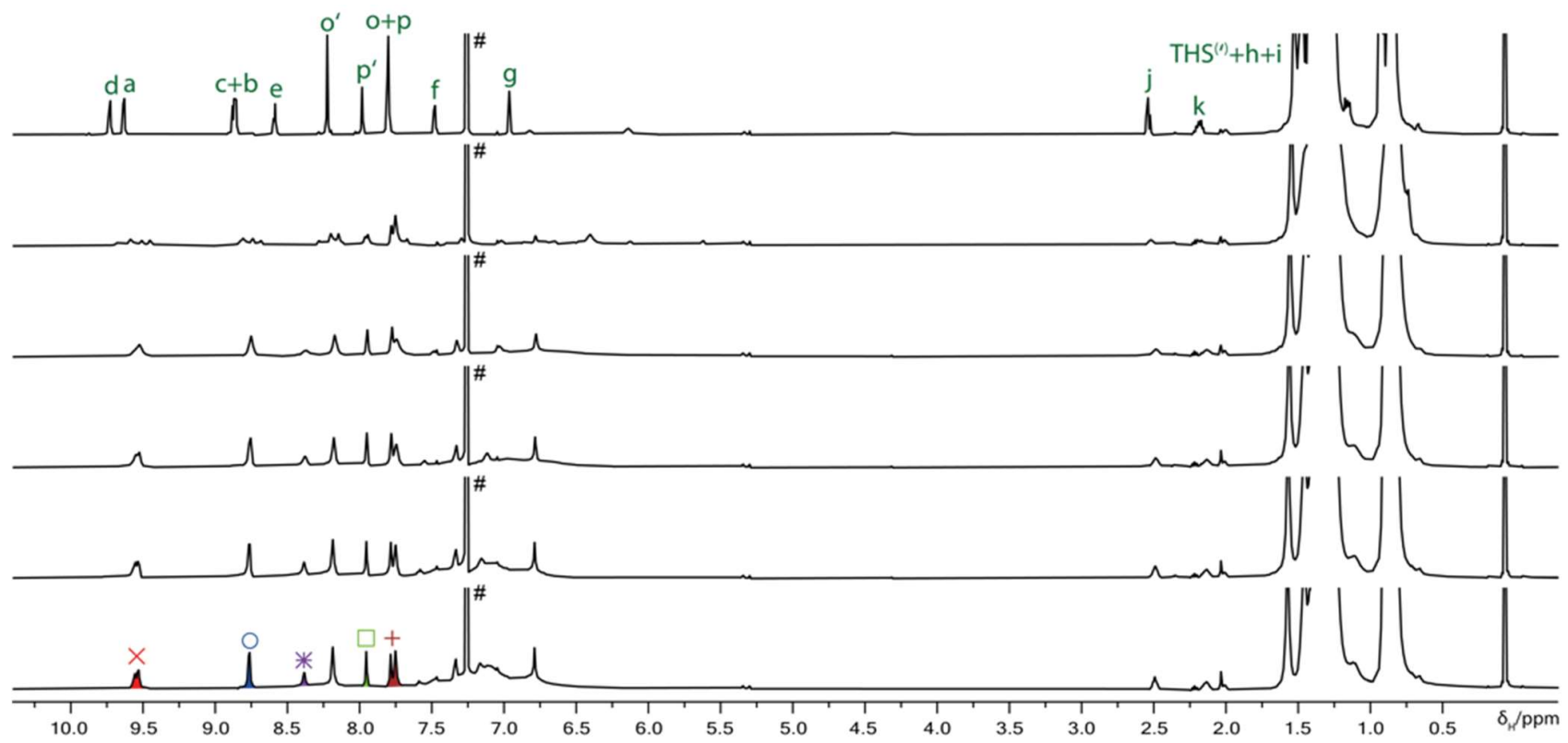

Figure S155. ${ }^{1} \mathrm{H}$ NMR spectra of the formation titration of $\left(\mathbf{S i}-\mathbf{I}-\mathbf{P} 4\left[\mathbf{b}_{\mathbf{2}} \mathbf{f}_{\mathbf{1}}\right]-\mathbf{S i}\right)_{\mathbf{2}} \bullet \mathbf{\bullet}(\mathbf{T 4})_{\mathbf{2}}\left(500 \mathrm{MHz}, \mathrm{CDCl}_{3}, 298 \mathrm{~K}\right)$. The top spectrum corresponds to unbound tetramer Si-I-P4 $\left[\mathbf{b}_{\mathbf{2}} \mathbf{f}_{\mathbf{1}}\right]-\mathbf{S i}$, and the bottom spectrum to the fully formed complex. Peaks assigned with \# arise from $\mathrm{CHCl}_{3}$. The highlighted resonances in the bottom spectrum indicate the signals used in the fitting of the diffusion decay curves of the ${ }^{1} \mathrm{H}$ DOSY spectrum of $\left(\mathbf{S i}-\mathrm{I}-\mathbf{P} 4\left[\mathbf{b}_{2} \mathbf{f}_{1}\right]-\mathrm{Si}\right)_{2} \bullet(\mathrm{T} 4)_{2}$. 


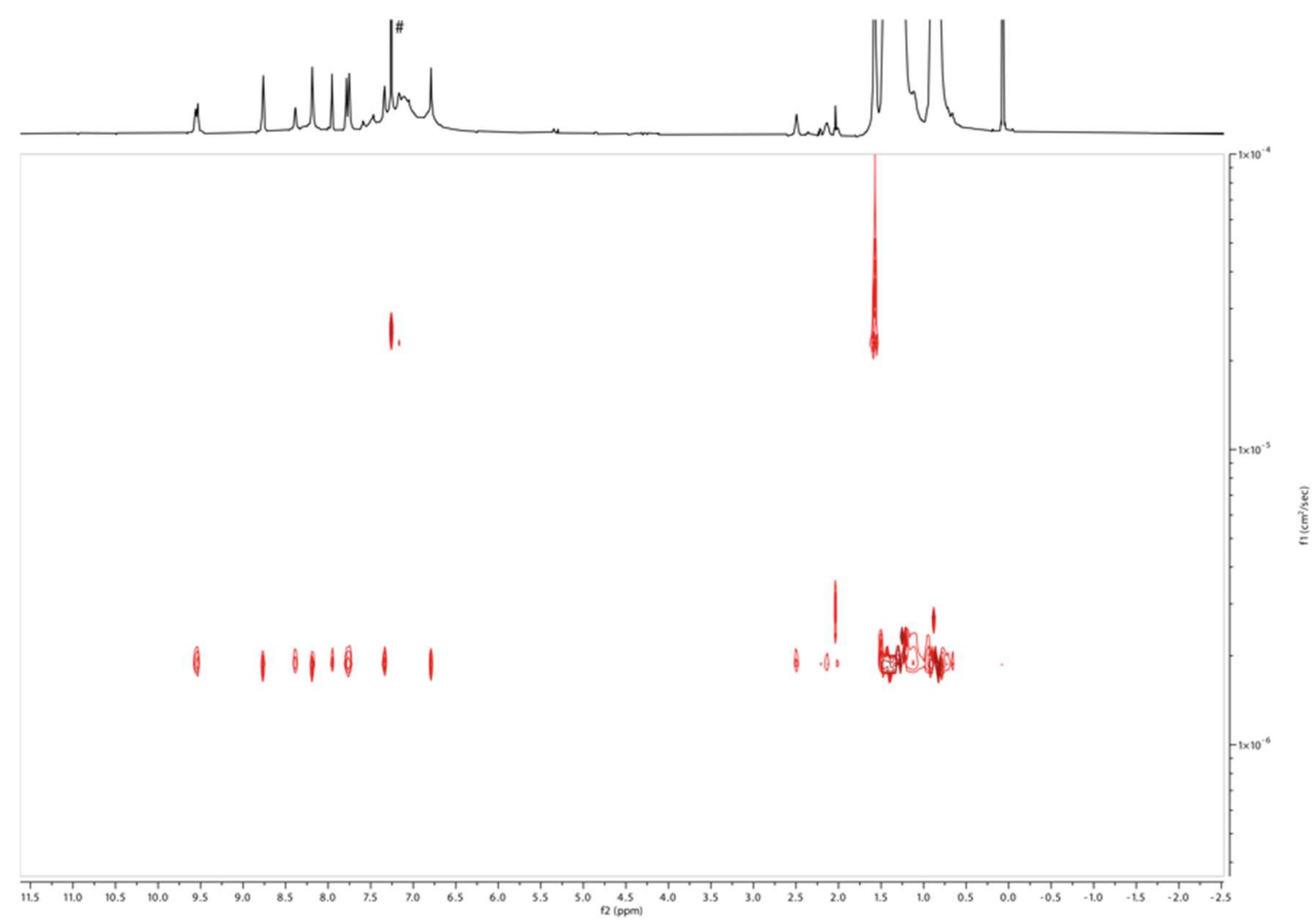

Figure S156. ${ }^{1} \mathrm{H}$ DOSY plot of complex (Si-I-P4 $\left.\left[\mathbf{b}_{2} \mathbf{f}_{1}\right]-\mathbf{S i}\right)_{2} \bullet(T 4)_{2}\left(500 \mathrm{MHz}, \mathrm{CDCl}_{3}, 298 \mathrm{~K}\right)$. Peak assigned with \# arises from $\mathrm{CHCl}_{3}$.

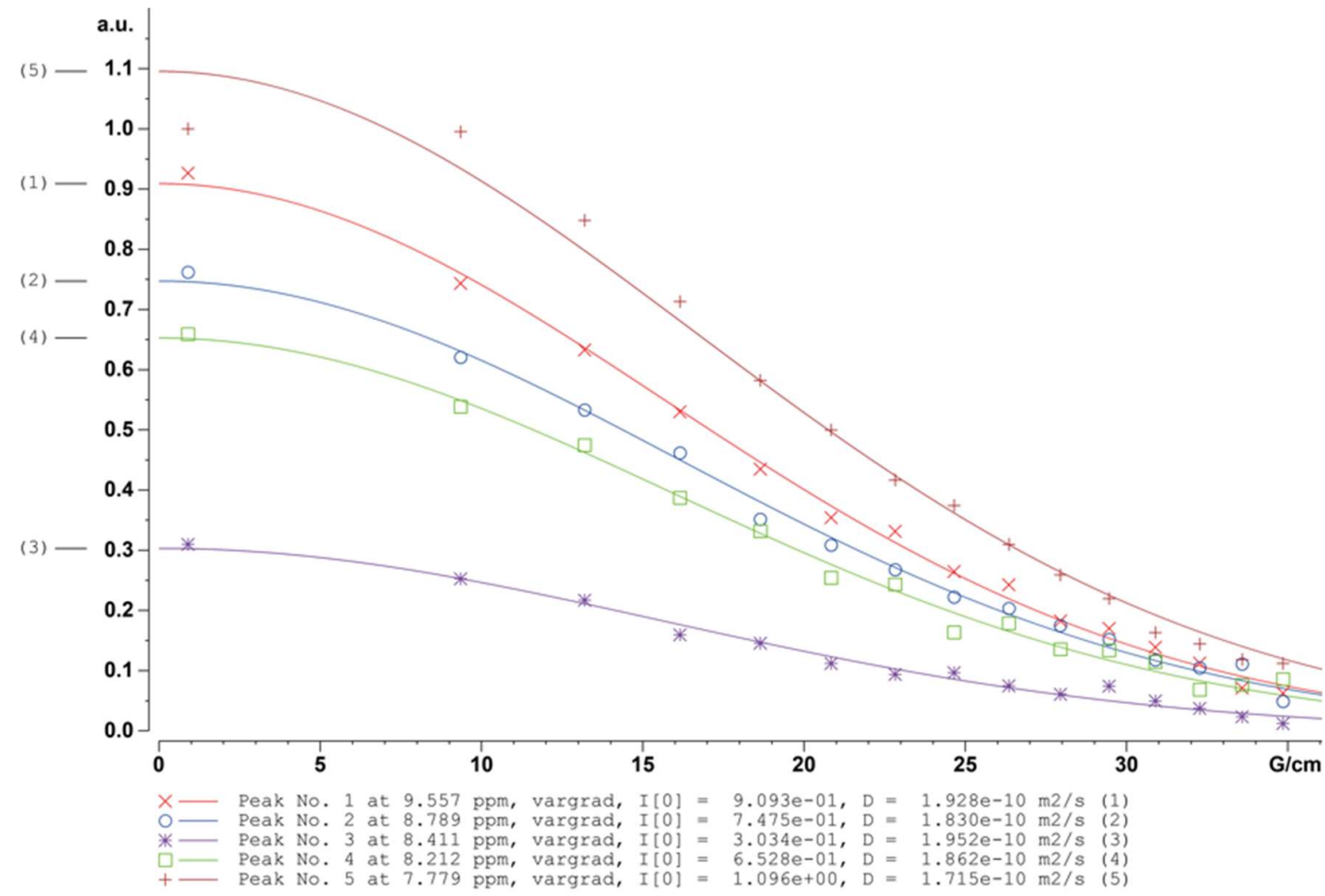

Figure S157. Fitted diffusion decay curves and resulting diffusion coefficients of (Si-I-P4[ $\left.\left.\mathbf{b}_{\mathbf{2}} \mathbf{f}_{\mathbf{1}}\right]_{-} \mathbf{- S i}\right)_{\mathbf{2}} \bullet \mathbf{\bullet}(\mathbf{T} \mathbf{4})_{\mathbf{2}}\left(500 \mathrm{MHz}, \mathrm{CDCl} \mathrm{H}_{3}, 298 \mathrm{~K}\right)$ with $\Delta$ $=100 \mathrm{~ms}, \delta=2 \mathrm{~ms}$, and $g=0.90-36.06 \mathrm{G} \mathrm{cm}^{-1}$. Averaging of the individual diffusion coefficients gives a mean diffusion coefficient of $1.86 \pm 0.09 \times 10^{-10} \mathrm{~m}^{2} \mathrm{~s}^{-1}$. 


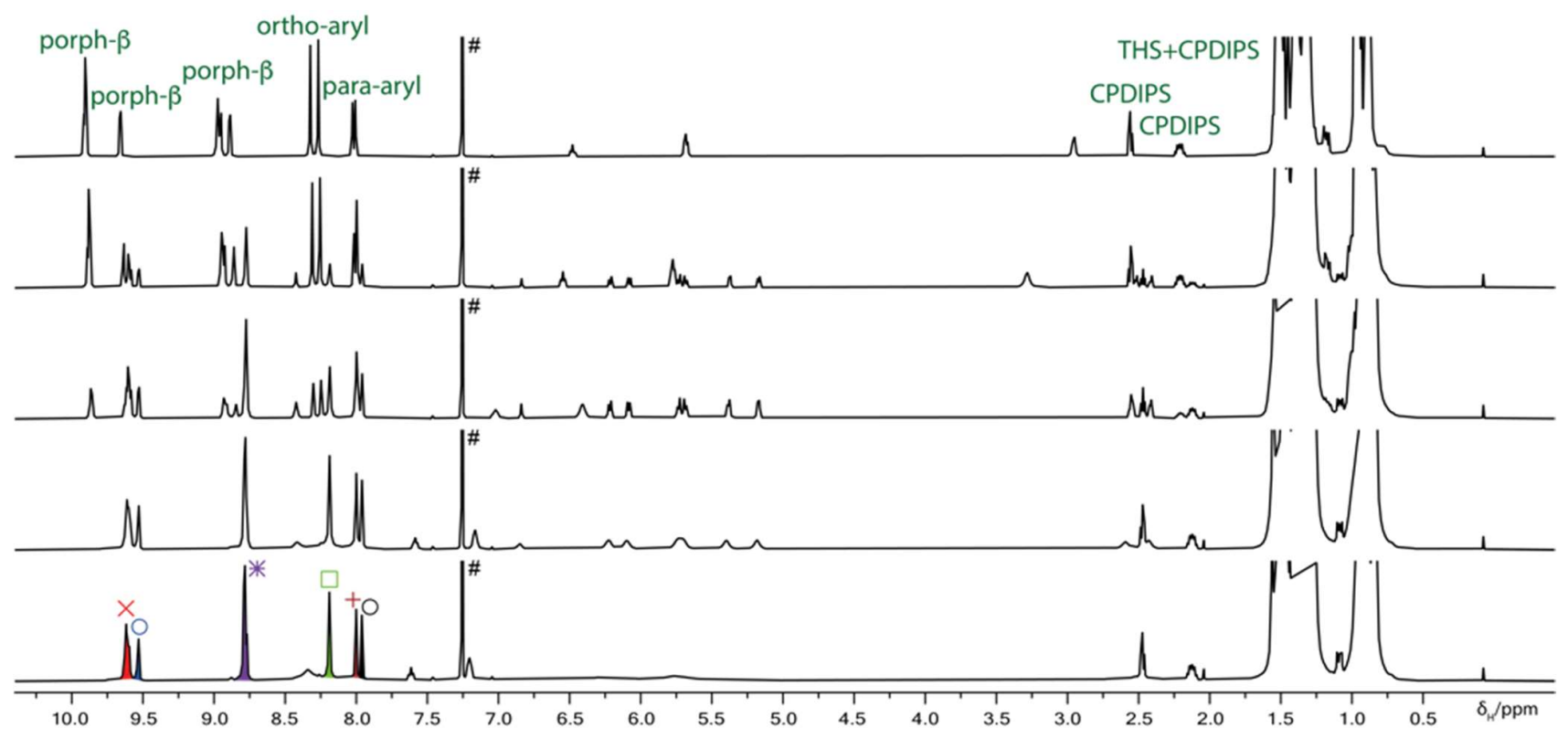

Figure S158. ${ }^{1} \mathrm{H}$ NMR spectra of the formation titration of (Si-I-P4[ $\left.\left.\mathbf{b}_{3}\right]-\mathrm{Si}\right) \bullet(\mathrm{T4})\left(500 \mathrm{MHz}, \mathrm{CDCl}_{3}, 298 \mathrm{~K}\right)$. The top spectrum corresponds to unbound tetramer $\mathbf{S i - I - P 4}\left[\mathbf{b}_{3}\right]-\mathbf{S i}$, and the bottom spectrum to the fully formed complex. Peaks assigned with \# arise from $\mathrm{CHCl}_{3}$. The highlighted resonances in the bottom spectrum indicate the signals used in the fitting of the diffusion decay curves of the ${ }^{1} \mathrm{H}$ DOSY spectrum of (Si-I-P4[ $\left.\left.\mathbf{b}_{3}\right]-\mathrm{Si}\right) \cdot(\mathbf{T} 4)$.

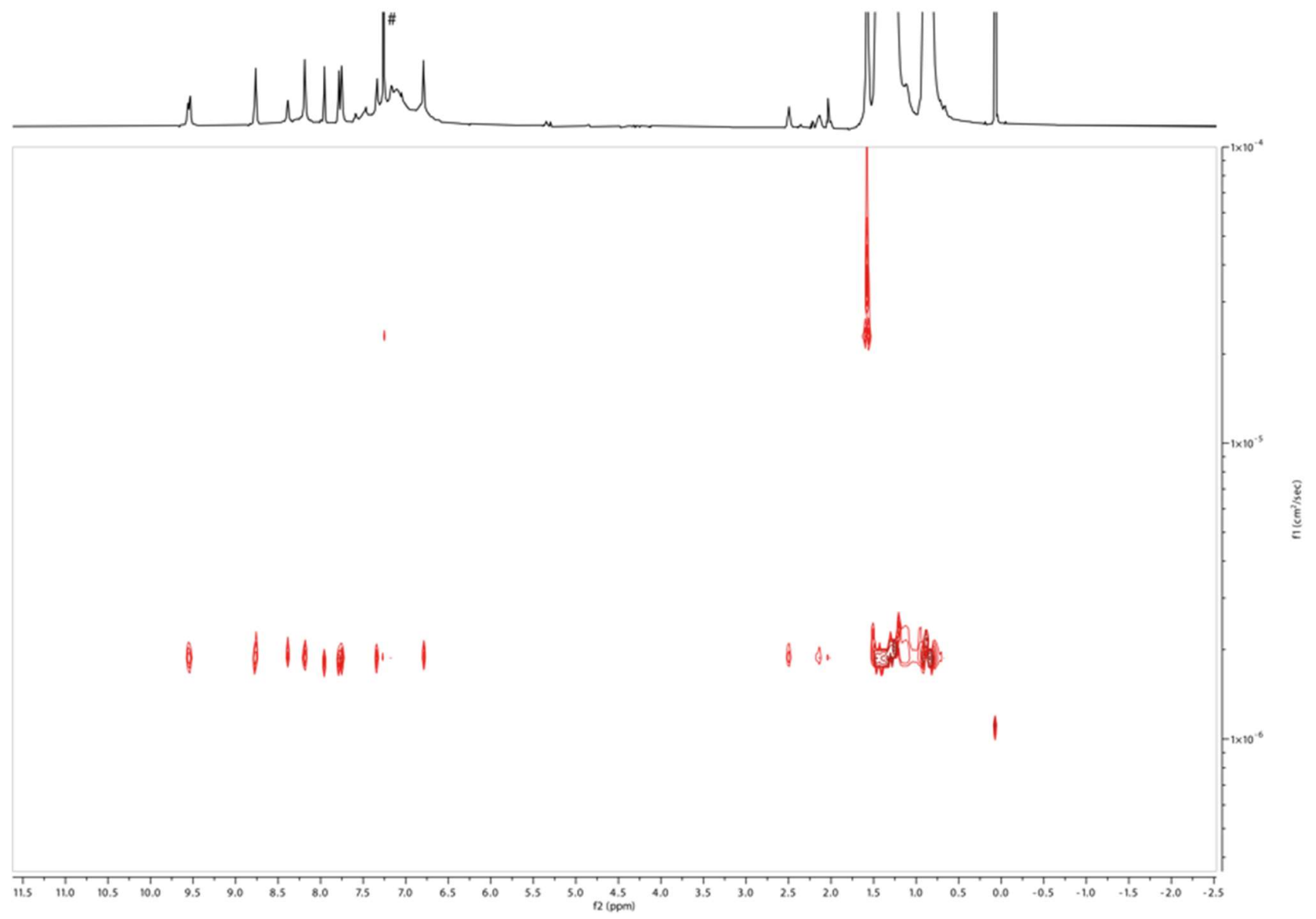

Figure S159. ${ }^{1} \mathrm{H}$ DOSY plot of complex (Si-I-P4[b $\left.\left.\mathbf{b}_{3}\right]-\mathrm{Si}\right) \bullet(\mathbf{T 4})\left(500 \mathrm{MHz}, \mathrm{CDCl}_{3}, 298 \mathrm{~K}\right)$. Peak assigned with \# arises from $\mathrm{CHCl}_{3}$. 


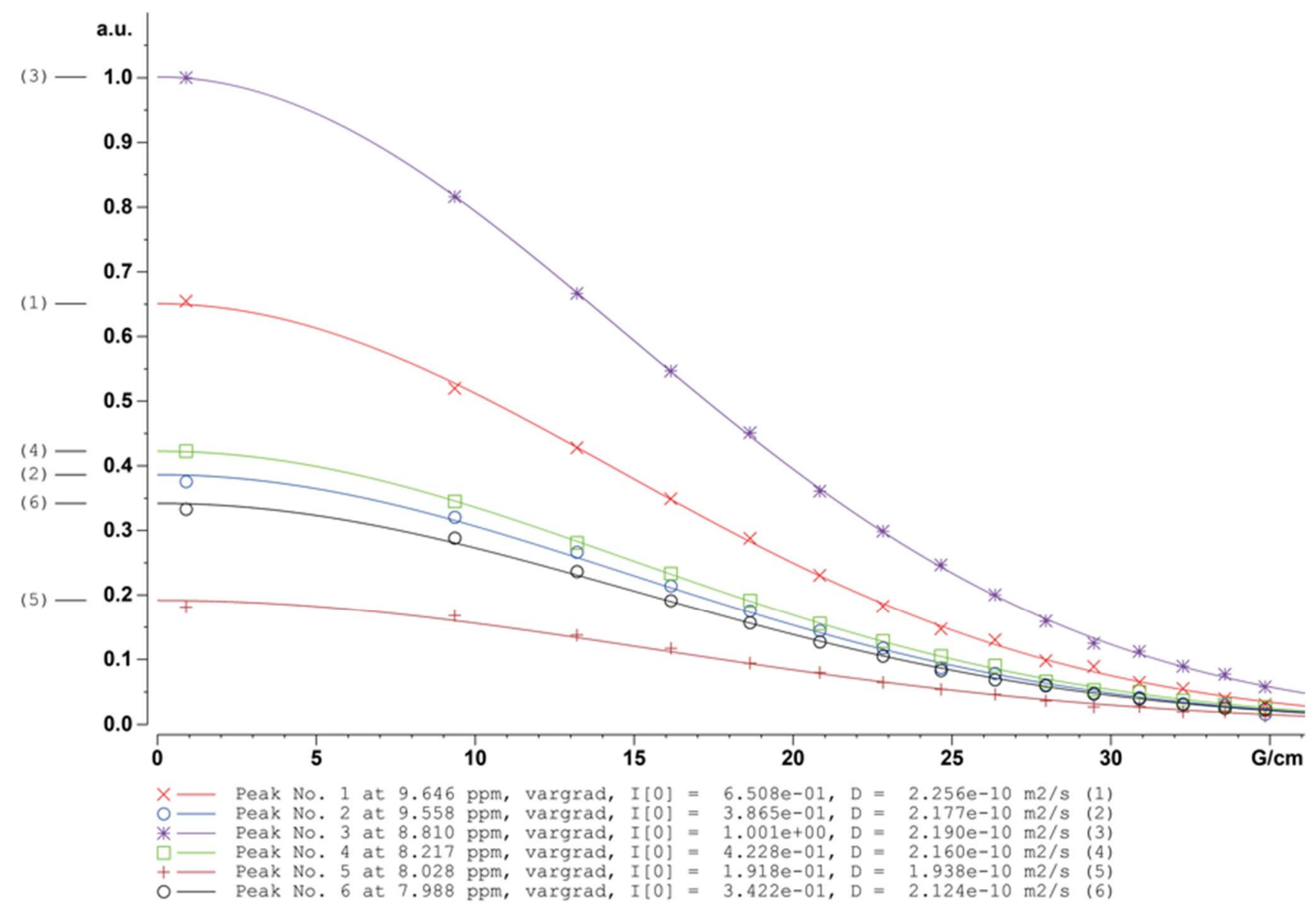

Figure S160. Fitted diffusion decay curves and resulting diffusion coefficients of (Si-I-P4[ $\left.\left.\mathbf{b}_{\mathbf{3}}\right]-\mathbf{S i}\right) \bullet(\mathbf{T 4})(500 \mathrm{MHz}, \mathrm{CDCl}, 298 \mathrm{~K})$ with $\Delta=$ $100 \mathrm{~ms}, \delta=2 \mathrm{~ms}$, and $g=0.90-36.06 \mathrm{G} \mathrm{cm}^{-1}$. Averaging of the individual diffusion coefficients gives a mean diffusion coefficient of $2.14 \pm 0.11 \times 10^{-10} \mathrm{~m}^{2} \mathrm{~s}^{-1}$.

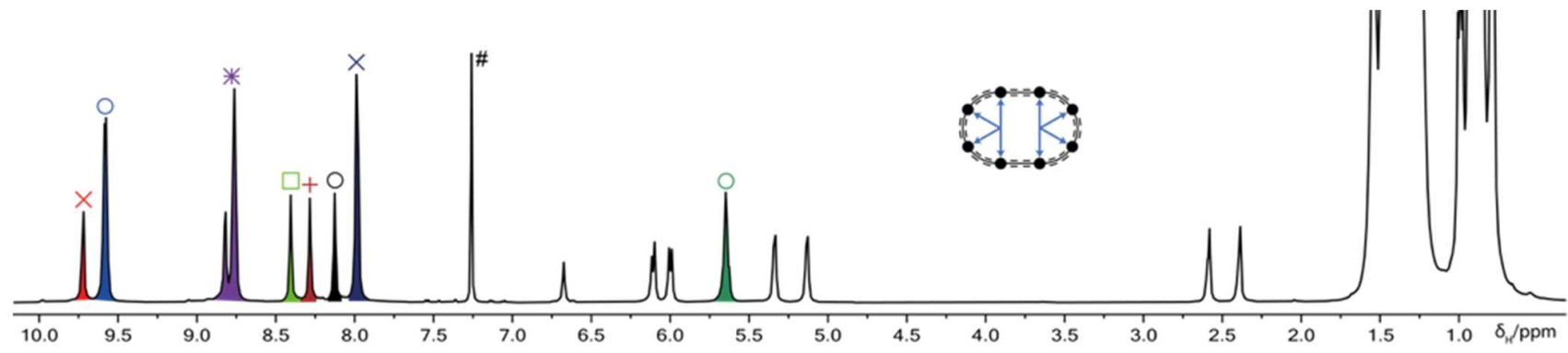

Figure S161. ${ }^{1} \mathrm{H}$ NMR spectrum of $\mathbf{c}-\mathbf{P 8}\left[\mathbf{b}_{8}\right] \bullet \cdot\left(T_{4}\right)_{2}\left(500 \mathrm{MHz}, \mathrm{CDCl}_{3}, 298 \mathrm{~K}\right)$. Peak assigned with \# arises from $\mathrm{CHCl}_{3} . \mathrm{The}$ highlighted resonances indicate the signals used in the fitting of the diffusion decay curves of the ${ }^{1} \mathrm{H}$ DOSY spectrum. 


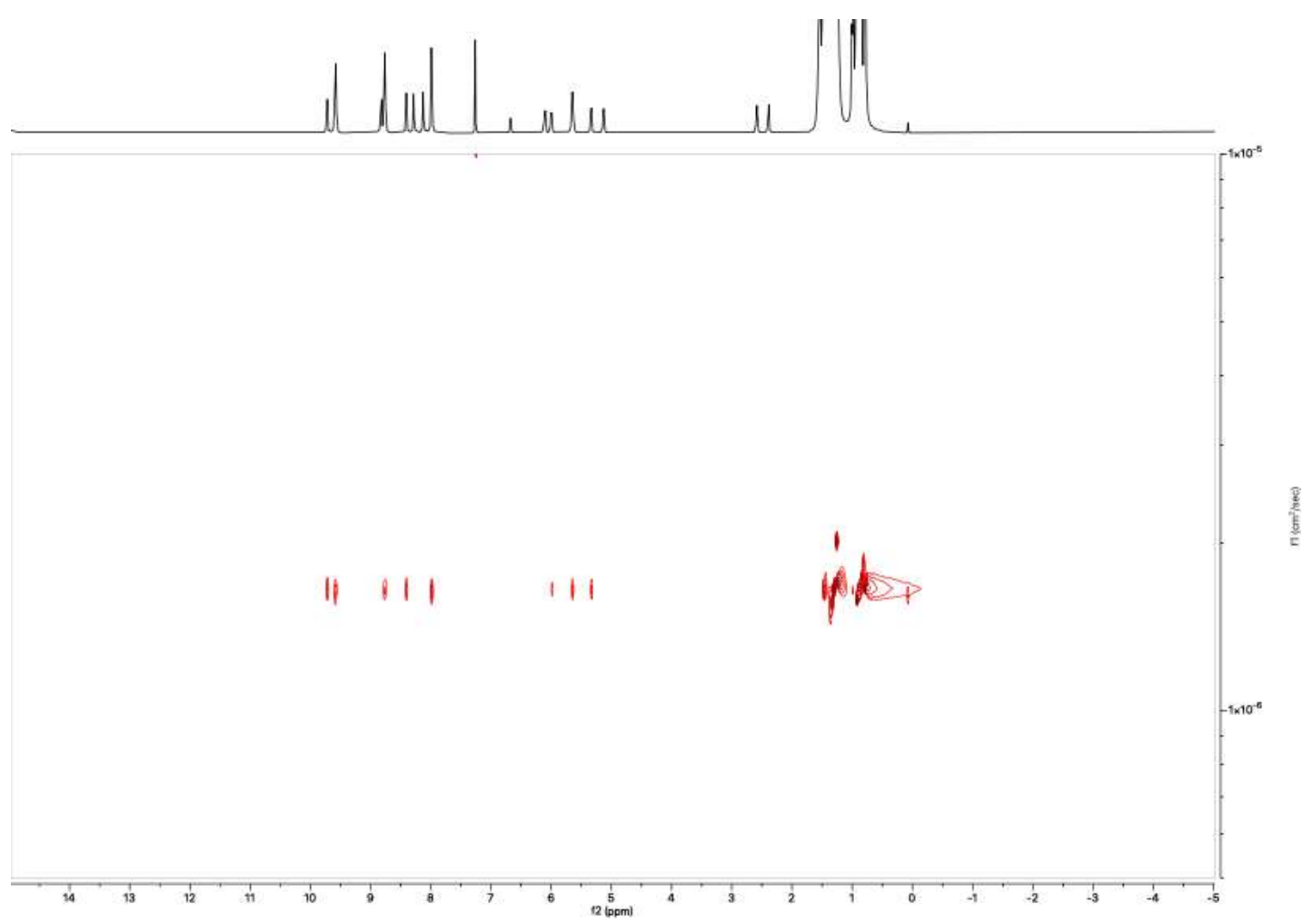

Figure S162. ${ }^{1} \mathrm{H}$ DOSY plot of complex c-P8[ $\left.\mathbf{b}_{8}\right] \bullet(T 4)_{2}\left(500 \mathrm{MHz}, \mathrm{CDCl}_{3}, 298 \mathrm{~K}\right)$. Peak assigned with \# arises from $\mathrm{CHCl}_{3}$.

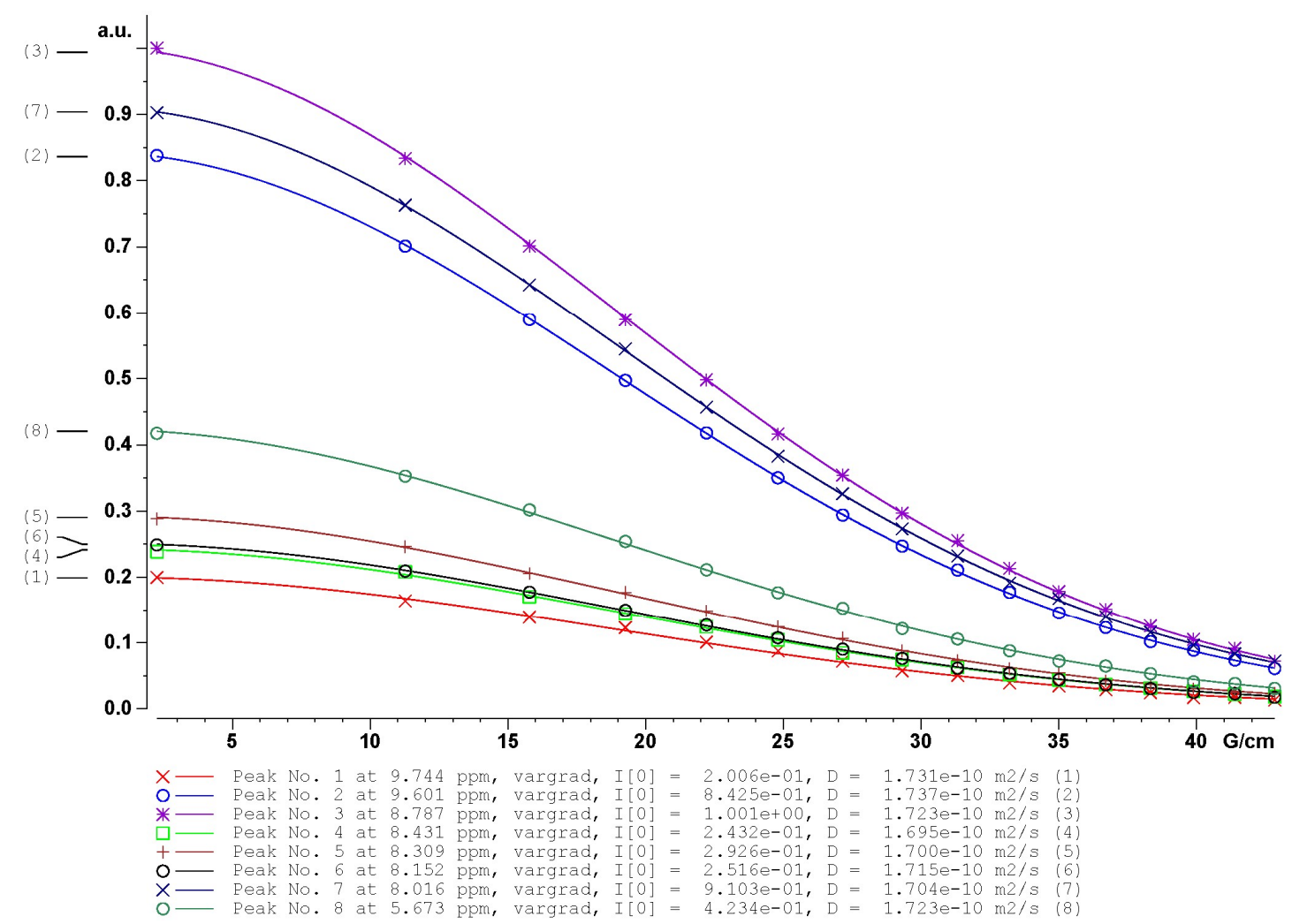

Figure S163. Fitted diffusion decay curves and resulting diffusion coefficients of $\boldsymbol{c}-\mathbf{P} 8\left[\mathbf{b}_{\mathbf{8}}\right]_{\bullet} \cdot(\mathbf{T 4})_{2}\left(500 \mathrm{MHz}, \mathrm{CDCl}_{3}, 298 \mathrm{~K}\right)$ with $\Delta=100 \mathrm{~ms}, \delta=1.75 \mathrm{~ms}$, and $g=2.25-42.9 \mathrm{G} \mathrm{cm}^{-1}$. Averaging of the individual diffusion coefficients gives a mean diffusion coefficient of $1.72 \pm 0.02 \times 10^{-10} \mathrm{~m}^{2} \mathrm{~s}^{-1}$. 


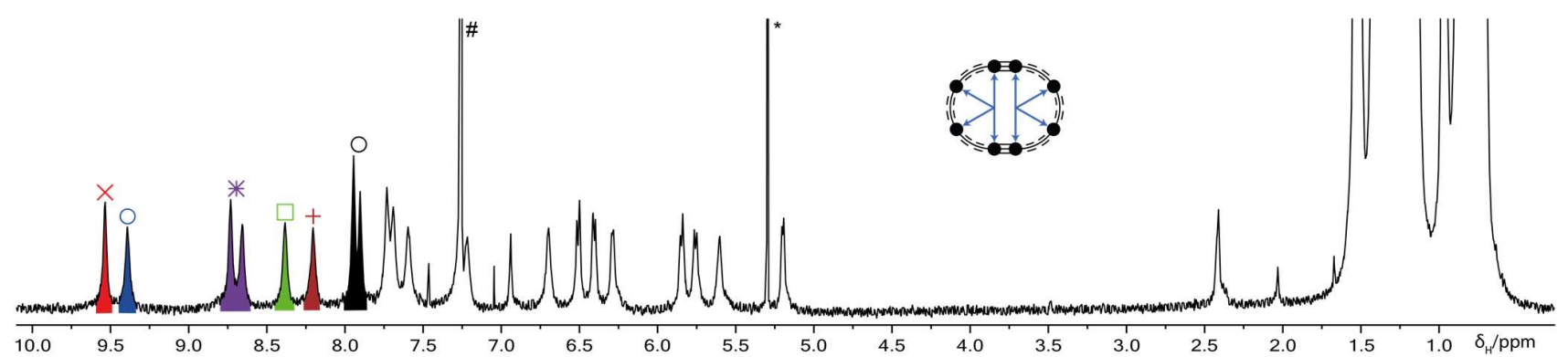

Figure S164. ${ }^{1} \mathrm{H}$ NMR spectrum of $\boldsymbol{c}-\mathbf{P} 8\left[\mathbf{b}_{6} \mathbf{f}_{2}\right]_{\bullet}\left(\mathrm{TT}_{4}\right)_{2}\left(500 \mathrm{MHz}, \mathrm{CDCl}_{3}, 298 \mathrm{~K}\right)$. Peaks assigned with \# and * arise from $\mathrm{CHCl} 3$ and $\mathrm{CH}_{2} \mathrm{Cl}_{2}$, respectively. The highlighted resonances indicate the signals used in the fitting of the diffusion decay curves of the ${ }^{1} \mathrm{H}$ DOSY spectrum.

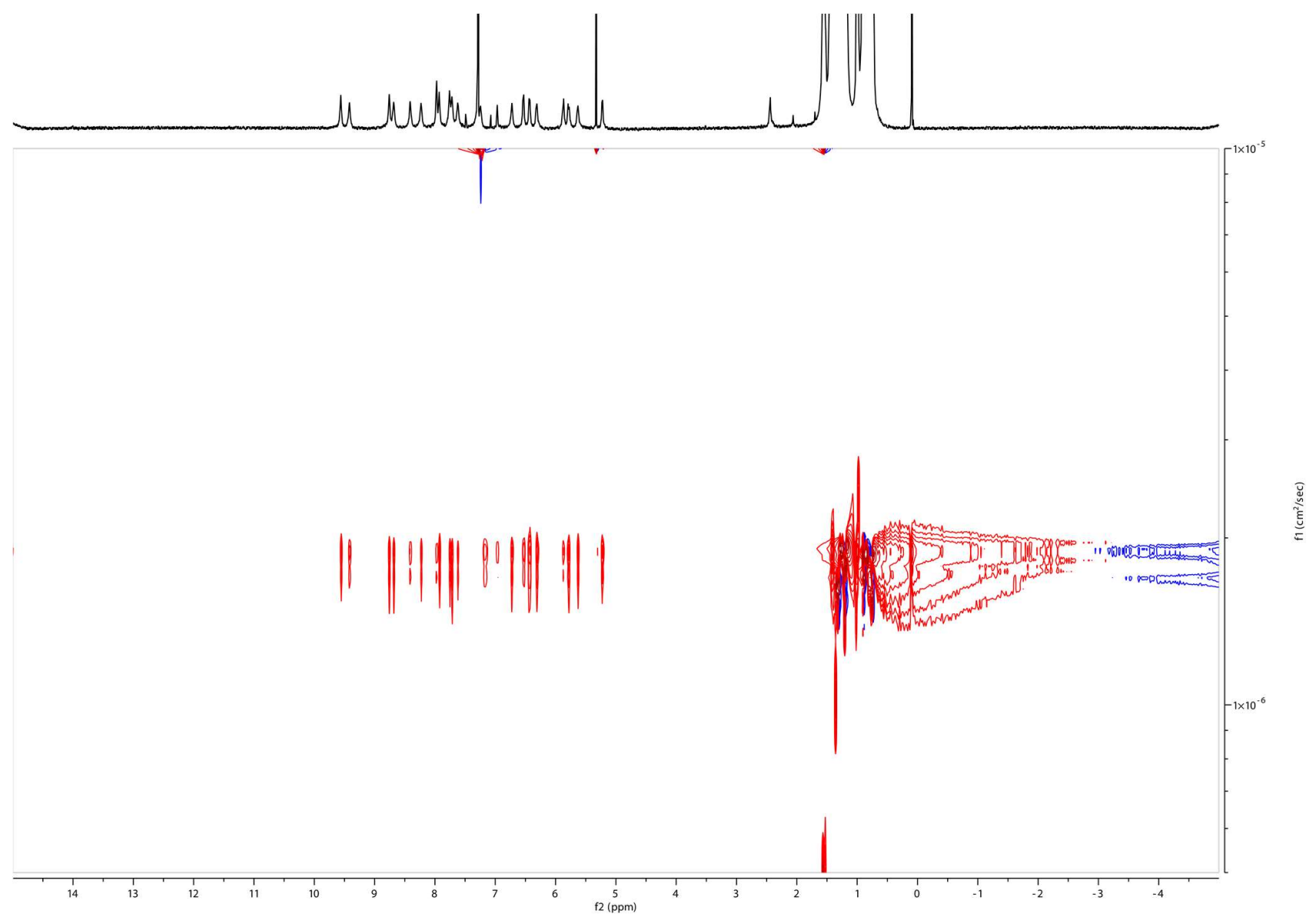

Figure S165. ${ }^{1} \mathrm{H}$ DOSY plot of complex $\boldsymbol{c}-\mathbf{P} 8\left[\mathbf{b}_{6} \mathbf{f}_{2}\right] \cdot(\mathbf{T 4})_{2}\left(500 \mathrm{MHz}, \mathrm{CDCl}_{3}, 298 \mathrm{~K}\right)$. 


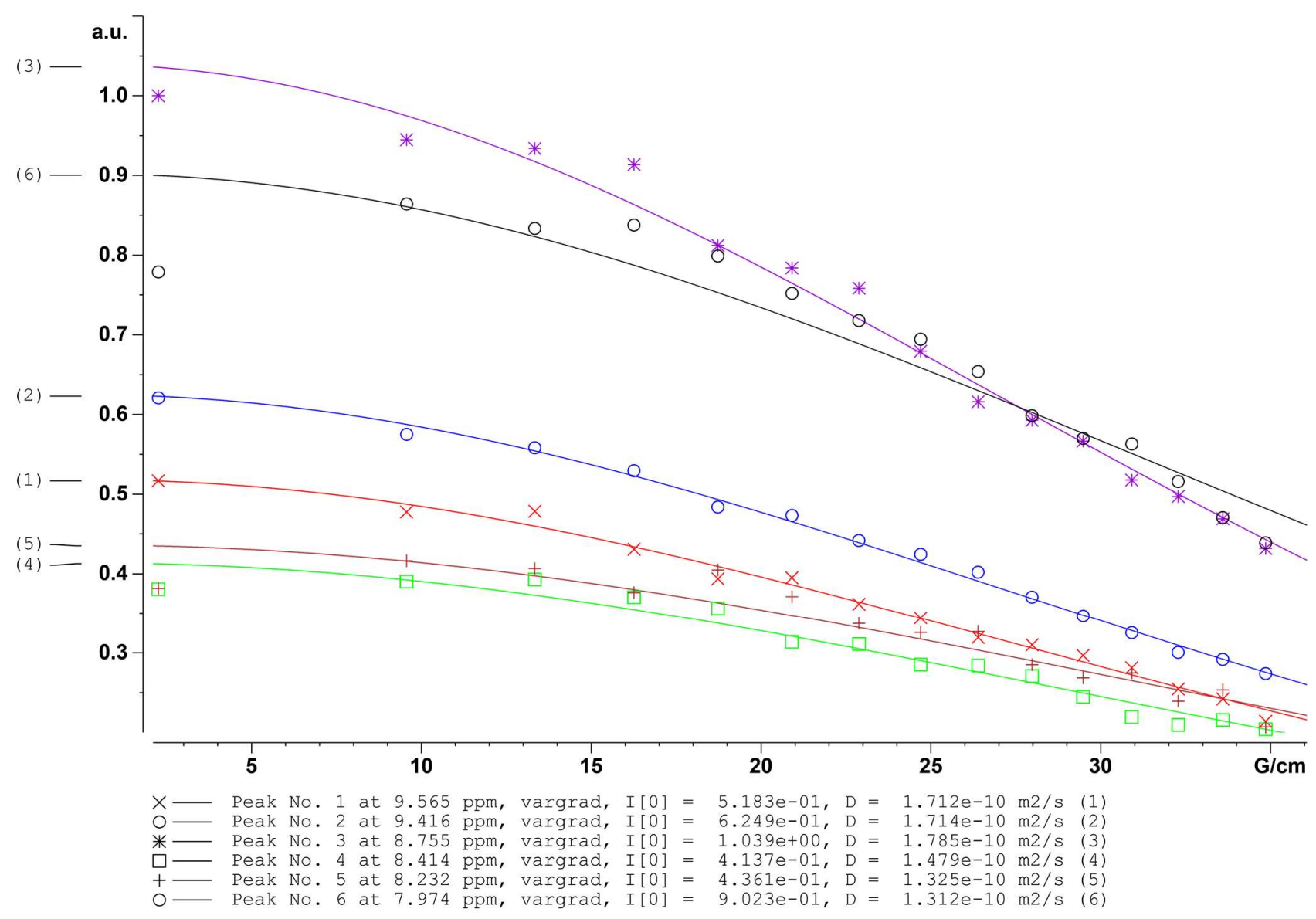

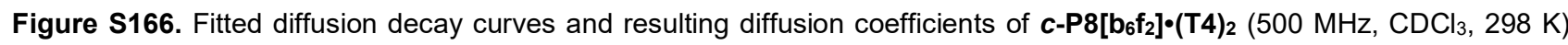
with $\Delta=100 \mathrm{~ms}, \delta=1.20 \mathrm{~ms}$, and $g=2.25-36.1 \mathrm{G} \mathrm{cm}^{-1}$. Averaging of the individual diffusion coefficients gives a mean diffusion coefficient of $1.55 \pm 0.21 \times 10^{-10} \mathrm{~m}^{2} \mathrm{~s}^{-1}$. 


\section{References}

(1) Keller, R.; Wycoff, H. Copper(I) Chloride. Inorg. Synth. 1946, 2, 1-4.

(2) Bols, P. S.; Anderson, H. L. Shadow Mask Templates for Site-Selective Metal Exchange in Magnesium Porphyrin Nanorings. Angew. Chem. Int. Ed. 2018, 57, 7874-7877.

(3) Peeks, M. D.; Claridge, T. D. W.; Anderson, H. L. Aromatic and Antiaromatic Ring Currents in a Molecular Nanoring. Nature 2017, 541, 200-203.

(4) Rickhaus, M.; Jirasek, M.; Tejerina, L.; Gotfredsen, H.; Peeks, M. D.; Haver, R.; Jiang, H.-W.; Claridge, T. D. W.; Anderson, H. L. Global Aromaticity at the Nanoscale. Nat. Chem. 2020, 12, 236-241.

(5) Grozema, F. C.; Houarner-Rassin, C.; Prins, P.; Siebbeles, L. D. A.; Anderson, H. L. Supramolecular Control of Charge Transport in Molecular Wires. J. Am. Chem. Soc. 2007, 129, 13370-13371.

(6) Parkinson, P.; Knappke, C. E. I.; Kamonsutthipaijit, N.; Sirithip, K.; Matichak, J. D.; Anderson, H. L.; Herz, L. M. Ultrafast Energy Transfer in Biomimetic Multistrand Nanorings. J. Am. Chem. Soc. 2014, 136, 8217-8220.

(7) Richert, S.; Limburg, B.; Anderson, H. L.; Timmel, C. R. On the Influence of the Bridge on Triplet State Delocalization in Linear Porphyrin Oligomers. J. Am. Chem. Soc. 2017, 139, 12003-12008.

(8) Holmes, D.; Lee, S.; Lotz, S.; Nguyen, S.; Schaller, G.; Schmidt-Radde, R.; Vollhardt, K. $\left(\eta^{6}-\right.$ [7]Heliphene)tricarbonylchromium via an Optimized Preparation of [7]Heliphene. Synthesis 2015, 47, 20382054.

(9) Li, G.; Yoon, K.-Y.; Zhong, X.; Zhu, X.; Dong, G. Efficient Bottom-Up Preparation of Graphene Nanoribbons by Mild Suzuki-Miyaura Polymerization of Simple Triaryl Monomers. Chem. Eur. J. 2016, 22, 9116-9120.

(10) Mallinger, A.; Crumpler, S.; Pichowicz, M.; Waalboer, D.; Stubbs, M.; Adeniji-Popoola, O.; Wood, B.; Smith, E.; Thai, C.; Henley, A. T.; Georgi, K.; Court, W.; Hobbs, S.; Box, G.; Ortiz-Ruiz, M.-J.; Valenti, M.; Brandon, A. D. H.; TePoele, R.; Leuthner, B.; Workman, P.; Aherne, W.; Poeschke, O.; Dale, T.; Wienke, D.; Esdar, C.; Rohdich, F.; Raynaud, F.; Clarke, P. A.; Eccles, S. A.; Stieber, F.; Schiemann, K.; Blagg, J. Discovery of Potent, Orally Bioavailable, Small-Molecule Inhibitors of WNT Signaling from a Cell-Based Pathway Screen. J. Med. Chem. 2015, 58, 1717-1735.

(11) Coey, J. M. D. Magnetostatics. Magnetism and Magnetic Materials, Cambridge University Press: Cambridge, 2010; pp 24-41.

(12) Marques, H. M.; Cukrowski, I. Molecular Mechanics Modelling of Porphyrins. Using Artificial Neural Networks to Develop Metal Parameters for Four-Coordinate Metalloporphyrins. Phys. Chem. Chem. Phys. 2002, 4, 58785887.

(13) Marques, H. M.; Cukrowski, I. Molecular Mechanics Parameters for the Modelling of Four-Coordinate $\mathrm{Zn}$ (II) Porphyrins. Phys. Chem. Chem. Phys. 2003, 5, 5499-5506.

(14) Goldstein, E.; Ma, B.; Lii, J.-H.; Allinger, N. L. Molecular Mechanics Calculations (MM3) on Nitriles and Alkynes. J. Phys. Org. Chem. 1996, 9, 191-202.

(15) Jarowski, P. D.; Diederich, F.; Houk, K. N. Structures and Stabilities of Diacetylene-Expanded Polyhedranes by Quantum Mechanics and Molecular Mechanics. J. Org. Chem. 2005, 70, 1671-1678.

(16) Stewart, J. J. P. Optimization of Parameters for Semiempirical Methods VI: More Modifications to the NDDO Approximations and Re-optimization of Parameters. J. Mol. Model. 2013, 19, 1-32.

(17) Frisch, M. J.; Trucks, G. W.; Schlegel H. B.; Scuseria, G. E.; Robb M. A.; Cheeseman J. R.; Scalmani, G.; Barone, V.; Petersson, G. A.; Nakatsuji, H.; Li, X.; Caricato, M.; Marenich, A. V.; Bloino, J.; Janesko, B. G.; Gomperts, R.; Mennucci B.; Hratchian, H. P.; Ortiz, J. V.; Izmaylov, A. F.; Sonnenberg, J. L.; WilliamsYoung, D.; Ding, F.; Lipparini, F.; Egidi, F.; Rega, N.; Zheng, G.; Liang, W.; Hada, M.; Ehara, M.; Toyota, K.; Fukuda, R.; Hasegawa, J.; Ishida, M.; Nakajima, T.; Honda, Y.; Kitao, O.; Nakai, H.; Vreven, T.; Throssell, K.; Montgomery Jr., J. A.; Peralta, J. E.; Ogliaro, F.; Bearpark, M. J.; Heyd, J. J.; Brothers, E. N.; Kudin, K. N.; Staroverov, V. N.; Keith, T. A.; Kobayashi, R.; Normand, J.; Raghavachari, K.; Rendell, A. P.; Burant, J. C.; Iyengar, S. S.; Tomasi, J.; Cossi, M.; Millam, J. M.; Klene, M.; Adamo, C.; Cammi, R.; Ochterski, J. W.; Martin, R. L.; Morokuma, K.; Farkas, O.; Foresman, J. B.; Fox, D. J. Gaussian 16, Revision A.03. Gaussian Inc.: Wallingford CT 2016.

(18) Ditchfield, R.; Hehre, W. J.; Pople, J. A. Self-Consistent Molecular-Orbital Methods. IX. An Extended GaussianType Basis for Molecular-Orbital Studies of Organic Molecules. J. Chem. Phys. 1971, 54, 724-728. 
(19) Hehre, W. J.; Ditchfield, R.; Pople, J. A. Self-Consistent Molecular Orbital Methods. XII. Further Extensions of Gaussian-Type Basis Sets for Use in Molecular Orbital Studies of Organic Molecules. J. Chem. Phys. 1972, 56, 2257-2261.

(20) Hariharan, P. C.; Pople, J. A. The Influence of Polarization Functions on Molecular Orbital Hydrogenation Energies. Theor. Chim. Acta 1973, 28, 213-222.

(21) Rassolov, V. A.; Pople, J. A.; Ratner, M. A.; Windus, T. L. 6-31G* Basis Set for Atoms K through Zn. J. Chem. Phys. 1998, 109, 1223-1229.

(22) Henderson, T. M.; Izmaylov, A. F.; Scalmani, G.; Scuseria, G. E. Can Short-Range Hybrids Describe LongRange-Dependent Properties? J. Chem. Phys. 2009, 131, 044108.

(23) Vydrov, O. A.; Scuseria, G. E. Assessment of a Long Range Corrected Hybrid Functional. J. Chem. Phys. 2006, 125, 234109.

(24) Vydrov, O. A.; Heyd, J.; Krukau, A.; Scuseria, G. E. Importance of Short-Range versus Long-Range HartreeFock Exchange for the Performance of Hybrid Density Functionals. J. Chem. Phys. 2006, 125, 074106.

(25) Vydrov, O. A.; Scuseria, G. E.; Perdew, J. P. Tests of Functionals for Systems with Fractional Electron Number. J. Chem. Phys. 2007, 126, 154109.

(26) Chen, Z.; Wannere, C. S.; Corminboeuf, C.; Puchta, R.; Schleyer, P. v. R. Nucleus-Independent Chemical Shifts (NICS) as an Aromaticity Criterion. Chem. Rev. 2005, 105, 3842-3888.

(27) Frisch, M. J.; Trucks, G. W.; Schlegel, H. B.; Scuseria, G. E.; Robb, M. A.; Cheeseman, J. R.; Scalmani, G.; Barone, V.; Mennucci, B.; Petersson, G. A.; Nakatsuji, H.; Caricato, M.; Li, X.; Hratchian, H. P.; Izmaylov, A. F.; Bloino, J.; Zheng, G.; Sonnenberg, J. L.; Hada, M.; Ehara, M.; Toyota, K.; Fukuda, R.; Hasegawa, J.; Ishida, M.; Nakajima, T.; Honda, Y.; Kitao, O.; Nakai, H.; Vreven, T.; Montgomery Jr., J. A.; Peralta, J. E.; Ogliaro, F.; Bearpark, M.; Heyd, J. J.; Brothers, E.; Kudin, K. N.; Staroverov, V. N.; Keith, T; Kobayashi, R.; Normand, J.; Raghavachari, K.; Rendell, A.; Burant, J. C.; Iyengar, S. S.; Tomasi, J.; Cossi, M.; Rega, N.; Millam, J. M.; Klene, M.; Knox, J. E.; Cross, J. B.; Bakken, V.; Adamo, C.; Jaramillo, J.; Gomperts, R.; Stratmann, R. E.; Yazyev, O.; Austin, A. J.; Cammi, R.; Pomelli, C.; Ochterski, J. W.; Martin, R. L.; Morokuma, K.; Zakrzewski, V. G.; Voth, G. A.; Salvador, P.; Dannenberg, J. J.; Dapprich, S.; Daniels, A. D.; Farkas, Ö.; Foresman, J. B.; Ortiz, J. V.; Cioslowski, J.; Fox, D. J. Gaussian 09 Revision D.01. Gaussian Inc. Wallingford CT, 2013.

(28) Geuenich, D.; Hess, K.; Koehler, F.; Herges, R. Anisotropy of the Induced Current Density (ACID), a General Method to Quantify and Visualize Electronic Delocalization. Chem. Rev. 2005, 105, 3758-3772.

(29) Furche, F.; Ahlrichs, R. Adiabatic Time-Dependent Density Functional Methods for Excited State Properties. J. Chem. Phys. 2002, 117, 7433-7447.

(30) Martin, R. L. Natural Transition Orbitals. J. Chem. Phys. 2003, 118, 4775-4777.

(31) Stejskal, E. O.; Tanner, J. E. Spin Diffusion Measurements: Spin Echoes in the Presence of a TimeDependent Field Gradient. J. Chem. Phys. 1965, 42, 288-292.

(32) Einstein, A. Über die von der molekularkinetischen Theorie der Wärme geforderte Bewegung von in ruhenden Flüssigkeiten suspendierten Teilchen. Ann. Phys. 1905, 322, 549-560.

(33) Hutin, M.; Sprafke, J. K.; Odell, B.; Anderson, H. L.; Claridge, T. D. W. A Discrete Three-Layer Stack Aggregate of a Linear Porphyrin Tetramer: Solution-Phase Structure Elucidation by NMR and X-ray Scattering. J. Am. Chem. Soc. 2013, 135, 12798-12807.

(34) Neufeld, R.; Stalke, D. Accurate molecular weight determination of small molecules via DOSY-NMR by using external calibration curves with normalized diffusion coefficients. Chem. Sci. 2015, 6, 3354-3364. 